\title{
IMPACT OF PLANT SPECIES, N FERTILIZATION AND ECOSYSTEM ENGINEERS ON THE STRUCTURE AND FUNCTION OF SOIL MICROBIAL COMMUNITIES
}

\author{
Dissertation \\ zur Erlangung des mathematisch-naturwissenschaftlichen Doktorgrades \\ "Doctor rerum naturalium" \\ der Georg-August-Universität Göttingen \\ im Promotionsprogramm Biologie \\ der Georg-August University School of Science (GAUSS) \\ vorgelegt von \\ Birgit Pfeiffer
}

aus Forst/ Lausitz

Göttingen 2013 
Betreuungsausschuss

Prof. Dr. Rolf Daniel, Genomische und angewandte Mikrobiologie, Institut für Mikrobiologie und Genetik; Georg-August-Universität Göttingen

PD Dr. Michael Hoppert, Allgemeine Mikrobiologie, Institut für Mikrobiologie und Genetik; Georg-August-Universität Göttingen

$\underline{\text { Mitglieder der Prüfungskommission }}$

Referent/in: Prof. Dr. Rolf Daniel, Genomische und angewandte Mikrobiologie, Institut für Mikrobiologie und Genetik; Georg-August-Universität Göttingen

Korreferent/in: PD Dr. Michael Hoppert, Allgemeine Mikrobiologie, Institut für Mikrobiologie und Genetik; Georg-August-Universität Göttingen

Weitere Mitglieder der Prüfungskommission:

Prof. Dr. Hermann F. Jungkunst, Geoökologie / Physische Geographie, Institut für Umweltwissenschaften, Universität Koblenz-Landau

Prof. Dr. Stefanie Pöggeler, Genetik eukaryotischer Mikroorganismen, Institut für Mikrobiologie und Genetik, Georg-August-Universität Göttingen

Prof. Dr. Stefan Irniger, Molekulare Mikrobiologie und Genetik, Institut für Mikrobiologie und Genetik, Georg-August-Universität Göttingen

Jun.-Prof. Dr. Kai Heimel, Molekulare Mikrobiologie und Genetik, Institut für Mikrobiologie und Genetik, Georg-August-Universität Göttingen

Tag der mündlichen Prüfung:

20.12.2013 
Two things are necessary for our work: unresting patience and the willingness to abandon something in which a lot of time and effort has been put.

Albert Einstein,

(Free translation from German to English)

Dedicated to my family. 


\section{Table of contents}

Table of contents

List of publications

III

A. GENERAL INTRODUCTION 1

1. BIODIVERSITY AND ECOSYSTEM FUNCTIONING AS IMPORTANT GLOBAL ISSUES

2. THE ROLE OF FOREST SOILS AS ECOSYSTEM AND MICROBIAL HABITAT 2

3. PARAMETERS INFLUENCING SOIL MICROBIAL COMMUNITY COMPOSITION AND ACTIVITY

3.1. EFFECT OF PLANT SPECIES IDENTITY AND DIVERSITY ON SOIL MICROBIAL COMMUNITIES

3.2. IMPACT OF ANTS ON SOIL MICROBIAL COMMUNITY COMPOSITION

4. 16S RRNA AND 16S RRNA GENES AS MOLECULAR MARKERS IN MICROBIAL ECOLOGY STUDIES

5. OBJECTIVES OF THIS THESIS 9

6. REFERENCES 11

B. PUBLICATIONS

B.I EFFECT OF TREE SPECIES IDENTITY, TREE SPECIES DIVERSITY, LEAF LITTER PRESENCE, AND SAMPLING TIME ON SOIL MICROBIAL COMMUNITIES

1. LEAF LITTER IS THE MAIN DRIVER FOR CHANGES IN BACTERIAL COMMUNITY STRUCTURES IN THE RHIZOSPHERE OF ASH AND BEECH

1.1. Supplementary data

2. ROOTS FROM BEECH (FAGUS SYLVATICA L.) AND ASH (FRAXINUS EXCELSIOR L.) DIFFERENTIALLY AFFECT SOIL MICROORGANISMS AND CARBON DYNAMICS

2.1. Supplementary data

3. TREE EFFECTS ON DIVERSITY AND STRUCTURE OF SOIL BACTERIAL AND FUNGAL COMMUNITIES

B.II IMPACT OF $N$ FERTILIZATION ON SOIL MICROBIAL COMMUNITIES AND GREENHOUSE GAS FLUXES 
1. THE INHIBITING EFFECT OF NITRATE FERTILIZATION ON METHANE UPTAKE OF A TEMPERATE FOREST SOIL IS INFLUENCED BY LABILE CARBON

2. N FERTILIZATION SHAPES THE COMPOSITION AND DIVERSITY OF ACTIVE SOIL BACTERIAL COMMUNITIES

3. COMBINED EFFECTS OF NITRATE AND LABILE C ON THE $\mathrm{N}_{2} \mathrm{O}$ EMISSIONS OF A TEMPERATE FOREST SOIL

B.III INFLUENCE OF LASIUS ANTS ACTING AS ECOSYSTEM ENGINEERS

1. NUTRIENT FLOW FROM ABOVEGROUND TO BELOWGROUND SYSTEMS AND CHANGES IN SOIL MICROBIAL COMMUNITY DRIVEN BY ANTS AND HOMOPTERAN HONEYDEW

1.1. Supplementary data

2. INFLUENCE OF LASIUS ANTS ON SOIL MICROBIAL COMMUNITIES IN GRASSLANDS - A FUNCTIONAL AND MOLECULAR APPROACH

B.IV MICROBIAL COMMUNITIES INHABITING BIOLOGICAL SOIL CRUSTS

1. BACTERIAL DIVERSITY IN BIOLOGICAL SOIL CRUSTS FROM EXTRAZONAL MOUNTAIN DRY STEPPES IN NORTHERN MONGOLIA

C. DISCUSSION

1. EFFECT OF TREE SPECIES IDENTITY, TREE SPECIES DIVERSITY, LEAF LITTER PRESENCE, AND SAMPLING TIME EFFECTS ON SOIL MICROBIAL COMMUNITIES

2. IMPACT OF RISING NITROGEN DEPOSITION INTO FOREST SOILS ON BACTERIAL ACTIVITY AND COMMUNITY COMPOSITION

3. INFLUENCE OF LASIUS ANTS ACTING AS ECOSYSTEM ENGINEERS 243

4. CONCLUSION $\quad \mathbf{2 4 4}$

5. REFERENCES $\mathbf{2 4 6}$

D. SUMMARY 253

Acknowledgments $\quad 255$

$\begin{array}{ll}\text { Curriculum vitae } & 257\end{array}$ 


\section{List of publications}

Fender, AC., Pfeiffer, B., Gansert, D., Leuschner, C., Daniel, R. and Jungkunst, HF. The inhibiting effect of nitrate fertilisation on methane uptake of a temperate forest soil is influenced by labile carbon. Biology and Fertility of Soils, 2012, Volume 48, Number 6, Pages 621-631

Kemmling, A., Pfeiffer, B., Daniel, R. and Hoppert, M. Bacterial diversity in biological soil crusts from extrazonal mountain dry steppes in northern Mongolia. Erforschung biologischer Ressourcen der Mongolei, 2012, Volume 12, Pages 437-449

Cesarz, S., Fender, AC., Beyer, F., Valtanen, K., Pfeiffer, B., Gansert, D., Hertel, D., Polle, A., Daniel, R., Leuschner C. and Scheu, S. Roots from beech (Fagus sylvatica L.) and ash (Fraxinus excelsior L.) differentially affect soil microorganisms and carbon dynamics. Soil Biology and Biochemistry, 2013, Volume 61, Pages 23-32

Pfeiffer, B., Fender, AC., Lasota, S., Jungkunst, HF., and Daniel, R. Leaf litter is the main driver for changes in bacterial community structures in the rhizosphere of ash and beech. Applied Soil Ecology, 2013, Volume 72, Pages 150-160 
"On any possible, reasonable or fair criterion, bacteria are - and always have beenthe dominant forms of life on Earth. "

S. J. Gould (1941-2002)

(paleontologist and evolutionary biologist)

\section{A. General introduction}

\section{Biodiversity and ecosystem functioning as important global issues}

Biodiversity was defined within the third Global Biodiversity Outlook (2010) as the variability among living organisms from all sources including, inter alia, terrestrial, marine and other aquatic ecosystems and the ecological complexes of which they are part. This includes diversity within species, between species and of ecosystems. Biodiversity can be measured as richness, evenness and heterogeneity. Richness is a measure of the number of unique life forms, evenness is a measure of the equitability among life forms, and heterogeneity is the measure of the dissimilarity among life forms (Cardinale et al. 2012). Biodiversity and ecosystem functioning are closely related. Ecosystem functions are processes that control energy, nutrient and organic matter fluxes such as the decomposition of dead plant material and the recycling of essential nutrients within an environment (Cardinale et al. 2012).

Consequences of changes in biodiversity, especially loss in biodiversity, were mainly studied with respect to plant and animal diversity (Chapin et al. 2000; Loreau et al. 2001; Petchey and Gaston 2002; Ives and Carpenter 2007; Hooper et al. 2012). Species diversity affects the function of ecosystems as well as the resilience and resistance of ecosystems to environmental changes (Chapin et al. 2000). Furthermore, biodiversity buffering environmental variations such as climate changes, increasing nitrogen depositions and carbon dioxide emissions enhances the efficiency and stability of ecosystem processes with time (Cardinale et al. 2012). A decrease in species diversity might force populations to a point where they become more and more vulnerable until they finally collapse. As a consequence, ecosystem functions could also collapse, when lost activities of particular organisms cannot be buffered, recovered or replaced by other species. Balvanera et al. (2006) found in a meta-analysis of 103 publications biodiversity effects to be weaker at the ecosystem than the community level and further to be negative at the population level. Within numerous experiments on effects of biodiversity loss, artificial gradients with respect to grassland plant diversity were 
analyzed (Tilman et al. 1996; Palmborg et al. 2005; Spehn et al. 2005; Tilman et al. 2006), but so far only a few studies explored artificial or natural gradients in forest tree diversity (Hooper et al. 2005; Leuschner et al. 2009; Jacob et al. 2010a). Furthermore, investigations on the relationship between biodiversity and ecosystem functions mainly focused on aboveground systems. Significant effects of biodiversity on the decomposer fauna were found by analyzing aboveground and belowground systems in grasslands (Scherber et al. 2010; Eisenhauer et al. 2012). The linkage between aboveground and belowground systems was rarely studied, especially with respect to forests and forest soils.

\section{The role of forest soils as ecosystem and microbial habitat}

The habitat soil, the so called pedosphere, is known as probably the most complex habitat on earth. It represents an enormously diverse, multifunctional and multicomponent system. Soils differ in organic and inorganic compounds, pore size, texture, and $\mathrm{pH}$. They are composed of mineral particles differing in size, shape and chemical composition, various stages of decomposed soil organic matter (SOM), soil gases and water, as well as dissolved minerals and dissolved organic matter (DOM) (Brady and Weil 2002). Soils are inhabited by plant roots, soil fauna and microbiota. Furthermore, soils are important contributors to the global nutrient cycle, and represent sources as well as sinks of methane $\left(\mathrm{CH}_{4}\right)$, nitrous oxide $\left(\mathrm{N}_{2} \mathrm{O}\right)$ and carbon dioxide $\left(\mathrm{CO}_{2}\right)$. Especially forest soils play a key role in the global nutrient cycle, as they have a considerable influence on the global greenhouse gas balance (Mosier 1998; Luyssaert et al. 2010). Carbon dioxide is removed from the atmosphere and converted to organic carbon by plants and microorganisms. Elevated $\mathrm{CO}_{2}$ concentrations stimulate plant growth which can only be sustained if sufficient $\mathrm{N}$ is available (Oren et al. 2001; Norby et al. 2010; Macdonald et al. 2011). Additionally, plants deposit C into soils through rhizodeposition and litter fall, which affects microbial activity and soil $\mathrm{C}$ sequestration. In return, microbial activity directly affects soil organic carbon concentrations and indirectly influences plant $\mathrm{C}$ accumulation by controlling the $\mathrm{N}$ cycle (Drake et al. 2011; Macdonald et al. 2011; Phillips et al. 2011). Important processes driving the C and $\mathrm{N}$ cycles are microbial mineralization activity, methanogenesis, $\mathrm{CH}_{4}$ consumption, $\mathrm{CO}_{2}$ fixation, $\mathrm{N}$ fixation, nitrification and denitrification (see Figure 1.). More precisely, nitrification and denitrification evoke the lion's share of $\mathrm{N}_{2} \mathrm{O}$ release (Bremner 1997; Bateman and Baggs 2005; Baggs 2008). 


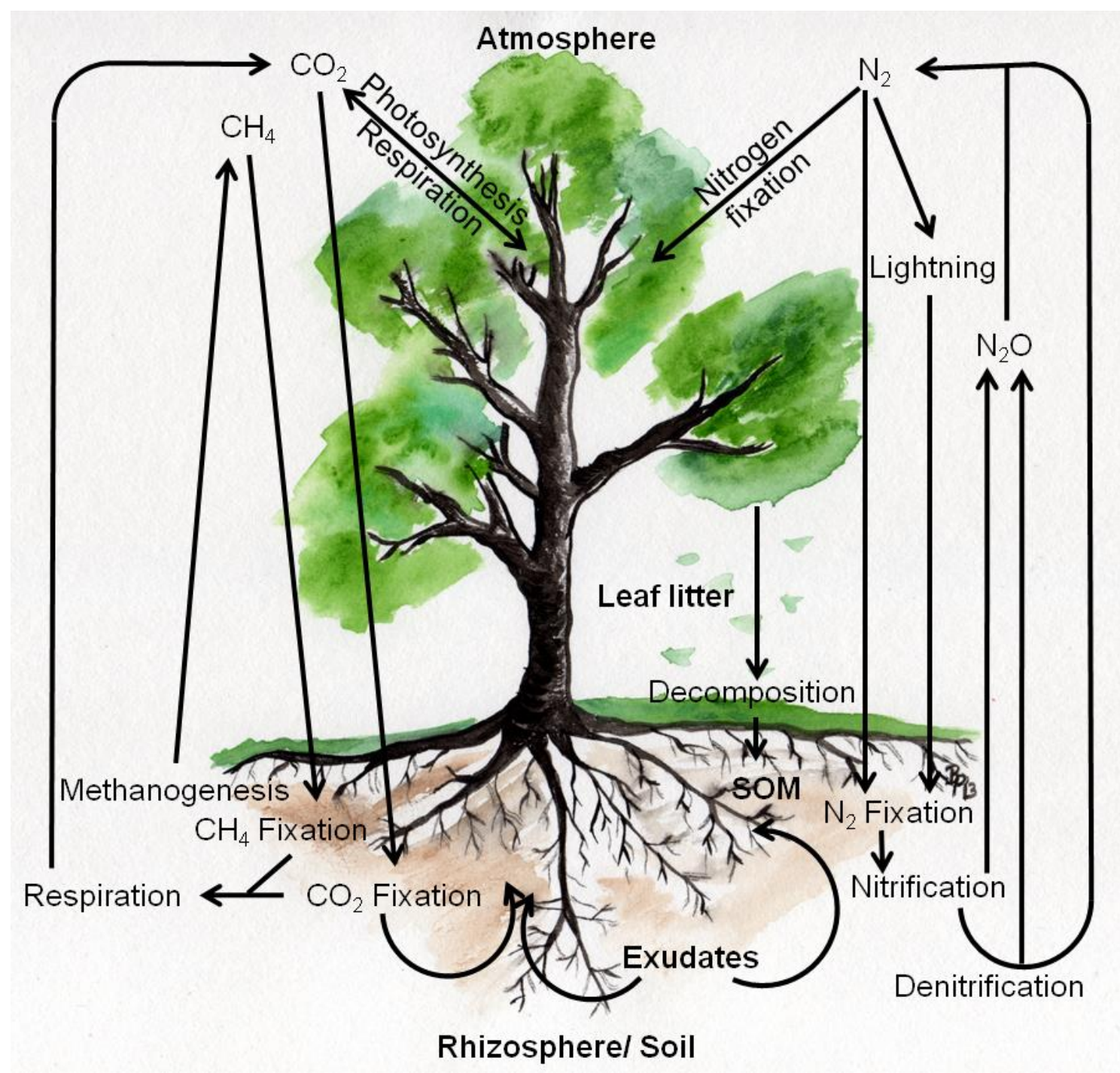

Figure 1. A simplified diagram of above- and belowground processes driving the global carbon (C) and nitrogen (N) cycles. Summarized according to Brady and Weil (2002).

Beside agricultural soils, temperate forest soils are relevant natural sources of atmospheric $\mathrm{N}_{2} \mathrm{O}$ (Kesik et al. 2005). Parameters controlling denitrification in soils are nitrate $\left(\mathrm{NO}_{3}{ }^{-}\right)$concentration, soil aeration and the labile $\mathrm{C}$ availability serving as energy source for $\mathrm{NO}_{3}{ }^{-}$catabolism (Firestone and Davidson 1989; Wrage et al. 2001; Ruser et al. 2006; Ciarlo et al. 2008). Nitrogen interacts strongly with the C cycle and thereby affects the $\mathrm{CO}_{2}$ and $\mathrm{CH}_{4}$ balance (Hungate et al. 2003; Gruber and Galloway 2008). Forests and forest soils are important sinks of carbon originating from $\mathrm{CO}_{2}$ and $\mathrm{CH}_{4}$. The stored $\mathrm{C}$ in aboveground biomass by European forests increased over the past decades, as harvesting was lower than growth (Ciais et al. 2008a; Ciais et al. 2008b). In contrast, likely due to higher belowground $\mathrm{C}$ allocation, root turnover and $\mathrm{N}$ fertilization grassland soils sequester more C than forest soils (Schulze et al. 2010). 
Furthermore, with approximately 3-5.7 $\mathrm{Tg} \mathrm{CH}_{4} \mathrm{yr}^{-1}$ temperate forest soils represent one of the most important terrestrial sinks for atmospheric $\mathrm{CH}_{4}$, (Dutaur and Verchot 2007; Curry 2009; Ishizuka et al. 2009). The atmospheric concentration of $\mathrm{CH}_{4}$ increased over the last 150 years by $248 \%$, from 715 ppb in pre-industrial times to 1774 ppb nowadays (Forster 2007). Methane reacts with hydroxyl radicals in the atmosphere and is consumed in aerobic soils by methylotrophic and methanotrophic soil microorganisms, and in anaerobic micro sites by nitrifying soil microorganisms (Mosier et al. 1991; Mosier 1998; Le Mer and Roger 2001).

Forest soils exhibit surface layers of varying thickness, so called $\mathrm{O}$ horizons, constituted of dead organic materials in various decomposition stages (Brady and Weil 2002). The A horizon of forest soil, containing some of the surface litter, is thinner compared to grassland soil (Brady and Weil 2002). Furthermore, a higher soil pH, temperature, respiration, amoeba abundance, $\mathrm{C}: \mathrm{N}$ ratio, and $\mathrm{NO}_{3}{ }^{-}$concentration, as well as an increased phosphorus (P), C, N and $\mathrm{NH}_{4}{ }^{+}$content, was detected in forest soils (Saviozzi et al. 2001; Alt et al. 2011; Nacke et al. 2011; Naether et al. 2012). A higher net uptake of greenhouse gases by forest soil than by grassland, peatland and cropland soils was shown (Schulze et al. 2010).

Soil is considered to harbor an extraordinarily diverse variety of microbial species. It probably represents the environment with the highest level of prokaryotic diversity on earth (Delmont et al. 2011). A few grams of soil can contain billions of microorganisms and thousands of different species (Knietsch et al. 2003). This enormous species pool is enabled through the remarkable range of niches and habitats present in soil. Aerobic and anaerobic micro-zones exist close to each other within soil and $\mathrm{pH}$, temperature, water and nutrient content can vary widely in an area of only a few square millimeters (Brady and Weil 2002). Furthermore, hot spots of decaying organic materials may be present within soils (Brady and Weil 2002). Forest soils are known to be phylum rich but species poor at the bacterial level whereas agricultural soils are phylum poor but species rich (Roesch et al. 2007). Furthermore, soil bacterial diversity and community structure differs significantly between forest and grassland soils (Nacke et al. 2011).

\section{Parameters influencing soil microbial community composition and activity}

Biotic and abiotic factors influencing the composition, activity and interaction of soil microbial communities are complex and still poorly understood. The knowledge on factors altering microbial diversity, abundance and distribution builds the basis to 
predict ecosystem responses to environmental changes and allows deciphering the role of single microbial taxa (Griffiths et al. 2011).

Numerous studies focusing on the role of microbial diversity for ecosystem functions are available (Torsvik and Øvreås 2002; Fierer and Jackson 2006; Wertz et al. 2006; Cuhel et al. 2010; Philippot et al. 2013). Wertz and his colleagues pointed out that the biogeochemical cycles analyzed in their studies will be more or less unaffected by loss in soil bacterial diversity, if not all functional groups are eliminated and the abundance of these groups can be recovered (Wertz et al. 2006; Wertz et al. 2007). This assumption is based on the high levels of functional redundancy which they observed for the analyzed functional groups. However, most of the studies concentrated on cataloguing bacterial diversity and changes in bacterial diversity affected by environmental disturbance. The outcome is that bacterial diversity in soils was underestimated so far and the perspective for future discoveries is overwhelming (Dunbar et al. 2002; Tringe et al. 2005). It is also well known that a huge variety of biotic and abiotic factors influence the composition and diversity of soil bacterial communities. Influencing abiotic factors are amongst others soil temperature, water content, $\mathrm{pH}$, nutrient content, soil aeration, soil texture, fertilization, and pesticide treatment. Biotic factors determining soil microbial communities include plant species identity and diversity, as well as animals of different trophic levels. Fierer and Jackson (2006) observed that soil $\mathrm{pH}$ represents a major predictor of bacterial richness, diversity and overall community composition. They detected the lowest level of diversity and richness in acidic soils. These results were supported by pyrosequencing data from Lauber et al. (2009), a wetland soil study by Hartman et al. (2008) and a pH gradient analysis of an arable soil conducted by Rousk et al. (2010). The extensive study of soil property influences on bacterial community structure conducted by Nacke and coworkers (2011) revealed that $\mathrm{pH}$ had the strongest effect, while management type and other soil properties had a minor impact. Furthermore, an influence of tree species on bacterial diversity was indicated, as diversity and richness estimates were different for the analyzed spruce and beech sites (Nacke et al. 2011). Other parameters which were shown to affect soil microbial communities comprise soil type, soil texture, C:N ratio, as well as mineral, carbon and nitrogen content (Sessitsch et al. 2001; Girvan et al. 2003; Fierer et al. 2007; Ge et al. 2010a; Ge et al. 2010b; Uroz et al. 2011). Hansel et al. (2008) found that bacterial community structure changed significantly along a soil depth profile, due to changes in carbon availability, water content, and $\mathrm{pH}$. 


\subsection{Effect of plant species identity and diversity on soil microbial communities}

The long discussed hypothesis that aboveground plant diversity drives the belowground microbial diversity was not answered sufficiently yet. Several studies found no clear relationship between soil bacterial diversity and plant diversity (Felske et al. 2000; Buckley and Schmidt 2001; Kowalchuk et al. 2002; Fierer and Jackson 2006; Zul et al. 2007). Contradictorily, it has been shown that plant diversity levels in grassland soils affect the bacterial community composition and diversity (Grüter et al. 2006). Two studies, both focusing on grassland soils, revealed a weak effect of plant composition on belowground bacterial community composition (Kennedy et al. 2004; Nunan et al. 2005). Furthermore, it has been shown that plant species such as clover, bean, or alfalfa impact bulk soil, rhizosphere and rhizoplane inhabiting microbial communities and also soil patterns (Wieland et al. 2001). However, whether these plant driven changes in community composition are direct or indirect effects remains unclear. Several studies reported on plant-dependent rhizosphere bacterial communities, which are directly affected by plant rhizodeposits and the thereby created microenvironment (Smalla et al. 2001; Kowalchuk et al. 2002; Kuske et al. 2002; Barea et al. 2005; Costa et al. 2006). This coupling is explained by close mutualistic interactions in this unique habitat. Nevertheless, these effects are limited to the rhizosphere and do not appear in microbial communities inhabiting bulk soil (Kennedy et al. 2004).

Roots release rhizodeposits into the rhizosphere which are available only in a limited area around the respective root. Rhizodeposits comprise mucilage, exudates and cells serving as $\mathrm{C}$ and nutrient source for microorganisms (Dennis et al. 2010). Plant species differ in their traits, which are reflected by root morphology, mycorrhizal symbiosis and litter quality. Beside the complex plant root system, litter is another $\mathrm{C}$ and nutrient source supplied by plants. Leaf litter builds the upper part of the soil horizon and is decomposed by a specialized fungal, archaeal and bacterial community and leaching. Different litter qualities are decomposed by particular decomposer species at different rates, as leaf litter with a low $\mathrm{C}: \mathrm{N}$ ratio and lignin content is preferred and its decomposition rates are higher (Jacob et al. 2010b). Additionally, the amount of litter present on soil and its interactions with abiotic factors such as temperature and moisture influence soil and litter bacterial community structures (Chemidlin Prevost-Boure et al. 2011). A complex cocktail of sugars, vitamins, ions, organic polymers (lignin), amino acids, organic acids, fatty acids and other primary and secondary metabolites is released 
from root exudation, decaying roots, or litter leaching and decomposition (Dennis et al. 2010; Gessner et al. 2010).

Root exudates are known to exhibit stimulatory or inhibitory effects on rhizosphere microbial communities (Uren 2007). Hartmann et al. (2009) were able to show this plant-driven alteration in bacterial community structures in the rhizosphere of herbaceous plants. Another effect of root exudation, nutrient uptake and $\mathrm{N}_{2}$ assimilation by plants is an acidification of soil, and thus an indirect impact of plant activity on soil microbial communities via $\mathrm{pH}$ changes (de Schrijver et al. 2012; Langenbruch et al. 2012). Nacke et al. (2011) found significant differences in bacterial community structure by comparing grassland and forest soils. Within a study conducted in Austria, soil bacterial communities in pine, oak-hornbeam and spruce-fir-beech forests were investigated. In comparison with other study sites the analyzed pine forest harbored distinct bacterial communities (Hackl et al. 2004). Nevertheless, only few surveys explored the impact of tree species identity and tree species diversity on soil-inhabiting bacterial communities and datasets allowing a robust statistical analysis are rare.

\subsection{Impact of ants on soil microbial community composition}

Another factor altering diversity, distribution, abundance, and activity of soil microbial communities are ecosystem engineers. Ecosystem engineers are organisms that directly or indirectly change resource availability by shifting the physical states of biotic or abiotic materials and thereby modify, maintain or create habitats (Jones et al. 1994). Ants are known to be ecosystem engineers, as they significantly alter physical, chemical and biological properties of their environment (Frouz et al. 2003; Frouz et al. 2005). Ants assigned to the family Formicidae within the order Hymenoptera are colonial insects which actively shape and use soil as a habitat. Nest construction activity alters soil properties such as $\mathrm{pH}$, water holding capacity, soil structure, and organic matter content, as well as exchangeable calcium $(\mathrm{Ca})$, magnesium $(\mathrm{Mg})$, kalium $(\mathrm{K})$ and phosphate $\left(\mathrm{PO}_{4}\right)$ (De Bruyn and Conacher 1990). Furthermore, it has been shown that ants affect the microorganism-driven $\mathrm{C}$ and $\mathrm{N}$ turnover as well as other microbial activities, as they are responsible for increased active respiration, denitrification, and methanogenesis in soil due to additional input of N-rich organic compounds and the inhibition of nitrogen fixation (Golichenkov et al. 2009).

Ants utilize resources efficiently due to their social behavior and affect as mutualistic partners and predators the structure of food webs (Letourneau and Dyer 1998; 
Schumacher and Platner 2009). Ants and aphids are common mutualistic partners. Ants collect honeydew produced by aphids and in return, protect aphids, provide shelter, brood care and remove exuviae and dead aphids (Banks 1962; Stadler and Dixon 2005; Matsuura and Yashiro 2006). Ant-tended aphids excrete smaller honeydew droplets containing a significantly higher concentration of amino acids, sucrose, and trehalose at a higher rate (Yao and Akimoto 2001; Yao 2002.). The honeydew collected and transported to ant nests can be used as $\mathrm{C}$ source by soil microbes and thereby affects soil microbial activity and community structure.

\section{16S rRNA and 16S rRNA genes as molecular markers in microbial ecology studies}

Culture-based approaches enabled the isolation, description and classification of several bacterial species. However, more than $99 \%$ of the expected bacterial species are not cultivable and the cultured bacteria are not representative for the soil environment (Amann and Ludwig 2000; Griffiths et al. 2011). The development of cultureindependent metagenomic techniques and the use of 16S rRNA genes as phylogenetic marker contributed to overcome the drawbacks of culture-dependent approaches.

The 16S rRNA is part of the small subunit of the ribosome and thus is present in each prokaryotic cell. Furthermore, the 16S rRNA gene contains highly conserved as well as variable regions which allow the determination of phylogenetic relashionships of the prokaryotic world. The construction of $16 \mathrm{~S}$ rRNA gene libraries and subsequent sequencing of derived clones improved our knowledge on soil bacterial populations in different habitats (Chandler et al. 1997; Brümmer et al. 2003; Heijs et al. 2007). A relatively new sequencing method, pyrosequencing, improved the assessment of the metagenomic diversity, avoiding biases introduced by the use of clone libraries (Shendure and Ji 2008). Although the use of 16S rRNA and 16S rRNA genes as phylogenetic marker exibits some drawbacks, it is so far the best way to analyze prokaryotic community structures and ecological interactions. Microbial community analysis based on rRNA genes includes DNA from dead or dormant populations, while rRNA-based community analysis reveals information on a microbial community that is or recently has been active (Griffiths et al. 2000; De Nobili et al. 2001; Lennon and Jones 2011). Therefore, the combination of RNA-based and DNA-based approaches may reveal the portion of the microbial community that is either active or primed to become active (DeAngelis and Firestone 2012). 


\section{Objectives of this thesis}

This study is intended to analyze the influence of different factors influencing soil microbial diversity, community composition and activity, such as tree species identity, tree species diversity, leaf litter overlay, $\mathrm{N}$ fertilization and ant activity. In order to estimate the contribution of single factors, most of the experiments were conducted under controlled field and laboratory conditions. Additionally, some studies analyzed the natural conditions to evaluate the adaptability of the results obtained under artificial conditions. Chapter B.I comprises three studies analyzing the influence of single tree species, tree species diversity, leaf litter and seasons on the soil inhabiting microbial community structure and activity. Chapter B.II includes three surveys assessing the influence of high $\mathrm{NO}_{3}{ }^{-}$depositions into soils on $\mathrm{CH}_{4}$ and $\mathrm{N}_{2} \mathrm{O}$ gas fluxes, and the soil inhabiting active microbial community in temperate broad-leaved forests. Chapter B.III consists of two studies analyzing the impact of ants and their activity on soil microbial communities. Furthermore, microbial communities present in biological soil crusts, sampled at two sites in extrazonal mountain dry steppes in northern Mongolia, were compared (Chapter B.IV). A schematic summary of the study concept is depicted in Figure 2. 


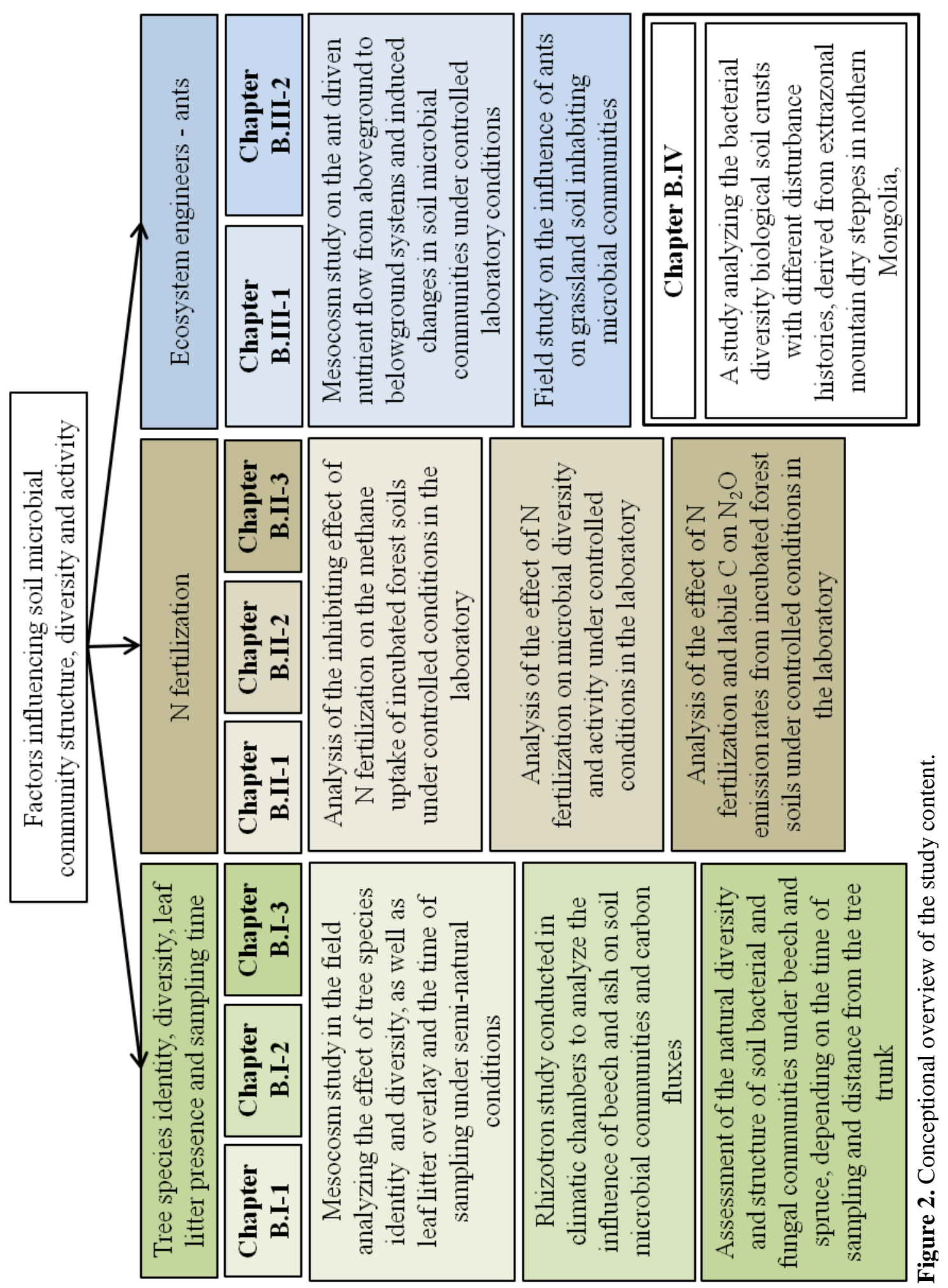




\section{References}

Alt, F., Oelmann, Y., Herold, N., Schrumpf, M. and Wilcke, W. (2011) Phosphorus partitioning in grassland and forest soils of Germany as related to land-use type, management intensity, and land use-related pH. Journal of Plant Nutrition and Soil Science 174, 195-209.

Amann, R. and Ludwig, W. (2000) Ribosomal RNA-targeted nucleic acid probes for studies in microbial ecology. FEMS Microbiology Reviews 24, 555-565.

Baggs, E.M. (2008) A review of stable isotope techniques for $\mathrm{N}_{2} \mathrm{O}$ source partitioning in soils: recent progress, remaining challenges and future considerations. Rapid Communications in Mass Spectrometry 22, 1664-1672.

Balvanera, P., Pfisterer, A.B., Buchmann, N., He, J.-S., Nakashizuka, T., Raffaelli, D. and Schmid, B. (2006) Quantifying the evidence for biodiversity effects on ecosystem functioning and services. Ecology Letters 9, 1146-1156.

Banks, C.J. (1962) Effects of the ant Lasius niger (L.) on insects preying on small populations of Aphis fabae Scop. on bean plants. Annals of Applied Biology 50, 669-679.

Barea, J., Pozo, M., Azcón, R. and Azcón-Aguilar, C. (2005) Microbial co-operation in the rhizosphere. Journal of Experimental Botany 56, 1761-1778.

Bateman, E.J. and Baggs, E.M. (2005) Contributions of nitrification and denitrification to $\mathrm{N}_{2} \mathrm{O}$ emissions from soils at different water-filled pore space. Biology and Fertility of Soils 41, 379-388.

Brady, N.C. and Weil, R.R. (2002) The Nature and Properties of Soils. Upper Saddler River, New Jersey 07458: Pearson Education.

Bremner, J. (1997) Sources of nitrous oxide in soils. Nutrient Cycling in Agroecosystems 49, 7-16.

Brümmer, I.H., Felske, A. and Wagner-Döbler, I. (2003) Diversity and seasonal variability of beta-Proteobacteria in biofilms of polluted rivers: analysis by temperature gradient gel electrophoresis and cloning. Applied and Environmental Microbiology 69, 4463-4473.

Buckley, D. and Schmidt, T. (2001) The Structure of Microbial Communities in Soil and the Lasting Impact of Cultivation. Microbial Ecology 42, 11-21. 
Cardinale, B.J., Duffy, J.E., Gonzalez, A., Hooper, D.U., Perrings, C., Venail, P., Narwani, A., Mace, G.M., Tilman, D., Wardle, D.A., Kinzig, A.P., Daily, G.C., Loreau, M., Grace, J.B., Larigauderie, A., Srivastava, D.S. and Naeem, S. (2012) Biodiversity loss and its impact on humanity. Nature 486, 59-67.

Chandler, D.P., Brockman, F.J. and Fredrickson, J.K. (1997) Use of 16S rDNA clone libraries to study changes in a microbial community resulting from ex situ perturbation of a subsurface sediment. FEMS Microbiology Reviews 20, 217-230.

Chapin, F.r., Zavaleta, E., Eviner, V., Naylor, R., Vitousek, P., Reynolds, H., Hooper, D., Lavorel, S., Sala, O., Hobbie, S., Mack, M. and Díaz, S. (2000) Consequences of changing biodiversity. Nature 405, 234-242.

Chemidlin Prevost-Boure, N., Maron, P.-A., Ranjard, L., Nowak, V., Dufrene, E., Damesin, C., Soudani, K. and Lata, J.-C. (2011) Seasonal dynamics of the bacterial community in forest soils under different quantities of leaf litter. Applied Soil Ecology 47, 14-23.

Ciais, P., Borges, A., Abril, G., Meybeck, M., Folberth, G., Hauglustaine, D. and Janssens, I. (2008a) The impact of lateral carbon fluxes on the European carbon balance. Biogeosciences 5, 1259-1271.

Ciais, P., Schelhaas, M.J., Zaehle, S., Piao, S.L., Cescatti, A., Liski, J., Luyssaert, S., Le-Maire, G., Schulze, E.D., Bouriaud, O., Freibauer, A., Valentini, R. and Nabuurs, G.J. (2008b) Carbon accumulation in European forests. Nature Geoscience 1, 425-429.

Ciarlo, E., Conti, M., Bartoloni, N. and Rubio, G. (2008) Soil $\mathrm{N}_{2} \mathrm{O}$ emissions and $\mathrm{N}_{2} \mathrm{O} /\left(\mathrm{N}_{2} \mathrm{O}+\mathrm{N}_{2}\right)$ ratio as affected by different fertilization practices and soil moisture. Biology and Fertility of Soils 44, 991-995.

Costa, R., Götz, M., Mrotzek, N., Lottmann, J., Berg, G. and Smalla, K. (2006) Effects of site and plant species on rhizosphere community structure as revealed by molecular analysis of microbial guilds. FEMS Microbiology Ecology 56, 236-249.

Cuhel, J., Simek, M., Laughlin, R., Bru, D., Chèneby, D., Watson, C. and Philippot, L. (2010) Insights into the effect of soil $\mathrm{pH}$ on $\mathrm{N}_{2} \mathrm{O}$ and $\mathrm{N}_{2}$ emissions and denitrifier community size and activity. Applied and Environmental Microbiology 76, 18701878.

Curry, C. (2009) The consumption of atmospheric methane by soil in a simulated future climate. Biogeosciences, 2355-2367. 
De Bruyn, L.A.L. and Conacher, A.J. (1990) The role of termites and ants in soil modification - a review. Soil Research 28, 55-93.

De Nobili, M., Contin, M., Mondini, C. and Brookes, P.C. (2001) Soil microbial biomass is triggered into activity by trace amounts of substrate. Soil Biology and Biochemistry 33, 1163-1170.

de Schrijver, A., de Frenne, P., Staelens, J., Verstraeten, G., Muys, B., Vesterdal, L., Wuyts, K., van Nevel, L., Schelfhout, S., de Neve, S. and Verheyen, K. (2012) Tree species traits cause divergence in soil acidification during four decades of postagricultural forest development. Global Change Biology 18, 1127-1140.

DeAngelis, K.M. and Firestone, M.K. (2012) Phylogenetic Clustering of Soil Microbial Communities by $16 \mathrm{~S}$ rRNA but Not $16 \mathrm{~S}$ rRNA Genes. Applied and Environmental Microbiology 78, 2459-2461.

Delmont, T.O., Robe, P., Cecillon, S., Clark, I.M., Constancias, F., Simonet, P., Hirsch, P.R. and Vogel, T.M. (2011) Accessing the soil metagenome for studies of microbial diversity. Applied and Environmental Microbiology 77, 1315-1324.

Dennis, P.G., Miller, A.J. and Hirsch, P.R. (2010) Are root exudates more important than other sources of rhizodeposits in structuring rhizosphere bacterial communities? FEMS Microbiology Ecology 72, 313-327.

Drake, J.E., Gallet-Budynek, A., Hofmockel, K.S., Bernhardt, E.S., Billings, S.A., Jackson, R.B., Johnsen, K.S., Lichter, J., McCarthy, H.R., McCormack, M.L., Moore, D.J.P., Oren, R., Palmroth, S., Phillips, R.P., Pippen, J.S., Pritchard, S.G., Treseder, K.K., Schlesinger, W.H., DeLucia, E.H. and Finzi, A.C. (2011) Increases in the flux of carbon belowground stimulate nitrogen uptake and sustain the long-term enhancement of forest productivity under elevated $\mathrm{CO}_{2}$. Ecology Letters 14, 349-357.

Dunbar, J., Barns, S., Ticknor, L. and Kuske, C. (2002) Empirical and theoretical bacterial diversity in four Arizona soils. Applied and Environmental Microbiology 68, 3035-3045.

Dutaur, L. and Verchot, L. (2007) A global inventory of the soil $\mathrm{CH}_{4}$ sink. Global Biogeochemical Cycles 21, -.

Eisenhauer, N., Cesarz, S., Koller, R., Worm, K. and Reich, P. (2012) Global change belowground: impacts of elevated $\mathrm{CO}_{2}$, nitrogen, and summer drought on soil food webs and biodiversity. Global Change Biology 18, 435-447. 
Felske, A., Wolterink, A., Van Lis, R., De Vos, W. and Akkermans, A. (2000) Response of a soil bacterial community to grassland succession as monitored by $16 \mathrm{~S}$ rRNA levels of the predominant ribotypes. Applied and Environmental Microbiology 66, 3998-4003.

Fierer, N., Bradford, M. and Jackson, R. (2007) Toward an ecological classification of soil bacteria. Ecology 88, 1354-1364.

Fierer, N. and Jackson, R. (2006) The diversity and biogeography of soil bacterial communities. Proceedings of the National Academy of Sciences U S A 103, 626631.

Firestone, M.K. and Davidson, E.A. (1989) Microbiological basis of $\mathrm{NO}$ and $\mathrm{N}_{2} \mathrm{O}$ production and consumption in soil. pp.7-21. Chichester: John Wiley \& Sons.

Forster, P., Ramaswamy, V., Artaxo, P., Bertsen, T., Betts, R., Fahey, D.W., Haywood, J., Lean, J., Lowe, D.C., Myhre, G., Nganga, J., Prinn, R., Raga, G., Schulz, M., Van Dorland, R. (2007) Changes in atmospheric constituents and in radiative forcing. Cambridge, United Kingdom and New York, NY, USA.: IPCC.

Frouz, J., Holec, M. and Kalč́́k, J. (2003) The effect of Lasius niger (Hymenoptera, Formicidae) ant nest on selected soil chemical properties. Pedobiologia 47, 205212.

Frouz, J., Kalcik, J. and Cudlin, P. (2005) Accumulation of phosphorus in nests of red wood ants Formica s. str. Annales Zoologici Fennici 42, 269-275.

Ge, Y., Chen, C., Xu, Z., Eldridge, S.M., Chan, K.Y., He, Y. and He, J.Z. (2010a) Carbon/nitrogen ratio as a major factor for predicting the effects of organic wastes on soil bacterial communities assessed by DNA-based molecular techniques. Environmental Science and Pollution Research 17, 807-815.

Ge, Y., Chen, C., Xu, Z., Oren, R. and He, J.-Z. (2010b) The Spatial Factor, Rather than Elevated CO2, Controls the Soil Bacterial Community in a Temperate Forest Ecosystem. Applied and Environmental Microbiology 76, 7429-7436.

Gessner, M., Swan, C., Dang, C., Mckie, B., Bardgett, R., Wall, D. and Hattenschwiler, S. (2010) Diversity meets decomposition. Trends in Ecology \& Evolution 25, 372380.

Girvan, M.S., Bullimore, J., Pretty, J.N., Osborn, A.M. and Ball, A.S. (2003) Soil Type Is the Primary Determinant of the Composition of the Total and Active Bacterial Communities in Arable Soils. Applied and Environmental Microbiology 69, 18001809. 
Golichenkov, M., Neimatov, A. and Kiryushin, A. (2009) Microbiological activity of soils populated by Lasius niger ants. Eurasian Soil Science, 788-792.

Griffiths, R.I., Thomson, B.C., James, P., Bell, T., Bailey, M. and Whiteley, A.S. (2011) The bacterial biogeography of British soils. Environmental Microbiology 13, 1642-1654.

Griffiths, R.I., Whiteley, A.S., O'Donnell, A.G. and Bailey, M.J. (2000) Rapid method for coextraction of DNA and RNA from natural environments for analysis of ribosomal DNA- and rRNA-based microbial community composition. Applied and Environmental Microbiology 66, 5488-5491.

Gruber, N. and Galloway, J.N. (2008) An Earth-system perspective of the global nitrogen cycle. Nature 451, 293-296.

Grüter, D., Schmid, B. and Brandl, H. (2006) Influence of plant diversity and elevated atmospheric carbon dioxide levels on belowground bacterial diversity. $B M C$ Microbiology 6, 68.

Hackl, E., Zechmeister-Boltenstern, S., Bodrossy, L. and Sessitsch, A. (2004) Comparison of diversities and compositions of bacterial populations inhabiting natural forest soils. Applied and Environmental Microbiology 70, 5057-5065.

Hansel, C.M., Fendorf, S., Jardine, P.M. and Francis, C.A. (2008) Changes in Bacterial and Archaeal Community Structure and Functional Diversity along a Geochemically Variable Soil Profile. Applied and Environmental Microbiology 74, 1620-1633.

Hartman, W., Richardson, C., Vilgalys, R. and Bruland, G. (2008) Environmental and anthropogenic controls over bacterial communities in wetland soils. Proceedings of the National Academy of Sciences U S A 105, 17842-17847.

Hartmann, A., Schmid, M., van Tuinen, D. and Berg, G. (2009) Plant-driven selection of microbes. Plant and Soil 321, 235-257.

Heijs, S., Haese, R., Wielen, P.J.J., Forney, L. and Elsas, J. (2007) Use of 16S rRNA Gene Based Clone Libraries to Assess Microbial Communities Potentially Involved in Anaerobic Methane Oxidation in a Mediterranean Cold Seep. Microbial Ecology 53, 384-398.

Hooper, D.U., Adair, E.C., Cardinale, B.J., Byrnes, J.E.K., Hungate, B.A., Matulich, K.L., Gonzalez, A., Duffy, J.E., Gamfeldt, L. and O'Connor, M.I. (2012) A global synthesis reveals biodiversity loss as a major driver of ecosystem change. Nature 486, $105-108$. 
Hooper, D.U., Chapin, F.S., Ewel, J.J., Hector, A., Inchausti, P., Lavorel, S., Lawton, J.H., Lodge, D.M., Loreau, M., Naeem, S., Schmid, B., Setälä, H., Symstad, A.J., Vandermeer, J. and Wardle, D.A. (2005) Effects of biodiversity on ecosystem functioning: A consensus of current knowledge. Ecological Monographs 75, 3-35. Hungate, B.A., Dukes, J.S., Shaw, M.R., Luo, Y. and Field, C.B. (2003) Nitrogen and Climate Change. Science 302, 1512-1513.

Ishizuka, S., Sakata, T., Sawata, S., Ikeda, S., Sakai, H., Takenaka, C., Tamai, N., Onodera, S.-i., Shimizu, T., Kan-na, K., Tanaka, N. and Takahashi, M. (2009) Methane uptake rates in Japanese forest soils depend on the oxidation ability of topsoil, with a new estimate for global methane uptake in temperate forest. Biogeochemistry 92, 281-295.

Ives, A.R. and Carpenter, S.R. (2007) Stability and Diversity of Ecosystems. Science 317, 58-62.

Jacob, M., Leuschner, C. and Thomas, F.M. (2010a) Productivity of temperate broadleaved forest stands differing in tree species diversity. Annals of Forest Science 67.

Jacob, M., Viedenz, K., Polle, A. and Thomas, F.M. (2010b) Leaf litter decomposition in temperate deciduous forest stands with a decreasing fraction of beech (Fagus sylvatica). Oecologia 164, 1083-1094.

Jones, C.G., Lawton, J.H. and Shachak, M. (1994) Organisms as ecosystem engineers. Oikos 69, 373-386.

Kennedy, N., Brodie, E., Connolly, J. and Clipson, N. (2004) Impact of lime, nitrogen and plant species on bacterial community structure in grassland microcosms. Environmental Microbiology 6, 1070-1080.

Kesik, M., Ambus, P., Baritz, R., Brüggemann, N., Butterbach-Bahl, K., Damm, M., Duyzer, J., Horváth, L., Kiese, R., Kitzler, B., Leip, A., Li, C., Pihlatie, M., Pilegaard, K., Seufert, G., Simpson, D., Skiba, U., Smiatek, G., Vesala, T. and Zechmeister-Boltenstern, S. (2005) Inventories of $\mathrm{N}_{2} \mathrm{O}$ and $\mathrm{NO}$ emissions from European forest soils. Biogeosciences Discuss 2, 779-827.

Knietsch, A., Waschkowitz, T., Bowien, S., Henne, A. and Daniel, R. (2003) Metagenomes of complex microbial consortia derived from different soils as sources for novel genes conferring formation of carbonyls from short-chain polyols on Escherichia coli. Journal of Molecular Microbiology and Biotechnology 5, 46-56. 
Kowalchuk, G., Buma, D., de Boer, W., Klinkhamer, P. and van Veen, J. (2002) Effects of above-ground plant species composition and diversity on the diversity of soilborne microorganisms. Antonie Van Leeuwenhoek 81, 509-520.

Kuske, C., Ticknor, L., Miller, M., Dunbar, J., Davis, J., Barns, S. and Belnap, J. (2002) Comparison of soil bacterial communities in rhizospheres of three plant species and the interspaces in an arid grassland. Applied and Environmental Microbiology 68, 1854-1863.

Langenbruch, C., Helfrich, M. and Flessa, H. (2012) Effects of beech (Fagus sylvatica), ash (Fraxinus excelsior) and lime (Tilia spec.) on soil chemical properties in a mixed deciduous forest. Plant and Soil 352, 389-403.

Lauber, C., Hamady, M., Knight, R. and Fierer, N. (2009) Pyrosequencing-Based Assessment of Soil pH as a Predictor of Soil Bacterial Community Structure at the Continental Scale. Applied and Environmental Microbiology 5111-5120.

Le Mer, J. and Roger, P. (2001) Production, oxidation, emission and consumption of methane by soils: A review. European Journal of Soil Biology 37, 25-50.

Lennon, J.T. and Jones, S.E. (2011) Microbial seed banks: the ecological and evolutionary implications of dormancy. Nature Reviews Microbiology 9, 119-130.

Letourneau, D.K. and Dyer, L.A. (1998) Experimental test in lowland tropical forest shows top-down effects through four trophic levels. Ecology 79, 1678-1687.

Leuschner, C., Jungkunst, H.F. and Fleck, S. (2009) Functional role of forest diversity: Pros and cons of synthetic stands and across-site comparisons in established forests. Basic and Applied Ecology 10, 1-9.

Loreau, M., Naeem, S., Inchausti, P., Bengtsson, J., Grime, J., Hector, A., Hooper, D., Huston, M., Raffaelli, D., Schmid, B., Tilman, D. and Wardle, D. (2001) Biodiversity and ecosystem functioning: current knowledge and future challenges. Science 294, 804-808.

Luyssaert, S., Ciais, P., Piao, S., Schulze, E., Jung, M., Zaehle, S., Schelhaas, M., Reichstein, M., Churkina, G., Papale, D., Abril, G., Beer, C., Grace, J., Loustau, D., Matteucci, G., Magnani, F., Nabuurs, G., Verbeeck, H., Sulkava, M., van der Werf, G., Janssens, I. and Team, C.-I.S. (2010) The European carbon balance. Part 3: forests. Global Change Biology 16, 1429-1450.

Macdonald, C.A., Anderson, I.C., Bardgett, R.D. and Singh, B.K. (2011) Role of nitrogen in carbon mitigation in forest ecosystems. Current Opinion in Environmental Sustainability 3, 303-310. 
Matsuura, K. and Yashiro, T. (2006) Aphid egg protection by ants: a novel aspect of the mutualism between the tree-feeding aphid Stomaphis hirukawai and its attendant ant Lasius productus. Naturwissenschaften 93, 506-510.

Mosier, A. (1998) Soil processes and global change. Biology and Fertility of Soils 27, 221-229.

Mosier, A., Schimel, D., Valentine, D., Bronson, K. and Parton, W. (1991) Methane and nitrous oxide fluxes in native, fertilized and cultivated grasslands. Nature 350, $330-332$.

Nacke, H., Thürmer, A., Wollherr, A., Will, C., Hodac, L., Herold, N., Schöning, I., Schrumpf, M. and Daniel, R. (2011) Pyrosequencing-based assessment of bacterial community structure along different management types in German forest and grassland soils. PLoS One 6, e17000.

Naether, A., Foesel, B.U., Naegele, V., Wüst, P.K., Weinert, J., Bonkowski, M., Alt, F., Oelmann, Y., Polle, A., Lohaus, G., Gockel, S., Hemp, A., Kalko, E.K., Linsenmair, K.E., Pfeiffer, S., Renner, S., Schöning, I., Weisser, W.W., Wells, K., Fischer, M., Overmann, J. and Friedrich, M.W. (2012) Environmental factors affect Acidobacterial communities below the subgroup level in grassland and forest soils. Applied and Environmental Microbiology 78, 7398-7406.

Norby, R.J., Warren, J.M., Iversen, C.M., Medlyn, B.E. and McMurtrie, R.E. (2010) $\mathrm{CO}_{2}$ enhancement of forest productivity constrained by limited nitrogen availability. Proceedings of the National Academy of Sciences U S A 107, 1936819373.

Nunan, N., Daniell, T., Singh, B., Papert, A., McNicol, J. and Prosser, J. (2005) Links between plant and rhizoplane bacterial communities in grassland soils, characterized using molecular techniques. Applied and Environmental Microbiology 71, 6784-6792.

Oren, R., Ellsworth, D.S., Johnsen, K.H., Phillips, N., Ewers, B.E., Maier, C., Schafer, K.V.R., McCarthy, H., Hendrey, G., McNulty, S.G. and Katul, G.G. (2001) Soil fertility limits carbon sequestration by forest ecosystems in a $\mathrm{CO}_{2}$-enriched atmosphere. Nature 411, 469-472.

Palmborg, C., Scherer-Lorenzen, M., Jumpponen, A., Carlsson, G., Huss-Danell, K. and Högberg, P. (2005) Inorganic soil nitrogen under grassland plant communities of different species composition and diversity. Oikos 110, 271-282. 
Petchey, O. and Gaston, K. (2002) Extinction and the loss of functional diversity. Proceedings of the Royal Society 269, 1721-1727.

Philippot, L., Spor, A., Hénault, C., Bru, D., Bizouard, F., Jones, C.M., Sarr, A. and Maron, P.A. (2013) Loss in microbial diversity affects nitrogen cycling in soil. ISME Journal 7(8), 1609-19

Phillips, R.P., Finzi, A.C. and Bernhardt, E.S. (2011) Enhanced root exudation induces microbial feedbacks to $\mathrm{N}$ cycling in a pine forest under long-term $\mathrm{CO}_{2}$ fumigation. Ecology Letters 14, 187-194.

Roesch, L., Fulthorpe, R., Riva, A., Casella, G., Hadwin, A., Kent, A., Daroub, S., Camargo, F., Farmerie, W. and Triplett, E. (2007) Pyrosequencing enumerates and contrasts soil microbial diversity. ISME Journal 283-290.

Rousk, J., Baath, E., Brookes, P., Lauber, C., Lozupone, C., Caporaso, J., Knight, R. and Fierer, N. (2010) Soil bacterial and fungal communities across a pH gradient in an arable soil. ISME Journal 4, 1340-1351.

Ruser, R., Flessa, H., Russow, R., Schmidt, G., Buegger, F. and Munch, J.C. (2006) Emission of $\mathrm{N}_{2} \mathrm{O}, \mathrm{N}_{2}$ and $\mathrm{CO}_{2}$ from soil fertilized with nitrate: effect of compaction, soil moisture and rewetting. Soil Biology and Biochemistry 38, 263274.

Saviozzi, A., Levi-Minzi, R., Cardelli, R. and Riffaldi, R. (2001) A comparison of soil quality in adjacent cultivated, forest and native grassland soils. Plant and Soil 233, 251-259.

Scherber, C., Eisenhauer, N., Weisser, W.W., Schmid, B., Voigt, W., Fischer, M., Schulze, E.-D., Roscher, C., Weigelt, A., Allan, E., Beszler, H., Bonkowski, M., Buchmann, N., Buscot, F., Clement, L.W., Ebeling, A., Engels, C., Halle, S., Kertscher, I., Klein, A.-M., Koller, R., Konig, S., Kowalski, E., Kummer, V., Kuu, A., Lange, M., Lauterbach, D., Middelhoff, C., Migunova, V.D., Milcu, A., Muller, R., Partsch, S., Petermann, J.S., Renker, C., Rottstock, T., Sabais, A., Scheu, S., Schumacher, J., Temperton, V.M. and Tscharntke, T. (2010) Bottomup effects of plant diversity on multitrophic interactions in a biodiversity experiment. Nature 468, 553-556.

Schulze, E.D., Ciais, P., Luyssaert, S., Schrumpf, M., Janssens, I.A., Thiruchittampalam, B., Theloke, J., Saurat, M., Bringezu, S., Lelieveld, J., Lohila, A., Rebmann, C., Jung, M., Bastviken, D., Abril, G., Grassi, G., Leip, A., Freibauer, A., Kutsch, W., Don, A., Nieschulze, J., BÖRner, A., Gash, J.H. and 
Dolman, A.J. (2010) The European carbon balance. Part 4: integration of carbon and other trace-gas fluxes. Global Change Biology 16, 1451-1469.

Schumacher, E. and Platner, C. (2009) Nutrient dynamics in a tritrophic system of ants, aphids and beans. Journal of Applied Entomology, 33-46.

Secretariat of the Convention on Biological Diversity (2010) Global Biodiversity Outlook 3. Montréal, 94 page

Sessitsch, A., Weilharter, A., Gerzabek, M.H., Kirchmann, H. and Kandeler, E. (2001) Microbial Population Structures in Soil Particle Size Fractions of a Long-Term Fertilizer Field Experiment. Applied and Environmental Microbiology 67, 42154224.

Shendure, J. and Ji, H. (2008) Next-generation DNA sequencing. Nature Biotechnology 26, $1135-1145$.

Smalla, K., Wieland, G., Buchner, A., Zock, A., Parzy, J., Kaiser, S., Roskot, N., Heuer, H. and Berg, G. (2001) Bulk and rhizosphere soil bacterial communities studied by denaturing gradient gel electrophoresis: plant-dependent enrichment and seasonal shifts revealed. Applied and Environmental Microbiology 67, 4742-4751.

Spehn, E.M., Hector, A., Joshi, J., Scherer-Lorenzen, M., Schmid, B., Bazeley-White, E., Beierkuhnlein, C., Caldeira, M.C., Diemer, M., Dimitrakopoulos, P.G., Finn, J.A., Freitas, H., Giller, P.S., Good, J., Harris, R., Högberg, P., Huss-Danell, K., Jumpponen, A., Koricheva, J., Leadley, P.W., Loreau, M., Minns, A., Mulder, C.P.H., O'Donovan, G., Otway, S.J., Palmborg, C., Pereira, J.S., Pfisterer, A.B., Prinz, A., Read, D.J., Schulze, E.D., Siamantziouras, A.S.D., Terry, A.C., Troumbis, A.Y., Woodward, F.I., Yachi, S. and Lawton, J.H. (2005) Ecosystem effects of biodiversity manipulation in european grasslands. Ecological Monographs 75, 37-63.

Stadler, B. and Dixon, A.F.G. (2005) Ecology and evolution of aphid-ant interaction. Annual Review of Ecology, Evolution, and Systematics 36, 345-372.

Tilman, D., Reich, P.B. and Knops, J.M.H. (2006) Biodiversity and ecosystem stability in a decade-long grassland experiment. Nature 441, 629-632.

Tilman, D., Wedin, D. and Knops, J. (1996) Productivity and sustainability influenced by biodiversity in grassland ecosystems. Nature 379, 718-720.

Torsvik, V. and Øvreås, L. (2002) Microbial diversity and function in soil: from genes to ecosystems. Current Opinion in Microbiology 5, 240-245. 
Tringe, S., von Mering, C., Kobayashi, A., Salamov, A., Chen, K., Chang, H., Podar, M., Short, J., Mathur, E., Detter, J., Bork, P., Hugenholtz, P. and Rubin, E. (2005) Comparative metagenomics of microbial communities. Science 308, 554-557.

Uren, N.C. (2007) Types, Amounts, and Possible Functions of Compounds Released into the Rhizosphere by Soil-Grown Plants. In The Rhizosphere. pp.1-21: CRC Press.

Uroz, S., Turpault, M.P., Delaruelle, C., Mareschal, L., Pierrat, J.C. and Frey-Klett, P. (2011) Minerals Affect the Specific Diversity of Forest Soil Bacterial Communities. Geomicrobiology Journal 29, 88-98.

Wertz, S., Degrange, V., Prosser, J., Poly, F., Commeaux, C., Freitag, T., Guillaumaud, N. and Roux, X. (2006) Maintenance of soil functioning following erosion of microbial diversity. Environmental Microbiology 8, 2162-2169.

Wertz, S., Degrange, V., Prosser, J., Poly, F., Commeaux, C., Guillaumaud, N. and Le Roux, X. (2007) Decline of soil microbial diversity does not influence the resistance and resilience of key soil microbial functional groups following a model disturbance. Environmental Microbiology 9, 2211-2219.

Wieland, G., Neumann, R. and Backhaus, H. (2001) Variation of Microbial Communities in Soil, Rhizosphere, and Rhizoplane in Response to Crop Species, Soil Type, and Crop Development. Applied and Environmental Microbiology 67, 5849-5854.

Wrage, N., Velthof, G.L., van Beusichem, M.L. and Oenema, O. (2001) Role of nitrifier denitrification in the production of nitrous oxide. Soil Biology and Biochemistry 33, 1723-1732.

Yao, I. and Akimoto, S.-i. (2001) Ant attendance changes the sugar composition of the honeydew of the drepanosiphid aphid Tuberculatus quercicola. Oecologia 128, $36-43$.

Yao, I., Akimoto, S.-I. (2002.) Flexibility in the composition and concentration of amino acids in honeydew of the drepanosiphid aphid Tuberculata quericola. . Ecological Entomology 27, 745-752.

Zul, D., Denzel, S., Kotz, A. and Overmann, J. (2007) Effects of plant biomass, plant diversity, and water content on bacterial communities in soil lysimeters: implications for the determinants of bacterial diversity. Applied and Environmental Microbiology 73, 6916-6929. 


\section{B. Publications}




\section{B.I Effect of tree species identity, tree species diversity, leaf litter presence, and sampling time on soil microbial communities}

To analyze the influence of single tree species, tree species diversity and leaf litter on the soil-inhabiting bacterial community structure and activity a mesocosms experiment was established. Therefore, soil with high natural carbonate content, which buffered the soil acidification caused by rhizodeposits, was used to exclude soil $\mathrm{pH}$ as influencing factor. The following hypotheses were tested applying denaturing gradient gel electrophoresis and amplicon-based sequencing of $16 \mathrm{~S}$ rRNA as molecular approach:

(1) Tree species, differing in physiology, leaf litter quality and type of mycorrhiza, affect soil bacterial community composition, diversity and activity.

(2) Leaf litter presence, acting as nutrient source and meliorating both temperature and water budget of the underlying mineral soil, influences the soil bacterial diversity and activity.

The impact of Fagus sylvatica L. (beech) and Fraxinus excelsior L. (ash) roots on the soil microbial community composition and carbon dynamics was assessed using double-split-root rhizotrons, distinguishing between root-induced and leaf littermediated effects. The following hypotheses were tested:

(1) Beech and ash differentially affect the structure of the microbial community thereby modifying soil processes and plant nutrient capture.

(2) Differences in microbial community structure are expected to result in differential decomposition of labeled ash litter and differential mobilization of nutrients from the litter.

(3) Further, we expected modifications of the soil microorganism community and soil processes to be most pronounced in the mixed treatment with both tree species present due to complementary effects of the two tree species.

Furthermore, the effects of tree species, sampling distance from the tree trunk at different soil depth, and season on the diversity and composition of soil bacterial and fungal communities was analyzed. Therefore, mineral soil samples were collected in 0$10 \mathrm{~cm}$ and 10-20 $\mathrm{cm}$ depth and $0.5 \mathrm{~m}, 1.5 \mathrm{~m}, 2.5$ and $3.5 \mathrm{~m}$ distance to the trunk of selected Fagus sylvatica L. and Picea abies L. trees. Pyrosequencing of the V3-V5 16S rRNA and the ITS rRNA gene regions was applied to assess the diversity and structure of soil bacterial and fungal communities. 


\section{1. \\ Leaf litter is the main driver for changes in bacterial community structures in the rhizosphere of ash and beech}

Birgit Pfeiffer ${ }^{1)}$, Ann-Catrin Fender ${ }^{2)}$, Sandra Lasota ${ }^{1)}$, Dietrich Hertel ${ }^{2)}$, Hermann F. Jungkunst $^{3)}$ and Rolf Daniel ${ }^{1)}$

Applied Soil Ecology (2013), Vol. 72, p. 150-160

${ }^{1)}$ Genomic and Applied Microbiology, University of Goettingen, Grisebachstr. 8, 37077 Goettingen, Germany

${ }^{2)}$ Plant Ecology and Ecosystems research, University of Goettingen, Untere Karspüle 2, 37073 Goettingen, Germany

${ }^{3)}$ Geoecology Physical Geography, Insitute for Environmental Sciences, University of KoblenzLandau, Fortstr. 7, 76829 Landau, Germany

\section{Author contributions to the work:}

Performed the experiments: B. Pfeiffer, AC. Fender, S. Lasota

Analyzed the data: $\quad$ B. Pfeiffer, AC. Fender

Wrote the paper: $\quad$ B. Pfeiffer, HF. Jungkunst, R. Daniel

Conceived and designed the experiments: HF. Jungkunst, R. Daniel, D. Hertel,

B. Pfeiffer 


\title{
Leaf litter is the main driver for changes in bacterial community structures in the rhizosphere of ash and beech
}

\author{
Birgit Pfeiffer ${ }^{\mathrm{a}}$, Ann-Catrin Fender ${ }^{\mathrm{b}}$, Sandra Lasota ${ }^{\mathrm{a}}$, Dietrich Hertel ${ }^{\mathrm{b}}$, \\ Hermann F. Jungkunst ${ }^{c}$, Rolf Daniel ${ }^{\mathrm{a}, *}$ \\ ${ }^{a}$ Genomic and Applied Microbiology, Institute of Microbiology and Genetics, Georg-August University of Goettingen, Grisebachstr. 8, 37077 Goettingen, \\ Germany \\ ${ }^{\mathrm{b}}$ Plant Ecology and Ecosystems research, Georg-August University of Goettingen, Untere Karspüle 2, 37073 Goettingen, Germany \\ ' Geoecology Physical Geography, Institute for Environmental Sciences, University of Koblenz-Landau, Fortstr. 7, 76829 Landau, Germany
}

\section{A R T I C L E I N F O}

\section{Article history:}

Received 18 January 2013

Received in revised form 6 June 2013

Accepted 14 June 2013

\section{Keywords:}

16S rRNA

Soil bacterial community composition

Soil bacterial diversity

DGGE

Mesocosms

\begin{abstract}
A B S T R A C T
The rhizosphere and the surrounding soil harbor an enormous microbial diversity and a specific community structure, generated by the interaction between plant roots and soil bacteria. The aim of this study was to address the influences of tree species, tree species diversity and leaf litter on soil bacterial diversity and community composition. Therefore, mesocosm experiments using beech, ash, lime, maple and hornbeam were established in 2006, and sampled in October 2008 and June 2009. Mesocosms were planted with one, three or five different tree species and treated with or without litter overlay.

Cluster analysis of DGGE-derived patterns revealed a clustering of 2008 sampled litter treatments in two separated clusters. The corresponding treatments sampled in 2009 showed separation in one cluster. PCA analysis based on the relative abundance of active proteobacterial classes and other phyla in beech and ash single-tree species mesocosm indicated an effect of sampling time and leaf litter on active bacterial community composition. The abundance of next-generation sequencing-derived sequences assigned to the Betaproteobacteria was higher in the litter treatments, indicating a higher activity, under these conditions. The Deltaproteobacteria, Nitrospira and Gemmatimonadetes showed an opposite trend and were more active in the mesocosms without litter. The abundance of alphaproteobacterial sequences was higher in mesocosms sampled in $2009(P=0.014)$, whereas the Acidobacteria were more active in 2008 $(P=0.014)$. At the family level, we found significant differences of the litter vs. non-litter treated group. Additionally, an impact of beech and ash as tree species on soil bacterial diversity was confirmed by the Shannon and Simpson indices. Our results suggest that leaf litter decomposition in pH-stable soils affect the soil bacterial composition, while tree species influence the soil bacterial diversity.
\end{abstract}

(c) 2013 Elsevier B.V. All rights reserved.

\section{Introduction}

Mankind has increased plant and animal extinction rates drastically by altering environments and transforming landscapes. The consequences of loss or changes of biodiversity, especially of vascular plant and animal diversity, have been analyzed in many studies (Chapin et al., 2000; Ives and Carpenter, 2007; Loreau et al., 2001; Petchey and Gaston, 2002; Reich et al., 2012). Chapin et al. (2000) pointed out that plant and animal species diversity affects the function of ecosystems as well as the resilience and resistance of ecosystems to environmental changes. A higher vulnerability caused by a decrease in species diversity might finally lead to population collapses. Therefore, predominantly provident environmental resource utilization is practiced in forestry management in

\footnotetext{
* Corresponding author. Tel.: +49551 393827, fax: +49 5513912181.

E-mail address: rdaniel@gwdg.de (R. Daniel).
}

Central Europe. Increasingly, mono-specific stands are being transformed into diverse and therefore, most likely, more stable stands. Although soil microorganisms mediate nearly all biogeochemical cycles in terrestrial ecosystems and are responsible for most nutrient transformations in soil (van der Heijden et al., 2008), the effect of above-ground plant diversity on soil microbial community composition and diversity is poorly understood (Fierer and Jackson, 2006; Torsvik and Øvreås, 2002; Wertz et al., 2006). Biogeochemical cycles, such as denitrification and nitrite oxidation are more or less unaffected by reduction of soil bacterial diversity (Wertz et al., 2007). This is due to high levels of redundancy for many gene families encoding enzymes and functions driving biogeochemical processes across different soil microbial groups. Thus, small-scale environmental perturbations that alter some microbial groups will not necessarily alter overall biogeochemical functioning of microbial communities (Cubbage et al., 2007; Fitter et al., 2005). However a tree species specific effect on both $\mathrm{C}\left(\mathrm{CH}_{4}\right)$ and $\mathrm{N}\left(\mathrm{N}_{2} \mathrm{O}\right)$ gas fluxes from soil, which are microbial mediated, has been shown (Fender 
et al., 2012). Therefore a complete redundancy of microbial community structure appears not likely if the effects on net gas fluxes from soils can be attributed to direct tree species impact.

Biotic and abiotic factors are also drivers of composition and diversity of soil bacterial communities. Fierer and Jackson (2006) demonstrated that the soil $\mathrm{pH}$ is a major factor driving bacterial richness, diversity and overall community composition by analyzing soils from across North and South America. They observed the lowest level of bacterial diversity and richness in acidic soils, which is in accordance with the low decomposition rates in acidic soils (Motavalli et al., 1995; van Bergen et al., 1998). The strong influence of soil $\mathrm{pH}$ on the soil bacterial community structure and diversity was also shown by $16 \mathrm{~S}$ rRNA gene sequence data from Lauber et al. (2009), a wetland soil study by Hartman et al. (2008) and a pH gradient analysis in an arable soil by Rousk et al. (2010). Furthermore, it is known that trees have a specific impact on the development of soil $\mathrm{pH}$, and therefore should have a differentiating impact on its associated soil microbial communities (de Schrijver et al., 2012; Holzwarth et al., 2011; Langenbruch et al., 2012).

In addition, Fierer and Jackson (2006) discovered no significant relationship between soil bacterial diversity and plant diversity. Other studies analyzing grassland and agricultural sites confirmed these results (Buckley and Schmidt, 2001; Felske et al., 2000; Kowalchuk et al., 2002). It has been shown that plant diversity levels in grassland soils significantly affect the below-ground bacterial community composition but not bacterial richness (Grüter et al., 2006). Two studies focusing on grassland soils showed a direct effect of plant composition on below-ground bacterial community structure, but also a more pronounced effect of physic-chemical factors (Kennedy et al., 2004; Nunan et al., 2005). Several grassland soil and agricultural crop studies focused on plant-dependent rhizosphere bacterial communities, which are directly affected by plant root exudates and other rhizodeposits (Barea et al., 2005; Costa et al., 2006; Kowalchuk et al., 2002; Kuske et al., 2002; Smalla et al., 2001). However, most of the surveys analyzing plant species and diversity effects on soil or rhizosphere bacterial communities were conducted in grassland or agricultural soils and so far, little is known about the influence of tree species and varying tree diversity levels on soil bacterial communities. Several studies analyzing the effect of leaf litter quality and species mixture on the decomposition rates and the decomposing bacterial community were performed (Aneja et al., 2006; Jacob et al., 2010; Kooijman, 2010). However, to our knowledge the influence of leaf litter on the soil-inhabiting bacterial community was not analyzed so far.

The aim of this study was to investigate the effect of tree species, tree species diversity and leaf litter on soil microbial diversity, abundance and activity using DGGE-based community profiling. For a more comprehensive analysis of tree species and leaf litter impact on the community composition of active soil bacteria, next-generation sequencing of $16 \mathrm{~S}$ rRNA amplicons was used. We hypothesized (a) that tree species, differing in physiology, leaf litter quality and type of mycorrhiza, affect soil bacterial community composition, diversity and activity; (b) that leaf litter presence, acting as nutrient source and meliorating both temperature and water budget of the underlying mineral soil, influences soil bacterial diversity and activity. The thickness of the forest floor (leaf litter horizons upon the soil) may vary considerably (from several decimeter to non-existent) depending on season, exposition (to the wind) or decomposition conditions. The variation of a leaf litter layer up to existing or non-existing is therefore realistic in natural forest ecosystems and may differentiate its soil microbial communities. To investigate this, a mesocosm experiment in which tree diversity ranged from a single species treatment to a five species treatment was established. The mesocosms resembled the present tree diversity in the national park Hainich in Thuringia, Germany. Additionally, treatments with and without leaf litter overlay were installed to unravel litter layer impact on total and active bacterial communities.

\section{Material and methods}

\subsection{Experimental set up and soil sampling}

In this study, the influence of tree species and tree species diversity on bacterial community composition in soil habitats was analyzed. Mesocosms (diameter, $60 \mathrm{~cm}$ ) were filled with 601 of silty soil, which had a $\mathrm{pH}\left(\mathrm{CaCl}_{2}\right)$ of 7.4 (Schlichting et al., 1995). The soil contained $2.56 \%$ humus, $0.14 \%$ nitrogen, and $1.48 \%$ organic carbon (supplemental Table S1). The established mesocosms simulated the soil conditions of most areas in the Hainich National Park, which is a common research site of some larger collaborative projects. The Hainich is a large deciduous forest $(16,000$ ha $)$ in Germany. It is located in the west of Thuringia and partly a national park (7500 ha), which was declared a World Natural Heritage site in 2011 by the UNESCO. In the past decades, this area underwent a transformation from a military training area to a mainly undisturbed deciduous forest. The dominant tree species are Acer pseudoplatanus L. (maple), Fagus sylvatica L. (European beech), Fraxinus excelsior L. (European ash), Carpinus betulus L. (hornbeam) and Tilia cordata P. Mill (lime). To set up the mesocosms experiments single-tree species, threetree species and five-tree species treatments were established in summer 2006. Each of these treatments was replicated 10 times. After litter fall, the litter was removed from five of these replicates randomly to establish the treatments without leaf litter overlay. Additionally, controls without tree species, and without litter were established. The single-tree species treatment contained 10 individuals of beech, ash or hornbeam per mesocosm. The three-tree species treatment contained mixtures of three individuals of three different tree species. The five-tree species treatment was planted with two individuals of maple, beech, ash, hornbeam and lime (supplemental Table S2 and Figure S1). These mesocosms were placed in the open field in the Experimental Botanical Garden of the University of Göttingen, completely randomized in three blocks, each containing three rows of 23 mesocosms. The area was sheltered against strong winds by a hedge and covered by a shading net (Wunderlich, Osterrode, Germany) to simulate light conditions in forests by the reduction of the solar radiation to $50-60 \%$ of the irradiance in the open field (supplemental Figure S2). Deciduous trees (approximately three years of age) were derived from a tree nursery and were barely colonized by mycorrhiza. The trees had grown for two growth periods before the first samples were taken to develop and establish their influence on soil microbial communities. During the growing season the mesocosms were watered three times a week to prevent drought stress as an influencing factor. The climatic conditions recorded between the two samplings in October 2008 and June 2009 are shown in supplemental Figure S3. The upper $10 \mathrm{~cm}$ of the soil were sampled from three of the five replicates and pooled to minimize potential heterogeneity of the sample and describe the average bacterial community composition of each treatment. The samples were immediately frozen in liquid nitrogen and stored at $-80^{\circ} \mathrm{C}$ prior to extraction of DNA and RNA. Since the mesocosms were almost completely filled with roots at the time of harvest, the analyzed "bulk" soil samples have been considered as rhizosphere, which is directly influenced by root exudates.

\subsection{Extraction of nucleic acids}

Genomic DNA was isolated from $250 \mathrm{mg}$ of soil per sample by employing the PowerSoil ${ }^{\mathrm{TM}}$ DNA isolation kit (MO BIO Laboratories Inc., Carlsbad, CA, USA). The final DNA elution step was carried 
out with $100 \mu \mathrm{l}$ sterile water. RNA was isolated from $2 \mathrm{~g}$ of soil per sample using the RNA PowerSoil ${ }^{\mathrm{TM}}$ total RNA isolation kit (MO BIO Laboratories Inc.) as indicated by the manufacturer. The resulting RNA pellet was dissolved in $100 \mu \mathrm{l}$ RNase-free water. For the removal of residual DNA contamination, the TURBO DNA-free ${ }^{\mathrm{TM}}$ kit (Life Technologies, Carlsbad, CA, USA) was used as described by the manufacturer. Subsequently, DNase-treated RNA was purified and concentrated using the RNeasy MinElute cleanup kit (Qiagen $\mathrm{GmbH}$, Hilden, Germany). The concentration of DNA and RNA extracts was quantified using a NanoDrop ND-1000 spectrophotometer (NanoDrop Technologies, Wilmington, DE, USA). Additionally, RNA integrity and concentration were analyzed using the Agilent 2100 Bioanalyzer and the Agilent RNA 6000 Nano kit (Agilent Technologies, Inc., Santa Clara, CA, USA).

\subsection{Denaturing gradient gel electrophoresis (DGGE)}

To analyze the bacterial communities present in the soil of the mesocosms by denaturing gradient gel electrophoresis (DGGE) a $550 \mathrm{bp}$-fragment comprising the V2-V3 region of the 16S rRNA gene was amplified using the primers $5^{\prime}$-CCTACGGGAGGCAGCAG$3^{\prime}$ (BAC 341F) and 5'-CCGTCAATTCCTTTRAGTTT-3' (BAC 907R) (Muyzer and Smalla, 1998; Muyzer et al., 1995). A GC clamp (5'-CGCCCGCCGCGCCCCGCGCCCGTCCCGCCGCCCCCGCCCG$3^{\prime}$ ) was attached to the $5^{\prime}$ terminus of the primer BAC $341 \mathrm{~F}$ (Muyzer et al., 1995). The PCR reaction mixture $(50 \mu \mathrm{l})$ contained $5 \mu \mathrm{l} \mathrm{Mg-}$ free polymerase buffer (Thermo Fisher Scientific, Inc., Waltham, MA, USA), $200 \mu \mathrm{M}$ of each of the four deoxynucleoside triphosphates, $2 \mathrm{mM} \mathrm{MgCl} 2,2 \mu \mathrm{M}$ of each of the primers, $1 \mathrm{U}$ of Taq DNA polymerase (Thermo Fisher Scientific, Inc.), and $20 \mathrm{ng}$ of isolated DNA as template. For the touchdown PCR, the following thermal cycling scheme was used: initial denaturation at $95^{\circ} \mathrm{C}$ for $2 \mathrm{~min}$, 13 cycles of denaturation at $94^{\circ} \mathrm{C}$ for $1 \mathrm{~min}$, annealing for $1 \mathrm{~min}$ at a decreasing temperature gradient ranging from $64^{\circ} \mathrm{C}$ to $51^{\circ} \mathrm{C}$ $\left(1^{\circ} \mathrm{C}\right.$ decrease per cycle), and extension at $72^{\circ} \mathrm{C}$ for $3 \mathrm{~min}$. Subsequently, 12 cycles of denaturation at $94^{\circ} \mathrm{C}$ for $1 \mathrm{~min}$, annealing for $1 \mathrm{~min}$ at $51^{\circ} \mathrm{C}$, and extension at $72^{\circ} \mathrm{C}$ for $3 \mathrm{~min}$ were performed. A final extension period at $72{ }^{\circ} \mathrm{C}$ for $10 \mathrm{~min}$ was carried out. Resulting PCR products were purified using the CyclePure PCR purification kit (Peqlab Biotechnologie GmbH, Erlangen, Germany) as recommended by the manufacturer.

To analyze RNA-based active soil bacterial communities the same primers as described above were used. Reverse transcription (RT) of isolated RNA and subsequent PCR of the resulting cDNA was performed with the OneStep RT-PCR kit (Qiagen GmbH, Hilden, Germany). The RT-PCR reaction mixture $(50 \mu \mathrm{l})$ was prepared as recommended by the manufacturer and supplemented with 50 ng of isolated RNA as template. The thermal cycling scheme was used as described above, except the replacement of the initial denaturation with a reverse transcription at $50{ }^{\circ} \mathrm{C}$ for $30 \mathrm{~min}$ and a subsequent denaturation at $95^{\circ} \mathrm{C}$ for $15 \mathrm{~min}$.

DGGE analysis of $16 \mathrm{~S}$ rRNA genes and transcripts was performed using the Ingeny phorU system (Ingeny International BV, The Netherlands). Approximately $500 \mathrm{ng}$ of purified amplicons were loaded onto a $9 \%(\mathrm{w} / \mathrm{v})$ polyacrylamide gel containing a $45 \%$ to $60 \%$ denaturing gradient (100\% denaturant consisted of $7 \mathrm{M}$ urea and $40 \%$ formamide). Electrophoresis was performed at $60^{\circ} \mathrm{C}$ and $100 \mathrm{~V}$ for $16 \mathrm{~h}$ in Tris-acetate-EDTA (TAE) buffer, containing $40 \mathrm{mM}$ Tris, $20 \mathrm{mM}$ acetic acid, and $1 \mathrm{mM}$ EDTA. Subsequently, the gels were stained with SYBR Gold (Life Technologies, Carlsbad, CA, USA). Randomly selected bands were excised from the gel and DNA was eluted by incubation in $100 \mu$ l of TAE buffer at $4{ }^{\circ} \mathrm{C}$ over night. A volume of $1 \mu \mathrm{l}$ resulting DNA solution was employed as template for reamplification of $16 \mathrm{~S}$ rRNA genes and transcripts, respectively. The above-described PCR reaction conditions, solutions and primers were employed, but primer $341 \mathrm{~F}$ was used without the attached GC clamp. Resulting PCR-products were purified, ligated into pCR2.1TOPO vector (Life Technologie,) and used to transform E. coli DH5 $\alpha$ cells according to the manufacturer's instructions. To estimate the number of different $16 \mathrm{~S}$ rRNA gene fragments co-migrating within the same DGGE band, plasmids derived from 12 clones per DGGE band were sequenced by the Göttingen Genomics Laboratory (University of Göttingen, Germany). The generated sequence data were edited using the gap4 program of the Staden Package (Bonfield et al., 1995). Taxonomic classification was performed by comparing the edited sequences to the most recent SILVA ribosomal RNA database (Pruesse et al., 2007) using BLAST (Altschul et al., 1990). Nucleotide sequences of the recombinant plasmids harboring $16 \mathrm{~S}$ rRNA genes have been submitted to GenBank under accession numbers JX985790 to JX986515.

The resulting DGGE profiles were analyzed with the GelCompare II software (Applied Maths, Kortrijk, Belgium). Therefore, contours of distorted gels were defined, densitometric curves were extracted and background subtraction was applied. Each sample lane was marked and delineated, indicating the present lane deformation and width. In the next step, densitometric curves were defined and the universal marker patterns were used as external reference to straighten and normalize each lane. Clustering was performed by using the unweighted pair group method with arithmetic mean (UPGMA) and the Jaccard coefficient of similarity, which takes only the presence or absence of a band into account. Position tolerance was set at $1 \%$.

\subsection{Pyrosequencing of $16 S$ rRNA gene transcripts}

To analyze the active bacterial community of beech and ash treated single-tree species mesocosms, the V2-V3 region of $16 \mathrm{~S}$ rRNA gene transcripts was reverse transcribed, amplified and the resulting PCR products were applied to pyrosequencing. The cDNA synthesis was performed using the SuperScript ${ }^{\mathrm{TM}}$ III reverse transcriptase (Life Technologies). For initial denaturation and primer annealing, a mixture $(14 \mu \mathrm{l})$ containing $100 \mathrm{ng}$ of isolated DNA-free RNA, as well as $2 \mu \mathrm{M}$ of the primer V3rev (see below) and $10 \mathrm{mM}$ dNTP mix was incubated for $5 \mathrm{~min}$ at $65^{\circ} \mathrm{C}$ and chilled on ice for at least $1 \mathrm{~min}$. The cDNA synthesis mixture $(6 \mu \mathrm{l})$ harboring $4.0 \mu \mathrm{l} 5$-fold first strand buffer, 0.1 M DTT, $40 \mathrm{U}$ RiboLock RNase inhibitor (Thermo Fisher Scientific, Inc.) and $200 \mathrm{U} \mathrm{SuperScript}^{\mathrm{TM}}$ III reverse transcriptase was added and incubated at $55^{\circ} \mathrm{C}$ for $90 \mathrm{~min}$. The reaction was terminated at $70^{\circ} \mathrm{C}$ for $15 \mathrm{~min}$. For the amplification of cDNA fragments, Phusion ${ }^{\circledR}$ hot start high-fidelity DNA polymerase (Thermo Fisher Scientific, Inc.) was used. The PCR reaction mixture $(50 \mu \mathrm{l})$ contained $10 \mu \mathrm{l}$ of five-fold Phusion HF buffer (Thermo Fisher Scientific, Inc.), $200 \mu \mathrm{M}$ of each of the four deoxynucleoside triphosphates, $1.25 \%$ DMSO, $2 \mu \mathrm{M}$ of each of the primers, $0.5 \mathrm{U}$ of DNA polymerase and $0.25 \mu \mathrm{l}$ of the previously synthesized cDNA. The thermal cycling scheme was as follows: initial denaturation at $98^{\circ} \mathrm{C}$ for $3 \mathrm{~min}, 25$ cycles of denaturation at $98^{\circ} \mathrm{C}$ for $15 \mathrm{~s}$, annealing and extension at $72^{\circ} \mathrm{C}$ for $20 \mathrm{~s}$, followed by a final extension period at $72^{\circ} \mathrm{C}$ for $2.5 \mathrm{~min}$. The primer set V2for (5'-CGTATCGCCTCCCTCGCGCCATCAG-MID-AGTGGCGGACGGGTGAGTAA- $\left.3^{\prime}\right)$ and V3rev (5'-CTATGCGCCTTGCCAGCCCGCTCAGMID-CGTATTACCGCGGCTGCTG-3'), containing pyrosequencing adaptors (underlined) and different standard multiplex identifiers (MID) was used for cDNA synthesis and amplification (modified from Schmalenberger et al., 2001). All samples were amplified in triplicate, pooled and purified using the peqGold gel extraction kit (Peqlab Biotechnologie GmbH, Erlangen, Germany). The PCR products were quantified using the Quant-iT dsDNA BR assay kit and a Qubit fluorometer (Life Technologies). The Göttingen Genomics Laboratory determined the sequences of the partial 16S rRNA gene transcripts by using a Roche GS-FLX 454 pyrosequencer and Titanium chemistry (Roche, Mannheim, Germany). The resulting 
sequence data have been deposited in the NCBI sequence read archive under accession number SRA060044.

\subsection{Processing and analysis of pyrosequencing-derived data sets}

Forward and reverse primer sequences, as well as sequences shorter than $300 \mathrm{bp}$ were removed from the pyrosequencingderived dataset using the QIIME software package (Caporaso et al., 2010a). In addition, sequences containing long homopolymers (>8 bp), unresolved nucleotides, or nucleotides with an average quality score lower than 25 were removed. In addition, denoising was carried out using the denoiser program version 0.91 (Reeder and Knight, 2010). Operational taxonomic units (OTUs) were determined by Uclust OTU picker 1.2.22q (Edgar, 2010) at 3\%, 5\%, 10\% and $20 \%$ genetic distance according to (Schloss and Handelsman, 2005). Potential chimeric sequences were removed by aligning representative sequences of each OTU using PyNast 1.1 (Caporaso et al., 2010b) and subsequent analysis using ChimeraSlayer 4.29 (Haas et al., 2011). Rarefaction curves and diversity indices (Shannon, ACE, Simpson, Chao1 and Michaelis-Menten fit) were calculated by employing the QIIME software package. To allow comparison to non QIIME-based analysis we corrected the Shannon index by multiplying it with $\ln 2$. Taxonomic classification was performed by comparing the preprocessed sequences to the most recent copy of the SILVA ribosomal RNA database using BLAST (SSURef_106_tax_silva_trunc.fasta) (Altschul et al., 1990). To compare the bacterial communities of different treated samples we tested for normal distribution of all identified phyla within the samples using the Shapiro-Wilk test. Furthermore, the influence of tree species, litter overlay and sampling time were analyzed by grouping data derived from identical treatments, together. To identify significant differences between the different treatment-groups, the $t$-test and for not normal-distributed data, the Mann-Whitneytest was applied using Sigma-Plot (Systat Software GmbH, Erkrath, Germany). A principal component analysis (PCA), based on the relative abundance of bacterial phyla and proteobacterial classes was performed using Canoco 4.5 (Microcomputer Power, Ithaca, NY, USA).

\section{Results and discussion}

\subsection{Fingerprints of bacterial community}

To analyze the effect of tree species and tree species diversity on soil microbial community composition, mesocosms experiments were established. The mesocosms contained single-tree species, as well as mixtures of three and five different tree species. Each treatment was replicated ten times. Additionally, the leaf litter layer was removed from five of the replicates. To analyze the microbial community composition derived from the different treatments, DGGE fingerprinting was performed. DNA was extracted from the different soil samples to analyze the whole bacterial community present in the mesocosms. To analyze the active bacterial community present in the differently treated mesocosms RNA was extracted and reverse transcribed. The $16 \mathrm{~S}$ rRNA-based fingerprints revealed more distinct bands per lane, than the 16S rRNA genebased fingerprint (20 bands per lane), but no differences between the treatments were observed for the 16S rRNA-based DGGE patterns (data not shown). Norris et al. (2002) also encountered an almost identical DGGE fingerprint based on 16S rRNA and 16S rRNA genes from soil microbial communities across a thermal gradient. Thus, the 16S rRNA-based results were not analyzed in detail.

In this study, 20 distinct bands were detected in each soil sample. Sixty-eight of these were selected randomly and excised from the DNA-based DGGE profiles (supplemental Figures S4 to S7).

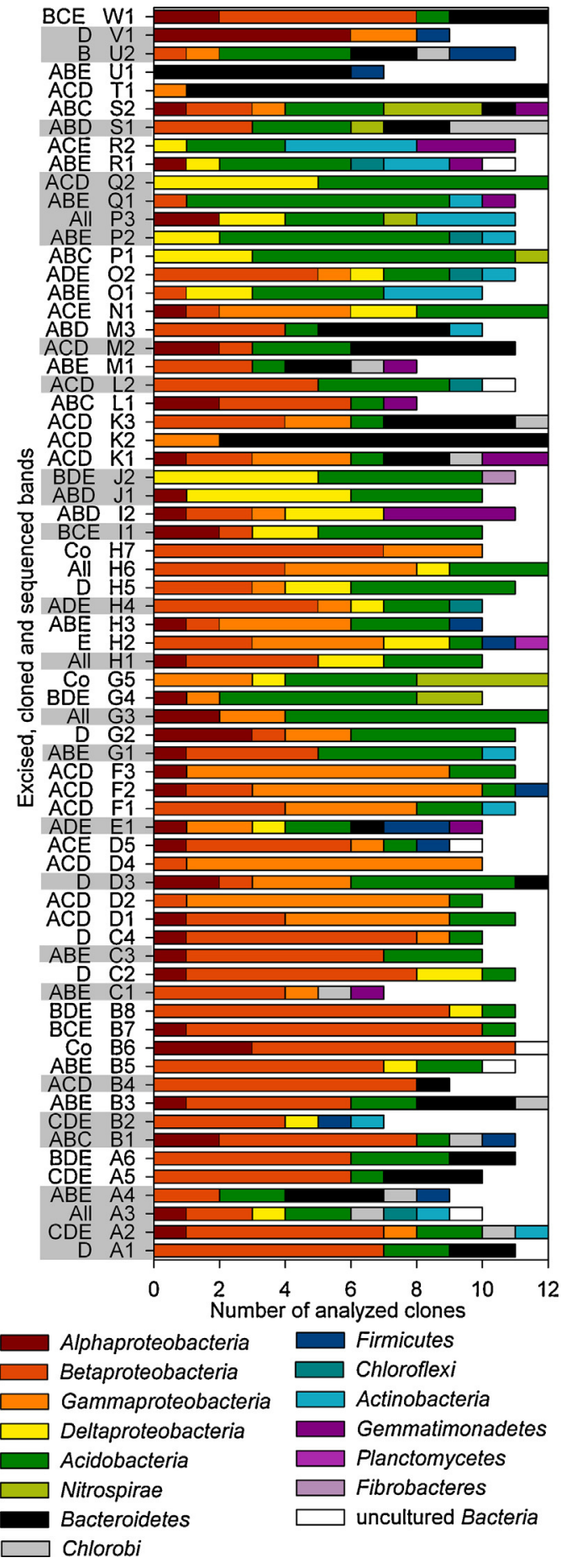

Fig. 1. Sequence assignment to proteobacterial classes, and other bacterial phyla of the excised, reamplified, cloned and sequenced DGGE-derived bands. Upper case letters indicate the different tree species used in this study (maple (A), beech (B), lime (C), hornbeam (D) and ash (E). The five tree species treatments are marked with All and the treatments without tree species and litter are marked with (Co). Additionally, litter treated samples are marked in grey. Numbered upper case letters indicate the excised and cloned bands and identical letters indicate bands excised at equal heights from different samples and DGGE-replicates.

These bands were reamplified, cloned into vectors, and sequenced to gain insight into the bacterial phyla captured by the $16 \mathrm{~S}$ rRNA gene DGGE approach (Fig. 1). In total, 726 16S rRNA gene sequences were obtained of which $44.7 \%$ were affiliated to the Proteobacteria. The proteobacterial class Betaproteobacteria represented $28.1 \%$ of all sequences obtained. Other proteobacterial 
classes identified were the Deltaproteobacteria (6.9\%), Alphaproteobacteria (6.9\%) and Gammaproteobacteria (2.8\%). Members of the phyla Acidobacteria and Bacteroidetes accounted for $23.7 \%$ and $9.4 \%$ of all sequences, respectively. In addition, Actinobacteria, Gemmatimonadetes, Chlorobi, Firmicutes Nitrospirae, Chloroflexi, Planctomycetes and Fibrobacteres, as well as some unclassified members of Bacteria were detected (less than $12.3 \%$ of all identified sequences). These phylogenetic groups were also identified in other surveys analyzing soil bacterial community structures (Janssen, 2006; Lauber et al., 2009; Nacke et al., 2011; Rousk et al., 2010; Will et al., 2010). Most DGGE bands occurred with different intensities in all treatments. Furthermore, all bands contained diverse co-migrating sequences. For example, band D and F, which occurred in all treatments, but were less intense in the ACD-Ex sample from 2009. DGGE bands D and F were dominated by the Gammaproteobacteria. DGGE band $\mathrm{K}$, which appeared exclusively in sample ACD-Ex from 2009 was dominated by the Bacteroidetes (Fig. 1).

Cluster analysis of the DNA-based DGGE fingerprints revealed two main clusters (Fig. 2). One cluster contained two single-tree species and seven of the three-tree species treated samples from 2009 with litter overlay. The second cluster comprised four subclusters (A, B, C and D). Subcluster A contained single-tree species, three-tree species and five-tree species samples, which were mainly without litter treatment. The hornbeam single-tree species sample treated with litter cluster separately from all other samples in subcluster A. Subcluster B encompassed two separate groups, of which one contained three single-tree species and litter-treated soil samples from 2008 and a second, which contained the control, the three-tree and the five-tree species samples without litter overlay, sampled in 2009. Subcluster C comprised only samples taken in 2008, whereas six of the three-tree species and litter-treated samples clustered separately from the other treatments. Subcluster D contained the remaining three and five-tree species treatments without litter overlay and the control. Thus, the cluster analysis indicated a combined effect of sampling time, and the presence or absence of a litter layer. A comparative cluster analysis of all three DGGE-replicates confirmed these results (supplemental Figure S8). A microcosm study conducted by Stres et al. (2008) detected no significant changes in bacterial community structure in response to seasonal changes in soil temperature and water content. An increase in forest topsoil temperature by $4{ }^{\circ} \mathrm{C}$ had no influence on bacterial community composition and biomass, but an increased microbial metabolic activity was observed (Schindlbacher et al., 2011). Therefore, an adaptation of the soil microbial community present in our mesocosms, with time to the presence or absence of a leaf litter layer and the leaf litter quality probably occurred. Leaf litter acts as a nutrient source, whereas different leaf litter species differing in their litter quality serve as fast or slow degradable nutrient resource. Litter derived from hornbeam posses a lower $\mathrm{C} / \mathrm{N}$ ratio and lignin content than beech, and thus is degraded faster and disappears in a relatively short time (Kooijman, 2010). Consequently, hornbeam leaf litter has only a minor impact on the soil bacterial community. The distant clustering of the litter-treated hornbeam single-tree species sample from 2009 compared to all other litter-treated samples supports this hypothesis. Five of the six litter-treated three-tree species samples from 2008 grouped separately in subcluster $\mathrm{C}$. The respective samples were also identified in the litter-treated group from 2009, which clustered distinctly from all other treatments sampled in 2008 and 2009. Additionally, the beech and ash, litter-treated single-tree species mesocosms that grouped separately in 2008 were also identified in the litter-treated cluster from 2009. Aneja et al. (2006) observed a strong effect of litter quality on the litter decomposing bacterial community by comparing decaying beech and spruce leaf litter by DGGE. They also recorded a $65 \%$ similarity between the leaf litter-decomposing bacterial community and the soil-inhabiting bacterial community.
Furthermore, the amount of litter covering the soil affects the bacterial community inhabiting the respective litter and soil (Chemidlin Prevost-Boure et al., 2011). Although the increased litter layer quantity was not measured, the amount of litter deposited by the growing trees was likely to increase over time. Taking the clustering of the controls into account, a slowly establishing and persistent influence of the litter layer on the soil-inhabiting bacterial community is indicated. Furthermore, an impact of tree species on the soil microbial community is unlikely, as the controls containing no tree species, cluster among the tree species treated samples, indicating no root-specific influence. To analyze tree species, seasonal and litter effects on active soil bacterial communities comprehensively at a higher taxonomic resolution, the single-tree species treatments covering the dominant tree species in the national park Hainich (beech and ash) were selected for a detailed analysis employing large-scale amplicon-based sequencing of 16S rRNA.

\subsection{Amplicon-based analysis of beech and ash single-tree species mesocosms}

The rRNA from beech-treated and ash-treated single-tree species mesocosms with and without litter layer were extracted, and the V2-V3 region of the 16S rRNA was amplified and sequenced. A total of $168,97416 \mathrm{~S}$ rRNA sequences were generated (Table S3). After preprocessing, including quality filtering and denoising, 117,312 high-quality sequences with an average read length of 415 bases were recovered and analyzed. We were able to assign all sequences to the domain Bacteria and classify all of them at phylum level.

\subsubsection{Bacterial diversity and richness}

Operational taxonomic units (OTUs) were identified at 3\%, and $20 \%$ sequence divergence and the same level of surveying effort $(10,200$ randomly selected sequences per sample). Subsequently, rarefaction curves, richness and diversity indices were determined for the analyzed active bacterial community. At 20\% genetic distance (phylum level), rarefaction curves were almost saturated, indicating that the surveying effort covered almost the full taxonomic diversity. Comparison of the number of observed OTUs with the number of OTUs predicted by Chao 1 and ACE richness estimators revealed that $74.1 \%$ to $83.0 \%$ of the estimated taxonomic diversity at $20 \%$ genetic distance was covered (Table S4). At 3\% genetic distance, rarefaction curves were not saturated, and the richness estimators indicated a coverage of $32.0 \%$ to $77.0 \%$, respectively. Additionally, the maximal number of OTUs expected was determined by non-linear regression based on the Michaelis-Menten fit metrics. Estimates of the diversity coverage using Michaelis-Menten fit ranged from $87.5 \%$ to $90.2 \%$ at $20 \%$ genetic distance and from $72.5 \%$ to $83.1 \%$ at $3 \%$ genetic distance. Thus, we did not survey the full extent of taxonomic diversity at $3 \%$ genetic distance, but a substantial fraction of the bacterial diversity was assessed by the surveying effort. The observed values were in the range of other amplicon-based 16S RNA gene studies in which different forest and grassland soils were analyzed (Nacke et al., 2011; Will et al., 2010).

Haegeman et al. (2013) recently recommended the use of Shannon and Simpson indices of diversity for sample comparisons, as the estimation of species richness is problematic, due to missing or insufficient information on the real number of rare species. Comparison of the diversity indices revealed a similar level of bacterial diversity in all analyzed samples. The Shannon indices of diversity at $20 \%$ sequence divergence were $2.66,2.74,2.89$ and 2.78 for the beech and ash treated samples from 2008 with litter and without litter overlay, and 2.51, 2.24, 2.97 and 2.20 for the corresponding samples from 2009 (supplemental Table S4). At 3\% sequence divergence the Shannon indices were 5.86, 5.89, 6.56 and 5.66 for 


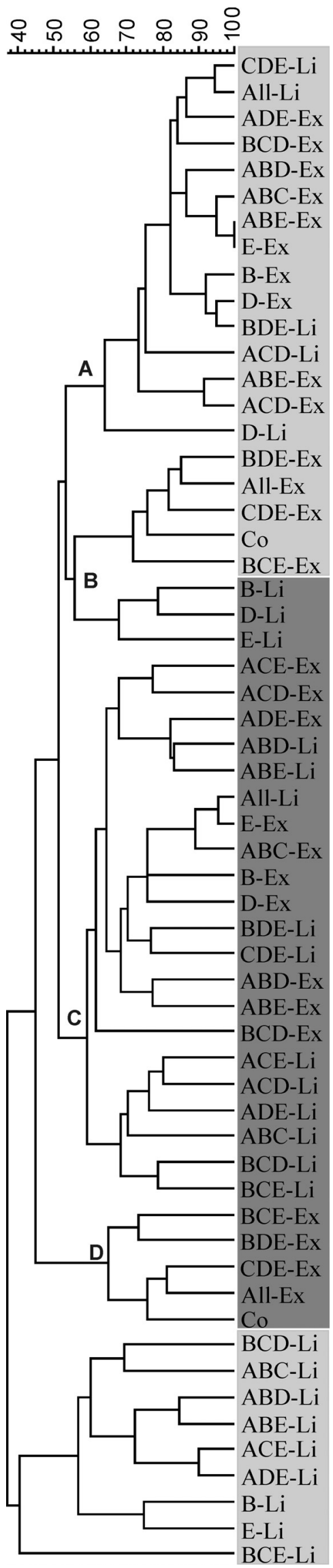

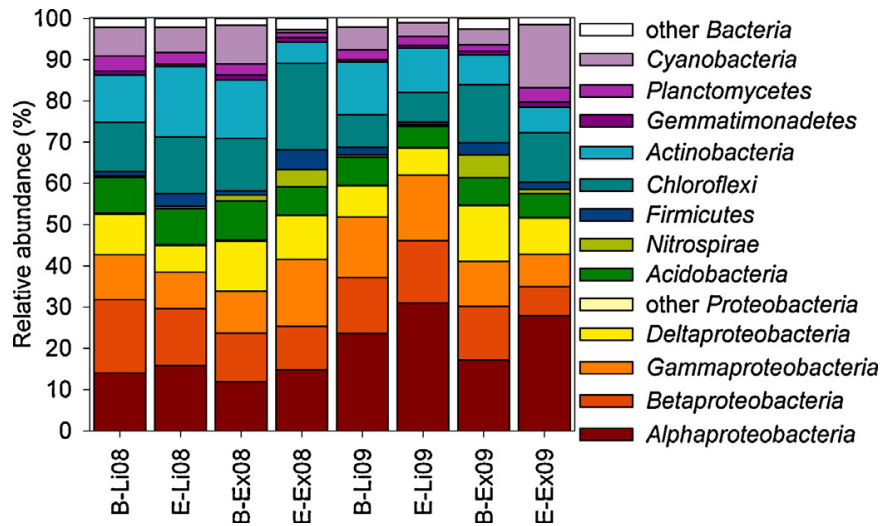

Fig. 3. Relative abundance of the most abundant $(>1 \%)$ proteobacterial classes and bacterial phyla occurring in the analyzed soil mesocosms. Sample numbers indicating the different treatments with beech (B) and ash saplings (E), with (Ex) and without litter removal (Li) and the sampling in October 2008 (08) and June 2009 (09).

samples taken in 2008, and 6.11, 5.64, 6.27 and 5.73 for samples taken in 2009 (supplemental Table S4). These values were in same range as in other studies employing the RDP database for analysis of amplicon-based 16S rRNA gene data (Nacke et al., 2011; Will et al., 2010). The Simpson index pointed to a high bacterial diversity within the analyzed soil samples, with little variation of $D$ for the beech-treated samples. The Simpson index was 0.990, 0.996, 0.992 and 0.993 for the beech-treated samples with and without litter layer sampled in 2008 and 2009, respectively. The Simpson index for the ash-treated samples varied more widely, with 0.991 , $0.984,0.972$ and 0.983 for treatments with and without litter layer sampled in 2008 and 2009, respectively. The diversity index calculations for RNA-based and DNA-based surveys are comparable, with the exception that 16S rRNA-based studies depict the active communities whereas the 16S rRNA gene-based studies reflect total bacterial communities. Active bacteria transcribe $16 \mathrm{~S}$ rRNA from the 16S rRNA genes and therefore analysis from these molecules can be correlated to bacterial diversity in the respective environment. In addition, studies based on 16S rRNA or 16S rRNA genes are not perfect, as taxa can contain different and genetically diverse operons (Klappenbach et al., 2000). Thus, the relative abundance of taxa with low operon copy numbers tend to be underestimated, while the abundance of taxa with high copy numbers might be overestimated (Větrovský and Baldrian, 2013). A study comparing bacterial community composition in forest soil based on RNA and DNA showed that several active bacterial OTUs were considerably underrepresented in the DNA-based survey (Baldrian et al., 2012).

\subsubsection{Distribution of phylogenetic groups.}

The active bacterial communities across all analyzed soils comprised 19 phyla and 13 candidate phyla (Fig. 3). The dominant phyla, were Proteobacteria, Chloroflexi, Actinobacteria, Acidobacteria, Cyanobacteria, Planctomycetes, Firmicutes and Nitrospirae accounting for $53.9 \%, 12.6 \%, 10.6 \%, 7.2 \%, 6.4 \%, 2.5 \%, 2.1 \%$ and $1.7 \%$ of all sequences, respectively (Fig. 3 ). The dominant classes of the

Fig. 2. Cluster analysis of DNA-derived DGGE profiles. Clustering was performed by the unweighted pair group method with arithmetic mean (UPGMA) using the Jaccard coefficient of similarity, which takes only the presence or absence of a band into account. Upper case letters indicate the different tree species used in this study (maple (A), beech (B), lime (C), hornbeam (D) and ash (E)). The five tree species treatments are marked with All. The control (Co) contained no tree species and no litter. The removal of litter is indicated by (Ex) and the presence of a litter layer is indicated by (Li). Samples marked in dark grey were taken in October 2008 and samples marked with light grey were sampled in Jun 2009. 
Proteobacteria were the Alphaproteobacteria, Betaproteobacteria, Gammaproteobacteria and Deltaproteobacteria, representing 19.5\%, $12.8 \%, 11.9 \%$ and $9.5 \%$, of all classified sequences, respectively. Despite different soil characteristics and survey methods, all abovementioned phylogenetic groups were also identified in DNA-based studies targeting soil bacterial community composition (Nacke et al., 2011; Janssen, 2006; Will et al., 2010). The Acidobacteria were identified as the predominant phylum in German grassland soil samples, representing $27.0 \%$ of all analyzed sequences (Will et al., 2010). Furthermore, a high relative abundance (19.6\%) of this phylum was observed in forest and grassland soil samples that vary in management type (Nacke et al., 2011). Several surveys have shown that soil $\mathrm{pH}$ is one of the main drivers of bacterial community composition (Fierer and Jackson, 2006; Lauber et al., 2009; Nacke et al., 2011; Rousk et al., 2010). Thus, the relatively low abundance of Acidobacteria in this RNA-based study indicated a reduced activity. This may result from the high soil $\mathrm{pH}\left(\mathrm{pH}\left(\mathrm{CaCl}_{2}\right)\right.$ 7.4) compared to the soils ( $\left.\mathrm{pH}\left(\mathrm{CaCl}_{2}\right) 3.0-7.4\right)$ in the studies by Will et al. (2010) and Nacke et al. (2011). Dimitriu and Grayston (2010) determined a linear decline in the relative abundance of Acidobacteria with increasing soil $\mathrm{pH}$ values. The comparison of 16S rRNA gene libraries derived from a variety of soils including forest, grassland and arid woodland soils revealed an average abundance of this phylum ranging from $5 \%$ to $46 \%$ (Janssen, 2006). Thus, the relative abundances of $5.20 \%$ to $9.48 \%$ for Acidobacteria recorded in this survey were comparable to those derived from the DNA-based approach. The remaining 24 rare phyla and candidate phyla included Bacteroidetes, Chlorobi, Fibrobacteres, Verrucomicrobia, Armatimonadetes, TM7 and WS3 ( $>0.5 \%$ of all sequences, Fig. 4).

The most abundant and thus, most active family across all analyzed samples were the Rhodospirillaceae (Alphaproteobacteria), representing $7.5 \%$ of all sequences. Members of this photosynthetically-active family are known to fix nitrogen via nitrogenase reaction (Madigan et al., 1984), and thus play a role in the nitrogen cycle. Several species belonging to the Rhodospirillaceae were isolated from soil (An et al., 2009; Ishii et al., 2011; Jung et al., 2011), indicating that this family is common in soil. Additionally, Rhodospirillaceae are known to grow anaerobically in the light as well as aerobically in the dark (Saunders, 1978), which accounts for their high activity in our mesocosms. Other highly abundant and active phylotypes were the Comamonadaceae (6.7\%),

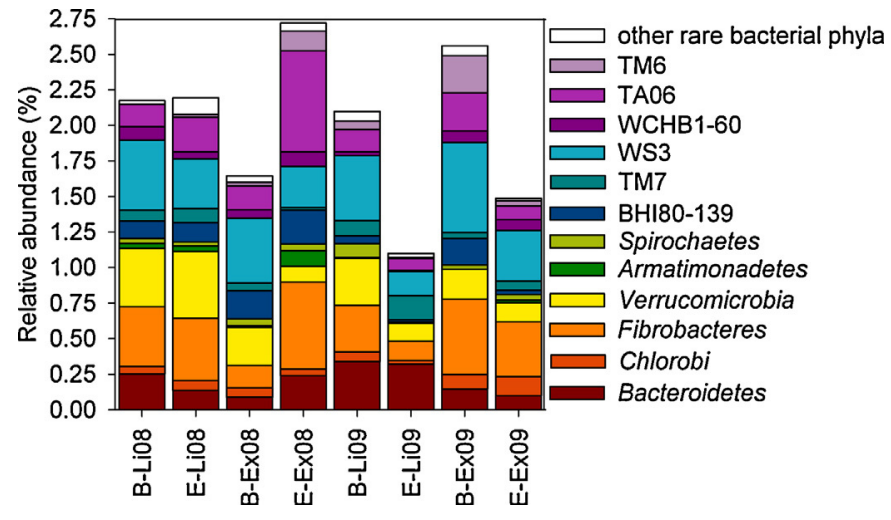

Fig. 4. Relative abundance of rare bacterial phyla $(<1 \%)$ occurring in the analyzed soil mesocosms. Sample numbers indicating the different treatments with beech (B) and ash saplings (E), with (Ex) and without litter removal (Li) and the sampling in October 2008 (08) and June 2009 (09).

Anaerolineaceae (3.6\%), Nannocystineae (3.3\%), Sinobacteraceae (3.0\%) and the Xanthomonadaceae (3.9\%).

Some of the recovered $16 \mathrm{~S}$ rRNA sequences exhibited $\geq 99$ identities to those of isolated soil-derived species such as Kribbella alba (0.2\%, Li et al., 2006), Nocardioides terrigena $(0.06 \%$, Yoon et al., 2007) and Humibacillus xanthopallidus (0.05\%, Kageyama et al., 2008). Additionally, some sequences could be assigned to the type I methanotrophic bacterium Methylobacter luteus (0.23\%, Bowman et al., 1993) and the ammonia-oxidizing bacterium Nitrosospira sp. Nsp17 (0.05\%, Aakra et al., 2001). Other identified bacterial species such as Pseudomonas sp. SHF7 (0.85\%), Nostocaceae cyanobacterium SAG B11.82 (0.55\%), Bacillus simplex (0.1\%), Lysobacter sp. 8L (0.31\%), Clostridium favososporum (0.1\%) and Azotobacter chroococcum $(0.1 \%)$ (supplemental Table S5) were also found within the analyzed samples.

\subsubsection{Tree species and litter overlay affect the composition and diversity of active soil bacterial communities.}

To analyze the differences between the analyzed single-tree species mesocosms, a principal component analysis (PCA) based on active bacterial phyla and proteobacterial classes was conducted (Fig. 5). The PCA confirmed differences between samples taken
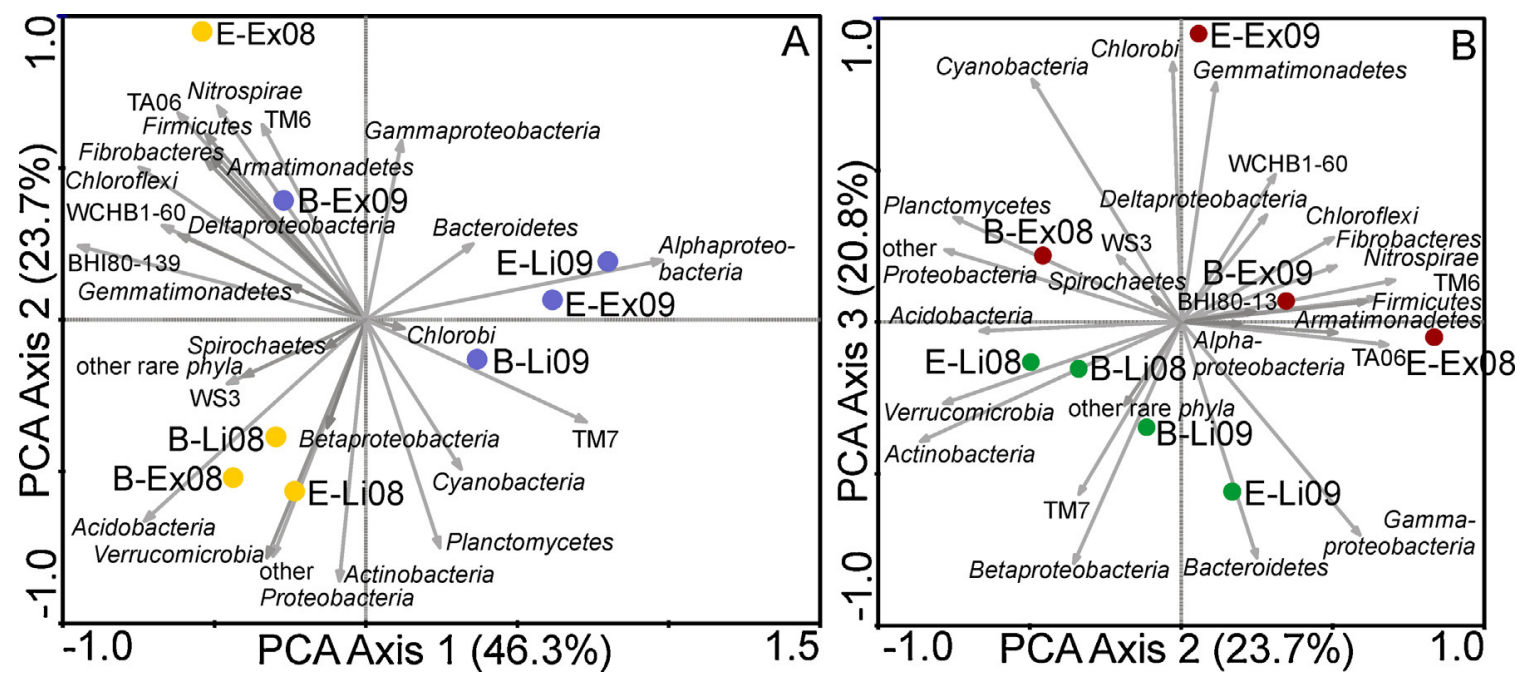

Fig. 5. Principal component analysis (PCA) of proteobacterial classes and bacterial phyla inhabiting the analyzed beech and ash single tree species treated mesocosms, with and without litter layer. Part (A) depicts the first and second axis (A) of the PCA and the present tree species are highlighted in yellow (beech) and blue (ash). Part (B) depicts the second and the third axis of the PCA, litter (red) and not litter (green) samples are highlighted.(For interpretation of the references to color in this figure legend, the reader is referred to the web version of this article.) 
Table 1

Mean relative abundance (in\%) and standard deviation of phyla and proteobacterial classes occurring in the different treatments. Samples were grouped and analyzed according to the time of sampling and the applied treatment. Different lower case letters indicate differences between samplings of 2008 and 2009 , upper case letters show differences between beech and ash and Greek letters indicate significant differences between the saplings with and without litter. Paired $t$-test with $P<0.05$.

\begin{tabular}{|c|c|c|c|c|c|c|}
\hline & 2008 & 2009 & beech & ash & litter & no litter \\
\hline Alpha-proteobacteria & $14.15 \pm 1.67 \mathbf{a}$ & $24.91 \pm 6.00 \mathbf{b}$ & $16.67 \pm 5.11$ & $22.38 \pm 8.25$ & $21.11 \pm 7.78$ & $17.94 \pm 6.98$ \\
\hline Beta-proteobacteria & $13.45 \pm 3.18$ & $12.18 \pm 3.55$ & $14.02 \pm 2.60$ & $11.61 \pm 3.62$ & $15.06 \pm 1.94 \alpha$ & $10.58 \pm 2.57 \beta$ \\
\hline Gamma-proteobacteria & $11.54 \pm 3.23$ & $12.32 \pm 3.66$ & $11.67 \pm 2.04$ & $12.19 \pm 4.46$ & $12.58 \pm 3.25$ & $11.28 \pm 3.54$ \\
\hline Delta-proteobacteria & $9.80 \pm 2.41$ & $9.12 \pm 3.12$ & $10.76 \pm 2.66$ & $8.16 \pm 2.05$ & $7.59 \pm 1.58 \boldsymbol{\alpha}$ & $11.33 \pm 2.00 \beta$ \\
\hline Other Proteobacteria & $0.22 \pm 0.12$ & $0.15 \pm 0.03$ & $0.24 \pm 0.09$ & $0.14 \pm 0.06$ & $0.18 \pm 0.07$ & $0.19 \pm 0.12$ \\
\hline Acidobacteria & $8.41 \pm 1.13 \mathbf{a}$ & $6.08 \pm 0.76 \mathbf{b}$ & $7.87 \pm 1.41$ & $6.62 \pm 1.57$ & $7.35 \pm 1.68$ & $7.14 \pm 1.63$ \\
\hline Nitrospirae & $1.63 \pm 1.74$ & $1.87 \pm 2.43$ & $1.98 \pm 2.39$ & $1.52 \pm 1.77$ & $0.48 \pm 0.09 \boldsymbol{\alpha}$ & $3.02 \pm 2.17 \boldsymbol{\beta}$ \\
\hline Firmicutes & $2.48 \pm 1.82$ & $1.78 \pm 0.97$ & $1.71 \pm 0.93$ & $2.55 \pm 1.80$ & $1.63 \pm 1.07$ & $2.63 \pm 1.66$ \\
\hline Chloroflexi & $14.86 \pm 4.18$ & $10.32 \pm 3.29$ & $11.67 \pm 2.62$ & $13.51 \pm 5.74$ & $10.22 \pm 3.16$ & $14.95 \pm 4.14$ \\
\hline Actinobacteria & $11.97 \pm 5.08$ & $9.24 \pm 3.04$ & $11.4 \pm 2.99$ & $9.81 \pm 5.42$ & $13.00 \pm 2.86$ & $8.22 \pm 4.07$ \\
\hline Gemmatimonadetes & $0.94 \pm 0.26$ & $0.84 \pm 0.3$ & $0.92 \pm 0.24$ & $0.87 \pm 0.32$ & $0.71 \pm 0.22 \alpha$ & $1.08 \pm 0.16 \boldsymbol{\beta}$ \\
\hline Planctomycetes & $2.61 \pm 1.01$ & $2.41 \pm 0.76$ & $2.59 \pm 0.87$ & $2.43 \pm 0.93$ & $2.77 \pm 0.65$ & $2.26 \pm 1.02$ \\
\hline Cyanobacteria & $5.79 \pm 3.65$ & $6.98 \pm 5.67$ & $6.41 \pm 2.37$ & $6.36 \pm 6.39$ & $5.45 \pm 1.58$ & $7.32 \pm 6.45$ \\
\hline Bacteroidetes & $0.18 \pm 0.08$ & $0.23 \pm 0.12$ & $0.21 \pm 0.11$ & $0.20 \pm 0.10$ & $0.26 \pm 0.09$ & $0.15 \pm 0.07$ \\
\hline Chlorobi & $0.06 \pm 0.01$ & $0.08 \pm 0.04$ & $0.07 \pm 0.02$ & $0.07 \pm 0.04$ & $0.06 \pm 0.02$ & $0.09 \pm 0.04$ \\
\hline Fibrobacteres & $0.41 \pm 0.19$ & $0.35 \pm 0.16$ & $0.36 \pm 0.16$ & $0.4 \pm 0.19$ & $0.33 \pm 0.14$ & $0.42 \pm 0.20$ \\
\hline Verrucomicrobia & $0.32 \pm 0.16$ & $0.2 \pm 0.09$ & $0.31 \pm 0.09$ & $0.21 \pm 0.17$ & $0.34 \pm 0.15$ & $0.18 \pm 0.07$ \\
\hline Armatimonadetes & $0.05 \pm 0.04$ & $0.01 \pm 0.01$ & $0.01 \pm 0.01$ & $0.05 \pm 0.05$ & $0.02 \pm 0.02$ & $0.04 \pm 0.05$ \\
\hline Spirochaetes & $0.04 \pm 0.01$ & $0.04 \pm 0.04$ & $0.05 \pm 0.03$ & $0.03 \pm 0.02$ & $0.04 \pm 0.04$ & $0.04 \pm 0.01$ \\
\hline Candidate division $\mathrm{BHI80-139}$ & $0.18 \pm 0.06$ & $0.07 \pm 0.07$ & $0.14 \pm 0.07$ & $0.11 \pm 0.1$ & $0.08 \pm 0.06$ & $0.16 \pm 0.09$ \\
\hline Candidate division TM7 & $0.06 \pm 0.04$ & $0.1 \pm 0.06$ & $0.07 \pm 0.03$ & $0.09 \pm 0.06$ & $0.12 \pm 0.04 \alpha$ & $0.04 \pm 0.02 \beta$ \\
\hline Candidate division WS3 & $0.4 \pm 0.09$ & $0.41 \pm 0.19$ & $0.51 \pm 0.08 \mathrm{~A}$ & $0.29 \pm 0.09 \mathrm{~B}$ & $0.37 \pm 0.14$ & $0.44 \pm 0.15$ \\
\hline Candidate division WCHB1-60 & $0.08 \pm 0.03$ & $0.05 \pm 0.04$ & $0.07 \pm 0.03$ & $0.06 \pm 0.04$ & $0.05 \pm 0.04$ & $0.08 \pm 0.02$ \\
\hline Candidate division TA06 & $0.32 \pm 0.26$ & $0.15 \pm 0.09$ & $0.19 \pm 0.05$ & $0.28 \pm 0.3$ & $0.16 \pm 0.07$ & $0.31 \pm 0.28$ \\
\hline Candidate division TM6 & $0.05 \pm 0.06$ & $0.09 \pm 0.11$ & $0.09 \pm 0.12$ & $0.05 \pm 0.06$ & $0.02 \pm 0.03$ & $0.12 \pm 0.11$ \\
\hline other rare bacterial phyla & $0.06 \pm 0.04$ & $0.05 \pm 0.03$ & $0.05 \pm 0.01$ & $0.05 \pm 0.05$ & $0.06 \pm 0.04$ & $0.04 \pm 0.02$ \\
\hline
\end{tabular}

in 2008 and 2009, except for one ash and one beech single-tree species sample without litter sampled in 2008 and 2009, respectively. A second grouping according to the presence or absence of a leaf litter layer was observed. Additionally, the analyzed samples were grouped according to the applied treatment (2008 vs. 2009 , beech vs. ash and litter vs. no litter) to analyze the differences between each treatment group. The Shapiro-Wilks tests for normal distribution indicate that Nitrospirae, Armatimonadetes and Candidate phyla TA06 and TM6 were not normally distributed among the analyzed soil samples, $(P$ values $<0.05)$. Comparison of the relative abundances of active taxonomic groups, detected in soil sampled in 2008 and 2009, revealed significant differences for Alphaproteobacteria $(P=0.014)$ and Acidobacteria $(P=0.014)$ (Table 1 and supplemental Table S6). The relative abundance of Alphaproteobacteria was higher in 2009, while the relative abundance of Acidobacteria was higher in 2008 (Table 1). Sheik et al. (2011) found that the warming treatment and soil water budget applied in their grassland soil study strongly influenced the soil bacterial population size and diversity. In addition, a increase in soil temperature by $4{ }^{\circ} \mathrm{C}$ increased microbial metabolic activity, although the bacterial community composition was not affected (Schindlbacher et al., 2011). Thus, the higher temperatures in May 2009 $\left(15.6 \pm 3.4^{\circ} \mathrm{C}\right)$ compared to October $2008\left(10.4 \pm 3.4^{\circ} \mathrm{C}\right)$ influenced the community composition of active soil bacteria (supplemental Figure S3).
The comparison of beech-treated and ash-treated mesocosms indicated an influence of tree species on the activity of candidate phylum WS3 (Table 1). The first representatives of this candidate phylum were discovered in a methanogenic aquifer-derived 16S rRNA gene clone library (Dojka et al., 1998). Members of this group were also found in bulk soil, on rice roots of flooded rice microcosms and in the suboxic zone of the Black Sea (Derakshani et al., 2001, Kirkpatrick et al., 2006). Beech had a positive effect on the relative abundance of candidate phylum WS3 (0.46\% to $0.63 \%$ ) compared to ash $(0.17 \%$ to $0.36 \% ; P=0.012)$. For all other phyla a significant effect of tree species on distribution of active bacterial phyla was not found (Table 1). Comparison of the rarefaction analyses of all beech with all ash-treated soil samples pointed to a higher diversity of active bacteria in the beech-treated mesocosms at 10\%, 5\% and $3 \%$ genetic distance (supplemental Figure S9). The mean Shannon as well as the mean Simpson index of diversity revealed a significantly higher $(P<0.05)$ diversity of active bacteria for the beech treatments at these genetic distances (Table 2), indicating an impact of tree species on the diversity of active soil bacterial communities. It is possible that these differences were induced through rhizodeposition, the release of carbon compounds, cell material and other substances from beech and ash roots to the rhizosphere and the surrounding soil. Beech and ash differ strongly in their traits, which is reflected by their root morphology, litter quality and mycorrhizal symbiosis. Beech has a higher specific root tip abundance,

Table 2

Mean bacterial diversity and standard deviation of the different treatment groups as assessed by the Shannon index $\left(H^{\prime}\right)$ and the Simpson index $(D)$. The samples were grouped and analyzed according to the applied treatment, beech vs. ash and litter vs. no litter. Different upper case letters indicate significant differences between the two groups analyzed. Tested with paired $t$-test $(P<0.05)$.

\begin{tabular}{|c|c|c|c|c|c|}
\hline Index & Genetic distance (\%) & Beech & Ash & Litter & No litter \\
\hline \multirow[t]{4}{*}{$\boldsymbol{H}^{\prime}$} & 3 & $6.198 \pm 0.295 A$ & $5.732 \pm 0.112 \mathbf{B}$ & $5.874 \pm 0.189$ & $6.057 \pm 0.432$ \\
\hline & 5 & $5.835 \pm 0.268 \mathrm{~A}$ & $5.413 \pm 0.087 \mathbf{B}$ & $5.528 \pm 0.170$ & $5.720 \pm 0.380$ \\
\hline & 10 & $4.878 \pm 0.218 \mathrm{~A}$ & $4.540 \pm 0.142 B$ & $4.605 \pm 0.171$ & $4.813 \pm 0.293$ \\
\hline & 20 & $2.754 \pm 0.210$ & $2.489 \pm 0.311$ & $2.536 \pm 0.217$ & $2.707 \pm 0.349$ \\
\hline \multirow[t]{4}{*}{$\boldsymbol{D}$} & 3 & $0.993 \pm 0.003 \mathrm{~A}$ & $0.984 \pm 0.005 B$ & $0.988 \pm 0.006$ & $0.989 \pm 0.006$ \\
\hline & 5 & $0.991 \pm 0.003 \mathrm{~A}$ & $0.981 \pm 0.004 \mathbf{B}$ & $0.985 \pm 0.005$ & $0.986 \pm 0.008$ \\
\hline & 10 & $0.980 \pm 0.005 \mathrm{~A}$ & $0.966 \pm 0.008 \mathbf{B}$ & $0.971 \pm 0.010$ & $0.975 \pm 0.011$ \\
\hline & 20 & $0.825 \pm 0.037$ & $0.755 \pm 0.081$ & $0.787 \pm 0.049$ & $0.793 \pm 0.094$ \\
\hline
\end{tabular}


Table 3

Mean relative abundance in percent and standard deviation of bacterial families occurring in the different treatments. Samples were grouped and analyzed according to the time of sampling and the applied treatment. Different Greek letters indicate significant differences between the saplings with and without litter. Paired $t$-test with $P<0.05$.

\begin{tabular}{|c|c|c|c|c|c|c|c|}
\hline Phylum & Family & 2008 & 2009 & Beech & Ash & Litter & No litter \\
\hline \multirow[t]{2}{*}{ Actinobacteria } & Mycobacteriaceae & $1.50 \pm 1.49$ & $1.48 \pm 1.07$ & $1.05 \pm 0.48$ & $1.93 \pm 1.63$ & $2.35 \pm 1.17 \alpha$ & $0.63 \pm 0.17 \beta$ \\
\hline & Nocardioidaceae & $2.38 \pm 1.48$ & $1.65 \pm 1.30$ & $2.38 \pm 1.24$ & $1.65 \pm 1.53$ & $2.9 \pm 0.98$ & $1.13 \pm 1.08$ \\
\hline \multirow{14}{*}{$\begin{array}{l}\text { Chloroflexi } \\
\text { Proteobacteria }\end{array}$} & Anaerolineaceae & $4.03 \pm 1.89$ & $3.10 \pm 0.83$ & $3.73 \pm 1.78$ & $3.40 \pm 1.25$ & $4.63 \pm 1.23 \alpha$ & $2.50 \pm 0.54 \beta$ \\
\hline & Caulobacteraceae & $1.25 \pm 0.33$ & $4.23 \pm 2.72$ & $1.70 \pm 0.64$ & $3.78 \pm 3.19$ & $3.15 \pm 2.7$ & $2.33 \pm 2.39$ \\
\hline & Hyphomicrobiaceae & $1.38 \pm 0.59$ & $1.58 \pm 1.00$ & $1.63 \pm 0.88$ & $1.33 \pm 0.73$ & $2.00 \pm 0.71 \alpha$ & $0.95 \pm 0.38 \beta$ \\
\hline & Rhodospirillaceae & $6.90 \pm 2.37$ & $11.18 \pm 3.74$ & $6.68 \pm 2.17$ & $11.40 \pm 3.49$ & $9.80 \pm 3.84$ & $8.28 \pm 3.94$ \\
\hline & Comamonadaceae & $7.55 \pm 3.32$ & $5.85 \pm 2.10$ & $7.80 \pm 2.66$ & $5.60 \pm 2.65$ & $8.53 \pm 2.26 \alpha$ & $4.88 \pm 1.82 \beta$ \\
\hline & Oxalobacteraceae & $0.80 \pm 0.39$ & $1.13 \pm 0.78$ & $1.03 \pm 0.31$ & $0.90 \pm 0.85$ & $1.38 \pm 0.51 \alpha$ & $0.55 \pm 0.34 \beta$ \\
\hline & Nitrosomonadaceae & $2.53 \pm 0.31$ & $2.38 \pm 0.59$ & $2.53 \pm 0.36$ & $2.38 \pm 0.56$ & $2.65 \pm 0.42$ & $2.25 \pm 0.42$ \\
\hline & Bdellovibrionaceae & $2.13 \pm 1.44$ & $1.65 \pm 0.21$ & $2.40 \pm 1.16$ & $1.38 \pm 0.46$ & $1.98 \pm 1.38$ & $1.80 \pm 0.58$ \\
\hline & Nannocystineae & $3.40 \pm 1.93$ & $3.13 \pm 2.36$ & $3.60 \pm 2.44$ & $2.93 \pm 1.77$ & $1.63 \pm 0.25 \alpha$ & $4.90 \pm 1.47 \beta$ \\
\hline & Sorangiineae & $1.38 \pm 0.60$ & $1.30 \pm 0.54$ & $1.55 \pm 0.58$ & $1.13 \pm 0.43$ & $1.63 \pm 0.3$ & $1.05 \pm 0.58$ \\
\hline & Methylococcaceae & $2.63 \pm 4.39$ & $0.93 \pm 0.39$ & $0.73 \pm 0.51$ & $2.83 \pm 4.26$ & $0.50 \pm 0.34$ & $3.05 \pm 4.11$ \\
\hline & Pseudomonadaceae & $0.55 \pm 0.39$ & $1.85 \pm 1.16$ & $0.83 \pm 0.54$ & $1.58 \pm 1.39$ & $1.68 \pm 1.3$ & $0.73 \pm 0.57$ \\
\hline & Sinobacteraceae & $3.03 \pm 0.55$ & $2.90 \pm 0.92$ & $2.40 \pm 0.18$ & $3.53 \pm 0.53$ & $3.13 \pm 0.89$ & $2.80 \pm 0.55$ \\
\hline & Xanthomonadaceae & $3.68 \pm 1.98$ & $4.13 \pm 3.38$ & $5.10 \pm 2.32$ & $2.70 \pm 2.50$ & $5.58 \pm 2.10$ & $2.23 \pm 1.90$ \\
\hline
\end{tabular}

specific fine root surface area (SRA) and specific fine root length (SRL) than ash (Meinen et al., 2009). Ash roots are characterized by higher fine root diameter than beech roots (Meinen et al., 2009). The roots of beech are colonized by ectomycorrhizal (EM) fungi whereas the roots of ash are inhabited by arbuscular mycorrhizal (AM) fungi (Smith and Read, 2008). Beech litter has a high C/N ratio (>50) and lignin content whereas ash litter is regarded as high quality litter due to its low $\mathrm{C} / \mathrm{N}$ ratio (approximately 28 ) and lignin content (Jacob et al., 2010). Fender et al. (2013) found in a laboratory experiment a higher release of organic acids and lowered $\mathrm{pH}$ in the proximity of beech roots compared to ash roots. In our study, the soil acidification caused by beech rhizodeposits was buffered by the high natural carbonate content of the soil used. Thus, the effect of $\mathrm{pH}$, which was shown in several studies as the main driver on soil microbial community structure, was excluded in our experiment.

Significant differences in the mean relative abundance of several active phyla and proteobacterial classes were determined by comparing litter-treated with litter-free ash and beech samples (Table 1). Betaproteobacteria were positively influenced by the litter layer $(P=0.032)$ whereas, Deltaproteobacteria $(P=0.026)$, Nitrospirae $(P=0.029)$, Gemmatimonadetes $(P=0.037)$ and Candidate phylum TM7 $(P=0.020)$ were negatively influenced by the litter overlay. Fierer et al. (2007) showed a positive correlation of betaproteobacterial abundance and carbon availability in soils, which is in accordance with our findings. They also observed a negative effect of carbon amendments on the relative abundance of Acidobacteria. In an additionally conducted meta-analysis, they found that Acidobacteria tended to be more abundant in rhizosphere and bulk soils with low $C$ availability. These results are in accordance with a survey from Eilers et al. (2010), who analyzed the effect of low molecular weight carbon substrates on total soil bacterial communities. However, the active acidobacterial community present in our study showed no significant differences while comparing litter vs. no litter treated and beech vs. ash planted samples. Furthermore, rarefaction curves calculated based on the relative abundance of active OTUs indicated a higher diversity of the active bacterial community in samples without leaf litter layer compared to the litter-treated samples. Thus, a litter decomposition-related shift and specialization of the active microbial community, which is reflected in a decrease of bacterial diversity, was expected. However, this litter treatment-related effect was not confirmed by the mean Shannon and the mean Simpson index of diversity (Table 2).

Frequently occurring bacterial families were also tested with respect to significant differences in their relative abundance between the different treatments (Table 3). Mycobacteriaceae $(P=0.029)$, Anaerolineaceae $(P=0.019), \quad$ Hyphomicrobiaceae
$(P=0.040), \quad$ Comamonadaceae $\quad(P=0.046), \quad$ Oxalobacteraceae $(P=0.037)$ and Nannocystineae $(P=0.005)$ showed significant differences with respect to the present litter layer (supplemental Table S7). The litter layer had a positive effect on the relative abundance of active Mycobacteriaceae, Anaerolineaceae, Hyphomicrobiaceae and Oxalobacteraceae, whereas the Nannocystineae were positively influenced by litter removal. Bacteria encounter a complex cocktail of sugars, vitamins, ions, organic polymers (lignin), amino acids, organic acids, fatty acids and other primary and secondary metabolites from root exudation, decaying roots, or leaf litter leaching and decomposition (Dennis et al., 2010; Gessner et al., 2010). Root exudates are known to have stimulatory or inhibitory effects on microbial communities inhabiting the plant rhizosphere (Uren 2007). Hartmann et al. (2009) showed this plant-driven selection of bacterial communities in the rhizosphere of different herbaceous plants. A more severe influence of other $C$ and nutrient sources as decaying roots, litter leaching and decomposition, compared to the readily available and fast degradable nutrient and energy sources supplied by root exudates was suggested by Dennis et al. (2010). Leaf litter decomposition is mainly influenced by its chemical composition and the leaf litter species mixture (Jacob et al., 2010). This is in accordance with the cluster analysis of the DGGE fingerprints, in which three-tree species litter treatments cluster separately from the other treatments. Diverse leaf litter species build a more balanced nutrient source for microbial communities and is thereby degraded faster than mono-species leaf litter. During the summer, tree species-rich stands in the Hainich possess just a small or no litter layer, while mono-species or species poor stands have a thick leaf litter layer. These observations were supported by a study on seasonal dynamics of bacterial communities under different leaf litter quantities conducted by Chemidlin Prevost-Boure et al. (2011).

\section{Conclusions}

Our study suggests a slowly establishing and persistent influence of the litter layer on the soil-inhabiting bacterial community, which supports the hypothesis that (b) leaf litter presence influences soil bacterial diversity and activity. Furthermore, the Simpson and Shannon indices showed significant difference in the diversity of active bacterial communities inhabiting beech and ash single-tree species mesocosms, which supports partially the hypothesis (a) that tree species affect soil bacterial community composition, diversity and activity. Nevertheless, litter presence in $\mathrm{pH}$ stable soils affected the analyzed bacterial communities more pronounced than the time of sampling and the tree species. Litter leaching and decomposition, which act as a constant long-term $\mathrm{C}$ 
and nutrient source in soils, exhibited a stronger influence on soil bacterial community composition than fast degradable rhizodeposits or decaying roots. Thus, different tree species and tree species diversity levels, and seasonal fluctuations have a minor effect on bacterial community composition. We conclude that leaf litter is the major driver of bacterial community composition in the rhizosphere of beech and ash. Therefore, a "feedback loop" between faster decomposing litter, and soil microbial composition and activity can be expected in forest soil.

\section{Acknowledgments}

We thank Andrea Thürmer, Sonja Voget and the Göttingen Genomics Laboratory sequencing team of the University of Göttingen for the support. We also thank Heiko Nacke, Silja Brady and Julia Grosse for valuable discussions and comments on the manuscript. This work was funded by the Ministry of Science and Culture of Lower Saxony and the "Niedersächsisches Vorab". The funding source had no role in study design, data collection, data analysis, data interpretation, writing of the report, and the decision to submit the article for publication.

\section{Appendix A. Supplementary data}

Supplementary data associated with this article can be found, in the online version, at http://dx.doi.org/10.1016/j.apsoil. 2013.06.008.

\section{References}

Aakra, A., Utåker, J.B., Pommerening-Röser, A., Koops, H.P., Nes, I.F., 2001. Detailed phylogeny of ammonia-oxidizing bacteria determined by rDNA sequences and DNA homology values. Int. J. Syst. Evol. Microbiol. 51, 2021-2030.

Altschul, S.F., Gish, W., Miller, W., Myers, E.W., Lipman, D.J., 1990. Basic local alignment search tool. J. Mol. Biol. 215, 403-410.

An, H., Zhang, L., Tang, Y., Luo, X., Sun, T., Li, Y., Wang, Y., Dai, J., Fang, C., 2009. Skermanella xinjiangensis sp. nov. isolated from the desert of Xinjiang, China. Int. J. Syst. Evol. Microbiol. 59, 1531-1534.

Aneja, M., Sharma, S., Fleischmann, F., Stich, S., Heller, W., Bahnweg, G., Munch, J., Schloter, M., 2006. Microbial colonization of beech and spruce litter-influence of decomposition site and plant litter species on the diversity of microbial community. Microb. Ecol. 52, 127-135.

Baldrian, P., Kolarik, M., Stursova, M., Kopecky, J., Valaskova, V., Vetrovsky, T., Zifcakova, L., Snajdr, J., Ridl, J., Vlcek, C., Voriskova, J., 2012. Active and total microbial communities in forest soil are largely different and highly stratified during decomposition. ISME J. 6, 248-258.

Barea, J., Pozo, M., Azcón, R., Azcón-Aguilar, C., 2005. Microbial co-operation in the rhizosphere. J. Exp. Bot. 56, 1761-1778.

Bonfield, J.K., Smith, K., Staden, R., 1995. A new DNA sequence assembly program. Nucleic Acids Res. 23, 4992-4999.

Bowman, J.P., Sly, L.I., Nichols, P.D., Hayward, A.C., 1993. Revised taxonomy of the methanotrophs: description of Methylobacter gen. nov., emendation of Methylococcus, validation of Methylosinus and Methylocystis species and a proposal that the family Methylococcaceae includes only the group I methanotrophs. Int. J. Syst. Bacteriol. 43, 735-753.

Buckley, D., Schmidt, T., 2001. The structure of microbial communities in soil and the lasting impact of cultivation. Microb. Ecol. 42, 11-21.

Caporaso, J., Kuczynski, J., Stombaugh, J., Bittinger, K., Bushman, F., Costello, E., Fierer, N., Pena, A., Goodrich, J., Gordon, J., Huttley, G., Kelley, S., Knights, D., Koenig, J., Ley, R., Lozupone, C., McDonald, D., Muegge, B., Pirrung, M., Reeder, J., Sevinsky, J., Tumbaugh, P., Walters, W., Widmann, J., Yatsunenko, T., Zaneveld, J., Knight, R., 2010a. QIIME allows analysis of high-throughput community sequencing data. Nat. Methods 7, 335-336.

Caporaso, J.G., Bittinger, K., Bushman, F.D., DeSantis, T.Z., Andersen, G.L., Knight, R., 2010b. PyNAST: a flexible tool for aligning sequences to a template alignment. Bioinformatics 26, 266-267.

Chapin, F., Zavaleta, r., Eviner, E., Naylor, V., Vitousek, R., Reynolds, P., Hooper, H., Lavorel, D., Sala, S., Hobbie, O., Mack, S., Díaz, M.S., 2000. Consequences of changing biodiversity. Nature 405, 234-242.

Chemidlin Prevost-Boure, N., Maron, P.-A., Ranjard, L., Nowak, V., Dufrene, E., Damesin, C., Soudani, K., Lata, J.-C., 2011. Seasonal dynamics of the bacterial community in forest soils under different quantities of leaf litter. Appl. Soil Ecol. $47,14-23$.

Costa, R., Götz, M., Mrotzek, N., Lottmann, J., Berg, G., Smalla, K., 2006. Effects of site and plant species on rhizosphere community structure as revealed by molecular analysis of microbial guilds. FEMS Microbiol. Ecol. 56, 236-249.
Cubbage, F., Mac Donagh, P., Sawinski, J., Rubilar, R., Donoso, P., Ferreira, A., Hoeflich, V., Olmos, V., Ferreira, G., Balmelli, G., Siry, J., Baez, M., Alvarez, J., 2007. Timber investment returns for selected plantations and native forests in South America and the southern United States. New For. 33, 237-255.

Dennis, P.G., Miller, A.J., Hirsch, P.R., 2010. Are root exudates more important than other sources of rhizodeposits in structuring rhizosphere bacterial communities? FEMS Microbiol. Ecol. 72, 313-327.

Derakshani, M., Lukow, T., Liesack, W., 2001. Novel bacterial lineages at the (sub) division level as detected by signature nucleotide-targeted recovery of $16 \mathrm{~S}$ rRNA genes from bulk soil and rice roots of flooded rice microcosms. Appl. Environ. Microbiol. 67, 623-631.

de Schrijver, A., de Frenne, P., Staelens, J., Verstraeten, G., Muys, B., Vesterdal, L., Wuyts, K., van Nevel, L., Schelfhout, S., de Neve, S., Verheyen, K., 2012. Tree species traits cause divergence in soil acidification during four decades of postagricultural forest development. Glob. Chang. Biol. 18, 1127-1140.

Dimitriu, P.A., Grayston, S.J., 2010. Relationship between soil properties and patterns of bacterial beta-diversity across reclaimed and natural boreal forest soils. Microb. Ecol. 59, 563-573.

Dojka, M., Hugenholtz, P., Haack, S., Pace, N., 1998. Microbial diversity in a hydrocarbon- and chlorinated-solvent-contaminated aquifer undergoing intrinsic bioremediation. Appl. Environ. Microbiol. 64, 3869-3877.

Edgar, R.C., 2010. Search and clustering orders of magnitude faster than BLAST. Bioinformatics 26, 2460-2461.

Eilers, K., Lauber, C., Knight, R., Fierer, N., 2010. Shifts in bacterial community structure associated with inputs of low molecular weight carbon compounds to soil. Soil Biol. Biochem., 896-903.

Felske, A., Wolterink, A., Van Lis, R., De Vos, W., Akkermans, A., 2000. Response of a soil bacterial community to grassland succession as monitored by $16 \mathrm{~S}$ rRNA levels of the predominant ribotypes. Appl. Environ. Microbiol. 66, 3998-4003.

Fender, A.-C., Pfeiffer, B., Gansert, D., Leuschner, C., Daniel, R., Jungkunst, H., 2012. The inhibiting effect of nitrate fertilisation on methane uptake of a temperate forest soil is influenced by labile carbon. Biol. Fertil. Soils 48, 621-631.

Fender, A.-C., Gansert, D., Jungkunst, H.F., Fiedler, S., Beyer, F., Schützenmeister, K., Thiele, B., Valtanen, K., Polle, A., Leuschner, C., 2013. Root-induced tree species effects on the source/sink strength for greenhouse gases $\left(\mathrm{CH}_{4}, \mathrm{~N}_{2} \mathrm{O}\right.$ and $\left.\mathrm{CO}_{2}\right)$ of a temperate deciduous forest soil. Soil Biol. Biochem. 57, 587-597.

Fierer, N., Bradford, M., Jackson, R., 2007. Toward an ecological classification of soil bacteria. Ecology 88, 1354-1364.

Fierer, N., Jackson, R., 2006. The diversity and biogeography of soil bacterial communities. PNAS 103, 626-631.

Fitter, A., Gilligan, C., Hollingworth, K., Kleczkowski, A., Twyman, R., Pitchford, J., Members of the N.S.B. Programme, 2005. Biodiversity and ecosystem function in soil. Funct. Ecol. 19, 369-377.

Gessner, M., Swan, C., Dang, C., Mckie, B., Bardgett, R., Wall, D., Hattenschwiler, S., 2010. Diversity meets decomposition. Trends Ecol. Evol. 25, 372-380.

Grüter, D., Schmid, B., Brandl, H., 2006. Influence of plant diversity and elevated atmospheric carbon dioxide levels on belowground bacterial diversity. BMC Microbiol. 6, 68.

Haas, B., Gevers, D., Earl, A., Feldgarden, M., Ward, D., Giannoukos, G., Ciulla, D., Tabbaa, D., Highlander, S. Sodergren, E., Methe, B., DeSantis, T., Petrosino, J., Knight, R., Birren, B., 2011. Chimeric 16S rRNA sequence formation and detection in Sanger and 454-pyrosequenced PCR amplicons. Genome Res. 21, 494-504.

Haegeman, B., Hamelin, J., Moriarty, J., Neal, P., Dushoff, J., Weitz, J.S., 2013. Robust estimation of microbial diversity in theory and in practice. ISME J., 1-10.

Hartman, W., Richardson, C., Vilgalys, R., Bruland, G., 2008. Environmental and anthropogenic controls over bacterial communities in wetland soils. PNAS 105, 17842-17847

Hartmann, A., Schmid, M., van Tuinen, D., Berg, G., 2009. Plant-driven selection of microbes. Plant Soil 321, 235-257.

Holzwarth, F.M., Daenner, M., Flessa, H., 2011. Effects of beech and ash on smallscale variation of soil acidity and nutrient stocks in a mixed deciduous forest. J. Plant Nutr. Soil Sci. 174, 799-808.

Ishii, S., Ohno, H., Tsuboi, M., Otsuka, S., Senoo, K., 2011. Identification and isolation of active $\mathrm{N}_{2} \mathrm{O}$ reducers in rice paddy soil. ISME J. 5, 1936-1945.

Ives, A.R., Carpenter, S.R., 2007. Stability and diversity of ecosystems. Science 317, $58-62$.

Jacob, M., Viedenz, K., Polle, A., Thomas, F.M., 2010. Leaf litter decomposition in temperate deciduous forest stands with a decreasing fraction of beech (Fagus sylvatica). Oecologia 164, 1083-1094.

Janssen, P., 2006. Identifying the dominant soil bacterial taxa in libraries of 16S rRNA and 16S rRNA genes. Appl. Environ. Microbiol. 72, 1719-1728.

Jung, H.M., Lee, J.S., Bae, H.M., Yi, T.H., Kim, S.Y., Lee, S.T., Im, W.T., 2011. Inquilinus ginsengisoli sp. nov. isolated from soil of a ginseng field. Int. J. Syst. Evol. Microbiol. 61, 201-204.

Kageyama, A., Matsumoto, A., Omura, S., Takahashi, Y., 2008. Humibacillus xanthopallidus gen. nov sp. nov. Int. J. Syst. Evol. Microbiol. 58, 1547-1551.

Kennedy, N., Brodie, E., Connolly, J., Clipson, N., 2004. Impact of lime, nitrogen and plant species on bacterial community structure in grassland microcosms. Environ. Microbiol. 6, 1070-1080.

Kirkpatrick, J., Oakley, B., Fuchsman, C., Srinivasan, S., Staley, J.T., Murray, J.W., 2006. Diversity and distribution of Planctomycetes and related bacteria in the suboxic zone of the Black Sea. Appl. Environ. Microbiol. 72, 3079-3083.

Klappenbach, J., Dunbar, J., Schmidt, T., 2000. rRNA operon copy number reflects ecological strategies of bacteria. Appl. Environ. Microbiol. 66, 1328-1333. 
Kooijman, A.M., 2010. Litter quality effects of beech and hornbeam on undergrowth species diversity in Luxembourg forests on limestone and decalcified marl. J. Veg. Sci. 21, 248-261.

Kowalchuk, G., Buma, D., de Boer, W., Klinkhamer, P., van Veen, J., 2002. Effects of above-ground plant species composition and diversity on the diversity of soil-borne microorganisms. Antonie Van Leeuwenhoek 81, 509-520.

Kuske, C., Ticknor, L., Miller, M., Dunbar, J., Davis, J., Barns, S., Belnap, J., 2002. Comparison of soil bacterial communities in rhizospheres of three plant species and the interspaces in an arid grassland. Appl. Environ. Microbiol. 68 , 1854-1863.

Langenbruch, C., Helfrich, M., Flessa, H., 2012. Effects of beech (Fagus sylvatica), ash (Fraxinus excelsior) and lime (Tilia spec.) on soil chemical properties in a mixed deciduous forest. Plant Soil 352, 389-403.

Lauber, C., Hamady, M., Knight, R., Fierer, N., 2009. Pyrosequencing-based assessment of soil pH as a predictor of soil bacterial community structure at the continental scale. Appl. Environ. Microbiol., 5111-5120.

Li, W.-J., Wang, D., Zhang, Y.-Q., Xu, L.-H., Jiang, C.-L., 2006. Kribbella yunnanensis sp. nov. Kribbella alba sp. nov., two novel species of genus Kribbella isolated from soils in Yunnan, China. Syst. Appl. Microbiol. 29, 29-35.

Loreau, M., Naeem, S., Inchausti, P., Bengtsson, J., Grime, J., Hector, A., Hooper, D., Huston, M., Raffaelli, D., Schmid, B., Tilman, D., Wardle, D., 2001. Biodiversity and ecosystem functioning: current knowledge and future challenges. Science 294, 804-808.

Madigan, M., Cox, S.S., Stegeman, R.A., 1984. Nitrogen fixation and nitrogenase activities in members of the family Rhodospirillaceae. J. Bacteriol. 157 73-78.

Meinen, C., Hertel, D., Leuschner, C., 2009. Biomass and morphology of fine roots in temperate broad-leaved forests differing in tree species diversity: is there evidence of below-ground overyielding? Oecologia 161, 99-111.

Motavalli, P.P., Palm, C.A., Parton, W.J., Elliott, E.T., Frey, S.D., 1995. Soil pH and organic C dynamics in tropical forest soils: evidence from laboratory and simulation studies. Soil Biol. Biochem. 27, 1589-1599.

Muyzer, G., Smalla, K., 1998. Application of denaturing gradient gel electrophoresis (DGGE) and temperature gradient gel electrophoresis (TGGE) in microbial ecology. Antonie Van Leeuwenhoek 73, 127-141.

Muyzer, G., Teske, A., Wirsen, C., Jannasch, H., 1995. Phylogenetic relationships of Thiomicrospira species and their identification in deep-sea hydrothermal ven samples by denaturing gradient gel electrophoresis of 16S rDNA fragments. Arch. Microbiol. 164, 165-172.

Nacke, H., Thürmer, A., Wollherr, A., Will, C., Hodac, L., Herold, N., Schöning, I., Schrumpf, M., Daniel, R., 2011. Pyrosequencing-based assessment of bacteria community structure along different management types in German forest and grassland soils. PLoS One 6, e17000.

Norris, T., Wraith, J., Castenholz, R., McDermott, T., 2002. Soil microbial community structure across a thermal gradient following a geothermal heating event. Appl. Environ. Microbiol. 68, 6300-6309.

Nunan, N., Daniell, T., Singh, B., Papert, A., McNicol, J., Prosser, J., 2005. Links between plant and rhizoplane bacterial communities in grassland soils, characterized using molecular techniques. Appl. Environ. Microbiol. 71, 6784-6792.

Petchey, O., Gaston, K., 2002. Extinction and the loss of functional diversity. Proc Biol. Sci. 269, 1721-1727.

Pruesse, E., Quast, C., Knittel, K., Fuchs, B.M., Ludwig, W., Peplies, J., Glöckner, F.O. 2007. SILVA: a comprehensive online resource for quality checked and aligned ribosomal RNA sequence data compatible with ARB. Nucleic Acids Res. 35 7188-7196.

Reeder, J., Knight, R., 2010. Rapidly denoising pyrosequencing amplicon reads by exploiting rank-abundance distributions. Nat. Methods 7, 668-669.

Reich, P.B., Tilman, D., Isbell, F., Mueller, K., Hobbie, S.E., Flynn, D.F., Eisenhauer, N. 2012. Impacts of biodiversity loss escalate through time as redundancy fades. Science 336, 589-592.
Rousk, J., Baath, E., Brookes, P., Lauber, C., Lozupone, C., Caporaso, J., Knight, R., Fierer, $\mathrm{N} ., 2010$. Soil bacterial and fungal communities across a $\mathrm{pH}$ gradient in an arable soil. ISME J. 4, 1340-1351.

Saunders, V.A., 1978. Genetics of Rhodospirillaceae. Microbiol. Rev. 42, 357-384

Schindlbacher, A., Rodler, A., Kuffner, M., Kitzler, B., Sessitsch, A., ZechmeisterBoltenstern, S., 2011. Experimental warming effects on the microbial community of a temperate mountain forest soil. Soil Biol. Biochem. 43 , $1417-1425$.

Schlichting, E., Blume, H.P. Stahr, K, 1995. Bodenkundliches Praktikum-Eine Einführung in pedologisches Arbeiten für Ökologen, insbesondere Land- und Forstwirte und für Geowissenschaftler. Blackwell, Wissenschaft, Berlin.

Schloss, P.D., Handelsman, J., 2005. Introducing DOTUR, a computer program for defining operational taxonomic units and estimating species richness. Appl. Environ. Microbiol. 71, 1501-1506.

Schmalenberger, A., Schwieger, F., Tebbe, C., 2001. Effect of primers hybridizing to different evolutionarily conserved regions of the small-subunit rRNA gene in PCR-based microbial community analyses and genetic profiling. Appl. Environ. Microbiol. 67, 3557-3563.

Sheik, C.S., Beasley, W.H., Elshahed, M.S., Zhou, X., Luo, Y., Krumholz, L.R., 2011 Effect of warming and drought on grassland microbial communities. ISME J. 5, 1692-1700.

Smalla, K., Wieland, G., Buchner, A., Zock, A., Parzy, J., Kaiser, S., Roskot, N., Heuer, H., Berg, G., 2001. Bulk and rhizosphere soil bacterial communities studied by denaturing gradient gel electrophoresis: plant-dependent enrichment and seasonal shifts revealed. Appl. Environ. Microbiol. 67, 4742-4751.

Smith, S.E., Read, D.J., 2008. Mycorrhizal Symbiosis. Academic Press, London, UK.

Stres, B., Danevcic, T., Pal, L., Fuka, M., Resman, L., Leskovec, S., Hacin, J., Stopar, D. Mahne, I., Mandic-Mulec, I., 2008. Influence of temperature and soil water content on bacterial, archaeal and denitrifying microbial communities in drained fen grassland soil microcosms. FEMS Microbiol. Ecol. 66, 110-122.

Torsvik, V., Øvreås, L., 2002. Microbial diversity and function in soil: from genes to ecosystems. Curr. Opin. Microbiol. 5, 240-245.

Uren, N.C., 2007. Types, amounts and possible functions of compounds released into the rhizosphere by soil-grown plants. In: Pinton, R., Varanini, Z., Nannipiero, P. (Eds.), The Rhizosphere: Biochemistry and Organic Substances at the Soil-Plant Interface. CRC Press, Boca Raton, pp. 1-21.

van Bergen, P.F., Nott, C.J., Bull, I.D., Poulton, P.R., Evershed, R.P., 1998. Organic geochemical studies of soils from the Rothamsted Classical Experiments-IV. Preliminary results from a study of the effect of soil $\mathrm{pH}$ on organic matter decay. Organ. Geochem. 29, 1779-1795.

van der Heijden, M., Bardgett, R., van Straalen, N., 2008. The unseen majority: soil microbes as drivers of plant diversity and productivity in terrestrial ecosystems. Ecol. Lett. 11, 296-310.

Větrovský, T., Baldrian, P., 2013. The variability of the 16S rRNA gene in bacterial genomes and its consequences for bacterial community analyses. PLoS One 8 , e57923.

Wertz, S., Degrange, V., Prosser, J., Poly, F., Commeaux, C., Freitag, T., Guillaumaud, N. Roux, X., 2006. Maintenance of soil functioning following erosion of microbial diversity. Environ. Microbiol. 8, 2162-2169.

Wertz, S., Degrange, V., Prosser, J., Poly, F., Commeaux, C., Guillaumaud, N., Le Roux X., 2007. Decline of soil microbial diversity does not influence the resistance and resilience of key soil microbial functional groups following a model disturbance. Environ. Microbiol. 9, 2211-2219.

Will, C., Thürmer, A., Wollherr, A., Nacke, H., Herold, N., Schrumpf, M. Gutknecht, J., Wubet, T., Buscot, F., Daniel, R., 2010. Horizon-specific bacterial community composition of German grassland soils, as revealed by pyrosequencing-based analysis of $16 \mathrm{~S}$ rRNA genes. Appl. Environ. Microbiol. 76, 6751-6759.

Yoon, J.H., Kang, S.J., Lee, S.Y., Oh, T.K., 2007. Nocardioides terrigena sp. nov isolated from soil. Int. J. Syst. Evol. Microbiol. 57, 2472-2475. 


\subsection{Supplementary data}

Figure S1 Mesocosm design. The control (a.) contained no trees. The maple one-tree treatment (b.), the maple/beech/lime three-tree treatment (c.) and the five-tree species treatment (d.) containing all selected tree species (maple (A), beech (B), lime (C), hornbeam (D) and ash (E)) are shown exemplarily.

Figure S2 Sample area in late summer 2008 (A), winter 2009 (B) and mesocosm set up (C). The sample area was located in the experimental botanical garden of the GeorgAugust University of Göttingen. The different treated mesocosms containing one-tree, three-tree and five-tree species were randomly distributed. The litter application was randomly performed amongst the depicted mesocosms.

Figure S3 Climate data. Overview of the climatic conditions in the time between the two samplings took place, obtained by a weather station located next to the sampling area.

Figure S4 DNA-based DGGE profile obtained from samples taken in June 2009. The marked bands were excised, reamplified and cloned to determine the underlying sequences. Equal upper case letters indicate bands excised from the same running height on the DGGE-Gel. Blast results of the underlying sequences are depicted in Figure 1.

Figure S5 Second replicate of the DNA-based DGGE profile obtained from samples taken in June 2009. The marked bands were excised, reamplified and cloned to determine the underlying sequences. Identical upper case letters indicate bands excised from the same running height on the DGGE-Gel. Blast results of the underlying sequences are depicted in Figure1.

Figure S6 Third replicate of the DNA-based DGGE profile obtained from samples taken in June 2009. The marked bands were excised, reamplified and cloned to determine the underlying sequences. Equal upper case letters indicate bands excised from the same running height on the DGGE-Gel. Blast results of the underlying sequences are depicted in Figure1. 
Figure S7 Three times replicated DNA-based DGGE profile obtained from samples taken in June 2009. The marked bands were excised, reamplified and cloned to determine the underlying sequences. Blast results of the underlying sequences are depicted in Figure1.

Figure S8 Cluster analysis of the three replicates of each DNA-derived DGGE profiles. Depicted are the litter-treated samples taken in 2008 (light green) and 2009 (dark green), and samples without litter overlay taken in 2008 (orange) and 2009 (red). Clustering was performed by the unweighted pair group method with arithmetic mean (UPGMA) using the Jaccard coefficient of similarity, which takes only the presence or absence of a band into account. Position tolerance was set at $1 \%$.

Figure S9 Rarefaction curves indicating the number of all observed OTU's within the beech and ash treated single-tree species mesocosms (A) and the single-tree species mesocosms treated without and with litter overlay (B). Depicted is the mean and the standard deviation of the sum of all OTU's observed for the beech-treated and ashtreated mesocosms without and with litter overlay at different levels of sequence divergence $(3,10$ and $20 \%)$. 
Table S1 Parameters of the soil used in mesocosms. Shown are the mean values and the standard deviation (SD) of the replicates in percent of dry weight (dw).

Table S2 Diversity levels and treatment of the soil mesocosms sampled in autumn 2008 and summer 2009, with (Ex) and without litter removal (Li).

Table S3 Sampling time, treatment and number of 16S rRNA gene sequences derived from the analyzed soil samples, before and after the removal of reads shorter than 300 bp, low quality reads, reads containing homopolymers longer than 8 bp and primer mismatches and potential chimeras, and denoising.

Table S4 Bacterial diversity assessed by Shannon index (H'), Simpson index (D) and species richness estimation in the beech-treated and ash-treated soil samples, with (Ex) and without (Li) litter removal.

Table S5 Number of sequences and identity to known species of the most abundant species identified in the amplicon-based dataset.

Table S6 Differences in the relative abundance of proteobacterial classes and other phyla occurring between different treatment groups. Samples were grouped according to treatment and differences in relative abundance of proteobacterial classes and phyla between each group and tested for significance. Tested with paired t-test $(P<0.05)$.

Table S7 Differences of frequently occurring phylotypes between different treatment groups. Samples were grouped according to treatment and differences in relative abundance of frequently occurring families between each group and tested for significance. Tested with paired t-test $(P<0.050)$. 


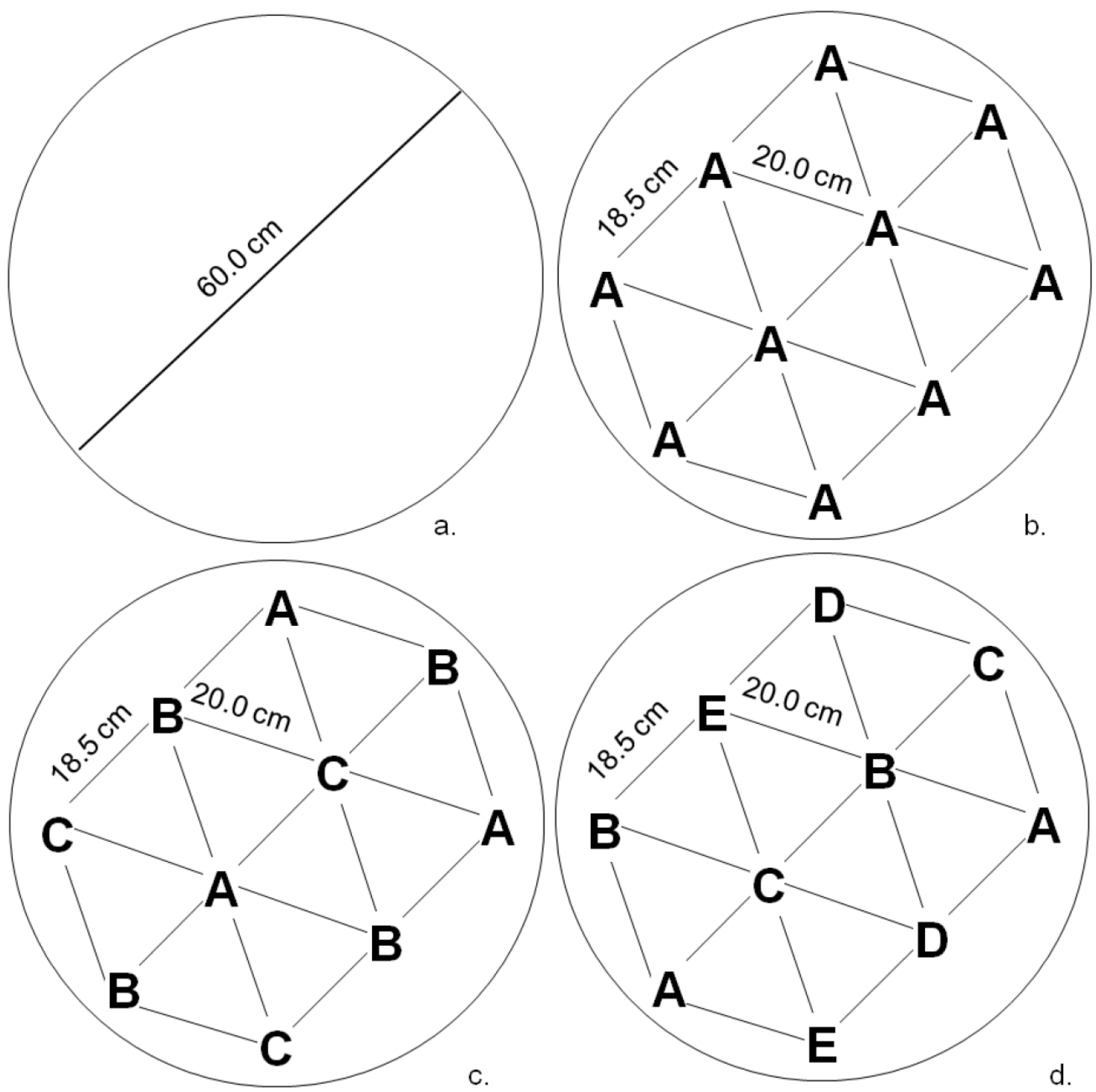

Figure S1. Mesocosm design. The control (a.) contained no trees. The maple one-tree treatment (b.), the maple/beech/lime three-tree treatment (c.) and the five-tree species treatment (d.) containing all selected tree species (maple (A), beech (B), lime (C), hornbeam (D) and ash (E)) are shown exemplarily. 

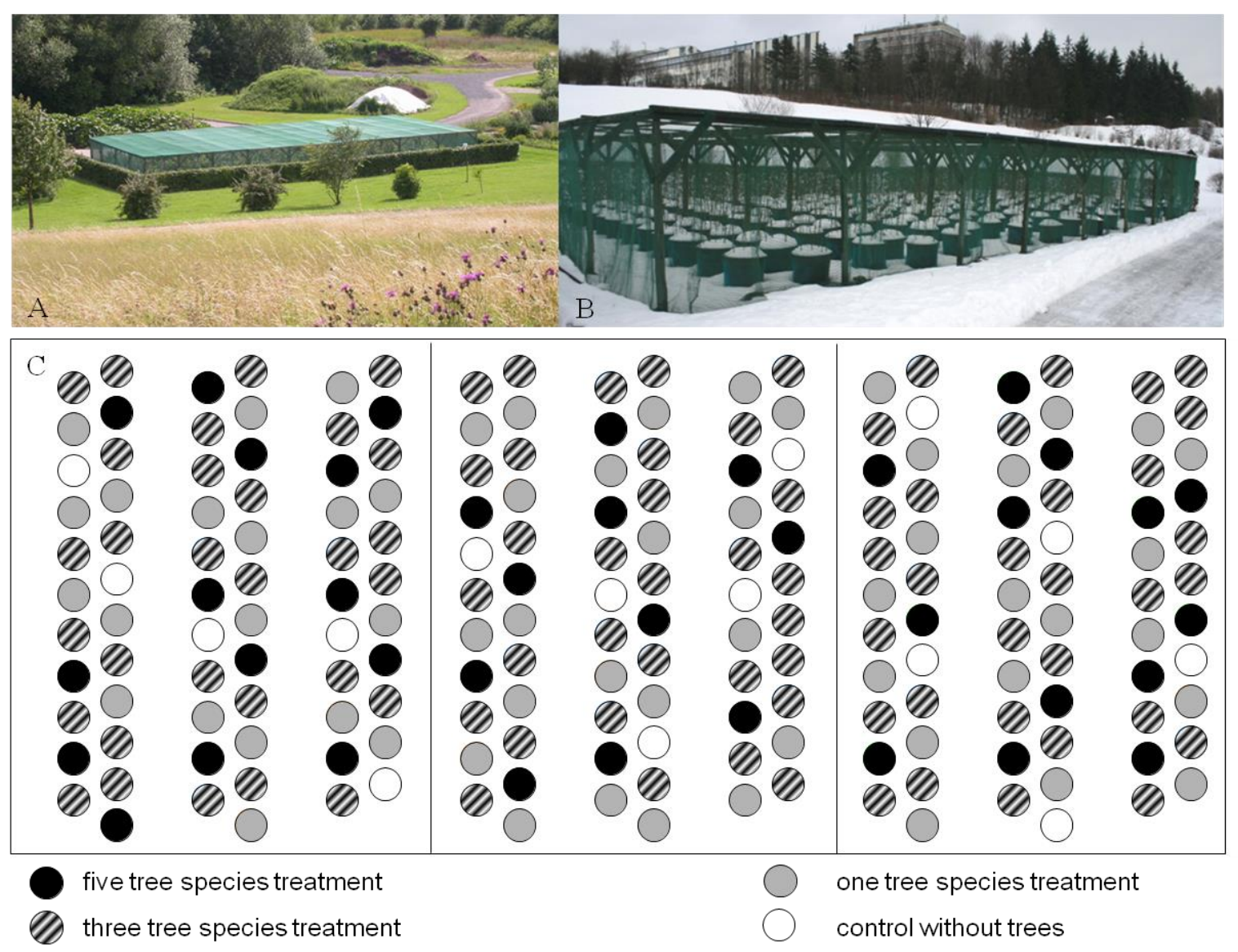

Figure S2. Sample area in late summer 2008 (A), winter 2009 (B) and mesocosm set up (C). The sample area was located in the experimental botanical garden of the GeorgAugust University of Göttingen. The different treated mesocosms containing one-tree, three-tree and five-tree species were randomly distributed. The litter application was randomly performed amongst the depicted mesocosms. 

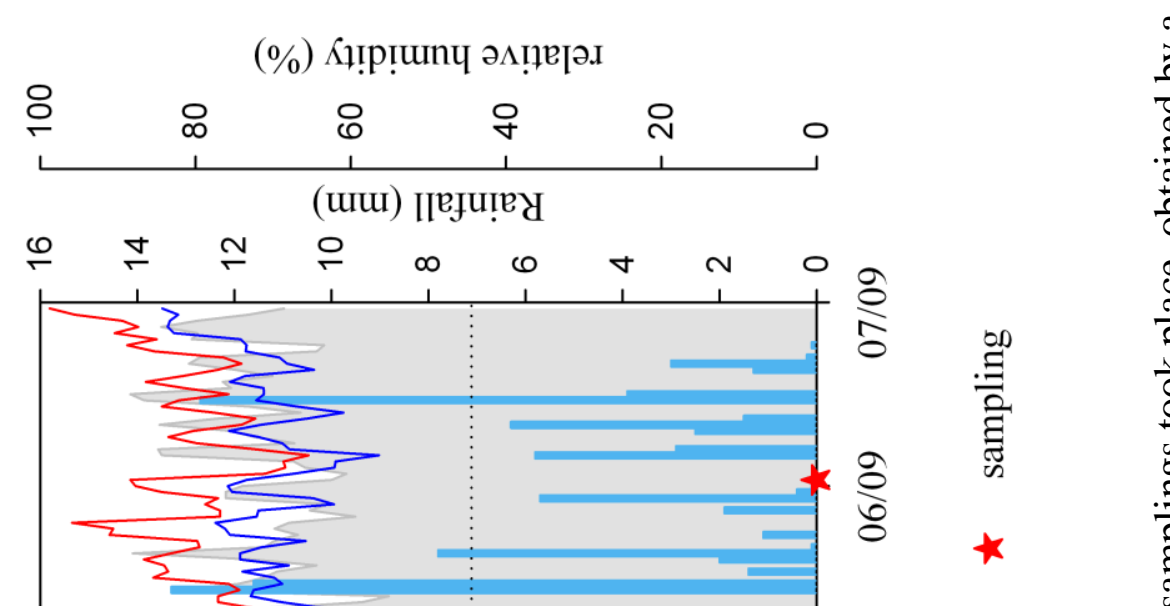

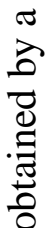

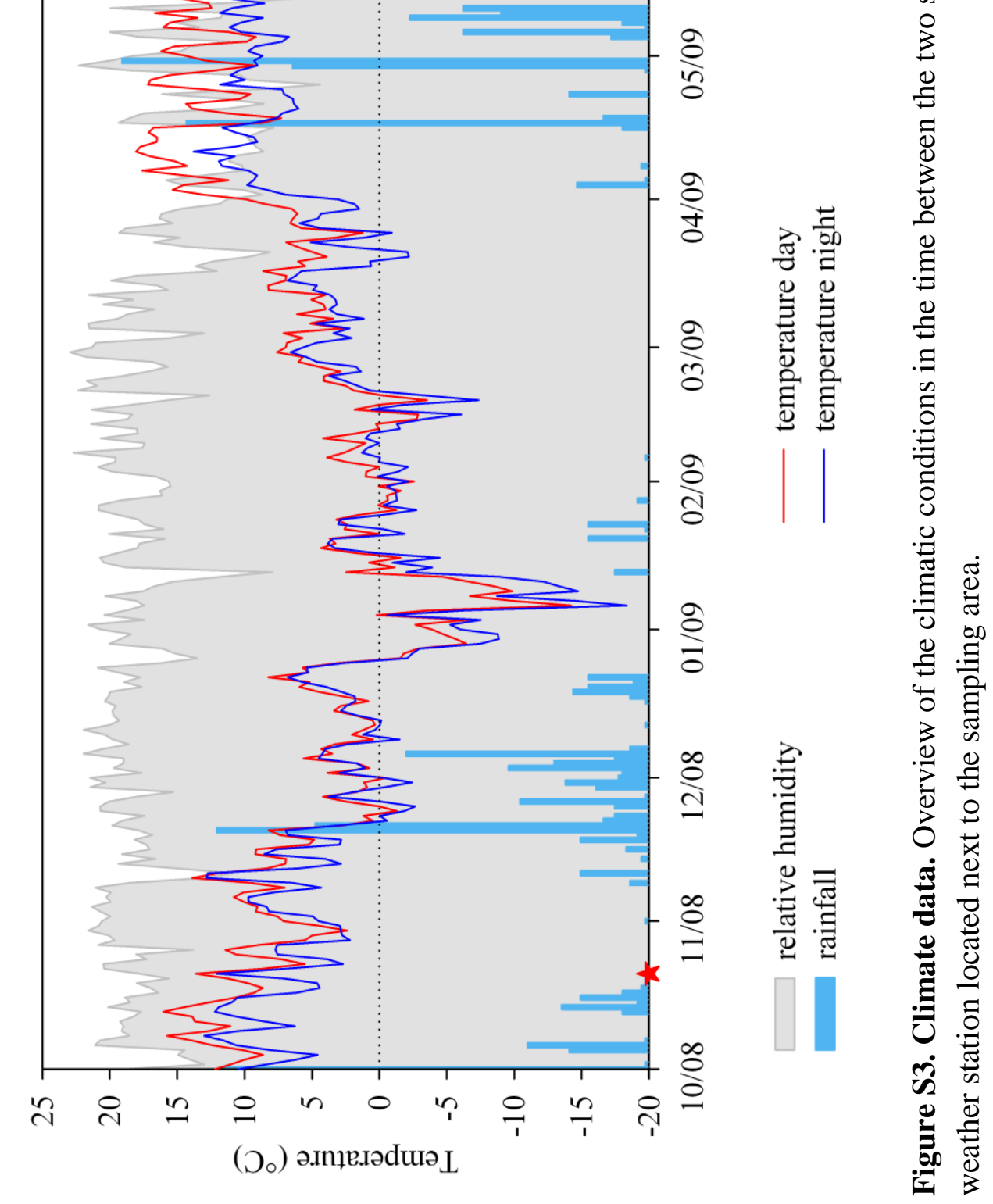




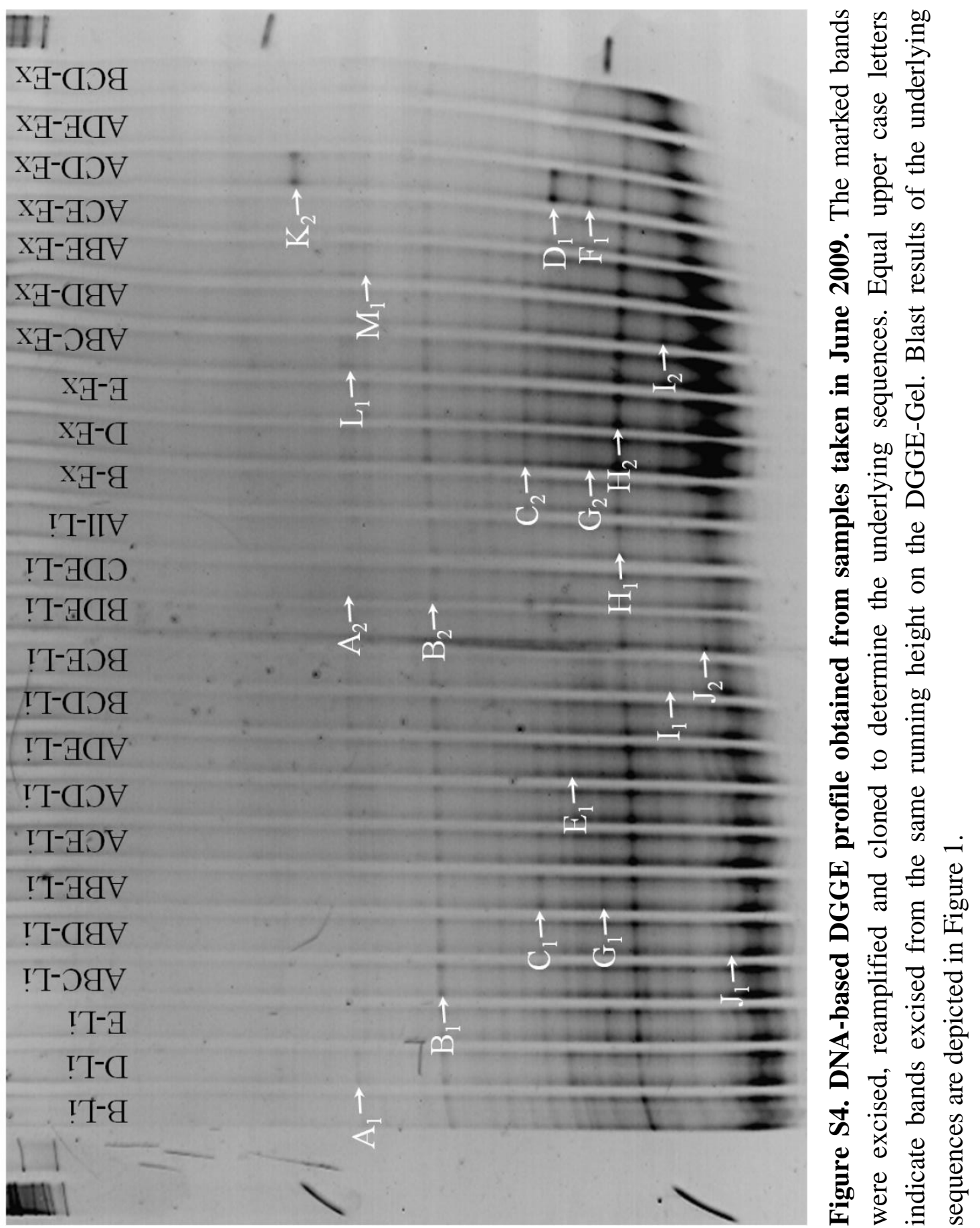




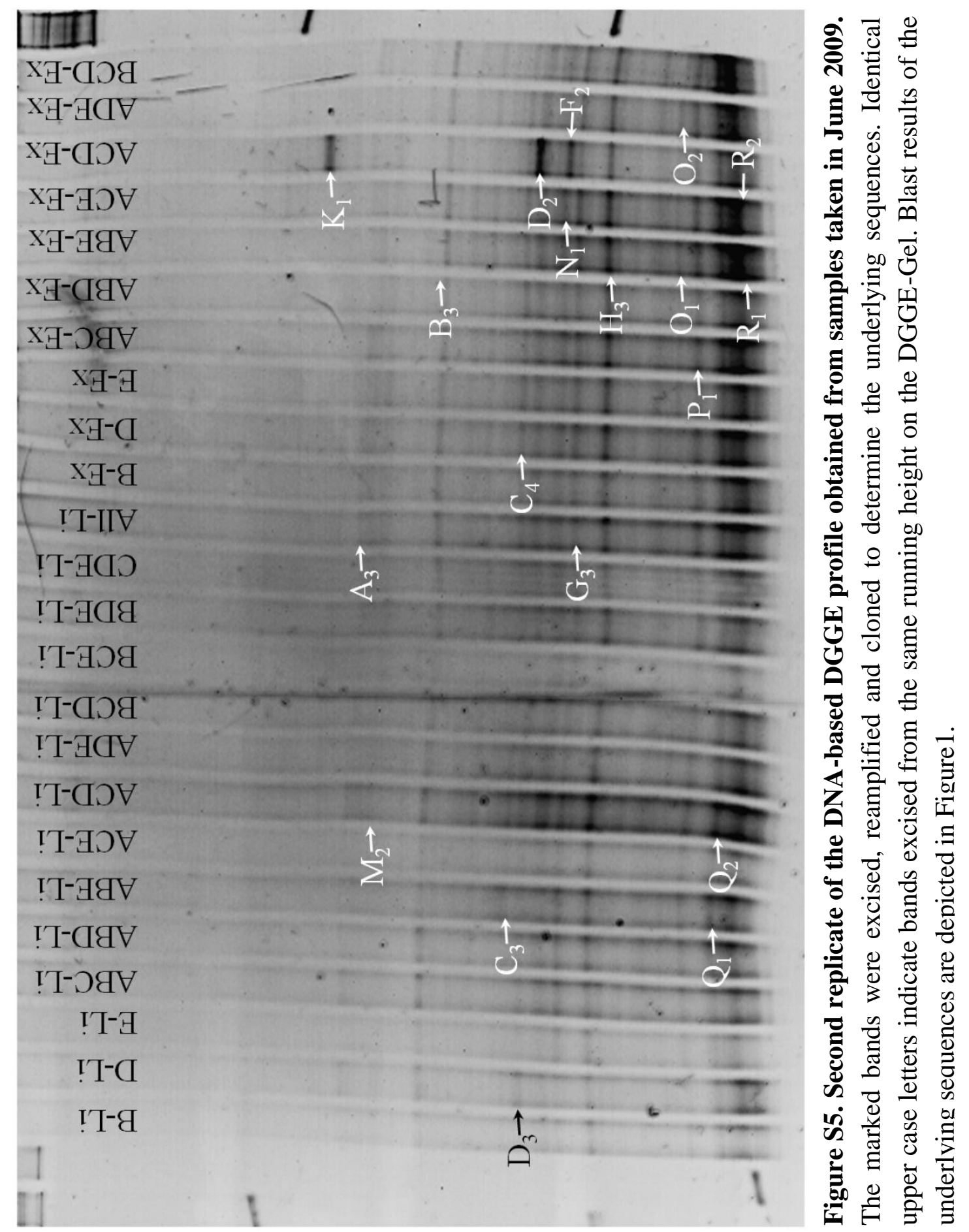




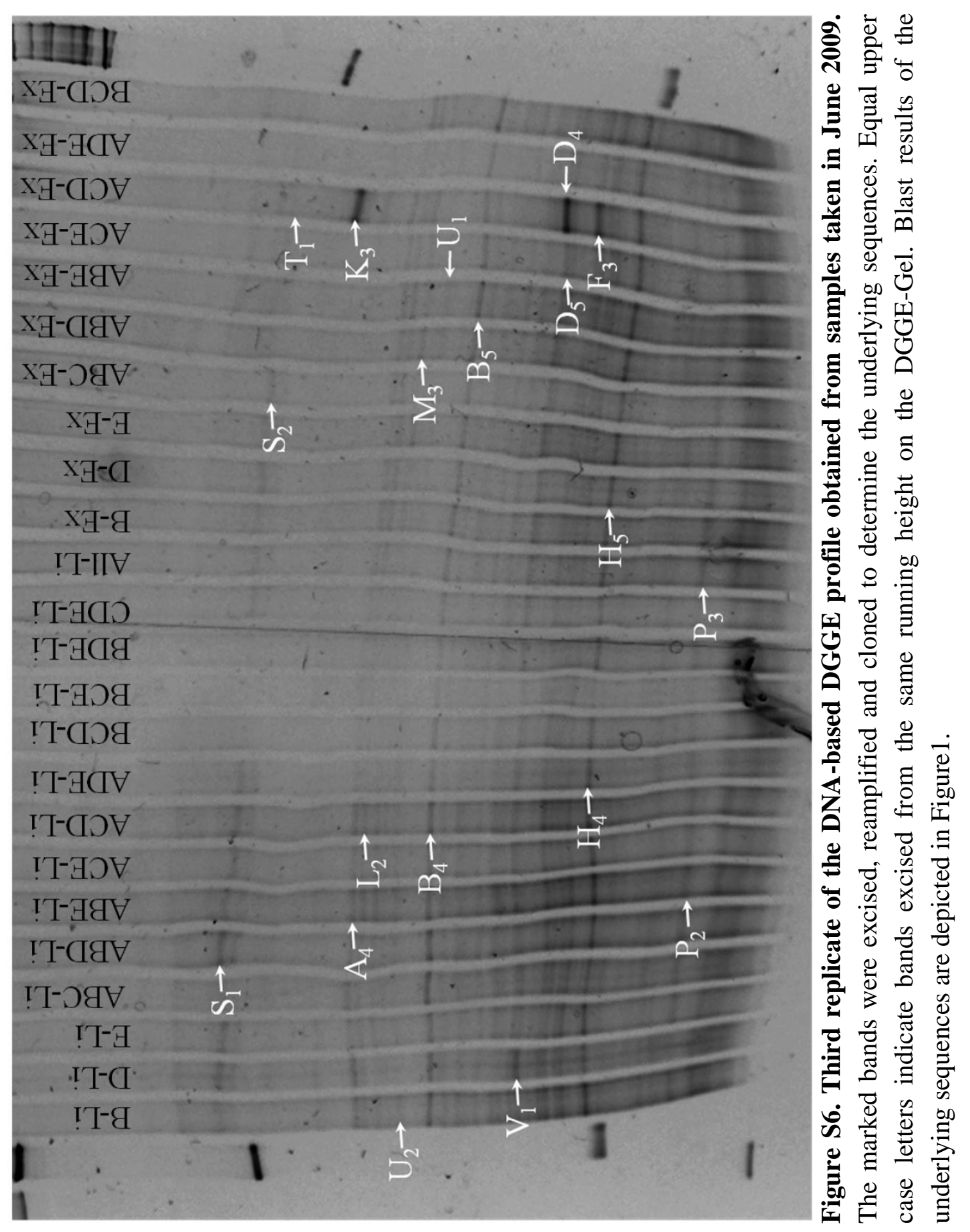




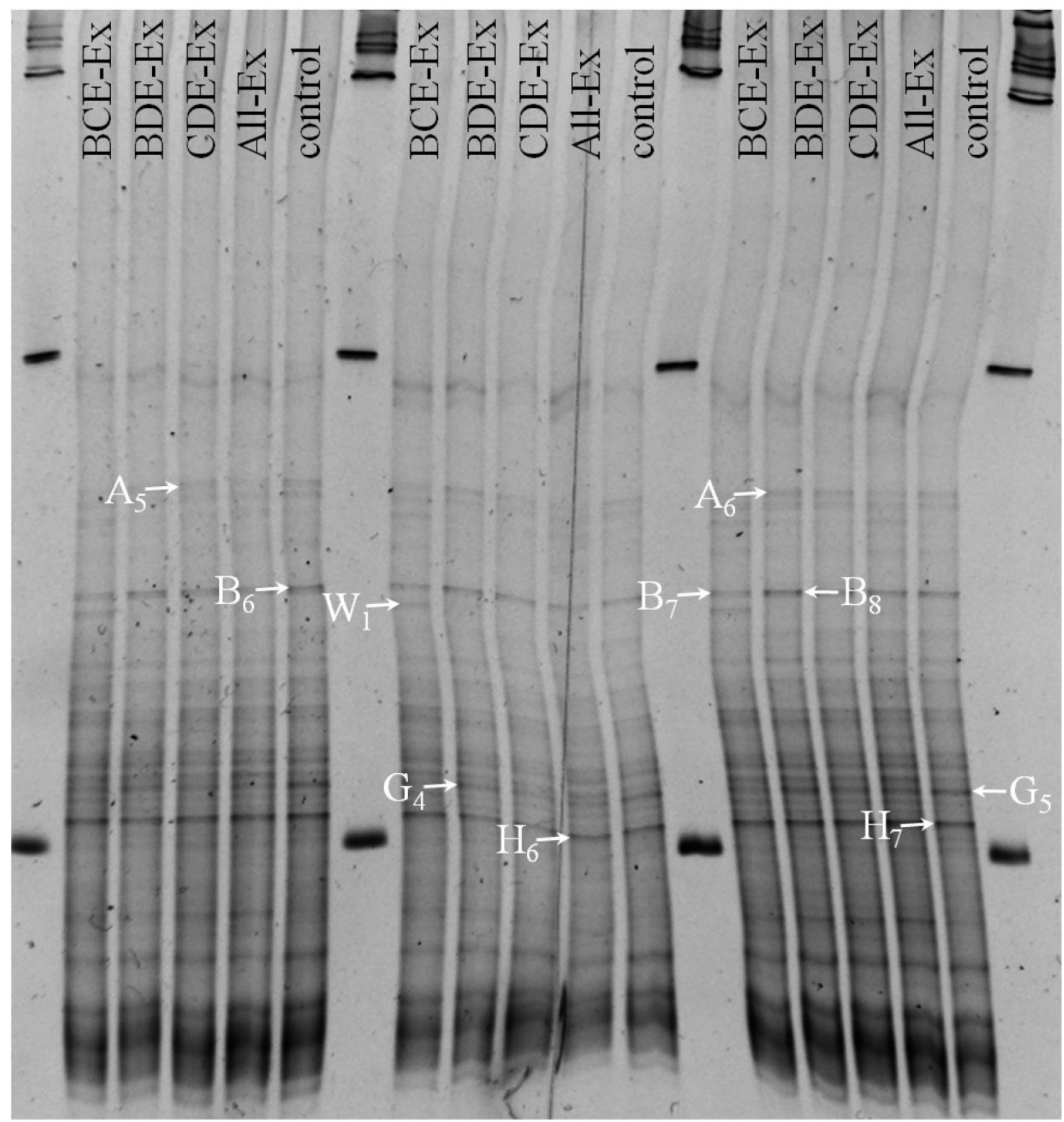

Figure S7. Three times replicated DNA-based DGGE profile obtained from samples taken in June 2009. The marked bands were excised, reamplified and cloned to determine the underlying sequences. Blast results of the underlying sequences are depicted in Figure1. 


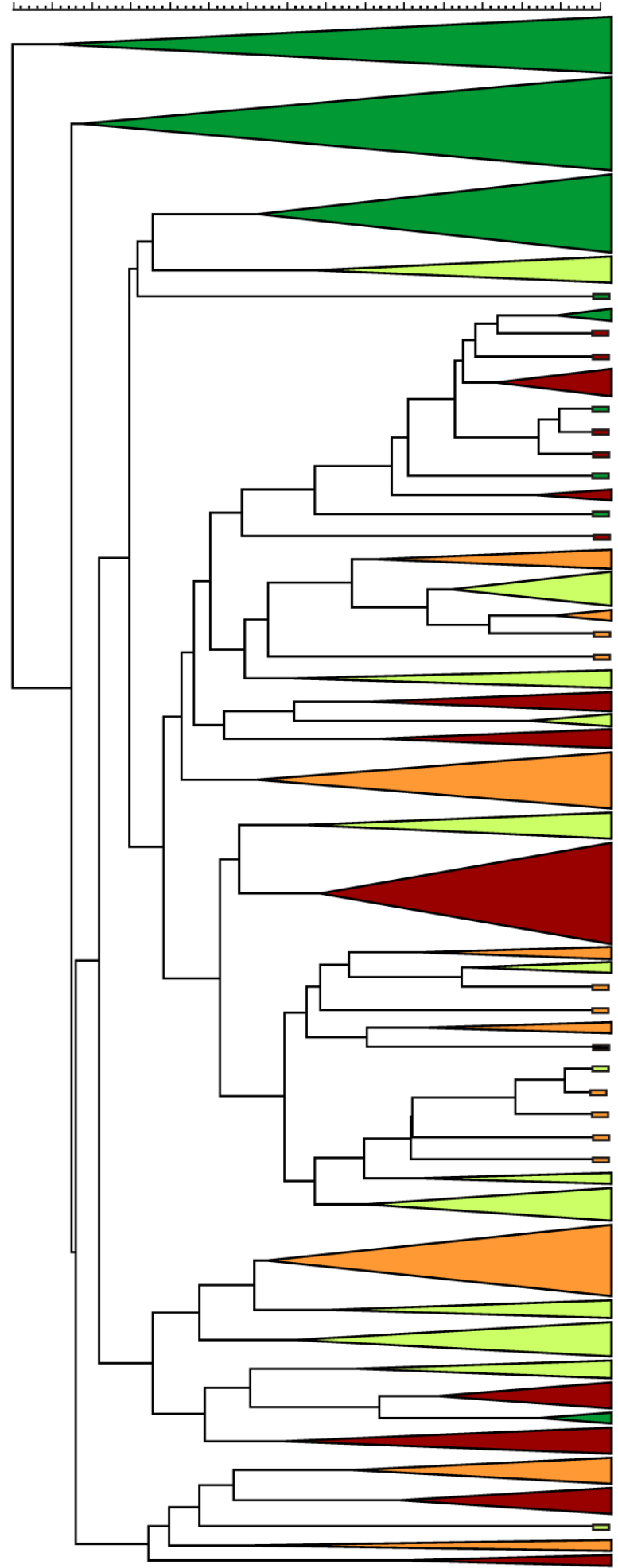

Figure S8. Cluster analysis of the three replicates of each DNA-derived DGGE profiles. Depicted are the litter-treated samples taken in 2008 (light green) and 2009 (dark green), and samples without litter overlay taken in 2008 (orange) and 2009 (red). Clustering was performed by the unweighted pair group method with arithmetic mean (UPGMA) using the Jaccard coefficient of similarity, which takes only the presence or absence of a band into account. Position tolerance was set at $1 \%$. 


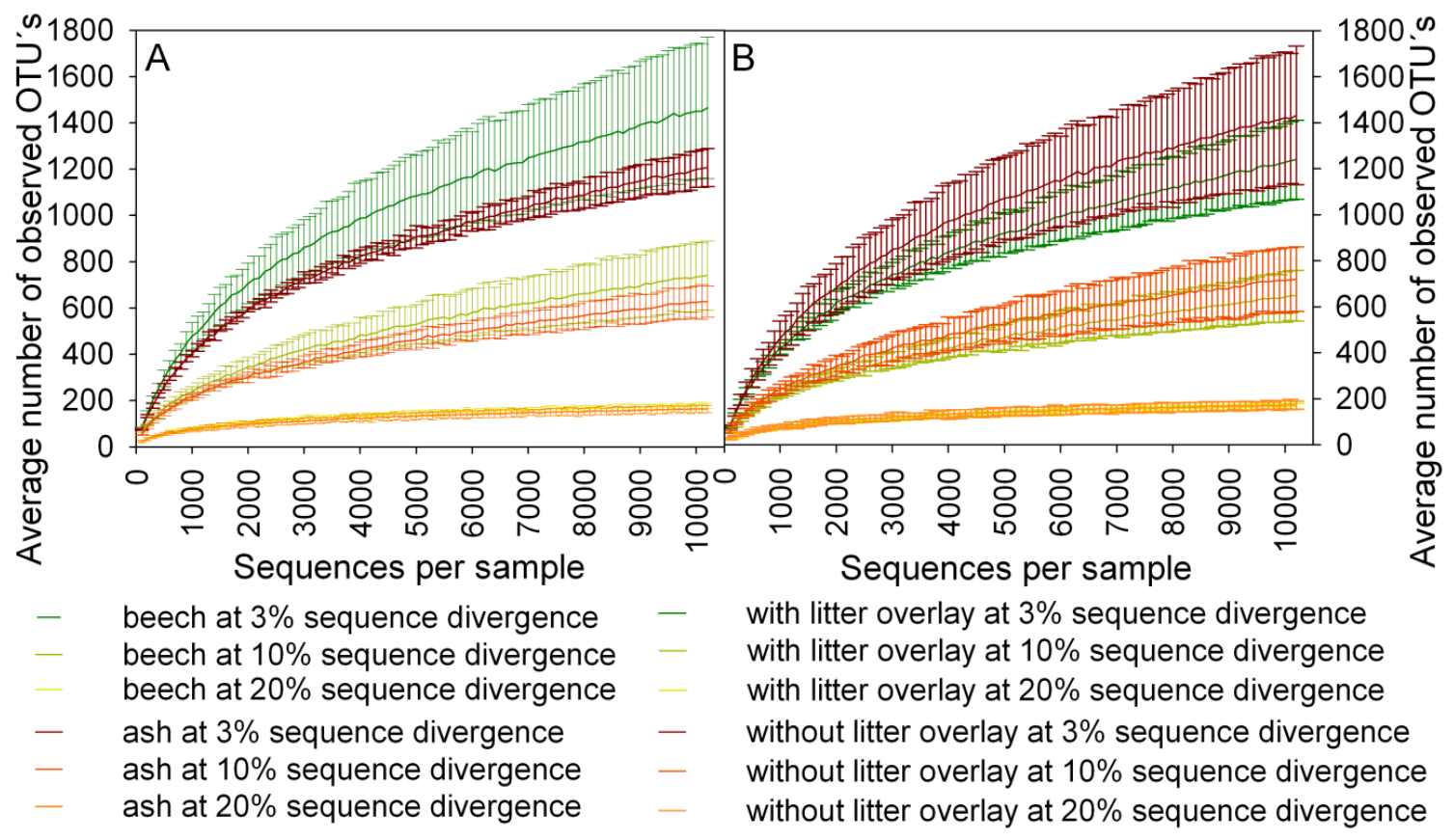

Figure S9. Rarefaction curves indicating the number of all observed OTU's within the beech and ash treated single-tree species mesocosms (A) and the single-tree species mesocosms treated without and with litter overlay (B). Depicted is the mean and the standard deviation of the sum of all OTU's observed for the beech-treated and ash-treated mesocosms without and with litter overlay at different levels of sequence divergence $(3,10$ and $20 \%)$. 
Table S1. Parameters of the soil used in mesocosms. Shown are the mean values and the standard deviation (SD) of the replicates in percent of dry weight (dw)

\begin{tabular}{ll}
\hline Soil parameters & Mean \pm SD \\
\hline Stones $(>2000 \mu \mathrm{m})$ & $3.7 \pm 2.3 \%$ of dw \\
\hline Fine earth $(<2000 \mu \mathrm{m})$ & \\
$\quad$ Sand $(63-2000 \mu \mathrm{m})$ & $10.6 \pm 0.6 \%$ of fine earth dw \\
$\quad$ Silt $(2-63 \mu \mathrm{m})$ & $71.3 \pm 0.9 \%$ of fine earth dw \\
$\quad$ Clay $(0-2 \mu \mathrm{m})$ & $18.1 \pm 0.5 \%$ of fine earth dw \\
\hline $\mathbf{N}_{\text {total }}$ & $0.14 \pm 0.01 \%$ of dw \\
$\mathbf{C}_{\text {org. }}$ & $1.48 \pm 0.19 \%$ of dw \\
Humus & $2.56 \pm 0.32 \%$ of dw \\
\hline pH CaCl & $7.4 \pm 0.07$ \\
pH KCl & $7.6 \pm 0.04$ \\
\hline
\end{tabular}


Table S2. Diversity levels and treatment of the soil mesocosms sampled in autumn 2008 and summer 2009, with (Ex) and without litter removal (Li).

\begin{tabular}{|c|c|c|c|c|c|c|c|}
\hline \multirow[b]{2}{*}{ Sample } & \multirow{2}{*}{$\begin{array}{c}\text { Diversity } \\
\text { level }\end{array}$} & \multicolumn{6}{|c|}{ Treatment } \\
\hline & & Litter & $\begin{array}{l}\text { Maple } \\
\text { (A) }\end{array}$ & $\begin{array}{l}\text { Beech } \\
\text { (B) }\end{array}$ & $\begin{array}{l}\text { Lime } \\
(\mathrm{C})\end{array}$ & $\begin{array}{l}\text { Hornbeam } \\
\text { (D) }\end{array}$ & $\begin{array}{l}\text { Ash } \\
\text { (E) }\end{array}$ \\
\hline $\mathrm{Co}$ & 0 & 0 & 0 & 0 & 0 & 0 & 0 \\
\hline B-Li & 1 & 1 & 0 & 1 & 0 & 0 & 0 \\
\hline D-Li & 1 & 1 & 0 & 0 & 0 & 1 & 0 \\
\hline E-Li & 1 & 1 & 0 & 0 & 0 & 0 & 1 \\
\hline ABC-Li & 3 & 1 & 1 & 1 & 1 & 0 & 0 \\
\hline ABD-Li & 3 & 1 & 1 & 1 & 0 & 1 & 0 \\
\hline ABE-Li & 3 & 1 & 1 & 1 & 0 & 0 & 1 \\
\hline ACD-Li & 3 & 1 & 1 & 0 & 1 & 1 & 0 \\
\hline ACE-Li & 3 & 1 & 1 & 0 & 1 & 0 & 1 \\
\hline ADE-Li & 3 & 1 & 1 & 0 & 0 & 1 & 1 \\
\hline BCD-Li & 3 & 1 & 0 & 1 & 1 & 1 & 0 \\
\hline BCE-Li & 3 & 1 & 0 & 1 & 1 & 0 & 1 \\
\hline BDE-Li & 3 & 1 & 0 & 1 & 0 & 1 & 1 \\
\hline CDE-Li & 3 & 1 & 0 & 0 & 1 & 1 & 1 \\
\hline All-Li & 5 & 1 & 1 & 1 & 1 & 1 & 1 \\
\hline B-Ex & 1 & 0 & 1 & 0 & 0 & 0 & 0 \\
\hline D-Ex & 1 & 0 & 0 & 0 & 1 & 0 & 0 \\
\hline E-Ex & 1 & 0 & 0 & 0 & 0 & 1 & 0 \\
\hline ABC-Ex & 3 & 0 & 0 & 0 & 0 & 0 & 1 \\
\hline ABD-Ex & 3 & 0 & 1 & 1 & 1 & 0 & 0 \\
\hline ABE-Ex & 3 & 0 & 1 & 1 & 0 & 1 & 0 \\
\hline ACD-Ex & 3 & 0 & 1 & 1 & 0 & 0 & 1 \\
\hline ACE-Ex & 3 & 0 & 1 & 0 & 1 & 1 & 0 \\
\hline ADE-Ex & 3 & 0 & 1 & 0 & 1 & 0 & 1 \\
\hline BCD-Ex & 3 & 0 & 1 & 0 & 0 & 1 & 1 \\
\hline BCE-Ex & 3 & 0 & 0 & 1 & 1 & 1 & 0 \\
\hline BDE-Ex & 3 & 0 & 0 & 1 & 1 & 0 & 1 \\
\hline CDE-Ex & 3 & 0 & 0 & 1 & 0 & 1 & 1 \\
\hline All-Ex & 5 & 0 & 1 & 1 & 1 & 1 & 1 \\
\hline
\end{tabular}


Table S3. Sampling time, treatment and number of 16S rRNA gene sequences derived from the analyzed soil samples, before and after the removal of reads shorter than 300 bp, low quality reads, reads containing homopolymers longer than 8 bp and primer mismatches and potential chimeras, and denoising

\begin{tabular}{lccccccc}
\hline Sample & $\begin{array}{c}\text { Sampling } \\
\text { time }\end{array}$ & $\begin{array}{c}\text { Litter } \\
(\mathrm{Li})\end{array}$ & $\begin{array}{c}\text { Beech } \\
(\mathrm{B})\end{array}$ & $\begin{array}{c}\text { Ash } \\
(\mathrm{E})\end{array}$ & $\begin{array}{c}\text { No. of } \\
\text { initial } \\
\text { sequences }\end{array}$ & $\begin{array}{c}\text { No. of } \\
\text { sequences } \\
\geq 300 \mathrm{bp}\end{array}$ & $\begin{array}{c}\text { Final no. } \\
\text { of } \\
\text { sequences }\end{array}$ \\
\hline B-Li08 & 21.10 .2008 & 1 & 1 & 0 & 15619 & 12030 & 11452 \\
E-Li08 & 21.10 .2008 & 1 & 0 & 1 & 13984 & 10906 & 10257 \\
B-Ex08 & 21.10 .2008 & 0 & 1 & 0 & 33568 & 22961 & 20194 \\
E-Ex08 & 21.10 .2008 & 0 & 0 & 1 & 14947 & 11166 & 10811 \\
\hline B-Li09 & 02.06 .2009 & 1 & 1 & 0 & 20565 & 15952 & 14722 \\
E-Li09 & 02.06 .2009 & 1 & 0 & 1 & 16543 & 12976 & 11837 \\
B-Ex09 & 02.06 .2009 & 0 & 1 & 0 & 22316 & 16464 & 15706 \\
E-Ex09 & 02.06 .2009 & 0 & 0 & 1 & 31432 & 23143 & 22333 \\
\hline
\end{tabular}


Table S4. Bacterial diversity assessed by Shannon index $\left(\mathrm{H}^{\prime}\right)$, Simpson index (D) and species richness estimation in the beech-treated and ash-treated soil samples, with (Ex) and without $(\mathrm{Li})$ litter removal.

\begin{tabular}{|c|c|c|c|c|c|c|c|}
\hline \multirow[b]{2}{*}{ Sample } & \multirow[b]{2}{*}{$\begin{array}{c}\text { Genetic } \\
\text { distance } \\
(\%)\end{array}$} & \multirow[b]{2}{*}{$\mathrm{H}^{\prime}$} & \multirow[b]{2}{*}{$\mathrm{D}$} & \multicolumn{4}{|c|}{ No. of operational taxonomic units } \\
\hline & & & & $\begin{array}{l}\text { Observed } \\
\text { species }\end{array}$ & Chao1 & $\mathrm{ACE}$ & $\begin{array}{l}\text { Michaelis- } \\
\text { Menten Fit }\end{array}$ \\
\hline \multirow{4}{*}{ B-Li08 } & 3 & 5.856 & 0.990 & 1093 & 1747 & 1482 & 1309 \\
\hline & 5 & 5.522 & 0.987 & 917 & 1465 & 1295 & 1097 \\
\hline & 10 & 4.662 & 0.977 & 552 & 843 & 831 & 661 \\
\hline & 20 & 2.658 & 0.817 & 158 & 204 & 203 & 178 \\
\hline \multirow{4}{*}{ E-Li08 } & 3 & 5.890 & 0.991 & 1104 & 1792 & 1590 & 1329 \\
\hline & 5 & 5.531 & 0.987 & 927 & 1428 & 1324 & 1112 \\
\hline & 10 & 4.679 & 0.976 & 565 & 845 & 876 & 680 \\
\hline & 20 & 2.735 & 0.831 & 161 & 198 & 211 & 179 \\
\hline \multirow{4}{*}{$\begin{array}{c}\text { B- } \\
\text { Ex08 }\end{array}$} & 3 & 6.559 & 0.996 & 1823 & 5052 & 3439 & 2515 \\
\hline & 5 & 6.148 & 0.994 & 1557 & 4028 & 3177 & 2197 \\
\hline & 10 & 5.113 & 0.986 & 925 & 1694 & 1739 & 1336 \\
\hline & 20 & 2.887 & 0.85 & 183 & 218 & 225 & 210 \\
\hline \multirow{4}{*}{$\begin{array}{c}\text { E- } \\
\text { Ex08 }\end{array}$} & 3 & 5.662 & 0.984 & 1209 & 2255 & 1894 & 1545 \\
\hline & 5 & 5.399 & 0.979 & 1053 & 1816 & 1596 & 1330 \\
\hline & 10 & 4.610 & 0.965 & 675 & 1107 & 1046 & 856 \\
\hline & 20 & 2.780 & 0.809 & 184 & 222 & 218 & 205 \\
\hline \multirow{4}{*}{ B-Li09 } & 3 & 6.105 & 0.992 & 1456 & 3613 & 2615 & 1931 \\
\hline & 5 & 5.737 & 0.989 & 1241 & 2649 & 2232 & 1662 \\
\hline & 10 & 4.727 & 0.974 & 775 & 1599 & 1630 & 1077 \\
\hline & 20 & 2.507 & 0.775 & 182 & 224 & 230 & 210 \\
\hline \multirow{4}{*}{ E-Li09 } & 3 & 5.644 & 0.979 & 1314 & 4214 & 2902 & 1802 \\
\hline & 5 & 5.321 & 0.977 & 1142 & 2975 & 2510 & 1596 \\
\hline & 10 & 4.352 & 0.956 & 703 & 1433 & 1516 & 1000 \\
\hline & 20 & 2.242 & 0.723 & 167 & 231 & 224 & 191 \\
\hline \multirow{4}{*}{$\begin{array}{c}\text { B- } \\
\text { Ex09 }\end{array}$} & 3 & 6.274 & 0.993 & 1471 & 2375 & 2035 & 1865 \\
\hline & 5 & 5.933 & 0.992 & 1216 & 1826 & 1673 & 1531 \\
\hline & 10 & 5.011 & 0.983 & 721 & 1113 & 1083 & 898 \\
\hline & 20 & 2.966 & 0.856 & 185 & 217 & 217 & 205 \\
\hline \multirow{4}{*}{$\begin{array}{c}\text { E- } \\
\text { Ex09 }\end{array}$} & 3 & 5.733 & 0.983 & 1216 & 1694 & 1554 & 1544 \\
\hline & 5 & 5.400 & 0.98 & 1006 & 1551 & 1404 & 1265 \\
\hline & 10 & 4.517 & 0.967 & 578 & 910 & 880 & 709 \\
\hline & 20 & 2.197 & 0.656 & 144 & 190 & 185 & 161 \\
\hline
\end{tabular}


Table S5. Number of sequences and identity to known species of the most abundant species identified in the amplicon-based dataset.

\begin{tabular}{llcc}
\hline Phylum & Genus/ Species & $\begin{array}{c}\text { Number of } \\
\text { sequences }\end{array}$ & $\begin{array}{c}\text { Identity } \\
(\%)\end{array}$ \\
\hline Actinobacteria & Kribbella alba & 230 & 99.03 \\
& Mycobacterium sp. & 113 & 99.06 \\
& Pseudonocardia sp. ACT-0146 & 83 & 99.68 \\
& Nocardioides terrigena & 71 & 99.51 \\
& Humibacillus xanthopallidus & 59 & 99.27 \\
& Rhodococcus sp. & 47 & 99.27 \\
& Mycobacterium neglectum & 28 & 99.51 \\
& Lechevalieria aerocolonigenes & 22 & 99.37 \\
& Streptomyces scabiei & 20 & 99.03 \\
Firmicutes & Nostocaceae cyanobacterium SAG B11.82 & 616 & 99.49 \\
& Phormidium sp. SAG 37.90 & 33 & 99.74 \\
& Cylindrospermum stagnale PCC 7417 & 25 & 99.24 \\
& Clostridium favososporum & 117 & 99.76 \\
& Bacillus simplex & 112 & 99.54 \\
& Paenibacillus sp. BG5 & 58 & 99.77 \\
& Sporacetigenium mesophilum & 21 & 99.02 \\
Proteobacteria & Afipia sp. Sptzw29 & 22 & 99.48 \\
& Caenimonas sp. TSX9-5 & 216 & 99.77 \\
& Nitrosospira sp. Nsp17 & 57 & 99.30 \\
& Acidovorax sp. GW2 & 24 & 99.48 \\
& Pseudomonas sp. SHF7 & 992 & 99.77 \\
& Lysobacter sp. 8L & 360 & 99.53 \\
& Methylobacter luteus & 266 & 99.29 \\
& Azotobacter chroococcum & 112 & 99.30 \\
& Xanthomonas sp. BRT8 & 97 & 99.77 \\
\hline & & &
\end{tabular}


Table S6. Differences in the relative abundance of proteobacterial classes and other phyla occurring between different treatment groups. Samples were grouped according to treatment and differences in relative abundance of proteobacterial classes and phyla between each group and tested for significance. Tested with paired t-test $(P<0.05)$.

\begin{tabular}{llll}
\hline & $\mathbf{2 0 0 8}$ vs. 2009 & Beech vs. ash & Litter vs. no litter \\
& $\boldsymbol{P}$ & $\boldsymbol{P}$ & $\boldsymbol{P}$ \\
\hline Alphaproteobacteria & $0.014^{*}$ & 0.283 & 0.566 \\
Betaproteobacteria & 0.615 & 0.322 & $0.032^{*}$ \\
Gammaproteobacteria & 0.761 & $1.000^{\mathrm{a}}$ & 0.609 \\
Deltaproteobacteria & 0.744 & 0.172 & $0.026^{*}$ \\
other Proteobacteria & 0.372 & 0.110 & 0.945 \\
Acidobacteria & $0.014^{*}$ & 0.280 & 0.856 \\
Nitrospirae & $0.886^{\mathrm{a}}$ & $0.886^{\mathrm{a}}$ & $0.029^{\mathrm{a}} *$ \\
Firmicutes & 0.527 & 0.440 & 0.347 \\
Chloroflexi & 0.139 & 0.581 & 0.119 \\
Actinobacteria & 0.392 & 0.626 & $0.200^{\mathrm{a}}$ \\
Gemmatimonadetes & 0.635 & 0.785 & $0.037^{*}$ \\
Planctomycetes & 0.762 & 0.812 & 0.427 \\
Cyanobacteria & 0.735 & 0.989 & $0.886^{\mathrm{a}}$ \\
Bacteroidetes & 0.546 & 0.919 & 0.084 \\
Chlorobi & $0.486^{\mathrm{a}}$ & 0.909 & 0.183 \\
Fibrobacteres & 0.629 & 0.794 & 0.481 \\
Verrucomicrobia & 0.269 & $0.343^{\mathrm{a}}$ & 0.112 \\
Armatimonadetes & 0.116 & 0.249 & 0.663 \\
Spirochaetes & 0.932 & 0.229 & 0.919 \\
Candidate division & 0.073 & 0.606 & 0.182 \\
BHI80-139 & 0.337 & 0.675 & $0.020^{*}$ \\
Candidate division TM7 & 0.946 & $0.012^{*}$ & 0.543 \\
Candidate division WS3 & 0.9672 & 0.144 \\
Candidate division & 0.262 & 0.772 & 0.332 \\
WCHB1-60 & 0.266 & 0.607 & 0.152 \\
Candidate division TA06 & $0.486^{\mathrm{a}}$ & 0.946 & 0.636 \\
Candidate division TM6 & 0.542 & & \\
other rare bacterial phyla & 0.54 & \\
\hline & & & \\
\hline
\end{tabular}

${ }^{a}$ Normality test and/or equal variance test failed. Mann-Whitney rank sum test was alternatively applied.

* Significant at the 0.05 probability level. 
Table S7. Differences of frequently occurring phylotypes between different treatment groups. Samples were grouped according to treatment and differences in relative abundance of frequently occurring families between each group and tested for significance. Tested with paired t-test $(P<0.050)$.

\begin{tabular}{llll}
\hline & $\mathbf{2 0 0 8}$ vs. 2009 & Beech vs. ash & $\begin{array}{l}\text { Litter vs. no } \\
\text { litter } \\
\boldsymbol{P}\end{array}$ \\
\hline Mycobacteriaceae & $\boldsymbol{P}$ & $\boldsymbol{P}$ & $0.029^{\mathrm{a}, *}$ \\
Nocardioidaceae & 0.489 & $0.886^{\mathrm{a}}$ & 0.051 \\
Anaerolineaceae & $0.686^{\mathrm{a}}$ & 0.489 & $0.019^{*}$ \\
Caulobacteraceae & $0.057^{\mathrm{a}}$ & 0.775 & $0.343^{\mathrm{a}}$ \\
Hyphomicrobiaceae & 0.743 & $0.886^{\mathrm{a}}$ & $0.040^{*}$ \\
Rhodospirillaceae & 0.102 & 0.620 & 0.599 \\
Comamonadaceae & 0.420 & 0.061 & $0.046^{*}$ \\
Oxalobacteraceae & 0.485 & 0.286 & $0.037^{*}$ \\
Nitrosomonadaceae & 0.669 & 0.792 & 0.227 \\
Bdellovibrionaceae & $1.000^{\mathrm{a}}$ & 0.669 & 0.823 \\
Nannocystineae & 0.863 & 0.152 & $0.005^{* *}$ \\
Sorangiineae & 0.858 & 0.670 & 0.128 \\
Methylococcaceae & $0.686^{\mathrm{a}}$ & $0.200^{\mathrm{a}}$ & $0.057^{\mathrm{a}}$ \\
Pseudomonadaceae & 0.077 & $0.686^{\mathrm{a}}$ & 0.229 \\
Sinobacteraceae & 0.823 & 0.355 & 0.556 \\
Xanthomonadaceae & 0.826 & 0.007 & 0.056 \\
\hline
\end{tabular}

${ }^{a}$ Normality test or equal variance test failed. Mann-Whitney rank sum test was alternatively applied.

* Significant at the 0.05 probability level.

** Significant at the 0.01 probability level. 
2.

\title{
Roots from beech (Fagus sylvatica L.) and ash (Fraxinus excelsior L.) differentially affect soil microorganisms and carbon dynamics
}

\begin{abstract}
Simone Cesarz, Ann-Catrin Fender ${ }^{2)}$, Friderike Beyer, Kerttu Valtanen, Birgit Pfeiffer ${ }^{2)}$, Dirk Gansert, Dietrich Hertel, Andrea Polle, Rolf Daniel ${ }^{2)}$ Christoph Leuschner ${ }^{1)}$ and Stefan Scheu
\end{abstract}

Soil Biology and Biochemistry (2013), Vol. 61, pp 23-32

1) J.F. Blumenbach Institute of Zoology and Anthropology, University Goettingen, Berliner Straße 28, 37073 Goettingen, Germany

${ }^{2)}$ Plant Ecology and Ecosystems research, University of Goettingen, Untere Karspüle 2, 37073 Goettingen, Germany

${ }^{3)}$ Department of Forest Botany and Tree Physiology, Georg August University Goettingen, Büsgenweg 2, 37077 Goettingen, Germany

${ }^{4)}$ Genomic and Applied Microbiology, University of Goettingen, Grisebachstr. 8, 37077 Goettingen, Germany

\section{Author contributions to the work:}

Performed the experiments: S. Cesarz, AC. Fender, F. Beyer, K. Valtanen, B. Pfeiffer Analyzed the data: S. Cesarz, AC. Fender, F. Beyer, K. Valtanen, B. Pfeiffer Wrote the paper: S. Cesarz, S. Scheu Conceived and designed the experiments: D. Gansert, D. Hertel, A. Polle, R. Daniel, C. Leuschner, S. Scheu 


\title{
Roots from beech (Fagus sylvatica L.) and ash (Fraxinus excelsior L.) differentially affect soil microorganisms and carbon dynamics
}

\author{
Simone Cesarz ${ }^{\mathrm{a}, \mathrm{b}, *}$, Ann-Catrin Fender ${ }^{\mathrm{c}}$, Friderike Beyer ${ }^{\mathrm{c}}$, Kerttu Valtanen ${ }^{\mathrm{d}}$, Birgit Pfeiffer ${ }^{\mathrm{e}}$, \\ Dirk Gansert ${ }^{c}$, Dietrich Hertel ${ }^{c}$, Andrea Polle ${ }^{\mathrm{d}}$, Rolf Daniel ${ }^{\mathrm{e}}$, Christoph Leuschner $^{\mathrm{c}}$, Stefan Scheu ${ }^{\mathrm{a}}$ \\ a J.F. Blumenbach Institute of Zoology and Anthropology, Georg August University Göttingen, Berliner Straße 28, 37073 Göttingen, Germany \\ ${ }^{\mathrm{b}}$ Institute of Ecology, Friedrich Schiller University Jena, Dornburger Str. 159, 07743 Jena, Germany \\ ${ }^{\mathrm{c}}$ Plant Ecology and Ecosystems Research, Georg August University Göttingen, Untere Karspüle 2, 37073 Göttingen, Germany \\ ${ }^{\mathrm{d}}$ Department of Forest Botany and Tree Physiology, Georg August University Göttingen, Büsgenweg 2, 37077 Göttingen, Germany \\ ${ }^{\mathrm{e}}$ Department of Genomic and Applied Microbiology, Institute of Microbiology and Genetics, Georg August University Göttingen, Grisebachstr. 8, 37077 Göttingen, Germany
}

\section{A R T I C L E I N F O}

\section{Article history:}

Received 14 October 2012

Received in revised form

5 February 2013

Accepted 7 February 2013

Available online 26 February 2013

\section{Keywords:}

${ }^{13} \mathrm{C}$

${ }^{15} \mathrm{~N}$

Bacteria

Carbon cycling

Decomposition

Fungi

Nitrogen

Soil food web

\begin{abstract}
A B S T R A C T
Knowledge about the influence of living roots on decomposition processes in soil is scarce but is needed to understand carbon dynamics in soil. We investigated the effect of dominant deciduous tree species of the Central European forest vegetation, European beech (Fagus sylvatica L.) and European ash (Fraxinus excelsior L.), on soil biota and carbon dynamics differentiating between root- and leaf litter-mediated effects. The influence of beech and ash seedlings on carbon and nitrogen flow was investigated using leaf litter enriched in ${ }^{13} \mathrm{C}$ and ${ }^{15} \mathrm{~N}$ in double split-root rhizotrons planted with beech and ash seedlings as well as a mixture of both tree species and a control without plants. Stable isotope and compound-specific fatty acid analysis $\left({ }^{13} \mathrm{C}\right.$-PLFA) were used to follow the incorporation of stable isotopes into microorganisms, soil animals and plants. Further, the bacterial community composition was analyzed using pyrosequencing of 16S rRNA gene amplicons. Although beech root biomass was significantly lower than that of ash only beech significantly decreased soil carbon and nitrogen concentrations after 475 days of incubation. In addition, beech significantly decreased microbial carbon use efficiency as indicated by higher specific respiration. Low soil pH probably increased specific respiration of bacteria suggesting that rhizodeposits of beech roots induced increased microbial respiration and therefore carbon loss from soil. Compared to beech $\delta^{13} \mathrm{C}$ and $\delta^{15} \mathrm{~N}$ signatures of gamasid mites in ash rhizotrons were significantly higher indicating higher amounts of litter-derived carbon and nitrogen to reach higher trophic levels. Similar $\delta^{13} \mathrm{C}$ signatures of bacteria and fine roots indicate that mainly bacteria incorporated root-derived carbon in beech rhizotrons. The results suggest that beech and ash differentially impact soil processes with beech more strongly affecting the belowground system via root exudates and associated changes in rhizosphere microorganisms and carbon dynamics than ash.
\end{abstract}

(c) 2013 Elsevier Ltd. All rights reserved.

\section{Introduction}

Soils store twice as much carbon as plants and the atmosphere together thereby forming an important component of the global carbon cycle (Schlesinger and Andrews, 2000). However, the way carbon is processed and how carbon dynamics are controlled still is not well understood. Knowledge on factors changing the flux of carbon from plants into the soil and controlling its turnover is of

\footnotetext{
* Corresponding author. Institute of Ecology, Friedrich Schiller University Jena, Dornburger Str. 159, 07743 Jena, Germany. Tel.: +49 3641949407.

E-mail addresses: simone.cesarz@gmx.de, Simone.Cesarz@uni-jena.de (S. Cesarz).
}

significant importance especially in face to global warming (McKinley et al., 2011).

In terrestrial ecosystems $90 \%$ of the annual biomass produced by plants enters the dead organic matter pool forming the basis of the decomposer system in soil (Gessner et al., 2010). Plant carbon enters the soil via two pathways, dead organic matter (leaf litter and dead roots) and root exudates. Soil chemical properties are mainly influenced by parent material and mineralogy but also by leaf litter forming the major resource of soil biota responsible for decomposition processes (Reich et al., 2005; Jacob et al., 2009; Langenbruch et al., 2012). Litter quality strongly influences soil $\mathrm{pH}$, as calcium and magnesium of the litter compete with $\mathrm{H}^{+}$and $\mathrm{Al}^{3+}$ for exchange sites on soil particle surfaces or organic matter (Reich et al., 2005). As a consequence, high pH often promotes higher microbial 
biomass resulting in higher soil respiration, mineralization and decomposition (Swift et al., 1979; Wardle, 1998). Low mineralization and decomposition rates are associated with high C-to-N ratios and high lignin contents as it is typical for recalcitrant litter. In contrast, Pollierer et al. (2007) highlighted that in temperate forests carbon does not enter the soil food web predominantly via litter but rather via roots. Rhizodeposits comprise labile exudates (e.g., sugars, amino acids and organic acids), but also complex molecules (e.g., polysaccharides, mucilage and proteins). Labile exudates control both community structure and activity of rhizosphere microorganisms (Paterson et al., 2009). Summarizing results of 95 plant ${ }^{14} \mathrm{C}$ labeling studies, Jones et al. (2004) estimated the loss of carbon by exudation to be equivalent to $5-10 \%$ of the net carbon fixed by plants and $25 \%$ of the carbon plants allocate to root growth. This supply of energy increases microbial biomass (Butler et al., 2004), acts as soil organic matter (SOM) priming agent (Bird et al., 2011) and alters the physical and chemical soil environment (Gregory, 2006). Microbial communities in rhizosphere and bulk soil are therefore responsible for root exudate-mediated changes in soil processes (Söderberg et al., 2004; Paterson et al., 2007). Since plant species differ in the quality and quantity of exudates (Jones et al., 2004), soil carbon dynamics are likely affected by plant species identity and diversity (Grayston et al., 1998; Steinbeiss et al., 2008).

Decomposition studies report both effects of individual plant species (Jacob et al., 2009) and positive mixing effects (Gartner and Cardon, 2004; Hättenschwiler et al., 2005). Until today, however, studies investigating the influence of plant diversity on belowground dynamics in forests are scare (but see Meinen et al., 2009) and most often only consider the effect of aboveground plant residues (Hättenschwiler and Gasser, 2005; Jacob et al., 2009, 2010). To what extent belowground processes mediated by roots and root exudates affect soil organisms and thereby carbon dynamics remains largely unknown. This lack of knowledge is unfortunate as $60 \%$ of the terrestrial carbon is bound in forests and its contribution to global carbon cycling is of fundamental importance (McKinley et al., 2011).

To improve knowledge on carbon dynamics in forest soils from a root perspective we used the common temperate broad-leaved tree species European beech (Fagus sylvatica L.) and European ash (Fraxinus excelsior L.) to differentiate between general and speciesspecific effects of living roots on soil organisms and decomposition of litter material in soil. Beech is the dominant tree species in many Central European deciduous forests. Ash often is associated with beech and is expected to increase in dominance in a warmer and drier climate (Broadmeadow and Ray, 2005). Life history traits of beech and ash differ strongly, e.g., speed of growth, root morphology, litter quality, mycorrhizal association, and nutrient, water and light use efficiency (Grime et al., 1997; Emborg, 1998). Beech has higher specific root tip abundance, specific fine root surface area (SRA) and specific fine root length (SRL), whereas ash roots are characterized by higher mean fine root diameter (Meinen et al., 2009). Roots of beech are colonized by ectomycorrhizal (EM) fungi and those of ash by arbuscular mycorrhizal (AM) fungi which differ in nutrient acquisition strategies (Smith and Read, 2008). Beech tolerates soil $\mathrm{pH}$ from acid to highly alkaline, while ash is restricted to soils of high base saturation (Weber-Blaschke et al., 2002). Litter of beech at more acidic sites has high C-to-N ratio $(>50)$ and high lignin content, while ash litter is regarded as high quality litter due to its low C-to-N ratio of about 28 and low lignin content (Jacob et al., 2010).

For allowing access to the root system and to investigate interactions between both tree species, beech and ash seedlings were planted into double split-root systems. The systems allowed dissecting root associated processes and belowground interactions between beech and ash. Carbon and nitrogen fluxes in soil were traced following the incorporation of ${ }^{13} \mathrm{C}$ and ${ }^{15} \mathrm{~N}$ from labeled ash litter into soil, bacteria, fungi, soil animals and plants. Ash litter was used to follow the uptake of resources from high quality litter materials by beech and ash as compared to more recalcitrant soil resources.

We hypothesized that (1) beech and ash differentially affect the structure of the microbial community thereby modifying soil processes and plant nutrient capture. Differences in microbial community structure are expected to (2) result in differential decomposition of labeled ash litter and differential mobilization of nutrients from the litter. Further, we expected (3) modifications of the soil microorganism community and soil processes to be most pronounced in the mixed treatment with both tree species present due to complementary effects of the two tree species.

\section{Material and methods}

\subsection{Rhizotrons}

Double split-root rhizotrons were used to separate root systems of two tree seedlings into compartments with root strands of one individual seedling at each side and a shared root compartment in the center where root strands of both tree seedlings could interact (Fig. 1). We focused on the middle compartment where the two root strands grew together. The central compartment had a volume of 7.61 and side compartments half the volume. Rhizotrons were $90 \mathrm{~cm}$ high and $64 \mathrm{~cm}$ wide, and were built from anodized aluminum covered at the front with a $10-\mathrm{mm}$ Perspex plate. They were tilted at $35^{\circ}$ to direct roots growing along the Perspex plate. The Perspex plate was covered with black scrim to ensure that roots grow in darkness. Rhizotrons were divided into six soil depth sections $(\mathrm{I}-\mathrm{VI})$. Each soil depth contained four experimental sites (ES), two in the center and two at the sides (Fig. 1). The back side of the rhizotrons was equipped with a cooling system keeping the temperature at a constant level of $20^{\circ} \mathrm{C}$ over the whole soil column. Climate conditions were set to $20^{\circ} \mathrm{C}$ air temperature, $70 \%$ relative air humidity and $10 \mathrm{~h}$ daylight in winter and $14 \mathrm{~h}$ in summer. The tree seedlings were illuminated (EYE Lighting, Clean Ace, Mentor, $\mathrm{OH}, \mathrm{USA}$ ) ensuring a minimum PPFD of $200 \pm 10 \mu \mathrm{mol} \mathrm{m}{ }^{-2} \mathrm{~s}^{-1}$ from June 2009 to October 2010. The experiment lasted for 475 days, i.e., plants were harvested after the second season.

\subsubsection{Soil and plants}

The soil was taken from a mixed temperate broadleaf forest dominated by F. sylvatica, F. excelsior and Tilia cordata in Central Germany (Hainich forest, $51^{\circ} 04^{\prime} \mathrm{N} 10^{\circ} 30^{\prime} \mathrm{E}$, about $350 \mathrm{~m}$ a.s.l.) from a depth of $0-10 \mathrm{~cm}$ after removing the litter. The soil type was a Stagnic Luvisol (IUSS Working Group WRB, 2007; 1.8\% sand, $80.2 \%$ silt and $18.1 \%$ clay) and free of carbonate $(<0.02 \%$ of total carbon) with a $\mathrm{pH}\left(\mathrm{H}_{2} \mathrm{O}\right)$ of $4.56 \pm 0.03$ and a gravimetric water content at date of sampling of $22.7 \%$. Initial total carbon amounted to $19.2 \pm 0.3 \mathrm{~g} \mathrm{~kg}^{-1}$ dry weight, initial total nitrogen averaged $1.56 \pm 0.01 \mathrm{~g} \mathrm{~kg}^{-1}$ dry weight and base saturation was $22.9 \pm 1.3 \%$. Each rhizotron was filled with $15.2 \mathrm{~L}$ of sieved soil (1 cm mesh) containing soil microflora and fauna. Volumetric soil water content was monitored three times a week with a TDR measurement device (Trime-FM, IMKO, Ettlingen, Germany), and kept at constant level by adding distilled water. Soil temperature was measured with NTC thermistors (Epcos, Munich, Germany), arranged vertically in the center of the rhizotrons at soil depths of $8,20,42.5$ and $70.5 \mathrm{~cm}$ at a distance of $2 \mathrm{~cm}$ from the Perspex plate. Data were recorded in 15-min intervals with a CR1000 data logger (combined with two AM416 Relay Multiplexer, Campbell Scientific Inc., Utah, USA). 
a)

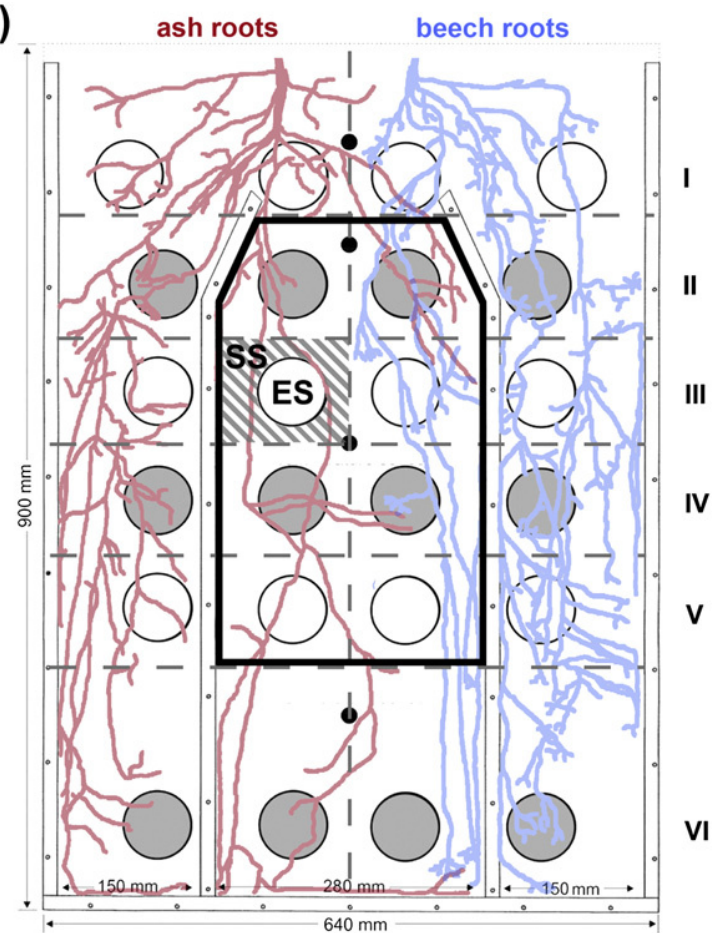

b)

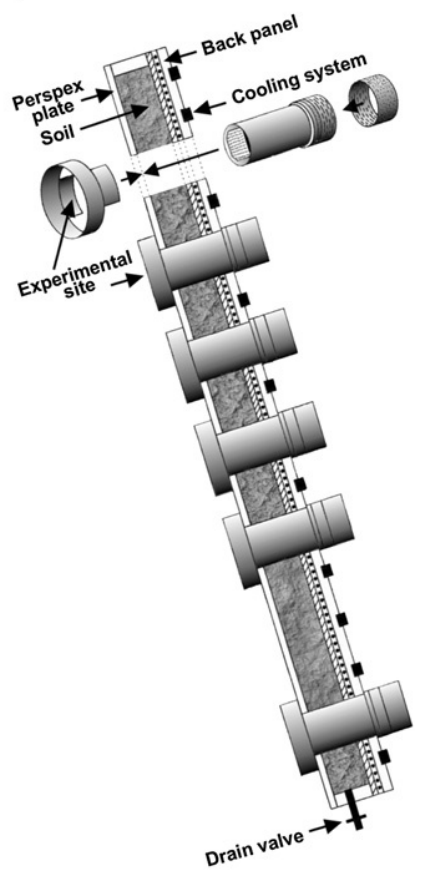

Fig. 1. Scheme of double split-root rhizotrons. (a) Front view of mixed species treatments with ash (left) and beech (right) roots interacting in the central compartment. Circles represent experimental sites (ES) with soil (open circles) or soil-litter mixture (gray circles). The shaded area refers to the surrounding sampling site (SS). Roman numerals indicate soil depths (I-VI). The bold rim in the central compartment from soil depth II to VI represents the sampling area. Black dots along the central dashed line refer to the position of temperature sensors. Dashed lines mark the sampling grid. (b) Side view of the double split-root rhizotron and assembly of ES. Tubes inside ES were withdrawn and the empty space filled with soil or soil-litter mixture allowing roots to grow into ES. A water flux based cooling system is installed at the back panel. A valve allowed drainage of the rhizotrons.

In spring 2009 beech (F. sylvatica) and ash (F. excelsior) seedlings with comparable root biomass were excavated in the Hainich forest with intact soil cores to preserve the root system. Initial shoot height was $23.1 \pm 1.2$ and $17.9 \pm 1.1 \mathrm{~cm}$, and root length was $12.1 \pm 0.7$ and $15.4 \pm 1.2 \mathrm{~cm}$ for beech and ash seedlings, respectively. At the start of the experiment, ash had significantly higher fine root biomass than beech, but tree species did not differ significantly in total root and total aboveground biomass (Table 1). Before planting, the soil material adhering to the root systems was removed by watering. The remaining soil-water mixture was used to equilibrate microbial communities in soil.

Fifty-three days after planting, $1.5 \mathrm{~g}$ labeled ash litter was added to ES of each of the treatments, i.e., the control, beech, ash and mixed rhizotrons at every second soil depth (II, IV, VI; see Fig. 1). Therefore, tubes were withdrawn and the empty space filled with soil or soillitter mixture. Prior to adding ash leaves (air dried, crushed to pieces $<1 \mathrm{~cm}$ ) were mixed with $40 \mathrm{~g}$ soil (air dried). The litter was labeled

Table 1

Means $\pm 1 \mathrm{SE}$ and $t$ - and $P$-values of plant biomass of beech and ash seedlings at the start of the experiment ( $g$ dry weight plant ${ }^{-1} ; n=5$ ). Significant effects are given in bold $(P<0.05)$.

\begin{tabular}{|c|c|c|c|c|}
\hline & \multicolumn{4}{|c|}{ Initial biomass } \\
\hline & \multirow{2}{*}{$\frac{\text { Beech }}{\text { Mean } \pm \text { SE }}$} & \multirow{2}{*}{$\frac{\text { Ash }}{\text { Mean } \pm \text { SE }}$} & \multirow[t]{2}{*}{$t$} & \multirow[t]{2}{*}{$P$} \\
\hline & & & & \\
\hline \multicolumn{5}{|c|}{ Biomass [g dw] per plant } \\
\hline Total & $2.04 \pm 0.46$ & $2.13 \pm 0.22$ & 0.15 & 0.7122 \\
\hline Total aboveground & $1.26 \pm 0.27$ & $1.25 \pm 0.15$ & 0.01 & 0.9294 \\
\hline Total belowground & $0.78 \pm 0.20$ & $0.88 \pm 0.08$ & 0.81 & 0.3933 \\
\hline Shoots & $0.88 \pm 0.22$ & $0.74 \pm 0.09$ & 0.27 & 0.6190 \\
\hline Leaves & $0.38 \pm 0.05$ & $0.52 \pm 0.07$ & 2.49 & 0.1530 \\
\hline Fine roots & $0.16 \pm 0.05$ & $0.41 \pm 0.08$ & 6.49 & 0.0343 \\
\hline Coarse roots & $0.64 \pm 0.17$ & $0.56 \pm 0.06$ & 0.08 & 0.7866 \\
\hline
\end{tabular}

with ${ }^{13} \mathrm{C}$ and ${ }^{15} \mathrm{~N}$ by incubating ash trees in the green house for one vegetation period with the $\mathrm{CO}_{2}$ concentration in air elevated by adding ${ }^{13} \mathrm{CO}_{2}$ (maximum concentration $1200 \mathrm{ppm}$ ) and by watering the soil with nutrient solution containing ${ }^{15} \mathrm{NO}_{3}{ }^{15} \mathrm{NH}_{4}$ (both 99 atom $\%$; Euriso-top, Saint-Aubin, Essonne, France). The solution contained $0.6 \mathrm{mM} \mathrm{CaCl}_{2}, 0.4 \mathrm{mM} \mathrm{MgSO}_{4}, 0.01 \mathrm{mM} \mathrm{FeCl}_{3}, 0.4 \mathrm{mM} \mathrm{K}_{3} \mathrm{PO}_{4}, 1.8 \mu \mathrm{M}$ $\mathrm{MnSO}_{4}, 0.064 \mu \mathrm{M} \mathrm{CuCl}, 0.15 \mu \mathrm{M} \mathrm{ZnCl}_{2}, 0.1 \mu \mathrm{M} \mathrm{MoO}_{3}, 5 \mathrm{mM} \mathrm{NO}_{3} \mathrm{NH}_{4}$ and $0.01 \mathrm{mM} \mathrm{H}_{3} \mathrm{BO}_{3}$. The stable isotope signature of the ash litter was $146.8 \pm 0.3 \%$ for $\delta^{13} \mathrm{C}$ and $13,139 \pm 60 \%$ for $\delta^{15} \mathrm{~N}$ (Table 2, see Table S1 for atom\% values).

\subsection{Experimental design}

The experiment was set up in a factorial design with the factors beech (absence and presence) and ash (absence and presence), resulting in the following treatments with four replicates each: (a) two beech seedlings (BB), (b) two ash seedlings (AA), (c) a mixture with one beech and one ash seedling ( $\mathrm{BA}$ or $\mathrm{AB}$, depending on target tree species), and (d) an unplanted control $(\mathrm{Co})$, resulting in rhizotrons without (B-: $C o$ and $A A)$ and with beech (B+: $B B$ and $B A)$, as well as rhizotrons without $(A-$ : $C o$ and $B B)$ and with ash $(A+: A A$ and $A B)$.

Table 2

Isotopic signatures of the soil, labeled ash litter and soil-litter-mixture at the start and end of the experiment after 422 days [means $\pm 1 \mathrm{SE} ; n=5$ except for samples taken at the end of the experiment which are pooled across treatments $(n=16)]$.

\begin{tabular}{|c|c|c|c|c|}
\hline & \multicolumn{3}{|l|}{ Start } & \multirow{2}{*}{$\begin{array}{l}\text { End } \\
\text { Soil-litter } \\
\text { mixture }\end{array}$} \\
\hline & Soil & Litter & $\begin{array}{l}\text { Soil-litter } \\
\text { mixture }\end{array}$ & \\
\hline & Mean \pm SE & Mean \pm SE & Mean \pm SE & Mean \pm SE \\
\hline$\delta^{13} \mathrm{C}[\% \mathrm{o}]$ & $-26.20 \pm 0.10$ & $146.80 \pm 0.32$ & $69.00 \pm 0.60$ & $-17.44 \pm 1.86$ \\
\hline$\delta^{15} \mathrm{~N}[\%]$ & $1.60 \pm 0.16$ & $13139.30 \pm 59.10$ & $6153.80 \pm 0.40$ & $577.38 \pm 124.88$ \\
\hline
\end{tabular}




\subsection{Sampling}

After 475 days rhizotrons were harvested. They were opened in horizontal position and a sampling grid was used to identify locations for sampling, i.e., at ES and the surrounding of these sites (SS; see Fig. 1). Samples from the depth layers II, III, IV and V of the central compartment were analyzed. As we were not interested in effects of soil depth we pooled the data from the four layers. In addition to soil samples, plant shoots and roots from each of the soil layers were taken for measuring plant biomass. Details on root biomass distribution along the soil depth gradient as well as on gas emissions are presented elsewhere (Fender et al., 2013).

\subsubsection{Plants}

At harvest shoot length and root collar diameter of seedlings were measured. Roots were separated from soil, washed and cleaned from adhering soil particles. To obtain overall plant biomass fine root biomass estimated from ES for mycorrhizal analysis were combined with plant biomass data from SS. Whenever possible three intact root strands of ca $7 \mathrm{~cm}$ length from each tree species per compartment and soil depths were taken and digitized on a flat-bed scanner for image analysis carried out using WinRhizo 2005c software (Régent Instruments Inc., Québec, QC, Canada) to determine specific fine root area (SRA; $\mathrm{cm}^{2} \mathrm{~g}^{-1}$ dry matter), specific fine root length (SRL; $\mathrm{cm} \mathrm{g}^{-1}$ dry matter) and total fine root surface. Thereafter, samples were oven-dried $\left(70^{\circ} \mathrm{C}, 48 \mathrm{~h}\right)$, weighed and milled for measurement of organic carbon $\left(\mathrm{C}_{\mathrm{org}}\right)$, total nitrogen $\left(\mathrm{N}_{\text {total }}\right)$ as well as $\delta^{13} \mathrm{C}$ and $\delta^{15} \mathrm{~N}$ signatures (Delta C, Finnigan MAT, Bremen, Germany).

\subsubsection{Mycorrhiza}

Colonization of roots at ES by mycorrhiza-forming fungi was determined. Fine roots were stored in Falcon tubes with moist tissue paper at $4{ }^{\circ} \mathrm{C}$ until analysis. Fine roots of beech were analyzed with a stereomicroscope (Leica M205 FA, Leica Microsystems, Wetzlar, Germany). The percentage of EM fungi colonization was calculated using the following equation:

EM fungi colonization [\%] $=\left(\frac{n \text { mycorrhizal root tips }}{n \text { vital root tips }}\right) \times 100$

Fine roots of ash were stored in $70 \% \mathrm{EtOH}$ at room temperature. For determining the colonization by AM fungi roots were stained with lactophenole-blue (Schmitz et al., 1991) and stored at room temperature in 50\% glycerol until microscopic inspection at $200 \times$ magnification. AM fungi colonization was calculated with the magnified intersection method of McGonigle et al. (1990) using a $10 \times 10$ grid. The abundance of vesicles, arbuscles and hyphae was calculated as percentage of mycorrhizal structures of the total number of intersections. The percentage of vesicles was taken as relative colonization rate of AM fungi and used for further calculations.

\subsubsection{Soil properties}

Soil $\mathrm{pH}$ was measured in a suspension of $10 \mathrm{~g}$ soil and $25 \mathrm{ml}$ $\mathrm{H}_{2} \mathrm{O}$ with a Vario pH meter (WTW GmbH, Weilheim, Germany). Soil water content was measured gravimetrically after drying at $105{ }^{\circ} \mathrm{C}$ for $24 \mathrm{~h}$. Nitrate and ammonium concentrations were measured by extracting soil samples in $0.5 \mathrm{M} \mathrm{K}_{2} \mathrm{SO}_{4}$ solution (1:3 wet soil mass-to-solution ratio). Samples were shaken for $1 \mathrm{~h}$ and filtered through Sartorius folded filters (Sartorius Stedim, Aubagne, France). Nitrate and ammonium concentrations of filtered extracts were analyzed using continuous flow injection colorimetry $\left(\mathrm{SAN}^{+}\right.$Continuous Flow Analyzer, Skalar Instruments, Breda, Netherlands). Nitrate was determined by copper cadmium reduction method (ISO method 13395) and ammonium was quantified by Berthelot reaction method (ISO method 11732). $\mathrm{C}_{\text {org, }}$ $\mathrm{N}_{\text {total }}$ as well as $\delta^{13} \mathrm{C}$ and $\delta^{15} \mathrm{~N}$ values were measured after grinding soil samples with a disc mill. Samples were analyzed with a coupled system consisting of an elemental analyzer (NA 1500, Carlo Erba, Mailand) and a mass spectrometer (Delta C, Finnigan MAT, Bremen, Germany).

\subsubsection{Microbial respiration}

Basal respiration (BAS), microbial biomass $\left(C_{\text {mic }}\right)$, and specific respiration $\left(\mathrm{qO}_{2}\right)$ were measured by substrate-induced respiration (SIR), i.e., the respiratory response of microorganisms to glucose (Anderson and Domsch, 1978). Before measurement, roots were removed and soil samples were sieved $(2 \mathrm{~mm})$. Measurements were done using an automated $\mathrm{O}_{2}$ microcompensation system (Scheu, 1992). BAS of microorganisms reflected their averaged oxygen consumption rate without the addition of glucose within 10$30 \mathrm{~h}$ after attachment of the samples to the analysis system. Subsequently, $4 \mathrm{mg}$ glucose $\mathrm{g}^{-1}$ soil dry weight was added as aqueous solution to the soil samples. The mean of the three lowest hourly measurements within the first $10 \mathrm{~h}$ was taken as the maximum initial respiratory response (MIRR). $C_{\text {mic }}\left(\mu \mathrm{g} \mathrm{C} \mathrm{g}{ }^{-1}\right)$ was calculated as $38 \times \operatorname{MIRR}\left(\mu \mathrm{O}_{2} \mathrm{~g}^{-1}\right.$ soil dry weight $\left.\mathrm{h}^{-1}\right)$ according to Beck et al. (1997). Microbial specific respiration $\mathrm{qO}_{2}\left(\mu \mathrm{l} \mathrm{O} \mathrm{O}^{-1} \mathrm{C}_{\mathrm{mic}} \mathrm{h}^{-1}\right)$ was calculated as $\mathrm{BAS} / \mathrm{C}_{\text {mic. }}$.

\subsubsection{Fatty acid analysis}

Before extraction of lipids, soil samples were sieved ( $2 \mathrm{~mm})$ and root and litter pieces were removed. Lipid extraction followed Frostegård et al. (1991). Bacterial biomass was estimated using the following PLFAs: a15:0, i15:0, i16:0, 16:1 $\omega 7$, i17:0, cy17:0 and cy 19:0; the PLFA 18:2 $\omega 6,9$ was used as fungal biomarker (Ruess and Chamberlain, 2010). A gas-chromatography-combustion-isotoperatio-monitoring-mass spectrometer (GC-C-IRM-MS) using Thermo Finnigan Trace GC coupled via a GP interface to a Delta Plus mass spectrometer (Finnigan, Bremen, Germany) was used to determine the isotopic composition of individual PLFAs. Fatty acid identification was verified by GC-MS using a Varian CP-3800 chromatograph coupled to a $1200 \mathrm{~L}$ mass spectrometer and a fused silica column (Phenomenex Zebron ZB-5MS, $30 \mathrm{~m}, 0.25 \mu \mathrm{m}$ film thickness, ID $0.32 \mathrm{~mm}$ ) and helium as carrier gas.

\subsubsection{Pyrosequencing}

$16 \mathrm{~S}$ rRNA as well as the $16 \mathrm{~S}$ rDNA were co-isolated to capture the active and the present microbial community; $2 \mathrm{~g}$ soil were extracted from control, beech and ash treatments using the RNA PowerSoil ${ }^{\mathrm{TM}}$ Total RNA Isolation Kit and DNA Elution Accessory Kit (MO BIO Laboratories Inc., Carlsbad, CA, USA). Residual DNA contaminations in RNA extracts were removed using the TURBO DNAfree $^{\mathrm{TM}}$ Kit (Ambion Applied Biosystems, Darmstadt, Germany). RNA was concentrated using the RNeasy MiniElute Kit (QIAGEN, Hilden, Germany). The nucleic acid concentration was estimated using a NanoDrop ND-1000 spectrophotometer (Peqlab Biotechnologie $\mathrm{GmbH}$, Erlangen, Germany).

The V2-V3 region of the 16S rRNA was reverse transcribed using the SuperScript ${ }^{\mathrm{TM}}$ III reverse transcriptase (Invitrogen, Karlsruhe, Germany). As template $100 \mathrm{ng}$ of the DNA-free RNA were applied. The resulting CDNA as well as the extracted DNA was amplified in triplicate using the Phusion ${ }^{\circledR}$ Hot Start High-Fidelity DNA polymerase (FINNZYMES, Espoo, Finland) as described by Nacke et al. (2011).

The following barcoded primer set was used for reverse transcription and amplification, containing the Roche 454 pyrosequencing adapters (underlined): V2for 5'-CTATGCGCCTTGCCAGCCCGCTCAGAGTGGCGGACGGGTGAGTAA-3' and V3rev 5'-CGTATCGCC TCCCTCGCGCCATCAGCGTATTACCGCGGCTGCTG-3' modified from

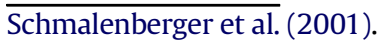


The PCR products were treated and purified as described by Nacke et al. (2011). All kits were used as described in the manufacturer's instructions. The Göttingen Genomics Laboratory determined the sequences of the partial 16S rRNA genes using a Roche GS-FLX 454 pyrosequencer (Roche, Mannheim, Germany) according to the manufacturer's instructions for amplicon sequencing.

Sequences shorter than $300 \mathrm{bp}$ were removed from the dataset. To minimize the bias introduced by pyrosequencing due to decreasing read precision at the end of the reads denoising was carried out using Denoiser 0.91 (Reeder and Knight, 2010). OTU determination was performed using uclust OTU picker 1.2.22q (Edgar, 2010) at genetic divergence of $3 \%, 5 \%$ and $20 \%$ according to Schloss and Handelsman (2005). The resulting datasets have been deposited in the GenBank short-read archive under accession number SRA050002.

\subsubsection{Soil animals}

Soil not needed for other analysis was taken to extract soil animals by heat (Kempson et al., 1963). Animals were preserved in saturated $\mathrm{NaCl}$ solution and kept at $-10{ }^{\circ} \mathrm{C}$ until analysis. The gamasid mite Hypoaspis aculeifer (G. Canestrini, 1884) was taken for stable isotope analysis as it occurred in sufficient numbers. Twenty adult mites were weighed into each tin capsule and dried at $40^{\circ} \mathrm{C}$ for $24 \mathrm{~h}$. Samples were analyzed as described above.

\subsection{Statistical analysis}

Two-way ANOVA was used to test for main effects of beech (Band $\mathrm{B}+)$, ash $(\mathrm{A}-$ and $\mathrm{A}+)$ and their interactions with data of the four soil depths pooled. To detect differences in plant biomass and mycorrhizal colonization contrasts were calculated in a GLM using pairwise $t$-test to account for dependence in mixed rhizotrons. $U$ Test was used for analyzing the number of root tips. Treatments in beech-only rhizotrons (BB) were compared to ash-only (AA) and beech-ash mixture (BA). Ash (AA) was also compared with beechash mixture (AB). Statistical analyses were done using SAS 9.2 (SAS Institute; Cary, NC, USA).

Discriminant function analysis (DFA) was used to analyze pyrosequencing data as well as fatty acid patterns combined with microbial respiration and soil chemical data. Differences of the bacterial composition in beech and ash rhizotrons and the control were calculated using non-multidimensional scaling (NMDS) to reduce dimensions in the dataset. DFA and NMDS were calculated using STATISTICA 7.0 for Windows (StatSoft, Tulsa, USA, 2001).

Means were compared using Tukey's Honestly Significant Difference test $(P<0.05)$. Data on plant biomass, isotopic signatures, SRA, SLR, number of fine root tips, $\mathrm{NO}_{3}^{-}, \mathrm{NH}_{4}^{+}, \mathrm{C}_{\text {org }}, \mathrm{N}_{\text {total }}$, microbial respiration and PLFA content were log-transformed and percentage data, i.e., colonization rate of mycorrhiza, were arcsine-square root transformed prior to statistical analyses to improve homogeneity of variance. Means given in text and tables are based on non-transformed data.

\section{Results}

\subsection{Plants and mycorrhizae}

After 475 days, total biomass of tree seedlings in BB rhizotrons was significantly lower than in AA and BA rhizotrons (Table 3). Fine and coarse root biomass were significantly lower in $B B$ rhizotrons compared to that of seedlings in AA $(-69 \%)$ and BA rhizotrons $(-62 \%)$ resulting in significantly lower total root biomass. Total biomass, total root biomass and coarse root biomass of seedlings in mixtures exceeded that of seedlings in monocultures, but this increase was only significant for beech $(60 \%, 62 \%, 70 \%$, respectively); biomass of ash seedlings in mixture increased by $11 \%, 17 \%$ and $23 \%$, respectively.

$\delta^{13} \mathrm{C}$ and $\delta^{15} \mathrm{~N}$ signatures in fine roots were significantly lower in BB than those in AA rhizotrons (Table 3; see Table S2 for atom\% values). SRA and SRL did not differ significantly between tree species but tended to be higher in beech (BB vs AA: $+6 \%$ and $+68 \%$, respectively), especially in the mixture (BA vs $A B:+24 \%$ and $+79 \%$, respectively). Generally, fine root tips of tree seedlings increased in mixed rhizotrons, especially beech in mixed rhizotrons had a significantly higher number of root tips than beech in monoculture by $+89 \%$ compared to ash in mixed rhizotrons and by $+54 \%$ compared to ash in monoculture. Mycorrhizal colonization of roots of beech in BB rhizotrons was significantly lower than that of roots of ash in AA rhizotrons, however, as beech and ash are colonized by different types of mycorrhiza the differences have to be interpreted with caution. Beech did not influence the colonization rate of ash by arbuscular mycorrhiza ( $A A$ vs $A B ;+2 \%$ ), whereas ash increased the colonization of beech by ectomycorrhiza (BB vs BA; $+45 \%$ ) although the effect was not significant (Table 3).

\subsection{Soil properties}

In general, the studied soil properties were strongly affected by beech and not by ash with interactions between tree species also being not significant (Table 4). Soil $\mathrm{pH}$ was significantly lower in $\mathrm{B}+$ $(4.54 \pm 0.08)$ than in $\mathrm{B}$ - rhizotrons $(4.80 \pm 0.06)$. In presence of beech $\mathrm{C}_{\text {org }}$ and $\mathrm{N}_{\text {total }}$ were significantly decreased by $-7 \%$ and $-6 \%$, respectively, but $\mathrm{NO}_{3}^{-}$and $\mathrm{NH}_{4}^{+}$concentrations remained unaffected (Table 4, see Table S3 for atom\% values). Further, $\delta^{13} \mathrm{C}$ and $\delta^{15} \mathrm{~N}$ of bulk soil were significantly lower in $\mathrm{B}+(-24.46 \pm 0.32 \%$ and $127.04 \pm 19.95 \%$, respectively) compared to $\mathrm{B}-$ rhizotrons $(-22.24 \pm 0.78 \%$ ond $265.25 \pm 48.79 \%$, respectively). Generally, after 422 days of litter incubation, the signatures of $\delta^{13} \mathrm{C}$ and $\delta^{15} \mathrm{~N}$ within the soil-litter-mixtures decreased strongly by 86 and 5576 delta units, respectively (Table 2; see Table S1 for atom\% values).

\subsection{Microorganisms}

$\mathrm{C}_{\text {mic }}$ was not significantly affected by tree species and averaged over all treatments $141.25 \pm 4.93 \mu \mathrm{g} \mathrm{C} \mathrm{g}{ }^{-1}$. However, $q \mathrm{O}_{2}$ was significantly higher in $\mathrm{B}+\left(0.0101 \pm 0.003 \mu \mathrm{l} \mathrm{O}_{2} \mathrm{mg}^{-1} \mathrm{C}_{\mathrm{mic}} \mathrm{h}^{-1}\right)$ than in $\mathrm{B}-$ rhizotrons ( $-16 \%$, Table 4$)$, which was due to marginally higher BAS in $\mathrm{B}+\left(1.39 \pm 0.08 \mu \mathrm{l} \mathrm{O}_{2} \mathrm{~h}^{-1} \mathrm{~g}^{-1}\right)$ as compared to $\mathrm{B}-$ rhizotrons $(-15 \%)$.

The ratio of fungal-to-bacterial marker PLFAs was significantly higher in $\mathrm{B}+(0.061 \pm 0.007)$ than in $\mathrm{B}$ - rhizotrons $(-53 \%)$ as the fungal biomass was higher in $B+\left(0.43 \pm 0.08 \mathrm{nmol} \mathrm{g}^{-1}\right.$ dry weight $)$ than in $B-$ rhizotrons $(-47 \%)$, whereas bacterial biomass remained unaffected.

Bacterial and total PLFA content were not significantly affected by the treatments and averaged $6.67 \pm 1.67$ and $7.00 \pm 0.53 \mathrm{nmol} \mathrm{g}^{-1}$ dry weight, respectively. The $\delta^{13} \mathrm{C}$ values of the fungal marker PLFA $18: 2 \omega 6,9$ were significantly lower in $\mathrm{B}+(-29.93 \pm 2.00 \%)$ than in $\mathrm{B}-$ rhizotrons $(-18.75 \pm 3.60 \%)$. Also, weighted $\delta^{13} \mathrm{C}$ values of bacterial PLFAs were lower in B+ $(-26.28 \pm 0.97 \%)$ than in Brhizotrons $(-24.40 \pm 0.84 \%)$, whereas in $\mathrm{A}+$ rhizotrons $(-24.87 \pm 1.01 \%)$ they tended to be higher than in A-rhizotrons $(-25.82 \pm 0.89 \%$ o $)$. In general, ash did not significantly influence $\delta^{13} \mathrm{C}$ values of marker PLFAs (Table 4; see Table S3 for atom\% values).

DFA suggested strong similarity in the composition of PLFAs in $\mathrm{BB}$ and BA rhizotrons. Both treatments differed strongly from AA and control treatments (Fig. 2). Differences were mainly due to low amounts of gram-negative (cy17:0) and gram-positive bacteria (i17:0) in beech rhizotrons. Higher fungal biomass and low pH in beech and mixed rhizotrons also contributed to the separation of these treatments but to a lower extent (Tables 5 and 6). Pyrosequencing of the bacterial community revealed high overlap of 
Table 3

GLM table of contrasts between rhizotrons planted with beech (BB), ash (AA), beech mixed with ash (BA) and ash mixed with beech (AB) for plant parameters of rhizotrons planted with beech, ash or both after 475 days as well as means \pm 1 SE of the respective parameters $(n=4)$. Significant effects are given in bold $(P<0.05)$. Atom\% values of plant compartments are given in Table S2.

\begin{tabular}{|c|c|c|c|c|c|c|c|c|c|c|}
\hline & \multicolumn{2}{|c|}{$B B$ vs $A A$} & \multicolumn{2}{|l|}{$B B$ va $B A$} & \multicolumn{2}{|c|}{$A A$ vs $A B$} & \multirow{2}{*}{$\frac{\mathrm{BB}(\text { pure beech })}{\text { Mean } \pm \mathrm{SE}}$} & \multirow{2}{*}{$\frac{\mathrm{AA}(\text { pure ash) }}{\text { Mean } \pm \mathrm{SE}}$} & \multirow{2}{*}{$\frac{\text { BA (beech in mixture) }}{\text { Mean } \pm S E}$} & \multirow{2}{*}{$\frac{\mathrm{AB} \text { (ash in mixture) }}{\text { Mean } \pm \mathrm{SE}}$} \\
\hline & $F$ & $P$ & $F$ & $P$ & $F$ & $P$ & & & & \\
\hline \multicolumn{11}{|c|}{ Biomass [g dw] per plant } \\
\hline Total & 8.82 & 0.0117 & 6.39 & 0.0266 & 0.00 & 0.9518 & $4.52 \pm 0.79$ & $12.08 \pm 1.69$ & $11.33 \pm 2.03$ & $13.50 \pm 2.33$ \\
\hline Total aboveground & 4.20 & 0.0629 & 2.91 & 0.1138 & 1.11 & 0.3128 & $1.85 \pm 0.38$ & $3.34 \pm 0.86$ & $4.29 \pm 1.01$ & $3.03 \pm 0.43$ \\
\hline Total root & 9.52 & 0.0094 & 6.96 & 0.0217 & 0.28 & 0.6035 & $2.67 \pm 0.50$ & $8.74 \pm 1.08$ & $7.04 \pm 1.08$ & $10.47 \pm 2.15$ \\
\hline Shoot & 1.24 & 0.2876 & 3.43 & 0.0889 & 0.12 & 0.7300 & $1.38 \pm 0.25$ & $1.78 \pm 0.32$ & $3.20 \pm 0.73$ & $2.64 \pm 0.41$ \\
\hline Leaves & 5.14 & 0.0426 & 0.53 & 0.4809 & 7.50 & 0.0180 & $0.46 \pm 0.14$ & $1.56 \pm 0.56$ & $1.08 \pm 0.34$ & $0.39 \pm 0.22$ \\
\hline Fine roots & 9.14 & 0.0106 & 4.60 & 0.0532 & 0.09 & 0.7669 & $0.78 \pm 0.18$ & $2.38 \pm 0.30$ & $1.80 \pm 0.27$ & $2.27 \pm 0.44$ \\
\hline Coarse roots & 7.95 & 0.0154 & 6.50 & 0.0255 & 0.59 & 0.4557 & $1.89 \pm 0.35$ & $6.36 \pm 0.87$ & $5.24 \pm 0.82$ & $8.21 \pm 1.91$ \\
\hline \multicolumn{11}{|c|}{$\delta^{13} \mathrm{C}[\%]$ plant compartments } \\
\hline Shoot & 5.14 & 0.0426 & 7.00 & 0.0214 & 2.12 & 0.1708 & $-29.09 \pm 0.32$ & $-28.07 \pm 0.28$ & $-27.90 \pm 0.22$ & $-27.40 \pm 0.26$ \\
\hline Leaves & 0.30 & 0.5955 & 0.25 & 0.6287 & 0.75 & 0.4029 & $-29.62 \pm 0.56$ & $-29.26 \pm 0.27$ & $-29.29 \pm 0.44$ & $-29.83 \pm 0.20$ \\
\hline Fine roots & 8.27 & 0.0139 & 0.04 & 0.8402 & 0.01 & 0.9395 & $-27.64 \pm 0.34$ & $-25.60 \pm 0.85$ & $-27.49 \pm 0.19$ & $-25.56 \pm 0.23$ \\
\hline Coarse roots & 12.86 & 0.0037 & 2.78 & 0.1215 & 0.06 & 0.8162 & $-28.35 \pm 0.31$ & $-25.74 \pm 0.76$ & $-27.15 \pm 0.31$ & $-25.92 \pm 0.32$ \\
\hline \multicolumn{11}{|c|}{$\delta^{15} \mathrm{~N}[\%$ o $]$ plant compartments } \\
\hline Shoot & 0.87 & 0.3701 & 0.07 & 0.8018 & 2.15 & 0.1682 & $171.27 \pm 30.67$ & $260.05 \pm 66.16$ & $154.54 \pm 18.34$ & $154.40 \pm 26.76$ \\
\hline Leaves & 5.34 & 0.0394 & 0.55 & 0.4741 & 1.98 & 0.1853 & $192.42 \pm 32.67$ & $316.50 \pm 43.37$ & $166.67 \pm 23.49$ & $228.28 \pm 15.10$ \\
\hline Fine roots & 4.77 & 0.0496 & 1.35 & 0.2674 & 4.07 & 0.0666 & $209.02 \pm 41.75$ & $396.07 \pm 99.34$ & $148.85 \pm 17.63$ & $214.48 \pm 22.80$ \\
\hline Coarse roots & 9.34 & 0.0100 & 0.10 & 0.7630 & 2.81 & 0.1196 & $193.66 \pm 27.78$ & $390.78 \pm 78.87$ & $178.50 \pm 12.60$ & $257.86 \pm 19.23$ \\
\hline \multicolumn{11}{|l|}{$\mathrm{SRA}^{\mathrm{a}}\left[\mathrm{m}^{2} / \mathrm{g}\right]$} \\
\hline Fine roots & 0.23 & 0.6385 & 0.05 & 0.8271 & 0.78 & 0.3950 & $485.16 \pm 15.36$ & $456.49 \pm 42.70$ & $509.00 \pm 54.07$ & $410.65 \pm 64.00$ \\
\hline \multicolumn{11}{|l|}{$\mathrm{SRL}^{\mathrm{a}}[\mathrm{m} / \mathrm{g}]$} \\
\hline Fine roots & 2.89 & 0.1150 & 0.50 & 0.4947 & 0.20 & 0.6596 & $2374.80 \pm 221.17$ & $1414.42 \pm 168.82$ & $3235.44 \pm 848.14$ & $1810.83 \pm 450.85$ \\
\hline \multicolumn{11}{|l|}{ Fine root tips } \\
\hline Number & -0.48 & 0.9970 & -13.16 & 0.0000 & 2.13 & 0.1750 & $1623.50 \pm 230.01$ & $2299.00 \pm 419.58$ & $3072.50 \pm 207.37$ & $3543.75 \pm 107.79$ \\
\hline \multicolumn{11}{|l|}{ Mycorrhiza [\%] } \\
\hline Colonization $^{\mathrm{b}}$ & 27.50 & 0.0002 & 3.07 & 0.1053 & 0.04 & 0.8481 & $37.81 \pm 8.58$ & $81.82 \pm 5.17$ & $54.80 \pm 6.51$ & $83.54 \pm 2.87$ \\
\hline
\end{tabular}

a SRA, specific root area; SRL, specific root length.

b Note that the different type of mycorrhiza in beech and ash demanded for special counting techniques, thus direct comparisons have to be treated with caution but allow comparison with trees in mixture.

Table 4

ANOVA table of $F$ - and $P$-values on the effect of beech and ash on soil and microbial parameters, and signatures in gamasid mites as well as means \pm 1 SE of the respective parameters in rhizotrons planted with beech (B) and ash (A) after 475 days $(n=4)$. Significant effects are given in bold $(P<0.05)$. Atom\% values of soil C and N, PLFA and gamasid mites are given in Table S3.

\begin{tabular}{|c|c|c|c|c|c|c|c|c|c|c|}
\hline & \multicolumn{2}{|l|}{ Beech } & \multicolumn{2}{|l|}{ Ash } & \multicolumn{2}{|c|}{ Beech $\times$ ash } & \multicolumn{2}{|l|}{$\mathrm{B}-$} & \multicolumn{2}{|l|}{$\mathrm{B}+$} \\
\hline & & & & & & & \multirow{2}{*}{$\frac{\mathrm{A}-(\text { Control })}{\text { Mean } \pm \mathrm{SE}}$} & \multirow{2}{*}{$\frac{\mathrm{A}+(\mathrm{Ash})}{\text { Mean } \pm \mathrm{SE}}$} & \multirow{2}{*}{$\frac{\mathrm{A}-(\text { Beech })}{\text { Mean } \pm \mathrm{SE}}$} & \multirow{2}{*}{$\frac{\mathrm{A}+(\text { Mixture })}{\text { Mean } \pm \mathrm{SE}}$} \\
\hline & $F$ & $P$ & $F$ & $P$ & $F$ & $P$ & & & & \\
\hline \multicolumn{11}{|l|}{ Soil data } \\
\hline $\mathrm{pH}\left(\mathrm{H}_{2} \mathrm{O}\right)$ & 5.77 & 0.0334 & 0.11 & 0.7436 & 0.02 & 0.8944 & $4.78 \pm 0.12$ & $4.83 \pm 0.05$ & $4.53 \pm 0.14$ & $4.55 \pm 0.11$ \\
\hline $\mathrm{N}-\mathrm{NO}_{3}^{-}\left[\mathrm{mg} \mathrm{kg}^{-1} \mathrm{dw}\right]$ & 1.00 & 0.3387 & 0.04 & 0.8532 & 0.62 & 0.4487 & $41.31 \pm 4.96$ & $42.88 \pm 3.20$ & $39.32 \pm 3.83$ & $35.14 \pm 5.93$ \\
\hline $\mathrm{N}-\mathrm{NH}_{4}^{+}\left[\mathrm{mg} \mathrm{kg}^{-1} \mathrm{dw}\right]$ & 0.01 & 0.9422 & 0.41 & 0.5360 & 0.38 & 0.5477 & $2.46 \pm 0.93$ & $1.47 \pm 0.63$ & $1.88 \pm 0.72$ & $1.86 \pm 0.69$ \\
\hline $\mathrm{C}_{\mathrm{org}}\left[\mathrm{mg} \mathrm{kg}^{-1} \mathrm{dw}\right]$ & 15.02 & 0.0022 & 0.08 & 0.7829 & 0.02 & 0.8980 & $1.89 \pm 0.04$ & $1.91 \pm 0.05$ & $1.76 \pm 0.03$ & $1.77 \pm 0.02$ \\
\hline$\delta^{13} \mathrm{C}$ soil $[\%$ o $]$ & 7.54 & 0.0177 & 1.73 & 0.2129 & 1.40 & 0.2604 & $-23.27 \pm 0.58$ & $-21.21 \pm 1.35$ & $-24.51 \pm 0.57$ & $-24.41 \pm 0.40$ \\
\hline $\mathrm{N}_{\text {total }}\left[\mathrm{mg} \mathrm{kg}^{-1} \mathrm{dw}\right]$ & 7.82 & 0.0162 & 0.24 & 0.6297 & 0.00 & 0.9687 & $0.18 \pm 0.00$ & $0.17 \pm 0.00$ & $0.17 \pm 0.00$ & $0.16 \pm 0.00$ \\
\hline$\delta^{15} \mathrm{~N}$ soil $[\%]$ & 7.42 & 0.0185 & 0.83 & 0.3816 & 0.31 & 0.5907 & $212.18 \pm 55.44$ & $318.33 \pm 78.47$ & $126.29 \pm 37.64$ & $127.79 \pm 20.99$ \\
\hline C-to-N ratio & 0.56 & 0.4677 & 0.98 & 0.3406 & 0.00 & 0.9932 & $10.78 \pm 0.24$ & $10.94 \pm 0.08$ & $10.66 \pm 0.16$ & $10.82 \pm 0.14$ \\
\hline $\mathrm{CEC}\left[\mu \mathrm{molc} \mathrm{g}^{-1} \mathrm{dw}\right]$ & 0.06 & 0.8162 & 1.33 & 0.2726 & 0.06 & 0.8109 & $189.78 \pm 3.98$ & $185.12 \pm 2.33$ & $191.98 \pm 9.94$ & $201.36 \pm 7.84$ \\
\hline Base saturation [\%] & 1.39 & 0.2638 & 0.04 & 0.8518 & 1.13 & 0.3108 & $20.21 \pm 0.29$ & $20.80 \pm 0.65$ & $19.90 \pm 0.99$ & $20.92 \pm 0.47$ \\
\hline \multicolumn{11}{|l|}{ Microbial parameters } \\
\hline BAS $\left[\mu l O_{2} h^{-1} g^{-1}\right]^{a}$ & 4.04 & 0.0674 & 0.09 & 0.7674 & 0.19 & 0.6701 & $1.18 \pm 0.09$ & $1.18 \pm 0.05$ & $1.41 \pm 0.07$ & $1.36 \pm 0.15$ \\
\hline 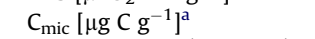 & 0.03 & 0.8643 & 0.48 & 0.5019 & 0.40 & 0.5365 & $150.03 \pm 13.65$ & $134.32 \pm 5.93$ & $139.79 \pm 6.62$ & $140.86 \pm 13.38$ \\
\hline$q \mathrm{O}_{2}\left[\mu \mathrm{IO}_{2} \mathrm{mg}^{-1} \mathrm{C}_{\mathrm{mic}} \mathrm{h}^{-1}\right]^{\mathrm{a}}$ & 9.00 & 0.0111 & 0.14 & 0.7178 & 1.59 & 0.2311 & $0.008 \pm 0.001$ & $0.009 \pm 0.000$ & $0.010 \pm 0.001$ & $0.010 \pm 0.001$ \\
\hline \multicolumn{11}{|l|}{ PLFA [nmol g ${ }^{-1}$ dry weight] } \\
\hline Total & 0.75 & 0.4025 & 0.00 & 0.9619 & 1.11 & 0.3130 & $7.22 \pm 1.32$ & $6.03 \pm 1.36$ & $6.57 \pm 0.55$ & $8.19 \pm 0.97$ \\
\hline Bacteria & 0.53 & 0.4801 & 0.01 & 0.9377 & 1.05 & 0.3262 & $6.95 \pm 1.20$ & $5.85 \pm 1.29$ & $6.25 \pm 0.52$ & $7.66 \pm 0.95$ \\
\hline Fungi & 3.36 & 0.0916 & 0.18 & 0.6757 & 1.20 & 0.2955 & $0.27 \pm 0.16$ & $0.18 \pm 0.07$ & $0.33 \pm 0.05$ & $0.53 \pm 0.15$ \\
\hline Fungi-to-bacteria ratio & 5.17 & 0.0422 & 0.33 & 0.5755 & 0.85 & 0.3752 & $0.032 \pm 0.017$ & $0.026 \pm 0.010$ & $0.050 \pm 0.008$ & $0.073 \pm 0.019$ \\
\hline \multicolumn{11}{|l|}{ PLFA $\delta^{13} \mathrm{C}[\%]$} \\
\hline Total & 2.43 & 0.1454 & 1.40 & 0.2590 & 0.30 & 0.5944 & $-22.80 \pm 2.37$ & $-21.49 \pm 2.09$ & $-27.14 \pm 0.60$ & $-23.55 \pm 2.51$ \\
\hline Bacteria & 2.01 & 0.1818 & 0.49 & 0.4960 & 0.51 & 0.4871 & $-24.38 \pm 1.47$ & $-24.43 \pm 1.05$ & $-27.25 \pm 0.45$ & $-25.31 \pm 1.89$ \\
\hline Fungi & 7.48 & 0.0181 & 0.08 & 0.7807 & 0.16 & 0.6941 & $-21.01 \pm 6.61$ & $-17.06 \pm 4.53$ & $-31.59 \pm 0.92$ & $-28.27 \pm 4.01$ \\
\hline \multicolumn{11}{|l|}{ Gamasid mites } \\
\hline$\delta^{13} \mathrm{C}[\%]$ & 20.59 & 0.0008 & 159.43 & $<\mathbf{0 . 0 0 0 1}$ & 7.80 & 0.0175 & $-23.37 \pm 0.86$ & $-13.89 \pm 0.31$ & $-20.19 \pm 1.40$ & $-8.78 \pm 0.43$ \\
\hline$\delta^{15} \mathrm{~N}[\%]$ & 25.75 & 0.0004 & 148.88 & $<0.0001$ & 11.93 & 0.0054 & $130.14 \pm 23.08$ & $713.33 \pm 43.37$ & $339.07 \pm 37.35$ & $1121.26 \pm 26.97$ \\
\hline
\end{tabular}

a $\mathrm{BAS}$, basal respiration; $\mathrm{C}_{\text {mic, }}$ microbial biomass; $q \mathrm{O}_{2}$, specific respiration. 


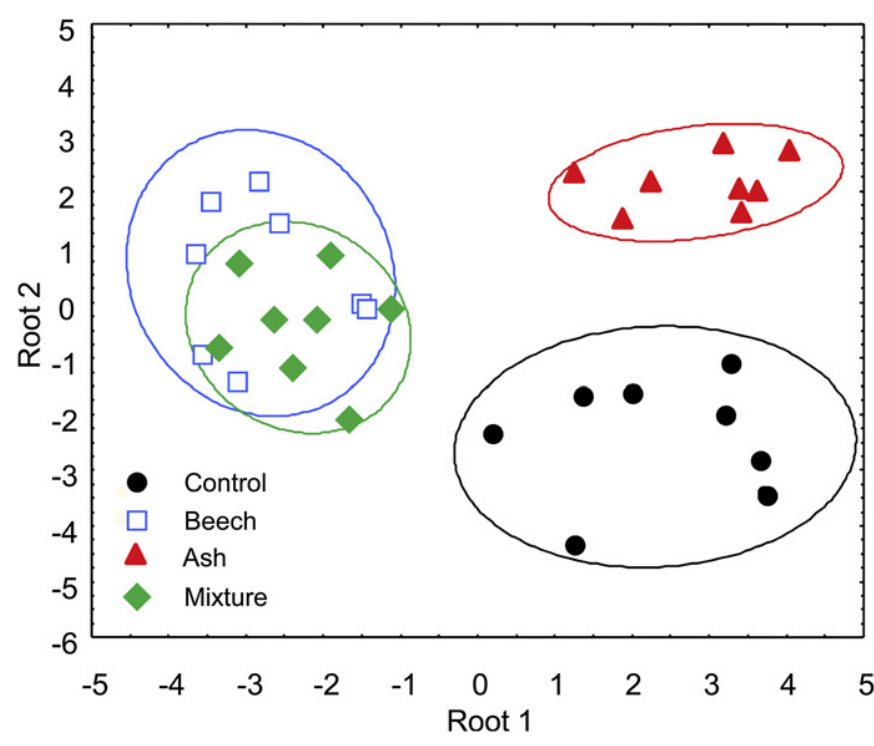

Fig. 2. Discriminant function analysis (DFA) of microbial PLFAs, microbial respiration and soil properties in rhizotrons without trees (control), with beech, ash and a mixture of beech and ash. Wilks' Lambda $0.0165, F_{(54,33)}=1.85, P=0.0296$. Ellipses represent confidence intervals at $P=0.05$.

bacterial phyla and species with little differences between the treatments (Fig. 3).

\subsection{Soil fauna/gamasid mites}

The $\delta^{13} \mathrm{C}$ and $\delta^{15} \mathrm{~N}$ from the added ash litter was incorporated into basal species of the soil food web as indicated by the label in the predatory mite $H$. aculeifer (Table 4 ; see Table S3 for atom\% values). The signatures suggest that incorporation of label was most pronounced in mixed rhizotrons (significant interaction between beech and ash) followed by AA, BB and control rhizotrons. Abundances of soil animal taxa extracted by heat, i.e., collembolans, gamasid and oribatid mites as well as earthworms, generally did not differ between treatments (Table S4).

\section{Table 5}

Summary of input variables of the discriminant function analysis (DFA), i.e., data on PLFA markers (nmol $\mathrm{g}^{-1}$ dry weight), soil properties and microbial respiration. Significant effects are given in bold $(P<0.05)$.

\begin{tabular}{|c|c|c|c|}
\hline & Wilks' lambda & $F(3,11)$ & $P$ \\
\hline \multicolumn{4}{|c|}{ Gram $^{+}$bacteria } \\
\hline $\mathrm{i} 15: 0$ & 0.0175 & 0.2171 & 0.8825 \\
\hline a15:0 & 0.0242 & 1.7284 & 0.2188 \\
\hline i16:0 & 0.0237 & 1.6062 & 0.2441 \\
\hline i17:0 & 0.0430 & 5.8991 & 0.0119 \\
\hline \multicolumn{4}{|c|}{ Gram $^{-}$bacteria } \\
\hline су17:0 & 0.0390 & 5.0135 & 0.0198 \\
\hline cy19:0 & 0.0239 & 1.6448 & 0.2358 \\
\hline \multicolumn{4}{|c|}{ Unspecified bacteria } \\
\hline $16: 1 \omega 7$ & 0.0250 & 1.8939 & 0.1891 \\
\hline \multicolumn{4}{|l|}{ Fungi } \\
\hline $18: 2 \omega 6,9$ & 0.0298 & 2.9597 & 0.0792 \\
\hline \multicolumn{4}{|c|}{ Microbial respiration } \\
\hline $\mathrm{BAS}^{\mathrm{a}}$ & 0.0178 & 0.2972 & 0.8267 \\
\hline $\mathrm{C}_{\text {mic }}{ }^{\mathrm{a}}$ & 0.0179 & 0.3145 & 0.8146 \\
\hline$q \mathrm{O}_{2}^{\mathrm{a}}$ & 0.0175 & 0.2325 & 0.8719 \\
\hline \multicolumn{4}{|c|}{ Soil properties } \\
\hline $\mathrm{pH}$ & 0.0320 & 3.4554 & 0.0549 \\
\hline $\mathrm{NO}_{3}^{-}$ & 0.0211 & 1.0298 & 0.4170 \\
\hline $\mathrm{NH}_{4}^{+}$ & 0.0188 & 0.5116 & 0.6825 \\
\hline $\mathrm{C}_{\text {org }}$ & 0.0182 & 0.3726 & 0.7745 \\
\hline $\mathrm{N}_{\text {total }}$ & 0.0261 & 2.1450 & 0.1524 \\
\hline$\delta^{13} \mathrm{C}$ & 0.0221 & 1.2510 & 0.3384 \\
\hline$\delta^{15} \mathrm{~N}$ & 0.0173 & 0.1733 & 0.9122 \\
\hline
\end{tabular}

${ }^{a}$ BAS, basal respiration; $\mathrm{C}_{\text {mic, }}$ microbial biomass; $q \mathrm{O}_{2}$, specific respiration.
Table 6

Means \pm 1 SE of PLFA markers ( $n$ mol g ${ }^{-1}$ dry weight) of the microbial community in rhizotrons planted with beech (B) and ash (A) after 475 days $(n=4)$.

\begin{tabular}{|c|c|c|c|c|}
\hline & \multicolumn{2}{|c|}{ Beech absent (B-) } & \multicolumn{2}{|c|}{ Beech present $(\mathrm{B}+)$} \\
\hline & $\begin{array}{l}\text { Ash absent } \\
(\mathrm{A}-) \text { (Control) }\end{array}$ & $\begin{array}{l}\text { Ash present } \\
(\mathrm{A}+) \text { (Ash) }\end{array}$ & $\begin{array}{l}\text { Ash absent } \\
\text { (A-) (Beech) }\end{array}$ & $\begin{array}{l}\text { Ash present } \\
(\mathrm{A}+) \text { (Mixture) }\end{array}$ \\
\hline & Mean \pm SE & Mean \pm SE & Mean \pm SE & Mean \pm SE \\
\hline \multicolumn{5}{|c|}{ Gram $^{+}$bacteria } \\
\hline i15:0 & $0.92 \pm 0.22$ & $0.81 \pm 0.36$ & $1.05 \pm 0.21$ & $1.59 \pm 0.35$ \\
\hline a15:0 & $1.41 \pm 0.29$ & $1.04 \pm 0.34$ & $1.40 \pm 0.24$ & $1.93 \pm 0.24$ \\
\hline $\mathrm{i} 16: 0$ & $0.70 \pm 0.08$ & $0.66 \pm 0.12$ & $0.80 \pm 0.06$ & $0.87 \pm 0.06$ \\
\hline $\mathrm{i} 17: 0$ & $0.62 \pm 0.05$ & $0.74 \pm 0.14$ & $0.42 \pm 0.04$ & $0.70 \pm 0.09$ \\
\hline \multicolumn{5}{|c|}{ Gram $^{-}$bacteria } \\
\hline су17:0 & $0.72 \pm 0.16$ & $0.77 \pm 0.13$ & $0.63 \pm 0.06$ & $0.84 \pm 0.16$ \\
\hline су19:0 & $1.22 \pm 0.58$ & $1.13 \pm 0.46$ & $1.13 \pm 0.22$ & $0.74 \pm 0.26$ \\
\hline \multicolumn{5}{|c|}{ Unspecified bacteria } \\
\hline $16: 1 \omega 7$ & $1.35 \pm 0.37$ & $0.70 \pm 0.35$ & $0.81 \pm 0.21$ & $0.98 \pm 0.44$ \\
\hline \multicolumn{5}{|l|}{ Fungi } \\
\hline $18: 2 \omega 6,9$ & $0.27 \pm 0.16$ & $0.18 \pm 0.07$ & $0.33 \pm 0.05$ & $0.53 \pm 0.15$ \\
\hline
\end{tabular}

\section{Discussion}

\subsection{Changes in the microbial community due to rhizodeposition}

Lower $\mathrm{pH}$ in the rhizosphere of beech likely contributed to favoring soil fungi supporting our hypothesis (1) that beech and ash differentially affect the structure of the microbial community. Acidification of the soil by beech is well known (Holzwarth et al., 2011; Langenbruch et al., 2012), however, commonly it has been ascribed to low concentrations of calcium and magnesium and high concentrations of recalcitrant compounds such as lignin in beech leaf litter (Reich et al., 2005; Hobbie et al., 2006; Hansen et al., 2009). As we excluded leaf litter fall from seedlings to the rhizotron soil surface and uniformly placed high quality ash litter in each of the treatments, the observed differences must have been due to the activity of beech roots. Indeed, in the vicinity of beech roots concentrations of formate and acetate were increased as compared to control rhizotrons in the same experiment, whereas in the vicinity of ash roots only the concentration of acetate increased (Fender et al., 2013). The release of organic acids increases nutrient

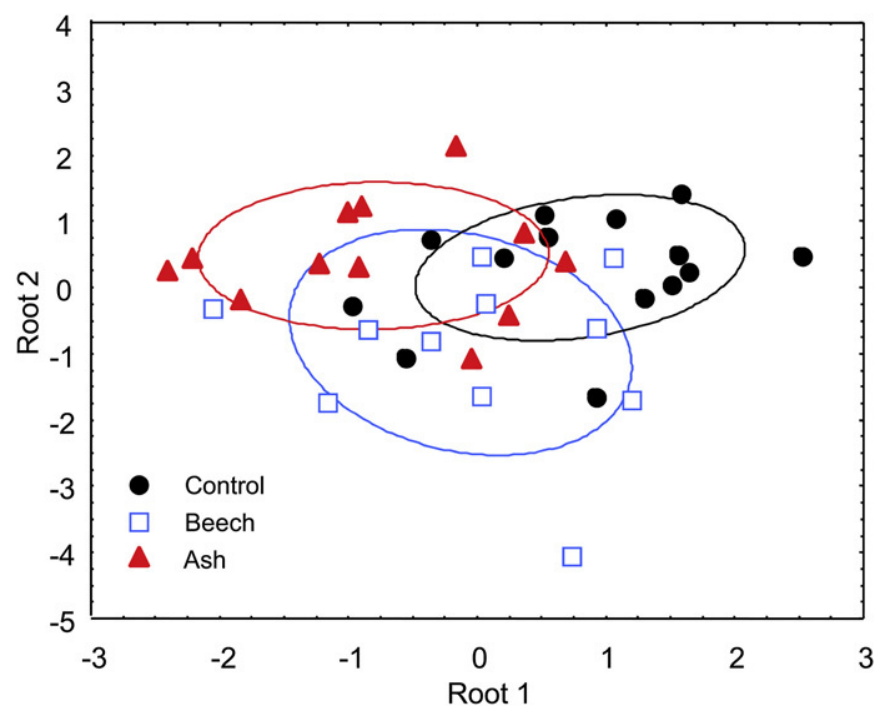

Fig. 3. Discriminant function analysis (DFA) of bacterial phyla based on pyrosequencing of $16 \mathrm{~S}$ rRNA in rhizotrons without trees (control) and with beech and ash seedlings after reducing data to six dimensions by multi dimensional scaling to 'nonmultidimensional scaling (NMDS). Wilks' Lambda 0.4996; $F_{(12,60)}=2.07 ; P=0.0325$. Ellipses represent confidence intervals at $P=0.05$. 
availability and this is facilitated by low pH (Jones et al., 2004); presumably, beech employs this strategy to increase nutrient mobilization and uptake. Low $\mathrm{pH}$ in the soil, however, predominantly is caused by the release of $\mathrm{H}^{+}$by roots rather than by dissociation of organic acids (Neumann and Römheld, 1999). Notably, acidification of the soil by beech roots occurred despite a comparatively lower root biomass in beech than ash rhizotrons. However, SRA and SRL were higher in B+ rhizotrons as compared to A+ rhizotrons. This suggests that the observed modifications were partly due to changes in root physiology rather than root biomass and number of fine root tips (Lehmann, 2003). Differences in the release rates of specific exudates of the two species presumably also contributed to the observed changes.

Bacterial community composition was little affected by tree roots as indicated by analysis of $16 \mathrm{~S}$ rRNA. The ratio of fungal-tobacterial biomass measured via fatty acid analysis increased in $\mathrm{B}+$ rhizotrons and reflected the general pattern of increasing fungal dominance at low $\mathrm{pH}$ accounting for differences in soil processes (Aciego Pietri and Brookes, 2008; Rousk et al., 2009). Fungal biomass was measured using 18:2 $\omega 6,9$ as marker PLFA (Ruess and Chamberlain, 2010; Frostegård et al., 2011) which includes EM and saprotrophic fungi (Kaiser et al., 2010). We suggest the change in

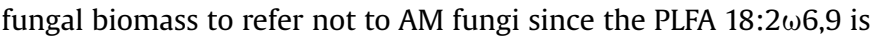
only found in very low densities in this type of fungi (Olsson and Johansen, 2000) and since the AM colonization rate did not change. Colonization by EM fungi in beech was relatively low ( $46 \pm 6 \%$, pooled data from BB and BA rhizotrons). This corresponds to low colonization rates in other greenhouse and rhizotron experiments (Dučić et al., 2009; Reich et al., 2009; Winkler et al., 2010) when compared to field data (Leuschner et al., 2004; Lang et al., 2011). Low EMF colonization rate and a stronger depletion of $\delta^{13} \mathrm{C}$ of PLFA $18: 2 \omega 6,9$ in B+ rhizotrons point to SOM decomposition suggesting that saprotrophic rather than EM fungi increased in beech rhizotrons as fine root tips and mycorrhiza were shown to have relatively similar signatures, whereas soil is stronger depleted in $\delta^{13} \mathrm{C}$ (Eissfeller et al., in press). We therefore suggest saprotrophic fungi to substantially contribute to changes in the fungal PLFA marker.

Combined data on PLFAs, soil properties and microbial respiration revealed high similarity of beech and mixed rhizotrons in DFA with these differing significantly from ash and control rhizotrons. The fatty acids i17:0 and cy 17:0 contributed most to this separation, with lesser contribution by $\mathrm{pH}$ and fungal biomass. The fatty acid i17:0 is regarded as marker for gram-positive bacteria whereas cy 17:0 characterizes gram-negative bacteria, the former considered to dominate in microorganisms being present in bulk soil whereas the latter in rhizosphere soil processing labile root derived carbon (Söderberg et al., 2004; Paterson et al., 2007). The relative abundance of both was lowest in BB rhizotrons suggesting that both suffered from the presence of beech roots, presumably due to beech increasing the competitive strength of saprotrophic fungi.

\subsection{Changes in decomposition due to different tree species}

Hypothesis (2) assuming that litter decomposition is differentially affected by tree species was supported by our data. Generally, stable isotope values of the litter-soil mixture in ES decreased strongly during incubation. Ash litter is known to decompose fast; in the field it disappears entirely after two years (Jacob et al., 2009). High and constant temperatures within the climate chambers $\left(20^{\circ} \mathrm{C}\right)$ contributed to fast decomposition of the litter in the rhizotrons. Data on higher $q \mathrm{O}_{2}$ (this study) and higher cumulative heterotrophic $\mathrm{CO}_{2}$ production in beech as compared to ash rhizotrons (Fender et al., 2013) suggest an overall higher stimulation of litter decomposition in beech root affected soil, i.e., higher carbon loss due to microbial respiration. High $\mathrm{H}^{+}$concentrations have been shown to limit bacterial growth, while low concentrations limit fungal growth (Rousk et al., 2009). The fact that $q^{\mathrm{O}_{2}}$ increased whereas bacterial biomass did not change suggests that the metabolic costs of rhizosphere bacteria increased at least at the end of the experiment. Presumably, lower soil pH in beech rhizotrons decreased the efficiency of bacteria to use carbon for biomass production by increasing respiratory losses.

$\delta^{13} \mathrm{C}$ values in fungal and bacterial PLFAs were depleted most in $\mathrm{B}+$ rhizotrons suggesting that bacteria and fungi incorporated less litter carbon in presence of beech roots than of ash also indicating a faster turnover of litter carbon. Further, the more depleted $\delta^{13} \mathrm{C}$ values in fungi compared to beech fine roots suggest that fungal carbon originated from soil organic matter in beech rhizotrons, whereas higher $\delta^{13} \mathrm{C}$ values in bacteria rather suggest bacteria to depend on root-derived carbon as their signatures resembled that of beech fine roots (Bowling et al., 2008).

Several studies found plant species identity to have stronger effects than plant diversity (De Deyn et al., 2004; Hättenschwiler and Gasser, 2005; Ball et al., 2009), with certain plant species acting as key species (Jacob et al., 2009). The strong effect of beech in this study is mediated by roots whereas ash had no effect suggesting that rhizodeposition in ash is of minor importance. Despite this low rhizosphere changes ash incorporated more litter nitrogen than beech (Lang and Polle, 2011; Schulz et al., 2011); potentially, ash is more effective in exploiting resources from fast decomposing litter such as ash leaves or by virtue of the higher root biomass production of ash in our experiment. Notably, ash seedlings incorporated more litter ${ }^{15} \mathrm{~N}$ than beech seedlings supporting the conclusion that the reduced $\mathrm{N}_{\text {total }}$ in $\mathrm{B}+$ rhizotrons was due to increased SOM decomposition and not due to plant uptake by beech. Notably, the uptake of ${ }^{15} \mathrm{~N}$ declined in mixture with ash. This corresponds to field observations where the $\mathrm{N}$ concentrations in ash declined in mixtures with other tree species and their ectomycorrhizal diversity (Lang and Polle, 2011). A higher uptake of $\mathrm{N}$ by ash roots was also found in a ${ }^{15} \mathrm{~N}$ tracer study in the Hainich forest where ash fine roots showed a significantly higher massspecific uptake of labeled $\mathrm{NH}_{4}^{+}$and glycine (but not of $\mathrm{NO}_{3}^{-}$) than beech roots (A. Jacob, unpubl. results).

\subsection{Channeling of litter-derived carbon into higher trophic levels}

Hypothesis (3) assuming that mixing of both tree species beneficially affects microorganisms thereby stimulating carbon turnover is supported in part by our data. Generally, mixing of tree species increased plant biomass, fine root tips, SRA, SRL and mycorrhizal colonization especially that of beech seedlings but did not affect soil chemistry and microbial biomass. However, soil chemistry and microbial data are point measures and do not reflect fluxes over the whole period of the experiment. As the plants are sinks for resources made available over the whole experimental time higher plant growth in mixed rhizotrons suggests that the gross flux of resources was greater in mixed rhizotrons.

Isotope analyses of food web components are a net measure over the long experimental period. Here, we measured $\delta^{13} \mathrm{C}$ and $\delta^{15} \mathrm{~N}$ being incorporated within the predatory mite H. aculeifer. $\delta^{13} \mathrm{C}$ and $\delta^{15} \mathrm{~N}$ values of $H$. aculeifer were significantly increased in mixed and ash rhizotrons suggesting that more litter-derived carbon and nitrogen entered basal species of the soil food web which served as prey for gamasid mites, such as nematodes and collembolans feeding on bacteria and fungi. In contrast, in control and beech rhizotrons $\delta^{13} \mathrm{C}$ values of $H$. aculeifer resembled those in Hainich beech forests $\left(\delta^{13} \mathrm{C}:-23.9 \pm 0.76 \% ; \delta^{15} \mathrm{~N}:+2.0 \pm 2.11 \%\right.$; Klarner et al., 2013) suggesting low incorporation of litter-derived carbon 
(and nitrogen) into the prey of $H$. aculeifer. However, the turnover of belowground $C$ in unplanted soil, i.e., the control, was numerously shown to be lower compared to planted soil (Kuzyakov, 2010; Bird et al., 2011), i.e., soil with beech trees. Low incorporation of litter resources in $\mathrm{BB}$ rhizotrons may point to the fast decomposition of ash litter and to the dominance of root derived resources as basis of the soil animal food web in beech forests as suggested earlier (Pollierer et al., 2007). Of course, measurements of a single species, i.e., $H$. aculeifer, do not allow to predict carbon and nitrogen cycling through the whole soil food web. However, since the soil fauna composition within the rhizotrons did not differ, we suggest tree species to significantly affect the amount and the way carbon is channeled through the soil food web.

\section{Conclusions}

The results suggest that the effect of living roots on litter decomposition, SOM dynamics and energy channels varies with tree species identity. Rhizodeposits have the potential to change soil $\mathrm{pH}$ with the potential to affect the metabolic activity of microorganisms. This propagates to higher trophic levels as tree species can impact the amount of litter-derived resource entering the soil food web and on energy channels. Effects of living roots are notoriously understudied and have to be included into studies on soil $C$ dynamics to understand carbon and nutrient cycling as well as soil food web functioning of forests.

\section{Acknowledgments}

We thank Dr. Lars Köhler and Dr. Heinz Coners for technical support and Martin Blumberg for GC-MS measurements. This study was funded by the Ministry of Science and Culture of Lower Saxony and the 'Niedersächsisches Vorab' as part of the Cluster of Excellence 'Functional Biodiversity Research'. We thank two anonymous reviewers for their comments which considerably improved our work.

\section{Appendix A. Supplementary data}

Supplementary data related to this article can be found at http:// dx.doi.org/10.1016/j.soilbio.2013.02.003.

\section{References}

Aciego Pietri, J.C., Brookes, P.C., 2008. Relationships between soil pH and microbial properties in a UK arable soil. Soil Biology and Biochemistry 40, 1856-1861.

Anderson, J.P.E., Domsch, K.H., 1978. A physiological method for the quantitative measurement of microbial biomass in soils. Soil Biology and Biochemistry 10, 215-221.

Ball, B.A., Bradford, M.A., Coleman, D.C., Hunter, M.D., 2009. Linkages between below and aboveground communities: decomposer responses to simulated tree species loss are largely additive. Soil Biology and Biochemistry 41, 1155-1163.

Beck, T., Joergensen, R.G., Kandeler, E., Makeschin, E., Nuss, E., Oberholzer, H.R., Scheu, S., 1997. An inter-laboratory comparison of ten different ways of measuring soil microbial biomass C. Soil Biology and Biochemistry 29, 1023-1032.

Bird, J.A., Herman, D.J., Firestone, M.K., 2011. Rhizosphere priming of soil organic matter by bacterial groups in a grassland soil. Soil Biology and Biochemistry 43 , $718-725$.

Bowling, D.R., Pataki, D.E., Randerson, J.T., 2008. Carbon isotopes in terrestrial ecosystem pools and $\mathrm{CO}_{2}$ fluxes. New Phytologist 178, 24-40.

Broadmeadow, M., Ray, D., 2005. Climate Change and British Woodland. Forestry Commission Information Note 69.

Butler, J.L., Bottomley, P.J., Griffith, S.M., Myrold, D.D., 2004. Distribution and turnover of recently fixed photosynthate in ryegrass rhizospheres. Soil Biology and Biochemistry 36, 371-382.

De Deyn, G.B., Raaijmakers, C.E., Ruijven, J.V., Berendse, F., van der Putten, W.H., 2004. Plant species identity and diversity effects on different trophic levels of nematodes in the soil food web. Oikos 106, 576-586.
Dučić, T., Berthold, D., Langenfeld-Heyser, R., Beese, F., Polle, A., 2009. Mycorrhizal communities in relation to biomass production and nutrient use efficiency in two varieties of Douglas fir (Pseudotsuga menziesii var. menziesii and var. glauca) in different forest soils. Soil Biology and Biochemistry 41, 742-753.

Edgar, R.C., 2010. Search and clustering orders of magnitude faster than BLAST. Bioinformatics 26, 2460-2461.

Eissfeller, V., Beyer, F., Valtanen, K., Hertel, D., Maraun, M., Polle, A., Scheu, S. Incorporation of plant carbon and microbial nitrogen into the rhizosphere food web of beech and ash. Soil Biology and Biochemistry, in press.

Emborg, J., 1998. Understorey light conditions and regeneration with respect to the structural dynamics of a near-natural temperate deciduous forest in Denmark. Forest Ecology and Management 106, 83-95.

Fender, A.-C., Gansert, D., Jungkunst, H.F., Fiedler, S., Beyer, F., Schützenmeister, K., Thiele, B., Valtanen, K., Polle, A., Leschner, C., 2013. Root-induced tree species effects on the source/sink strength for greenhouse gases $\left(\mathrm{CH}_{4}, \mathrm{~N}_{2} \mathrm{O}\right.$ and $\left.\mathrm{CO}_{2}\right)$ of a temperate deciduous forest soil. Soil Biology and Biochemistry, http:// dx.doi.org/10.1016/j.soilbio.2012.08.004.

Frostegärd, Â., Tunlid, A., Bääth, E., 1991. Microbial biomass measured as total lipid phosphate in soils of different organic content. Journal of Microbiological Methods 4, 151-163.

Frostegård, Å., Tunlid, A., Bååth, E., 2011. Use and misuse of PLFA measurements in soils. Soil Biology and Biochemistry 43, 1621-1625.

Gartner, T.B., Cardon, Z.G., 2004. Decomposition dynamics in mixed-species leaf litter. Oikos 104, 230-246.

Gessner, M.O., Swan, C.M., Dang, C.K., McKie, B.G., Bardgett, R.D., Wall, D.H., Hättenschwiler, S., 2010. Diversity meets decomposition. Trends in Ecology \& Evolution 25, 372-380

Grayston, S.J., Wang, S., Campbell, C.D., Edwards, A.C., 1998. Selective influence of plant species on microbial diversity in the rhizosphere. Science 30, 369-378.

Gregory, P.J., 2006. Roots, rhizosphere and soil: the route to a better understanding of soil science? European Journal of Soil Science 57, 2-12.

Grime, J.P., Thompson, K., Hunt, R., Hodgson, J.G., Cornelissen, J.H.C., Rorison, I.H., Hendry, G.A.F., Ashenden, T.W., Askew, A.P., Band, S.R., Booth, R.E., Bossard, C.C., Campbell, B.D., Cooper, J.E.L., Davison, A.W., Gupta, P.L., Hall, W., Hand, D.W. Hannah, M.A., Hillier, S.H., Hodkinson, D.J., Jalili, A., Liu, Z., Mackey, J.M.L., Matthews, N., Mowforth, M.A., Neal, A.M., Reader, RJ. Reiling, K., RossFraser, W., Spencer, R.E., Sutton, F., Tasker, D.E., Thorpe, P.C., Whitehouse, J., 1997 Integrated screening validates primary axes of specialisation in plants. Oikos 79 259-281.

Hansen, K., Vesterdal, L., Schmidt, I.K., Gundersen, P., Sevel, L., Bastrup-Birk, A. Pedersen, L.B., Bille-Hansen, J., 2009. Litterfall and nutrient return in five tree species in a common garden experiment. Forest Ecology and Management 257, 2133-2144.

Hobbie, S.E., Reich, P.B., Oleksyn, J., Ogdahl, M., Zytkowiak, R., Hale, C., Karolewski, P., 2006. Tree species effects on decomposition and forest floor dynamics in a common garden. Ecology 87, 2288-2297.

Holzwarth, F.M., Daenner, M., Flessa, H., 2011. Effects of beech and ash on smallscale variation of soil acidity and nutrient stocks in a mixed deciduous forest. Journal of Plant Nutrition and Soil Science 174, 799-808.

Hättenschwiler, S., Gasser, P., 2005. Soil animals alter plant litter diversity effects on decomposition. Proceedings of the National Academy of Sciences of the United States of America 102, 1519-1524.

Hättenschwiler, S., Tiunov, A.V., Scheu, S., 2005. Biodiversity and litter decomposition in terrestrial ecosystems. Annual Review of Ecology, Evolution, and Systematics 36, 191-218.

Jacob, M., Viedenz, K., Polle, A., Thomas, F.M., 2010. Leaf litter decomposition in temperate deciduous forest stands with a decreasing fraction of beech (Fagus sylvatica). Oecologia 164, 1083-1094.

Jacob, M., Weland, N., Platner, C., Schaefer, M., Leuschner, C., Thomas, F.M., 2009. Nutrient release from decomposing leaf litter of temperate deciduous forest trees along a gradient of increasing tree species diversity. Soil Biology and Biochemistry 41, 2122-2130.

Jones, D.L., Hodge, A., Kuzyakov, Y., 2004. Plant and mycorrhizal regulation of rhizodeposition. New Phytologist 163, 459-480.

Kaiser, C., Frank, A., Wild, B., Koranda, M., Richter, A., 2010. Negligible contribution from roots to soil-borne phospholipid fatty acid fungal biomarkers 18:2w6,9 and 18:1w9. Soil Biology and Biochemistry 42, 1650-1652.

Kempson, D., Lloyd, M., Ghelardi, R., 1963. A new extractor for woodland litter. Pedobiologia 3, 1-21.

Klarner, B., Maraun, M., Scheu, S., 2013. Trophic diversity and niche partitioning in species rich predator guild - natural variations in stable isotope ratios $\left({ }^{13} \mathrm{C} /{ }^{12} \mathrm{C}\right.$, ${ }^{15} \mathrm{~N} /{ }^{14} \mathrm{~N}$ ) of mesostigmatid mites (Acari, Mesostigmata) from Central European beech forests. Soil Biology and Biochemistry, http://dx.doi.org/10.1016/ j.soilbio.2012.08.013.

Kuzyakov, Y., 2010. Priming effects: interactions between living and dead organic matter. Soil Biology and Biochemistry 42, 1363-1371.

Lang, C., Seven, J., Polle, A., 2011. Host preferences and differential contributions of deciduous tree species shape mycorrhizal species richness in a mixed Central European forest. Mycorrhiza 21, 297-308.

Lang, C., Polle, A., 2011. Ectomycorrhizal fungal diversity, tree diversity and root nutrient relations in a mixed Central European forest. Tree Physiology 31, 531-538.

Langenbruch, C., Helfrich, M., Flessa, H., 2012. Effects of beech (Fagus sylvatica), ash (Fraxinus excelsior) and lime (Tilia spec.) on soil chemical properties in a mixed deciduous forest. Plant and Soil 352, 389-403. 
Lehmann, J., 2003. Subsoil root activity in tree-based cropping systems. Plant and Soil 255, 319-331.

Leuschner, C., Hertel, D., Schmid, I., Koch, O., Muhs, A., Hölscher, D., 2004. Stand fine root biomass and fine root morphology in old-growth beech forests as a function of precipitation and soil fertility. Plant and Soil 258, 43-56.

McGonigle, T.P., Millers, M.H., Evans, D.G., Fairchild, G.L., Swan, J.A., 1990. A new method which gives an objective measure of colonization of roots by vesiculararbuscular mycorrhizal fungi. New Phytologist 115, 495-501.

McKinley, D.C., Ryan, M.G., Birdsey, R.A., Giardina, C.P., Harmon, M.E., Heath, L.S. Houghton, R.A., Jackson, R.B., Morrison, J.F., Murray, B.C., Pataki, D.E., Skog, K.E., 2011. A synthesis of current knowledge on forests and carbon storage in the United States. Ecological Applications 21, 1902-1924.

Meinen, C., Hertel, D., Leuschner, C., 2009. Biomass and morphology of fine roots in temperate broad-leaved forests differing in tree species diversity: is there evidence of below-ground overyielding? Oecologia 161, 99-111.

Nacke, H., Thürmer, A., Wollherr, A., Will, C., Hodac, L., Herold, N., Schöning, I, Schrumpf, M., Daniel, R., 2011. Pyrosequencing-based assessment of bacterial community structure along different management types in German forest and grassland soils. PloS One 6, e17000.

Neumann, G., Römheld, V., 1999. Root excretion of carboxylic acids and protons in phosphorus-deficient plants. Plant and Soil 211, 121-130.

Olsson, P.A., Johansen, A., 2000. Lipid and fatty acid composition of hyphae and spores of arbuscular mycorrhizal fungi at different growth stages. Mycological Research 104, 429-434.

Paterson, E., Gebbing, T., Abel, C., Sim, A., Telfer, G., 2007. Rhizodeposition shapes rhizosphere microbial community structure in organic soil. New Phytologist $173,600-610$

Paterson, E., Midwood, A.J., Millard, P., 2009. Through the eye of the needle: a review of isotope approaches to quantify microbial processes mediating soi carbon balance. New Phytologist 184, 19-33.

Pollierer, M.M., Langel, R., Körner, C., Maraun, M., Scheu, S., 2007. The underestimated importance of belowground carbon input for forest soil animal food webs. Ecology Letters 10, 729-736.

Reeder, J., Knight, R., 2010. Rapidly denoising pyrosequencing amplicon reads by exploiting rank abundance distributions. Nature Methods 7, 668-669.

Reich, M., Göbel, C., Kohler, A., Buée, M., Martin, F., Feussner, I., Polle, A., 2009. Fatty acid metabolism in the ectomycorrhizal fungus Laccaria bicolor. New Phytologist 182, 950-964.

Reich, P.B., Oleksyn, J., Modrzynski, J., Mrozinski, P., Hobbie, S.E., Eissenstat, D.M., Chorover, J., Chadwick, O.A., Hale, C.M., Tjoelker, M.G., 2005. Linking litter calcium, earthworms and soil properties: a common garden test with 14 tree species. Ecology Letters 8, 811-818.

Rousk, J., Brookes, P.C., Bååth, E., 2009. Contrasting soil pH effects on fungal and bacterial growth suggest functional redundancy in carbon mineralization. Applied and Environmental Microbiology 75, 1589-1596.
Ruess, L., Chamberlain, P.M., 2010. The fat that matters: soil food web analysis using fatty acids and their carbon stable isotope signature. Soil Biology and Biochemistry 42, 1898-1910.

Scheu, S., 1992. Automated measurement of the respiratory response of soil microcompartments: active microbial biomass in earthworm faces. Soil Biology and Biochemistry 24, 1113-1118.

Schlesinger, W.H., Andrews, J.A., 2000. Soil respiration and the global carbon cycle. Biogeochemistry 48, 7-20.

Schloss, P.D., Handelsman, J., 2005. Introducing DOTUR, a computer program for defining operational taxonomic units and estimating species richness. Applied and Environmental Microbiology 71, 1501-1506.

Schmalenberger, A. Schwieger, F., Tebbe, C., 2001. Effect of primers hybridizing to different evolutionarily conserved regions of the small-subunit rRNA Gene in PCR-based microbial community analyses and genetic profiling. Applied and Environmental Microbiology 67, 3557-3563.

Schulz, H., Härtling, S., Stange, C.F., 2011. Species-specific differences in nitrogen uptake and utilization by six European tree species. Journal of Plant Nutrition and Soil Science 174, 28-37.

Schmitz, O., Danneberg, G., Hundeshagen, B., Klinger, A., Bothe, H., 1991. Quantification of vesicular-arbuscular mycorrhiza by biochemical parameters. Journal of Plant Physiology 139, 104-114.

Smith, S., Read, D.J., 2008. Mycorrhizal Symbiosis. Academic Press, Cambridge, UK. Steinbeiss, S., Befller, H., Engels, C., Temperton, V.M., Buchmann, N., Roscher, C. Kreutziger, Y., Baade, J., Habekost, M., Gleixner, G., 2008. Plant diversity positively affects short-term soil carbon storage in experimental grasslands. Global Change Biology 14, 2937-2949.

Swift, M.J., Heal, O.W., Anderson, J.M., 1979. Decomposition in Terrestrial Ecosystems. University of California Press, Berkeley.

Söderberg, K.H., Probanza, A., Jumpponen, A., Bååth, E., 2004. The microbial community in the rhizosphere determined by community-level physiological profiles (CLPP) and direct soil- and cfu-PLFA techniques. Applied Soil Ecology 25, 135-145.

Wardle, D.A., 1998. Review controls of temporal variability of the soil microbial biomass: a global-scale synthesis. Soil Biology and Biochemistry 30, 1867-1878.

Weber-Blaschke, G., Claus, M., Rehfuss, K.E, 2002. Growth and nutrition of ash (Fraxinus excelsior L.) and sycamore (Acer pseudoplatanus L.) on soils of different base saturation in pot experiments. Forest Ecology and Management 167, 43-56.

Winkler, J.B., Dannenmann, M., Simon, J., Pena, R., Offermann, C., Sternad, W. Clemenz, C., Naumann, P.S., Gasche, R., Kögel-Knabner, I., Gessler, A. Rennenberg, H., Polle, A., 2010. Carbon and nitrogen balance in beech roots under competitive pressure of soil-borne microorganisms induced by girdling, drought and glucose application. Functional Plant Biology 37, 879-889. 


\subsection{Supplementary data}

Table S1 Atom\% values of the used soil, labeled ash litter and of the soil-litter mixture in experimental sites at the start of the experiment and at the end after 422 days of litter incubation (means $\pm 1 \mathrm{SE}$ ). Soil, litter and the soil-litter mixture samples at the start were replicated $n=5$, whereas soil-litter mixture samples of the end were pooled across all treatments $(\mathrm{n}=16)$.

Table S2 Means \pm 1 SE of atom\% values of plant parameters influenced by beech (B) and ash (A) in rhizotrons after 475 days $(n=4)$.

Table S3 Means \pm 1 SE of atom\% values of soil C and N, PLFA and gamasid mites as influenced by beech (B) and ash (A) in rhizotrons after 475 days $(n=4)$.

Table S4. ANOVA table of $F$ - and $P$-values as well as means \pm 1 SE for soil animal taxa extracted by heat from rhizotrons influenced by beech (B) and ash (A) after 475 days $(n=4)$. Means refer to densities in the middle part of the microcosms. 


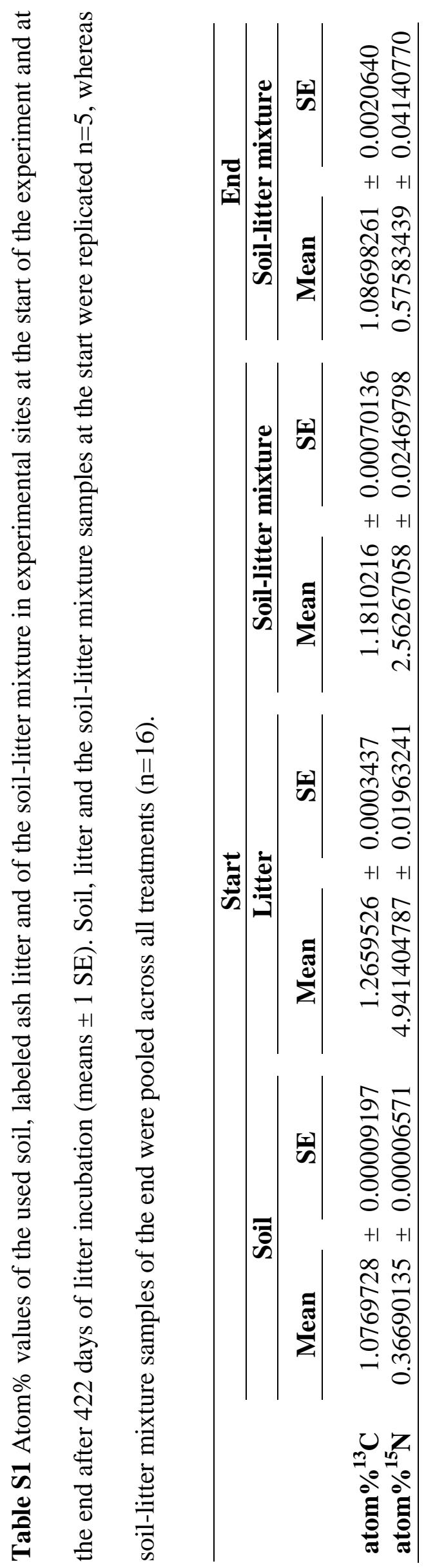




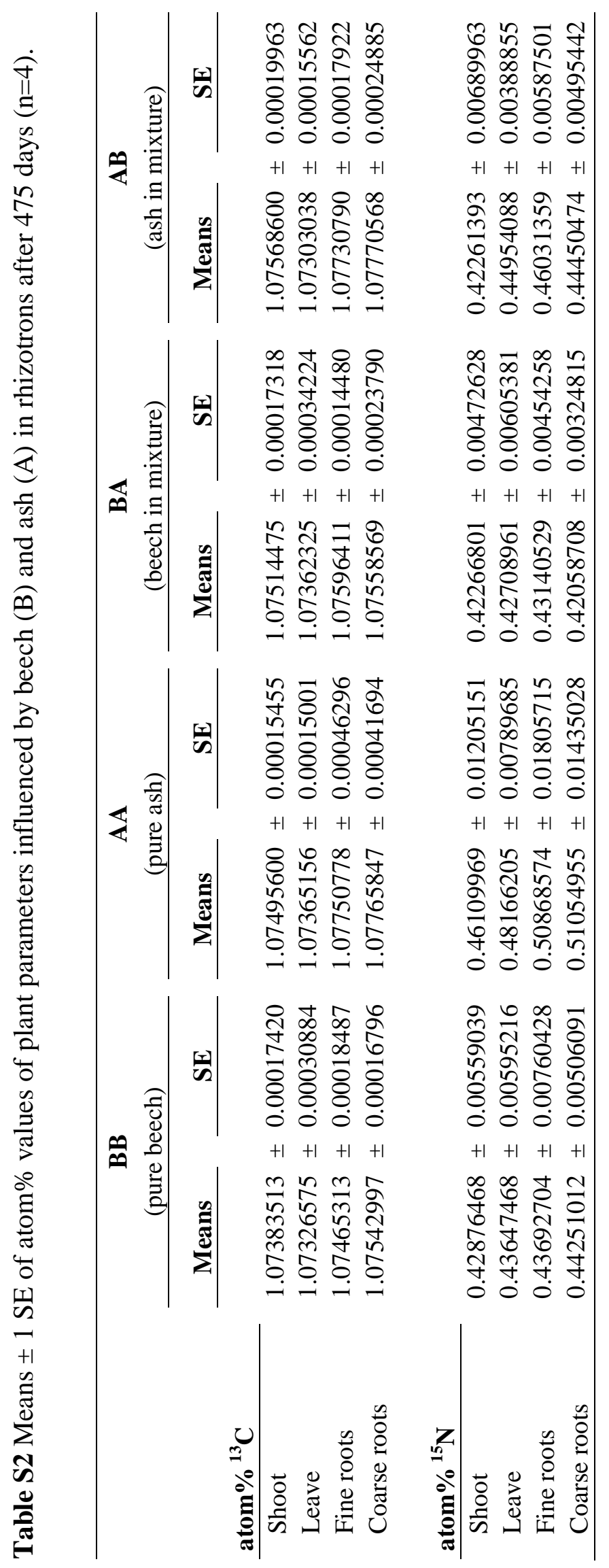




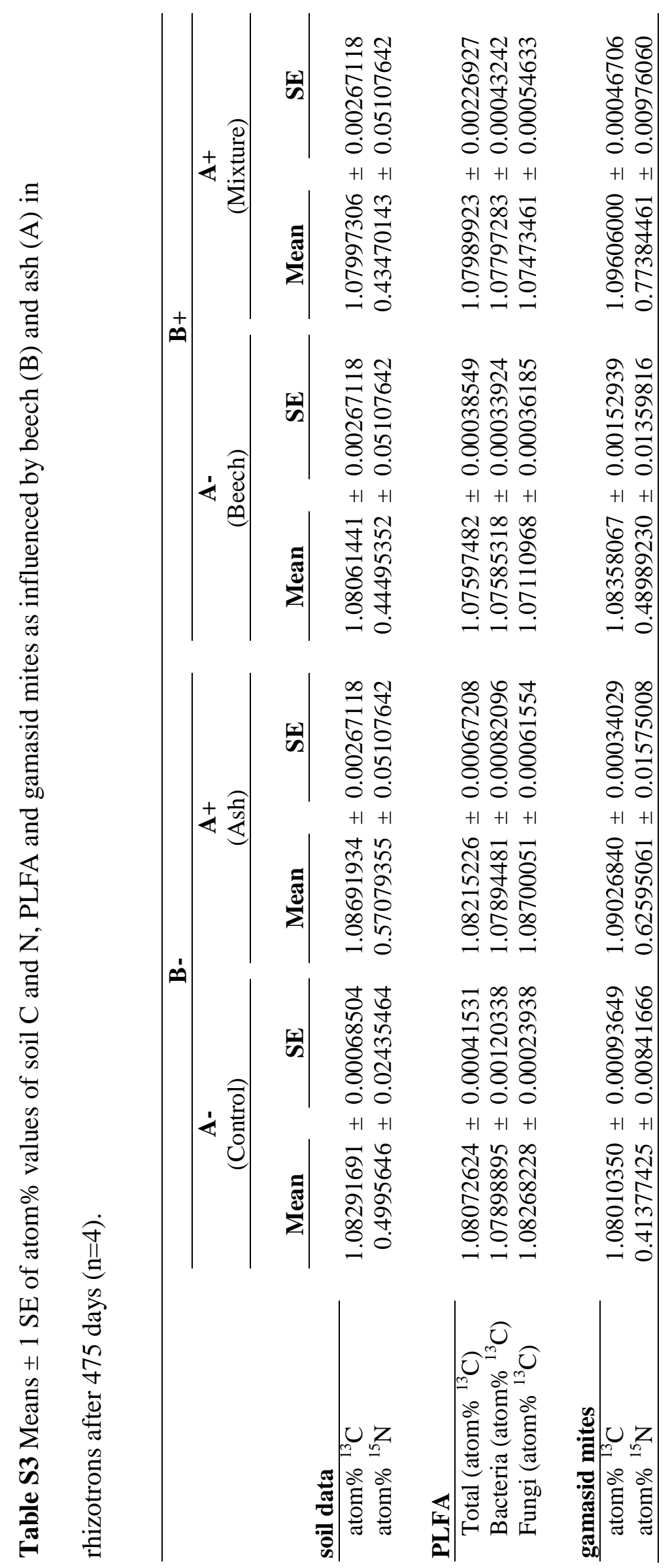




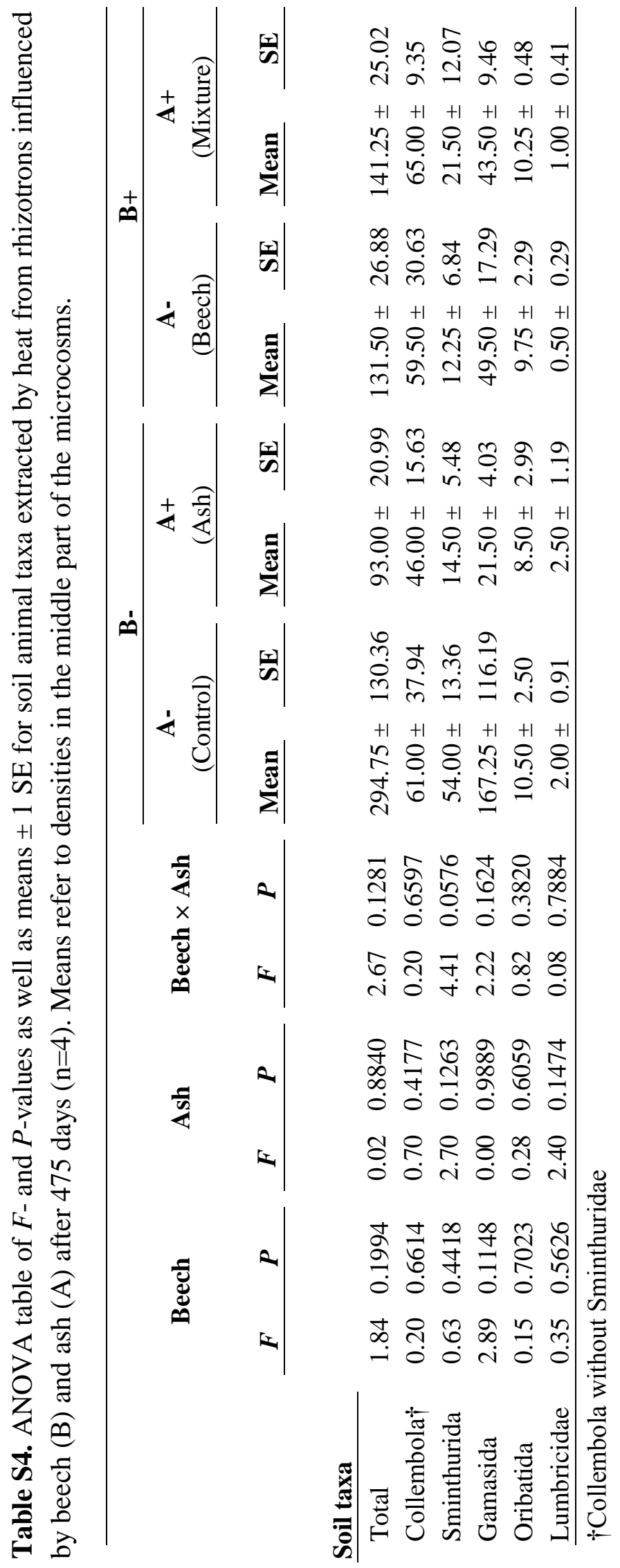


3.

\title{
Tree effects on diversity and structure of soil bacterial and fungal communities
}

\author{
Kezia Goldmann ${ }^{1} \uparrow$, Heiko Nacke ${ }^{2} \dagger$, Ingo Schöning ${ }^{3} \dagger$, Birgit Pfeiffer ${ }^{2}$, Kristin Kaiser $^{2}$, \\ G. Castillo-Villamizar ${ }^{2}$, Tesfaye Wubet ${ }^{3}$, Marion Schrumpf ${ }^{3}$, François Buscot ${ }^{1}$, Rolf \\ Daniel $^{2,4}$
}

Manuscript draft

${ }^{1)}$ Department of Soil Ecology, UFZ-Helmholtz Centre for Environmental Research, Halle

${ }^{2)}$ Department of Genomic and Applied Microbiology, Institute of Microbiology and Genetics, Georg-August University Göttingen

${ }^{3)}$ Max Planck Institute for Biogeochemistry, Jena

4) Göttingen Genomics Laboratory, Institute of Microbiology and Genetics, GeorgAugust University Göttingen

$\dagger$ K. G., H. N. and I. S. contributed equally to this work.

\section{Author contributions to the work:}

Performed the experiments: K. Goldmann, H. Nacke, I. Schöning, B. Pfeiffer, K. Kaiser, G. Castillo-Villamizar, T. Wubet

Analyzed the data: K. Goldmann, H. Nacke, I. Schöning, B. Pfeiffer, K. Kaiser, G. Castillo-Villamizar, T. Wubet

Wrote the paper: $\quad$ K. Goldmann, H. Nacke, I. Schöning, R. Daniel, M. Schrumpf, F. Buscot

Conceived and designed the experiments: M. Schrumpf, F. Buscot, R. Daniel 


\section{Introduction}

Soil physical, chemical and biological properties can be altered by tree species-specific litter, root exudates and nutrient uptake (Priha and Smolander, 1999; Augusto et al., 2002; Ayres et al., 2009; Cesarz et al., 2013). It has been indicated that different tree species such as Fagus sylvatica L. (European beech) and Picea abies L. (Norway spruce) can directly or indirectly (e.g., by modification of soil characteristics) evoke soil microbial community shifts (Lejon et al., 2005; Thoms et al., 2010; Nacke et al., 2011). Nevertheless, a number of available studies aiming to describe drivers of soil microbial diversity and community structure focused on impacts of agricultural plants, whereas effects of tree species have been rarely explored (Priha and Smolander, 1997; AcostaMartínez et al., 2008; Haichar et al., 2008; Li et al., 2012; Wubet et al., 2012).

Beech and Norway spruce represent dominant trees in European forests and exhibit high commercial importance (Cesarz et al., 2013; Hanewinkel et al., 2013). Since the 19th century planting of Norway spruce to reforest devastated forest sites in Central Europe was very common (Berger and Berger, 2012). It has been reported that replacement of beech by spruce species is associated with changes in soil structure, acidity and humus form (e.g., Berger and Berger, 2012). The constitution as well as decomposability of leaf and needle litter originating from these broad-leaved and coniferous tree species, respectively, varies significantly (Priha and Smolander, 1997). Needle litter waxes and phenolic compounds are highly recalcitrant towards biological degradation, whereas leaf litter contains higher amounts of more easily decomposable substances (Nykvist, 1963; Priha and Smolander, 1997). Furthermore, root system and exudation differs significantly between beech and spruce species. Spruce is typically shallow rooted, whereas beech is able to acquire nutrients from a wide range of soil horizons through its deep root system (so called 'base-pump'). The root exudates released by these trees can vary seasonally in quantity as well as in composition (Geßler et al., 1998) thereby influencing the microbial community structure.

To evaluate the importance of beech and spruce in shaping forest ecosystem characteristics, an improved knowledge about the impacts of these trees is required. Currently, detailed information on soil bacterial and fungal community composition and the factors shaping it in beech and spruce dominated forests is lacking. In many previous studies, methods providing coarse phylogenetic information were used to identify effects of tree species on soil microbial communities. Differences in genetic structures of soil bacterial and fungal communities in spruce, Douglas-fir, oak and 
beech plots in France were indicated by automated ribosomal intergenic spacer analysis (ARISA) profiles (Lejon et al., 2005). Furthermore, Jiang et al. (2012) found distinct bacterial and fungal communities in soil beneath broad-leaved and coniferous species based on DGGE profiles. To unravel statistically significant effects of tree species, sampling distance from the tree trunk at different soil depth, and season on the diversity and composition of groups of ecologically important soil bacteria and fungal communities the use of high throughput sequencing methods is required. Thus in this study, we applied pyrosequencing of the V3-V5 16S and the ITS rRNA gene region to assess diversity as well as structure of soil bacterial and fungal communities, respectively, under Fagus sylvatica L. and Picea abies L. These marker genes have been chosen, as they allow a taxonomic resolution up to the genus level (Wubet et al. 2012; Schneider et al., 2013). 


\section{Materials and Methods}

\section{Sampling, soil properties and DNA extraction}

All soil samples were derived from forest sites located within the German Biodiversity Exploratory Hainich-Dün (Fischer et al., 2010). The effects of Fagus sylvatica L. and Picea abies L. on soil bacterial and fungal communities within samples from 4 transects per tree species were analyzed. Mineral soil samples were collected in 0-10 cm and 10$20 \mathrm{~cm}$ depth using split tubes with a diameter of $5 \mathrm{~cm}$ (Eijkelkamp Agrisearch Equipment, Giesbeck, Netherlands). Samples were taken in a distance of $0.5 \mathrm{~m}, 1.5 \mathrm{~m}$, $2.5 \mathrm{~m}$ and $3.5 \mathrm{~m}$ away from the trunks of the selected trees. This allows the identification of potential gradients in bacterial and fungal community structure and diversity within the tree crown. The life cycle of microbes inhabiting forest soil can be strongly affected by seasons through changes in abiotic and biotic factors (Thoms et al., 2013). Therefore, sampling was performed within two seasons, early summer and autumn. Subsequently, a total of 128 composite soil samples (derived from two seasons, eight trees, four sampling distances and two soil depths), were sieved (2-4 mm mesh size), homogenized and subsamples were frozen for nucleic acids extraction.

An aliquot of $50 \mathrm{~g}$ fresh soil was used for $\mathrm{pH}$ and $\mathrm{CN}$ analysis. The aliquots were airdried and sieved to $<2 \mathrm{~mm}$ in order to isolate the fine earth, which is free of coarse stones and roots. The $\mathrm{pH}$ was measured in duplicate with a glass electrode in the supernatant of 1:2.5 mixtures of soil and $0.01 \mathrm{M} \mathrm{CaCl}_{2}$. The remaining soil was ground to $<100 \mu \mathrm{m}$. Ground samples were analyzed for total carbon and nitrogen by dry combustion with the $\mathrm{CN}$ analyzer 'Vario Max' (Elementar Analysensysteme GmbH, Hanau, Germany). Inorganic carbon (IC) concentrations were determined with the same analyzer after ignition of samples for 16 hours at $450^{\circ} \mathrm{C}$. The organic carbon concentrations equaled the differences between total carbon concentration and inorganic carbon concentration.

Total microbial community DNA was extracted from approximately $2 \mathrm{~g}$ of the frozen soil per sample by employing the PowerSoil total RNA isolation kit, the PowerSoil DNA elution accessory kit, and the PowerClean DNA Clean-Up kit (MoBio Laboratories, Carlsbad, CA, USA) according to the manufacturer's instruction. DNA concentrations were quantified by using a NanoDrop UV-Vis spectrophotometer (Peqlab Biotechnologie GmbH, Erlangen, Germany) according to the manufacturer's protocol. 
Amplification and pyrosequencing of partial 16S rRNA genes and ITS rDNA

The V3-V5 region of bacterial 16S rRNA genes was amplified by PCR. The PCR reaction mixture $(50 \mu \mathrm{l})$ contained $10 \mu \mathrm{l}$ fivefold reaction buffer (Phusion HF buffer, Thermo Fisher Scientific Inc., Germany), $200 \mu \mathrm{M}$ of each of the four deoxynucleoside triphosphates, 5\% DMSO, $1 \mathrm{U}$ Phusion high fidelity DNA polymerase (Thermo Fisher Scientific Inc.), approximately $25 \mathrm{ng}$ DNA as template, and $4 \mu \mathrm{M}$ of each of the primers. Primers used were 343F (Liu et al., 2007) containing a sample-specific MID (Extended Multiplex Identifier, size: ten nucleotides) and Roche 454 pyrosequencing adaptor A (underlined), and 907R (Cuesta Garrote et al., 2011) containing Roche 454 pyrosequencing adaptor B (underlined) (343F, 5'CCATCTCATCCCTGCGTGTCTCCGACTCAG-MID-TACGGRAGGCAGCAG-3'; 907R,

\section{CCTATCCCCTGTGTGCCTTGGCAGTCTCAGCCGTCAATTCMTTTGAGT-3').}

The PCR reactions were initiated at $98^{\circ} \mathrm{C}(2 \mathrm{~min})$, followed by 25 cycles of $98^{\circ} \mathrm{C}(45$ sec), $58^{\circ} \mathrm{C}(45 \mathrm{sec})$ and $72^{\circ} \mathrm{C}(40 \mathrm{sec})$, and ended with incubation at $72^{\circ} \mathrm{C}$ for $5 \mathrm{~min}$.

To produce fungal ITS rDNA amplicon libraries primer ITS1F (Gardes and Bruns, 1993) containing Roche 454 pyrosequencing adaptor B and a sample-specific MID, as well as primer ITS4 (White et al., 1990) containing Roche 454 pyrosequencing adaptor A have been used (see also Wubet et al., 2012). The PCR reactions were performed in a total volume of $50 \mu \mathrm{l}$ reaction mix containing $1 \mu \mathrm{l}$ DNA template (7-15 ng), $25 \mu \mathrm{l}$ Go Taq Green Master mix (Promega, Mannheim, Germany) and $1 \mu 125$ pmol of each of the ITS region-specific primers. Touchdown PCR conditions as described by Wubet et al. (2012) were used to amplify fungal ITS rDNA.

All samples were amplified in triplicate, purified using the peqGold gel extraction kit (Peqlab Biotechnologie $\mathrm{GmbH}$ ) and the Qiagen gel extraction kit (Qiagen, Hilden, Germany) as recommended by the manufacturer, and pooled in equal amounts. Quantification of PCR products was performed using the Quant-iT dsDNA BR assay kit and a Qubit fluorometer (Life Technologies GmbH, Karlsruhe, Germany). Sequences of partial 16S rRNA genes and fungal ITS rDNA were decoded at the Göttingen Genomics Laboratory and the Department of Soil Ecology (UFZ-Helmholtz Centre for Environmental Research, Halle, Germany), respectively, by using a Roche GS-FLX 454 pyrosequencer (Roche, Mannheim, Germany) and Titanium chemistry as recommended by the manufacturer. 


\section{Pyrosequencing data processing and analysis}

All generated sequences were reassigned to single samples based on the different MIDs. Quality filtering of 16S rRNA gene and ITS rDNA sequences was performed using QIIME (Caporaso et al., 2010) and mothur (version 1.29.2) (Schloss et al., 2009), respectively. Bacterial and fungal sequences shorter than 200 and $300 \mathrm{bp}$, respectively, as well as those exhibiting low quality values (bacteria, <25; fungi, <20) or long homopolymers (>8 bp) were removed. In addition, 16S rRNA gene and ITS rDNA sequences containing more than two and eight primer mismatches, respectively, were sorted out. Removal of pyrosequencing noise and potential chimeric sequences was performed using Acacia (Bragg et al., 2012) and UCHIME (Edgar et al., 2011), respectively. UCLUST (Edgar, 2010) and Cd-hit (version 4.5.4) (Li and Godzik, 2006) were applied to determine bacterial and fungal OTUs, respectively. To taxonomically classify OTUs, partial 16S rRNA gene sequences were compared with the SILVA SSU database release 111 (Pruesse et al., 2007) and ITS rDNA sequences were queried against the UNITE database for molecular identification of fungi (Abarenkov et al., 2010) using BLAST. Subsequently, the Shannon index (Shannon CE, 1948) as well as the Chao1 index (Chao and Bunge, 2002) were calculated.

\section{Statistical analyses}

Effects of tree species (Fagus sylvatica L. and Picea abies L.), sampling distance to the trunks of the selected trees, season, and soil properties on fungal and bacterial communities were identified using $\mathrm{R}$ packages based on relative abundances of the microbial taxa, OTUs and diversity indices. 


\section{Preliminary Results}

General characteristics of the soil samples and the pyrosequencing-derived dataset

Within this study, data on diversity and structure of bacterial and fungal communities present in 128 soil samples derived from the German Biodiversity Exploratory HainichDün (Fischer et al., 2010) has been gathered by applying pyrosequencing of 16S rRNA genes and the ITS region. Soil (0-10 and 10-20 cm depth) has been collected in two different periods of the year, early summer and autumn, under four Fagus sylvatica L. and Picea abies L. trees, respectively. The soils (soil type: luvisol) have been removed in varying sampling distance $(0.5 \mathrm{~m}, 1.5 \mathrm{~m}, 2.5 \mathrm{~m}$ and $3.5 \mathrm{~m})$ to the trunks of the eight selected trees.

Pyrosequencing of the V3-V5 region of bacterial 16S rRNA genes and fungal ITS rDNA yielded approximately $1,520,000$ and 480,000 reads, respectively. In a preliminary analysis of quality filtered sequencing data, diversity and community structure of soil bacteria and fungi within samples collected in autumn has been assessed. A total number of 13,600 and 791 bacterial and fungal operational taxonomic units (OTUs), respectively, were identified at a genetic distance of $3 \%$. The dominant bacterial phyla across all autumn samples were Acidobacteria (38\%), Proteobacteria (34\%), Actinobacteria (11\%), Chloroflexi (5\%), Gemmatimonadetes (4\%), Bacteroidetes (2\%), Nitrospirae (2\%) and Cyanobacteria (1\%). Soil fungi were dominated by the phyla Basidiomycota (48\%) and Ascomycota (36\%).

Community profiles of bacteria and fungi inhabiting beech and spruce surrounding soil Overall bacterial diversity as assessed by the Shannon index was, as expected, significantly higher than fungal diversity in soil beneath beech (Fagus sylvatica L.) and spruce (Picea abies L.) trees (Fig. 1). The fungal diversity within 10-20 cm soil depth was significantly higher at the spruce site compared to the beech forest (Fig. 1). Furthermore, overall bacterial and fungal diversity was largely driven by soil $\mathrm{pH}$ within spruce forest soil (Fig. 2). 


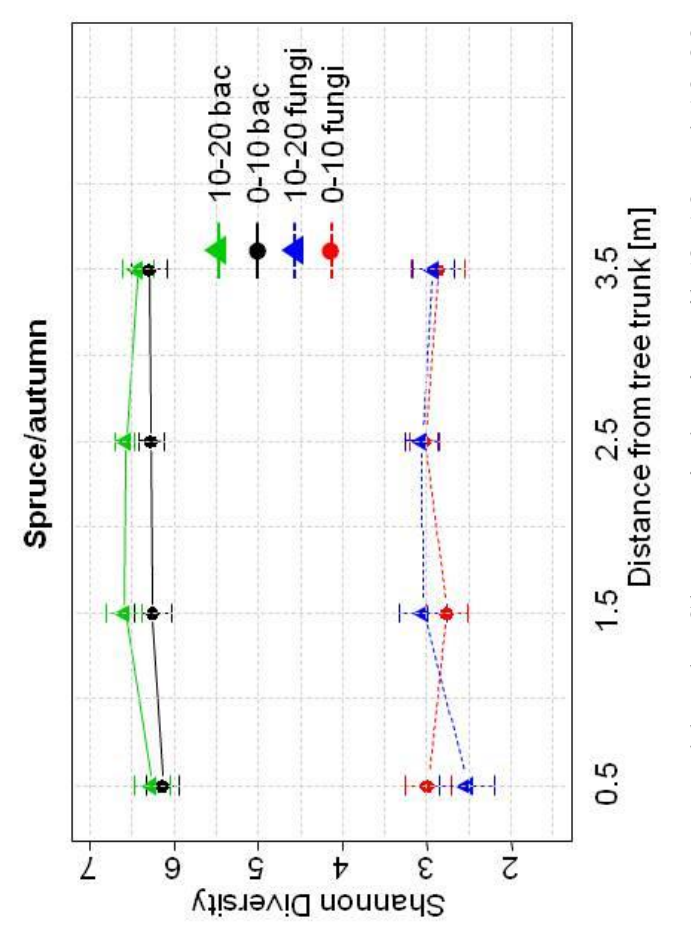

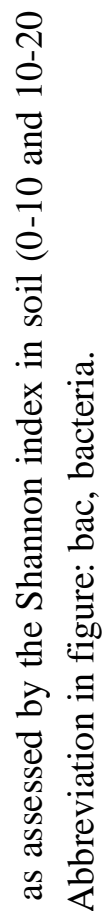

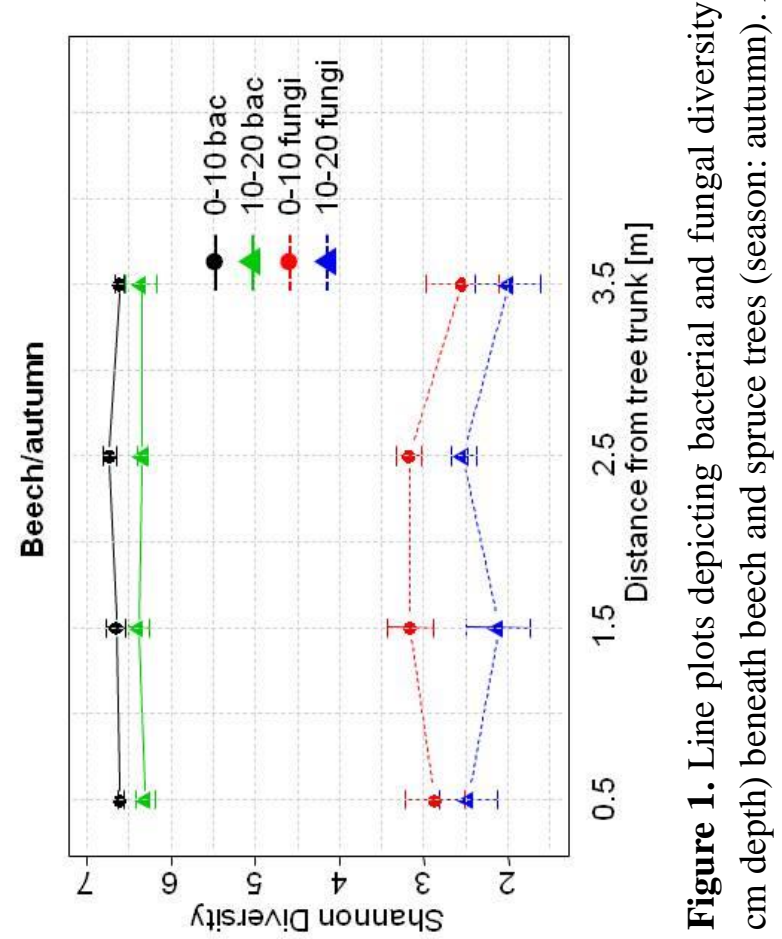



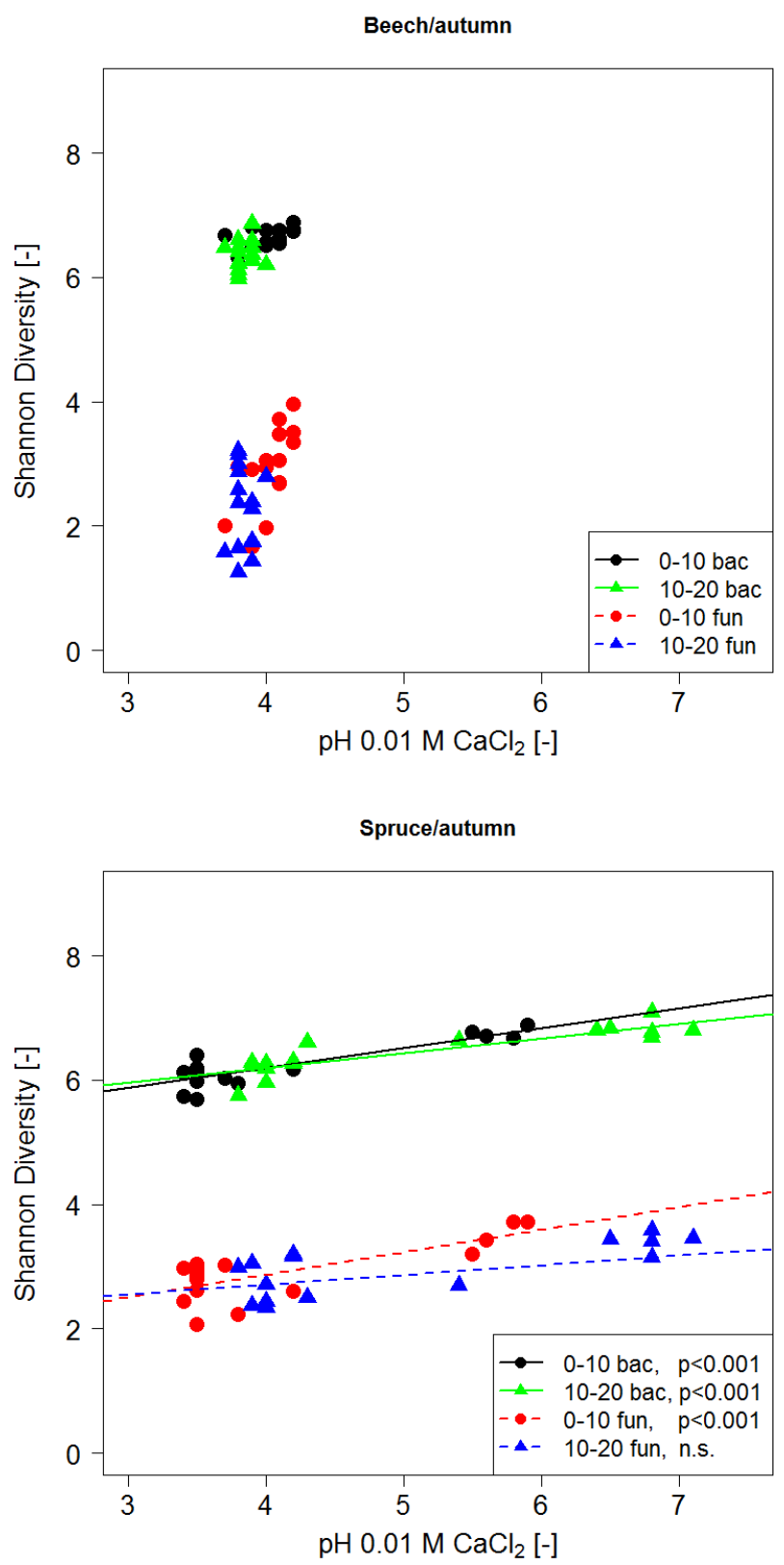

Figure 2. Correlations between $\mathrm{pH}$ and Shannon diversity in soil (0-10 and $10-20 \mathrm{~cm}$ depth) beneath beech and spruce trees (season: autumn). Abbreviations in figure: bac, bacteria; fun, fungi.

The comparison of OTUs determined in soil under Fagus sylvatica L. and Picea abies L. using Non-metric Multidimensional Scaling (NMDS) ordination analysis revealed a significant tree species impact on bacterial and fungal community composition $(P=$ 0.0001) (Fig. 3). 


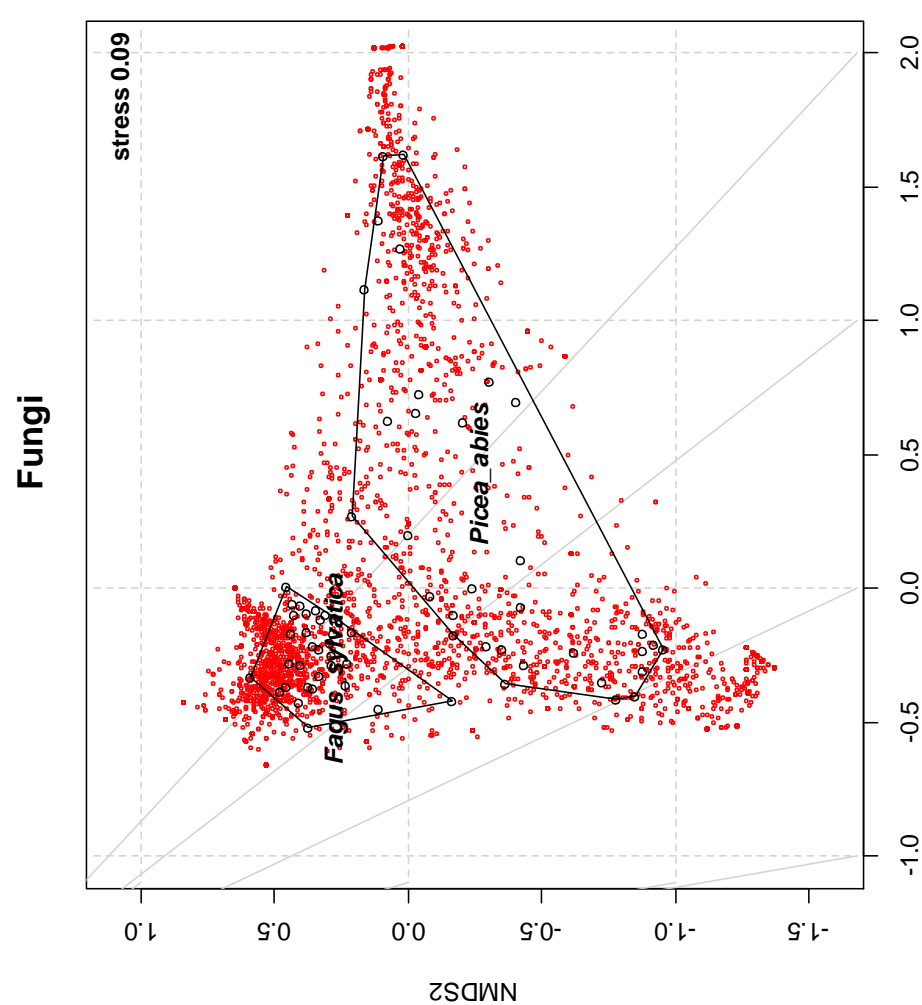

ฮ్

ㅇ.

4

我

8

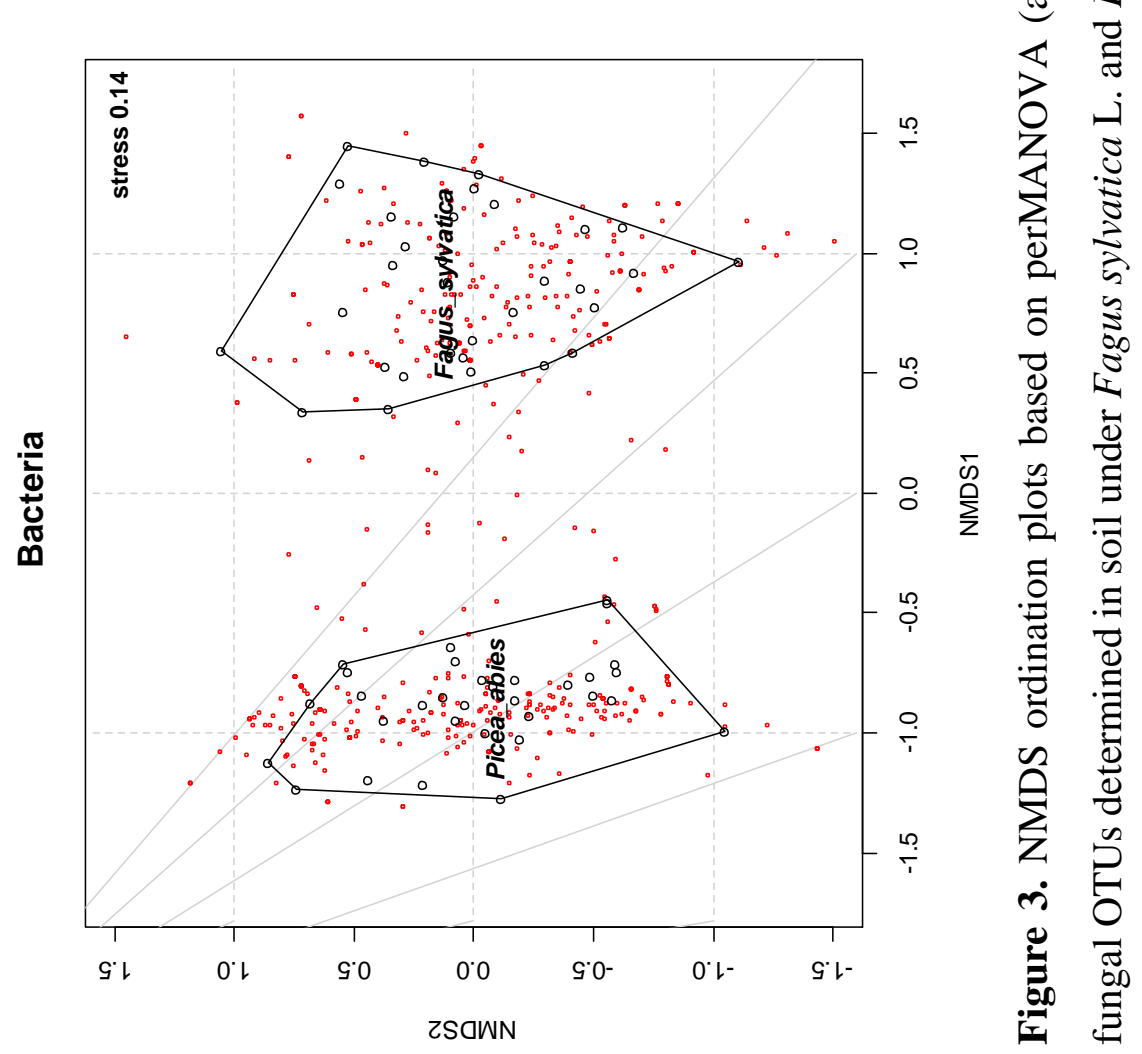




\section{Outlook}

Data derived from soil samples collected in early summer, comprising 16S rRNA gene and ITS sequences as well as soil characteristics, will be included to complete analysis of seasonal effects on bacterial and fungal diversity and community structure. A nucleic acids co-extraction method has been used to isolate DNA as well as RNA from the 128 soil samples. Metatranscriptomes of selected samples will be analyzed by shotgun pyrosequencing of cDNA generated from enriched mRNA. This approach allows assessment of tree effects on gene expression patterns of different taxa as well as investigation of microbial functional traits in Fagus sylvatica L. and Picea abies L. dominated forest soils. 


\section{References:}

Abarenkov K, Nilsson RH, Larsson KH, Alexander IJ, Eberhardt U, Erland S, Hфiland K, Kjøller R, Larsson E, Pennanen T, Sen R, Taylor AFS, Tedersoo L, Ursing BM, Vrålstad T, Liimatainen K, Peintner U, Kõljalg U (2010). The UNITE database for molecular identification of fungi - recent updates and future perspectives. New Phytologist 186: 281-285.

Acosta-Martínez V, Dowd S, Sun Y, Allen V (2008) Tag-encoded pyrosequencing of bacterial diversity in a single soil type as affected by management and land use. Soil Biology and Biochemistry 40: 2762-2770.

Augusto L, Ranger J, Binkley D, Rothe A (2002). Impact of several common tree species of European temperate forests on soil fertility. Annals of Forest Science 59: 233-253.

Ayres E, Steltzer H, Berg S, Wallenstein MD, Simmons BL, Wall DH (2009). Tree species traits influence soil physical, chemical, and biological properties in high elevation forests. PLoS ONE 4: e5964.

Berger TW, Berger P (2012). Greater accumulation of litter in spruce (Picea abies) compared to beech (Fagus sylvatica) stands is not a consequence of the inherent recalcitrance of needles. Plant and soil 358: 349-369.

Bragg L, Stone G, Imelfort M, Hugenholtz P, Tyson GW (2012). Fast, accurate errorcorrection of amplicon pyrosequences using Acacia. Nature Methods 27: 425-426.

Caporaso JG, Kuczynski J, Stombaugh J, Bittinger K, Bushman FD, Costello EK, Fierer N, Peña AG, Goodrich JK, Gordon JI, Huttley GA, Kelley ST, Knights D, Koenig JE, Ley RE, Lozupone CA, McDonald D, Muegge BD, Pirrung M, Reeder J, Sevinsky JR, Turnbaugh PJ, Walters WA, Widmann J, Yatsunenko T, Zaneveld J, Knight R (2010). QIIME allows analysis of high-throughput community sequencing data. Nature Methods 7: 335-336.

Cesarz S, Fender AC, Beyer F, Valtanen K, Pfeiffer B, Gansert D, Hertel D, Polle A, Daniel R, Leuschner C, Scheu S (2013). Roots from beech (Fagus sylvatica L.) and ash (Fraxinus excelsior L.) differentially affect soil microorganisms and carbon dynamics. Soil Biology and Biochemistry 61: 23-32.

Chao A, Bunge J (2002). Estimating the number of species in a stochastic abundance model. Biometrics 58: 531-539. 
Cuesta Garrote N, Sánchez Navarro MM, Arán Aís F, Orgíles Barceló (2011). Natural antimicrobial agents against the microbiota associated with insoles. In: Science and technology against microbial pathogens: research, development and evaluation (Ed: Méndez-Vilas A). World Scientific Publishing Co. Pte. Ltd.: Singapore, pp 109-113.

Edgar RC (2010). Search and clustering orders of magnitude faster than BLAST. Bioinformatics 26: 2460-2461.

Edgar RC, Haas BJ, Clemente JC, Quince C, Knight R (2011). UCHIME improves sensitivity and speed of chimera detection. Bioinformatics 27: 2194-2200.

Fischer M, Bossdorf O, Gockel S, Hänsel F, Hemp A, Hessenmöller D, Korte G, Nieschulze J, Pfeiffer S, Prati D, Renner S, Schöning I, Schumacher U, Wells K, Buscot F, Kalko EKV, Linsenmair KE, Schulze ED, Weisser WW (2010). Implementing large-scale and long-term functional biodiversity research: The Biodiversity Exploratories. Basic and Applied Ecology 11: 473-485.

Gardes M, Bruns TD (1993). ITS primers with enhanced specificity for basidiomycetes - application to the identification of mycorrhizae and rusts. Molecular Ecology 2: 113-118.

Geßler A, Schneider S, Weber P, Hanemann U, Rennenberg H (1998). Soluble N compounds in trees exposed to high loads of $\mathrm{N}$ : a comparison between the roots of Norway spruce (Picea abies) and beech (Fagus sylvatica) trees grown under field conditions. New Phytologist 138: 385-399.

Haichar FZ, Marol C, Berge O, Rangel-Castro JI, Prosser JI, Balesdent J, Heulin T, Achouak W (2008). Plant host habitat and root exudates shape soil bacterial community structure. ISME Journal 2: 1221-1230.

Hanewinkel M, Cullmann DA, Schelhaas MJ, Nabuurs GJ, Zimmermann NE (2013). Climate change may cause severe loss in the economic value of European forest land. Nature Climate Change 3: 203-207.

Jiang Y, Chen C, Xu Z, Liu Y (2012). Effects of single and mixed species forest ecosystems on diversity and function of soil microbial community in subtropical China. Journal of Soils and Sediments 12: 228-240.

Lejon DP, Chaussod R, Ranger J, Ranjard L (2005). Microbial community structure and density under different tree species in an acid forest soil (Morvan, France). Microbial Ecology 50: 614-625. 
Li R, Khafipour E, Krause DO, Entz MH, de Kievit TR, Fernando WG (2012). Pyrosequencing reveals the influence of organic and conventional farming systems on bacterial communities. PLoS ONE 7: e51897.

Li W, Godzik A (2006) Cd-hit: a fast program for clustering and comparing large sets of protein or nucleotide sequences. Bioinformatics 22: 1658-1659.

Liu Z, Lozupone C, Hamady M, Bushman FD, Knight R (2007). Short pyrosequencing reads suffice for accurate microbial community analysis. Nucleic Acids Research 35: e120.

Priha O, Smolander A (1997). Microbial biomass and activity in soil and litter under Pinus sylvestris, Picea abies and Betula pendula at originally similar field afforestation sites. Biology and Fertility of Soils 24: 45-51.

Priha O, Smolander A (1999). Nitrogen transformations in soil under Pinus sylvestris, Picea abies and Betula pendula at two forest sites. Soil Biology and Biochemistry 31: 965-977.

Pruesse E, Quast C, Knittel K, Fuchs BM, Ludwig W, Peplies J, Glöckner FO (2007) SILVA: a comprehensive online resource for quality checked and aligned ribosomal RNA sequence data compatible with ARB. Nucleic Acids Research 35: 7188-7196.

Nacke H, Thürmer A, Wollherr A, Will C, Hodac L, Herold N, Schöning I, Schrumpf M, Daniel R (2011). Pyrosequencing-based assessment of bacterial community structure along different management types in German forest and grassland soils. PLoS ONE 6: e17000.

Nykvist N (1963). Leaching and decomposition of water-soluble organic substances from different types of leaf and needle litter. Studia Forestalia Suecica 3: 1-31.

Schloss PD, Westcott SL, Ryabin T, Hall JR, Hartmann M, Hollister EB, Lesniewski RA, Oakley BB, Parks DH, Robinson CJ, Sahl JW, Stres B, Thallinger GG, Van Horn DJ, Weber CF (2009). Introducing mothur: open-source, platformindependent, community-supported software for describing and comparing microbial communities. Applied and Environmental Microbiology 75: 7537-7541.

Schneider D, Arp G, Reimer A, Reitner J, Daniel R (2013). Phylogenetic analysis of a microbialite-forming microbial mat from a hypersaline lake of the kiritimati atoll, central pacific. PLoS ONE 8: e66662.

Shannon CE (1948). A mathematical theory of communication. Bell System Technical Journal 27: 379-423. 
Thoms C, Gattinger A, Jacob M, Thomas FM, Gleixner G (2010). Direct and indirect effects of tree diversity drive soil microbial diversity in temperate deciduous forest. Soil Biology and Biochemistry 42: 1558-1565.

Thoms C, Gleixner G (2013). Seasonal differences in tree species' influence on soil microbial communities. Soil Biology and Biochemistry http://dx.doi.org/10.1016/j.soilbio.2013.05.018.

White TJ, Bruns TD, Lee SB, Taylor JW (1990). Amplification and direct sequencing of fungal ribosomal RNA genes for phylogenetics. In: PCR protocols - a guide to methods and applications (Eds: Innis MA, Gelfand DH, Sninsky JJ, White TJ). Academic press, San Diego, CA, pp 315-322.

Wubet T, Christ S, Schöning I, Boch S, Gawlich M, Schnabel B, Fischer M, Buscot F (2012). Differences in soil fungal communities between European beech (Fagus sylvatica L.) dominated forests are related to soil and understory vegetation. PLoS ONE 7: e47500. 


\section{B.II Impact of $\mathbf{N}$ fertilization on soil microbial communities and greenhouse gas fluxes}

To unravel the influence of $\mathrm{NO}_{3}{ }^{-}$soil depositions on $\mathrm{CH}_{4}$ and $\mathrm{N}_{2} \mathrm{O}$ gas fluxes and the soil-inhabiting active microbial community in temperate broad-leaved forests, a laboratory experiment was conducted. We analyzed the effects of $\mathrm{NO}_{3}{ }^{-}$fertilization in combination with limited and unlimited labile $\mathrm{C}$ supply on the $\mathrm{CH}_{4}$ uptake of a deciduous forest soil. The following hypotheses were tested:

(1) High $\mathrm{NO}_{3}{ }^{-}$input leads to a relevant reduction in $\mathrm{CH}_{4}$ uptake of the forest soil.

(2) Glucose neither enhances nor inhibits $\mathrm{CH}_{4}$ uptake when added alone.

(3) Glucose addition incombination with $\mathrm{NO}_{3}{ }^{-}$increases the inhibiting effect of $\mathrm{NO}_{3}{ }^{-}$on $\mathrm{CH}_{4}$ uptake.

Furthermore, the influence of high $\mathrm{NO}_{3}{ }^{-}$inputs on the diversity and composition of the active bacterial and archaeal community present in these incubated soils was analyzed. Pyrosequencing based on 16S rRNA was applied to test the following hypotheses:

(1) The $\mathrm{N}$ fertilization reduces the diversity and shapes the community structure of active soil microbia by promoting a denitrifying bacterial and archaeal community.

(2) The addition of high concentrations of $\mathrm{N}\left(200 \mathrm{~kg} \mathrm{~N} \mathrm{ha}^{-1} \mathrm{yr}^{-1}\right)$ forces the bacterial diversity and community composition to a point, where the lost bacterial diversity cannot be recovered and the microbial-driven biogeochemical processes collapse.

Subsequently, the impact of high $\mathrm{NO}_{3}{ }^{-}$amounts added to a temperate forest soil, in combination with limited and unlimited $\mathrm{C}$ availability, on $\mathrm{N}_{2} \mathrm{O}$ emissions was analyzed. The following hypotheses were tested:

(1) Even though many forest soils contain large stocks of C, the availability of labile $\mathrm{C}$ for $\mathrm{N}_{2} \mathrm{O}$ emissions is limited, with the consequence that repeated high $\mathrm{N}$ inputs do not result in a corresponding additive increase of the $\mathrm{N}_{2} \mathrm{O}$ release rate.

(2) High amounts of labile $\mathrm{C}$ in forest soils lead to similar $\mathrm{N}_{2} \mathrm{O}$ emission rates as the application of high $\mathrm{N}$ amounts.

(3) The addition of labile $\mathrm{C}$ to forest soil affected by chronic $\mathrm{N}$ addition must result in very high $\mathrm{N}_{2} \mathrm{O}$ emissions exceeding the sum of rates measured in soils treated with $\mathrm{N}$ or $\mathrm{C}$ sources alone. 
1.

The inhibiting effect of nitrate fertilization on methane uptake of a temperate forest soil is influenced by labile carbon

Ann-Catrin Fender ${ }^{1)}$, Birgit Pfeiffer ${ }^{2)}$, Dirk Gansert ${ }^{1)}$, Christoph Leuschner ${ }^{1)}$, Rolf Daniel $^{2)}$ and Hermann F. Jungkunst ${ }^{3)}$

Biology and Fertility of Soils (2011), Vol. 48, Issue 6, pp 621-631

${ }^{1)}$ Plant Ecology and Ecosystems research, University of Goettingen, Untere Karspüle 2, 37073 Goettingen, Germany

${ }^{2)}$ Genomic and Applied Microbiology, University of Goettingen, Grisebachstr. 8, 37077 Goettingen, Germany

${ }^{3)}$ Geoecology Physical Geography, Insitute for Environmental Sciences, University of KoblenzLandau, Fortstr. 7, 76829 Landau, Germany

\section{Author contributions to the work:}

Performed the experiments: AC. Fender, B. Pfeiffer

Analyzed the data: AC. Fender, B. Pfeiffer

Wrote the paper: AC. Fender, HF. Jungkunst,

Conceived and designed the experiments: HF. Jungkunst, AC. Fender, R. Daniel 


\title{
The inhibiting effect of nitrate fertilisation on methane uptake of a temperate forest soil is influenced by labile carbon
}

\author{
Ann-Catrin Fender • Birgit Pfeiffer • Dirk Gansert • \\ Christoph Leuschner • Rolf Daniel • \\ Hermann F. Jungkunst
}

Received: 8 October 2011 / Revised: 13 December 2011 / Accepted: 23 December 2011

(C) Springer-Verlag 2012

\begin{abstract}
Upland soils are the most important terrestrial sink for the greenhouse gas $\mathrm{CH}_{4}$. The oxidation of $\mathrm{CH}_{4}$ is highly influenced by reactive $\mathrm{N}$ which is increasingly added to many ecosystems by atmospheric deposition and thereby also alters the labile $\mathrm{C}$ pool in the soils. The interacting effects of soil $\mathrm{N}$ availability and the labile $\mathrm{C}$ pool on $\mathrm{CH}_{4}$ oxidation are not well understood. We conducted a laboratory experiment with soil columns consisting of homogenised topsoil material from a temperate broad-leaved forest to study the net $\mathrm{CH}_{4}$ flux under the combined or isolated addition of $\mathrm{NO}_{3}{ }^{-}$and glucose as a labile $\mathrm{C}$ source. Addition of $\mathrm{NO}_{3}{ }^{-}$and glucose reduced the net $\mathrm{CH}_{4}$ uptake of the soil by $86 \%$ and $83 \%$, respectively. The combined addition of both agents led to a nearly complete inhibition of $\mathrm{CH}_{4}$ uptake (reduction by 99.4\%). Our study demonstrates a close link between the availability of $\mathrm{C}$ and $\mathrm{N}$ and the rate of $\mathrm{CH}_{4}$ oxidation in temperate forest soils. Continued deposition of $\mathrm{NO}_{3}{ }^{-}$has the potential to reduce the sink strength of temperate forest soils for $\mathrm{CH}_{4}$.
\end{abstract}

A.-C. Fender $(\bowtie) \cdot$ D. Gansert $\cdot$ C. Leuschner

Plant Ecology and Ecosystems Research, University of Göttingen,

Untere Karspüle 2,

37073 Göttingen, Germany

e-mail: afender@gwdg.de

B. Pfeiffer $\cdot$ R. Daniel

Genomic and Applied Microbiology, University of Göttingen,

Grisebachstr. 8,

37077 Göttingen, Germany

H. F. Jungkunst

Landscape Ecology, University of Göttingen,

Goldschmidtstr. 5 ,

37077 Göttingen, Germany
Keywords $\mathrm{CH}_{4}$ uptake $\cdot \mathrm{NO}_{3}{ }^{-} \cdot$ Glucose $\cdot$ Soil moisture Interaction of $\mathrm{C}$ and $\mathrm{N}$ cycles $\cdot \mathrm{N}$ deposition

\section{Introduction}

Methane $\left(\mathrm{CH}_{4}\right)$ has a 25 times higher global warming potential than carbon dioxide $\left(\mathrm{CO}_{2}\right)$. Its present concentration in the atmosphere has more than doubled from 715 to 1774 ppb since pre-industrial times over the past 150 years (Forster et al. 2007). Hence, $\mathrm{CH}_{4}$ contributes about $15 \%$ to the present greenhouse effect of the long-lived greenhouse gases (Forster et al. 2007). Beside chemical oxidation in the troposphere (Crutzen 1991; Denman et al. 2007), biological oxidation in aerobic soils by methanotrophs and nitrifiers represents the second strongest absorber of atmospheric $\mathrm{CH}_{4}$ (Smith et al. 2000; Le Mer and Roger 2001; Denman et al. 2007). In a recent study, Dutaur and Verchot (2007) calculated the global $\mathrm{CH}_{4}$ sink of soils to $22.4 \mathrm{Tg}$ year ${ }^{-1}$. The $\mathrm{CH}_{4}$ uptake of soils in the temperate zone accounts for nearly half of this global sink $\left(10.4 \mathrm{Tg} \mathrm{CH}_{4}\right.$ year $\left.{ }^{-1}\right)$. It is estimated that temperate forest soils contribute between 3 and 5.7 $\mathrm{Tg} \mathrm{CH}_{4}$ year $^{-1}$ to this sink (Curry 2007; Dutaur and Verchot 2007; Ishizuka et al. 2009). Therefore, any change in the $\mathrm{CH}_{4}$ sink strength of temperate forest soils as resulting from nitrogen $(\mathrm{N})$ deposition, liming or fertilisation activities, altered forest management or forest conversion is of global interest.

Over the past 200 years, temperate forest ecosystems have already received more than ten times higher anthropogenic $\mathrm{N}$ inputs through atmospheric deposition than in preindustrial times (Holland et al. 1999; Nadelhoffer et al. 1999; Galloway and Cowling 2002; Holland et al. 2005; Magnani et al. 2007). Many studies reported N deposition to be an important factor in the control of $\mathrm{CH}_{4}$ uptake by forest 
soils (Kasimir-Klemedtsson et al. 1997; Butterbach-Bahl et al. 1998). Liu and Greaver (2009) assumed that anthropogenic $\mathrm{N}$ addition reduces $\mathrm{CH}_{4}$ uptake by 3.9 to $9.1 \mathrm{Tg}$ $\mathrm{CH}_{4}$ year $^{-1}$ at the global scale. These figures compare well with the estimate of Dutaur and Verchot (2007) of a reduction by $17 \%$ to $40 \%$ of the $\mathrm{CH}_{4}$ sink strength. Due to the strong impact of $\mathrm{N}$ addition on $\mathrm{CH}_{4}$ uptake, intensive research in the laboratory and the field has addressed this topic (Goldman et al. 1995; Bradford et al. 2001b, 2001a; Jang et al. 2006; Borken and Brumme 2009; Bodelier 2011b). In various field studies (King and Schnell 1994a; Dobbie and Smith 1996; Steinkamp et al. 2001) and laboratory experiments (Adamsen and King 1993; Bender and Conrad 1994; Priemé and Christensen 1997; MacDonald et al. 1997), evidence was found for an inhibiting effect of ammonium $\left(\mathrm{NH}_{4}^{+}\right)$fertilisation on $\mathrm{CH}_{4}$ oxidation in forest soils. A reduction of $\mathrm{CH}_{4}$ oxidation by $\mathrm{NH}_{4}{ }^{+}$addition has been explained by substrate competition between $\mathrm{NH}_{4}{ }^{+}$and $\mathrm{CH}_{4}$ at the binding sites of the catalysing enzyme $\mathrm{CH}_{4}$ monooxygenase (MMO) in the first step of the $\mathrm{CH}_{4}$ oxidation pathway (Bédard and Knowles 1989; Topp and Pattey 1997) resulting in enhanced $\mathrm{NH}_{4}^{+}$oxidation. Other explanations are non-competitive effects exerted by the sideproduct hydroxylamine during $\mathrm{NH}_{4}{ }^{+}$oxidation (Mancinelli 1995), the production of toxic nitrite $\left(\mathrm{NO}_{2}{ }^{-}\right)$during $\mathrm{NH}_{4}{ }^{+}$ oxidation (King and Schnell 1994b) and osmotic effects resulting from the formation of salts in the course of fertilisation (Dunfield and Knowles 1995; Gulledge and Schimel 1998). Furthermore, several studies reported a negative effect of oxidised $\mathrm{N}\left(\mathrm{NO}_{3}{ }^{-}\right)$on the $\mathrm{CH}_{4}$ oxidation in soil (Priemé and Christensen 1997; Wang and Ineson 2003; Reay and Nedwell 2004; Xu and Inubushi 2004; Ishizuka et al. 2009). This inhibiting effect has been explained by (a) the production of toxic concentrations of $\mathrm{NO}_{2}^{-}$in anaerobic microsites (Adamsen and King 1993; Whalen 2000; Wang and Ineson 2003) or (b) the osmotic effect of salts (Dunfield and Knowles 1995; Gulledge and Schimel 1998). However, the underlying mechanisms of these non-competitive inhibiting effects of oxidised $\mathrm{N}$ on $\mathrm{CH}_{4}$ uptake are not yet sufficiently understood.

There is a recent debate on the influence of $\mathrm{N}$ addition on carbon (C) turnover and $\mathrm{C}$ stocks in forest soils (Magnani et al. 2007; Dezi et al. 2010; Janssens et al. 2010). According to de Vries et al. (2009), the C sequestration in European forest soils has increased as a consequence of the $\mathrm{N}$ deposition in the range of 5 to $23 \mathrm{~kg} \mathrm{C}$ per $\mathrm{kg} \mathrm{N}$ added. Thus, it is likely that a continuing high $\mathrm{N}$ input into forest soils will further increase the amount of labile $\mathrm{C}$. There is a need to study the consequences of increasing amounts of labile $\mathrm{C}$ and $\mathrm{N}$ in forest soils and their interaction on $\mathrm{CH}_{4}$ oxidation which is not well understood. Schnell and King (1995) studied the influences of C compounds as glucose, starch, yeast extract, methanol, ethanol, formate, acetate, malate or lactate on the $\mathrm{CH}_{4}$ oxidation of incubated forest soil. According to their results, these $\mathrm{C}$ compounds neither inhibit nor stimulate $\mathrm{CH}_{4}$ oxidation. However, the applied concentration may have not been high enough to influence the physiology and activity of the $\mathrm{CH}_{4}$ oxidising community; moreover, the interaction with $\mathrm{N}$ availability was not addressed.

In this study, we focused on the effects of $\mathrm{NO}_{3}{ }^{-}$fertilisation in combination with the application of labile $\mathrm{C}$ (glucose) on the $\mathrm{CH}_{4}$ uptake of a deciduous forest soil. We tested the hypotheses that (1) high $\mathrm{NO}_{3}{ }^{-}$input leads to a relevant reduction in the $\mathrm{CH}_{4}$ uptake of the forest soil, (2) glucose neither enhances nor inhibits $\mathrm{CH}_{4}$ uptake when added alone, but (3) in combination with $\mathrm{NO}_{3}{ }^{-}$, it increases the inhibiting effect of $\mathrm{NO}_{3}{ }^{-}$on $\mathrm{CH}_{4}$ uptake.

\section{Materials and methods}

\section{Soil characteristics and soil sampling}

The soil used for the experiment was sampled in a mixed broad-leaved temperate forest in Hainich National Park, Thuringia, Germany $\left(51^{\circ} 04^{\prime} \mathrm{N} 10^{\circ} 30^{\prime} \mathrm{E}\right)$ and was immediately prepared for incubation. At the sampling site, the dominating tree species are Fagus sylvatica L., Fraxinus excelsior L., Tilia cordata Mill., Tilia platyphyllos Scop., Carpinus betulus L., Acer pseudoplatanus L. and Acer platanoides L. The soil type is a Stagnic Luvisol (IUSS Working Group WRB 2007) of silty texture containing $1.8 \%$ sand, $80.2 \%$ silt and $18.1 \%$ clay. The sampled soil was free of carbonate $\left(<0.02 \%\right.$ of $\left.\mathrm{C}_{\text {total }}\right)$, had a $\mathrm{pH}(\mathrm{KCl})$ of 3.8 and a base saturation of $22.9 \%$. Material of the upper 0 to $10 \mathrm{~cm}$ of the mineral soil was collected, excluding litter material. After collecting the soil material, it was homogenised by passing it through a 5-mm sieve.

\section{Experimental setup}

For the main experiment, 16 Plexiglass cylinders $(50 \mathrm{~cm}$ in height, $17 \mathrm{~cm}$ in diameter) were used and each filled with $4 \mathrm{~kg}$ of the freshly sieved soil. The water content at the start was $22.7 \%$ of the fresh weight. The columns were placed in a random arrangement in the laboratory. A supplementary experiment with 16 additional soil columns of the same dimensions and treated alike was conducted to (1) repeat the findings of the main experiment as well as to (2) exclude possible other effects like proposed inhibitory effects of salt addition and to (3) to have a control without labile $\mathrm{C}$ addition. Before the start of the main experiment, we kept the incubated soil for a period of 62 days under laboratory conditions to equilibrate the microbial soil community to the climatic conditions and to balance the gas exchange after 
disturbing the natural soil structure. After this pre-experimental phase, the experiment with two treatments (addition of $\mathrm{NO}_{3}{ }^{-}$ and glucose) lasted for another 62 days with three experimental phases (first, second and third $\mathrm{N}$-fertilisation phase) being distinguished (days 1-20, 21-41 and 42-62, respectively). In the main experiment, the $\mathrm{N}$ treatment was replicated eight times. The effect of $\mathrm{C}$ addition on $\mathrm{CH}_{4}$ was interpreted in comparison to the fluxes of the respective $\mathrm{N}$ treatment before $\mathrm{C}$ addition. At day 0 of the experiment (start of first $\mathrm{N}$ fertilisation phase), day 20 (start of second N-fertilisation phase) and day 41 (start of third $\mathrm{N}$-fertilisation phase), eight randomly chosen soil columns were fertilised with a $\mathrm{KNO}_{3}$ solution in deionised water with an equivalent of $200 \mathrm{~kg} \mathrm{~N} \mathrm{ha}^{-1}$. The amount of added water was adjusted to reach a water-filled pore space (WFPS) level of $80 \%$. At day 42 (start of third N-fertilisation phase), all 16 soil columns were additionally treated with a glucose solution (equivalent to $9,419 \mathrm{~kg} \mathrm{C} \mathrm{ha}^{-1}$ ) to simulate unlimited supply of labile $\mathrm{C}$ in the soil (both in the $\mathrm{N}$-fertilised and the untreated control columns). The addition of $\mathrm{N}$ and $\mathrm{C}$ increased the total $\mathrm{N}$ $\left(\mathrm{N}_{\text {total }}\right)$ and organic $\mathrm{C}\left(\mathrm{C}_{\text {org }}\right)$ pools in the soil columns in comparison to the initial $\mathrm{N}_{\text {total }}$ and $\mathrm{C}_{\text {org }}$ contents by absolute amounts of $7.7 \%$ and $8.0 \%(\mathrm{~N})$ and by $33.8 \%$ and $36.0 \%(\mathrm{C})$ on day 42 of the experiment in the control and the $\mathrm{N}$-fertilised columns, respectively.

In the supplementary experiment with fourfold replication, we examined the response of $\mathrm{CH}_{4}$ uptake to the addition of either $\mathrm{KNO}_{3}\left(\mathrm{NO}_{3}{ }^{-}\right.$source), $\mathrm{K}_{2} \mathrm{SO}_{4}$ (to test for effects of high $\mathrm{K}$ concentrations) or glucose (as a labile $\mathrm{C}$ source) using the same amounts of $\mathrm{N}, \mathrm{K}$ and $\mathrm{C}$ (200 kg N ha ${ }^{-1}$, $552 \mathrm{~kg} \mathrm{~K} \mathrm{ha}{ }^{-1}, 9,419 \mathrm{~kg} \mathrm{C} \mathrm{ha}^{-1}$, respectively) and the same soil and cultivation conditions as in the main experiment. Furthermore, the initial soil conditions (apart from a higher $\mathrm{C}_{\text {org }}$ concentration, Table 2) and all analytical procedures were identical to those in the main experiment. The goal of the supplementary experiment with duration of 21 days was to compare the effects of $\mathrm{KNO}_{3}$ and $\mathrm{K}_{2} \mathrm{SO}_{4}$ and to study the effect of a labile $\mathrm{C}$ source independent from the $\mathrm{NO}_{3}{ }^{-}$effect. This additional experiment also served for measuring the $\mathrm{NH}_{4}{ }^{+}$concentrations in the soil after $\mathrm{NO}_{3}{ }^{-}$ addition because these data were lost in the main experiment due to technical shortcomings.

The soil columns were installed in a greenhouse with $14 \mathrm{~h}$ of low daylight $\left(100 \mu \mathrm{mol} \mathrm{m} \mathrm{m}^{-2} \mathrm{~s}^{-1}\right.$ PPFD; OSRAM cool white, Lightcolor 840, Munich, Germany). The waterfilled pore space was measured every week by weighing the soil columns. The pore volume and the water-filled pore space were calculated by assuming a particle density of $2.65 \mathrm{~g} \mathrm{~cm}^{-3}$ (Schlichting et al. 1995) and by referring to the measured soil bulk density at the experiment's beginning. The soil temperature of each soil column was measured at a depth of $7.5 \mathrm{~cm}$ and a horizontal distance to the column edge of $3 \mathrm{~cm}$ using NTC thermistors (Epcos, Munich, Germany) that were logged in 15-min intervals with a CR10 data logger (Campbell Scientific Inc., UT, USA). The soil temperature did not differ between the treatments, but decreased slightly by $3^{\circ} \mathrm{C}$ over the course of the experiment (mean of $22.8 \pm 0.2^{\circ} \mathrm{C}$ in the $\mathrm{N}$-fertilised and the control treatment).

\section{Chemical soil analysis}

Before the start of the experiment, we analysed five replicate samples for the chemical properties of soil (Table 1). The $\mathrm{pH}$ $(\mathrm{KCl})$ was analysed in a suspension of $10 \mathrm{~g}$ soil in $1 \mathrm{M} \mathrm{KCl}$ solution using a Vario $\mathrm{pH}$ meter (WTW GmbH, Weilheim, Germany). The cation exchange capacity (CEC) of the soil was measured by percolating five samples of $2 \mathrm{~g}$ fresh soil with $0.2 \mathrm{M} \mathrm{BaCl}$. The percolates were analysed with an ICP-AES (Optima 3000 XL, PerkinElmer, MA, USA). The base saturation was calculated as the percentage of base cations ( $\mathrm{Na}, \mathrm{K}, \mathrm{Ca}$ and $\mathrm{Mg}$ ) in CEC. The bulk density of the soil material in the columns was determined using steel cores with a defined volume of $100.93 \mathrm{~cm}^{3}$. Before and after drying the soil cores at $105^{\circ} \mathrm{C}$ for $24 \mathrm{~h}$, the soil was weighed, and the bulk density of the dry material was calculated. At day 0 of the fertilisation experiment, the bulk density of the homogenised material was $1.05 \pm 0.02 \mathrm{~g} \mathrm{~cm}^{-3}$. The particle size distribution was determined with the sieving and pipette method (Schlichting et al. 1995). The concentrations of organic $\mathrm{C}\left(\mathrm{C}_{\text {org }}\right)$ and total $\mathrm{N}\left(\mathrm{N}_{\text {total }}\right)$ were analysed with a $\mathrm{C} / \mathrm{N}$ analyzer (Vario EL, Elementar, Hanau, Germany). The concentrations of $\mathrm{N}-\mathrm{NO}_{3}{ }^{-}$and $\mathrm{N}-$ $\mathrm{NH}_{4}{ }^{+}$in $\mathrm{mg} \mathrm{kg}^{-1} \mathrm{dw}$ were measured by extracting $8 \mathrm{~g}$ fresh soil with $0.5 \mathrm{M} \mathrm{K}_{2} \mathrm{SO}_{4}$ solution (ratio of wet soil mass to solution, 1:3) within the following 2 to $3 \mathrm{~h}$ after collecting the soil. The samples were shaken for $1 \mathrm{~h}$ and passed through folded filters (FT-4-303-150, Sartorius Stedim, Aubagne, France). The $\mathrm{NO}_{3}{ }^{-}$and $\mathrm{NH}_{4}{ }^{+}$concentrations of the filtered extracts were analysed by continuous flow injection colorimetry (SAN+Continuous Flow Analyzer, Skalar Instruments, Breda, The Netherlands). The $\mathrm{NO}_{3}{ }^{-}$ concentrations were determined with the copper-cadmiumreduction method (ISO method 13395), and those of $\mathrm{NH}_{4}{ }^{+}$ with the Berthelot reaction method (ISO method 11732).

At day 0 and at the end of the experiment, soil solution was sampled from the soil column by irrigating the soil with $500 \mathrm{ml}$ of distilled water. The percolating water was passed through filter papers (MN 85/70 BF, Macherey-Nagel, Düren, Germany) and the soil solution analysed with the DOC analyser (Dimatoc 100, Dimatec, Essen, Germany) to measure the concentration of dissolved organic $\mathrm{C}$. The concentration of $\mathrm{NO}_{3}{ }^{-}$in the soil solution was analysed by ion chromatography (761 Compact IC, Metrohm, Herisau, Switzerland). 
Table 1 Selected chemical parameters in the soil solution of the columns of the N-fertilised and the unfertilised control treatment in different phases of the experiment (means $\pm 1 \mathrm{SE}$ of each eight columns)

\begin{tabular}{|c|c|c|c|c|c|}
\hline \multirow[t]{2}{*}{ Experimental phase } & \multirow[t]{2}{*}{ Day 0} & Unfertilised control (N0) & $\mathrm{N}$-fertilised (N1) & Unfertilised control (N0) & $\mathrm{N}$-fertilised (N1) \\
\hline & & \multicolumn{2}{|l|}{ Day 41 (without glucose) } & \multicolumn{2}{|l|}{ Day 62 (glucose added) } \\
\hline $\mathrm{pH}(\mathrm{KCl})$ & $3.82 \pm 0.03$ & $3.84 \pm 0.08 \mathrm{aA}$ & $4.23 \pm 0.06 \mathrm{bA}$ & $4.49 \pm 0.07 \mathrm{aB}$ & $5.63 \pm 0.16 \mathrm{bB}$ \\
\hline $\mathrm{C}_{\text {org }}\left[\mathrm{g} \mathrm{kg}^{-1} \mathrm{dw}\right]$ & $19.84 \pm 0.44$ & $20.44 \pm 0.37 \mathrm{aA}$ & $19.20 \pm 0.25 \mathrm{bA}$ & $22.99 \pm 0.58 \mathrm{aB}$ & $22.62 \pm 0.28 \mathrm{aB}$ \\
\hline $\mathrm{N}_{\text {total }}\left[\mathrm{g} \mathrm{kg}^{-1} \mathrm{dw}\right]$ & $1.89 \pm 0.03$ & $2.08 \pm 0.03 \mathrm{aA}$ & $2.40 \pm 0.08 \mathrm{bA}$ & $1.99 \pm 0.01 \mathrm{aA}$ & $2.42 \pm 0.09 \mathrm{bA}$ \\
\hline $\mathrm{C} / \mathrm{N}\left[\mathrm{g} \mathrm{g}^{-1}\right]$ & $10.50 \pm 0.19$ & $9.85 \pm 0.10 \mathrm{aA}$ & $8.02 \pm 0.17 \mathrm{bA}$ & $11.52 \pm 0.18 \mathrm{aB}$ & $9.41 \pm 0.30 \mathrm{bB}$ \\
\hline $\mathrm{NO}_{3}^{-}\left[\mathrm{mg} \mathrm{Nkg}^{-1} \mathrm{dw}\right]$ & $6.39 \pm 0.28$ & ND & ND & $0.60 \pm 0.80 \mathrm{a}$ & $35.78 \pm 5.70 \mathrm{~b}$ \\
\hline $\mathrm{NH}_{4}^{+}\left[\mathrm{mg} \mathrm{Nkg}^{-1} \mathrm{dw}\right]$ & $7.85 \pm 0.28$ & ND & ND & $1.53 \pm 0.32 \mathrm{a}$ & $34.50 \pm 4.59 b$ \\
\hline $\mathrm{DOC}\left[\mathrm{mg} \mathrm{l}^{-1}\right]$ & $19.4 \pm 1.91$ & ND & ND & $515.3 \pm 89.9 \mathrm{a}$ & $273.2 \pm 51.7 b$ \\
\hline $\mathrm{NO}_{3}{ }^{-}\left[\mathrm{mg} \mathrm{l}^{-1}\right]$ & $9.6 \pm 3.50$ & ND & ND & $30.5 \pm 23.6 \mathrm{a}$ & $363.35 \pm 114.7 \mathrm{a}$ \\
\hline
\end{tabular}

Day 0 refers to the start of the experiment; day 41 is 6 weeks after the first $\mathrm{N}$ fertilisation and day 62 is 3 weeks after the third $\mathrm{N}$ fertilisation combined with glucose addition. Lower case letters indicate significant differences between the $\mathrm{N}$-fertilised and the control treatment within a given experimental phase $(P<0.05$, Wilcoxon $U$-test); different upper case letters indicate significant differences between columns before and after glucose addition $(P<0.05$, Wilcoxon signed rank test $)$

$N D$ parameter not detected

Gas flux analysis

Gas fluxes of $\mathrm{CH}_{4}$ at the soil surface were measured three times per week in the headspace volume of soil columns. The headspace volume in the Plexiglass columns was $8.6 \mathrm{~L}$. The chambers were closed for $1 \mathrm{~h}$. At 0, 20, 40 and $60 \mathrm{~min}$ elapsed time after lid closure, gas samples were taken from the chamber headspace by flushing gas-tight 50-ml sample syringes with headspace air, using a needle and two threeway valves. The gas concentrations were analysed by a computer-controlled gas chromatographic system with a flame ionization detector for $\mathrm{CH}_{4}$ (Shimadzu GC-14B, Kyoto, Japan). A detailed description of the gas chromatograph was given by Loftfield et al. (1997). The gas fluxes were calculated from the linear increase of gas concentration, which was measured during the chamber emplacement.

\section{Data analysis}

Statistical analyses were performed using SAS 9.1 software (Statistical Analysis System, SAS Institute Inc., Cary, USA). Cumulative gas fluxes were calculated by summing up all measurements for each column considering the number of measurements and the corresponding duration of the measuring phase. Frequency distributions were tested for normality with the Shapiro-Wilk test. One-way GLM with the TukeyKramer test was used to identify significant differences among the N-treatment means for cumulative $\mathrm{CH}_{4}$ fluxes and soil properties showing normal distribution. Not normaldistributed soil parameters were analysed with the Wilcoxon $U$-test. Differences among normal-distributed $\mathrm{CH}_{4}$ flux data of the different $\mathrm{C}$ treatments were assessed with the paired $t$ test. The Wilcoxon signed rank test was used to identify differences between the $\mathrm{C}$ treatments in not normal-distributed soil parameters (this single test was carried out with the $\mathrm{R}$ statistical package, version 2.11.1, R Foundation for Statistical Computing, Vienna, Austria). Linear regression analysis was conducted to relate $\mathrm{CH}_{4}$ flux to WFPS. For all analyses, significance was determined at $P<0.05$.

\section{Results}

Physical and chemical soil characteristics

Important chemical properties of the soil in the columns before the start of the experiment (day 0), at the end of the second $\mathrm{N}$ fertilisation phase (day 41) and 3 weeks after the combined application of $\mathrm{N}$ and $\mathrm{C}$ (day 62) are listed in Table 1. At the end of the second $\mathrm{N}$ fertilisation (day 41) and the end of the third experimental phase (combined addition of $\mathrm{N}$ and glucose, day 62$)$, the $\mathrm{pH}(\mathrm{KCl})$ in the $\mathrm{N}$-fertilised columns was significantly higher (by 0.4 and $1.1 \mathrm{pH}$ units, respectively) than in the unfertilised control. The glucose application strongly increased the $\mathrm{pH}$ by 0.7 (control) and 1.4 units ( $\mathrm{N}$-fertilised) compared with the corresponding $\mathrm{N}$ treatment before glucose was applied. At the $21^{\text {st }}$ and $42^{\text {nd }}$ day of the experiment (with the addition of $\mathrm{N}$ or $\mathrm{N}$ and $\mathrm{C}$ ), the WFPS was adjusted to approximately $80 \%$ (Fig. 1a). Subsequently, WFPS gradually declined due to soil evaporation with a slope of $-1.53 \pm 0.22 \% \mathrm{~d}^{-1}$ in the unfertilised soil columns and $-1.53 \pm 0.24 \% \mathrm{~d}^{-1}$ in the fertilised columns.

The effect of $\mathrm{NO}_{3}{ }^{-}$, glucose and $\mathrm{K}_{2} \mathrm{SO}_{4}$ on $\mathrm{C}_{\text {org }}$ and the mineral $\mathrm{N}$ concentration in the soil was investigated in the supplementary experiment (Table 2). The addition of $\mathrm{KNO}_{3}$ increased the $\mathrm{NO}_{3}{ }^{-}$and $\mathrm{NH}_{4}{ }^{+}$concentrations in the soil 
Fig. $1 \mathrm{CH}_{4}$ uptake and waterfilled pore space of the soil (WFPS) in soil columns conised with $\mathrm{NO}_{3}{ }^{-}$or unfertilised control during the experiment of 62 days duration. Given are mean values $\pm 1 \mathrm{SE}$ of each eight columns per N-treatment. The N-fertilization consisted of a total addition of $200 \mathrm{~kg} \mathrm{~N}$ ha ${ }^{-1}$ year ${ }^{-1}$ given as $\mathrm{KNO}_{3}$ on three occasions (first to third fertilisation). On day 41 of the experiment, all columns received additionally a glucose solution (equivalent to $9,419 \mathrm{~kg} \mathrm{C} \mathrm{ha}^{-1}$ ) as a labile C source taining forest soil, either fertil-

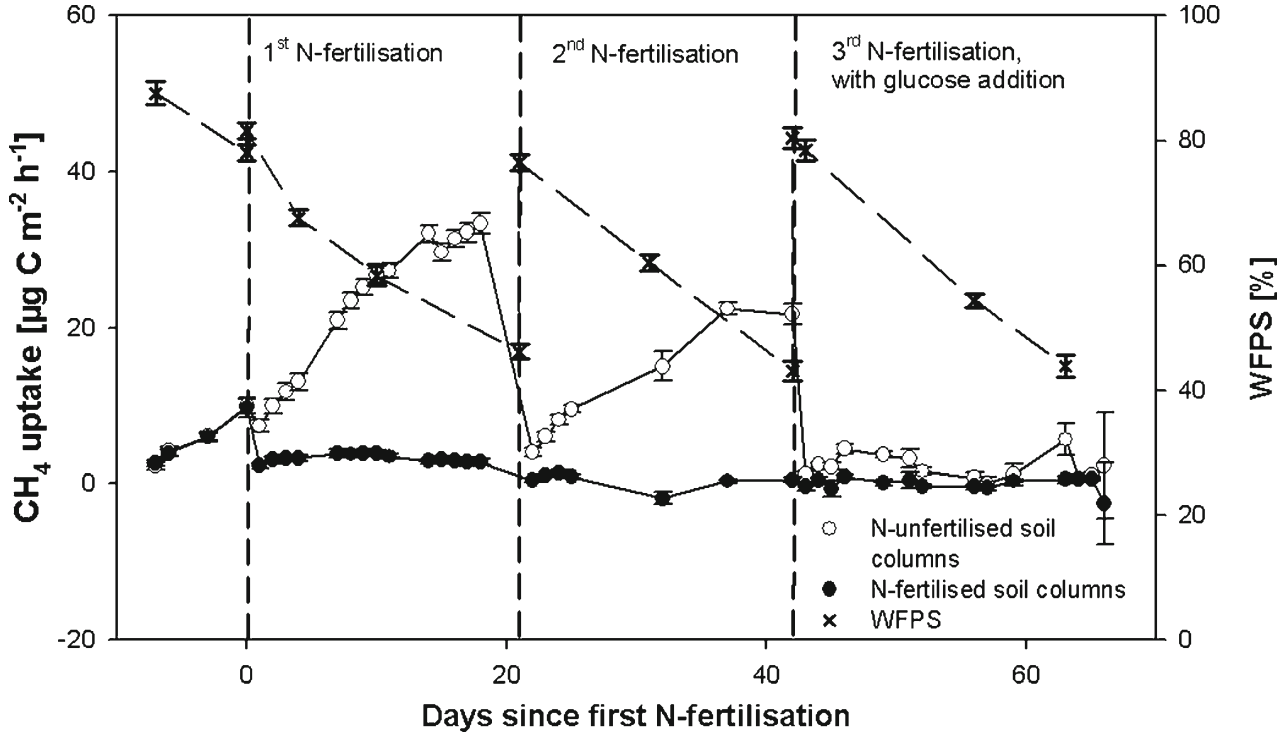

columns by $891 \%$ and $244 \%$, respectively. $\mathrm{K}_{2} \mathrm{SO}_{4}$ increased the $\mathrm{NO}_{3}{ }^{-}$and $\mathrm{NH}_{4}{ }^{+}$concentrations in the soil by $243 \%$ and $134 \%$, respectively. Glucose led to a significant increase of $\mathrm{C}_{\text {org }}$ and a decline by $81 \%$ and $47 \%$ of $\mathrm{NO}_{3}{ }^{-}$and $\mathrm{NH}_{4}{ }^{+}$, respectively.

\section{$\mathrm{CH}_{4}$ fluxes}

During the first phase of the main experiment, the unfertilised control columns showed enhanced uptake of $\mathrm{CH}_{4}$ with declining WFPS. Maximum uptake (33.31 $1.36 \mu \mathrm{g}$ $\mathrm{C} \mathrm{m}^{-2} \mathrm{~h}^{-1}$ ) was measured at day 17 when WFPS had dropped to $49.50 \pm 1.64 \%$. In contrast, $\mathrm{NO}_{3}{ }^{-}$fertilisation reduced $\mathrm{CH}_{4}$ uptake considerably (Fig. 1). The $\mathrm{CH}_{4}$ uptake of the fertilised soil remained constantly low at $3.23 \pm 0.14 \mu \mathrm{g} \mathrm{C} \mathrm{m}^{-2} \mathrm{~h}^{-1}$ during the first experimental phase. In the second phase of the experiment, the maximum uptake of the unfertilised soil was $22.45 \pm$ $0.74 \mu \mathrm{g} \mathrm{C} \mathrm{m}^{-2} \mathrm{~h}^{-1}$. In the $\mathrm{N}$-fertilised soil columns, the second $\mathrm{N}$ application led to an even stronger inhibition of $\mathrm{CH}_{4}$ uptake than during the first phase. The first and second $\mathrm{NO}_{3}{ }^{-}$addition significantly reduced the cumulative $\mathrm{CH}_{4}$ uptake of the N- fertilised soil columns by $86 \%$ in the first and by $97 \%$ in the second phase compared with the unfertilised columns (Fig. 2).

Glucose application also led to a large reduction in $\mathrm{CH}_{4}$ uptake with average rates of only $2.41 \pm 1.70 \mu \mathrm{g}$ $\mathrm{C} \mathrm{m}^{-2} \mathrm{~h}^{-1}$ during the third phase. The cumulative $\mathrm{CH}_{4}$ uptake after glucose application was significantly lower in both the unfertilised control and in the $\mathrm{N}$-fertilised columns than in the first and second experimental phases before glucose application (Fig. 2). The glucose addition inhibited $\mathrm{CH}_{4}$ uptake to a similar extent (by $83 \%$ ) as did the first $\mathrm{NO}_{3}{ }^{-}$ addition. After combined $\mathrm{NO}_{3}{ }^{-}$and glucose addition in the third phase, the $\mathrm{CH}_{4}$ uptake was almost completely suppressed (reduction by $99.4 \%$ compared with the uptake of the control during the first phase, Fig. 2).

In the unfertilised control treatment of the main experiment, we found a strong negative correlation between $\mathrm{CH}_{4}$ uptake and WFPS with a large slope factor (higher $\mathrm{CH}_{4}$ uptake at lower soil moisture) in the first and second phase of the experiment $\left(R^{2}=0.679\right.$ and 0.788 , respectively, Fig. 3). After adding $\mathrm{NO}_{3}{ }^{-}$in the fertilised treatment, this relationship had a much smaller slope (first phase $R^{2}=0.14$ ),

Table 2 Chemical properties of the soil before (Day 0) and 21 days after the addition of $\mathrm{KNO}_{3}, \mathrm{~K}_{2} \mathrm{SO}_{4}$ or glucose compared with the control treatment in the supplementary experiment (means $\pm 1 \mathrm{SE}, n=4$ )

\begin{tabular}{|c|c|c|c|c|c|}
\hline & Day 0 & Control & $\mathrm{KNO}_{3}$ & $\mathrm{~K}_{2} \mathrm{SO}_{4}$ & Glucose \\
\hline $\mathrm{pH}(\mathrm{KCl})$ & ND & $4.32 \pm 0.11 \mathrm{a}$ & $4.15 \pm 0.09 \mathrm{a}$ & $4.12 \pm 0.07 \mathrm{a}$ & $4.20 \pm 0.04 \mathrm{a}$ \\
\hline $\mathrm{C}_{\text {org }}\left[\mathrm{g} \mathrm{kg}^{-1} \mathrm{dw}\right]$ & $29.20 \pm 0.55$ & $29.00 \pm 0.23 \mathrm{ab}$ & $27.61 \pm 0.54 \mathrm{a}$ & $29.00 \pm 0.23 \mathrm{ab}$ & $32.8 \pm 1.76 \mathrm{~b}$ \\
\hline $\mathrm{N}_{\text {total }}\left[\mathrm{g} \mathrm{kg}^{-1} \mathrm{dw}\right]$ & $2.00 \pm 0.02$ & $1.95 \pm 0.03 \mathrm{a}$ & $2.02 \pm 0.05 \mathrm{a}$ & $1.96 \pm 0.01 \mathrm{a}$ & $1.89 \pm 0.02 \mathrm{a}$ \\
\hline $\mathrm{C} / \mathrm{N}\left[\mathrm{g} \mathrm{g}^{-1}\right]$ & $14.69 \pm 0.32$ & $14.91 \pm 0.15 \mathrm{a}$ & $13.70 \pm 0.16 \mathrm{a}$ & $14.80 \pm 0.08 \mathrm{a}$ & $17.32 \pm 0.89 \mathrm{~b}$ \\
\hline $\mathrm{N}-\mathrm{NO}_{3}{ }^{-}\left[\mathrm{mg} \mathrm{kg}^{-1} \mathrm{dw}\right]$ & $3.27 \pm 0.61$ & $5.07 \pm 3.00 \mathrm{ab}$ & $45.15 \pm 2.44 \mathrm{c}$ & $12.34 \pm 1.07 b$ & $0.94 \pm 0.81 \mathrm{a}$ \\
\hline $\mathrm{N}-\mathrm{NH}_{4}^{+}\left[\mathrm{mg} \mathrm{kg}^{-1} \mathrm{dw}\right]$ & $4.79 \pm 0.25$ & $3.96 \pm 1.86 \mathrm{a}$ & $9.65 \pm 0.85 \mathrm{~b}$ & $5.29 \pm 0.77 \mathrm{a}$ & $2.10 \pm 1.50 \mathrm{a}$ \\
\hline
\end{tabular}

Lower case letters indicate significant differences between the four treatments $(P<0.05$, Wilcoxon $U$-test $)$

$N D$ parameter not detected 


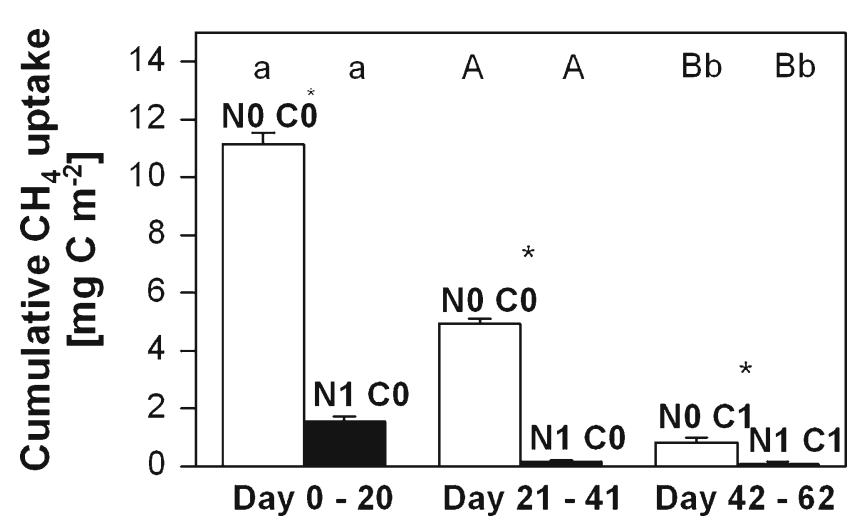

Fig. 2 Calculated cumulative $\mathrm{CH}_{4}$ uptake in the different treatments during 20 days in the first, second or third phase of the experiment. Treatment acronyms are: $\mathrm{NO}=$ no $\mathrm{NO}_{3}{ }^{-}$fertilisation, $\mathrm{NI}=\mathrm{NO}_{3}{ }^{-}$fertilisation $\left(200 \mathrm{~kg} \mathrm{~N} \mathrm{ha}^{-1}\right.$ as $\left.\mathrm{KNO}_{3}\right), C 0=$ no glucose addition, $C l=$ glucose addition $\left(9,419 \mathrm{~kg} \mathrm{C} \mathrm{ha}^{-1}\right)$. Given are means $\pm 1 \mathrm{SE}$ ( $n=8$ columns per treatment). Asterisks mark significant differences between the $\mathrm{N}$-fertilised and the respective control treatment for each phase $(P<0.05$, Tukey-Kramer test), different lower case letters indicate significant differences between the first and third experimental phases for the columns of the $C l$ and $C 0$ treatments, and capital letters mark such differences between the second and the third phases $(P<0.05$, paired $t$ test $)$

or disappeared entirely (second phase). After glucose addition, no correlation between $\mathrm{CH}_{4}$ uptake and WFPS was observed irrespective of the $\mathrm{N}$ treatment.

The supplementary experiment with $\mathrm{KNO}_{3}, \mathrm{~K}_{2} \mathrm{SO}_{4}$ or glucose addition showed after 20 days a cumulated $\mathrm{CH}_{4}$ uptake of only $2.86 \pm 0.21 \mathrm{mg} \mathrm{C} \mathrm{m}{ }^{-2}$ in the $\mathrm{KNO}_{3}$ treatment, which is equivalent to about half the rate of the control (5.84 \pm $1.2 \mathrm{mg} \mathrm{C} \mathrm{m}^{-2}$ ). In contrast, the columns treated with $\mathrm{K}_{2} \mathrm{SO}_{4}$ exhibited an enhanced uptake of $7.22 \pm 0.18 \mathrm{mg} \mathrm{C} \mathrm{m}^{-2}$, which was significantly higher than the control (Fig. 4). The glucose application resulted in the smallest cumulated $\mathrm{CH}_{4}$ fluxes of the three treatments $\left(-0.04 \pm 0.27 \mathrm{mg} \mathrm{C} \mathrm{m}^{-2}\right.$, difference significant to the other treatments).

\section{Discussion}

Our study showed that $\mathrm{KNO}_{3}$ relevantly inhibits the $\mathrm{CH}_{4}$ uptake of a temperate deciduous forest soil. We found a significant reduction of the cumulative $\mathrm{CH}_{4}$ uptake by $86 \%$ after a first addition of $\mathrm{KNO}_{3}$ equivalent to $200 \mathrm{~kg} \mathrm{~N}^{-1}$ (10.4 $\mu \mathrm{mol} \mathrm{N} \mathrm{g}^{-1}$ dry soil). A second addition of the same amount of $\mathrm{N}$ induced a further decline to a rate of only $3 \%$ of the control (i.e., a reduction by $97 \%$ ). The effect of $\mathrm{NO}_{3}{ }^{-}$on $\mathrm{CH}_{4}$ uptake was quite variable in earlier field studies and laboratory experiments. Rigler and Zechmeister-Boltenstern (1999) found a stimulation of the $\mathrm{CH}_{4}$ uptake of an acidic spruce forest soil after low inputs of $0.71 \mu \mathrm{mol} \mathrm{N} \mathrm{g}{ }^{-1}$ dry soil under laboratory conditions (which is a 15 th of the $10.4 \mu \mathrm{mol} \mathrm{N} \mathrm{g}{ }^{-1}$ dry soil applied in our study). The authors assumed that $\mathrm{CH}_{4}$ oxidising bacteria may benefit from low $\mathrm{N}$ inputs, overcoming $\mathrm{N}$ limitation of bacterial growth. In contrast, repeated high inputs of a total of 140 and $530 \mathrm{~kg} \mathrm{~N}-\mathrm{NO}_{3}{ }^{-} \mathrm{ha}^{-1}$ showed no effect on $\mathrm{CH}_{4}$ uptake of a boreal spruce forest soil under field conditions (Whalen and Reeburgh 2000). Other field and laboratory approaches support our finding of reduced $\mathrm{CH}_{4}$ uptake as a response to $\mathrm{NO}_{3}{ }^{-}$ addition (Butterbach-Bahl et al. 1998; Reay and Nedwell 2004; Ishizuka et al. 2009). Nitrate amendments from 0.17 to $29.96 \mu \mathrm{mol} \mathrm{N} \mathrm{g}{ }^{-1}$ to soils of temperate mixed hardwood and coniferous forests resulted in a reduction by $10-50 \%$ of the initial $\mathrm{CH}_{4}$ consumption (Wang and Ineson 2003; $\mathrm{Xu}$ and Inubushi 2004). A reduction by $86 \%$ and $97 \%$ measured in our study indicates an even more pronounced inhibition of $\mathrm{CH}_{4}$ uptake after two consecutive additions of $10.4 \mu \mathrm{mol} \mathrm{N} \mathrm{g}{ }^{-1}$ dry soil than reported in earlier studies.

Previous studies suggested that the mechanisms of $\mathrm{CH}_{4}$ uptake inhibition in the course of $\mathrm{NO}_{3}{ }^{-}$addition are linked to (a) substrate competition at the enzyme level and (b) noncompetitive effects by the formation of suppressing compounds. High concentrations of $\mathrm{NO}_{2}{ }^{-}$formed after the addition of $\mathrm{NO}_{3}{ }^{-}$are a well-studied inhibiting factor of microbial activity (Bancroft et al. 1979). Principally, the activity of $\mathrm{NO}_{2}^{-}$is relatively high under alkaline $\mathrm{pH}$ conditions, at low temperatures or under anaerobic conditions (van Cleemput and Samater 1995). The forest soil used in this study had a low $\mathrm{pH}$ value of 4.8 , an average temperature of $23^{\circ} \mathrm{C}$, a moisture content of less than $80 \%$ WFPS and contained an $\mathrm{O}_{2}$ concentration close to $210 \mathrm{hPa}$ (data not shown; measured with $\mathrm{O}_{2}$-sensitive micro-optodes, sensor type PSt1 with a resolution between $\pm 0.1 \mathrm{hPa} \mathrm{O}_{2}$ at concentrations of $2 \mathrm{hPa} \mathrm{O}_{2}$ and $\pm 0.87 \mathrm{hPa} \mathrm{O}$ at concentrations of $207 \mathrm{hPa} \mathrm{O}_{2}$, with a measurement range between 0 and $500 \mathrm{hPa}$, Oxy-10 mini and Microx TX3 devices, PreSens $\mathrm{GmbH}$, Regensburg, Germany). Hence, high levels of $\mathrm{NO}_{2}{ }^{-}$ are not very likely as an inhibiting factor of $\mathrm{CH}_{4}$ oxidation in our study. Several authors suggested that low osmotic potentials or salt effects caused by high cation concentrations might be another possible non-competitive inhibiting factor associated with $\mathrm{N}$ fertilisation (Crill et al. 1994; Hütsch et al. 1994; Bradford et al. 2001a, Bodelier and Laanbroek 2004). A desorption of $\mathrm{NH}_{4}{ }^{+}$from cation exchange sites by high activities of $\mathrm{H}^{+}, \mathrm{Na}^{+}$and $\mathrm{K}^{+}$cations is one possible mechanism reducing $\mathrm{CH}_{4}$ oxidation (King and Schnell 1998), while other authors suggested that a lowered soil water potential is responsible for the inhibiting effect of these cations on $\mathrm{CH}_{4}$ uptake (Nesbit and Breitenbeck 1992; Schnell and King 1996). Wang and Ineson (2003) showed that the effect of $\mathrm{K}_{2} \mathrm{SO}_{4}$ on $\mathrm{CH}_{4}$ uptake by a forest soil was only weak (7.0 to $56.1 \mu \mathrm{mol} \mathrm{K} \mathrm{g}^{-1} \mathrm{dw}$ ), whereas the same concentration of $\mathrm{KNO}_{3}$ strongly depressed consumption rates (7.1 to $56.2 \mu \mathrm{mol} \mathrm{g}^{-1} \mathrm{dw}$ of $\mathrm{N}$ and $\mathrm{K}$, respectively). In our supplementary experiment, $\mathrm{CH}_{4}$ uptake remained 
Fig. 3 Dependence of $\mathrm{CH}_{4}$ uptake rate on the water-filled pore space in the soil (WFPS) in $\mathrm{N}$-fertilised and unfertilised control columns in the first, second and third phase of the experiment (seven up to 14 measurements per phase in each eight columns per treatment). Nitrogen was added as $200 \mathrm{~kg} \mathrm{~N} \mathrm{ha}^{-1}\left(\mathrm{KNO}_{3}\right)$ at the beginning of the three phases; in the third phase, glucose $\left(9,419 \mathrm{~kg} \mathrm{C} \mathrm{ha}^{-1}\right)$ was additionally added as a labile $\mathrm{C}$ source

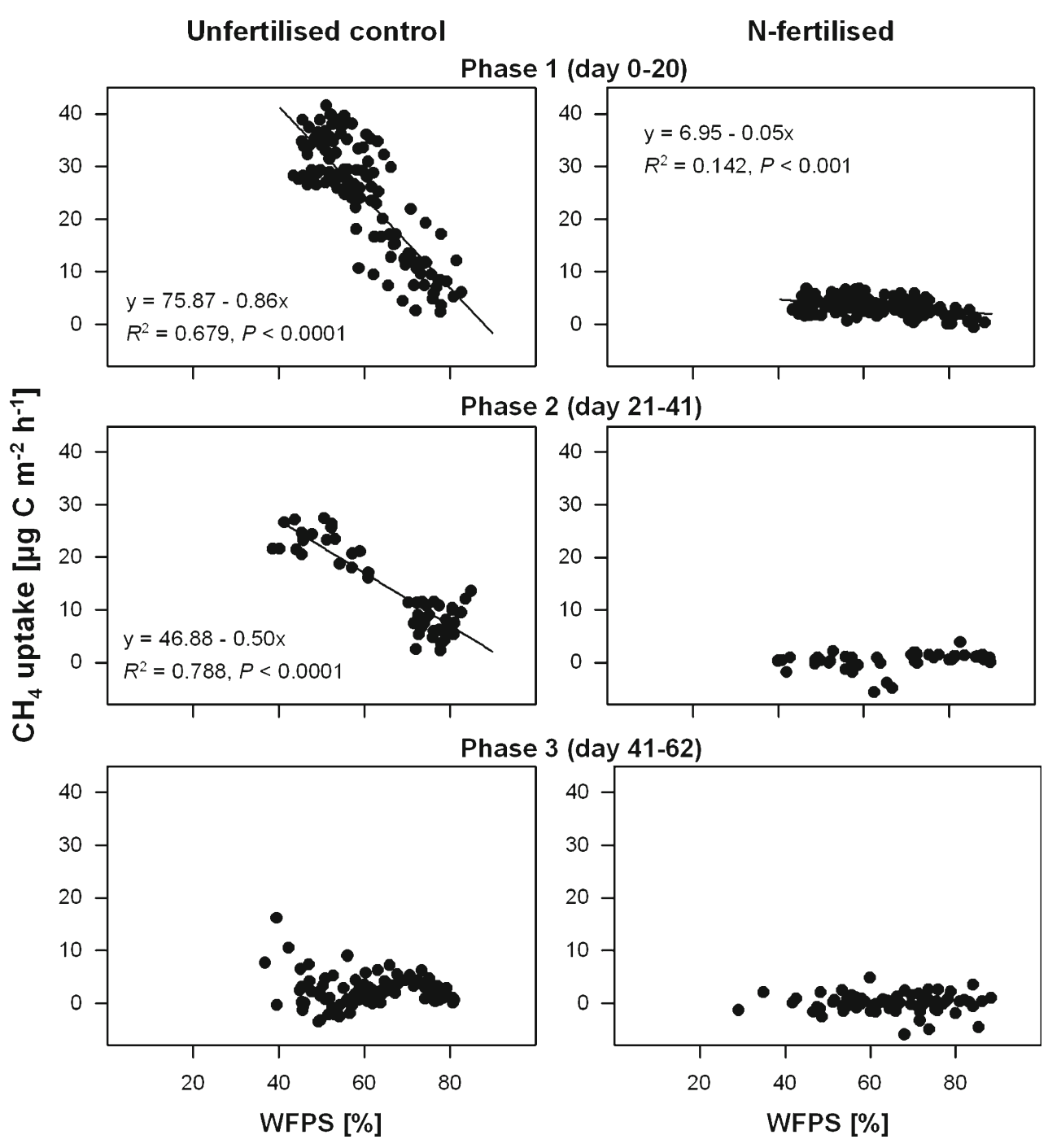

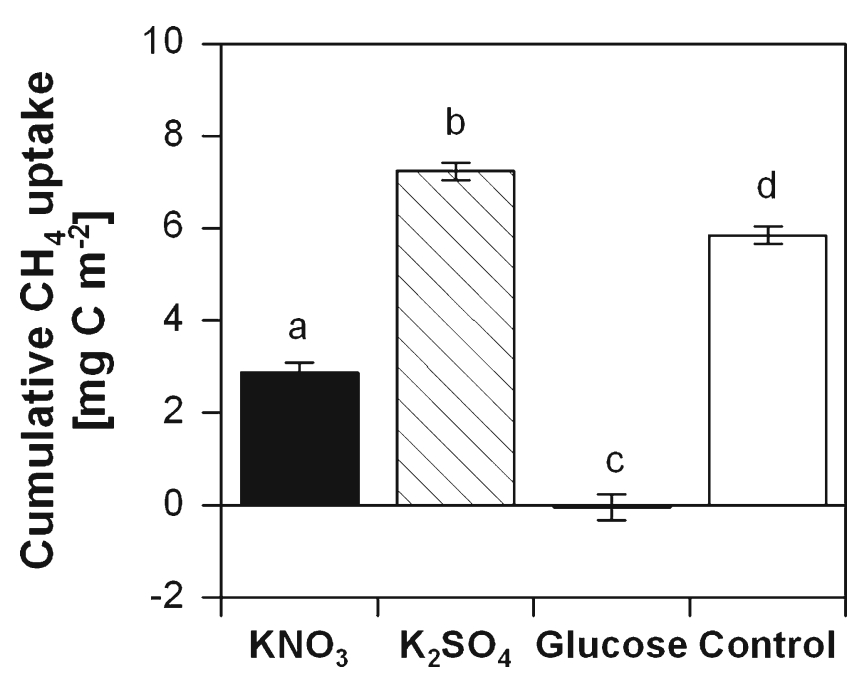

Fig. 4 Calculated cumulative $\mathrm{CH}_{4}$ uptake after the addition of $\mathrm{KNO}_{3}$, $\mathrm{K}_{2} \mathrm{SO}_{4}$ or glucose compared with the control treatment in the supplementary experiment (means $\pm 1 \mathrm{SE}, n=4)$. Lower case letters indicate significant differences between the four treatments $(P<0.05$, Tukey-Kramer test) high after the addition of $10.4 \mu \mathrm{mol} \mathrm{K} \mathrm{g}{ }^{-1} \mathrm{dw}$ in the form of $\mathrm{K}_{2} \mathrm{SO}_{4}$, while the addition of $\mathrm{KNO}_{3}$ with the same amount of $\mathrm{K}$ reduced $\mathrm{CH}_{4}$ uptake by $51 \%$. Thus, a co-determining effect of $\mathrm{K}$ on the reduction of $\mathrm{CH}_{4}$ uptake appears unlikely. The aerobic methanotrophs are a group of methylotrophic bacteria, which are able to use $\mathrm{CH}_{4}$ and other $\mathrm{C} 1$ compounds as their sole energy and $\mathrm{C}$ source (Trotsenko and Murrell 2008; Dedysh and Dunfield 2011). Recent studies also showed the existence of facultative methanotrophy in the genera Methylocystis (Belova et al. 2011; Im and Semrau 2011), Methylocapsa (Dedysh et al. 2005; Dunfield et al. 2010) and Methylocella (Dedysh et al. 2005; Theisen et al. 2005). First analysis of the bacterial community within our soil columns derived from the first phase of the experiment shows the presence of the facultative methanotroph genera Methylocystis, as well as Methylocella and Methylocapsa, but in very low abundances (data not shown). We found Nitrosospira in the unfertilised soils, but not in the fertilised soil indicating another option of $\mathrm{CH}_{4}$ oxidation using $\mathrm{NH}_{4}{ }^{+}$ monooxygenase (Holmes et al. 1995; Kolb et al. 2005, data 
not shown). In our main experiment, the $\mathrm{NH}_{4}^{+}$concentrations increased by $340 \%$ compared with the initial concentration after $\mathrm{N}$ and $\mathrm{C}$ addition and consequently, fertilised columns showed significantly higher $\mathrm{NH}_{4}^{+}$concentrations than the control columns. Similarly, in our supplementary experiment, a single addition of $\mathrm{NO}_{3}{ }^{-}$resulted in by $244 \%$ higher $\mathrm{NH}_{4}{ }^{+}$concentrations. These increases indicate that the frequently observed inhibition by $\mathrm{NH}_{4}{ }^{+}$must also play a key role for the reduction of $\mathrm{CH}_{4}$ uptake in our experiments. Why $\mathrm{NO}_{3}{ }^{-}$addition led to the strong increase in $\mathrm{NH}_{4}{ }^{+}$concentrations remains unclear. Among the possible mechanisms are a stimulation of $\mathrm{N}$ mineralisation by the $\mathrm{NO}_{3}{ }^{-}$pulse (Kuzyakov et al. 2000), the assimilation of $\mathrm{NO}_{3}{ }^{-}$in bacterial biomass and the subsequent release of $\mathrm{NH}_{4}{ }^{+}$after cell death (Cabello et al. 2009), or perhaps dissimilatory $\mathrm{NO}_{3}{ }^{-}$reduction to $\mathrm{NH}_{4}{ }^{+}$in anoxic micro-patches by bacteria.

In general, the WFPS and the $\mathrm{O}_{2}$ content of the soil are recognised to be the main controlling factors of the temporal variation in $\mathrm{CH}_{4}$ uptake (Castro et al. 1995; Bowden et al. 1998). Increased soil water content functions as a physical barrier for $\mathrm{CH}_{4}$ diffusion into the soil, thereby reducing $\mathrm{CH}_{4}$ uptake (Nesbit and Breitenbeck 1992; Castro et al. 1995). In a field study under natural $\mathrm{N}$ supply, Guckland et al. (2009) confirmed the tight negative correlation of $\mathrm{CH}_{4}$ uptake and WFPS in the soil of the Hainich forest, where the soil material of our experiment was collected. This negative relation was also found in our experiment under the unfertilised control conditions, but it disappeared with $\mathrm{NO}_{3}{ }^{-}$ addition and its dominant effect on $\mathrm{CH}_{4}$ oxidation (Fig. 3). Guckland et al. (2009) measured hourly $\mathrm{CH}_{4}$ uptake rates of 10 to $30 \mu \mathrm{g} \mathrm{C} \mathrm{m}{ }^{-2} \mathrm{~h}^{-1}$ in the National Park Hainich, where our soil material was collected, during midsummer 2007, when soil temperature was $12-14^{\circ} \mathrm{C}$ and WFPS ranged from $40 \%$ to $70 \%$. Although in our study $\mathrm{CH}_{4}$ uptake of the soil was not investigated under natural conditions, the same range of $\mathrm{CH}_{4}$ uptake was observed $\left(13-33 \mu \mathrm{g} \mathrm{C} \mathrm{m}{ }^{-2} \mathrm{~h}^{-1}\right.$, when WFPS ranged from $40 \%$ to $70 \%$ as well).

Our experiment evidenced not only the strong inhibiting effect of $\mathrm{NO}_{3}{ }^{-}$on $\mathrm{CH}_{4}$ oxidation but also a negative effect by an added labile $\mathrm{C}$ compound. With the addition of $576 \mu \mathrm{mol} \mathrm{C} \mathrm{g}^{-1} \mathrm{dw}$ soil in the form of glucose, the $\mathrm{CH}_{4}$ uptake of unfertilised soil declined by $83 \%$; adding glucose to $\mathrm{NO}_{3}{ }^{-}$-fertilised soil caused a reduction by $54 \%$ of the initial cumulative $\mathrm{CH}_{4}$ uptake under $\mathrm{NO}_{3}{ }^{-}$fertilisation in the second phase. The repression of $\mathrm{CH}_{4}$ uptake by the combined action of added $\mathrm{N}$ and $\mathrm{C}$ was in its absolute amount even larger than the single effects of $\mathrm{N}$ and $\mathrm{C}$. Compared with the control of the second experimental phase with no addition of $\mathrm{N}$ and $\mathrm{C}$, the cumulative $\mathrm{CH}_{4}$ uptake of the soil treated with $\mathrm{NO}_{3}{ }^{-}$and glucose was reduced by $99.4 \%$, more than the $86 \%$ by $\mathrm{N}$ and $83 \%$ by $\mathrm{C}$ addition. To our knowledge, only few studies so far have dealt with the underlying mechanisms of the effect of alternative labile $\mathrm{C}$ sources on $\mathrm{CH}_{4}$ oxidation (i.e., Schnell and King 1995; Benstead et al. 1998). One possible explanation for the inhibition of $\mathrm{CH}_{4}$ uptake by added labile $\mathrm{C}$ sources is the stimulation of heterotrophic microbial processes. We measured an increasing rate of $\mathrm{N}$ cycling after the addition of glucose, especially in the treatment with $\mathrm{NO}_{3}{ }^{-}$addition where the emission of $\mathrm{N}_{2} \mathrm{O}$ was strongly enforced. Nitrate-reducing microorganisms must have been abundant in the soil microbial community in the $\mathrm{N} 1 \mathrm{C} 1$ treatment while other processes such as methanotrophy were apparently suppressed. Facultative $\mathrm{CH}_{4}$ oxidizers are capable of utilising multicarbon compounds, as acetate, succinate, pyruvate, malate or ethanol as their sole $\mathrm{C}$ and energy source (Dedysh and Dunfield 2011). Thus, the obvious suppression of $\mathrm{CH}_{4}$ uptake in the last phase of our experiment could be the consequence of a shift in preference of the methylotrophic bacteria from $\mathrm{CH}_{4}$ to another multicarbon or C1 substrate, as acetate, pyruvate, ethanol or other sideproducts of glucose-utilising bacteria. The two enzymes responsible for the oxidation of $\mathrm{CH}_{4}$ are the particulate and the soluble $\mathrm{CH}_{4}$ monooxygenase (pMMO and sMMO). The genus Methylocella owns only sMMO, which is repressed in the presence of preferred $\mathrm{C}$ sources as acetate, malate or other multicarbon substrates (Theisen et al. 2005). In the case of the genera Methylocapsa and Methylacystis, which prefer $\mathrm{CH}_{4}, \mathrm{pMMO}$ and sMMO are present and not repressed in the presence of other C compounds (Dedysh and Dunfield 2011). Finally, we cannot exclude that the apparent low $\mathrm{CH}_{4}$ uptake rate observed in the $\mathrm{N} 1 \mathrm{C} 1$ treatment is partly caused by enhanced $\mathrm{CH}_{4}$ production because the addition of suitable $\mathrm{C}$ substrates may increase methanogenesis under anaerobic conditions (Topp and Pattey 1997; Dalal et al. 2007, Win et al. 2010, Sasada et al. 2011). In fact, the soil moisture conditions in our experiment (40-80\% WFPS) do not exclude the possibility that methanogenesis took place in anaerobic microsites of the not water-saturated soil (Kotiaho et al. 2010). In conclusion, our results suggest that $\mathrm{NO}_{3}{ }^{-}$and labile $\mathrm{C}$ compounds are agents that may significantly affect $\mathrm{CH}_{4}$ uptake in temperate forest soils, in addition to the known factors temperature, WFPS and $\mathrm{NH}_{4}{ }^{+}$.

For the coming decades, a significant rise in temperatures and in the precipitation extremes is predicted for the temperate zone (IPCC 2007). Another important factor will be atmospheric $\mathrm{N}$ deposition, which is expected to remain relatively high in large regions of Central Europe and eastern North America (Galloway et al. 2008). How these expected trends will affect the biogeochemical cycles in forest ecosystems and the chemical state of forest soils is a matter of recent discussion. Much current research focused on alterations of soil $\mathrm{C}$ storage and decomposition processes under changed temperature and $\mathrm{N}$ immission climates (Janssens et al. 2010), but the interaction between $\mathrm{CH}_{4}$ 
uptake and the $\mathrm{C}$ and $\mathrm{N}$ dynamics in forest soils as schematically described in Dubbs and Whalen (2010) has not received much attention yet (Thornton et al. 2007). The suppression of the $\mathrm{CH}_{4}$ oxidising community by increasing $\mathrm{N}$ may last for decades caused by the narrow and slowgrowing community (Bodelier 2011a), so that the $\mathrm{CH}_{4}$ sink of forest soils might be changed in the long-term. For a number of structurally different forest sites in the Hainich forest, Guckland et al. (2009) reported relatively high $\mathrm{CH}_{4}$ uptake rates in the range of 2.0 to $3.4 \mathrm{~kg} \mathrm{C} \mathrm{ha}^{-1}$ year ${ }^{-1}$. Guckland et al. (2009) detected no significant correlation between $\mathrm{CH}_{4}$ uptake and the soil content of $\mathrm{C}_{\text {org }}$ and $\mathrm{NO}_{3}{ }^{-}$. However, $\mathrm{N}$ deposition is rather low in the region with $13 \mathrm{~kg} \mathrm{~N} \mathrm{ha}^{-1}$ year $^{-1}$ (Mund 2004) and complementary studies in forest stands with higher $\mathrm{N}$ input are needed to analyse the interaction between soil $\mathrm{C}$ and $\mathrm{N}$ availability and $\mathrm{CH}_{4}$ oxidation under field conditions.

\section{Conclusions}

Our study supports the hypothesis of an inhibition of $\mathrm{CH}_{4}$ uptake by $\mathrm{NO}_{3}{ }^{-}$in a biologically active deciduous forest soil. The inhibition by $\mathrm{NO}_{3}^{-}$was shown to be linked to increasing $\mathrm{NH}_{4}{ }^{+}$concentrations. The hypothesis of unchanged $\mathrm{CH}_{4}$ uptake after addition of high amounts of labile $\mathrm{C}$ was disproved. In contrast, we found a strong inhibiting influence of a labile $\mathrm{C}$ source (glucose) on $\mathrm{CH}_{4}$ uptake. The simultaneous addition of $\mathrm{NO}_{3}{ }^{-}$and a labile $\mathrm{C}$ source showed that the inhibiting effects of $\mathrm{N}$ and $\mathrm{C}$ are more than additive, and the suppression of $\mathrm{CH}_{4}$ uptake by high soil moisture contents is masked by the dominant $\mathrm{N}$ and $\mathrm{C}$ influence on this process. These findings underpin the need to investigate the interactions between the availability of $\mathrm{NO}_{3}{ }^{-}$and labile $\mathrm{C}$ sources on the process of $\mathrm{CH}_{4}$ oxidation in forest soils. Clearly, our results cannot simply be extrapolated to the field situation because we conducted our experiment with $\mathrm{N}$ loads $>200 \mathrm{~kg} \mathrm{ha}^{-1}$, which is much more than the 10 to $70 \mathrm{~kg} \mathrm{~N}$ ha year ${ }^{-1}$ of $\mathrm{N}$ deposition measured currently in temperate European forests (Dise et al. 1998; Holland et al. 2005; Simpson et al. 2006). However, we used artificially high doses of $\mathrm{N}$ and labile $\mathrm{C}$ to demonstrate that the process of $\mathrm{CH}_{4}$ uptake in soils is controlled by a number of additional factors that mostly have been ignored so far. Thus, this process is more difficult to predict under changing climatic and chemical conditions in future than previously thought.

Acknowledgments This study was funded by the Ministry of Science and Culture of Lower Saxony and the "Niedersächsisches Vorab"; the support is gratefully acknowledged. We appreciate the laboratory assistance provided by Klaus Schützenmeister. We are grateful for the very helpful suggestions of the two anonymous reviewers as their comments highly improved the manuscript.

\section{References}

Adamsen APS, King GM (1993) Methane consumption in temperate and subarctic forest soils: rates, vertical zonation, and responses to water and nitrogen. Appl Environ Microbiol 59:485-490

Bancroft K, Grant IF, Alexander M (1979) Toxicity of $\mathrm{NO}_{2}$ : effect of nitrite on microbial activity in an acid soil. Appl Environ Microbiol 38:940-944

Bédard C, Knowles R (1989) Physiology, biochemistry, and specific inhibitors of $\mathrm{CH}_{4}, \mathrm{NH}_{4}{ }^{+}$, and $\mathrm{CO}$ oxidation by methanotrophs and nitrifiers. Microbiol Mol Biol Rev 53:68-84

Belova S, Baani M, Suzina N, Bodelier P, Liesack W, Dedysh S (2011) Acetate utilization as a survival strategy of peat-inhabiting Methylocystis spp. Environ Microbiol Rep 3:36-46

Bender M, Conrad R (1994) Microbial oxidation of methane, ammonium and carbon monoxide, and turnover of nitrous oxide and nitric oxide in soils. Biogeochemistry 27:97-112

Benstead J, King GM, Williams HG (1998) Methanol promotes atmospheric methane oxidation by methanotrophic cultures and soils. Appl Environ Microbiol 64:1091-1098

Bodelier PLE (2011a) Toward understanding, managing, and protecting microbial ecosystems. Front Microbiol. doi:10.3389/ fmicb.2011.00080

Bodelier PLE (2011b) Interactions between nitrogenous fertilizers and methane cycling in wetland and upland soils. Curr Opin Environ Sustainability 3:379-388

Bodelier PLE, Laanbroek HJ (2004) Nitrogen as a regulatory factor of methane oxidation in soils and sediments. FEMS Microbiol Ecol 47:265-277

Borken W, Brumme R (2009) Methane uptake by temperate forest soils. In: Brumme R, Khanna PK (eds) Functioning and management of European beech Ecosystems. Springer Verlag, Berlin Heidelberg, pp 369-385

Bowden RD, Newkirk KM, Rullo GM (1998) Carbon dioxide and methane fluxes by a forest soil under laboratory-controlled moisture and temperature conditions. Soil Biol Biochem 30:15911597

Bradford MA, Ineson P, Wookey PA, Lappin-Scott HM (2001a) The effects of acid nitrogen and acid sulphur deposition on $\mathrm{CH}_{4}$ oxidation in a forest soil: a laboratory study. Soil Biol Biochem 33:1695-1702

Bradford MA, Wookey P, Ineson P, Lappin-Scott H (2001b) Controlling factors and effects of chronic nitrogen and sulphur deposition on methane oxidation in a temperate forest soil. Soil Biol Biochem 33:93-102

Butterbach-Bahl K, Gasche R, Huber C, Kreutzer K, Papen H (1998) Impact of $\mathrm{N}$-input by wet deposition on $\mathrm{N}$-trace gas fluxes and $\mathrm{CH}_{4}$-oxidation in spruce forest ecosystems of the temperate zone in Europe. Atmos Environ 32:559-564

Cabello P, Roldán MD, Castillo F, Moreno-Vivián C (2009) Nitrogen cycle. Encyclopedia of Microbiology 1:299-321

Castro MS, Steudler PA, Melillo JM, Aber JD, Bowden RD (1995) Factors controlling atmospheric methane consumption by temperate forest soils. Global Biogeochem Cycles 9:1-10

Crill PM, Martikainen PJ, Nykänen H, Silvola J (1994) Temperature and $\mathrm{N}$ fertilization effects on methane oxidation in a drained peatland soil. Soil Biol Biochem 26:1331-13393

Crutzen PJ (1991) Methane's sinks and sources. Nature 350:380-381

Curry CL (2007) Modeling the soil consumption of atmospheric methane at the global scale. Global Biogeochem Cycles 21:GB4012. doi:10.1029/2006GB002818

Dalal RC, Allen DE, Livesley SJ, Richards G (2007) Magnitude and biophysical regulators of methane emission and consumption in the Australian agricultural, forest, and submerged landscapes: a review. Plant Soil 309:43-76 
Dedysh SN, Dunfield PF (2011) Facultative and obligate methanotrophs how to identify and differentiate them. Methods Enzymol 495:31-44

Dedysh SN, Knief C, Dunfield PF (2005) Methylocella species are facultatively methanotrophic. J Bacteriol 187:4665-4670

Denman KL, Brasseur G, Chidthaisong A, Ciais P, Cox PM, Dickinson RE, Hauglustaine D, Heinze C, Holland E, Jacob D, Lohmann U, Ramachandran S, da Silva Dias PL, Wofsy SC, Zhang X (2007) Couplings between changes in the climate system and biogeochemistry. Cambridge University Press, Cambridge, United Kingdom and New York, NY, USA

De Vries W, Solberg S, Dobbertin M, Sterba H, Laubhann D, van Oijen M, Evans C, Gundersen P, Kros J, Wamelink GWW, Reinds GJ, Sutton MA (2009) The impact of nitrogen deposition on carbon sequestration by European forests and heathlands. Forest Ecol Manag 258:1814-1823

Dezi S, Medlyn BE, Tonon G, Magnani F (2010) The effect of nitrogen deposition on forest carbon sequestration: a model-based analysis. Global Change Biol 16:1470-1486

Dise NB, Matzner E, Gundersen P (1998) Synthesis of nitrogen pools and fluxes from European forest ecosystems. Water Air Soil Poll 105:143-154

Dobbie KE, Smith KA (1996) Comparison of $\mathrm{CH}_{4}$ oxidation rates in woodland, arable and set aside soils. Soil Biol Biochem 28:13571365

Dubbs LL, Whalen SC (2010) Reduced net atmospheric $\mathrm{CH}_{4}$ consumption is a sustained response to elevated $\mathrm{CO}_{2}$ in a temperate forest. Biol Fertil Soils 46:597-606

Dunfield PF, Belova SE, Vorob'ev EV, Cornish SL, Dedysh SN (2010) Methylocapsa aurea sp. nov., a facultative methanotroph possessing a particulate methane monooxygenase, and emended description of the genus Methylocapsa. Int J Syst Evol Microbiol 60:2659-2664

Dunfield P, Knowles R (1995) Kinetics of inhibition of methane oxidation by nitrate, nitrite, and ammonium in a humisol. Appl Environ Microbiol 61:3129-3135

Dutaur L, Verchot LV (2007) A global inventory of the soil $\mathrm{CH}_{4}$ sink. Global Biogeochem Cycles 21:GB4013. doi:10.1029/ 2006GB002734

Forster P, Ramaswamy V, Artaxo P, Bertsen T, Betts R, Fahey DW, Haywood J, Lean J, Lowe DC, Myhre G, Nganga J, Prinn R, Raga G, Schulz M, Van Dorland R (2007) Changes in atmospheric constituents and in radiative forcing. Cambridge University Press, Cambridge, United Kingdom and New York, NY, USA, IPCC

Galloway JN, Cowling EB (2002) Reactive nitrogen and the world: 200 years of change. Ambio 31:64-71

Galloway JN, Townsend AR, Erisman JW, Bekunda M, Cai Z, Freney JR, Martinelli LA, Seitzinger SP, Sutton MA (2008) Transformation of the nitrogen cycle: recent trends, questions, and potential solutions. Science 320:889-892

Goldman MB, Groffman PM, Pouyat RV, McDonnell MJ, Pickett STA (1995) $\mathrm{CH}_{4}$ uptake and $\mathrm{N}$ availability in forest soils along an urban to rural gradient. Soil Biol Biochem 27:281-286

Guckland A, Flessa H, Prenzel J (2009) Controls of temporal and spatial variability of methane uptake in soils of a temperate deciduous forest with different abundance of European beech (Fagus sylvatica L.). Soil Biol Biochem 41:1659-1667

Gulledge J, Schimel JP (1998) Low-concentration kinetics of atmospheric $\mathrm{CH}_{4}$ oxidation in soil and mechanism of $\mathrm{NH}_{4}{ }^{+}$inhibition. Appl Environ Microbiol 64:4291-4298

Holland EA, Braswell BH, Sulzman J, Lamarque J-F (2005) Nitrogen deposition onto the United States and Western Europe: synthesis of observations and models. Ecol Appl 15:38-57

Holland EA, Dentener FJ, Braswell BH, Sulzman JM (1999) Contemporary and pre-industrial global reactive nitrogen budgets. Biogeochemistry $46: 7-43$
Holmes AJ, Costello A, Lidstrom ME, Murrell JC (1995) Evidence that particulate methane monooxygenase and ammonia monooxygenase may be evolutionarily related. FEMS Microbiol Lett 132:203-208

Hütsch BW, Webster CP, Powlson DS (1994) Methane oxidation in soil as affected by land use, soil $\mathrm{pH}$ and $\mathrm{N}$ fertilization. Soil Biol Biochem 26:1613-1622

Im J, Semrau JD (2011) Pollutant degradation by a Methylocystis strain SB2 grown on ethanol: bioremediation via facultative methanotrophy. FEMS Microbiol Lett 318:137-142

IPCC (2007) Climate change 2007: Synthesis report. Contribution of working groups I, II and III to the fourth assessment report of the Intergovernmental Panel on Climate Change. IPCC, Geneva, Switzerland

Ishizuka S, Sakata T, Sawata S, Ikeda S, Sakai H, Takenaka C, Tamai N, S-ichi O, Shimizu T, Kan-na K, Tanaka N, Takahashi M (2009) Methane uptake rates in Japanese forest soils depend on the oxidation ability of topsoil, with a new estimate for global methane uptake in temperate forest. Biogeochemistry 92:281-295

IUSS Working Group WRB (2007) World reference base for soil resources 2006, first update 2007. FAO, Rome

Jang I, Lee S, Hong J-H, Kang H (2006) Methane oxidation rates in forest soils and their controlling variables: a review and a case study in Korea. Ecol Res 21:849-854

Janssens IA, Dieleman W, Luyssaert S, Subke J-A, Reichstein M, Ceulemans R, Ciais P, Dolman AJ, Grace J, Matteucci G, Papale D, Piao SL, Schulze E-D, Tang J, Law BE (2010) Reduction of forest soil respiration in response to nitrogen deposition. Nature Geosci 3:315-322

Kasimir-Klemedtsson Å, Klemedtsson L, Berglund K, Martikainen P, Silvola J, Oenema O (1997) Greenhouse gas emissions from farmed organic soils: a review. Soil Use Manage 13:245-250

King GM, Schnell S (1998) Effects of ammonium and non-ammonium salt additions on methane oxidation by Methylosinus trichosporium $\mathrm{OB} 3 \mathrm{~b}$ and Maine forest soils. Appl Environ Microbiol 64:253-257

King GM, Schnell S (1994a) Effect of increasing atmospheric methane concentration on ammonium inhibition of soil methane consumption. Nature 370:282-284

King GM, Schnell S (1994b) Ammonium and nitrite inhibition of methane oxidation by Methylobacter albus BG8 and Methylosinus trichosporium $\mathrm{OB} 3 \mathrm{~b}$ at low methane concentrations. Appl Environ Microbiol 60:3508-3513

Kolb S, Knief C, Dunfield PF, Conrad R (2005) Abundance and activity of uncultured methanotrophic bacteria involved in the consumption of atmospheric methane in two forest soils. Environ Microbiol 7:1150-1161

Kotiaho M, Fritze H, Merilä P, Juottonen H, Leppälä M, Laine J, Laiho R, Yrjälä K, Tuittila E-S (2010) Methanogen activity in relation to water table level in two boreal fens. Biol Fertil Soils 46:567-575

Kuzyakov Y, Friedel J, Stahr K (2000) Review of mechanisms and quantification of priming effects. Soil Biol Biochem 32:1485-1498

Le Mer J, Roger P (2001) Production, oxidation, emission and consumption of methane by soils: A review. Eur J Soil Biol 37:25-50

Liu L, Greaver TL (2009) A review of nitrogen enrichment effects on three biogenic GHGs: the $\mathrm{CO}_{2}$ sink may be largely offset by stimulated $\mathrm{N}_{2} \mathrm{O}$ and $\mathrm{CH}_{4}$ emission. Ecol Lett 12:1103-1117

Loftfield N, Flessa H, Augustin J, Beese F (1997) Automated gas chromatographic system for rapid analysis of the atmospheric trace gases methane, carbon dioxide, and nitrous oxide. J Environ Qual 26:560-564

MacDonald JA, Skiba U, Sheppard LJ, Ball B, Roberts JD, Smith KA, Fowler D (1997) The effect of nitrogen deposition and seasonal variability on methane oxidation and nitrous oxide emission rates in an upland spruce plantation and moorland. Atmos Environ 31:3693-3706 
Magnani F, Mencuccini M, Borghetti M, Berbigier P, Berninger F, Delzon S, Grelle A, Hari P, Jarvis PG, Kolari P, Kowalski AS, Lankreijer H, Law BE, Lindroth A, Loustau D, Manca G, Moncrieff JB, Rayment M, Tedeschi V, Valentini R, Grace J (2007) The human footprint in the carbon cycle of temperate and boreal forests. Nature 447:848-850

Mancinelli RL (1995) The regulation of methane oxidation in soil. Annu Rev Microbiol 49:581-605

Mund M (2004) Carbon pools of European beech forests (Fagus sylvatica) under different silvicultural management. $\mathrm{PhD}$ thesis, Faculty of Forestry and Forest Ecology, University of Göttingen

Nadelhoffer KJ, Emmett BA, Gundersen P, Kjonaas OJ, Koopmans CJ, Schleppi P, Tietema A, Wright RF (1999) Nitrogen deposition makes a minor contribution to carbon sequestration in temperate forests. Nature 398:145-148

Nesbit SP, Breitenbeck GA (1992) A laboratory study of factors influencing methane uptake by soils. Agr Ecosyst Environ 41:39-54

Priemé A, Christensen S (1997) Seasonal and spatial variation of methane oxidation in a Danish spruce forest. Soil Biol Biochem 29:1165-1172

Reay DS, Nedwell DB (2004) Methane oxidation in temperate soils: effects of inorganic N. Soil Biol Biochem 36:2059-2065

Rigler E, Zechmeister-Boltenstern S (1999) Oxidation of ethylene and methane in forest soils-effect of $\mathrm{CO}_{2}$ and mineral nitrogen. Geoderma 90:147-159

Sasada Y, Win KT, Nonaka R, Win AT, Toyota K, Motobayashi T, Hosomi M, Dingjiang C, Lu J (2011) Methane and $\mathrm{N}_{2} \mathrm{O}$ emissions, nitrate concentrations of drainage water, and zinc and copper uptake by rice fertilized with anaerobically digested cattle or pig slurry. Biol Fertil Soils 47:949-956

Schlichting E, Blume H-P, Stahr K (1995) Bodenkundliches PraktikumEine Einführung in pedologisches Arbeiten für Ökologen, insbesondere Land- und Forstwirte und für Geowissenschaftler. Blackwell Wissenschaft, Berlin

Schnell S, King G (1996) Responses of methanotrophic activity in soils and cultures to water stress. Appl Environ Microbiol 62:3203-3209

Schnell S, King GM (1995) Stability of methane oxidation capacity to variations in methane and nutrient concentrations. FEMS Microbiol Ecol 17:285-294

Simpson D, Butterbach-Bahl K, Fagerli H, Kesik M, Skiba U, Tang S (2006) Deposition and emissions of reactive nitrogen over European forests: a modelling study. Atmos Environ 40:5712-5726
Smith KA, Dobbie KE, Ball BC, Bakken LR, Sitaula BK, Hansen S, Brumme R, Borken W, Christensen S, Priemé A, Fowler D, Macdonald JA, Skiba U, Klemedtsson L, Kasimir-Klemedtsson A, Degórska A, Orlanski P (2000) Oxidation of atmospheric methane in Northern European soils, comparison with other ecosystems, and uncertainties in the global terrestrial sink. Global Change Biol 6:791-803

Steinkamp R, Butterbach-Bahl K, Papen H (2001) Methane oxidation by soils of an $\mathrm{N}$ limited and $\mathrm{N}$ fertilized spruce forest in the Black Forest, Germany. Soil Biol Biochem 33:145-153

Theisen AR, Ali MH, Radajewski S, Dumont MG, Dunfield PF, McDonald IR, Dedysh SN, Miguez CB, Murrell JC (2005) Regulation of methane oxidation in the facultative methanotroph Methylocella silvestris BL2. Mol Microbiol 58:682-692

Thornton PE, Lamarque JF, Rosenbloom NA, Mahowald NM (2007) Influence of carbon-nitrogen cycle coupling on land model response to $\mathrm{CO}_{2}$ fertilization and climate variability. Global Biogeochem Cycles 21:GB4018. doi: 10.1029/2006GB002868

Topp E, Pattey E (1997) Soils as sources and sinks for atmospheric methane. Can J Soil Sci 77:167-177

Trotsenko YA, Murrell JC (2008) Metabolic aspects of aerobic obligate methanotrophy. Adv Appl Microbiol 63:183-229

Van Cleemput O, Samater AH (1995) Nitrite in soils: accumulation and role in the formation of gaseous $\mathrm{N}$ compounds. Fert Res 45:81-89

Wang Z-P, Ineson P (2003) Methane oxidation in a temperate coniferous forest soil: effects of inorganic N. Soil Biol Biochem 35:427433

Whalen SC (2000) Influence of $\mathrm{N}$ and non- $\mathrm{N}$ salts on atmospheric methane oxidation by upland boreal forest and tundra soils. Biol Fertil Soils 31:279-287

Whalen SC, Reeburgh WS (2000) Effect of nitrogen fertilization on atmospheric methane oxidation in boreal forest soils. Chemosphere 2:151-155

Win KT, Nonaka R, Toyota K, Motobayashi T, Hosomi M (2010) Effects of option mitigating ammonia volatilization on $\mathrm{CH}_{4}$ and $\mathrm{N}_{2} \mathrm{O}$ emissions from a paddy field fertilized with anaerobically digested cattle slurry. Biol Fertil Soils 46:589-595

Xu X, Inubushi K (2004) Effects of N sources and methane concentrations on methane uptake potential of a typical coniferous forest and its adjacent orchard soil. Biol Fertil Soils 40:215-221 
2.

\section{$\mathbf{N}$ fertilization shapes the composition and diversity of active soil bacterial communities}

Birgit Pfeiffer ${ }^{1)}$, Ann-Catrin Fender ${ }^{2)}$, Hermann F. Jungkunst $^{3)}$ and Rolf Daniel ${ }^{1)}$

Manuscript draft

\footnotetext{
${ }^{1)}$ Genomic and Applied Microbiology, University of Goettingen, Grisebachstr. 8, 37077 Goettingen, Germany

${ }^{2)}$ Plant Ecology and Ecosystems research, University of Goettingen, Untere Karspüle 2, 37073 Goettingen, Germany

${ }^{3)}$ Geoecology Physical Geography, Insitute for Environmental Sciences, University of KoblenzLandau, Fortstr. 7, 76829 Landau, Germany
}

\section{Author contributions to the work:}

Performed the experiments: B. Pfeiffer, AC. Fender Analyzed the data: B. Pfeiffer, AC. Fender

Wrote the paper: $\quad$ B. Pfeiffer, HF. Jungkunst, R. Daniel

Conceived and designed the experiments: HF. Jungkunst, B. Pfeiffer, R. Daniel 


\begin{abstract}
The anthropogenic input of nitrogen species into soil alters the labile carbon pool and thereby enhances the microbial-driven release of nitrous oxide and inhibits microbialdriven methane uptake. To study the influence of highly elevated nitrogen inputs (200 $\mathrm{kg} \mathrm{N} \mathrm{ha}{ }^{-1} \mathrm{yr}^{-1}$ ) on the active prokaryotic community a microcosm experiment was carried out using topsoil from a temperate broad-leaved forest. Diversity and composition of the active prokaryotic soil community (Bacteria and Archaea) were assessed by pyrosequencing-based analysis of 16S rRNA amplicons generated from environmental RNA. The soil bacterial communities were dominated by Proteobacteria, Acidobacteria, Chloroflexi, Actinobacteria and Firmicutes, and the archaeal community by Thaumarchaeota.

Fertilization reduced the diversity of active soil bacterial communities significantly at all levels of genetic divergence. Furthermore, the bacterial community structure changed over time towards a denitrifying bacterial community. We observed a significant increase of the genus Rhodanobacter, which is capable of complete denitrification, from $2.36 \pm 0.9 \%$ in non-fertilized samples to $46.87 \pm 20.3 \%$ in fertilized samples. The archaeal community composition was not significantly affected by fertilization. Furthermore, it was indicated that low-abundant methanotrophic bacteria contributed significantly to the uptake of methane in the analyzed forest soil. Thus, fertilization shaped the present active bacterial community and resulted in reduction of bacterial diversity. Greenhouse gas fluxes were influenced negatively by fertilization, potentially causing a higher global warming feedback due to inhibited methane uptake and higher $\mathrm{N}_{2} \mathrm{O}$ emissions.
\end{abstract}




\section{Introduction}

Human activity considerably altered the nitrogen $(\mathrm{N})$ cycle by an increased $\mathrm{N}$ release into the atmosphere, which is followed by increasing $\mathrm{N}$ deposition into soils, ground water and surface water [1-3]. The anthropogenic sources leading to an increased release of nitrogen in the form of nitrogen oxides $\left(\mathrm{NO}_{\mathrm{x}}\right)$, nitrous oxide $\left(\mathrm{N}_{2} \mathrm{O}\right)$ and ammonia $\left(\mathrm{NH}_{3}\right)$ are animal breeding, crop production, $\mathrm{N}$ fertilization of agricultural sites, fuel combustion, biomass burning, and industrial processes [4]. Consequently, atmospheric anthropogenic $\mathrm{N}$ deposition into forest soils increased more than ten-fold over the past two centuries [5-8]. $\mathrm{N}$ deposition rates of 10 to $70 \mathrm{~kg} \mathrm{~N} \mathrm{ha}^{-1} \mathrm{yr}^{-1}$ were measured in temperate European forests [6,9-11]. As the structure and function of soil microbial communities are affected by $\mathrm{N}$ and carbon availability, the anthropogenic depositions of nitrogen in form of $\mathrm{NH}_{4}{ }^{+}$and $\mathrm{NO}_{\mathrm{x}}$ shape soil bacterial community composition [12-14]. Microbial biomass in forest soil is influenced negatively by $\mathrm{N}$ fertilization $[15,16]$. Soil microbial communities play an essential role in environmental key processes, such as organic material breakdown, mineralization and nutrient cycling and are the main drivers of the global $\mathrm{N}$ and $\mathrm{C}$ cycle $[17,18]$. Moreover, biologically driven processes as nitrogen $\left(\mathrm{N}_{2}\right)$ fixation, nitrification and denitrification are key reactions of the global $\mathrm{N}$ cycle [19]. Soil processes, releasing $\mathrm{N}_{2} \mathrm{O}$ to the atmosphere are nitrification and denitrification. The latter contributes most to the release of $\mathrm{N}_{2} \mathrm{O}$ [2022]. Parameters controlling denitrification in soils are $\mathrm{NO}_{3}{ }^{-}$concentration, soil aeration and the availability of labile $\mathrm{C}$, which serves as energy source for $\mathrm{NO}_{3}{ }^{-}$catabolism [2326].

Forests are important constituents of the global $\mathrm{C}$ and $\mathrm{N}$ cycle. Large fractions of $\mathrm{C}$ and $\mathrm{N}$ are stored in forest soil [3,27]. Furthermore, forests are considered to be an important sink of $\mathrm{CH}_{4}$ and a relevant source of $\mathrm{N}_{2} \mathrm{O}$ emission [28,29]. Both processes are in terms of global warming influenced negatively by $\mathrm{N}$ depositions, as $\mathrm{CH}_{4}$ uptake is inhibited and $\mathrm{N}_{2} \mathrm{O}$ emissions are enhanced [30,31]. Nitrogen interacts strongly with the $\mathrm{C}$ cycle and thereby affects the carbon dioxide $\left(\mathrm{CO}_{2}\right)$ and methane $\left(\mathrm{CH}_{4}\right)$ balance [30,31]. Methane is in addition to $\mathrm{N}_{2} \mathrm{O}$ and $\mathrm{CO}_{2}$ an important greenhouse gas. The atmospheric concentration of $\mathrm{CH}_{4}$ increased over the last 150 years from $715 \mathrm{ppb}$ in pre-industrial times to $1774 \mathrm{ppb}$ nowadays [32]. Main sinks of atmospheric $\mathrm{CH}_{4}$ are the oxidation to $\mathrm{CO}_{2}$ by hydroxyl radicals in the atmosphere, the consumption in aerobic soils by methylotrophic and methanotrophic soil microorganisms and nitrifying soil 
microorganisms in anaerobic soil microenironments [33-35]. Dutaur and Verchot [29] found higher $\mathrm{CH}_{4}$ uptake rates in forests than in other ecosystems such as grassland or tundra

In addition, $\mathrm{N}$ in its various forms impacts directly or indirectly four of the most reactive greenhouse gases $\left(\mathrm{CH}_{4}, \mathrm{~N}_{2} \mathrm{O}, \mathrm{CO}_{2}\right.$ and $\left.\mathrm{O}_{3}\right)$ [30-32]. Thus, it is crucial to understand the impact of elevated $\mathrm{N}$ deposition into soils on the active microbial community and the resulting influence on greenhouse gas fluxes. The aim of this study was to increase the understanding of the influence of high $\mathrm{NO}_{3}{ }^{-}$inputs on the diversity and community composition of active bacterial and archaeal groups present in forest soils. We hypothesized (1) that $\mathrm{N}$ fertilization reduces the diversity and shapes the community structure of active soil microbiota by promoting denitrifying bacterial and archaeal communities. Furthermore, we hypothesized (2) that the addition of high concentrations of $\mathrm{N}\left(200 \mathrm{~kg} \mathrm{~N} \mathrm{ha}^{-1} \mathrm{yr}^{-1}\right)$ leads to a irreversible loss of bacterial diversity and as a consequence to a collapse of microbial-driven biogeochemical processes. 


\section{Material and Methods}

\section{Soil Sampling, Soil Characteristics and Experimental Set-up}

To analyze the changes of microbial community composition under ambient and elevated $\mathrm{N}$ supply soil material was collected from the upper $0-10 \mathrm{~cm}$ of the soil profile from a mixed broad-leaved temperate forest in the Hainich National Park, Thuringia, Germany $\left(51^{\circ} 04^{\prime} \mathrm{N} 10^{\circ} 30^{\prime} \mathrm{E}\right)$. Permits were kindly provided by the state environmental office responsible for the National Park Hainich (Nationalpark Verwaltung Hainich, Bad Langensalza, Germany). The samples were frozen in liquid nitrogen and stored at $80^{\circ} \mathrm{C}$ prior to extraction of RNA.The soil type was characterized as Stagnic Luvisol (IUSS Working Group WRB, 2007), which was composed of $1.8 \%$ sand, $80.2 \%$ silt and $18.1 \%$ clay. The $\mathrm{pH}_{\mathrm{KCl}}$ value was 3.8 and base saturation $22.9 \%$. The soil contained $19.84 \pm 0.44 \mathrm{~g} \mathrm{~kg}^{-1}$ dry weight organic $\mathrm{C}\left(\mathrm{C}_{\text {org }}\right)$ and $1.89 \pm 0.03 \mathrm{~g} \mathrm{~kg}^{-1}$ dry weight total nitrogen $\left(\mathrm{N}_{\text {total }}\right)$. The $\mathrm{C}: \mathrm{N}$ ratio was $10.5 \pm 0.19 \mathrm{~g} \mathrm{~g}^{-1}$. The soil was free of carbonate (< $0.02 \%$ of total C). Acrylic glass columns $(\mathrm{n}=16)$ with a height of $0.5 \mathrm{~m}$ and a diameter of $0.17 \mathrm{~m}$ were filled each with $4 \mathrm{~kg}$ of freshly sieved and homogenized soil. These soil microcosms were placed randomly in a laboratory and kept untreated for 62 days to allow the microbial community to adapt to the soil and climatic conditions, and establish a stable gas exchange after disturbance of the natural soil structure. At starting day of the experiment, eight randomly selected microcosms were fertilized using a solution of $\mathrm{KNO}_{3}$ in deionized water, equivalent to $200 \mathrm{~kg} \mathrm{~N} \mathrm{ha}^{-1}$. The volume of water added to the soil was adjusted to establish a water-filled pore space (WFPS) of $80 \%$. At day 20, a second $\mathrm{N}$ application was conducted. At day 3 and day 41 of the experiment, soil samples were taken directly after gas flux measurements from the upper $10 \mathrm{~cm}$ of each of the 16 microcosms. The samples were used for analyses of the soil-inhabiting microbial community and soil parameters. Soil characteristics were obtained at the beginning and end of the experiment as described by Fender and co-workers [36].

\section{Gas Flux Analysis}

The $\mathrm{CO}_{2}, \mathrm{CH}_{4}$ and $\mathrm{N}_{2} \mathrm{O}$ gas flux analyses were performed three times per week in the headspace of the soil microcosms. The headspace volume in the acrylic glass columns was 8.6 L. The columns were closed during the gas sampling for $1 \mathrm{~h}$. After 0, 20, 40 and $60 \mathrm{~min}$, gas samples were taken from the columns headspace by flushing gas-tight 50 $\mathrm{ml}$ sample syringes with headspace air using a needle and two three-way valves. The 
gas concentrations were analyzed by a computer-controlled gas chromatographic system with a ${ }^{63} \mathrm{Ni}$ electron capture detector for $\mathrm{CO}_{2}, \mathrm{CH}_{4}$ and $\mathrm{N}_{2} \mathrm{O}$ (Shimadzu GC-14B, Kyoto, Japan). The gas fluxes were calculated from the linear increase of the gas concentration recorded during lid closure.

Statistical analyses were performed using SAS 9.1 software (Statistical Analysis System, SAS Institute Inc., Cary, USA). Cumulative gas fluxes were calculated by summing up all measurements for each column considering the number of measurements and the corresponding duration of the measuring phase. Frequency distributions were tested for normality with the Shapiro-Wilk test. One-way GLM with a Tukey-Kramer post hoc test was used to identify significant differences among the $\mathrm{N}$ treatment means for cumulative $\mathrm{N}_{2} \mathrm{O}, \mathrm{CH}_{4}$ and $\mathrm{CO}_{2}$ fluxes and soil properties in the datasets with normal distribution. Non-normally distributed soil parameters were analysed with the Wilcoxon U-test. Linear regression analysis was conducted to relate $\mathrm{CH}_{4}$ flux to WFPS. For all analyses, significance was determined at $\mathrm{P}<0.05$.

\section{Extraction of RNA}

Total RNA was isolated from $2 \mathrm{~g}$ of soil per sample using the RNA PowerSoil ${ }^{\mathrm{TM}}$ total RNA isolation kit as recommended by the manufacturer (MO BIO Laboratories Inc., Carlsbad, CA, USA). The resulting RNA pellet was dissolved in $100 \mu 1$ RNase-free water. Residual DNA contaminations were removed using the TURBO DNA-free ${ }^{\mathrm{TM}}$ kit (Ambion Applied Biosystems, Darmstadt, Germany) as described by the manufacturer. Subsequently, DNase-treated RNA was purified and concentrated using the RNeasy MinElute cleanup kit (Qiagen GmbH, Hilden, Germany). The concentration of the RNA extracts was quantified using a NanoDrop ND-1000 spectrophotometer (Peqlab Biotechnologie $\mathrm{GmbH}$, Erlangen, Germany). Additionally, the RNA integrity and concentration was checked using the Agilent 2100 Bioanalyzer and the Agilent RNA 6000 Nano kit (Agilent Technologies, Inc., Santa Clara CA, USA) as recommended by the manufacturer.

\section{Amplification and Sequencing of 16S rRNA and Other Transcripts}

To analyze the active bacterial community within soil columns, the V2-V3 region of 16S rRNA gene transcripts was reverse transcribed, amplified and the resulting PCR products were applied to pyrosequencing. Additionally, the active archaeal and methanotrophic community was analyzed by amplicon-based approaches. The used 
specific primer sets contained the Roche 454 pyrosequencing adaptors (underlined) and different GS FLX Standard Multiplex Identifiers (MID) consisting of ten bases. For Bacteria the forward primer used was V2for CGTATCGCCTCCCTCGCGCCATCAGMID-AGTGGCGGACGGGTGAGTAA and the reverse primer used was V3rev CTATGCGCCTTGCCAGCCCGCTCAG-MID-CGTATTACCGCGGCTGCTG (modified from [37]). For amplification of archaeal 16S rRNA genes the forward primer Arch8F CGTATCGCCTCCCTCGCGCCATCAG-MID-TCCGGTTGATCCTGCCGG [38] and the reverse primer Arch958R CTATGCGCCTTGCCAGCCCGCTCAG-MIDYCCGGCGTTGAMTCCAATT [39] were used. The methanotrophic community was analyzed using the following primer sets specific for type I and type II methanotrophs: Type

\section{CTATGCGCCTTGCCAGCCCGCTCAG-MID-CCATGGTGTTCCTTCMGAT}

(modified from [40]), and type II CGTATCGCCTCCCTCGCGCCATCAG-MIDGGGAMGATAATGACGGTACCWGGA

and

CTATGCGCCTTGCCAGCCCGCTCAG-MID-GTCAARAGCTGGTAAGGTTC [40].

The cDNA synthesis was performed using the SuperScript ${ }^{\mathrm{TM}}$ III reverse transcriptase (Invitrogen, Karlsruhe). For initial denaturation and primer annealing, a mixture (14 $\mu 1)$ containing $100 \mathrm{ng}$ of isolated DNA-free RNA, as well as $2 \mu \mathrm{M}$ of the reverse primer and $10 \mathrm{mM}$ dNTP mix was incubated for $5 \mathrm{~min}$ at $65^{\circ} \mathrm{C}$ and chilled on ice for at least 1 min. The cDNA synthesis mixture $(6 \mu 1)$ containing $4.0 \mu \mathrm{l} 5$-fold first strand buffer, 0.1 M DTT, 40 U RiboLock RNase inhibitor (MBI Fermentas, St. Leon-Rot, Germany), and $200 \mathrm{U}_{\text {SuperScript }}{ }^{\mathrm{TM}}$ III reverse transcriptase was incubated at $55{ }^{\circ} \mathrm{C}$ for $90 \mathrm{~min}$. The reaction was terminated at $70{ }^{\circ} \mathrm{C}$ for $15 \mathrm{~min}$. For the amplification of the cDNA fragments, the Phusion ${ }^{\circledR}$ hot start high-fidelity DNA polymerase (FINNZYMES, Espoo, Finland) was used. The PCR reaction mixture $(50 \mu \mathrm{l})$ contained $10.0 \mu \mathrm{l}$ 5-fold Phusion HF buffer (FINNZYMES,), $200 \mu \mathrm{M}$ of each of the four deoxynucleoside triphosphates, $1.25 \%$ DMSO, $2 \mu \mathrm{M}$ of each primer, $0.5 \mathrm{U}$ DNA polymerase and $0.25 \mu 1$ of the previously synthesized cDNA. The thermal cycling scheme was applied as follows: initial denaturation at $98{ }^{\circ} \mathrm{C}$ for $3 \mathrm{~min}, 25$ cycles of denaturation at $98{ }^{\circ} \mathrm{C}$ for $15 \mathrm{~s}$, annealing and extension at $72{ }^{\circ} \mathrm{C}$ for $20 \mathrm{~s}$, followed by a final extension period at $72{ }^{\circ} \mathrm{C}$ for $2.5 \mathrm{~min}$. All samples were amplified in triplicate, pooled and purified using the peqGold gel extraction kit (Peqlab Biotechnologie GmbH, Erlangen, Germany). The PCR products were quantified using the Quant-iT dsDNA BR assay kit and a Qubit 
fluorometer (Invitrogen). The Göttingen Genomics Laboratory determined the sequences of the partial 16S rRNA gene transcripts using a Roche GS-FLX 454 pyrosequencer and Titanium chemistry (Roche, Mannheim, Germany). The resulting sequence data have been deposited in the NCBI sequence read archive (SRA) under accession number SRA061821.

\section{Processing of Pyrosequencing-derived Datasets}

Forward and reverse primer sequences as well as sequences shorter than $300 \mathrm{bp}$ were removed from the pyrosequencing-derived datasets using the QIIME software package [41]. In addition, sequences containing long homopolymers (>8 bp), unresolved bases or bases with an average quality score below 25 were removed using the QIIME script split_libraries.py (supplemental Table S1). Denoising of the remaining sequences was carried out using the denoiser program version 0.91 [42]. Additionally, we removed unclipped reverse primer sequences, which were not detected by split_library.py, using cutadapt with default settings [43]. Operational taxonomic units (OTUs) were determined by UCLUST OTU picker $1.2 .22 q$ [44] at 3, 5, 10 and $20 \%$ genetic divergence according to Schloss and Handelsmann [45]. Potential chimeric sequences were removed by aligning representative sequences of each OTU using PyNast 1.1 [46] and subsequent analysis using ChimeraSlayer 4.29 [47]. Rarefaction curves and diversity indices (Shannon, ACE, Chao1 and Michaelis-Menten fit) were calculated by employing the QIIME script alpha_diversity.py at the same level of surveying effort. To allow comparison to non-QIIME-based analysis, we corrected the Shannon index by multiplying it with $\ln 2$. Taxonomic classification was performed by comparison of the OTUs clustered at 3\% genetic divergence with the most recent copy of the SILVA ribosomal RNA database using BLAST [48]. To compare the bacterial and archaeal communities and the calculated diversity indices of non-fertilized and fertilized soil samples, and identify significant differences between these treatment groups the t-test and for not normal-distributed data the Mann-Whitney-test was applied using SigmaPlot (Systat Software GmbH, Erkrath, Germany). Additionally, a redundancy analysis (RDA) was performed using Canoco 4.5 (Microcomputer Power, Ithaca, NY, USA). 


\section{Results and Discussion}

\section{Diversity and General Characteristics of the Analyzed Bacterial Communities}

To identify the dominant active bacterial taxa and analyze the active bacterial community derived from $\mathrm{N}$-fertilized and non-fertilized soil samples the V2-V3 region of the 16S rRNA was amplified and sequenced. After preprocessing including quality filtering and denoising, 87,610 high-quality sequences with an average read length of 404 bases were recovered and analyzed (supplemental Table S1). We were able to assign all sequences to the domain Bacteria and classify them all below the domain level. Operational taxonomic units (OTUs) were identified at 3, 5, 10 and 20\% sequence divergence and the same level of surveying effort (3,800 randomly selected sequences per sample). Subsequently, rarefaction curves, richness and diversity indices were determined.

At phylum level (20\% genetic divergence), rarefaction curves of all samples were almost saturated, indicating that the survey effort covered almost the full taxonomic diversity present in the analyzed soil samples. Estimates of the bacterial diversity using Michaelis-Menten fit indicated that 84 to $92 \%$ of the expected taxonomic diversity at phylum level was covered by the surveying effort (supplementary Table S2 and Table S3). At 3, 5 and $10 \%$ sequence divergence rarefaction curves were not saturated. Using Michaelis-Menten fit coverages of 71 to $80 \%$ were estimated. Thus, at higher taxonomic resolutions a substantial fraction, but not the full extent of taxonomic diversity was covered by the surveying effort. Other amplicon-based studies, which analyzed different forest and grassland soils, observed a similar coverage [49, 50,51]. The Shannon index of diversity $\left(\mathrm{H}^{\prime}\right)$ was used to quantify and compare bacterial diversity in the soil microcosms, as suggested by Haegeman et al. [52]. At 3\% sequence divergence, the values ranged from 2.4 to 5.32, suggesting that the diversity in the analyzed fertilized and non-fertilized microcosms varies strongly (supplementary Tables S2 and S3). 


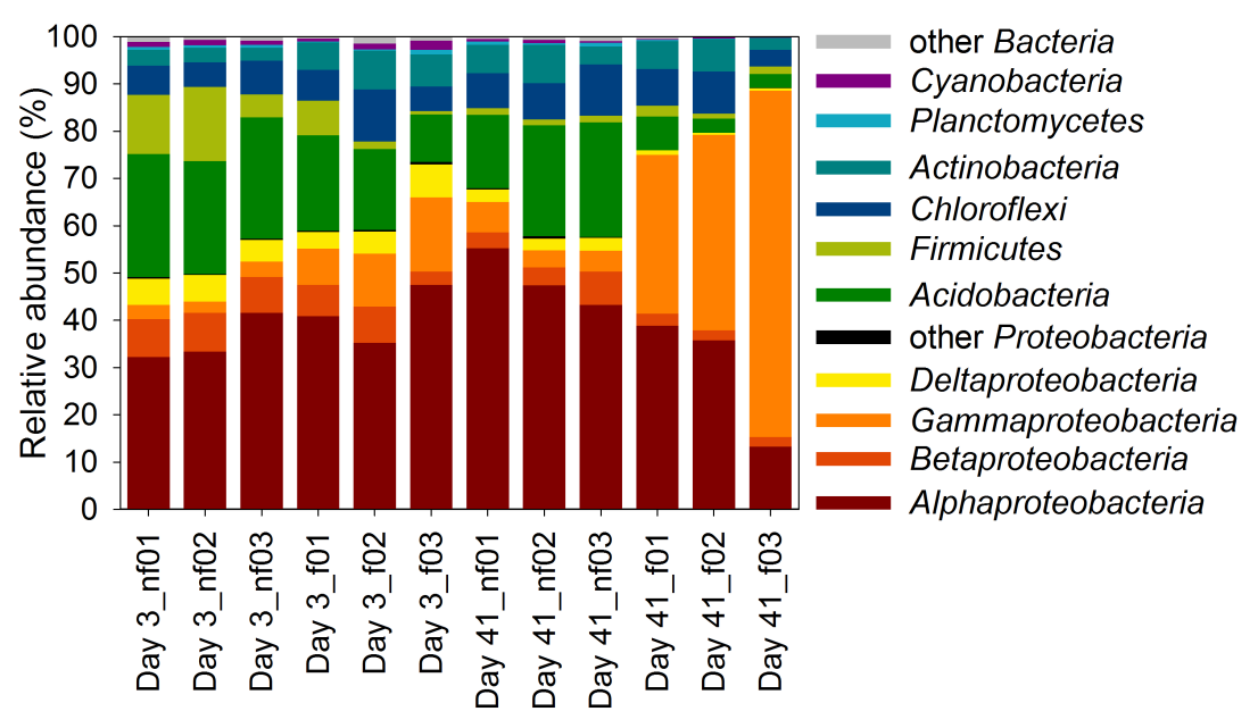

Figure 1. Relative abundance of proteobacterial classes and other abundant phyla. The fertilized (f) and non-ferilized (nf) soil columns were sampled 3 and 41 days after the first fertilization.

The active bacterial communities across all analyzed soil samples comprised 18 phyla and 8 candidate phyla (Figure 1 and supplemental Figure S1). The Proteobacteria, Acidobacteria, Chloroflexi, Actinobacteria and Firmicutes were the dominant phyla accounting for $64.6,16.6,7.3,5.2$ and $4.3 \%$ of all classified sequences, respectively. The Cyanobacteria and Planctomycetes represented $0.7 \%$ of all sequences. Baldrian et al. [53] identified the Proteobacteria, Acidobacteria, Actinobacteria and Firmicutes as the dominating phylogenetic groups in unmanaged spruce forest soil by using RNAbased and DNA-based amplicon approaches. Applying terminal restriction fragment length polymorphism (T-RFLP), Hackl et al. [54] identified the Proteobacteria, the Holophaga/Acidobacterium division, Verrucomicrobia, Planctomycetes and the Cytophaga/Flexibacter/Bacteroides group (CFB) as the dominant bacterial groups in the analyzed forest soils. Thus, the dominant active phyla identified in this study were also identified in other 16S rRNA gene-based field studies. In this study, the Alphaproteobacteria, Gammaproteobacteria, Betaproteobacteria and Deltaproteobacteria representing 38.7, 17.2, 5.2 and 3.4\% of all classified sequences, respectively, were the dominant classes within the Proteobacteria. These proteobacterial classes were predominant in oak-hornbeam, spruce-fir-beech and pine forest soils analyzed by Hackl et al. [54]. The remaining 19 rare phyla and candidate phyla including the Nitrospirae (0.23\%), Bacteroidetes (0.05\%), Gemmatimonadetes (0.05\%), Verrucomicrobia (0.05\%), Armatimonadetes (0.05\%) and TM6 (0.09\%) 
accounted for $0.7 \%$ of all analyzed sequences (supplemental Figure S1). By comparing thirty-two libraries based on 16S rRNA and 16S rRNA gene extracts derived from different soils, Janssen [55] identified the Proteobacteria, Acidobacteria, Actinobacteria, Verrucomicrobia, Bacteroidetes, Chloroflexi, Planctomycetes, Gemmatimonadetes and Firmicutes as the dominant phyla. Thus, the active bacterial community present in our incubated forest soil was comparable to bacterial communities derived by DNA-based and RNA-based analyses of 16S rRNA genes from open land and natural forest soils. DNA-based analyses of the microbial community assess the potential of the entire soil-inhabiting community, as the active, dormant and dead populations are captured, while RNA-based analyses reveal the microbial community which is active at the time of sampling [56-58]. Although, studies based on 16S rRNA gene analysis are not perfect, as taxa can contain different and genetically diverse 16S rRNA operons. Thus, the relative abundances of taxa with low operon copy numbers tend to be underestimated and those with high copy numbers might be overestimated $[59,60]$. Furthermore, the bacterial diversity might be overestimated due to the intragenomic heterogeneity of $16 \mathrm{~S}$ rRNA genes [61]. A study, comparing bacterial community composition in forest soil based on RNA and DNA showed that several active bacterial OTUs were considerably underrepresented in the DNA-based survey [53]. The comparison of phylogenetic clustering of RNA-based and DNA-based microbial communities suggested a function-driven clustering of RNA-based assessed communities in response to dynamic environmental conditions, which was not observed for DNA-based assessed communities [62]. Furthermore, RNA-based studies reflect past, current and future activities and provide a basis for generating and testing important hypotheses [63].

\section{Impact of $\mathrm{NO}_{3}{ }^{-}$Fertilization on Active Forest Soil Bacterial Communities}

To analyze the effect of $\mathrm{NO}_{3}{ }^{-}$fertilization on bacterial diversity, we calculated the mean Shannon index of diversity. The t-test revealed significant differences between the fertilized and non-fertilized samples taken at day 41 of the experiment (Table 1). The comparison of the fertilized samples taken at day 3 with fertilized samples taken at day 41 of the experiment revealed a significant decrease in Shannon index. A decline in phylogenetic diversity of the active bacterial community over time and duration of fertilization was found independently from the level of genetic divergence. This decline in diversity was also shown by the average rarefaction curves (supplementary Figure 
S2). The average number of OTUs was lower in fertilized samples taken at day 41 than in all other analyzed samples.

Table 1. Mean bacterial diversity and standard deviation of the different treatment groups as assessed by the Shannon index $\left(\mathbf{H}^{\prime}\right)$ of diversity. Lower case letters indicate significant differences between the different fertilization treatments. Upper case letters mark significant differences between the time of sampling. Tested with paired t-test $(P<0.05, \mathrm{n}=3)$.

\begin{tabular}{lllll}
\hline $\begin{array}{l}\text { Genetic } \\
\text { divergence }\end{array}$ & $\begin{array}{l}\text { Day 3 } \\
\text { non-fertilized }\end{array}$ & $\begin{array}{c}\text { Day 3 } \\
\text { fertilized }\end{array}$ & $\begin{array}{l}\text { Day 41 } \\
\text { non-fertilized }\end{array}$ & $\begin{array}{l}\text { Day 41 } \\
\text { fertilized }\end{array}$ \\
\hline $3 \%$ & $5.186 \pm 0.142^{\mathrm{aA}}$ & $5.039 \pm 0.246^{\mathrm{aA}}$ & $4.918 \pm 0.135^{\mathrm{aA}}$ & $3.280 \pm 0.823^{\mathrm{bB}}$ \\
$5 \%$ & $4.781 \pm 0.107^{\mathrm{aA}}$ & $4.679 \pm 0.222^{\mathrm{aA}}$ & $4.551 \pm 0.168^{\mathrm{aA}}$ & $2.995 \pm 0.757^{\mathrm{bB}}$ \\
$10 \%$ & $3.802 \pm 0.139^{\mathrm{aA}}$ & $3.706 \pm 0.146^{\mathrm{aA}}$ & $3.469 \pm 0.151^{\mathrm{aB}}$ & $2.281 \pm 0.606^{\mathrm{bB}}$ \\
$20 \%$ & $2.472 \pm 0.0845^{\mathrm{aA}}$ & $2.401 \pm 0.0574^{\mathrm{aA}}$ & $2.281 \pm 0.103^{\mathrm{aA}}$ & $1.413 \pm 0.377^{\mathrm{bB}}$ \\
\hline
\end{tabular}

To expose relationships between the community compositions a redundancy analysis (RDA) was performed. RDA was based on the relative abundance of active proteobacterial classes and other bacterial phyla, the applied treatment, $\mathrm{CH}_{4}$ uptake, $\mathrm{N}_{2} \mathrm{O}$ and $\mathrm{CO}_{2}$ emissions and WFPS values measured (Figure 2). The $P$ value of all canonical axes depicted was 0.008 , indicating that the observed pattern was nonrandom. All samples grouped according to the applied treatment and time of sampling. Fertilized samples taken at day 41 clustered separately from all other samples, indicating a strong impact of fertilization on the inhabiting bacterial community. The three fertilized samples taken 3 days after the first fertilization grouped together, but closer to the non-fertilized than to the fertilized samples taken 41 days after the first fertilization. The RDA revealed a strong response of Gammaproteobacteria to fertilization. Clustering of Bacteroidetes and Actinobacteria also indicated a positive effect of fertilization on the activity of these phyla, whereas the clustering of the remaining identified phyla indicated a higher activity of these phyla (e.g. Acidobacteria, Planctomycetes and Verrucomicrobia) in non-fertilized samples.

We observed a significant increase of the relative abundance of Alphaproteobacteria and Gammaproteobacteria in the non-fertilized samples taken at days 3 and 41 of the experiment, which ranged from $35.7 \pm 5.09 \%$ to $48.6 \pm 6.09 \%$ and $2.9 \pm 0.45 \%$ to 4.83 $\pm 1.39 \%$, respectively. The relative abundance of Firmicutes, Cyanobacteria and Bacteroidetes showed an opposite behavior (Table 2). In fertilized samples, the relative abundance of Gammaproteobacteria increased significantly $(P=0.012$, supplemental 
Table S4) whereas the relative abundances of Gemmatimonadetes and Verrucomicrobia decreased in samples taken at day 3 and day 41 of the experiment (Table 2).

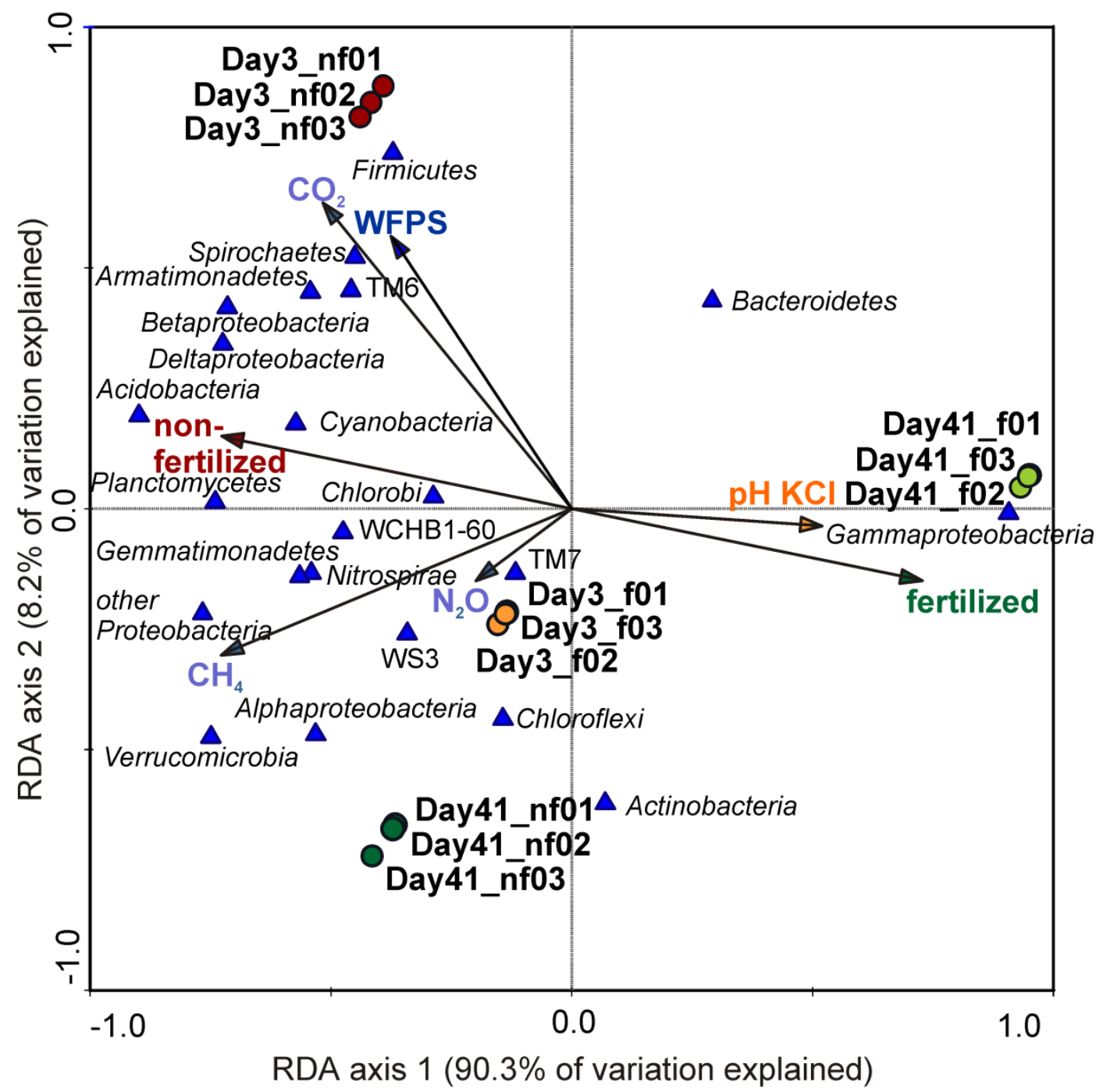

Figure 2. Redundancy analysis (RDA) based on the relative abundance of proteobacterial classes and other bacterial phyla. Fertilized (f) samples taken at day 3 and day 41 of the experiment were highlighted in orange and light green, while non-fertilized (nf) samples at the respective days were highlighted in red and dark green.

Furthermore, we recorded significant differences in community composition between non-fertilized and fertilized samples taken at day 3 and day 41. At day 3, the relative abundance of Acidobacteria was significantly higher $(P=0.037)$ in non-fertilized samples $(21.1 \pm 4.88 \%)$ than in fertilized $(4.37 \pm 2.42 \%)$. In contrast, the relative abundance of Actinobacteria was significantly higher in fertilized samples $(P=0.006)$. Comparison of non-fertilized and fertilized samples taken at day 41 revealed a 
significant decrease of Acidobacteria, Deltaproteobacteria, other Proteobacteria, Planctomycetes, Cyanobacteria and Verrucomicrobia in fertilized samples (Table 2). The opposite was found for the abundance of Gammaproteobacteria, which was significantly higher in fertilized than in non-fertilized samples $(P<0.001$, Table 2$)$.

Table 2. Mean relative abundance and standard deviation of abundant soil bacterial phyla in non-fertilized and fertilized microcosms. Lower case letters indicate significant differences between the different fertilization treatments. Upper case letters mark significant differences between sampling dates. Tested with paired t-test $(P<0.05, \mathrm{n}=3)$.

\begin{tabular}{|c|c|c|c|c|}
\hline Phylogenetic group & $\begin{array}{l}\text { Day } 3 \\
\text { non-fertilized } \\
(\%)\end{array}$ & $\begin{array}{l}\text { Day } 3 \\
\text { fertilized } \\
(\%)\end{array}$ & $\begin{array}{l}\text { Day } 41 \\
\text { non-fertilized } \\
(\%)\end{array}$ & $\begin{array}{l}\text { Day } 41 \\
\text { fertilized } \\
(\%)\end{array}$ \\
\hline Alphaproteobacteria & $35.71 \pm 5.09^{\mathrm{aA}}$ & $41.21 \pm 6.12^{\mathrm{a} A}$ & $48.6 \pm 6.09^{\mathrm{aB}}$ & $29.29 \pm 13.94^{\mathrm{aA}}$ \\
\hline Betaproteobacteria & $7.96 \pm 0.3^{\mathrm{aA}}$ & $5.69 \pm 2.59^{\mathrm{aA}}$ & $4.76 \pm 2.01^{\mathrm{aA}}$ & $2.22 \pm 0.31^{\mathrm{aA}}$ \\
\hline Deltaproteobacteria & $5.23 \pm 0.63^{\mathrm{aA}}$ & $5.06 \pm 1.75^{\mathrm{aA}}$ & $2.59 \pm 0.15^{\mathrm{aA}}$ & $0.61 \pm 0.28^{\mathrm{bB}}$ \\
\hline Gammaproteobacteria & $2.9 \pm 0.45^{\mathrm{aA}}$ & $11.51 \pm 4.06^{\mathrm{aA}}$ & $4.83 \pm 1.39^{\mathrm{aB}}$ & $49.43 \pm 21.06^{\mathrm{bB}}$ \\
\hline Other Proteobacteria & $0.27 \pm 0.06^{\mathrm{aA}}$ & $0.37 \pm 0.1^{\mathrm{aA}}$ & $0.34 \pm 0.17^{\mathrm{aA}}$ & $0.03 \pm 0.01^{\mathrm{bA}}$ \\
\hline Acidobacteria & $25.19 \pm 1.12^{\mathrm{aA}}$ & $15.79 \pm 5.18^{\mathrm{bA}}$ & $21.06 \pm 4.88^{\mathrm{aA}}$ & $4.37 \pm 2.42^{\mathrm{bB}}$ \\
\hline Firmicutes & $11.02 \pm 5.6^{\mathrm{aA}}$ & $3.16 \pm 3.6^{\mathrm{aA}}$ & $1.38 \pm 0.1^{\mathrm{aB}}$ & $1.64 \pm 0.6^{\mathrm{aA}}$ \\
\hline Chloroflexi & $6.17 \pm 1^{\mathrm{aA}}$ & $7.65 \pm 3.06^{\mathrm{aA}}$ & $8.63 \pm 1.9^{\mathrm{aA}}$ & $6.75 \pm 2.84^{\mathrm{aA}}$ \\
\hline Actinobacteria & $3.05 \pm 0.3^{\mathrm{aA}}$ & $6.89 \pm 1.19^{\mathrm{bA}}$ & $5.94 \pm 2.2^{\mathrm{aA}}$ & $5.11 \pm 2.24^{\mathrm{aA}}$ \\
\hline Planctomycetes & $0.62 \pm 0.06^{\mathrm{aA}}$ & $0.49 \pm 0.41^{\mathrm{aA}}$ & $0.6 \pm 0.23^{\mathrm{aA}}$ & $0.09 \pm 0.09^{\mathrm{bA}}$ \\
\hline Cyanobacteria & $0.99 \pm 0.13^{\mathrm{aA}}$ & $1.23 \pm 0.68^{\mathrm{aA}}$ & $0.55 \pm 0.13^{\mathrm{aB}}$ & $0.17 \pm 0.1^{\mathrm{bA}}$ \\
\hline Bacteroidetes & $0.08 \pm 0.02^{\mathrm{aA}}$ & $0.03 \pm 0.03^{\mathrm{bA}}$ & $0.01 \pm 0.012^{\mathrm{aB}}$ & $0.09 \pm 0.14^{\mathrm{aA}}$ \\
\hline Nitrospirae & $0.24 \pm 0.12^{\mathrm{aA}}$ & $0.32 \pm 0.21^{\mathrm{aA}}$ & $0.263 \pm 0.12^{\mathrm{aA}}$ & $0.08 \pm 0.02^{\mathrm{aA}}$ \\
\hline Gemmatimonadetes & $0.06 \pm 0.02^{\mathrm{aA}}$ & $0.10 \pm 0.05^{\mathrm{aA}}$ & $0.06 \pm 0.04^{\mathrm{aA}}$ & $0.01 \pm 0.01^{\mathrm{aB}}$ \\
\hline Verrucomicrobia & $0.05 \pm 0.03^{\mathrm{aA}}$ & $0.08 \pm 0.03^{\mathrm{aA}}$ & $0.09 \pm 0.01^{\mathrm{aA}}$ & $0 \pm 0^{\mathrm{bB}}$ \\
\hline Armatimonadetes & $0.10 \pm 0.08^{\mathrm{aA}}$ & $0.05 \pm 0.04^{\mathrm{aA}}$ & $0.04 \pm 0.02^{\mathrm{aA}}$ & $0.003 \pm 0.006^{\mathrm{aA}}$ \\
\hline
\end{tabular}

\section{Impact of $\mathrm{NO}_{3}{ }^{-}$Fertilization on Gammaproteobacteria}

The Gammaproteobacteria responded strongly to the applied fertilization. To analyze the relationship of Gammaproteobacteria and the applied treatment RDA based on the relative abundance of all identified gammaproteobacterial orders was performed (Figure 3 ). The $P$ value for all canonical axes depicted was 0.008 , indicating that the observed pattern was non-random. The Xanthomonadales was the most abundant gammaproteobacterial order, which also showed the strongest response to $\mathrm{NO}_{3}{ }^{-}$ fertilization. The fertilized samples grouped together and distantly from the nonfertilized samples. 


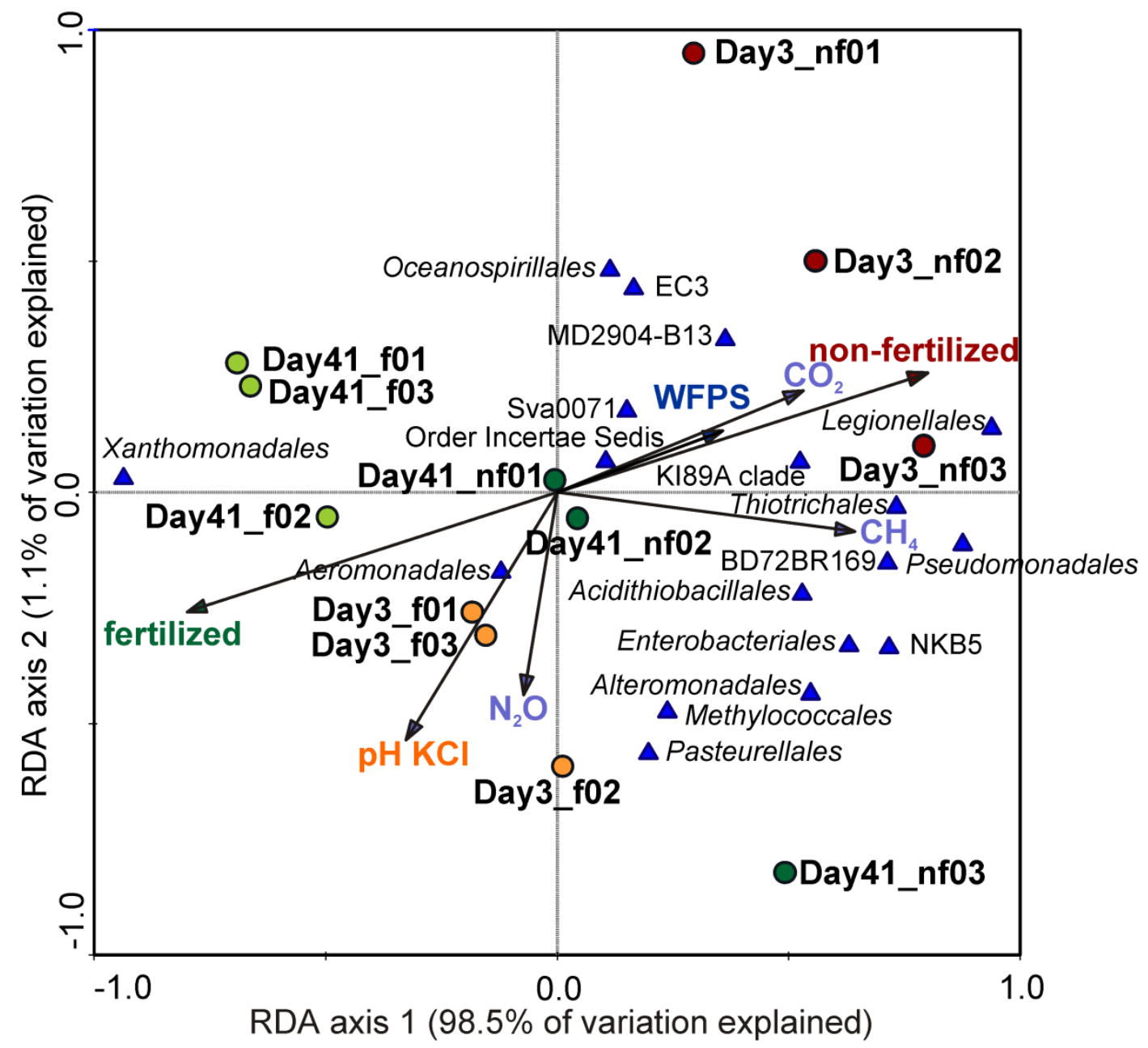

Figure 3. Redundancy analysis (RDA) based on the relative abundance of gammaproteobacterial classes. Fertilized samples taken at day 3 and day 41 of the experiment are highlighted in orange and light green, while non-fertilized (nf) samples are highlighted in red and dark green.

We found a significant increase in the relative abundance of Xanthomonadales by comparing non-fertilized and fertilized samples taken at days $3(P=0.018,02.16 \pm 0.2 \%$ vs. $10.1 \pm 03.57 \%)$ and 41 of the experiment ( $P=0.021,3.99 \pm 1.23 \%$ vs. $49.1 \pm 21.2 \%$ ). Additionally, a significant increase of relative abundance was found between fertilized day 3 samples and day 41 samples $(P=0.035,10.1 \pm 3.57 \%$ vs. $49.1 \pm 21.2 \%)$. The predominant genus within Xanthomonadales was Rhodanobacter, accounting for up to $69.8 \%$ of the entire bacterial community (Figure 4). Correspondingly, we found a significant increase in the relative abundances of this genus in fertilized samples compared to non-fertilized samples taken at day $3(P=0.013,1.26 \pm 0.24 \%$ vs. 8.17 $\pm 2.8 \%)$ and day $41(P=0.019,2.36 \pm 0.9 \%$ vs. $46.87 \pm 20.3 \%)$. 


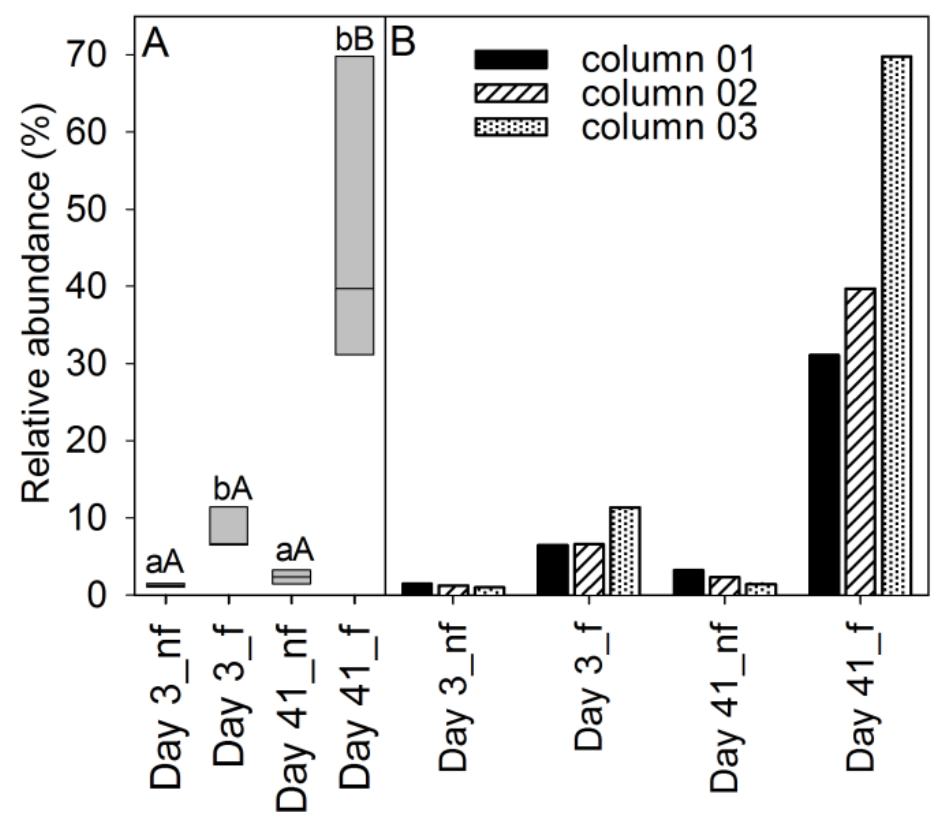

Figure 4. Box Plot (A) and relative abundance (B) of the genus Rhodanobacter present in fertilized (f) and non-fertilized (nf) mesocosms. Lower case letters indicate significant differences between the different fertilization treatments. Upper case letters mark significant differences between the time of sampling. Tested with paired t-test $(\mathrm{P}<0.05 ; \mathrm{n}=3)$.

Furthermore, comparison of the fertilized samples taken at day 3 and day 41 of the experiment revealed that the relative abundance of this genus increased significantly $(P$ $=0.031$ ). Thus, we assume a strong but temporarily delayed impact of $\mathrm{NO}_{3}{ }^{-}$fertilization on the activity of the genus Rhodanobacter, as the abundance increased in fertilized samples with time (Figure 4). Members of the genus Rhodanobacter such as Rhodanobacter denitrificans sp. [64], Rhodanobacter panaciterrae sp. [65], Rhodanobacter soli [66], Rhodanobacter ginsengisoli sp. and Rhodanobacter terrae sp. [67] were isolated mainly from soil samples. The facultative anaerobic Rhodanobacter denitrificans sp. is capable of complete denitrification whereas Rhodanobacter ginsengisoli sp. and Rhodanobacter terrae sp. were tested negative for nitrate reduction [64,67]. Van den Heuvel et al. [68] showed that Rhodanobacter thiooxydans is capable of denitrification, also at the rather low $\mathrm{pH}$ values present in our soil microcosms (approximately 3.83 in non-ferilized columns and 4.23 in fertilized columns). In this study, some 16S rRNA sequences showed high identities to Rhodanobacter sp. DCY45 (970 sequences, 98.15\% identity) and Rhodanobacter ginsengisoli (886 sequences, 98.15\% identity), but the main fraction showed lower identities $(<97 \%)$ to $16 \mathrm{~S}$ rRNA gene sequences of known and characterized Rhodanobacter members. It has been 
shown that Rhodanobacter is the dominating gammaproteobacterial genus in soils and groundwater with low $\mathrm{pH}$ values and elevated nitrate content $[68,69]$. In accordance with these results, the relative abundance of Rhodanobacter increased with fertilization and time, indicating an increased activity of that genus and a major contribution to the denitrification process. This was also supported by the measured nitrous oxide emission rates, which increased from $130.81 \pm 21.59 \mu \mathrm{g} \mathrm{N} \mathrm{m}^{-2} \mathrm{~h}^{-1}$ at day 0 (measured before the first fertilization) to $1544.87 \pm 402.53 \mu \mathrm{g} \mathrm{N} \mathrm{m}^{-2} \mathrm{~h}^{-1}$ at day 3 and then dropped to 15.13 $\pm 0.92 \mu \mathrm{g} \mathrm{N} \mathrm{m}^{-2} \mathrm{~h}^{-1}$ at day 21 of the experiment (Figure 5). The second fertilization had a less pronounced influence on the nitrous oxide emission rates. This effect could be explained by (a) higher activity of bacterial species capable of complete denitrification and (b) less available carbon as substrate for denitrification at the time of the second fertilization. The total $\mathrm{N}$ concentration was significantly higher in fertilized soil microcosms, due to the additional $\mathrm{N}$ supply but total $\mathrm{C}$ concentration was significantly lower in these microcosms. This indicated a consumption of this essential element (C) by growth and activity of the soil microbiota. Thus, $\mathrm{C} / \mathrm{N}$ ratios dropped throughout the experiment in $\mathrm{N}$-fertilized and also in non-fertilized microcosms from $10.50 \pm 0.19 \mathrm{~g} \mathrm{~g}^{-1}$ to $8.02 \pm 0.17 \mathrm{~g} \mathrm{~g}^{-1}$ and $9.85 \pm 0.10 \mathrm{~g} \mathrm{~g}^{-1}$, respectively [36]. In general, a lower $\mathrm{C} / \mathrm{N}$ ratio indicates a higher bioavailability of $\mathrm{C}$ but in our experiment limitation of available $\mathrm{C}$ is likely, as no additional $\mathrm{C}$ sources were added in the course of the experiment. Accordingly, $\mathrm{CO}_{2}$ emission rates measured in fertilized and non-fertilized microcosms decreased with time and indicated a reduction of available $\mathrm{C}$ concentration in the analyzed soil samples over time (Figure 5). 


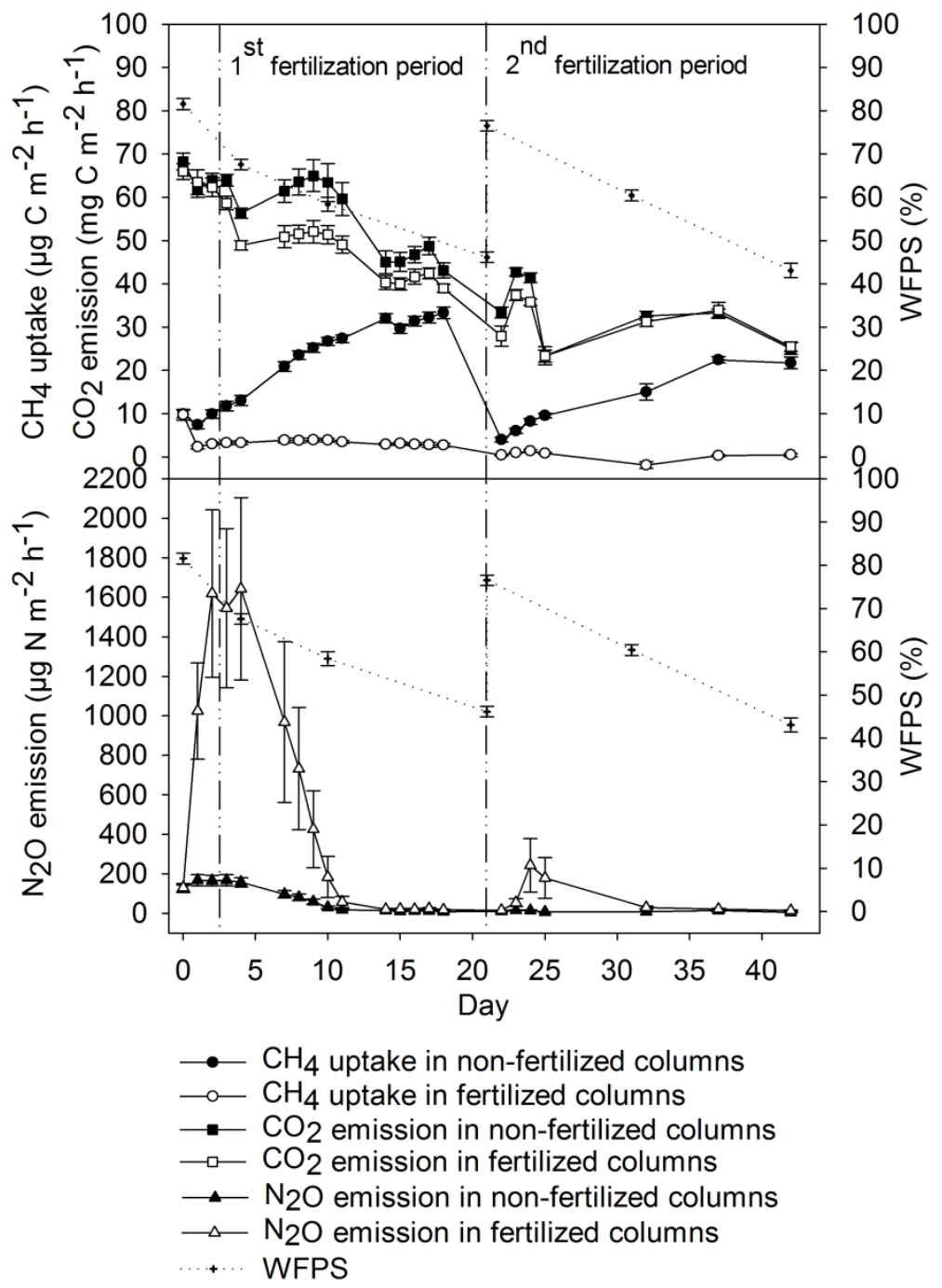

Figure 5. Gas fluxes in the fertilized and non-fertilized soil microcosms. Depicted are the water filed pore space (WFPS), nitrous oxide $\left(\mathrm{N}_{2} \mathrm{O}\right)$ and carbon dioxid $\left(\mathrm{CO}_{2}\right)$ emissions, as well as the methane $\left(\mathrm{CH}_{4}\right)$ uptake measured in fertilized and non-ferilized soil microcosms $(\mathrm{n}=8)$.

\section{Shifts in Methanotrophic Bacterial Communities}

To analyze the observed impact of $\mathrm{N}$ fertilization on $\mathrm{CH}_{4}$ gas fluxes in detail, the methanatrophic bacterial community was analyzed using specific primers targeting type I and type II methanotrophs. After preprocessing of the dataset 131,142 (type I) and 285,962 (type II) high-quality sequences were recovered and analyzed (supplementary Table S7). The datasets derived using type II-specific primers included sequences closely related to the facultative methanotrophic genus Methylocella (Beijerinckiaceae) and the facultative methylotrophic genus Methylovirgula (Beijerinckiaceae) [71,72]. Other genera capable of using methane as $\mathrm{C}$ source identified were the type I 
methanotroph Methylophaga and the type II methanotrophs Hyphomicrobium $3.25 \%$ and $4.67 \%$ of the sequences), Methylovirgula (up to $0.2 \%$ of all sequences) and the Methylocystaceae, Methylococcaceae and Methylobacteriaceae (up to $0.14 \%$ of all sequences). Significant differences in the relative abundance of these genera between fertilized and non-fertilized microcosoms were not found. Thus, alteration of the abundance of these genera does not explain the significantly higher methane uptake rates of non-fertilized soil microcosms observed by Fender et al. [36] (Figure 5). Furthermore, we identified the genus Nitrosospira in low abundance in the bacterial dataset. Nitrosospira accounted for 0.12 and $0.14 \%$ of the analyzed bacterial sequences in non-fertilized samples, and 0.03 and $0.02 \%$ in fertilized samples taken 3 and 41 days after the first fertilization, respectively. Another explanation for the increased $\mathrm{CH}_{4}$ consumption in non-fertilized mesocosms could be the ammonia monooxygenase (AMO) activity of genus Nitrosospira. It was shown that the AMO is closely related to the membrane-bound particulate methane monooxygenase (pMMO) and both enzymes are capable of oxidizing methane to methanol $[73,74]$. Thus, the bacterial genus Nitrosospira and the archaeal genus Candidatus Nitrosotalea (see below), potentially contribute to the methane uptake observed in non-fertilized samples [74-76]. Additionally, $\mathrm{N}$ fertilization increased the $\mathrm{NH}_{4}{ }^{+}$concentration, which could inhibit methane oxidation by methane and ammonia monooxygenases [77,78].

\section{Shifts in Archaeal Communities}

Active archaeal communities inhabiting the fertilized and non-fertilized soil microcosms were also analyzed. After sequence processing 28,780 high-quality archaeal 16S rRNA gene sequences were recovered (supplemental Table S5). Calculation of rarefaction curves revealed that the full taxonomic diversity present in the soil samples was covered by the surveying effort at 20 and 3\% genetic divergence (supplementary Figure S3). Estimates of the archaeal diversity using Michaelis-Menten fit indicate that 64 to $86 \%$ and 85 to $98 \%$ of the expected taxonomic diversity at 20 and $3 \%$ genetic divergence, respectively, were covered by the surveying effort (supplementary Table S6). The archaeal communities were predominated by Thaumarchaeota accounting for 94.4 to $100 \%$ of all archaeal sequences. The second most abundant phylum was Euryarchaeota, which comprised 0.16 to $5.56 \%$ of all archaeal sequences. The Thaumarchaeota assigned sequences were furthermore classified as Soil Crenarchaeotic Group (SCG), South African Gold Mine Gp 1 
(SAGMCG-1) and terrestrial group. The identified Euryarchaeota comprised only Halobacteria and Thermoplasmata. Interestingly, significant differences of the active archaeal classes inhabiting the fertilized and non-fertilized soil columns were not observed (Table 3). At genus level, the relative abundance of the Candidatus Nitrosotalea belonging to the Thaumarcheota was higher in non-fertilized $(40.4 \pm 4.12 \%$ at day 3 and $45.3 \pm 13.7 \%$ at day 41$)$ than in fertilized soil columns $(28.0 \pm 6.4 \%$ at day 3 and $17.3 \pm 27.4 \%$ at day 41 ). The eponym of Candidatus Nitrosotalea, the archaeon Nitrosotalea devanaterra is a chemolithotrophic, obligately acidophilic ammonia oxidizer [70].

Table 3. Mean relative abundance and standard deviation of archaeal classes in nonfertilized and fertilized microcosms. Lower case letters indicate significant differences between the different fertilization treatments. Upper case letters mark significant differences between sampling dates. Tested with paired t-test $(P<0.05)$.

\begin{tabular}{|c|c|c|c|c|}
\hline Archaeal class & $\begin{array}{l}\text { Day } 3 \\
\text { non-fertilized } \\
(\%)\end{array}$ & $\begin{array}{l}\text { Day } 3 \\
\text { fertilized } \\
(\%) \\
\end{array}$ & $\begin{array}{l}\text { Day } 41 \\
\text { non-fertilized } \\
(\%) \\
\end{array}$ & $\begin{array}{l}\text { Day } 41 \\
\text { fertilized } \\
(\%)\end{array}$ \\
\hline $\begin{array}{l}\text { Soil Crenarcheotic } \\
\text { Group (SCG) }\end{array}$ & $58.3 \pm 11.2^{\mathrm{aA}}$ & $57.3 \pm 3.22^{\mathrm{aA}}$ & $51.2 \pm 8.81^{\mathrm{aA}}$ & $59.9 \pm 27.7^{\mathrm{aA}}$ \\
\hline $\begin{array}{l}\text { South African Gold } \\
\text { Mine GP } 1 \\
\text { (SAGMCG-1) }\end{array}$ & $40.2 \pm 11.0^{\mathrm{aA}}$ & $40.9 \pm 2.91^{\mathrm{aA}}$ & $46.1 \pm 8.18^{\mathrm{aA}}$ & $31.6 \pm 31.1^{\mathrm{aA}}$ \\
\hline Terrestrial group & $1.21 \pm 0.299^{\mathrm{aA}}$ & $1.43 \pm 0.729^{\mathrm{aA}}$ & $1.97 \pm 0.729^{\mathrm{aA}}$ & $5.86 \pm 3.32^{\mathrm{aA}}$ \\
\hline Halobacteria & $0.0799 \pm 0.092^{\mathrm{aA}}$ & $0 \pm 0^{\mathrm{aA}}$ & $\begin{array}{l}0.0089 \\
\pm 0.0178^{\mathrm{aA}}\end{array}$ & $0 \pm 0^{\mathrm{aA}}$ \\
\hline Thermoplasmata & $0.125 \pm 0.179^{\mathrm{aA}}$ & $0.345 \pm 0.335^{\mathrm{aA}}$ & $0.64 \pm 0.275^{\mathrm{aA}}$ & $2.62 \pm 2.65^{\mathrm{aA}}$ \\
\hline
\end{tabular}




\section{Conclusions}

Our study revealed a significant reduction of active soil bacterial community diversity in fertilized soil microcosms, as shown by the Shannon indices and rarefaction curves. Furthermore, functional groups could be related to significantly different green house gas fluxes (elevated $\mathrm{N}_{2} \mathrm{O}$ release and reduced $\mathrm{CH}_{4}$ uptake). The relative abundance of the genus Rhodanobacter increased significantly in fertilized microcosms. The archaeal community composition was not affected significantly by $\mathrm{N}$ fertilization, although a shift in the relative abundance of the nitrifying, archaeal genus Nitrosotalea was observed. Furthermore, our results indicate that low-abundant methylotrophic, methanotrophic, and nitrifying species considerably contribute to the uptake of methane in the forest soil-containing microcosms. $\mathrm{N}$ fertilization changed the community composition of active soil bacteria over time by promoting denitrifying bacterial species. These results supported our hypothesis (1) that the $\mathrm{N}$ fertilization reduces the diversity and shape the community structure of active soil prokaryotic communities. A collapse of the active bacterial community after the addition of $200 \mathrm{~kg} \mathrm{~N} \mathrm{ha}^{-1} \mathrm{yr}^{-1}$ was not observed, although the bacterial diversity was reduced and the bacterial community composition shifted towards a denitrifying community. The remaining question is how much $\mathrm{N}$ deposition to soils can be buffered by the present bacterial community.

\section{Acknowledgements}

We thank Andrea Thürmer, Sonja Voget and the $\mathrm{G}_{2} \mathrm{~L}$ sequencing team for the support. We also thank Martin Engelhaupt, Kristin Kaiser and Sarah Herzog for valuable discussions and comments on the manuscript. 


\section{References}

1. Duce R, LaRoche J, Altieri K, Arrigo K, Baker A, et al. (2008) Impacts of atmospheric anthropogenic nitrogen on the open ocean. Science 320: 893-897.

2. Galloway JN, Townsend AR, Erisman JW, Bekunda M, Cai Z, et al. (2008) Transformation of the nitrogen cycle: recent trends, questions, and potential solutions. Science 320: 889-892.

3. Galloway J, Aber J, Erisman J, Seitzinger S, Howarth R, et al. (2003) The nitrogen cascade. Bioscience 53: 341-356.

4. Janssens IA, Dieleman W, Luyssaert S, Subke JA, Reichstein M, et al. (2010) Reduction of forest soil respiration in response to nitrogen deposition. Nature Geosci 3: 315-322.

5. Magnani F, Mencuccini M, Borghetti M, Berbigier P, Berninger F, et al. (2007) The human footprint in the carbon cycle of temperate and boreal forests. Nature 447: $848-850$

6. Holland EA, Braswell BH, Sulzman J, Lamarque J-F (2005) Nitrogen deposition onto the United States and Western Europe: Synthesis of observations and models. Ecol Appl 15: 38-57.

7. Holland E, Dentener F, Braswell B, Sulzman J (1999) Contemporary and preindustrial global reactive nitrogen budgets. Biogeochemistry 46: 7-43.

8. Galloway JN, Cowling EB (2002) Reactive Nitrogen and The World: 200 Years of Change. AMBIO: A Journal of the Human Environment 31: 64-71.

9. Dise NB, Matzner E, Gundersen P (1998) Synthesis of Nitrogen Pools and Fluxes from European Forest Ecosystems. Water Air Soil Poll 105: 143-154.

10. Simpson D, Butterbach-Bahl K, Fagerli H, Kesik M, Skiba U, et al. (2006) Deposition and emissions of reactive nitrogen over European forests: A modelling study. Atmos Environ 40: 5712-5726.

11. Galloway J, Dentener F, Capone D, Boyer E, Howarth R, et al. (2004) Nitrogen cycles: past, present, and future. Biogeochemistry 70: 153-226.

12. Ramirez KS, Lauber CL, Knight R, Bradford MA, Fierer N (2010) Consistent effects of nitrogen fertilization on soil bacterial communities in contrasting systems. Ecology 91: 3463-3470. 
13. Frey SD, Knorr M, Parrent JL, Simpson RT (2004) Chronic nitrogen enrichment affects the structure and function of the soil microbial community in temperate hardwood and pine forests. Forest Ecol Manag 196: 159-171.

14. Nemergut DR, Townsend AR, Sattin SR, Freeman KR, Fierer N, et al. (2008) The effects of chronic nitrogen fertilization on alpine tundra soil microbial communities: implications for carbon and nitrogen cycling. Environ Microbiol 10: 3093-3105.

15. Wallenstein MD, McNulty S, Fernandez IJ, Boggs J, Schlesinger WH (2006) Nitrogen fertilization decreases forest soil fungal and bacterial biomass in three long-term experiments. Forest Ecol Manag 222: 459-468.

16. Lee K-H, Jose S (2003) Soil respiration, fine root production, and microbial biomass in cottonwood and loblolly pine plantations along a nitrogen fertilization gradient. Forest Ecol Manag 185: 263-273.

17. Francis CA, Beman JM, Kuypers MM (2007) New processes and players in the nitrogen cycle: the microbial ecology of anaerobic and archaeal ammonia oxidation. ISME J 1: 19-27.

18. Prosser JI, Nicol GW (2008) Relative contributions of archaea and bacteria to aerobic ammonia oxidation in the environment. Environ Microbiol 10: 29312941.

19. Zumft WG (1997) Cell biology and molecular basis of denitrification. Microbiol Mol Biol Rev 61: 533-616.

20. Bateman EJ, Baggs EM (2005) Contributions of nitrification and denitrification to $\mathrm{N}_{2} \mathrm{O}$ emissions from soils at different water-filled pore space. Biol Fert Soils 41: 379-388.

21. Bremner J (1997) Sources of nitrous oxide in soils. Nutr Cycl Agroecosys 49: 7-16.

22. Baggs EM (2008) A review of stable isotope techniques for $\mathrm{N}_{2} \mathrm{O}$ source partitioning in soils: recent progress, remaining challenges and future considerations. Rapid Commun Mass Sp 22: 1664-1672.

23. Ciarlo E, Conti M, Bartoloni N, Rubio G (2008) Soil $\mathrm{N}_{2} \mathrm{O}$ emissions and $\mathrm{N} 2 \mathrm{O} /(\mathrm{N} 2 \mathrm{O}+\mathrm{N} 2)$ ratio as affected by different fertilization practices and soil moisture. Biol Fert Soils 44: 991-995.

24. Firestone MK, Davidson EA (1989) Microbiological basis of $\mathrm{NO}$ and $\mathrm{N}_{2} \mathrm{O}$ production and consumption in soil. Chichester: John Wiley \& Sons. pp. 7-21. 
25. Ruser R, Flessa H, Russow R, Schmidt G, Buegger F, et al. (2006) Emission of $\mathrm{N}_{2} \mathrm{O}, \mathrm{N}_{2}$ and $\mathrm{CO}_{2}$ from soil fertilized with nitrate: effect of compaction, soil moisture and rewetting. Soil Biol Biochem 38: 263-274.

26. Wrage N, Velthof GL, van Beusichem ML, Oenema O (2001) Role of nitrifier denitrification in the production of nitrous oxide. Soil Biol Biochem 33: 17231732.

27. Luyssaert S, Ciais P, Piao S, Schulze E, Jung M, et al. (2010) The European carbon balance. Part 3: forests. Global Change Biol 16: 1429-1450.

28. Jungkunst H, Freibauer A, Neufeldt H, Bareth G (2006) Nitrous oxide emissions from agricultural land use in Germany - a synthesis of available annual field data. J Plant Nutr Soil Sc 169: 341-351.

29. Dutaur L, Verchot L (2007) A global inventory of the soil CH4 sink. Global Biogeochem Cy 21: 1-9.

30. Gruber N, Galloway JN (2008) An Earth-system perspective of the global nitrogen cycle. Nature 451: 293-296.

31. Hungate BA, Dukes JS, Shaw MR, Luo Y, Field CB (2003) Nitrogen and Climate Change. Science 302: 1512-1513.

32. IPCC (2007) Intergovernmental panel on Climate change 2007: The physical science basis. Cambridge, United Kingdom and New York, NY, USA,. 996 pp. p.

33. Mosier A (1998) Soil processes and global change. Biol Fert Soil 27: 221-229.

34. Mosier A, Schimel D, Valentine D, Bronson K, Parton W (1991) Methane and nitrous oxide fluxes in native, fertilized and cultivated grasslands. Nature 350: 330-332.

35. Le Mer J, Roger P (2001) Production, oxidation, emission and consumption of methane by soils: A review. Eur J Soil Biol 37: 25-50.

36. Fender A-C, Pfeiffer B, Gansert D, Leuschner C, Daniel R, et al. (2012) The inhibiting effect of nitrate fertilisation on methane uptake of a temperate forest soil is influenced by labile carbon. Biol Fert Soils 48: 621-631.

37. Schmalenberger A, Schwieger F, Tebbe C (2001) Effect of primers hybridizing to different evolutionarily conserved regions of the small-subunit rRNA gene in PCR-based microbial community analyses and genetic profiling. Appl Environ Microbiol 67: 3557-3563. 
38. Simon C, Wiezer A, Strittmatter A, Daniel R (2009) Phylogenetic diversity and metabolic potential revealed in a glacier ice metagenome. Appl Environ Microbiol 75: 7519-7526.

39. DeLong EF (1992) Archaea in coastal marine environments. Proc Natl Acad Sci U S A 89: $5685-5689$.

40. Chen Y, Dumont M, Cebron A, Murrell J (2007) Identification of active methanotrophs in a landfill cover soil through detection of expression of $16 \mathrm{~S}$ rRNA and functional genes. Environ Microbiol 9: 2855-2869.

41. Caporaso J, Kuczynski J, Stombaugh J, Bittinger K, Bushman F, et al. (2010) QIIME allows analysis of high-throughput community sequencing data. Nat Methods 7: 335-336.

42. Reeder J, Knight R (2010) Rapidly denoising pyrosequencing amplicon reads by exploiting rank-abundance distributions. Nat Methods 7: 668-669.

43. Martin M (2011) Cutadapt removes adapter sequences from high-throughput sequencing reads. EMBnetjournal; Vol 17, No 1: Next Generation Sequencing Data Analysis.

44. Edgar RC (2010) Search and clustering orders of magnitude faster than BLAST. Bioinformatics 26: 2460-2461.

45. Schloss PD, Handelsman J (2005) Introducing DOTUR, a computer program for defining operational taxonomic units and estimating species richness. Appl Environ Microbiol 71: 1501-1506.

46. Caporaso JG, Bittinger K, Bushman FD, DeSantis TZ, Andersen GL, et al. (2010) PyNAST: a flexible tool for aligning sequences to a template alignment. Bioinformatics 26: 266-267.

47. Haas B, Gevers D, Earl A, Feldgarden M, Ward D, et al. (2011) Chimeric 16S rRNA sequence formation and detection in Sanger and 454-pyrosequenced PCR amplicons. Genome Res 21: 494-504.

48. Altschul SF, Gish W, Miller W, Myers EW, Lipman DJ (1990) Basic local alignment search tool. J Mol Biol 215: 403-410.

49. Pfeiffer B, Fender A-C, Lasota S, Hertel D, Jungkunst HF, et al. (2013) Leaf litter is the main driver for changes in bacterial community structures in the rhizosphere of ash and beech. Appl Soil Ecol 72: 150-160. 
50. Nacke H, Thürmer A, Wollherr A, Will C, Hodac L, et al. (2011) Pyrosequencingbased assessment of bacterial community structure along different management types in German forest and grassland soils. PLoS One 6: e17000.

51. Will C, Thürmer A, Wollherr A, Nacke H, Herold N, et al. (2010) Horizon-specific bacterial community composition of German grassland soils, as revealed by pyrosequencing-based analysis of 16S rRNA genes. Appl Environ Microbiol 76: 6751-6759.

52. Haegeman B, Hamelin J, Moriarty J, Neal P, Dushoff J, et al. (2013) Robust estimation of microbial diversity in theory and in practice. ISME J.

53. Baldrian P, Kolarik M, Stursova M, Kopecky J, Valaskova V, et al. (2012) Active and total microbial communities in forest soil are largely different and highly stratified during decomposition. Isme J 6: 248-258.

54. Hackl E, Zechmeister-Boltenstern S, Bodrossy L, Sessitsch A (2004) Comparison of diversities and compositions of bacterial populations inhabiting natural forest soils. Appl Environ Microbiol 70: 5057-5065.

55. Janssen $P$ (2006) Identifying the dominant soil bacterial taxa in libraries of $16 \mathrm{~S}$ rRNA and 16S rRNA genes. Appl Environ Microbiol 72: 1719-1728.

56. Griffiths RI, Whiteley AS, O'Donnell AG, Bailey MJ (2000) Rapid method for coextraction of DNA and RNA from natural environments for analysis of ribosomal DNA- and rRNA-based microbial community composition. Appl Environ Microbiol 66: 5488-5491.

57. De Nobili M, Contin M, Mondini C, Brookes PC (2001) Soil microbial biomass is triggered into activity by trace amounts of substrate. Soil Biol Biochem 33: 1163-1170.

58. Lennon JT, Jones SE (2011) Microbial seed banks: the ecological and evolutionary implications of dormancy. Nat Rev Micro 9: 119-130.

59. Klappenbach J, Dunbar J, Schmidt T (2000) rRNA operon copy number reflects ecological strategies of bacteria. Appl Environ Microbiol 66: 1328-1333.

60. Větrovský T, Baldrian P (2013) The variability of the $16 \mathrm{~S}$ rRNA gene in bacterial genomes and its consequences for bacterial community analyses. PLoS One 8: e57923.

61. Sun D-L, Jiang X, Wu QL, Zhou N-Y (2013) Intragenomic Heterogeneity of 16 S rRNA Genes Causes Overestimation of Prokaryotic Diversity. Appl Environ Microbiol 79: 5962-5969. 
62. DeAngelis KM, Firestone MK (2012) Phylogenetic Clustering of Soil Microbial Communities by 16S rRNA but Not 16S rRNA Genes. Appl Environ Microbiol 78: 2459-2461.

63. Blazewicz SJ, Barnard RL, Daly RA, Firestone MK (2013) Evaluating rRNA as an indicator of microbial activity in environmental communities: limitations and uses. ISME J.

64. Prakash O, Green SJ, Jasrotia P, Overholt WA, Canion A, et al. (2012) Rhodanobacter denitrificans sp. nov., isolated from nitrate-rich zones of a contaminated aquifer. Int J Syst Evol Microbiol 62: 2457-2462.

65. Wang L, An DS, Kim SG, Jin FX, Lee ST, et al. (2011) Rhodanobacter panaciterrae sp. nov., a bacterium with ginsenoside-converting activity isolated from soil of a ginseng field. Int J Syst Evol Microbiol 61: 3028-3032.

66. Bui TPN, Kim Y-J, Kim H, Yang D-C (2010) Rhodanobacter soli sp. nov., isolated from soil of a ginseng field. Int J Syst Evol Microbiol 60: 2935-2939.

67. Weon HY, Kim BY, Hong SB, Jeon YA, Kwon SW, et al. (2007) Rhodanobacter ginsengisoli sp. nov. and Rhodanobacter terrae sp. nov., isolated from soil cultivated with Korean ginseng. Int J Syst Evol Microbiol 57: 2810-2813.

68. van den Heuvel RN, van der Biezen E, Jetten MS, Hefting MM, Kartal B (2010) Denitrification at $\mathrm{pH} 4$ by a soil-derived Rhodanobacter-dominated community. Environ Microbiol 12: 3264-3271.

69. Green SJ, Prakash O, Jasrotia P, Overholt WA, Cardenas E, et al. (2012) Denitrifying bacteria from the genus Rhodanobacter dominate bacterial communities in the highly contaminated subsurface of a nuclear legacy waste site. Appl Environ Microbiol 78: 1039-1047.

70. Lehtovirta-Morley LE, Stoecker K, Vilcinskas A, Prosser JI, Nicol GW (2011) Cultivation of an obligate acidophilic ammonia oxidizer from a nitrifying acid soil. P Natl Acad Sci USA.

71. Dedysh SN, Knief C, Dunfield PF (2005) Methylocella species are facultatively methanotrophic. J Bacteriol 187: 4665-4670.

72. Vorob'ev AV, de Boer W, Folman LB, Bodelier PL, Doronina NV, et al. (2009) Methylovirgula ligni gen. nov., sp. nov., an obligately acidophilic, facultatively methylotrophic bacterium with a highly divergent mxaF gene. Int J Syst Evol Microbiol 59: 2538-2545. 
73. Holmes AJ, Costello A, Lidstrom ME, Murrell JC (1995) Evidence that particulate methane monooxygenase and ammonia monooxygenase may be evolutionarily related. FEMS Microbiol Lett 132: 203-208.

74. Klotz MG, Norton JM (1998) Multiple copies of ammonia monooxygenase (amo) operons have evolved under biased AT/GC mutational pressure in ammoniaoxidizing autotrophic bacteria. FEMS Microbiol Lett 168: 303-311.

75. Cao H, Auguet J-C, Gu J-D (2013) Global Ecological Pattern of AmmoniaOxidizing Archaea. PLoS ONE 8: e52853.

76. Stein LY, Roy R, Dunfield PF (2012) Aerobic Methanotrophy and Nitrification: Processes and Connections. eLS: John Wiley \& Sons, Ltd.

77. Bédard C, Knowles R (1989) Physiology, biochemistry, and specific inhibitors of $\mathrm{CH}_{4}, \mathrm{NH}_{4}{ }^{+}$, and $\mathrm{CO}$ oxidation by methanotrophs and nitrifiers. Microbiol Rev 53: 68-84.

78. Topp E, Pattey E (1997) Soils as sources and sinks for atmospheric methane. Can J Soil Sci 77: 167-177. 


\section{Supporting Information}

Figure S1. Relative abundance of rare bacterial phyla occurring in fertilized (f) and non-ferilized (nf) soil microcosms.

Figure S2. Mean rarefaction curves indicating the number of observed bacterial OTUs in fertilized and non-fertilized soil columns at day 3 and 41 of the experiment.

Figure S3. Mean rarefaction curves indicating the number of observed archaeal OTUs in fertilized and non-fertilized soil columns at day 3 and 41 of the experiment.

Table S1. Number of bacterial 16S rRNA gene sequences derived from the analyzed non-fertilized (nf) and fertilized (f) soil samples.

Table S2. Bacterial diversity as assessed by the Shannon index $\left(\mathrm{H}^{\prime}\right)$ and species richness estimation in non-fertilized (nf) and fertilized (f) microcosms at day 3.

Table S3. Bacterial diversity as assessed by the Shannon index $\left(\mathrm{H}^{\prime}\right)$ and species richness estimation in non-fertilized (nf) and fertilized (f) microcosms at day 41.

Table S4. Differences of the relative abundance of proteobacterial classes, and other bacterial phyla present in the non-fertilized (nf) and fertilized (f) microcosms.

Table S5. Number of archaeal 16S rRNA gene sequences derived from the analyzed non-fertilized (nf) and fertilized (f) soil samples.

Table S6. Archaeal diversity as assessed by the Shannon index $\left(\mathrm{H}^{\prime}\right)$ and species richness estimation in non-fertilized (nf) and fertilized (f) microcosms.

Table S7. Number of $16 \mathrm{~S}$ rRNA gene sequences derived from the analyzed nonfertilized (nf) and fertilized (f) soil samples using primers specific for methanotrophic bacteria of type I and type II. 


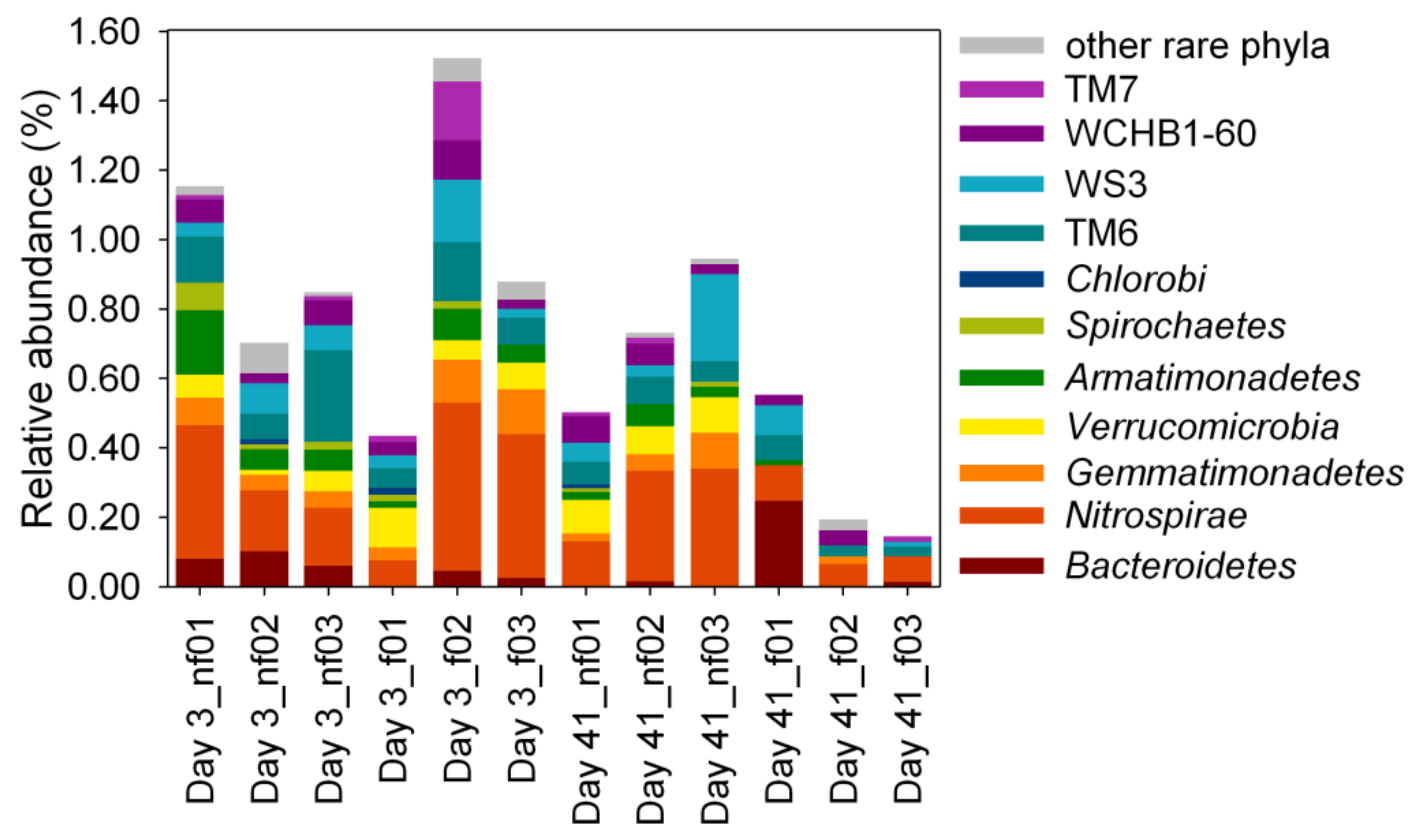

Figure S1. Relative abundance of rare bacterial phyla occurring in fertilized (f) and non-ferilized (nf) soil microcosms. The soil columns were sampled 3 and 41 days after the first fertilization. 

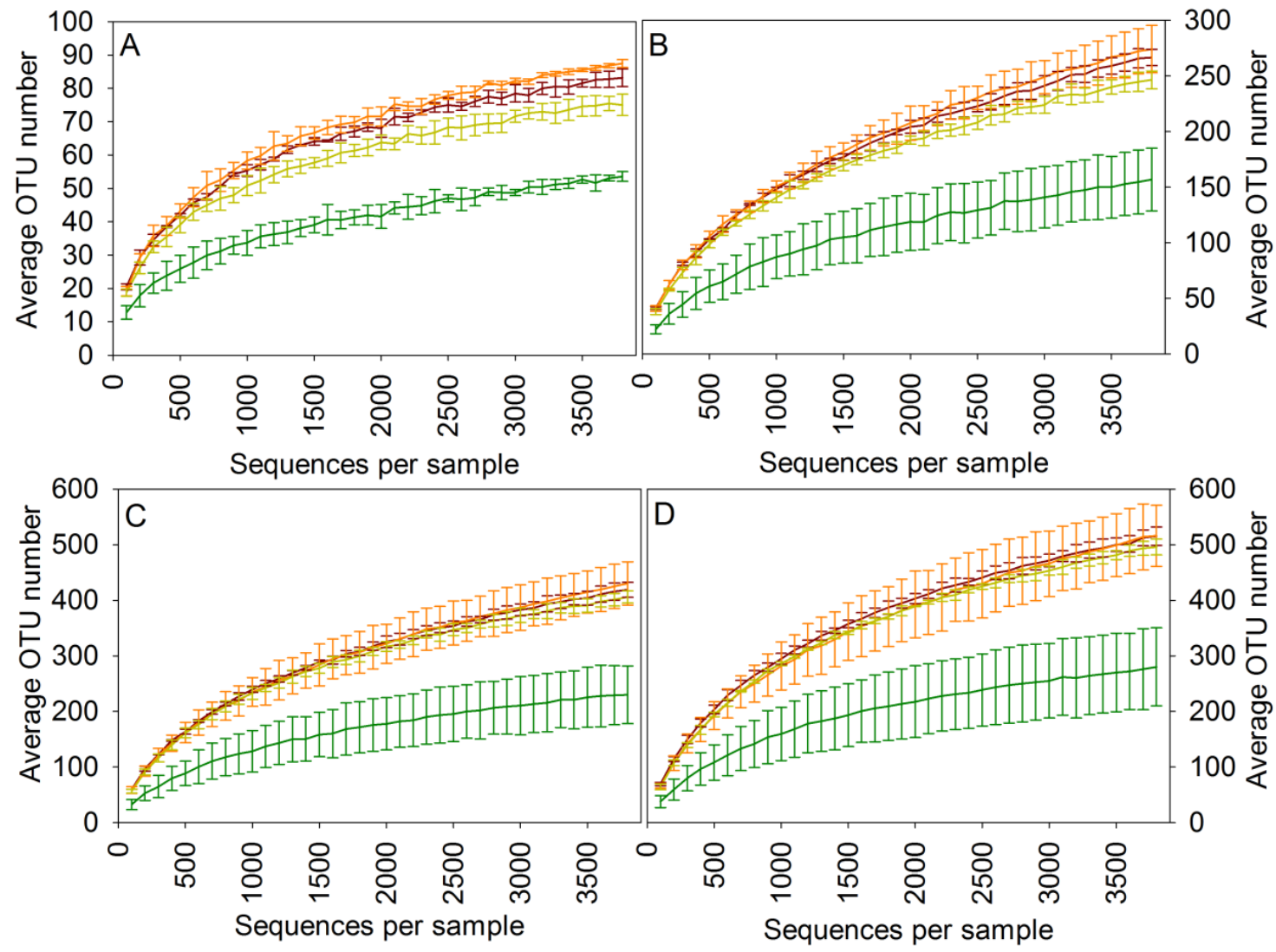

Day 3 non-fertilized

Day 41 non-fertilized

Day 3 fertilized

Day 41 fertilized

Figure S2. Mean rarefaction curves indicating the number of observed bacterial OTUs in fertilized and non-fertilized soil columns at day 3 and 41 of the experiment. Depicted are the mean and the standard deviation of the sum of all OTUs observed at 20 (A), 10 (B), 5 (C) and 3\% (D) genetic divergence. 


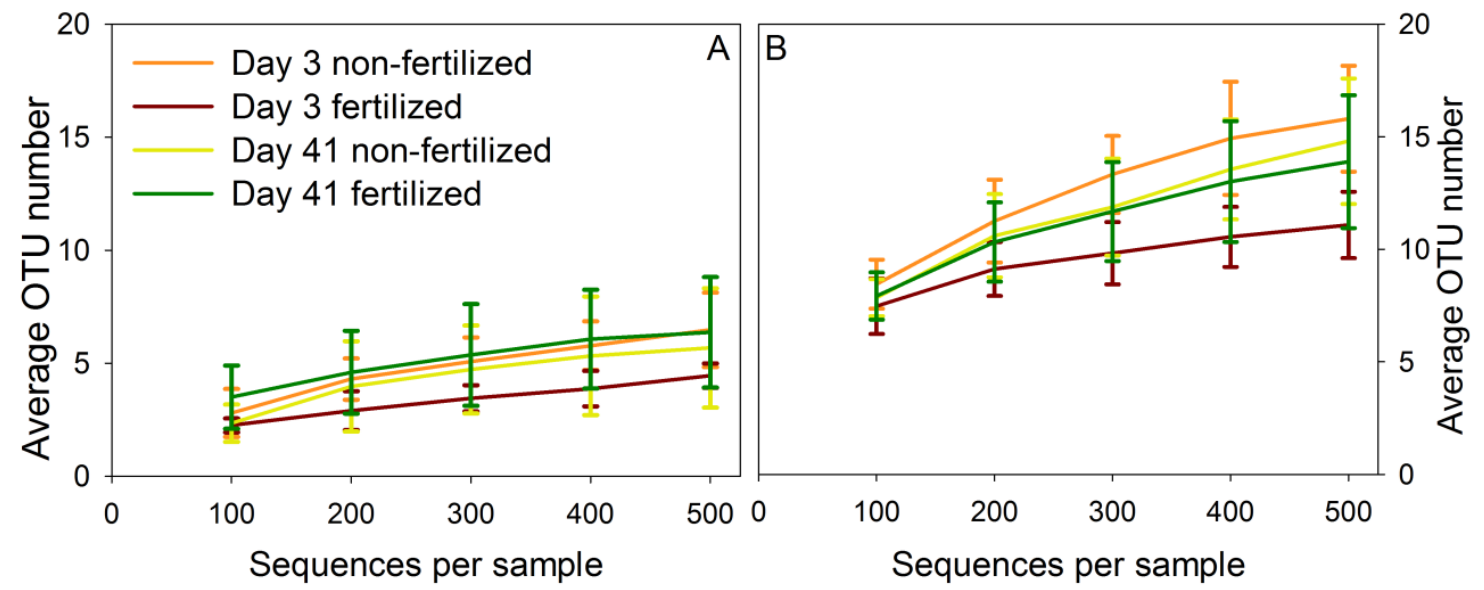

Figure S3. Mean rarefaction curves indicating the number of observed archaeal OTUs in fertilized and non-fertilized soil columns at day 3 and 41 of the experiment. Depicted are the mean and the standard deviation of the sum of all OTUs observed at 20 (A) and 3\% (B) genetic divergence. 
Table S1. Number of bacterial 16S rRNA gene sequences derived from the analyzed non-fertilized (nf) and fertilized (f) soil samples. The final number was recovered after removal of sequences with low quality (quality score $<25$ ), containing homopolymers longer than $8 \mathrm{bp}$ and primer mismatches. In addition, denoising and removal of potential chimeras were performed.

\begin{tabular}{llll}
\hline Sample & $\begin{array}{l}\text { No. of initial } \\
\text { sequences }\end{array}$ & $\begin{array}{l}\text { No. of sequences } \\
\mathbf{3 0 0} \text { bp }\end{array}$ & $\begin{array}{l}\text { Final no. of } \\
\text { sequences }\end{array}$ \\
\hline Day 3_nf01 & 10547 & 8331 & 7613 \\
Day 3_nf02 & 9324 & 7483 & 6974 \\
Day 3_nf03 & 11747 & 9182 & 8549 \\
Day 3_f01 & 7368 & 5956 & 5416 \\
Day 3_f02 & 12219 & 9739 & 9140 \\
Day 3_f03 & 5342 & 4389 & 4043 \\
Day 41_nf01 & 12721 & 10127 & 9335 \\
Day 41_nf02 & 8881 & 6856 & 6374 \\
Day 41_nf03 & 9407 & 7388 & 6863 \\
Day 41_f01 & 9185 & 7414 & 6962 \\
Day 41_f02 & 11979 & 10112 & 9384 \\
Day 41_f03 & 8807 & 7479 & 6957 \\
\hline
\end{tabular}


Table S2. Bacterial diversity as assessed by the Shannon index $\left(\mathrm{H}^{\prime}\right)$ and species richness estimation in non-fertilized (nf) and fertilized (f) microcosms at day 3. Each treatment was replicated three times and sampled 3 days after the first fertilization.

\begin{tabular}{|c|c|c|c|c|c|c|}
\hline \multirow[t]{2}{*}{ Sample } & \multirow{2}{*}{$\begin{array}{l}\text { Genetic } \\
\text { divergence } \\
(\%)\end{array}$} & \multirow[t]{2}{*}{$\mathbf{H}^{\prime}$} & \multicolumn{4}{|c|}{ No. of operational taxonomic units (OTUs) } \\
\hline & & & $\begin{array}{l}\text { Observed } \\
\text { (doubles/singles) }\end{array}$ & $\overline{\mathrm{ACE}}$ & Chao1 & $\begin{array}{l}\text { Michaelis- } \\
\text { Menten Fit }\end{array}$ \\
\hline $\begin{array}{l}\text { Day 3_nf01 } \\
\text { 3_n }\end{array}$ & 3 & 5.319 & $532(76 / 192)$ & 742 & 775 & 682 \\
\hline Day 3_nf01 & 5 & 4.884 & $437(61 / 172)$ & 649 & 680 & 566 \\
\hline Day 3_nf01 & 10 & 3.911 & $278(42 / 118)$ & 447 & 444 & 366 \\
\hline Day 3_nf01 & 20 & 2.490 & $81(9 / 20)$ & 97 & 103 & 90 \\
\hline Day 3_nf02 & 3 & 5.203 & $505(64 / 178)$ & 684 & 751 & 639 \\
\hline Day 3_nf02 & 5 & 4.788 & $407(53 / 147)$ & 565 & 611 & 513 \\
\hline Day 3_nf02 & 10 & 3.850 & $259(37 / 103)$ & 398 & 404 & 328 \\
\hline Day 3_nf02 & 20 & 2.546 & $84(13 / 21)$ & 105 & 101 & 94 \\
\hline Day 3_nf03 & 3 & 5.036 & $508(66 / 193)$ & 724 & 789 & 660 \\
\hline Day 3_nf03 & 5 & 4.670 & $417(56 / 163)$ & 610 & 649 & 538 \\
\hline Day 3_nf03 & 10 & 3.646 & $268(36 / 112)$ & 423 & 437 & 348 \\
\hline Day 3_nf03 & 20 & 2.380 & $85(10 / 25)$ & 115 & 113 & 96 \\
\hline Day 3_f01 & 3 & 4.939 & $463(34 / 205)$ & 745 & 1077 & 587 \\
\hline Day 3_f01 & 5 & 4.535 & $387(37 / 181)$ & 684 & 819 & 503 \\
\hline Day 3_f01 & 10 & 3.603 & $265(38 / 114)$ & 434 & 433 & 351 \\
\hline Day 3_f01 & 20 & 2.389 & $88(12 / 26)$ & 113 & 116 & 102 \\
\hline Day 3_f02 & 3 & 5.319 & $583(78 / 207)$ & 780 & 859 & 768 \\
\hline Day 3_f02 & 5 & 4.935 & $463(63 / 168)$ & 637 & 684 & 595 \\
\hline Day 3_f02 & 10 & 3.873 & $267(37 / 103)$ & 398 & 406 & 335 \\
\hline Day 3_f02 & 20 & 2.463 & $88(10 / 28)$ & 124 & 124 & 99 \\
\hline Day 3_f03 & 3 & 4.858 & $507(52 / 279)$ & 1183 & 1239 & 716 \\
\hline Day 3_f03 & 5 & 4.569 & $443(51 / 231)$ & 932 & 957 & 615 \\
\hline Day 3_f03 & 10 & 3.643 & $298(44 / 137)$ & 523 & 508 & 408 \\
\hline Day 3_f03 & 20 & 2.350 & $87(10 / 18)$ & 100 & 101 & 97 \\
\hline
\end{tabular}


Table S3. Bacterial diversity as assessed by the Shannon index $\left(\mathrm{H}^{\prime}\right)$ and species richness estimation in non-fertilized (nf) and fertilized (f) microcosms at day 41. Each treatment was replicated three times and was sampled 41 days after the first fertilization.

\begin{tabular}{lllllll}
\hline Sample & $\begin{array}{l}\text { Genetic } \\
\text { divergence }\end{array}$ & H' $^{\prime}$ & \multicolumn{3}{l}{ No. of operational taxonomic units (OTUs) } \\
\cline { 4 - 6 }$(\boldsymbol{\%})$ & & $\begin{array}{l}\text { Observed } \\
\text { (doubles/singles) }\end{array}$ & ACE & Chao1 & $\begin{array}{l}\text { Michaelis- } \\
\text { Menten Fit }\end{array}$ \\
\hline Day 41_nf01 & 3 & 4.762 & $514(75 / 190)$ & 706 & 754 & 689 \\
Day 41_nf01 & 5 & 4.389 & $413(58 / 157)$ & 586 & 625 & 546 \\
Day 41_nf01 & 10 & 3.342 & $253(36 / 101)$ & 378 & 393 & 330 \\
Day 41_nf01 & 20 & 2.197 & $77(10 / 22)$ & 101 & 100 & 87 \\
Day 41_nf02 & 3 & 4.993 & $487(56 / 174)$ & 657 & 754 & 619 \\
Day 41_nf02 & 5 & 4.539 & $390(51 / 145)$ & 551 & 597 & 498 \\
Day 41_nf02 & 10 & 3.428 & $237(36 / 87)$ & 343 & 341 & 299 \\
Day 41_nf02 & 20 & 2.251 & $71(9 / 16)$ & 84 & 84 & 79 \\
Day 41_nf03 & 3 & 4.998 & $490(62 / 177)$ & 677 & 741 & 625 \\
Day 41_nf03 & 5 & 4.725 & $414(54 / 151)$ & 586 & 623 & 519 \\
Day 41_nf03 & 10 & 3.636 & $250(33 / 98)$ & 383 & 401 & 313 \\
Day 41_nf03 & 20 & 2.396 & $79(10 / 20)$ & 98 & 99 & 87 \\
Day 41_f01 & 3 & 4.038 & $355(40 / 119)$ & 460 & 531 & 449 \\
Day 41_f01 & 5 & 3.749 & $291(34 / 108)$ & 409 & 462 & 369 \\
Day 41_f01 & 10 & 2.815 & $185(23 / 66)$ & 258 & 278 & 230 \\
Day 41_f01 & 20 & 1.759 & $55(8 / 14)$ & 70 & 67 & 60 \\
Day 41_f02 & 3 & 3.398 & $272(29 / 103)$ & 381 & 449 & 347 \\
Day 41_f02 & 5 & 3.001 & $223(29 / 88)$ & 331 & 355 & 286 \\
Day 41_f02 & 10 & 2.406 & $149(18 / 63)$ & 239 & 253 & 190 \\
Day 41_f02 & 20 & 1.469 & $51(8 / 18)$ & 76 & 71 & 58 \\
Day 41_f03 & 3 & 2.404 & $212(22 / 94)$ & 338 & 418 & 285 \\
Day 41_f03 & 5 & 2.235 & $187(21 / 88)$ & 321 & 363 & 258 \\
Day 41_f03 & 10 & 1.623 & $134(19 / 63)$ & 240 & 233 & 187 \\
Day 41_f03 & 20 & 1.011 & $54(7 / 19)$ & 77 & 77 & 64 \\
\hline & & & & & &
\end{tabular}


Table S4. Differences of the relative abundance of proteobacterial classes, and other bacterial phyla present in the non-fertilized (nf) and fertilized (f) microcosms. The respective soil columns were sampled 3 and 41 days after the first fertilization. Tested with paired t-test $(P<0.05, \mathrm{n}=3)$.

\begin{tabular}{lllll}
\hline & $\begin{array}{l}\text { Day 3_nf vs. } \\
\text { Day3_f }\end{array}$ & $\begin{array}{l}\text { Day41_nf vs. } \\
\text { Day41_f }\end{array}$ & $\begin{array}{l}\text { Day3_nf vs. } \\
\text { Day41_nf }\end{array}$ & $\begin{array}{l}\text { Day3_f vs. } \\
\text { Day41_f }\end{array}$ \\
\cline { 2 - 5 } & $\boldsymbol{P}$ & $\boldsymbol{P}$ & $\boldsymbol{P}$ & $\boldsymbol{P}$ \\
\hline Alphaproteobacteria & 0.298 & 0.093 & $0.048^{*}$ & 0.247 \\
Betaproteobacteria & 0.206 & 0.096 & 0.053 & 0.082 \\
Deltaproteobacteria & 0.100 & $0.022^{*}$ & 0.085 & $0.038^{*}$ \\
Gammaproteobacteria & 0.886 & $<0.001^{* * *}$ & $0.002^{* *}$ & $0.012^{*}$ \\
Other Proteobacteria & 0.237 & $0.034^{*}$ & 0.582 & 0.100 \\
Acidobacteria & $0.037^{*}$ & $0.006^{* *}$ & 0.226 & $0.026^{*}$ \\
Firmicutes & 0.110 & 0.700 & $0.041^{*}$ & 0.509 \\
Chloroflexi & 0.472 & 0.396 & 0.119 & 0.730 \\
Actinobacteria & $0.006^{* *}$ & 0.670 & 0.100 & 0.289 \\
Planctomycetes & 0.607 & $0.022^{*}$ & 0.886 & 0.172 \\
Cyanobacteria & 0.700 & $0.015^{*}$ & $0.015 *$ & 0.100 \\
Bacteroidetes & $0.034^{*}$ & 0.365 & $0.005^{* *}$ & 0.477 \\
Nitrospirae & 0.602 & 0.053 & 0.845 & 0.125 \\
Gemmatimonadetes & 0.277 & 0.115 & 0.986 & $0.042^{*}$ \\
Verrucomicrobia & 0.202 & $<0.001^{* * *}$ & 0.058 & $0.008^{* *}$ \\
Armatimonadetes & 0.366 & 0.071 & 0.226 & 0.083 \\
\hline
\end{tabular}

* Significant at the 0.05 probability level.

** Significant at the 0.01 probability level.

*** Significant at the 0.001 probability level. 
Table S5. Number of archaeal 16S rRNA gene sequences derived from the analyzed non-fertilized (nf) and fertilized (f) soil samples. The final number was recovered after removal of sequences with low quality (quality score $<25$ ), containing homopolymers longer than $8 \mathrm{bp}$ and primer mismatches. In addition, denoising and removal of potential chimeras were performed.

\begin{tabular}{llll}
\hline Sample & $\begin{array}{l}\text { No. of } \\
\text { initial } \\
\text { sequences }\end{array}$ & $\begin{array}{l}\text { No. of } \\
\text { sequences } \\
\mathbf{2} 200 \text { bp }\end{array}$ & $\begin{array}{l}\text { Final no. of } \\
\text { sequences }\end{array}$ \\
\hline Day 3_nf01 & 1317 & 590 & 520 \\
Day 3_nf02 & 2124 & 945 & 855 \\
Day 3_nf03 & 8443 & 3608 & 3215 \\
Day 3_nf04 & 3673 & 1620 & 1434 \\
Day 3_f01 & 1397 & 625 & 540 \\
Day 3_f02 & 1658 & 666 & 608 \\
Day 3_f03 & 1665 & 840 & 632 \\
Day 3_f04 & 1828 & 828 & 713 \\
Day 41_nf01 & 5676 & 2417 & 2124 \\
Day 41_nf02 & 3342 & 1576 & 1385 \\
Day 41_nf03 & 16108 & 7155 & 6534 \\
Day 41_nf04 & 5687 & 2787 & 2466 \\
Day 41_f01 & 14561 & 6154 & 5635 \\
Day 41_f02 & 2632 & 1142 & 927 \\
Day 41_f03 & 2227 & 1490 & 1192 \\
\hline
\end{tabular}


Table S6. Archaeal diversity as assessed by the Shannon index $\left(\mathrm{H}^{\prime}\right)$ and species richness estimation in non-fertilized (nf) and fertilized (f) microcosms. Samples were taken 3 and 41 days after the first fertilization.

\begin{tabular}{|c|c|c|c|c|c|}
\hline \multirow[t]{2}{*}{ Sample } & \multirow{2}{*}{$\begin{array}{l}\text { Genetic } \\
\text { divergence } \\
(\%)\end{array}$} & \multirow[t]{2}{*}{$\mathbf{H}^{\prime}$} & \multicolumn{3}{|c|}{ No. of operational taxonomic units } \\
\hline & & & $\begin{array}{l}\text { Observed } \\
\text { (doubles/singles) }\end{array}$ & Chao1 & $\begin{array}{l}\text { Michaelis-Menten } \\
\text { Fit }\end{array}$ \\
\hline$\overline{\text { Day 3_nf01 }}$ & 3 & 2.136 & $18(2 / 7)$ & 24 & 21 \\
\hline Day 3_nf01 & 20 & n.d. & $8(0 / 4)$ & 13 & 10 \\
\hline Day 3_nf02 & 3 & 2.255 & $18(2 / 8)$ & 29 & 21 \\
\hline Day 3_nf02 & 20 & n.d. & $7(1 / 5)$ & 15 & 14 \\
\hline Day 3_nf03 & 3 & 2.145 & $17(2 / 7)$ & 27 & 20 \\
\hline Day 3_nf03 & 20 & n.d. & $7(1 / 4)$ & 12 & 12 \\
\hline Day 3_nf04 & 3 & 2.054 & $12(1 / 4)$ & 16 & 13 \\
\hline Day 3_nf04 & 20 & n.d. & $5(1 / 2)$ & 6 & 6 \\
\hline Day 3_f01 & 3 & 1.757 & $10(0 / 3)$ & 13 & 10 \\
\hline Day 3_f01 & 20 & n.d. & $4(0 / 3)$ & 6 & 5 \\
\hline Day 3_f02 & 3 & 2.2 & $12(0 / 3)$ & 17 & 13 \\
\hline Day 3_f02 & 20 & n.d. & $4(0 / 2)$ & 6 & 6 \\
\hline Day 3_f03 & 3 & 2.404 & $13(0 / 3)$ & 16 & 13 \\
\hline Day 3_f03 & 20 & n.d. & $4(0 / 2)$ & 5 & 4 \\
\hline Day 3_f04 & 3 & 2.112 & $10(2 / 1)$ & 10 & 10 \\
\hline Day 3_f04 & 20 & n.d. & $5(1 / 1)$ & 5 & 6 \\
\hline Day 41_nf01 & 3 & 2.167 & $19(4 / 6)$ & 23 & 24 \\
\hline Day 41_nf01 & 20 & n.d. & $8(1 / 3)$ & 10 & 11 \\
\hline Day 41_nf02 & 3 & 2.087 & $14(3 / 4)$ & 16 & 16 \\
\hline Day 41_nf02 & 20 & n.d. & $7(2 / 2)$ & 8 & 9 \\
\hline Day 41_nf03 & 3 & 1.926 & $13(2 / 4)$ & 15 & 14 \\
\hline Day 41_nf03 & 20 & n.d. & $2(0 / 1)$ & 3 & 3 \\
\hline Day 41_nf04 & 3 & 1.688 & $12(2 / 3)$ & 15 & 14 \\
\hline Day 41_nf04 & 20 & n.d. & $5(2 / 2)$ & 6 & 8 \\
\hline Day 41_f01 & 3 & 2.218 & $15(2 / 4)$ & 18 & 16 \\
\hline Day 41_f01 & 20 & n.d. & $4(1 / 1)$ & 4 & 4 \\
\hline Day 41_f02 & 3 & 1.738 & 17 & 19 & 20 \\
\hline Day 41_f02 & 20 & n.d. & $7(1 / 2)$ & 8 & 8 \\
\hline Day 41_f03 & 3 & 2.468 & 17 & 19 & 18 \\
\hline Day 41_f03 & 20 & n.d. & $8(1 / 3)$ & 10 & 10 \\
\hline
\end{tabular}

n.d., not determined 
Table S7. Number of $16 \mathrm{~S}$ rRNA gene sequences derived from the analyzed nonfertilized (nf) and fertilized (f) soil samples using primers specific for methanotrophic bacteria of type I and type II. The final number was recovered after removal of sequences with low quality (quality score <25), containing homopolymers longer than $8 \mathrm{bp}$ and primer mismatches. In addition, denoising and removal of potential chimeras were performed.

\begin{tabular}{|c|c|c|c|c|c|c|}
\hline \multirow[b]{2}{*}{ Sample } & \multicolumn{3}{|l|}{ Type I } & \multicolumn{3}{|l|}{ Type II } \\
\hline & $\begin{array}{l}\text { No. of } \\
\text { initial } \\
\text { sequences }\end{array}$ & $\begin{array}{l}\text { No. of } \\
\text { sequence } \\
\text { S } \\
\geq \mathbf{3 0 0 ~ b p} \\
\end{array}$ & $\begin{array}{l}\text { Final no. } \\
\text { of } \\
\text { sequences }\end{array}$ & $\begin{array}{l}\text { No. of } \\
\text { initial } \\
\text { sequences }\end{array}$ & $\begin{array}{l}\text { No. of } \\
\text { sequences } \\
\geq 300 \text { bp }\end{array}$ & $\begin{array}{l}\text { Final no. } \\
\text { of } \\
\text { sequences }\end{array}$ \\
\hline Day 3_nf01 & 16206 & 11878 & 10732 & 11891 & 10379 & 9232 \\
\hline Day 3_nf02 & 12888 & 9336 & 8524 & 33499 & 28611 & 25332 \\
\hline Day 3_nf03 & 12203 & 9005 & 8165 & 21517 & 18289 & 16253 \\
\hline Day 3_nf04 & 9734 & 7267 & 6400 & 12574 & 9516 & 8406 \\
\hline Day 3 f01 & 15678 & 11985 & 10630 & 25816 & 22037 & 19270 \\
\hline Day 3_f02 & 16269 & 15831 & 10433 & 44762 & 38283 & 33863 \\
\hline Day 3_f03 & 13109 & 9561 & 8567 & 44589 & 38025 & 33978 \\
\hline Day 3_f04 & 15494 & 11278 & 10047 & 16162 & 14155 & 12335 \\
\hline $\begin{array}{l}\text { Day } \\
\text { 41_nf01 }\end{array}$ & 14657 & 10946 & 9887 & 26013 & 22051 & 19795 \\
\hline $\begin{array}{l}\text { Dāy } \\
41 \text { nf02 }\end{array}$ & 12561 & 5789 & 5235 & 28428 & 23873 & 21651 \\
\hline $\begin{array}{l}\text { Dāy } \\
41 \text { nf03 }\end{array}$ & 10013 & 7381 & 6543 & 9677 & 8384 & 7651 \\
\hline $\begin{array}{l}\text { Dāy } \\
41 \text { nf04 }\end{array}$ & 16152 & 12268 & 10801 & 11291 & 9744 & 8716 \\
\hline Day 41_f01 & 12613 & 9702 & 8524 & 41591 & 35195 & 31958 \\
\hline Day 41_f02 & 21613 & 8515 & 7643 & 37318 & 31197 & 27530 \\
\hline Day 41_f03 & 13415 & 10287 & 9011 & 12872 & 11057 & 9992 \\
\hline
\end{tabular}


3.

\title{
Combined effects of nitrate and labile $\mathrm{C}$ on the $\mathrm{N}_{2} \mathrm{O}$
} emissions of a temperate forest soil

\author{
Ann-Catrin Fender ${ }^{1)}$, Christoph Leuschner ${ }^{1)}$, Birgit Pfeiffer ${ }^{2)}$, Rolf Daniel ${ }^{2)}$ and Hermann \\ F. Jungkunst ${ }^{3)}$
}

Manuscript draft

${ }^{1)}$ Plant Ecology and Ecosystems research, University of Goettingen, Untere Karspüle 2, 37073 Goettingen, Germany

${ }^{2)}$ Genomic and Applied Microbiology, University of Goettingen, Grisebachstr. 8, 37077 Goettingen, Germany

${ }^{3)}$ Geoecology Physical Geography, Insitute for Environmental Sciences, University of KoblenzLandau, Fortstr. 7, 76829 Landau, Germany

\section{Author contributions to the work:}

Performed the experiments: AC. Fender, B. Pfeiffer

Analyzed the data: AC. Fender, B. Pfeiffer

Wrote the paper: AC. Fender, HF. Jungkunst

Conceived and designed the experiments: HF. Jungkunst, AC. Fender, R. Daniel 


\begin{abstract}
Temperate forest soils have the potential to significantly increase atmospheric $\mathrm{N}_{2} \mathrm{O}$ concentrations when receiving high nitrogen deposition from the atmosphere. Since most of the $\mathrm{N}_{2} \mathrm{O}$ released is a by-product of heterotrophic microbial activity, a sufficiently large labile $\mathrm{C}$ pool is a perquisite for elevated $\mathrm{N}_{2} \mathrm{O}$ net release. In a twofactorial laboratory experiment we tested the combined effects of high $\mathrm{N}$ addition and unlimited labile $\mathrm{C}$ availability on the $\mathrm{N}_{2} \mathrm{O}$ emission from a temperate deciduous forest soil. The $\mathrm{N}_{2} \mathrm{O}$ emissions were increased eightfold after a single addition of $200 \mathrm{~kg} \mathrm{~N}^{-}$ 1 as $\mathrm{KNO}_{3}$, while a second $\mathrm{N}$ addition resulted in no further increase. Addition of high amounts of labile $\mathrm{C}$ (glucose, $9419 \mathrm{~kg} \mathrm{C} \mathrm{ha}^{-1}$ ) increased the cumulative $\mathrm{N}_{2} \mathrm{O}$ emissions 39-fold in unfertilised soil in the $41 \mathrm{~d}$ following application. The combination of $\mathrm{N}$ and $\mathrm{C}$ addition led to a 70 -fold increase in the $\mathrm{N}_{2} \mathrm{O}$ emission related to untreated soil. Our results warrant that the role of labile $\mathrm{C}$ and its interaction with $\mathrm{N}$ availability has to be considered in future predictions of $\mathrm{N}_{2} \mathrm{O}$ emissions from temperate forest soils.
\end{abstract}

Key Words: decomposition, nitrogen availability, nitrous oxide, organic carbon, trace gas emission 


\section{Introduction}

The atmospheric concentration of $\mathrm{N}_{2} \mathrm{O}$, one of the most important anthropogenic greenhouse gases with a global warming potential 298 times larger than that $\mathrm{CO}_{2}$, has increased by $19 \%$ since pre-industrial times (Forster et al., 2007). Main sources of $\mathrm{N}_{2} \mathrm{O}$ are agriculture, land-use changes and biomass burning; it is predicted that globally increasing reactive nitrogen $\left(\mathrm{N}_{\mathrm{r}}\right)$ deposition and higher temperatures will further increase the atmospheric $\mathrm{N}_{2} \mathrm{O}$ concentrations (De Vries et al., 2006; Denman et al., 2007; Galloway et al., 2008; Janssens et al., 2010). $\mathrm{N}_{2} \mathrm{O}$ is mainly produced by heterotrophic microorganisms that depend on the availability of labile carbon (C).

Forests are important components in the cycles of $\mathrm{C}$ and $\mathrm{N}$ on earth (Mosier, 1998; Luyssaert et al., 2010); a large part of the ecosystem $\mathrm{C}$ and $\mathrm{N}$ pools of forests is typically stored in the soil (Galloway et al., 2003; Luyssaert et al., 2010). Beside agricultural soils, upland forest soils are considered as main sources of $\mathrm{N}_{2} \mathrm{O}$ in Europe (Butterbach-Bahl et al., 2002; Kesik et al., 2005; Jungkunst et al., 2006). However, the contribution of European forests to the global $\mathrm{N}_{2} \mathrm{O}$ emissions is still not entirely clear (Pihlatie et al., 2005). Nevertheless, it is undisputed that, on a global scale, forests have the greatest source potential for the expected increase in $\mathrm{N}_{2} \mathrm{O}$ emissions in future (Reay et al., 2008).

Processes in upland soils that may lead to $\mathrm{N}$ release in the atmosphere are denitrification, dissimilatory nitrate reduction to ammonium (DNRA), and nitrification (Bremmer, 1997; Bateman and Baggs, 2005), all of which are biologically driven and producing $\mathrm{N}_{2} \mathrm{O}$ as an intermediate by-product. Denitrification and DNRA are more important than nitrification in moist soil with a water-filled pore space (WFPS) $>60 \%$ (Ciarlo et al., 2008; Baggs, 2011). There is a general consensus that atmospheric $\mathrm{N}_{2} \mathrm{O}$ originating from soils is mainly produced in the course of denitrification (Baggs, 2008). Important controlling factors of denitrification are soil aeration and soil $\mathrm{NO}_{3}{ }^{-}$ concentration (Firestone and Davidson, 1989), which have been intensively studied in their effect on the $\mathrm{N}_{2} \mathrm{O}$ emissions from soil (Fazzolari et al., 1998; Williams et al., 1998; Vor et al., 2003; Ruser et al., 2006; Ciarlo et al., 2008).

For more than 30 years it has been recognised that beside the $\mathrm{N}$ availability labile $\mathrm{C}$ is an important regulator of denitrification and $\mathrm{N}_{2} \mathrm{O}$ emissions from soils ecause denitrification depends on labile $\mathrm{C}$ as energy source for catabolising $\mathrm{NO}_{3}{ }^{-}$(Smith and Tiedje, 1979; Firestone and Davidson, 1989; Wrage et al., 2001). How different C compounds and quantities are affecting denitrification and $\mathrm{N}_{2} \mathrm{O}$ emissions has been 
investigated in laboratory studies (Fazzolari et al., 1998; Murray et al., 2004; Wang et al., 2005; Henry et al., 2008; Morley and Baggs, 2010). Most studies that compared the effects of $\mathrm{C}$ and $\mathrm{N}$ addition on $\mathrm{N}_{2} \mathrm{O}$ emissions observed a similarly large stimulation by the two agents (Weier et al., 1993; Gillam et al., 2008). However, the interaction between enhanced $\mathrm{N}$ and labile $\mathrm{C}$ availability on $\mathrm{N}_{2} \mathrm{O}$ emissions has only rarely been studied (Azam et al., 2002; Gillam et al., 2008) and thus is still not completely understood. We are not aware of a study where the effects of added $\mathrm{C}$ and $\mathrm{N}$ compounds on the $\mathrm{N}_{2} \mathrm{O}$ emission of a forest soil were studied under controlled laboratory conditions. More research is needed in particular for assessing the complex interacting effects of increasing amounts of $\mathrm{N}$, elevated atmospheric $\mathrm{CO}_{2}$, and higher temperatures in future climates on the $\mathrm{N}_{2} \mathrm{O}$ emissions from forest soils. A first step is to investigate the influence of unlimited $\mathrm{C}$ availability and high $\mathrm{N}$ supply on the $\mathrm{N}_{2} \mathrm{O}$ emissions of soil columns under controlled laboratory conditions.

While many forest soils contain relatively large organic $\mathrm{C}$ stocks, the amount of labile $\mathrm{C}$ can still be high or low (Magill and Aber, 2000; Tiunov and Scheu, 2004; Milcu et al., 2011). Under future climatic conditions, labile $C$ might be an important regulator either mitigating or accelerating the emissions of the greenhouse gas $\mathrm{N}_{2} \mathrm{O}$ (Murray et al., 2004; Morley and Baggs, 2010). Rising temperatures and the expected increase in atmospheric $\mathrm{CO}_{2}$ may increase the availability of labile $\mathrm{C}$ for $\mathrm{N}_{2} \mathrm{O}$-producing organisms (Denman et al., 2007), which is mainly released to soil through rhizodeposits and in the course of heterotrophic decomposition processes (Kirschbaum, 2004; Allison et al., 2010; Kuzyakov, 2011). However, enhanced microbial activity may simultaneously reduce the pool of labile $\mathrm{C}$ available for $\mathrm{N}_{2} \mathrm{O}$ production when organic matter is more rapidly decomposed to $\mathrm{CO}_{2}$ (Blagodatskaya and Kuzyakov, 2008). It is not yet clear, how increased or reduced availability of labile $\mathrm{C}$ in soils is affecting the release of $\mathrm{N}_{2} \mathrm{O}$. If higher temperatures and $\mathrm{N}$ deposition increase the availability of labile $\mathrm{C}$, a large increase in $\mathrm{N}_{2} \mathrm{O}$ emissions from forest soils can be expected. If $\mathrm{C}$ availability is not increased or even decreased, no dramatic increase in $\mathrm{N}_{2} \mathrm{O}$ release should occur. More available labile $\mathrm{C}$ has been found to promote denitrification with the possible result that a higher proportion of nitrate $\left(\mathrm{NO}_{3}{ }^{-}\right)$is reduced to the end-product $\mathrm{N}_{2}$ instead of the intermediate by-product $\mathrm{N}_{2} \mathrm{O}$ (Morley and Baggs, 2010). However, $\mathrm{N}_{2}$ is only produced when $\mathrm{O}_{2}$ is lacking in anaerobic microsites. Climate change scenarios predict warmer summers and, for many regions of Central Europe, also reduced summer rainfall 
(Werner and Gerstengarbe, 2007), which makes it unlikely that hypoxia and anoxia will be more widespread in temperate forest soils in future.

We experimentally examined the influence of large amounts of added $\mathrm{NO}_{3}{ }^{-}$, simulating high atmospheric deposition scenarios, on the $\mathrm{N}_{2} \mathrm{O}$ emissions of a temperate forest soil under conditions of potentially limited or unlimited labile $\mathrm{C}$ availability (glucose addition). Therefore, our study focused on the potential of $\mathrm{C}$ and $\mathrm{N}$ availability and their interactive effects to change the $\mathrm{N}_{2} \mathrm{O}$ emissions of this soil under controlled constant soil and climatic conditions. We hypothesised that (1) even though many forest soils contain large stocks of $\mathrm{C}$, the availability of labile $\mathrm{C}$ for $\mathrm{N}_{2} \mathrm{O}$ emissions is limited, with the consequence that repeated high $\mathrm{N}$ inputs do not result in a corresponding additive increase of the $\mathrm{N}_{2} \mathrm{O}$ release rate, and (2) high amounts of labile $\mathrm{C}$ in forest soils lead to similar $\mathrm{N}_{2} \mathrm{O}$ emission rates as the application of high $\mathrm{N}$ amounts, as it was found in studies on non-forest soils (Weier et al., 1993; Bateman and Baggs, 2005). We further hypothesised (3) that the addition of labile $\mathrm{C}$ to forest soil affected by chronic $\mathrm{N}$ addition must result in very high $\mathrm{N}_{2} \mathrm{O}$ emissions exceeding the sum of rates measured in soils treated with $\mathrm{N}$ or $\mathrm{C}$ sources alone. 


\section{Materials and Methods}

Soil characteristics and soil sampling

The soil was sampled in a mixed broad-leaved temperate forest in the Hainich National Park, Thuringia, Germany $\left(51^{\circ} 04^{\prime}\right.$ N $10^{\circ} 30^{\prime}$ E). The soil type is a Stagnic Luvisol (IUSS Working Group WRB, 2007) of silty texture composed of $1.8 \%$ sand, $80.2 \%$ silt and $18.1 \%$ clay. The soil contained no carbonate ( $<0.02 \%$ of total C), $19.84 \pm 0.44 \mathrm{~g} \mathrm{~kg}-1$ $\mathrm{dw}$ organic $\mathrm{C}\left(\mathrm{C}_{\mathrm{org}}\right)$ and $1.89 \pm 0.03 \mathrm{~g} \mathrm{~kg}^{-1} \mathrm{dw}$ total nitrogen $\left(\mathrm{N}_{\text {total }}\right.$, Table 1$)$. The $\mathrm{pH}$ $(\mathrm{KCl})$ was 3.8 and base saturation was $22.9 \%$. The soil material was taken from the upper $0-10 \mathrm{~cm}$ of the soil profile, passed through a $5 \mathrm{~mm}$-sieve and homogenised before insertion into the soil columns.

Table 1. Selected chemical parameters in the soil solution of the columns of the N-fertilised and the unfertilised control treatment in different phases of the experiment

\begin{tabular}{|c|c|c|c|c|c|}
\hline & & $\begin{array}{l}\text { Unfertilised } \\
\text { control (N0) }\end{array}$ & $\begin{array}{l}\text { N-fertilised } \\
\text { (N1) }\end{array}$ & $\begin{array}{l}\text { Unfertilised } \\
\text { control (N0) }\end{array}$ & $\begin{array}{l}\text { N-fertilised } \\
\text { (N1) }\end{array}$ \\
\hline $\begin{array}{l}\text { Experimental } \\
\text { phase }\end{array}$ & Day $0^{\text {a) }}$ & \multicolumn{2}{|c|}{ Day 41 after $\mathrm{N}$ addition } & \multicolumn{2}{|c|}{ Day 41 after $\mathrm{N}$ addition } \\
\hline pH (KCl) & $\begin{array}{l}3.82 \\
\pm 0.03\end{array}$ & $3.84 \mathrm{aA}^{\mathrm{b})} \pm 0.08$ & $4.23 \mathrm{bA} \pm 0.06$ & $4.49 \mathrm{aB} \pm 0.07$ & $5.63 \mathrm{bB} \pm 0.16$ \\
\hline $\begin{array}{l}C_{\text {org }} \\
{\left[g^{-1} \mathrm{~kg}^{-1} \mathrm{dw}\right]}\end{array}$ & $\begin{array}{l}19.84 \\
\pm 0.44\end{array}$ & $20.44 \mathrm{aA} \pm 0.37$ & $19.2 \mathrm{bA} \pm 0.25$ & $22.99 \mathrm{aB} \pm 0.58$ & $22.62 \mathrm{aB} \pm 0.28$ \\
\hline $\begin{array}{l}N_{\text {total }} \\
{\left[g^{-1} \mathrm{~kg}^{-1} \mathrm{dw}\right]}\end{array}$ & $\begin{array}{l}1.89 \\
\pm 0.03\end{array}$ & $2.08 \mathrm{aA} \pm 0.03$ & $2.4 \mathrm{bA} \pm 0.08$ & $1.99 \mathrm{aA} \pm 0.01$ & $2.42 \mathrm{bA} \pm 0.09$ \\
\hline $\begin{array}{l}\mathrm{C}: \mathrm{N} \\
{\left[\mathrm{g} \mathrm{g}^{-1}\right]}\end{array}$ & $\begin{array}{l}10.5 \\
\pm 0.19\end{array}$ & $9.85 \mathrm{aA} \pm 0.10$ & $8.02 \mathrm{bA} \pm 0.17$ & $11.52 \mathrm{aB} \pm 0.18$ & $9.41 \mathrm{bB} \pm 0.30$ \\
\hline $\begin{array}{l}\mathrm{NO}_{3}^{-} \\
{\left[\mathrm{mg} \mathrm{N} \mathrm{kg}^{-1} \mathrm{dw}\right]}\end{array}$ & $\begin{array}{l}6.39 \\
\pm 0.28\end{array}$ & n. d. & n. d. & $0.6 \mathrm{a} \pm 0.80$ & $35.78 b \pm 5.70$ \\
\hline $\begin{array}{l}\mathrm{NH}_{4}^{+} \\
{\left[\mathrm{mg} \mathrm{N} \mathrm{kg}^{-1} \mathrm{dw}\right]}\end{array}$ & $\begin{array}{l}7.85 \\
\pm 0.28\end{array}$ & n. d. & n. d. & $1.53 \mathrm{a} \pm 0.32$ & $34.5 b \pm 4.59$ \\
\hline
\end{tabular}

${ }^{a)}$ Given are means \pm 1 SE of each eight columns. Day 0 refers to the start of the experiment, day 41 is six weeks after the first $\mathrm{N}$ fertilisation and day 62 is three weeks after the third $\mathrm{N}$ fertilisation combined with glucose addition.

${ }^{b)}$ Lower case letters indicate significant differences between the $\mathrm{N}$-fertilised and the control treatment within a given experimental phase $(P<0.05$, Wilcoxon U-test); different upper case letters indicate significant differences between columns before and after glucose addition $(P<$ 0.05, Wilcoxon signed rank test). n. d. = parameter not determined 
Experimental setup

A main experiment was established with 16 acrylic glass columns $(0.50 \mathrm{~m}$ in height, $0.17 \mathrm{~m}$ in diameter), to test the effect of adding two substances, (1) $\mathrm{NO}_{3}{ }^{-}$and (2) glucose. The $\mathrm{NO}_{3}{ }^{-}(\mathrm{N})$ treatment was studied in eight replicate soil columns (eight $\mathrm{N}$ treated and eight control columns). The effect of glucose (C) addition was examined in all 16 columns by comparing the measured trace gas fluxes before and after adding the C source. A supplementary two-factorial experiment with 12 additional soil columns of the same dimensions and treated alike was conducted in which $\mathrm{N}$ and $\mathrm{C}$ addition were independent treatments and not subsequently added as the $\mathrm{C}$ source in the main experiment $(n=4$, Table 2). Each of the acrylic glass cylinders was filled with $4 \mathrm{~kg}$ of fresh sieved soil; the water content at the experiment's start was $22.7 \%$ of the fresh weight. The soil columns were placed in a random arrangement in the laboratory. Before starting the experiment, we kept the cylinders filled with soil for $62 \mathrm{~d}$ under laboratory conditions. This was for allowing the soil microbial community to adapt to the new soil and climatic conditions and reach a steady-state gas exchange after disturbing the natural soil structure. The experiment was divided into four periods (day 0 -- 20, 21 -- 41, 42 -- 62 and 63 - 83, respectively). On all three dates with $\mathrm{N}$ addition, the same eight randomly chosen soil columns were fertilised with a $\mathrm{KNO}_{3}$ solution in deionised water with an equivalent of $200 \mathrm{~kg} \mathrm{~N} \mathrm{ha}^{-1}$, i.e., on day 0 of the experiment (first $\mathrm{N}$ application), day 20 (second $\mathrm{N}$ application) and day 41 (third $\mathrm{N}$ application). The amount of water added was adjusted to a WFPS level of $80 \%$ on day 0 , day 20,41 and 62. On day 41 (start of the third $\mathrm{N}$ fertilisation phase), all 16 soil columns were additionally treated with a glucose solution (equivalent to $9419 \mathrm{~kg} \mathrm{C} \mathrm{ha}^{-1}$ ) to simulate unlimited supply of labile $\mathrm{C}$ in the soil in both the $\mathrm{N}$-fertilised and the untreated control columns. The addition of $\mathrm{N}$ increased the $\mathrm{N}_{\text {total }}$ pool in the soil columns in comparison to the initial $\mathrm{N}_{\text {total }}$ content by $7.7 \%$ after the first $\mathrm{N}$ addition (measured on day 20) and $8.0 \% \mathrm{~N}$ after the second $\mathrm{N}$ addition (measured on day 41 ); the $\mathrm{C}_{\text {org }}$ pool increased by $33.8 \%$ and $36.0 \%$ (measured on day 62) due to the glucose addition in the control and the $\mathrm{N}$-fertilised columns, respectively. 
Table 2. Selected chemical parameters of the soil before (day 0) and $20 \mathrm{~d}$ after the addition of $\mathrm{KNO}_{3}$ or glucose compared to the control treatment in the supplementary experiment

\begin{tabular}{|c|c|c|c|c|c|c|c|c|}
\hline \multirow[b]{2}{*}{ pH (KCl) } & \multicolumn{2}{|l|}{ Day 0} & \multicolumn{2}{|l|}{ Control } & \multicolumn{2}{|l|}{$\mathrm{KNO}_{3}$} & \multicolumn{2}{|c|}{ Glucose } \\
\hline & n.d. & & $4.32 \mathrm{a}^{\mathrm{a})}$ & \pm 0.11 & $4.15 \mathrm{a}$ & \pm 0.09 & $4.20 \mathrm{a}$ & \pm 0.04 \\
\hline $\begin{array}{l}C_{\text {org }} \\
{\left[g_{\text { kg }}^{-1}\right.} \\
\text { dw] }\end{array}$ & 29.20 & \pm 0.55 & $29.00 \mathrm{ab}$ & \pm 0.23 & $27.61 \mathrm{a}$ & \pm 0.54 & $32.8 b$ & \pm 1.76 \\
\hline $\begin{array}{l}N_{\text {total }} \\
{\left[g_{\text { kg }}^{-1}\right.} \\
\text { dw] }\end{array}$ & 2.00 & \pm 0.02 & $1.95 \mathrm{a}$ & \pm 0.03 & $2.02 \mathrm{a}$ & \pm 0.05 & $1.89 \mathrm{a}$ & \pm 0.02 \\
\hline $\begin{array}{l}\mathrm{C}: \mathbf{N} \\
{\left[\mathrm{g} \mathrm{g}^{-1}\right]}\end{array}$ & 14.69 & \pm 0.32 & $14.91 \mathrm{a}$ & \pm 0.15 & $13.70 \mathrm{a}$ & \pm 0.16 & $17.32 b$ & \pm 0.89 \\
\hline $\begin{array}{l}\mathrm{NO}_{3}^{-} \\
{\left[\mathrm{mg} \mathrm{N} \mathrm{kg}^{-}\right.} \\
\left.{ }_{\mathbf{1}} \mathrm{dw}\right]\end{array}$ & 3.27 & \pm 0.61 & $5.07 \mathrm{a}$ & \pm 3.00 & $45.15 b$ & \pm 2.44 & $0.94 \mathrm{a}$ & \pm 0.81 \\
\hline $\begin{array}{l}\mathrm{NH}_{4}^{+} \\
{\left[\mathrm{mg} \mathrm{N} \mathrm{kg}^{-}\right.} \\
{ }_{1} \mathrm{dw}^{-}\end{array}$ & 4.79 & \pm 0.25 & $3.96 a$ & \pm 1.86 & $9.65 b$ & \pm 0.85 & $2.10 \mathrm{a}$ & \pm 1.50 \\
\hline
\end{tabular}

In the supplementary experiment, we examined the response of the $\mathrm{N}_{2} \mathrm{O}$ and $\mathrm{CO}_{2}$ fluxes to the addition of either $\mathrm{KNO}_{3}$ (as $\mathrm{N}$ source) or glucose (as labile $\mathrm{C}$ source) using the same amounts of $\mathrm{N}$ and $\mathrm{C}$ (200 $\mathrm{kg} \mathrm{N} \mathrm{ha}^{-1}$ and $9419 \mathrm{~kg} \mathrm{C} \mathrm{ha}^{-1}$, respectively) compared to a control treatment each with $n=4$ columns, and the same cultivation conditions as in the main experiment. Further, the initial soil conditions (except for a higher $\mathrm{C}_{\text {org }}$ concentration of 29.2 vs. $19.8 \mathrm{~g} \mathrm{C} \mathrm{kg}^{-1}$, Table II) and all analytical procedures were identical to those in the main experiment. Apart from separating the $\mathrm{N}$ and $\mathrm{C}$ effects, this additional experiment also served for measuring the ammonium $\left(\mathrm{NH}_{4}{ }^{+}\right)$ concentrations in the soil after $\mathrm{NO}_{3}{ }^{-}$addition because these data were lost in the main experiment due to technical shortcomings.

The soil columns of both experiments were installed in a greenhouse with $14 \mathrm{~h}$ of daylight with low intensity $\left(100 \mu \mathrm{mol} \mathrm{m} \mathrm{m}^{-2} \mathrm{~s}^{-1}\right.$ PPFD; OSRAM cool white, lightcolor 840, Munich, Germany). The WFPS was measured every week by weighing the soil columns. The pore volume and the WFPS were calculated by assuming a particle density of $2.65 \mathrm{~g} \mathrm{~cm}^{-3}$ (Schlichting et al., 1995) and by referring to the measured soil bulk density at the beginning of the experiment. The soil temperature of each soil column was measured at a depth of $7.5 \mathrm{~cm}$ and a horizontal distance to the column edge 
of $3 \mathrm{~cm}$ using NTC thermistors (Epcos, Munich, Germany) that were logged in $15 \mathrm{~min}$ intervals with a CR10 data logger (Campbell Scientific Inc., Utah, USA). The soil temperature did not differ between the treatments, but decreased by $3^{\circ} \mathrm{C}$ over the course of the experiment (mean of $22.8 \pm 0.2^{\circ} \mathrm{C}$ in the $\mathrm{N}$-fertilised and the control treatment).

Gas flux analysis

The fluxes of $\mathrm{CO}_{2}$ and $\mathrm{N}_{2} \mathrm{O}$ at the soil surface were measured three times per week in the headspace of the soil columns. The headspace volume in the acrylic glass columns was $8.6 \mathrm{~L}$. The chambers were closed for $1 \mathrm{~h}$. After 0, 20, 40 and $60 \mathrm{~min}$, gas samples were taken from the chamber headspace by flushing gas-tight $50-\mathrm{ml}$ sample syringes with headspace air, using a needle and two three-way valves. Due to extremely high $\mathrm{CO}_{2}$ and $\mathrm{N}_{2} \mathrm{O}$ fluxes, the time intervals had to be reduced to $1.5 \mathrm{~min}$ directly after $\mathrm{C}$ addition. The gas concentrations were analysed by a computer-controlled gas chromatographic system with a ${ }^{63} \mathrm{Ni}$ electron capture detector for $\mathrm{CO}_{2}$ and $\mathrm{N}_{2} \mathrm{O}$ (Shimadzu GC-14B, Kyoto, Japan). A detailed description of the gas chromatograph is given by Loftfield et al., (1997). The gas fluxes were calculated from the linear increase of the gas concentration recorded during lid closure.

Soil analysis

Before the start of the experiment, we analysed five soil samples for their chemical properties (Table 1). The $\mathrm{pH}(\mathrm{KCl})$ was measured in a suspension of $10 \mathrm{~g}$ soil in $1 \mathrm{M}$ $\mathrm{KCl}$ solution using a Vario $\mathrm{pH}$ meter (WTW GmbH, Weilheim, Germany). The cation exchange capacity (CEC) of the soil was investigated by percolating $2 \mathrm{~g}$ fresh soil with $0.2 \mathrm{M} \mathrm{BaCl}$. The percolates were analysed with an ICP-AES (Optima $3000 \mathrm{XL}$, PerkinElmer, Massachusetts, USA). The base saturation at the cation exchangers was calculated as the percentage of base cations ( $\mathrm{Na}, \mathrm{K}, \mathrm{Ca}$ and $\mathrm{Mg}$ ) in CEC. The bulk density of the soil material in the columns was determined using steel cores with a defined volume of $100.93 \mathrm{~cm} 3$ and drying the soil at $105^{\circ} \mathrm{C}$ for 24 hours. On day 0 of the fertilisation experiment, the bulk density of the homogenised material was $1.05 \pm$ $0.02 \mathrm{~g} \mathrm{~cm}^{-3}$. The particle size distribution was determined with the sieving and pipette method (Schlichting et al., 1995). The concentrations of $\mathrm{C}_{\text {org }}$ and $\mathrm{N}_{\text {total }}$ were analysed with a $\mathrm{C} / \mathrm{N}$ analyzer (Vario EL, Elementar, Hanau, Germany). The concentrations of $\mathrm{NO}_{3}{ }^{-}$and $\mathrm{NH}_{4}{ }^{+}$(both in $\mathrm{mg} \mathrm{N} \mathrm{kg}{ }^{-1} \mathrm{dw}$ ) were measured by extracting $8 \mathrm{~g}$ fresh soil with $0.5 \mathrm{M} \mathrm{K}_{2} \mathrm{SO}_{4}$ solution (ratio of wet soil mass to solution: 1:3) directly after collecting 
the soil. The samples were shaken for $1 \mathrm{~h}$ and passed through folded filters (FT-4-303150, Sartorius Stedim, Aubagne, France). The $\mathrm{NO}_{3}{ }^{-}$and $\mathrm{NH}_{4}{ }^{+}$concentrations of the filtered extracts were analysed by continuous flow injection colorimetry (SAN+ Continuous Flow Analyzer, Skalar Instruments, Breda, The Netherlands). The $\mathrm{NO}_{3}{ }^{-}$ concentrations were determined with the copper-cadmium-reduction method (ISO method 13395), those of NH4+ with the Berthelot reaction method (ISO method 11732). On day 0 and at the end of the experiment, soil solution was sampled from the soil columns by irrigating the soil with $500 \mathrm{ml}$ of distilled water. The percolating water was passed through filter papers (MN 85/70 BF, Macherey-Nagel, Düren, Germany) and the soil solution was analysed with a DOC analyser (Dimatoc 100, Dimatec, Essen, Germany) for the concentration of dissolved organic $\mathrm{C}$. The concentration of $\mathrm{NO}_{3}{ }^{-}(\mathrm{mg}$ $\mathrm{L}^{-1}$ ) in the soil solution was analysed by ion chromatography (761 Compact IC, Metrohm, Herisau, Switzerland).

Data analysis

Statistical analyses were performed using SAS 9.1 software (Statistical Analysis System, SAS Institute Inc., Cary, USA). Cumulative gas fluxes were calculated by summing up all measurements for each column considering the number of measurements and the corresponding duration of the measuring phase. Frequency distributions were tested for normality with the Shapiro-Wilk test. One-way GLM with a Tukey-Kramer post hoc test was used to identify significant differences among the $\mathrm{N}$ treatment means for cumulative $\mathrm{N}_{2} \mathrm{O}$ and $\mathrm{CO}_{2}$ fluxes and soil properties in the datasets with normal distribution. Not normal-distributed soil parameters were analysed with the Wilcoxon U-test. Differences among normal-distributed $\mathrm{N}_{2} \mathrm{O}$ and $\mathrm{CO}_{2}$ flux data of the two $\mathrm{C}$ treatments were assessed with the paired t-test. The Wilcoxon signed rank test was used to identify differences between the $\mathrm{C}$ treatments in not normal-distributed soil parameters (this single test was carried out with the $\mathrm{R}$ statistical package, version 2.11.1, R Foundation for Statistical Computing, Vienna, Austria). For all analyses, significance was determined at $P<0.05$. 


\section{Results}

\section{$\mathrm{N}_{2} \mathrm{O}$ fluxes}

In the main experiment, the cumulative $\mathrm{N}_{2} \mathrm{O}$ emissions during the first $41 \mathrm{~d}$ (two fertilisation periods) were significantly higher in $\mathrm{N}$-fertilised soil compared to the unfertilised control (Fig. 1a). The first $\mathrm{N}$ addition led to significantly higher cumulative $\mathrm{N}_{2} \mathrm{O}$ emissions (278.1 $\pm 80.0 \mathrm{mg} \mathrm{N} \mathrm{m}^{-2} 20 \mathrm{~d}^{-1}$, day 0 -- 20) than the second $\mathrm{N}$ addition $\left(38.4 \pm 18.3 \mathrm{mg} \mathrm{N} \mathrm{m}^{-2} 20 \mathrm{~d}^{-1}\right.$, day $21-$ 41). During the first $\mathrm{N}$ fertilisation period, maximum $\mathrm{N}_{2} \mathrm{O}$ effluxes of $1642.4 \pm 461.6 \mu \mathrm{g} \mathrm{N} \mathrm{m}{ }^{-2} \mathrm{~h}^{-1}$ were measured, whereas the second $\mathrm{N}$ addition only led to maximum values of $243.7 \pm 135.6 \mu \mathrm{g} \mathrm{N} \mathrm{m} \mathrm{N}^{-2}$. Both maximum values were recorded four days after the $\mathrm{N}$ application (Fig. 2a). During day 21 -- 41, the unfertilised soil columns showed lower $\mathrm{N}_{2} \mathrm{O}$ emissions than during day 0 -21 as well $\left(34.5 \pm 4.9 \mathrm{mg} \mathrm{N} \mathrm{m}^{-2} 20 \mathrm{~d}^{-1}\right.$ vs. $\left.5.3 \pm 0.3 \mathrm{mg} \mathrm{N} \mathrm{m}^{-2} 20 \mathrm{~d}^{-1}\right)$.

The application of glucose induced significantly higher cumulative $\mathrm{N}_{2} \mathrm{O}$ emissions (between day 42 and 83) in both the unfertilised control and the $\mathrm{N}$-fertilised soil than in the reference period before $\mathrm{C}$ addition in the main experiment (Fig 1a). The combined addition of $\mathrm{C}$ and $\mathrm{N}$ compounds on day 41 resulted in significantly higher cumulative $\mathrm{N}_{2} \mathrm{O}$ fluxes than the single $\mathrm{C}$ and $\mathrm{N}$ additions. After the addition of glucose, the unfertilised control (treatment C1N0) and the $\mathrm{N}$-fertilised treatment (C1N1) reached similarly high maxima of $\mathrm{N}_{2} \mathrm{O}$ emissions $\left(13221.2 \pm 3253.4 \mu \mathrm{g} \mathrm{N} \mathrm{m}^{-2} \mathrm{~h}^{-1}\right.$ on day 43 and $11169.8 \pm 1320.4 \mu \mathrm{g} \mathrm{N} \mathrm{m}^{-2} \mathrm{~h}^{-1}$ on day 49 , respectively). After adding irrigation water on day 62 , the $\mathrm{N}_{2} \mathrm{O}$ emission of the $\mathrm{N}$-unfertilised control remained constant at a relatively low level, whereas the emissions of the $\mathrm{N}$-fertilised columns climbed to a very high maximum $\left(24135.6 \pm 4028.1 \mu \mathrm{g} \mathrm{N} \mathrm{m}^{-2} \mathrm{~h}^{-1}\right.$, on day 65).

In the supplementary experiment, the $\mathrm{N}$ addition led to 2.3 times higher cumulative $\mathrm{N}_{2} \mathrm{O}$ emissions than the control soil during the $41 \mathrm{~d}$-period $(P>0.05$, Fig. $1 \mathrm{~b})$, whereas the cumulative $\mathrm{N}_{2} \mathrm{O}$ efflux of the soil with $\mathrm{C}$ addition was even significantly 3.1 -fold higher than in the control. Compared to the main experiment, the peaks in $\mathrm{N}_{2} \mathrm{O}$ emissions were lower in all treatments (Fig. 3a). 

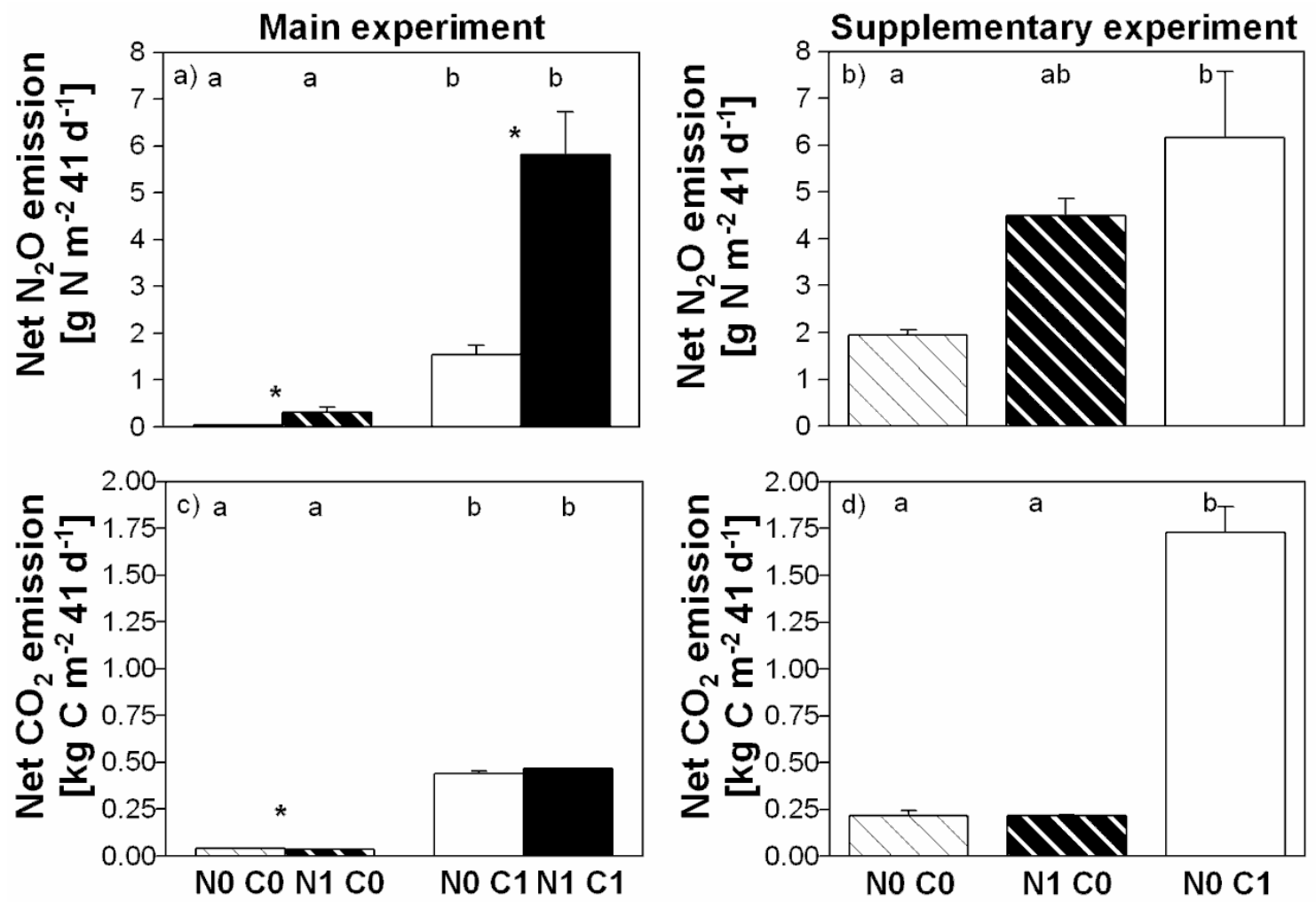

Fig. 1. Cumulative $\mathrm{N}_{2} \mathrm{O}(\mathrm{a}, \mathrm{b})$ and $\mathrm{CO}_{2}$ emissions (c, d) in the four different treatments of the main experiment $(\mathrm{a}, \mathrm{c})$ or the three treatments of the supplementary experiment $(\mathrm{b}, \mathrm{d})$ in the $41 \mathrm{~d}$ following $\mathrm{N}$ and $\mathrm{C}$ addition. Treatment acronyms are: $\mathrm{N} 0=$ no nitrate fertilisation, $\mathrm{N} 1=$ nitrate fertilisation (200 $\mathrm{kg} \mathrm{N}$ ha 1 as $\left.\mathrm{KNO}_{3}\right), \mathrm{C} 0=$ no glucose addition, $\mathrm{C} 1=$ glucose addition (9419 $\mathrm{kg} \mathrm{C} \mathrm{ha-1}$ ). Given are means \pm 1 SE. Main experiment: $\mathrm{n}=8$ columns per treatment; asterisks mark significant differences between the $\mathrm{N}$-fertilised and the respective control treatment for each phase $(P<0.05$, Tukey-Kramer test), different lower case letters indicate significant differences between the columns of the $\mathrm{C} 1$ and $\mathrm{C} 0$ treatments $(P<0.05$, paired t-test). Supplementary experiment: Different lower case letters indicate significant differences between the treatments ( $=4, P<0.05$, Tukey-Kramer test). 

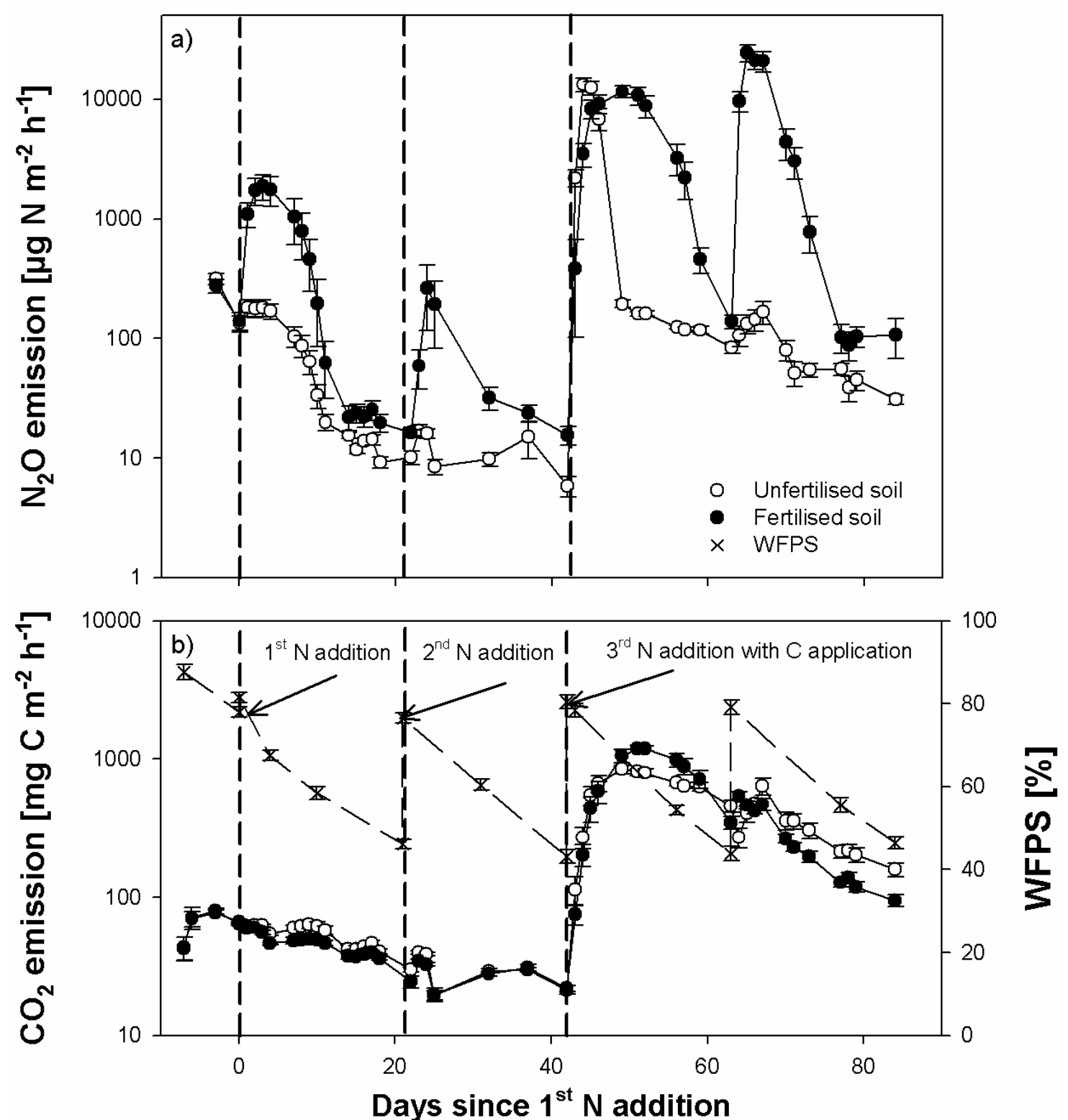

Fig. 2. a) $\mathrm{N}_{2} \mathrm{O}$ emissions of the soil columns with forest soil that was either fertilised with $\mathrm{NO}_{3}{ }^{-}$ or unfertilised (control) during the main experiment of $83 \mathrm{~d}$ duration. b) $\mathrm{CO}_{2}$ efflux and waterfilled pore space (WFPS). Given are mean values $\pm 1 \mathrm{SE}$ of each 8 columns per $\mathrm{N}$-treatment, the y axis is depicted in logarithmic scale. The $\mathrm{N}$ fertilisation consisted of a total addition of $200 \mathrm{~kg}$ $\mathrm{N} \mathrm{ha}^{-1}$ year ${ }^{-1}$ given as $\mathrm{KNO}_{3}$ on three occasions (first to third fertilisation). On day 41 of the experiment, all columns received additionally a glucose solution (equivalent to $9419 \mathrm{~kg} \mathrm{C} \mathrm{ha}^{-1}$ ) as a labile $\mathrm{C}$ source. 


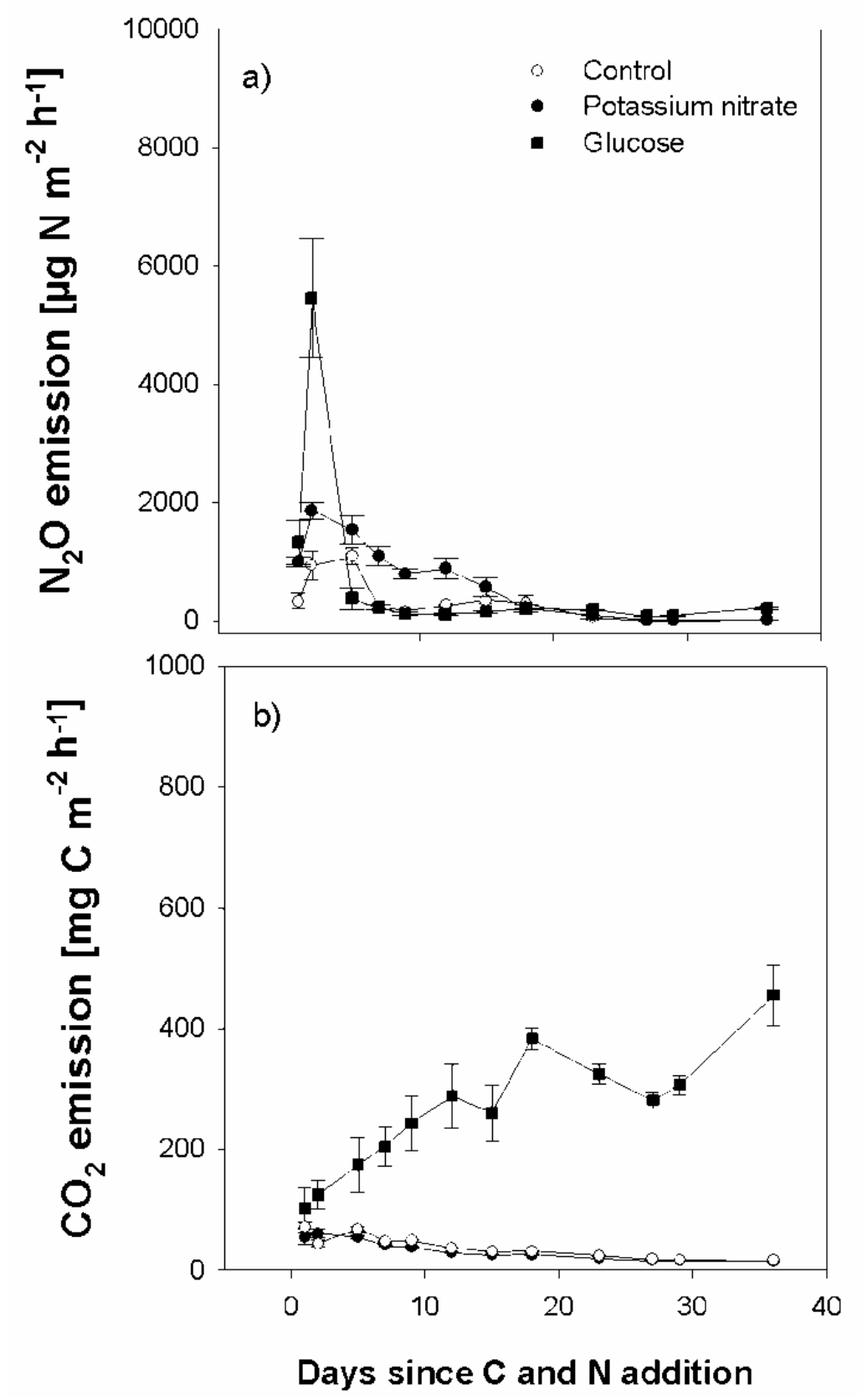

Fig. 3 a) $\mathrm{N}_{2} \mathrm{O}$ emissions of the soil columns with forest soil that was either fertilised with $\mathrm{NO}_{3}{ }^{-}$, glucose or unfertilised (control) during the supplementary experiment of $41 \mathrm{~d}$ duration. b) $\mathrm{CO}_{2}$ efflux of the same soil columns. Given are mean values $\pm 1 \mathrm{SE}$ of each 4 columns per treatment. The $\mathrm{N}$ fertilisation consisted of a total addition of $200 \mathrm{~kg} \mathrm{~N}^{-1}$ year ${ }^{-1}$ given as $\mathrm{KNO}_{3}$ on three occasions (first to third fertilisation). The glucose treated soil columns received a glucose solution (equivalent to $9419 \mathrm{~kg} \mathrm{C} \mathrm{ha}^{-1}$ ) as a labile $\mathrm{C}$ source. 
$\mathrm{CO}_{2}$ fluxes

The glucose addition resulted in 11-fold and 13-fold increases of cumulative $\mathrm{CO}_{2}$ emissions in the unfertilised (C1N0) control and N-fertilised treatment (C1N1), respectively (Fig. 1c). The cumulative $\mathrm{CO}_{2}$ emission measured at the soil surface was significantly higher in the unfertilised soil columns (CON0) in comparison to the fertilised columns (CON1) during the first $41 \mathrm{~d}$. For the second $41 \mathrm{~d}, \mathrm{~N}$ fertilisation combined with glucose addition $(\mathrm{C} 1 \mathrm{~N} 1)$ increased the $\mathrm{CO}_{2}$ emission not significantly compared to the columns without $\mathrm{N}$ addition (C1N0). The combined effect of $\mathrm{C}$ addition and $\mathrm{N}$ fertilisation was negligible compared to the single effect of glucose addition. After the first and second $\mathrm{NO}_{3}$ - addition of each $200 \mathrm{~kg} \mathrm{~N} \mathrm{ha}^{-1}$ (on day 0 and day 20), the $\mathrm{CO}_{2}$ efflux tended to decrease in both treatments with time (Fig. 2b). The addition of glucose led to a dramatic stimulation of soil respiration with maximum peaks of $\mathrm{CO}_{2}$ efflux of $842.0 \pm 58.3 \mathrm{mg} \mathrm{C} \mathrm{m}^{-2} \mathrm{~h}^{-1}$ (on day 49) and $1191.1 \pm 51.6 \mathrm{mg} \mathrm{C}$ $\mathrm{m}^{-2} \mathrm{~h}^{-1}$ (on day 52) in the unfertilised control and the $\mathrm{N}$-fertilised columns, respectively. As in the main experiment, the cumulative $\mathrm{CO}_{2}$ emissions in the supplementary experiment were significantly (6-fold) higher after adding a high concentration of labile $\mathrm{C}$ than in the control soil without $\mathrm{C}$ addition, whereas the $\mathrm{N}$ treatment without glucose addition led to no $\mathrm{CO}_{2}$ flux stimulation (Fig 1d). Compared to the main experiment, the $\mathrm{CO}_{2}$ emissions of all treatments were lower in the supplementary experiment (Fig. 3b).

Soil chemical and physical characteristics

The chemical properties of the soil in the columns before the start of the experiment (day 0 ), at the end of the second $\mathrm{N}$ fertilisation phase (day 41), and after the combined application of $\mathrm{C}$ and $\mathrm{N}$ (day 62) are listed in Table I. After the second $\mathrm{N}$ fertilisation (day 41) and at the end of the third experimental phase (combined addition of $\mathrm{C}$ and $\mathrm{N}$, day 62), the total $\mathrm{N}$ concentration in the $\mathrm{N}$-fertilised columns was significantly higher (by 0.32 and $0.43 \mathrm{~g} \mathrm{~N} \mathrm{~kg}^{-1} \mathrm{dw}$, respectively) than in the unfertilised columns. After $\mathrm{N}$ addition, the $\mathrm{C}_{\text {org }}$ content of the $\mathrm{N}$-fertilised soil columns was significantly lower than that of the control soil. The glucose application did not alter the $\mathrm{N}_{\text {total }}$ content compared to the columns' $\mathrm{N}$ content before glucose application. The addition of $\mathrm{C}$ enhanced the $\mathrm{C}_{\text {org }}$ content significantly by $2.55 \mathrm{~g} \mathrm{C} \mathrm{kg}^{-1} \mathrm{dw}$ and $3.42 \mathrm{~g} \mathrm{C} \mathrm{kg}^{-1} \mathrm{dw}$ in the unfertilised control and $\mathrm{N}$-fertilised soil, respectively. The soil moisture in the columns was adjusted to $80 \%$ WFPS on day 20, 41 and 62 of the experiment and showed a more or less continuous decrease due to evaporation at a rate of $-1.53 \% \mathrm{~d}^{-1}$ in all treatments to 
approach approximately $40 \%$ moisture content before the start of the next manipulation event (Fig 2a, 2b).

The independent effect of $\mathrm{NO}_{3}{ }^{-}$and glucose on the $\mathrm{NO}_{3}{ }^{-}$and $\mathrm{NH}_{4}{ }^{+}$concentrations in the soil was investigated in the supplementary experiment (Table II). The $\mathrm{NO}_{3}{ }^{-}$and $\mathrm{NH}_{4}{ }^{+}$ concentrations in the soil columns increased significantly by $891 \%$ and $244 \%$, respectively, after the addition of $200 \mathrm{~kg} \mathrm{~N} \mathrm{ha}^{-1}$ in the form of $\mathrm{KNO}_{3}$. The addition of $9419 \mathrm{~kg} \mathrm{C} \mathrm{ha}^{-1}$ (glucose) decreased the $\mathrm{NO}_{3}{ }^{-}$and $\mathrm{NH}_{4}{ }^{+}$concentrations non-significantly by $81 \%$ and $47 \%$, respectively. 


\section{Discussion}

While the first amount of $\mathrm{NO}_{3}^{-}$added $\left(200 \mathrm{~kg} \mathrm{~N} \mathrm{ha}^{-1}\right.$ equivalent to $\left.145 \mathrm{mg} \mathrm{N} \mathrm{kg}^{-1}\right)$ increased the $\mathrm{N}_{2} \mathrm{O}$ emissions 8-fold, a same dose applied 20 d later led to no further stimulation of $\mathrm{N} 2 \mathrm{O}$ release despite improved $\mathrm{NO}_{3}{ }^{-}$availability. The insensitivity of the $\mathrm{N}_{2} \mathrm{O}$ emissions to further substrate addition points toward $\mathrm{C}$ limitation of $\mathrm{NO}_{3}{ }^{-}$ reduction in our experimental system as it was assumed in earlier studies (Weier et al., 1993; Gillam et al., 2008). Further support for our first hypothesis assuming limitation of $\mathrm{N}_{2} \mathrm{O}$ emissions by labile $\mathrm{C}$ in the soil is provided by the tremendous stimulation of emissions observed after adding glucose at saturating amounts. In fact, adding $9419 \mathrm{~kg}$ $\mathrm{C} \mathrm{ha}{ }^{-1}$ (equivalent to $6.9 \mathrm{~g} \mathrm{C} \mathrm{kg}^{-1}$ soil) had, with a 39-fold increase in emissions compared to the control, a larger effect on $\mathrm{N}_{2} \mathrm{O}$ emission than applying $200 \mathrm{~kg} \mathrm{~N} \mathrm{ha}^{-1}$. Thus, hypothesis 2 is falsified. Clearly, we added glucose at a saturating dose; the stimulation of $\mathrm{N}_{2} \mathrm{O}$ emission might have been similarly large by $\mathrm{C}$ and $\mathrm{N}$ if both elements had been added in a ratio of about 20:1, simulating a biomass $\mathrm{C} / \mathrm{N}$ ratio of 20. In earlier studies, the response of $\mathrm{N}_{2} \mathrm{O}$ emission to $\mathrm{N}$ application ranged from no change to a fivefold stimulation of $\mathrm{N} 2 \mathrm{O}$ emission after $\mathrm{KNO}_{3}$ addition at doses of 10 to $277 \mathrm{mg}$ $\mathrm{N} \mathrm{kg}^{-1}$ soil (Weier et al., 1993; McKenney et al., 2001; Gillam et al., 2008; Jäger et al., 2011); the largest increase in $\mathrm{N}_{2} \mathrm{O}$ efflux was measured after adding $63.4 \mathrm{mg} \mathrm{N} \mathrm{kg}^{-1}$ soil, i.e. half the amount added in our study (Ciarlo et al., 2008). Table 3 compiles the existing literature data on the effect of glucose and $\mathrm{KNO}_{3}{ }^{-}$on $\mathrm{N}_{2} \mathrm{O}$ emissions from agricultural soils. For glucose addition, two- to tenfold increases of the $\mathrm{N}_{2} \mathrm{O}$ emissions have been reported (Azam et al., 2002; Murray et al., 2004; Gillam et al., 2008), which was comparable to the effect of $\mathrm{N}$ addition (Weier et al., 1993; Bateman and Baggs 2005). While our $\mathrm{N}$ effect is well in the range of literature data, this is not the case with our very large labile $\mathrm{C}$ effect (Table 3 ). 


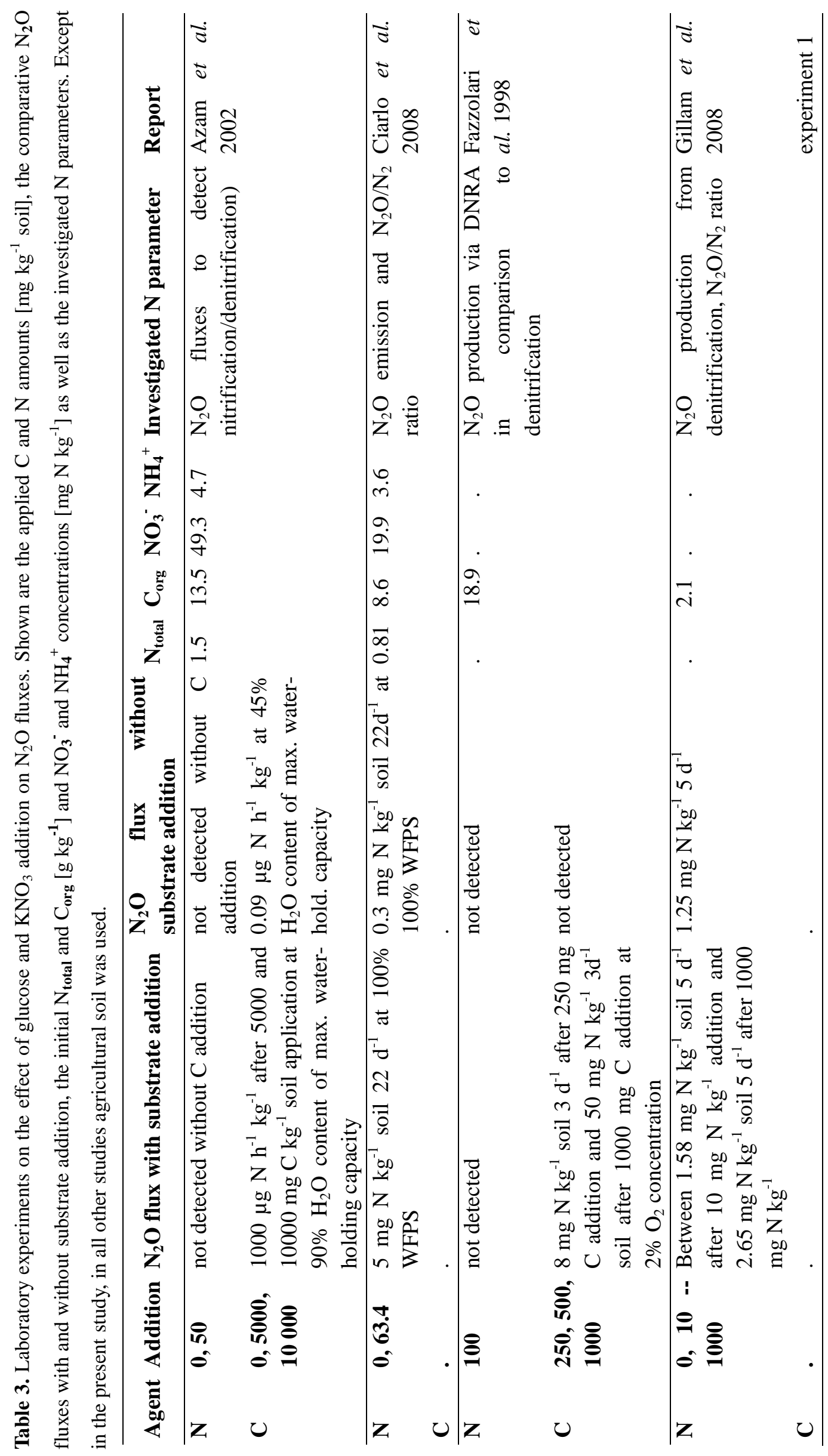




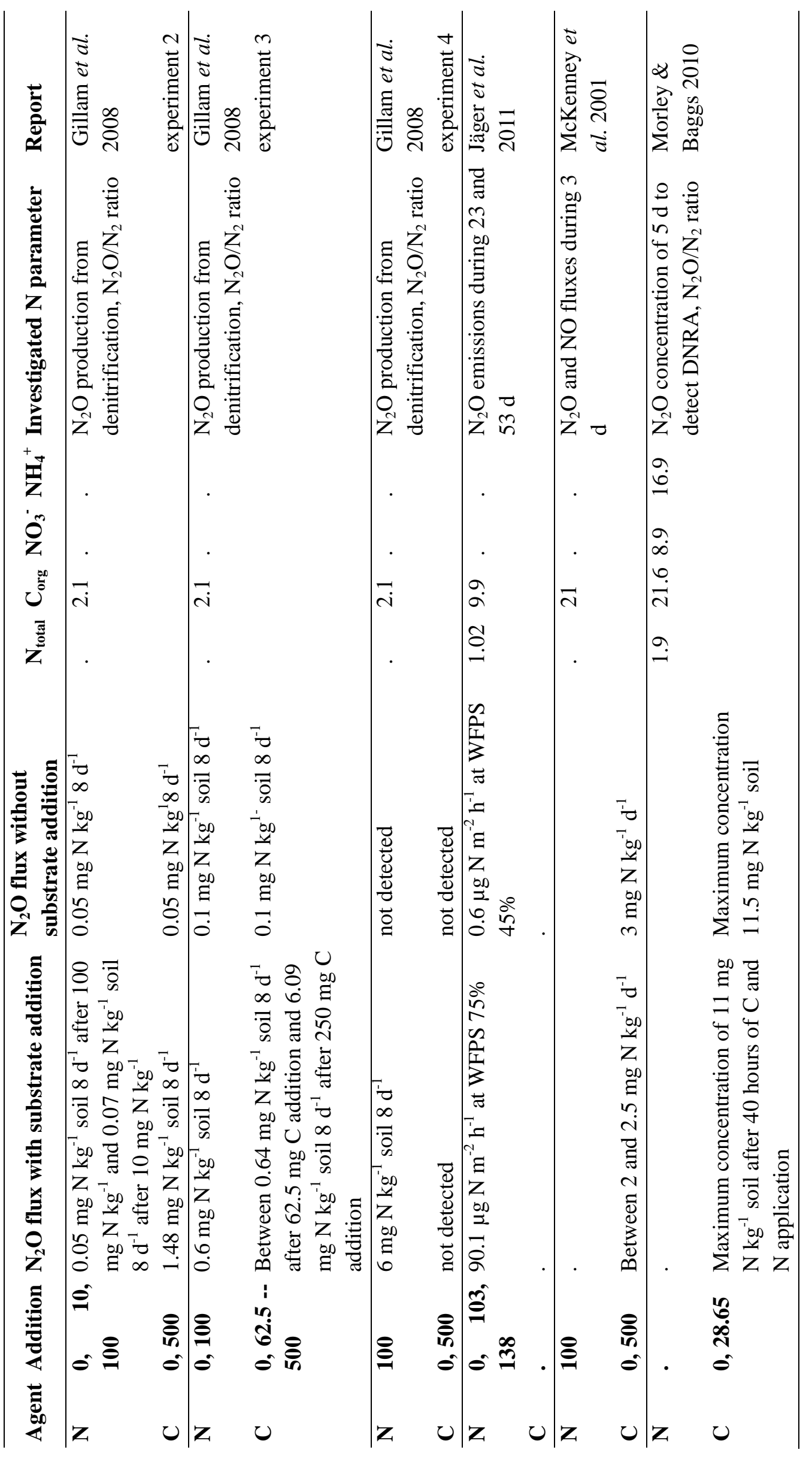




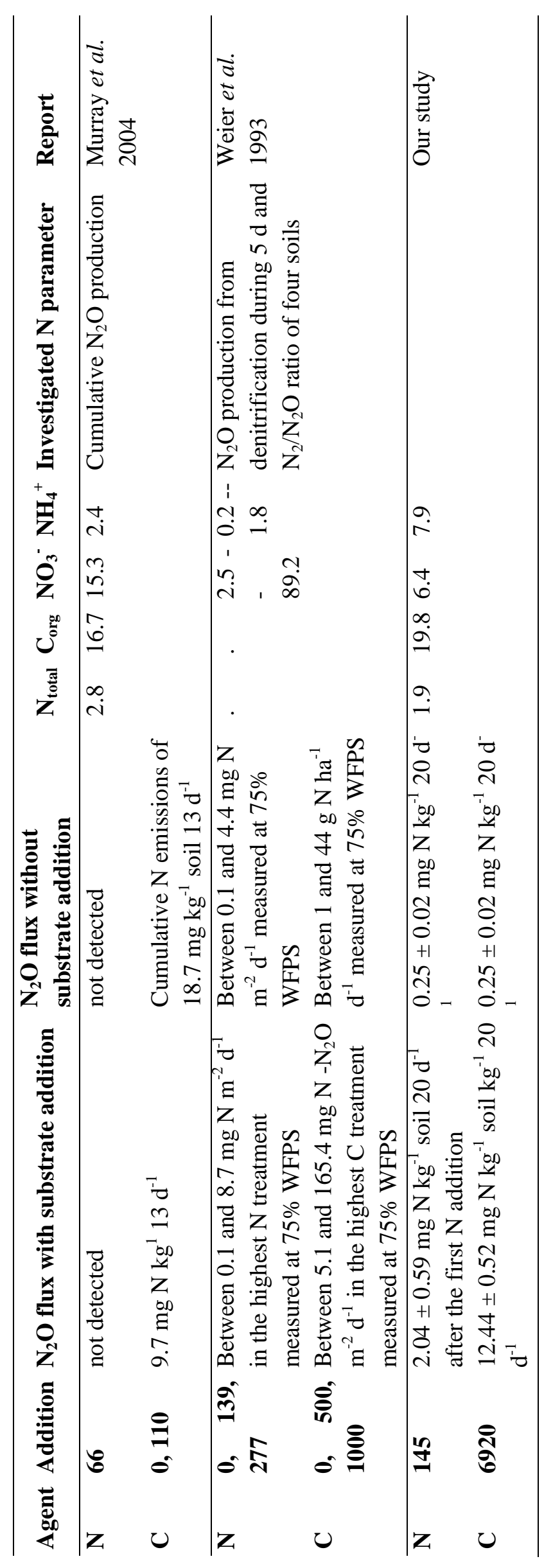


The relatively high soil moisture in our soil columns (40 -- 80\% WFPS) suggests that much of the $\mathrm{N}_{2} \mathrm{O}$ released was produced in the course of dissimilatory processes. Fazzolari et al., (1998) assumed that DNRA dominates over denitrification when glucose and $\mathrm{NO}_{3}{ }^{-}$are added at $\mathrm{C} / \mathrm{N}$ ratios $>4$. Thus, the glucose- $\mathrm{C} / \mathrm{NO}_{3}{ }^{-}-\mathrm{N}$ ratio of 48 in our experiment suggests that DNRA was the main $\mathrm{N}_{2} \mathrm{O}$-producing process in the soil columns after adding $\mathrm{N}$ and $\mathrm{C}$ sources. The increase in the soil $\mathrm{NH}_{4}{ }^{+}$concentration after $\mathrm{NO}_{3}{ }^{-}$and glucose addition is another indication that DNRA was much more important than denitrification under these soil conditions, supporting the recently formulated assumption that the potential of DNRA to release $\mathrm{N}_{2} \mathrm{O}$ after $\mathrm{C}$ and $\mathrm{N}$ addition may have been underestimated (Morley and Baggs 2010; Baggs, 2011).

The large effect of $\mathrm{C}$ availability on overall soil microbial activity is clearly visible from the fact that the $\mathrm{CO}_{2}$ efflux from both the control and $\mathrm{N}$ fertilisation treatments were 4to 6-fold higher in the supplementary experiment with $30 \%$ higher $\mathrm{C}_{\text {org }}$ concentrations than in the respective treatments of the main experiment $\left(29.2 \mathrm{~g} \mathrm{C} \mathrm{kg}^{-1}\right.$ soil compared to $19.8 \mathrm{~g} \mathrm{C} \mathrm{kg}^{-1}$ ). However, not only soil respiration was higher in the supplementary experiment but the $\mathrm{N}_{2} \mathrm{O}$ emissions of the control and the $\mathrm{N}$ treatments as well. The higher $\mathrm{CO}_{2}$ and $\mathrm{N}_{2} \mathrm{O}$ emissions without $\mathrm{C}$ addition in the supplementary experiment might be caused by more readily bio-available $\mathrm{C}$ in the soil compared to the main experiment.

It is known that elevated concentrations of labile $\mathrm{C}$ as a readily available energy source may have priming effects either on soil organic matter (SOM) mineralisation by increasing the activity of decomposing microorganisms (real priming effect) or on higher microbial metabolic activity and microbial biomass turnover (apparent priming effect; Blagodatskaya and Kuzyakov, 2008). In our study, the high C availability led to a tremendous increase in heterotrophic microbial activity as indicated by 10 - and 5 -fold higher $\mathrm{CO}_{2}$ emission rates compared to the control in the main and supplementary experiments, respectively. Furthermore, the addition of glucose in the supplementary and the main experiment resulted in similarly high cumulative $\mathrm{N}_{2} \mathrm{O}$ emissions during the $41 \mathrm{~d}$-experimental period despite differences in initial $\mathrm{C}_{\text {org }}$ indicating that the large increase in the availability of labile $\mathrm{C}$ superimposed any differences in initial $\mathrm{C}$ availability in the soils of the two experiments. The negligible effect of the second $\mathrm{N}$ addition and the large increase of the $\mathrm{N}_{2} \mathrm{O}$ and the $\mathrm{CO}_{2}$ emissions after the $\mathrm{C}$ addition in the main experiment allow the conclusion that the SOM in the soil columns contained 
only a relatively small proportion of readily available $\mathrm{C}$ that could be utilised for microbial $\mathrm{C}$ and $\mathrm{N}$ turnover processes.

When our results are compared to other published data (see Table 3), the stimulation of $\mathrm{N}_{2} \mathrm{O}$ emission by the first $\mathrm{N}$ addition is nevertheless large, despite the dominating effect of labile $\mathrm{C}$ in our experiment. Thus, the limitation of $\mathrm{NO}^{-}$reduction by low substrate availability must have been more severe in our study than in many other experiments that were conducted with agricultural soils. For example, Gillam et al., (2008) added $1 \mathrm{~g}$ $\mathrm{N} \mathrm{kg}^{-1}$ soil, i.e. 7 times more $\mathrm{N}$ than we did, and found only a doubling of $\mathrm{N}_{2} \mathrm{O}$ emissions compared to the control. According to pyrosequencing analysis, Rhodanobacter spec. occurred in significantly higher densities in $\mathrm{N}$ fertilised soil than in unfertilised soil after the second $\mathrm{N}$ addition $(2.36 \pm 0.52 \%$ vs. $46.87 \pm 11.72 \%$ on day 41). Since these gammaproteobacteria are known to be denitrifying microorganisms, it is very likely that they largely contributed to the high $\mathrm{N}_{2} \mathrm{O}$ emissions from the $\mathrm{N}$ fertilised soil (Prakash et al. 2011; Green et al. 2012; Kostka et al. 2012).

Our data indicate that the addition of high doses of labile $\mathrm{C}$ and $\mathrm{NO}_{3}{ }^{-}$may act in a synergistic way on the $\mathrm{N}_{2} \mathrm{O}$ production because combined $\mathrm{C}$ and $\mathrm{N}$ addition increased $\mathrm{N}_{2} \mathrm{O}$ emissions 70-fold while the separate effects of $\mathrm{C}$ and $\mathrm{N}$ led only to 39- and 8-fold increases of $\mathrm{N}_{2} \mathrm{O}$ release supporting our hypothesis (3). This is pointing to a positive interaction between large labile $\mathrm{C}$ and $\mathrm{NO}_{3}{ }^{-}$in their effect on $\mathrm{N}_{2} \mathrm{O}$ emission. In a laboratory experiment with silty clay, a combined $\mathrm{NO}_{3}{ }^{-}$and glucose application led to a 100 times higher emission than a glucose application alone (Azam et al., 2002). Similarly, in an experiment of eight days duration, Gillam et al. (2008) found cumulative $\mathrm{N}_{2} \mathrm{O}$ emissions of $4.75 \mathrm{mg} \mathrm{N}$ kg-1 soil after combined $\mathrm{C}$ and $\mathrm{N}$ addition, whereas $\mathrm{N}$ addition alone led to a $\mathrm{N}_{2} \mathrm{O}$ emission rate not higher than the unfertilised control (0.05 mg N kg${ }^{-1}$ soil) and to an emission of $1.48 \mathrm{~N} \mathrm{~kg}^{-1}$ soil when only $\mathrm{C}$ was added. The latter experiment with no significant stimulation of $\mathrm{N}_{2} \mathrm{O}$ emission by $\mathrm{NO}_{3}{ }^{-}$ addition was conducted with agricultural soil where $\mathrm{C}$ limitation of microbial activity may have been stronger than in forest soil. Despite this difference to our study, the experiments with agricultural and forest soils have in common that labile $\mathrm{C}$ and $\mathrm{N}$ availability seem to interact and that the labile $\mathrm{C}$ concentration is exerting a major control on the $\mathrm{N}$ dynamics in the soil.

The present study aimed at characterising the potential of altering $\mathrm{N}_{2} \mathrm{O}$ emissions from forest soils by adding $\mathrm{C}$ and $\mathrm{N}$ sources in high doses. It is clear that labile $\mathrm{C}$ and $\mathrm{NO}_{3}{ }^{-}$ were available in concentrations that exceed the natural levels in temperate deciduous 
forest soils by far. However, for a better understanding of possible changes in greenhouse gas emissions under altered climate conditions, it is important to know how higher concentrations of labile $\mathrm{C}$ and $\mathrm{NO}_{3}{ }^{-}$would change $\mathrm{N}_{2} \mathrm{O}$ emissions at clearly detectable levels. A likely scenario for the coming decades is that temperature, atmospheric $\mathrm{CO}_{2}$ concentration and precipitation extremes are all increasing on a global scale (IPCC, 2007), while atmospheric N deposition will remain high in Central Europe and eastern North America (Galloway et al., 2008). It is not yet clear whether the SOM pool of temperate forests will decrease or increase under these predicted alterations. The major fraction of SOM consists of complex recalcitrant $\mathrm{C}$ compounds that are difficult to catabolise. However, at higher temperature and elevated $\mathrm{CO}_{2}$, the decomposition of complex C compounds could be accelerated (Davidson and Janssens, 2006; Allison et al., 2010; Kuzyakov, 2011). Further, the rhizodeposition of C compounds may increase under elevated $\mathrm{CO}_{2}$ (Kuzyakov, 2011, Phillips et al. 2011). How much labile C would be released under higher temperature and elevated $\mathrm{CO}_{2}$ concentration is not yet known, but it could largely exceed the current $C$ availability as Phillips et al. (2011) found by $50 \%$ higher exudation rates of $\mathrm{C}$. In this study, we highlighted that such an increase of labile $\mathrm{C}$ may offset a $\mathrm{C}$ limitation of $\mathrm{N}$ cycling in forest soils. Thus, the currently low $\mathrm{N}_{2} \mathrm{O}$ emission rates of $<10 \mu \mathrm{g} \mathrm{N} \mathrm{m}{ }^{-2} \mathrm{~h}^{-1}$, as they were measured under field conditions in the temperate broad-leaved Hainich forest (Guckland et al., 2010), where the soil of our experiments was collected, might substantially increase in future decades. 


\section{Conclusion}

Our study showed that the availability of labile $\mathrm{C}$ can be a key factor controlling the $\mathrm{N}_{2} \mathrm{O}$ emissions from forest soils. Additionally, our laboratory experiment gave hints on the potential of continued high $\mathrm{N}$ deposition in combination with higher temperatures and elevated $\mathrm{CO}_{2}$ to largely alter $\mathrm{N}_{2} \mathrm{O}$ emission mainly when changes in $\mathrm{C}$ availability in forest soils occur simultaneously. Although our experiment could not answer the question how moderate changes in $\mathrm{C}$ and $\mathrm{N}$ amounts alter the $\mathrm{N}_{2} \mathrm{O}$ emissions of a temperate forest soil, the importance of $\mathrm{C}$ and $\mathrm{N}$ could be clearly shown. The crucial question is whether the climatic and chemical changes will increase or decrease the availability of labile $\mathrm{C}$ for soil microorganisms; this topic deserves further research. It is clear, however, that the role of labile $\mathrm{C}$ and its interaction with $\mathrm{N}$ availability has not been considered sufficiently enough in predictions of $\mathrm{N}_{2} \mathrm{O}$ emissions under a variable climate in different ecosystems.

\section{Acknowledgments}

This study was funded by the Ministry of Science and Culture of Lower Saxony and the "Niedersächsisches Vorab"; the support is gratefully acknowledged. We appreciate the laboratory assistance provided by Hannes Haupt and Klaus Schützenmeister and thank Felix Heitkamp for reading the manuscript. 


\section{References}

Allison, S.D., Wallenstein, M.D. and Bradford, M.A. 2010. Soil-carbon response to warming dependent on microbial physiology. Nature Geosci. 3: 336--340.

Azam, F., Müller, C., Weiske, A., Benckiser, G. and Ottow, J. 2002. Nitrification and denitrification as sources of atmospheric nitrous oxide -- role of oxidizable carbon and applied nitrogen. Biol Fertil Soils 35: 54--61.

Baggs, E.M. 2008. A review of stable isotope techniques for $\mathrm{N}_{2} \mathrm{O}$ source partitioning in soils: recent progress, remaining challenges and future considerations. Rapid Commun. Mass Sp. 22: 1664--1672.

Baggs, E.M. 2011. Soil microbial sources of nitrous oxide: recent advances in knowledge, emerging challenges and future direction. Curr. Opin. Env. Sustain. 3: $321--327$.

Bateman, E.J. and Baggs, E.M. 2005. Contributions of nitrification and denitrification to $\mathrm{N}_{2} \mathrm{O}$ emissions from soils at different water-filled pore space. Biol. Fertil. Soils 41: 379--388.

Blagodatskaya, E. and Kuzyakov, Y. 2008. Mechanisms of real and apparent priming effects and their dependence on soil microbial biomass and community structure: critical review. Biol. Fertil. Soils 45: 115--131.

Bremmer, J.M. 1997. Sources of nitrous oxide in soils. Nutr. Cycl. Agroecosys. 49: 7-16.

Butterbach-Bahl, K., Gasche, R., Willibald, G. and Papen, H. 2002. Exchange of Ngases at the Höglwald forest--A summary. Plant Soil 240: 117--123.

Ciarlo, E., Conti, M., Bartoloni, N. and Rubio, G. 2008. Soil $\mathrm{N}_{2} \mathrm{O}$ emissions and $\mathrm{N}_{2} \mathrm{O} /\left(\mathrm{N}_{2} \mathrm{O}+\mathrm{N}_{2}\right)$ ratio as affected by different fertilization practices and soil moisture. Biol Fertil Soils 44: 991--995.

Davidson, E.A. and Janssens, I.A. 2006. Temperature sensitivity of soil carbon decomposition and feedbacks to climate change. Nature 440: 165--173.

Denman, K.L., Brasseur, G., Chidthaisong, A., Ciais, P., Cox, P.M., Dickinson, R.E., Hauglustaine, D., Heinze, C., Holland, E., Jacob, D., Lohmann, U., Ramachandran, S., da Silva Dias, P.L., Wofsy, S.C. and Zhang, X. 2007. Couplings between changes in the climate system and biogeochemistry. Cambridge University Press, Cambridge, United Kingdom and New York, NY, USA. 
Fazzolari, É., Nicolardot, B. and Germon, J.C. 1998. Simultaneous effects of increasing levels of glucose and oxygen partial pressures on denitrification and dissimilatory nitrate reduction to ammonium in repacked soil cores. Eur. J. Soil Biol. 34: 47--52.

Firestone, M.K. and Davidson, E.A.. 1989. Microbial basis of $\mathrm{NO}$ and $\mathrm{N}_{2} \mathrm{O}$ production and consumption in soil. p. 7--21. In Andreae, M.O., Schimel, D.S. (eds.), Exchange of trace gases between terrestrial ecosystems and the atmosphere. Life Science Reports. John Wileys \& Sons, Chichester, New York, Brisbane, Toronto, Singapore.

Forster, P., Ramaswamy, V., Artaxo, P., Bertsen, T., Betts, R., Fahey, D.W., Haywood, J., Lean, J., Lowe, D.C., Myhre, G., Nganga, J., Prinn, R., Raga, G., Schulz, M. and Van Dorland, R. 2007. Changes in atmospheric constituents and in radiative forcing. IPCC, Cambridge University Press, Cambridge, United Kingdom and New York, NY, USA.

Galloway, J.N., Aber, J.D., Erisman, J.W., Seitzinger, S.P., Howarth, R.W., Cowling, E.B. and Cosby, B.J. 2003. The nitrogen cascade. BioScience 53: 341.

Galloway, J.N., Townsend, A.R., Erisman, J.W., Bekunda, M., Cai, Z., Freney, J.R., Martinelli, L.A., Seitzinger, S.P. and Sutton, M.A. 2008. Transformation of the nitrogen cycle: recent trends, questions and potential solutions. Science 320: 889--892.

Gillam, K.M., Zebarth, B.J. and Burton, D.L. 2008. Nitrous oxide emissions from denitrification and the partitioning of gaseous losses as affected by nitrate and carbon addition and soil aeration. Can. J. Soil. Sci. 88: 133--143.

Green, S.J., Prakash, O., Jasrotia, P., Overholt, W.A., Cardenas, E., Hubbard, D., Tiedje, J.M., Watson, D.B., Schadt, C.W., Brooks, S.C. and Kostka, J.E. 2012. Denitrifying bacteria from the genus Rhodanobacter dominate bacterial communities in the highly contaminated subsurface of a nuclear legacy waste site. Appl. Environ. Microbiol. 78: 1039--1047.

Guckland, A., Corre, M.D. and Flessa, H. 2010. Variability of soil $\mathrm{N}$ cycling and $\mathrm{N}_{2} \mathrm{O}$ emission in a mixed deciduous forest with different abundance of beech. Plant Soil 336: 25--38.

Henry, S., Texier, S., Hallet, S., Bru, D., Dambreville, C., Chèneby, D., Bizouard, F., Germon, J.C. and Philippot, L. 2008. Disentangling the rhizosphere effect on 
nitrate reducers and denitrifiers: insight into the role of root exudates. Environ. Microbiol. 10: 3082--3092.

IPCC. 2007. Climate change 2007: Synthesis report. Contribution of working groups I, II and III to the fourth assessment report of the Intergovernmental Panel on Climate Change. IPCC, Geneva, Switzerland.

IUSS Working Group WRB. 2007. World reference base for soil resources 2006, first update 2007. FAO, Rome.

Jäger, N., Stange, C.F., Ludwig, B. and Flessa, H. 2011. Emission rates of $\mathrm{N}_{2} \mathrm{O}$ and $\mathrm{CO}_{2}$ from soils with different organic matter content from three long-term fertilization experiments - a laboratory study. Biol. Fertil. Soils 47: 483--494.

Janssens, I.A., Dieleman, W., Luyssaert, S., Subke, J.-A., Reichstein, M., Ceulemans, R., Ciais, P., Dolman, A.J., Grace, J., Matteucci, G., Papale, D., Piao, S.L., Schulze, E.-D., Tang, J. and Law, B.E. 2010. Reduction of forest soil respiration in response to nitrogen deposition. Nature Geosci. 3: 315--322.

Jungkunst, H.F., Freibauer, A., Neufeldt, H. and Bareth, G. 2006. Nitrous oxide emissions from agricultural land use in Germany - a synthesis of available annual field data. J. Plant Nutr. Soil Sc. 169: 341--351.

Kesik, M., Ambus, P., Baritz, R., Brüggemann, N., Butterbach-Bahl, K., Damm, M., Duyzer, J., Horváth, L., Kiese, R., Kitzler, B., Leip, A., Li, C., Pihlatie, M., Pilegaard, K., Seufert, S., Simpson, D., Skiba, U., Smiatek, G., Vesala, T. and Zechmeister-Boltenstern, S. 2005. Inventories of $\mathrm{N}_{2} \mathrm{O}$ and $\mathrm{NO}$ emissions from European forest soils. Biogeosciences 2: 353--375.

Kirschbaum, M.U.F. 2004. Soil respiration under prolonged soil warming: are rate reductions caused by acclimation or substrate loss? Global Change Biol. 10:1870--1877.

Kostka, J.E., Green, S.J., Rishishwar, L., Prakash, O., Katz, L.S., Mariño-Ramírez, L., Jordan, I.K., Munk, C., Ivanova, N., Mikhailova, N., Watson, D.B., Brown, S.D., Palumbo, A.V. and Brooks S.C. 2012. Genome sequences for six Rhodanobacter strains, isolated from soils and the terrestrial subsurface, with variable denitrification capabilities. J. Bacteriol. 194: 4461--4462.

Kuzyakov, Y. 2011. Ecology: Prime time for microbes. Nature Clim. Change 1:295-297. 
Loftfield, N., Flessa, H., Augustin, J. and Beese, F. 1997. Automated gas chromatographic system for rapid analysis of the atmospheric trace gases methane, carbon dioxide and nitrous oxide. J. Environ. Qual. 26: 560--564.

Luyssaert, S., Ciais, P., Piao, S., Schulze, E.D., Jung, M., Zaehle, S., Schelhaas, M., Reichstein, M., Churkina, G., Papale, D., Abril, G., Beer, C., Grace, J., Loustau, D., Matteucci, G., Magnani, F., Nabuurs, G.J., Verbeeck, H., Sulkava, M., Van der Werf, G.R. and Janssens, I.A. 2010. The European carbon balance. Part 3: forests. Global Change Biol. 16: 1429--1450.

Magill, A.H. and Aber., J.D. 2000. Variation in soil net mineralization rates with dissolved organic carbon additions. Soil Biol Biochem 32: 597--601.

McKenney, D., Drury, C. and Wang, S. 2001. Effects of oxygen on denitrification inhibition, repression and derepression in soil columns. Soil Sci. Soc. Am. J. 65: $126--132$.

Milcu, A., Heim, A., Ellis, R.J., Scheu, S. and Manning, P. 2011. Identification of general patterns of nutrient and labile carbon control on soil carbon dynamics across a successional gradient. Ecosystems 14: 710--719.

Morley, N. and Baggs, E.M. 2010. Carbon and oxygen controls on $\mathrm{N}_{2} \mathrm{O}$ and $\mathrm{N}_{2}$ production during nitrate reduction. Soil Biol Biochem 42: 1864--1871.

Mosier, A.R. 1998. Soil processes and global change. Biol. Fertil. Soils 27: 221--229.

Murray, P.J., Hatch, D.J., Dixon, E.R., Stevens, R.J., Laughlin, R.J. and Jarvis, S.C. 2004. Denitrification potential in a grassland subsoil: effect of carbon substrates. Soil Biol. Biochem. 36: 545--547.

Phillips R.P., Finzi A.C., Bernhardt E. S. 2011. Enhanced root exudation induces microbial feedbacks to $\mathrm{N}$ cycling in a pine forest under long-term $\mathrm{CO}_{2}$ fumigation. Ecology Letters 14: 187--194.

Pihlatie, M., Rinne, J., Ambus, P., Pilegaard, K., Dorsey, J.R., Rannik, Ü., Markkanen, T., Launiainen, S. and Vesala, T. 2005. Nitrous oxide emissions from a beech forest floor measured by eddy covariance and soil enclosure techniques. Biogeosciences 2: 377--387.

Prakash, O., Green, S.J., Jasrotia, P., Overholt, W.A., Canion, A., Watson, D.B., Brooks, S.C. and Kostka, J.E. 2011. Description of Rhodanobacter denitrificans sp. nov., isolated from nitrate-rich zones of a contaminated aquifer. Int. J. Syst. Evol. Microbiol. DOI: 10.1099/ijs.0.035840-0 
Reay, D.S., Dentener, F., Smith, P., Grace, J. and Feely, R.A. 2008. Global nitrogen deposition and carbon sinks. Nature Geosci. 1: 430--437.

Ruser, R., Flessa, H., Russow, R., Schmidt, G., Buegger, F. and Munch, J.C. 2006. Emission of $\mathrm{N}_{2} \mathrm{O}, \mathrm{N}_{2}$ and $\mathrm{CO}_{2}$ from soil fertilized with nitrate: effect of compaction, soil moisture and rewetting. Soil Biol. Biochem. 38: 263--274.

Schlichting, E., Blume, H.-P. and Stahr, K. 1995. Bodenkundliches Praktikum -- Eine Einführung in pedologisches Arbeiten für Ökologen, insbesondere Land- und Forstwirte und für Geowissenschaftler. Blackwell Wissenschaft, Berlin.

Smith M.S., Tiedje J.M. 1979. Phases of denitrification following oxygen depletion in soil. Soil Biol and Biochem 11: 261--267.

Tiunov, A.V. and Scheu, S. 2004. Carbon availability controls the growth of detritivores (Lumbricidae) and their effect on nitrogen mineralization. Oecologia 138: 83-90.

Vor, T., Dyckmans, J., Loftfield, N., Beese, F. and Flessa, H. 2003. Aeration effects on $\mathrm{CO}_{2}, \mathrm{~N}_{2} \mathrm{O}$ and $\mathrm{CH}_{4}$ emission and leachate composition of a forest soil. J. Plant Nutr. Soil Sc. 166: 39--45.

De Vries, W., Reinds G..J., Gundersen, P. and Sterba, H. 2006. The impact of nitrogen deposition on carbon sequestration in European forests and forest soils. Global Change Biol. 12: 1151--1173.

Wang, L., Cai, Z., Yang, L. and Meng, L. 2005. Effects of disturbance and glucose addition on nitrous oxide and carbon dioxide emissions from a paddy soil. Soil Till. Res. 82: 185--194.

Weier, K., Doran, J., Power, J. and Walters, D. 1993. Denitrification and the dinitrogen/nitrous oxide ratio as affected by soil water, available carbon and nitrate. Soil Sci. Soc. Am. J. 57: 66--72.

Werner, P.C. and Gerstengarbe, F.-W. 2007. Welche Klimaänderungen sind in Deuschland zu erwarten? p. 56--59. In Endlicher, W., Gerstengarbe, F.-W. (eds.), Der Klimawandel - Einblicke, Rückblicke und Ausblicke. PotsdamInstitut für Klimafolgenforschung und und Humboldt-Universität zu Berlin, Potsdam.

Williams, P.H., Jarvis, S.C. and Dixon, E. 1998. Emission of nitric oxide and nitrous oxide from soil under field and laboratory conditions. Soil Biol. Biochem. 30: 1885--1893. 
Wrage, N., Velthof, G., van Beusichem, M. and Oenema, O. 2001. Role of nitrifier denitrification in the production of nitrous oxide. Soil Biol. Biochem. 33: 1723-1732. 


\section{B.III Influence of Lasius ants acting as ecosystem engineers}

To analyze the impact of ants and their activity on soil microbial communities, two experiments were conducted. A microcosm survey analyzed the influence of ant activity on the nitrogen flow between aboveground and belowground systems and soil microbial community composition. We applied stable isotope techniques to track theant driven nitrogen distribution and DGGE as molecular approach to analyze the soil bacterial community. The following hypotheses were tested:

(1) Aphid honeydew will increase nutrient availability for microbes in the litter layer and will lead to higher microbial biomass.

(2) Contrastingly, tending ants will reduce the amount of honeydew dropping onto the litter what will decrease microbial biomass in return.

(3) Ants are suggested to increase the nitrogen flux from aboveground to belowground system. This will affect the soil microbial biomass and the community structure of bacteria.

The functional diversity and community composition of microbial communities in Lasius ant nests and the surrounding soil from two different grassland habitats (Leptosol and Cambisol) was studied in the second survey. Microbial community functioning was analyzed by measuring the response of microorganisms to an array of different substrates added to soil samples from Lasius ant nest mounds and the surrounding soil. The microbial community structure present in the nests of the two different ant species (Lasius niger and L. flavus) and in the surrounding soil was compared using DGGE as molecular approach. 
1.

\section{Nutrient flow from aboveground to belowground systems and changes in soil microbial community driven by ants and homopteran honeydew}

Evelyn Gerund ${ }^{1}$, Birgit Pfeiffer ${ }^{2}$, Rolf Daniel $^{2}$, and Christian Platner ${ }^{1,3}$

Manuscript draft

${ }^{1)}$ Abteilung Ökologie, Johann-Friedrich-Blumenbach Institut für Zoologie und Anthropologie, Georg-August-Universität, Berliner Str. 28, 37073 Göttingen, Germany

${ }^{2)}$ Genomic and Applied Microbiology, University of Göttingen, Grisebachstr. 8, 37077 Göttingen, Germany

${ }^{3)}$ Experimentelle Ökologie und Ökosystembiologie, Universität Bielefeld, Universitätsstr. 25, 33615 Bielefeld, Germany

\section{Author contributions to the work:}

Performed the experiments: E. Gerund, B. Pfeiffer

Analyzed the data: E. Gerund, B. Pfeiffer

Wrote the paper: $\quad$ E. Gerund, B. Pfeiffer, C. Platner, R. Daniel

Conceived and designed the experiments: C. Platner, R. Daniel 


\begin{abstract}
In a microcosm experiment, we studied the interaction between ants (Lasius niger), aphids (Aphis fabae), and the soil microbial community. We addressed the question whether ants alter the nitrogen flow between aboveground and belowground systems using stable isotope techniques and whether ants change the soil microbial community using DGGE. The common bean, Phaseolus vulgaris, was labeled with ${ }^{15} \mathrm{~N}$ and served as host plant for aphids. Consequently, the $\delta^{15} \mathrm{~N}$ content in aphids increased (to 136.1 $\%$ ) In addition, the flow of nitrogen via honeydew and ant movement to neighboring Arrhenaterum elatius plants was quantified.

After eight weeks, $2.7 \%$ of the nitrogen in ant larvae originated from the plant/aphidsystem, and $\delta^{15} \mathrm{~N}$ values in adult ant workers increased strongly from $2.4 \%$ to $16.9 \%$. The presence of aphids increased microbial biomass in the litter layer and increased the abundance of bacterial populations in soil. The presence of ants reduced the amount of honeydew dropping on the litter surface, which led to lower microbial biomass in the litter layer. On the contrary, ants promoted the transport of material from the aboveground to the belowground system resulting in increased $\delta^{15} \mathrm{~N}$ signature in soil as compared to litter and increased basal respiration and microbial biomass in soils, presumably due to faeces deposition and dropping of food remains. Further, ants altered the structure of bacterial populations in soil promoting a more balanced community structure.
\end{abstract}

\title{
Keywords
}

Formicidae, delta N-15, nitrogen, microbial activity 


\section{Introduction}

Ants form a dominant component of the invertebrate food web in many terrestrial ecosystems and exert major impacts on the aboveground and belowground system (Hölldobler and Wilson, 1990; Letourneau and Dyer, 1998; Pêtal, 1998). Due to communication and cooperation, ants strongly influence their environment (Brian, 1983; Hölldobler and Wilson, 1990). In addition, ants act as ecosystem engineers (Jones, 1994) influencing soil properties, such as soil structure, soil $\mathrm{pH}$, water holding capacity, organic matter content, and exchangeable $\mathrm{Ca}, \mathrm{Mg}, \mathrm{K}$, and $\mathrm{PO}_{4}$ by nest construction (Lobry de Bruyn and Conacher, 1990). The transport of honeydew, prey and organic substances into their nest and the addition of secretions and excreta affect the nutrient distribution in soil. Furthermore, ants also affect the structure of food webs (Letourneau and Dyer, 1998) by acting as mutualistic partners and predators (Schumacher and Platner, 2009). Mutualistic relationships between ants and aphids are common. Aphids provide honeydew to ants and in return the ants provide services to aphids such as protection against enemies (Way, 1954 and 1963; Stadler and Dixon, 2005) and removing dead bodies and exuviae (Banks, 1962). The intensity of ant-aphid mutualism increases with honeydew quality and quantity (Bristow, 1984; Fischer et al., 2001). Due to ant presence, aphids alter the quantity and quality of their honeydew. In presence of ants, aphids excrete smaller droplets of honeydew at a higher rate, and honeydew containing a significantly higher concentration of amino acids (Yao and Akimoto, 2002) sucrose, and trehalose (Yao and Akimoto, 2001).

Ants directly influence soil fertility, as they alter the amount of honeydew dropping to soil by collecting it. Furthermore, they change the physical soil conditions by constructing chambers and galleries. Through these processes, ants alter the flux of carbon and nitrogen through ecosystems.

Approximately one-third of the honeydew produced by aphids may fall to the ground (Wellenstein, 1980), forming an important component of soil fertility (Choudhury, 1985). Stadler (2006) analyzed the effects of ants and aphid honeydew on spruce litter. Addition of honeydew significantly increased dissolved organic carbon (DOC) as a direct result of honeydew leaching, and decreased inorganic $\mathrm{N}$ concentrations in leachates. The author proposed that the dropped honeydew fuels the growth of microorganisms on the spruce needles resulting in the immobilization of $\mathrm{N}$, thereby increasing plant nutrient limitation. 
We used stable isotopes to identify food sources of ants (Post, 2002), building on a previous laboratory and field study (Sanders and Platner, 2007; Schumacher and Platner, 2009). In microcosms seedlings with Phaseolus vulgaris L. were labeled with ${ }^{15} \mathrm{~N}$ and infested with Aphis fabae Scopoli to follow the flux of nitrogen from plants to aphids to the soil system. Moreover, we wanted to gain insight into the effect of ants on nitrogen flow between aboveground and belowground systems and on the soil microbial community studied by molecular analyses and respiration measurements. We hypothesize that (1) aphid honeydew will increase nutrient availability for microbes in the litter layer and will lead to higher microbial biomass. (2) In contrast, tending ants will reduce the amount of honeydew dropping onto the litter what will decrease microbial biomass. (3) Ants are suggested to increase the nitrogen flux from above- to belowground system, what will affect the soil microbial biomass and the community structure of bacteria. 


\section{Material and Methods}

Labeling procedure and microcosm set-up

The experiment was set up in microcosms (aluminum pot, $20 \mathrm{~cm}$ id, $19 \mathrm{~cm}$ height) filled with $2.4 \mathrm{~kg}$ autoclaved loamy sand soil (LUFA Standard Soil Type 2.2; $2.36 \pm 0.29 \%$ organic $\mathrm{C}, \mathrm{pH}\left[0.01 \mathrm{M} \mathrm{CaCl}_{2}\right] 5.6 \pm 0.4$, cation exchange capacity $11 \pm 2 \mathrm{mval} / 100 \mathrm{~g}$ ). To establish diverse microbial communities, we added $100 \mathrm{ml}$ of an inoculant to every microcosm. For the inoculant, $1 \mathrm{~kg}$ fresh soil from a dry hillside of the Werra valley (Witzenhausen Freudenthal, Northern Hesse, Germany; for details see Platner 2006) was mixed with 11 of $0.9 \% \mathrm{NaCl}$ solution and shaken for half an hour. The soil for the inoculant was a shallow Pararendzina (Leptosol) on Triassic limestone with a diverse herb layer dominated by Brachypodium pinnatum (L.).

A layer of $10 \mathrm{~g}$ dry autoclaved grass litter was added to each microcosm. The microcosms were closed by a transparent perspex cylinder $(19 \mathrm{~cm} \mathrm{id}, 25 \mathrm{~cm}$ height $)$ with removable gauze $(2 \mu \mathrm{m})$ on top (supplementary Figure S1). In each cylinder a 2 $\mu \mathrm{m}$ gauze was inserted to create two compartments within the microcosm. Outside each microcosm, a pot with labeled Phaseolus vulgaris was fixed, only their shoot hanging in compartment one of the cylinder (=P. vulgaris side) (supplementary Figure S1). During the experiment P. vulgaris served as host plants for aphids (Aphis fabae). In compartment two, five Arrhenatherum elatius (L.) seedlings were planted (=A. elatius side) to quantify the ${ }^{15} \mathrm{~N}$ flow from honeydew to the neighboring plants. $P$. vulgaris seeds (breed Solido) were sown six weeks before the start of the experiment. The plants were labeled with urea solution $\left(2\right.$ atom $\%{ }^{15} \mathrm{~N}$ ) for 23 days (Schmidt and Scrimgeour, 2001) by brushing seedling-shoots daily once the shoots reached the two-leave stage. In summary, every plant was labeled with approximately $4 \mathrm{~mL}$ of urea solution $\left(2 \mathrm{~g} \mathrm{~L}^{-1}\right)$. Each $P$. vulgaris shoot was infested with 25 apterous $A$. fabae individuals of similar size. Aphids were reared on unlabeled $P$. vulgaris before adding them to the experimental containers. Aphid colonies were allowed to develop for two days before ant colonies were added to respective treatments. Each ant colony consisted of 100 Lasius niger (L.) workers and 80 larvae. Ant colonies originated from a single mother that was collected from dry grassland located near Göttingen, Germany, in September 2007.

In the absence of ants, the honeydew fell on the ground or became attached to bean leaves, whereas in presence of ants the honeydew was collected by ant workers. In 
treatments with honeydew exclusion, the experimental microcosms included an additional Perspex pane beneath the $P$. vulgaris shoot to prevent honeydew from falling onto the ground. During the experiment, the panes were changed every five days. The following treatments were established: (1) without ants and without honeydew (A- H-) (honeydew excluded by pane), (2) without ants and with honeydew (A- H+) (honeydew falling to the ground), (3) with ants and without honeydew (A+ H-), and (4) with ants and with honeydew $(\mathrm{A}+\mathrm{H}+)$. Control microcosms were established without aphids and ants.

The experiment was conducted in a greenhouse in Göttingen from September to November 2007. Additional lighting was provided by Osram lamps (36 W/21-840 Lumilux plus) to allow a $12 \mathrm{~h}$ period of light.

We used a blocked, two-factorial design with the factors 'ants' (with and without) and 'honeydew' (with and without). In total 32 experimental microcosms were divided into eight blocks; we arranged the four treatments randomly within each block. Four control microcosms were established between every second block. Microcosms within blocks were rotated every third day.

Data collection and statistical analyses

At the end of the experiment, living aphids, L. niger workers and larvae were collected by hand and frozen at $-20{ }^{\circ} \mathrm{C}$. Then, samples were freeze-dried and biomass (dry weight) was quantified. P. vulgaris shoots were clipped at the point where shoots reached into the microcosm. Plant material was dried at $105{ }^{\circ} \mathrm{C}$ for three days before biomass was determined.

We measured stable isotopes $\left({ }^{15} \mathrm{~N}\right)$ and total nitrogen from pulverized plant material, litter, soil, frozen ants and aphids, with two replicates for each sample. We analyzed ants in total to avoid skew results due to different isotopic signatures among tissues (Tillberg et al., 2006). Bean shoots with the aphid colonies were removed 5 days before the ants were collected. This 5 day period without food for ants will empty the crop content to a marginal rate. Ratio of ${ }^{15} \mathrm{~N} /{ }^{14} \mathrm{~N}$ was measured by a coupled system consisting of an elemental analyzer (Carlo Erba NA 2500) and a gas isotope mass spectrometer (Finnigan Deltaplus). Isotope ratio was expressed in $\delta$ units as $\delta^{15} \mathrm{~N}$ [\%o] $=$ $\left(R_{\text {Sample }}-R_{\text {Standard }}\right) / R_{\text {Standard }} x 1000$, where $R$ is the ratio of ${ }^{15} \mathrm{~N} /{ }^{14} \mathrm{~N}$, respectively. The standard for ${ }^{15} \mathrm{~N}$ is atmospheric nitrogen. Acetanilide $\left(\mathrm{C}_{8} \mathrm{H}_{9} \mathrm{NO}\right.$, Merck, Darmstadt $)$ served for internal calibration; the mean standard deviation of samples was $<0.1 \%$. 
Grass litter was removed by hand. In each microcosm, three soil samples were collected: one from the surface $(3 \mathrm{~cm})$ of the P. vulgaris compartment ( $P$. vulgaris side), one from the surface $(3 \mathrm{~cm})$ of the A. elatius compartment (A. elatius side), and one between the compartments at a depth of about $10 \mathrm{~cm}$ (ground soil) (supplementary Figure S1). Litter and soil samples were homogenized by stirring. Subsamples were taken to analyze microbial basal respiration, microbial biomass (substrate-induces respiration, SIR; Anderson and Domsch, 1978; Scheu, 1992), and soil water content (gravimetrically).

The effect of 'ants' and 'honeydew' on the bacterial soil community was assessed by denaturing gradient gel electrophoresis (DGGE) of soil DNA derived from samples of eight replicated microcosms per treatment. Soil samples for molecular analyses were stored at $-80{ }^{\circ} \mathrm{C}$ until analysis. Genomic DNA was isolated from $250 \mathrm{mg}$ of soil by employing the UltraClean PowerSoil ${ }^{\mathrm{TM}}$ DNA Isolation Kit (MO BIO Laboratories Inc., Carlsbad, CA, USA) according to the manufacturer's protocol. The final DNA elution step was carried out with $100 \mu$ l sterile $\mathrm{H}_{2} \mathrm{O}$.

For DGGE, $560 \mathrm{bp}$ fragments of the 16S rRNA gene including the variable regions V3, V4 and V5 were amplified by employing the primers 5'- CCTACGGGAGGCAGCAG3' (BAC 341F) and 5'-CCGTCAATTCCTTTRAGTTT-3' (BAC 907R) (Muyzer et al., 1995; Muyzer and Smalla, 1998). Additionally, a GC clamp (5'CGCCCGCCGCGCCCCGCGCCCGTCCCGCCGCCCCCGCCCG-3') was attached at the 5' terminus of primer BAC 341F (Muyzer et al., 1995). The PCR reaction mixture $(50 \mu \mathrm{l})$ contained $5 \mu \mathrm{l} \mathrm{Mg-free} \mathrm{polymerase} \mathrm{buffer} \mathrm{(MBI} \mathrm{Fermentas,} \mathrm{St.} \mathrm{Leon-Rot,}$ Germany), $200 \mu \mathrm{M}$ of each of the four deoxynucleoside triphosphates, $2 \mathrm{mM} \mathrm{MgCl} 2,2$ $\mu \mathrm{M}$ of each of the primers, $1 \mathrm{U}$ of Taq DNA polymerase (MBI Fermentas), and $20 \mathrm{ng}$ of isolated DNA as template. The following thermal cycling scheme was used: initial denaturation at $95{ }^{\circ} \mathrm{C}$ for $2 \mathrm{~min}, 13$ cycles of denaturation at $94{ }^{\circ} \mathrm{C}$ for $1 \mathrm{~min}$, annealing for $1 \mathrm{~min}$ at a decreasing temperature gradient ranging from $64{ }^{\circ} \mathrm{C}$ to $51{ }^{\circ} \mathrm{C}\left(1{ }^{\circ} \mathrm{C}\right.$ decrease per cycle), and extension at $72{ }^{\circ} \mathrm{C}$ for $3 \mathrm{~min}$. Subsequently, 12 cycles of denaturation at $94{ }^{\circ} \mathrm{C}$ for $1 \mathrm{~min}$, annealing for $1 \mathrm{~min}$ at $51{ }^{\circ} \mathrm{C}$, and extension at $72{ }^{\circ} \mathrm{C}$ for 3 min were performed. A final extension period at $72{ }^{\circ} \mathrm{C}$ for $10 \mathrm{~min}$ was carried out. The size of the resulting PCR products was controlled by agarose gelelectrophoresis. Subsequently, the PCR products were purified by using CyclePure PCR purification kit (Peqlab Biotechnologie GmbH, Erlangen, Germany) as recommended by the 
manufacturer. The concentration of purified PCR products was quantified using a NanoDrop ND-1000 spectrophotometer (Peqlab Biotechnologie GmbH).

DGGE analysis of 16S rRNA genes was performed using the INGENY phorU system (Ingeny International BV, The Netherlands). Purified bacterial amplicons (500 ng) were applied to a $9 \%$ (wt/vol) polyacrylamide gel containing a $45 \%$ to $60 \%$ denaturing gradient (100\% denaturant consisted of $7 \mathrm{M}$ urea and $40 \%$ formamide). Electrophoresis was performed at $60{ }^{\circ} \mathrm{C}$ and $100 \mathrm{~V}$ for $16 \mathrm{~h}$ in Tris-Acetate-EDTA (TAE) buffer, which consisted of $40 \mathrm{mM}$ Tris, $20 \mathrm{mM}$ acetic acid, and $1 \mathrm{mM}$ EDTA. Subsequently, the gels were stained with SYBR Gold (Invitrogen, Karlsruhe, Germany). The obtained DGGE fingerprints (see supplementary material Figure S4A and B) were digitalized and a cluster analysis using the GelCompare II software (Applied Maths, Kortrijk, Belgium) was performed. Clustering was performed using the unweighted pair group method with mathematical averages (dice coefficient of similarity). Background subtraction was applied and position tolerance was set to $1 \%$.

Prominent bands were excised and stored in $100 \mu \mathrm{l}$ TAE buffer overnight. Subsequently, $1 \mu \mathrm{l}$ of the resulting DNA-containing buffer solution was used as template for reamplification by employing the above mentioned primers BAC $341 \mathrm{~F}$ without attached GC-clamp and BAC 907R. The PCR was performed as described above. Subsequently, purified PCR products were ligated into pCR2.1 vector using TOPO TA Cloning Kit and resulting plasmids were transferred to E. coli DH5 $\alpha$ cells, according to the manufacturer's protocol (Invitrogen GmbH, Darmstadt Germany). Plasmids have been isolated from recombinant clones and the insert sequences were determined by the Göttingen Genomics Laboratory. Classification of the sequences was performed by similarity searches using BLAST (Altschul et al. 1990) against the most recent SILVA database 108 (Pruesse et al., 2007). Nucleotide sequence accession numbers of the excised, reamplified, cloned and sequenced DGGE-bands have been deposited in the GenBank database under accession numbers JQ582986 to JQ583188.

Statistical analyses of biomass and isotope data were done by two factor analyses of variance (SAS 8.1, SAS Institute Inc., Cary, USA), and differences between means were inspected by Tukey's honestly significant difference test (Sokal and Rohlf, 2001). The effect of 'aphids' was analyzed using one-way GLM comparing the control with the treatment witout ants and with honeydew (A-H+; supplementary Figure S2). Data on basal respiration and microbial biomass were analyzed by a MANCOVA (Scheiner, 2001) with the mean soil water content as co-variable. 


\section{Results}

Plant and aphid biomasses

Aboveground biomass of $P$. vulgaris did not differ between treatments, but aboveground biomass in experimental microcosms with aphids (mean $\pm S E, n=8$ : $1112.2 \pm 533.1 \mathrm{mg}$ dry weight beans and shoot within microcosm) was significantly higher than in the control without aphids (mean $\pm \mathrm{SE}, \mathrm{n}=4: 527.5 \pm 79.2 \mathrm{mg}$; Table 1, supplementary Figure S2). Plants without aphids produced almost no beans (one plant with a yield of $100 \mathrm{mg}$ dry weight), whereas aphid infested plants produced a mean yield of $564.1 \pm 72.4 \mathrm{mg}$ dry weight $(\mathrm{n}=32)$. Ants significantly increased the number of living alate aphids in A. fabae colonies (8.6 \pm 5.4 individuals without ants, $25.1 \pm 7.5$ ind. with ants, $\mathrm{n}=16 ; \mathrm{F}_{1,21}=4.48, \mathrm{p}=0.0464$, supplementary Figure S3). Biomass of A. elatius shoots and roots were not affected by treatments (supplementary Figure S3).

Table 1. Effects of 'aphids' on the biomass (dry weight), $\delta^{15} \mathrm{~N}$ content (\%o), $\mathrm{H}_{2} \mathrm{O}$ of soil dry weight (\%), basal respiration ( $\mu \mathrm{g} \mathrm{O}_{2} \mathrm{~g}^{-1}$ dry wt $\mathrm{h}^{-1}$ ) and microbial biomass ( $\mu \mathrm{g} \mathrm{C}_{\mathrm{mic}} \mathrm{g}^{-1}$ dry wt). All comparisons were made using a one-way GLM. P-values of marginal significant effects $-p$ $<0.1-$ are presented with three decimal places. $\mathrm{df}=$ degree of freedom.

\begin{tabular}{llll}
\hline & df & $\mathrm{F}$ & $\mathrm{p}$ \\
\hline Biomass $P$. vulgaris shoot & 1 & $\mathbf{1 8 . 2 9}$ & $\mathbf{0 . 0 0 0 8}$ \\
Biomass A. elatius shoot & 1 & 1.84 & 0.20 \\
Biomass A. elatius root & 1 & 0.90 & 0.36 \\
\hline$\delta^{15} \mathrm{~N}$ P. vulgaris shoot & 1 & $\mathbf{5 . 2 8}$ & $\mathbf{0 . 0 3 7 5}$ \\
$\delta^{15} \mathrm{~N}$ A. elatius shoot & 1 & 3.44 & 0.085 \\
$\delta^{15} \mathrm{~N}$ A. elatius root & 1 & 3.72 & 0.074 \\
$\delta^{15} \mathrm{~N}$ litter & 1 & $\mathbf{6 . 2 9}$ & $\mathbf{0 . 0 2 5 0}$ \\
$\delta^{15} \mathrm{~N}$ soil $P$. vulgrais side & 1 & 3.70 & 0.075 \\
$\delta^{15} \mathrm{~N}$ soil ground & 1 & $\mathbf{1 1 . 2 9}$ & $\mathbf{0 . 0 0 4 7}$ \\
$\delta^{15} \mathrm{~N}$ soil A. elatius side & 1 & 1.08 & 0.32 \\
\hline Litter moisture & 1 & $\mathbf{6 . 6 1}$ & $\mathbf{0 . 0 2 2 2}$ \\
Soil moisture $P$. vulgrais side & 1 & $\mathbf{4 . 9 8}$ & $\mathbf{0 . 0 4 2 6}$ \\
Soil moisture ground & 1 & $\mathbf{1 1 . 3 1}$ & $\mathbf{0 . 0 0 4 6}$ \\
Soil moisture A. elatius side & 1 & $\mathbf{9 . 9 9}$ & $\mathbf{0 . 0 0 6 9}$ \\
\hline Basal respiration litter & 1 & 3.77 & 0.073 \\
Basal respiration $P$. vulgaris side & 1 & 0.02 & 0.88 \\
Basal respiration ground & 1 & 3.55 & 0.080 \\
basal respiration A.elatius side & 1 & $\mathbf{4 . 7 4}$ & $\mathbf{0 . 0 4 7 0}$ \\
\hline Microbial biomass litter & 1 & $\mathbf{1 2 8 . 9 0}$ & $<\mathbf{0 . 0 0 0 1}$ \\
Microbial biomass $P$. vulgaris side & 1 & 0.70 & 0.42 \\
Microbial biomass ground & 1 & $\mathbf{8 . 5 9}$ & $\mathbf{0 . 0 1 0 9}$ \\
Microbial biomass A.elatius side & 1 & 0.12 & 0.74 \\
\hline
\end{tabular}


Stable isotopes, basal respiration and microbial biomass

The $\delta^{15} \mathrm{~N}$ isotope signature of unlabeled $P$. vulgaris shoots inhabited by aphids was 4.5 \%. $\delta^{15} \mathrm{~N}$ values in labeled aphid-infested $P$. vulgaris shoots $(\mathrm{n}=8)$ were significantly lower than in control microcosms without aphids $(-34 \%, n=4$, Table 1 , Figure 1 and supplementary Figure S2). On average, $\delta^{15} \mathrm{~N}$ values of aphids were $8 \%$ lower than those of $P$. vulgaris shoots (Figure 1). The $\delta^{15} \mathrm{~N}$ values of ants and ant larvae increased during the experiment (on average 7-fold and 2.5-fold, respectively, Figure 1). At the end of the experiment $2.7 \%$ of the nitrogen in ant larvae originated from plant nitrogen. This incorporation originated from the plant/aphid-system and represents the material flow from aphids to ants and a proportion of $10.8 \%$ nitrogen gained from this flow.

Aphids in microcosm increased the $\delta^{15} \mathrm{~N}$ values in shoots and roots of A. elatius compared to controls (32\% and $37 \%$, respectively; Table 1, Figure 1 and supplementary Figure S2), but stable isotope incorporation of roots and shoots were not affected by 'ants' or 'honeydew'.

Water content did not differ significantly between treatments in any of the soil or litter samples. In the litter layer aphid presence significantly increased moisture, $\delta^{15} \mathrm{~N}$ values, microbial biomass $\left(\mathrm{C}_{\mathrm{mic}}\right)$ and marginally basal respiration (BAS) compared to control without aphids (Table 2, Figure 2, supplementary Figure S2). When aphids were tended by ants, $\mathrm{C}_{\mathrm{mic}}$ in the litter decreased significantly $(-22 \%$, Table 4 , Figure $3 \mathrm{a}$ and supplementary Figure S3). Only without ants honeydew droppings lead to higher BAS and $\mathrm{C}_{\text {mic }}$ in the litter, but when ants inhabited the microcosm this was not the case (interaction between 'ants' and 'honeydew'; Table 3, b, Figure 2a, 3a).

When honeydew dropped to the soil, BAS and $\mathrm{C}_{\text {mic }}$ in soil taken beneath the P. vulgaris shoots decreased (- $18 \%$ and - $34 \%$, respectively), but both parameters increased in presence of ants $(+20 \%$ and $+8 \%$, respectively; Table 3, Figure $2 \mathrm{~b}, 3 \mathrm{~b}$ and supplementary Figure S3).

Ants significantly increased BAS in soil samples from microcosm ground $(+20 \%$, Table 3a, Figure 2c and supplementary Figure S3). Moreover ant presence resulted in significant higher $\delta^{15} \mathrm{~N}$ values in soil samples from both the P. vulgaris $(+38 \%)$ and the A. elatius side (+ $21 \%$; Table 2, supplementary Figure S3).In all soil samples, BAS and $\mathrm{C}_{\text {mic }}$ differed significantly between blocks (Table 3 and 4).

A summary of the effect of aphid honeydew (comparison between A-H+ treatments and controls) as well as the effect of 'ants' and 'honeydew' between experimental treatments can be found in Figures S2 an S3 of the supplementary material. 

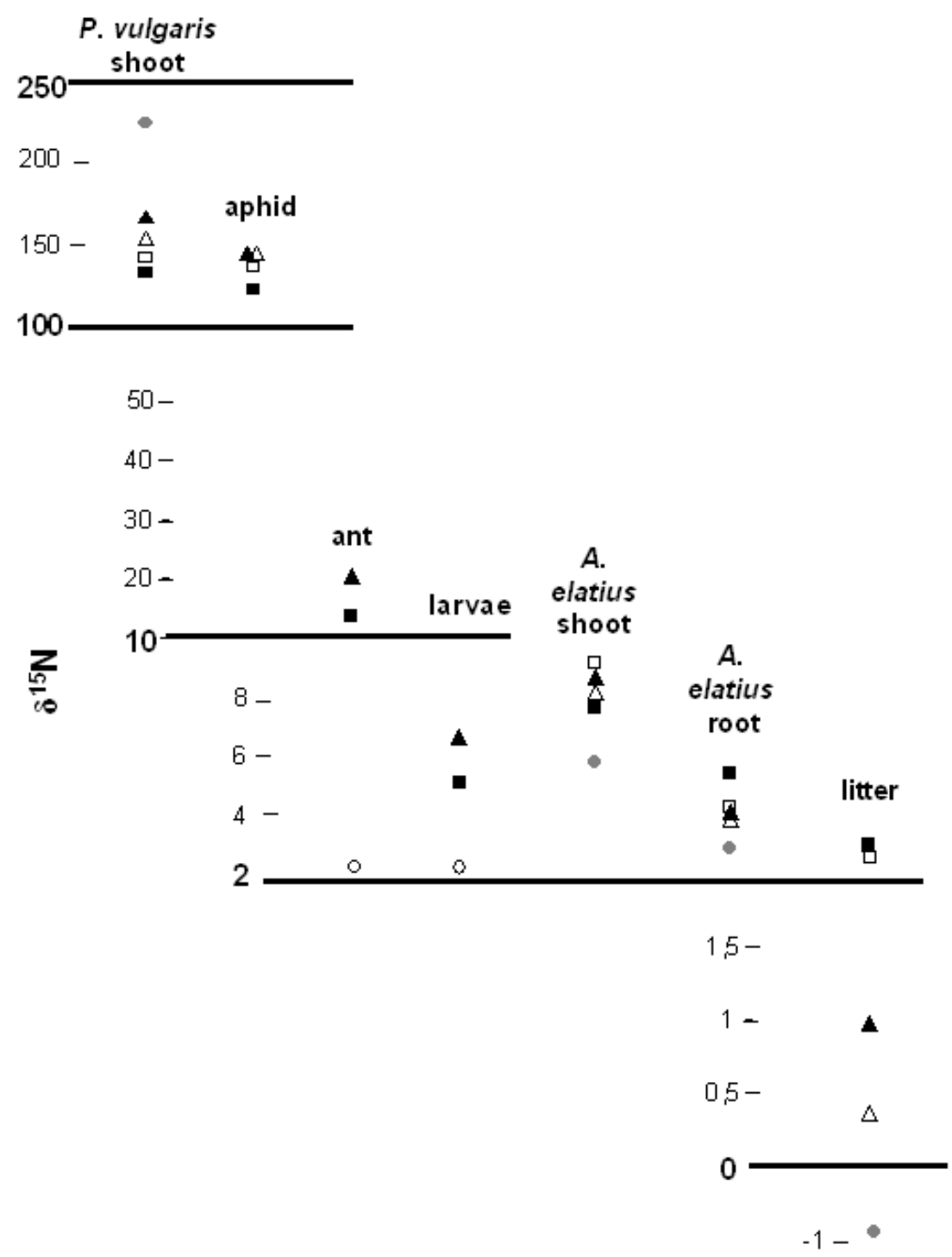
$\triangle \mathrm{A}-\mathrm{H}-$
口 $\mathrm{A}-\mathrm{H}+$
A $\mathrm{A}+\mathrm{H}-$
- $\mathrm{A}+\mathrm{H}+$
- control
- origin colony

Figure 1. $\delta^{15} \mathrm{~N}$ content (\%) in P. vulgaris, A. fabae, L. niger and A. elatius, as well as in litter and soil samples of the different microcosm treatments. The different treatments are indicated as follows: $\mathrm{A}-=$ without ants; $\mathrm{A}+=$ with ants; $\mathrm{H}-$ without honeydew; $\mathrm{H}+$ with honeydew; control = without any treatment. 

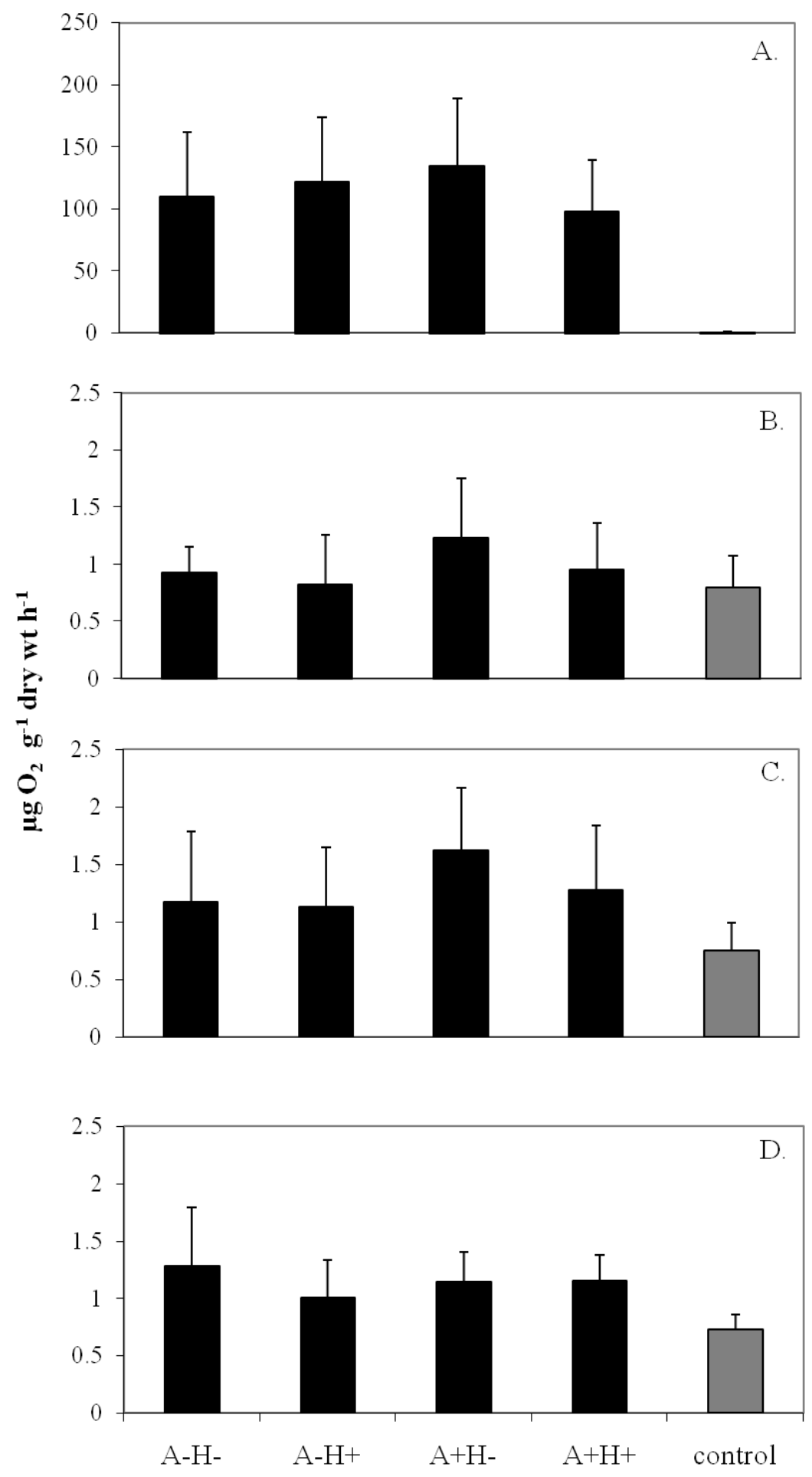

Figure 2. Basal respiration in the litter layer (A.), the soil of the P. vulgaris sides (B.), the ground soil (C.) and the soil of A. elatius sides (D.). The different treatments are indicated as follows: A- = without ants; $\mathrm{A}+=$ with ants; $\mathrm{H}-$ without honeydew; $\mathrm{H}+$ with honeydew; control = without any treatment. 

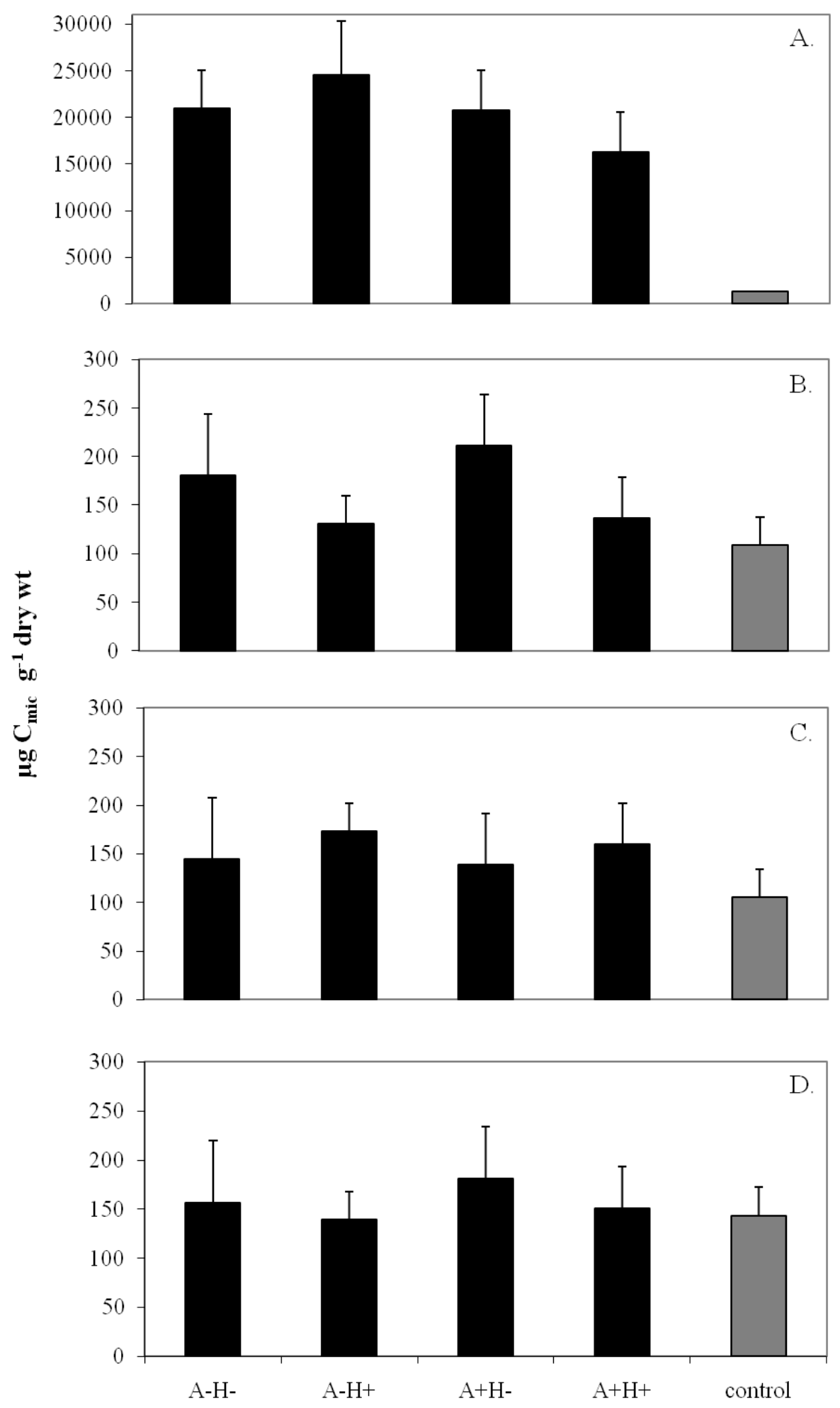

Figure 3. Microbial biomass in the litter layer (A.), the soil of the P. vulgaris sides (B.), the ground soil (C.) and the soil of A. elatius sides (D.). The different treatments are indicated as follows: $\mathrm{A}-=$ without ants; $\mathrm{A}+=$ with ants; $\mathrm{H}-$ without honeydew; $\mathrm{H}+$ with honeydew; control = without any treatment. 
Table 2. Effects of 'ants' and 'honeydew' on the $\delta^{15} \mathrm{~N}$ contents. All comparisons were made using a two-way ANOVA. P-values of marginal significant effects $-\mathrm{p}<0.1-$ are presented with three decimal places. $\mathrm{df}=$ degree of freedom.

\begin{tabular}{|c|c|c|c|c|c|c|c|c|c|c|c|}
\hline & \multirow[b]{2}{*}{$\mathrm{df}$} & \multicolumn{2}{|c|}{$\delta^{15} \mathrm{~N}$ aphid } & \multicolumn{2}{|l|}{$\begin{array}{l}\log \\
\text { litter }\end{array}$} & \multicolumn{2}{|c|}{$\begin{array}{l}\delta^{15} \mathrm{~N} \text { soil } P . \\
\text { vulgaris side }\end{array}$} & \multirow{2}{*}{$\begin{array}{l}\delta^{15} \mathrm{~N} \\
\text { soil } \\
\mathrm{F}\end{array}$} & \multirow{2}{*}{$\begin{array}{l}\text { ground } \\
\mathrm{p}\end{array}$} & \multicolumn{2}{|c|}{$\begin{array}{l}\delta^{15} \mathrm{~N} \text { soil } \\
\text { elatius side }\end{array}$} \\
\hline & & $\mathrm{F}$ & $\mathrm{p}$ & $\mathrm{F}$ & $\mathrm{p}$ & $\mathrm{F}$ & $\mathrm{p}$ & & & $\mathrm{F}$ & $\mathrm{p}$ \\
\hline ants & 1 & 0.39 & 0.54 & 3.19 & 0.092 & 4.73 & 0.0411 & 0.03 & 0.86 & 5.27 & 0.0320 \\
\hline honeydew & 1 & 2.37 & 0.14 & 3.22 & 0.091 & 0.08 & 0.78 & 0.62 & 0.44 & 0.06 & 0.82 \\
\hline block & 7 & 2.21 & 0.087 & 0.44 & 0.87 & 6.55 & 0.0004 & 6.06 & 0.0006 & 9.35 & $<0.0001$ \\
\hline ants*ho & 1 & 0.09 & 0.77 & 0.53 & 0.48 & 0.23 & 0.64 & 0.03 & 0.87 & 1.26 & 0.27 \\
\hline
\end{tabular}

Table 3. Effects of 'ants' and 'honeydew' on basal respiration (BAS, $\mu \mathrm{g} \mathrm{O} \mathrm{g}^{-1}$ dry wt $\mathrm{h}^{-1}$ ). All comparisons were made using a MANOVA with the mean soil water content as covariable. Pvalues of marginal significant effects $-\mathrm{p}<0.1$ - are presented with three decimal places. $\mathrm{df}=$ degree of freedom.

\begin{tabular}{|c|c|c|c|c|c|c|c|c|c|c|c|c|}
\hline & \multirow[b]{3}{*}{$\mathrm{df}$} & \multirow{2}{*}{\multicolumn{2}{|c|}{$\begin{array}{l}\text { soil } P \\
\text { vulgaris side }\end{array}$}} & \multirow{2}{*}{\multicolumn{2}{|c|}{ ground soil }} & \multirow{2}{*}{\multicolumn{2}{|c|}{$\begin{array}{l}\text { soil A. } \\
\text { elatius side }\end{array}$}} & \multirow[t]{2}{*}{ litter } & \multirow[b]{3}{*}{$\mathrm{p}$} & \multirow[b]{3}{*}{$\begin{array}{l}\text { Wilks' } \\
\text { Lambda }\end{array}$} & \multirow[b]{3}{*}{$\mathrm{F}$} & \multirow[b]{3}{*}{$\mathrm{p}$} \\
\hline & & & & & & & & & & & & \\
\hline & & $\mathrm{F}$ & $\mathrm{p}$ & F & $\mathrm{p}$ & $\mathrm{F}$ & $\mathrm{p}$ & $\mathrm{F}$ & & & & \\
\hline $\begin{array}{l}\text { Mean soil } \\
\text { moisture }\end{array}$ & 1 & 3.80 & 0.065 & 0.45 & 0.51 & 5.64 & 0.0277 & 3.69 & 0.069 & 0.5466 & 3.53 & 0.0286 \\
\hline block & 7 & 2.76 & 0.0351 & 6.50 & 0.0004 & 5.95 & 0.0008 & 1.23 & 0.33 & 0.0752 & 2.35 & 0.0026 \\
\hline ants & 1 & 5.67 & 0.0273 & 5.63 & 0.0278 & 0.36 & 0.56 & 0.20 & 0.66 & 0.5874 & 2.99 & 0.0489 \\
\hline honeydew & 1 & 3.46 & 0.078 & 2.45 & 0.13 & 3.19 & 0.090 & 0.81 & 0.38 & 0.6595 & 2.19 & 0.11 \\
\hline ants*ho & 1 & 1.80 & 0.20 & 1.78 & 0.20 & 0.74 & 0.40 & 4.30 & 0.051 & 0.5394 & 3.63 & 0.0259 \\
\hline
\end{tabular}

Table 4. Effects of 'ants' and 'honeydew' on microbial biomass $\left(\mathrm{C}_{\text {mic }}, \mu \mathrm{g} \mathrm{C}_{\text {mic }} \mathrm{g}^{-1}\right.$ dry wt). All comparisons were made using a MANOVA with the mean soil water content as covariable. Pvalues of marginal significant effects $-\mathrm{p}<0.1$ - are presented with three decimal places. $\mathrm{df}=$ degree of freedom.

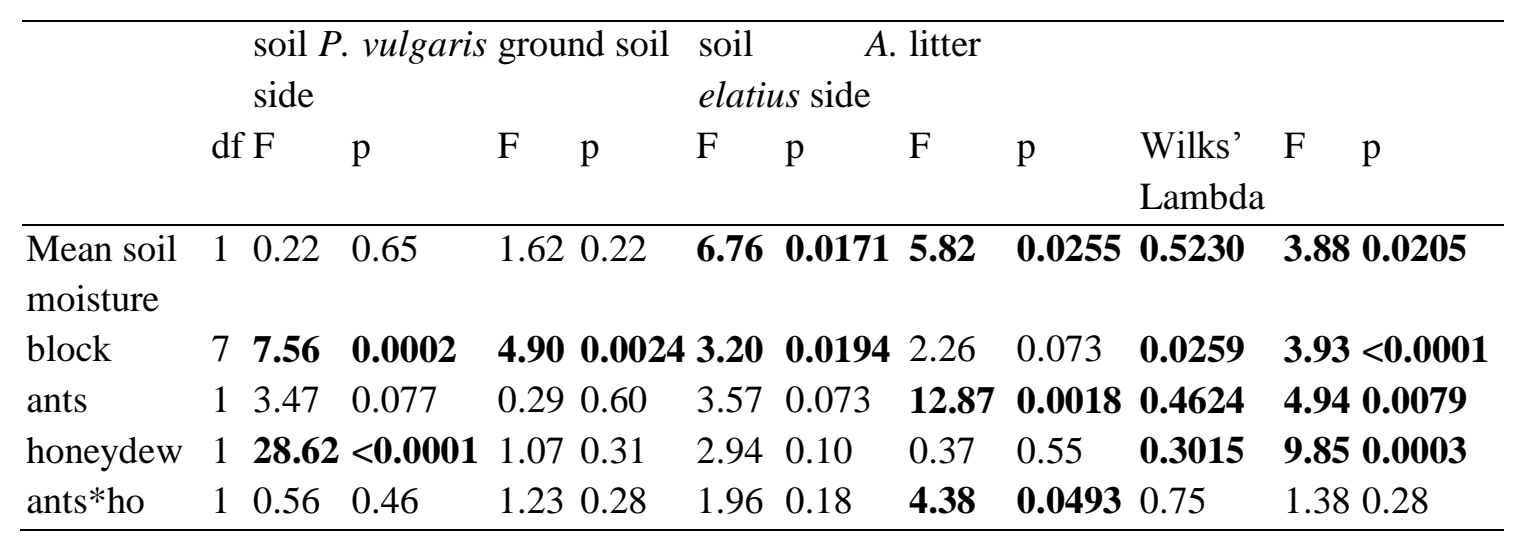


Bacterial community analysis

The dendrograms obtained from DGGE analysis (Figure 4) did not show a distinct clustering of the 'ant' and 'honeydew' treatments. This is due to the high variation of the banding patterns within 'ant' treatments. Correspondingly, bacterial communities from control soil samples did not cluster in one group, which is separated from the different treatments.

Twenty six dominant bands (marked in supplementary Figure S4A and B) were excised from the gels, cloned and sequenced. Phylogenetic analysis of the 16S rRNA gene sequence data showed that the Proteobacteria were most abundant, representing $57 \%$ of the analyzed sequences. Firmicutes accounted for $25 \%$, Actinobacteria for $11 \%$, Gemmatimonadetes for $2.5 \%$ and Acidobacteria for $3 \%$ of the analyzed 16S rRNA gene sequences. Within Proteobacteria, Betaproteobacteria (43\%) were the predominant class followed by Gammaproteobacteria (38 \%) and Alphaproteobacteria (17\%). Among the most frequently occurring Phyla, $98 \%$ of the betaproteobacterial sequences were attributed to the order of Burkholderiales (97-100\% identity) and 78 $\%$ of these sequences could be ascribed to the Oxalobacteracea. Of the gammaproteobacterial sequences, $90 \%$ belonged to the Xanthomonadales (92 - $100 \%$ identity) amongst which the Xanthomonadaceae accounted for $86 \%$ (99 - $100 \%$ identity). Arenimonas was the main representative of the Xanthomonadaceae, representing $64.5 \%$ of the sequenced clones. About $96 \%$ of the sequences attributed to the Firmicutes belong to the class Bacilli (96 - $100 \%$ identity). The Bacilli-assigned sequences belonged to the Paenibacillaceae (16\% of the sequences; $96-98 \%$ identity), the Bacillaceae (32.6\% of the sequences; $99-100 \%$ identity) and the Alicyclobacillaceae, all of the genus Tumebacillus (51\% of the sequences; 97 - $100 \%$ identity).

The analysis of bands $\mathrm{G}, \mathrm{H}$, and $\mathrm{T}$ revealed that these representative picked bands, occurring at the same height and in every treatment, mainly represented Betaproteobacteria and Gammaproteobacteria (Figure 5). Some clones could also be attributed to the Firmicutes and Alphaproteobacteria. The sequences, which were determined for band $\mathrm{D}$ and $\mathrm{W}$, which occur randomly, were all affiliated to the genus Tumebacillus. Bands B, C and V occurred also at the same height and in every treatment, but with different intensities. These bands were dominated by Gammaproteobacteria. In summary, no distinct separation of the different treatments was visible in the DGGE banding patterns and the cluster analysis. 


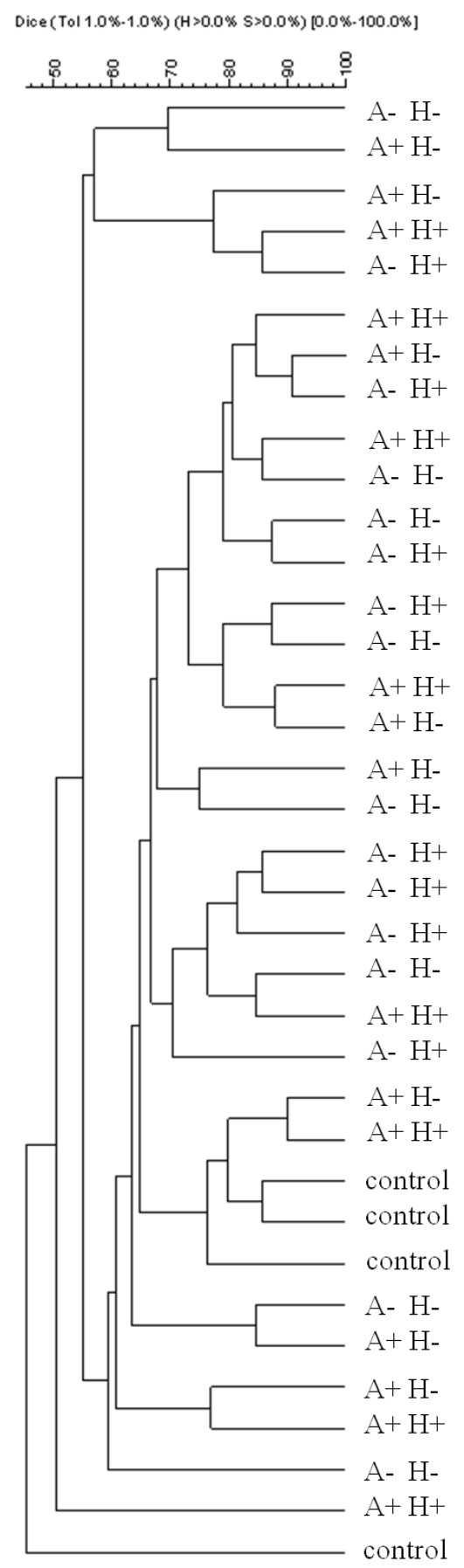

Figure 4. Dendrogram showing the cluster analysis of the digitized bacterial DGGE fingerprints. The UPMGA method was applied, which takes the presence or absence of bands at certain positions in each lane into account. The different treatments are indicated as follows: A$=$ without ants; $\mathrm{A}+=$ with ants; $\mathrm{H}-$ without honeydew $\mathrm{H}+$ with honeydew; control $=$ without any treatment. 


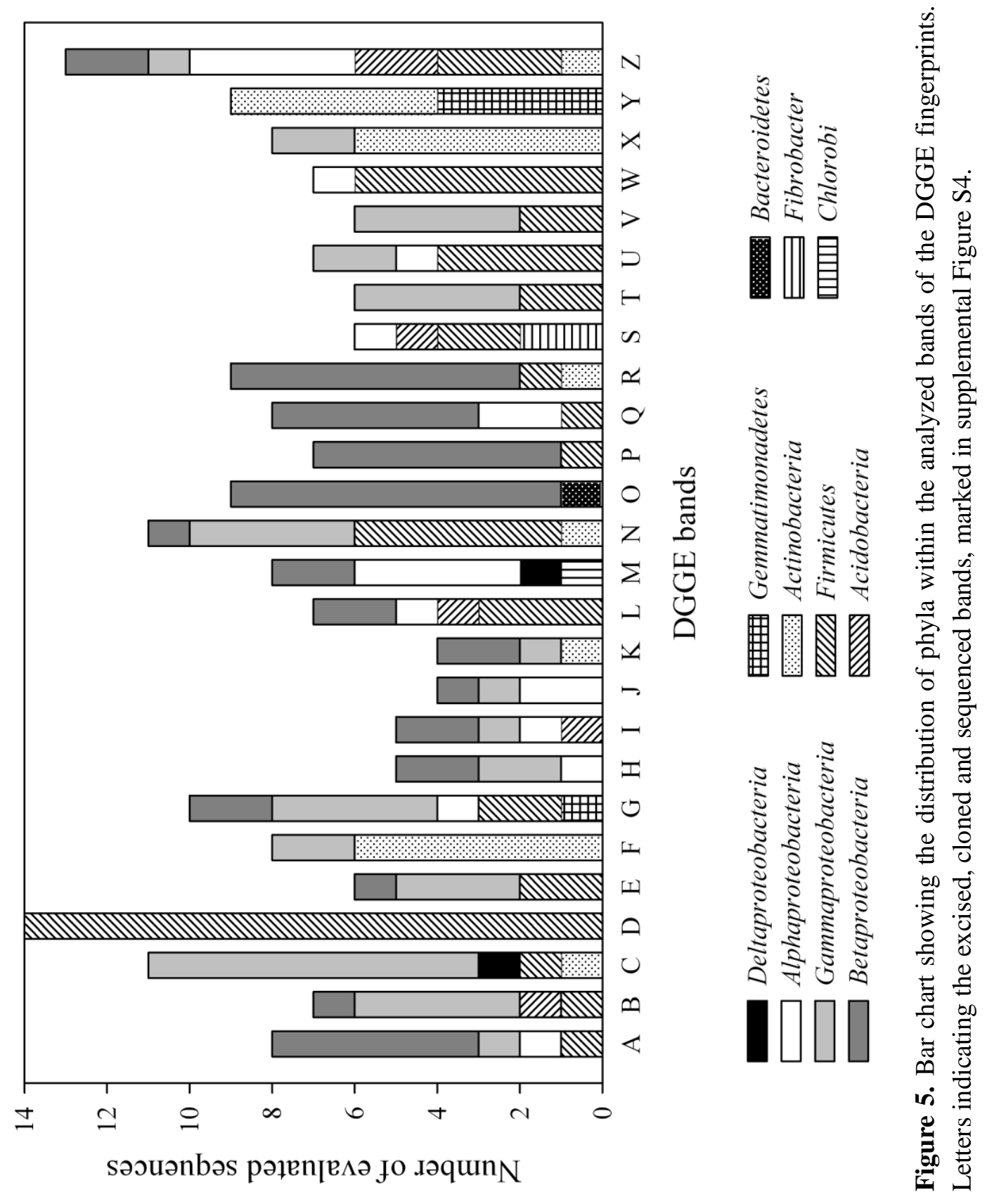




\section{Discussion}

Aphids feed on the labeled plant phloem sap and the uptake of the ${ }^{15} \mathrm{~N}$ isotopes by aphids was measured in aphids' tissue. The labeling procedure of plants increased the $\delta^{15} \mathrm{~N}$ content in aphids by $97 \%$, but the infection of $P$. vulgaris by aphids reduced $\delta^{15} \mathrm{~N}$ values of shoots by $34 \%$, suggesting that aphids reduced uptake of ${ }^{15} \mathrm{~N}$ added. Altogether, labeling the host plant of aphids allowed us to follow the nitrogen flow via honeydew, litter, and soil between the different compartments within the microcosms.

Ants collect the honeydew to cover their demand on carbohydrates. The initial value of ants and larvae at the start of the experiment was nearly equal between ants $(2.4 \%)$ and their larvae $(2.3 \%)$. At the end of the experiment larvae and adult workers had incorporated the $\delta^{15} \mathrm{~N}$ isotope into their tissue (5.6\% and $16.9 \%$, respectively). The crop content of workers could not be responsible for isotope signature, because plants and aphids were removed five days before ants were collected and the crops should have been empty. The increase of $\delta^{15} \mathrm{~N}$ in workers may reflect the larval diet, as ants are holometabolous insects, which obtain their biomass mainly during the larval stage (Blüthgen et al., 2003).

In our study, no changes in aphid colony biomass were detected due to ant presence, but attendance led to the development of significantly more alate aphids. This result indicated that ants promoted aphids' spreading during the experiment. Contrary to our results, recent studies have found that the occurrence of winged adults is negatively associated with ant attendance (Dixon, 1998; Kindlmann et al., 2007). During the experiment $61 \%$ of the workers died and $56 \%$ of the larvae died or developed to adult workers, what lead to lower honeydew and protein demand of ant colonies and consequently to less tending on aphids Decreasing ant activity on previously tended aphid colonies could have stimulated the production of winged individuals.

Microbial biomass and basal respiration in the litter layer depended on aphid and ant activity. Compared to the control, aphid presence led to significantly higher microbial biomass in the litter layer suggesting that honeydew dropping to the ground beneficially affected litter microorganism. Presence of ants annihilated this link between aphids and litter microorganisms. Presumably, this was due to collection of honeydew by the ants thereby reducing the amount of honeydew dropping to the ground. When aphids are tended by ants, they often increase the frequency of honeydew excretion to increase attractiveness to ants. Moreover, the honeydew of tended aphids contains significantly higher concentration of amino acids (Yao and Akimoto, 2002), sucrose and trehalose 
(Yao and Akimoto, 2001). Llewllyn and Leckstein (1978) reported that unattended larval A. fabae reared on broad beans utilized $54 \%$ of their energy intake for growth, 4 $\%$ was lost during respiration and $42 \%$ was excreted as honeydew. Wellenstein (1980) reported that under natural conditions approximately $1 / 3$ of the honeydew produced by aphids is falling to the ground with ants reducing the amount of honeydew dropping to the soil by about $50 \%$ (Seeger and Filser, 2008). Honeydew and its varying amounts and ingredients due to ant attendance can also have effects in the belowground system. The presence of ants significantly increased $\delta^{15} \mathrm{~N}$ content $(P$. vulgaris side and A. elatius side) and basal respiration ( $P$. vulgaris side and ground samples) in the soil, indicating that ant activity increase the transport from the aboveground to the belowground system. Significantly increased microbial biomass and basal respiration in natural $L$. flavus nests in comparison to the surrounding soils were reported in a study carried out by Platner (2006) in a calcareous grassland. The increase of these soil parameters due to ant presence might be caused by the intake of prey and mixing soil and litter due to nest construction (Skinner, 1980).

Further molecular analysis to investigate the bacterial community composition using PCR-DGGE and cluster analysis of the obtained fingerprints revealed no clear differences among the different treatments, as well as among the control. Patterns D and W, which appeared at the same height, predominantly occur in treatments with honeydew. Sequence analysis revealed that the obtained sequences could be attributed to the type strain Bacillales bacterium Gsoil $1105^{\mathrm{T}}$ of the genus Tumebacillius (Firmicutes), that is known to assimilate sucrose, among other sugars (Baek et al., 2011). We also identified the family Oxalobacteraceae (Burkholderia), which is metabolic divers and has some nitrogen fixing members. Most of these sequences showed identities between $98-100 \%$ to the genus Massilia, which is known to utilize the amino acid L-alanin as well as some sugars as L-arabinose, cellobiose, maltose and mannose (La Scola et al., 1998). Additionally the genus Arenimonas was identified within our microcosms, as well as in the controls. Kwon et al. (2007) proposed this genus, belonging to the family Xanthomonadaceae. It was shown that members of the genus Arenimonas are able to hydrolyze the amino acids, arginine and phenylalanine (Kwon et al., 2007; Aslam et al., 2009). Sugar-rich honeydew is a readily available resource that also provides amino acids for microorganisms and that can be consumed rapidly. It has been assumed that beside other substrates, the most common limiting factor for microbial growth in soils is the lack of carbon (Scheu and Schaefer, 1998). 
The additional input of sugars and nitrogen-rich organic compounds into the soil, promoted by ants supports prokaryotic organisms, which degrade these substances. Thus the ant effect on soil bacterial communities can be more pronounced in natural systems, where the ants`impact is longer established. 


\section{Conclusions}

The $\delta^{15} \mathrm{~N}$ signal of plants spread from aphids to honeydew to ants. We followed the $\delta^{15} \mathrm{~N}$ trace from the aboveground to the belowground system into the litter and, into the soil in the presence of ants. Without ants, honeydew increased the biomass of litter microorganisms, whereas ant presence altered honeydew amounts in the litter and consequently biomass of litter and also soil microorganisms. In ground soil, honeydew increased the abundance of the already existing soil bacterial populations, whereas ants promoted a more balanced structure between populations, but with different patterns. In this experiment, we could show, that aphids can increase nutrient availability for microorganisms inhabiting the litter and that ants alter the nutrient flow within the system and transfer of nutrients into soil. Thus, aphids have a strong impact on the belowground system, nutrient availability and microbial communities, and this effect is highly dependent on the tending activity of ants.

\section{Acknowledgements}

We thank Matthias Schaefer, Sonja Migge-Kleian and Carola Simon for valuable discussions and comments on the manuscript. The work of R. D. and B. P. was supported by the *Functional biodiversity research 1 b-cluster of excellence*, which is funded by the Ministry of Science and Culture of Lower Saxony and the "Niedersächsisches Vorab". 


\section{References}

Altschul, S.F., Gish, W., Miller, W., Myers, E.W., Lipman, D.J., 1990. Basic local alignment search tool. J. Mol. Biol. 215, 403-410.

Anderson, J.P.E., Domsch, K.H., 1978. A physiological method for the quantitative measurement of microbial biomass in soils. Soil Biol. Biochem. 10, 215-221.

Anderson, C., McShea, D.W., 2001. Intermediate-level parts in insect societies: adaptive structures that ants build away from the nest. Insectes Soc. 48, 291301.

Aslam, Z., Park, J.H., Kim, S.W., Jeon, C.O., Chung, Y.R., 2009. Arenimonas oryziterrae sp. nov., isolated from a field of rice (Oryza sativa L.) managed under a no-tillage regime, and reclassification of Aspromonas composti as Arenimonas composti comb. nov. Int. J. Syst. Evol. Microbiol. 59, 2967-2972.

Baek, S.-H., Cui, Y., Kim, S.-C., Cui, C.-H., Yin, C., Lee, S.-T., and Im, W.-T., 2011. Tumebacillus ginsengisoli sp. nov., isolated from soil of a ginseng field. Int. J. Syst. Evol. Microbiol. 61, 1715-1719.

Banks, J.C., 1962. Effects of the ant Lasius niger (L.) on insects preying on small populations of Aphis fabae (Scop.) on bean plants. Ann. Appl. Biol. 50, 669679.

Banks, J.C., Macaulay, E.D.M., 1967. Effects of Aphis fabae (Scop.) and of its attendant ants and insects predators on yields of field beans (Vicia faba L.). Ann. Appl. Biol. 60, 445-453.

Blüthgen, N., Gebauer, G., Fiedler, K., 2003. Disentangling a rainforest food web using stable isotopes: dietary diversity in a species-rich ant community. Oecologia $137,426-435$.

Brian, M.V., 1983. Social insects. Chapman and Hall, London.

Bristow, C.M., 1984. Differential benefits from ant attendance to two species of Homoptera on New York iron weed. J. Anim. Ecol. 53, 775-726.

Bronstein, J.L., 1994. Conditional outcomes in mutualistic interactions. Trends Ecol. Evol. 9, 214-217.

Choudhury, Y.D., 1985. Aphid honeydew - a reappraisal of Owen and Wiegert Hypotheses. Oikos 45, 287-290.

Cushman, J.H., Addicot, J.F., 1991. Conditional interactions in ant-herbivore mutualism. In: Ant-plant interactions. Ed. by Huxley CR, Cutler DF, Oxford University Press, Oxford, 92-119. 
Cushman, J.H., Whitham, T.G., 1991. Competition mediating the outcome of a mutualism: protective services of ants as a limiting resource for membracids. Am. Nat. 138, 789-797.

Dixon, A.F.G., Agarwala, B.K., 1999. Ladybird-induced life-history changes in aphids. Proc. R. Soc. Lond B 266, 1549-1553.

Fischer, M.K., Shingleton, A.W., 2001. Host plant and ants influence the honeydew sugar composition of aphids. Funct. Ecol. 15, 544550.

Fischer, R.C., Ölzand, S.M., Wanek, W., Mayer, V., 2005a. The fate of Corydalis cava elaiosomes within an ant colony of Myrmica rubra: elaiosomes are preferentially fed to larvae. Insec. Soc. 52, 55-62.

Fischer, M.K., Völk1, W., Hoffmann, H., 2005b. Honeydew production and honeydew sugar composition of polyphagous black bean aphid, Aphis fabae (Hemiptera, Aphididae) on various host plants and implications for ant attendance. Eur. J. Entomol. 102, 155-160.

Hölldobler, B., Wilson, E.O., 1990. The ants. Springer, Berlin, Heidelberg, New York.

Jones, C.G., Lawton, J.H., Shachak, M., 1994. Organisms as ecosystem engineers. Oikos 69, 373-386.

Kindlmann, P., Hullé, M., Stadler, B., 2007. Timing of dispersal: effects of ants on aphids. Oecologia 152, 625-631.

Kunert, G., Weisser, W.W., 2003. The interplay between density- and trait mediated effects in predator-prey interactions: a case study in aphid wing polymorphism. Oecologia 135, 304-312.

Kwon, S.W., Kim, B.Y., Weon, H.Y., Baek, Y.K., Go, S.J., 2007. Arenimonas donghaensis gen. nov., sp. nov., isolated from seashore sand. Int. J. Syst. Evol. Microbiol. 57, 954-958.

La Scola, B., Birtles, R..J., Mallet, M.-N., Raoult, D., 1998. Massilia timonae gen. nov., sp. nov., isolated from blood of an immunocompromised patient with cerebellar lesions. J. Clin. Microbiol. 36, 2847-2852.

Letourneau, D.K., Dyer, L.A., 1998. Experimental test in lowland tropical forest shows top-down effects through four trophic levels. Ecology 79, 1678-1687.

Llewellyn, M., Leckstein, P.M., 1978. A comparison of energy budgets and growth efficiency for Aphis fabae Scop. reared on synthetic diets with aphids reared on broad beans. Ent. exp. and appl. 23, 66-71. 
Lobry de Bruyn, L.A., Conacher, A.J., 1990 The role of termites and ants in soil modification: a review. Aust. J. Soil Res. 28, 55-93.

Morales, M.A., 2000. Survivorship of ant-tended membracid as a function of ant recruitment. Oikos 90, 469-476.

Müller, C.B., Godfray, H.C.J., 1999. Predators and mutualists influence the exclusion of aphid species from natural communities. Oecologia 119, 120-125.

Muyzer, G., Teske, A., Wirsen, C.O., Jannasch, H.W., 1995. Phylogenetic relationships of Thiomicrospira species and their identification in deep-sea hydrothermal vent samples by denaturing gradient gel electrophoresis of $16 \mathrm{~S}$ rDNA fragments. Arch. Microbiol. 164, 165-172.

Muyzer, G., Smalla, K., 1998. Application of denaturing gradient gel electrophoresis (DGGE) and temperature gradient gel electrophoresis (TGGE) in microbial ecology. Antonie van Leewenhoek 73, 127-141.

Pêtal, J., 1998. The influence of ants on carbon and nitrogen mineralization in drained fen soil. Appl. Soil Ecol. 9, 271-275.

Platner, C., 2006. Ameisen als Schlüsseltiergruppe in einem Grasland. Studien zu ihrer Bedeutung für die Tiergemeinschaft, das Nahrungsnetz und das Ökosystem. Biodiversity and Ecology Series 1, Universitätsverlag, Göttingen.

Pontin, A.J., 1958. A preliminary note on the eating of aphids by ants of the genus Lasius (Hym., Formicidae). Entomol. Monthly Mag. 94, 9-11.

Post, D.M., 2002. Using stable isotopes to estimate trophic position: models methods and assumptions. Ecology 83, 703-718.

Pruesse, E., Quast, C., Knittel, K., Fuchs, B.M., Ludwig, W., Peplies, J., Glöckner, F.O., 2007. SILVA: a comprehensive online resource for quality checked and aligned ribosomal RNA sequence data compatible with ARB. Nucleic Acids Res. 35, 7188-7196

Sanders, D., Platner, C., 2007. Intraguild interactions between spiders and ants and topdown control in a grassland food web. Oecologia 150, 611-624.

Scheiner, S.M., 2001. Manova. In: Scheiner, S.M., Gurevitch, J.: Design and Analysis of Ecological Experiments. 2nd ed. Oxford University Press, Oxford, New York.

Scheu, S., 1992. Automated measurement of the respiratory response of soil microcompartments: active microbial biomass in earthworm faeces. Soil Biol. Biochem. 24, 1113-1118. 
Scheu, S., Schaefer, M., 1998. Bottom-up control of the soil macrofauna community in a beechwood on limestone: Manipulation of food resources. Ecology 79, 15731585 .

Schmidt, O., Scrimgeour, C.M., 2001. A simple urea leaf-feeding method for the production of 13C and 15N labelled plant material. Plant Soil 229, 197-202.

Schumacher, E., Platner, C., 2009. Nutrient dynamics in a tritrophic system of ants, aphids and beans. J. Appl. Entomol. 133, 33-46.

Seeger, J., Filser, J., 2008. Bottom-up down from the top: Honeydew as a carbon source for soil organisms. Eur. J. Soil Biol. 44, 483-490.

Skinner, G.J., 1980. The Feeding Habits of the Wood-Ant, Formica rufa (Hymenoptera: Formicidae), in Limestone Woodland in North-West England. J. Anim. Ecol. 49, 417-433.

Stadler, B., Dixon, A.F.B., 2005. Ecology and evolution of aphid-ant interactions. Ann. Rev. Ecol. Evol. Syst. 36, 345-372.

Stadler, B., Schramm, A., Kalbitz, K., 2006. Ant-mediated effect on spruce litter decomposition, solution chemistry, and microbial activity. Soil Biol. Biochem. $38,561-572$.

Sokal, R.R., Rohlf, F.J., 2001. Biometry. 4th edition. WH Freeman and Co., New York.

Tillberg, C.V., McCarthy, D.P., Dolezal, A.G., Suarez, A.V., 2006. Measuring the trophic ecology of ants using stable isotopes. Insect. Soc. 53, 65-69.

Völkl, W., Woodring, J., Fischer, M., Lorenz, M.W., Hoffmann, K.H., 1999. Ant-aphid mutualisms: the impact of honeydew production and honeydew sugar composition on ant preferences. Oecologia 118, 483-491.

Way, M.J., 1954. Studies on the association of the ant Oecophylla longinoda (Latr.) (Formicidae) with the scale insect Saissetia zanzibarensis Williams (Coccidae). Bull. Entomol. Res. 45, 113-134.

Way, M.J., 1963. Mutualism between ants and honeydew-producing Homoptera. Ann. Rev. Entomol. 8, 307-344.

Wellenstein, G., 1980. Auswirkung hügelbauender Waldameisen der Formica rufaGruppe auf forstschädliche Raupen und das Wachstum der Waldbäume. Z. Ang. Entomol. 89, 144-157.

Woodring, J., Wiedemann, R., Fischer, M.K., Hoffmann, K.H., Völkl, W., 2004. Honeydew amino acids in relation to sugars and their role in the establishment of 
ant-attendance hierarchy in eight species of aphids feeding on tansy (Tanacetum vulgare). Physiol. Entomol. 29, 311-319.

Yao, I., Akimoto, S., 2001. Ant attendance changes the sugar composition of the honeydew of the drepanosiphid aphid Tuberculatus quercicola. Oecologia 128, $36-43$.

Yao, I., Akimoto, S.-I., 2002. Flexibility in the composition and concentration of amino acids in honeydew of the drepanosiphid aphid Tuberculata quericola. Ecol. Entomol. 27, 745-752. 


\subsection{Supplementary data}

Figure S1 Experimental set-up, showing the microcosm harboring the ant population (=A. elatius side) and the pot harboring the Phaseolus vulgaris L. seedlings infested with Aphis fabae Scopoli (=P. vulgaris side).

Figure S2 Illustration of the effects of aphids and aphid honeydew on the litter and the soil of the $P$. vulgaris side, the A. elatius side and the ground soil, as well as on the $P$. vulgaris and A. elatius plants. Effects determined by comparison of external 'control' without aphids and treatment with aphids and without ants and pane ('A-H+').

Figure S3 Graphical summary of the effects of ants and aphid honeydew on the soil of the $P$. vulgaris and A. elatius sides, as well as the ground soil of experimental treatments.

Figure S4 DGGE profiles (A. and B.) derived from the bacterial community of the ground soil of the four different treatments. For each sample $500 \mathrm{ng}$ of PCR product were applied to a DGGE gel containing $9 \%$ acrylamide and 45 to $60 \%$ denaturant. The excised and sequenced banding patterns (Fig. 5) are marked. The different treatments are indicated as follows: A- = without ants; $\mathrm{A}+=$ with ants; $\mathrm{H}-$ without honeydew; $\mathrm{H}+$ with honeydew; control = without any treatment. 


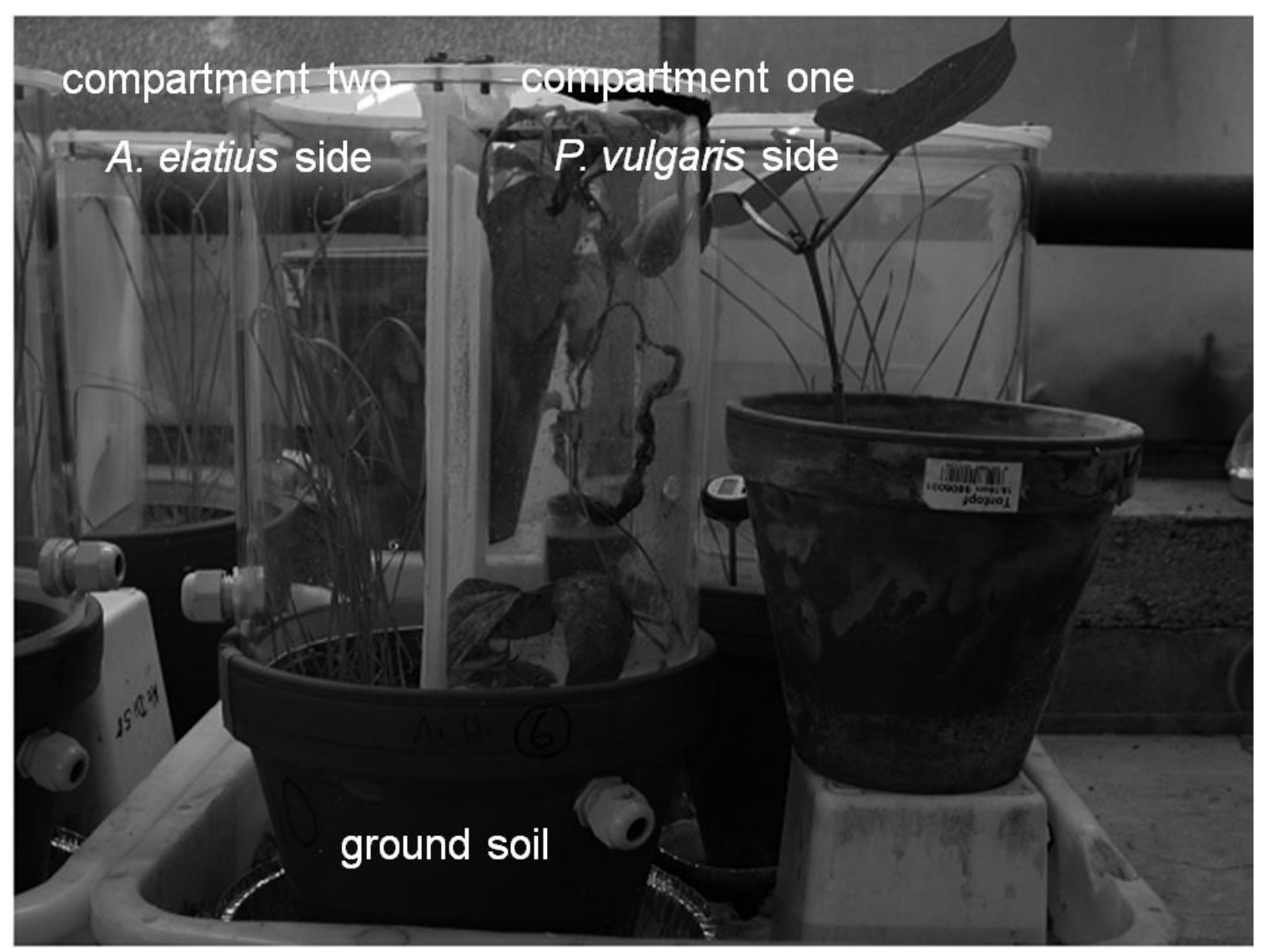

Figure S1. Experimental set-up, showing the microcosm harboring the ant population (=A. elatius side) and the pot harboring the Phaseolus vulgaris L. seedlings infested with Aphis fabae Scopoli (=P. vulgaris side). 


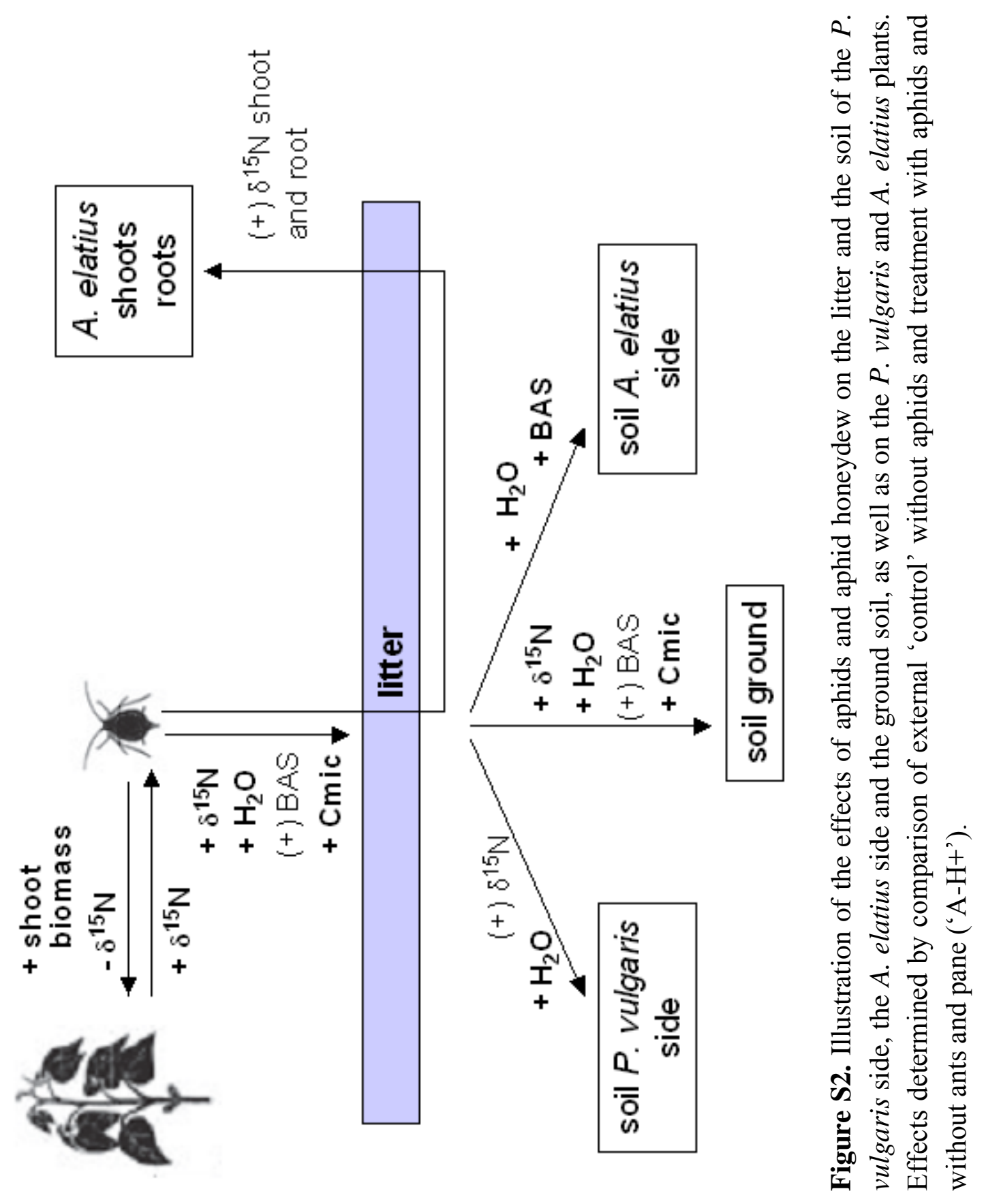




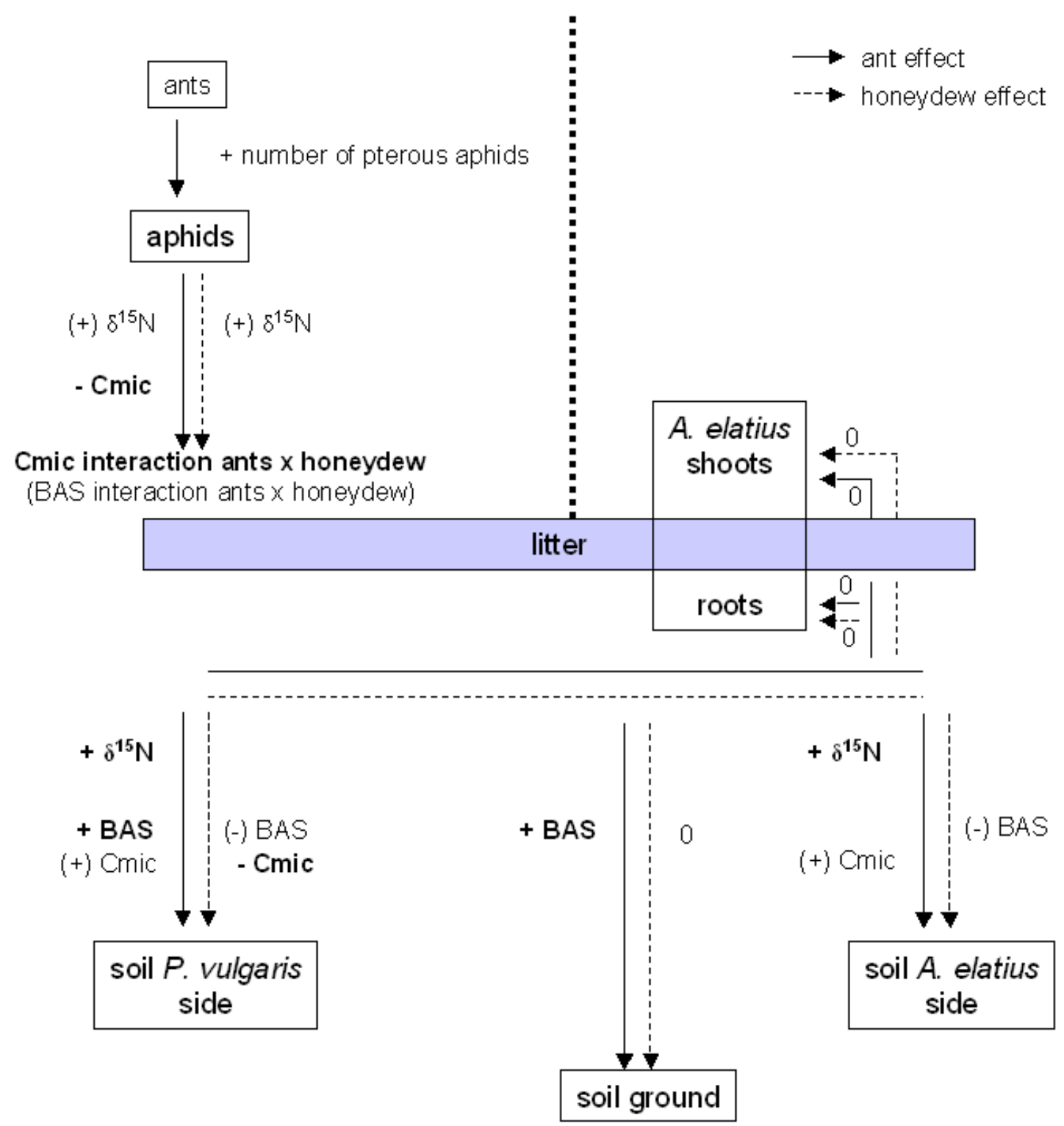

Figure S3. Graphical summary of the effects of ants and aphid honeydew on the soil of the $P$. vulgaris and A. elatius sides, as well as the ground soil of experimental treatments. 




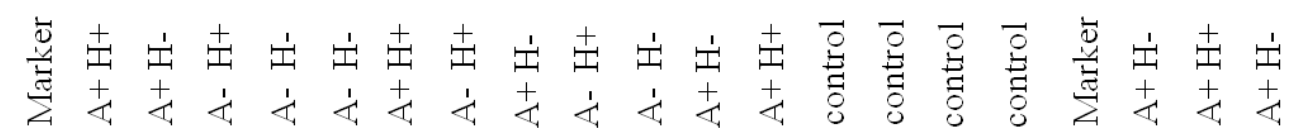

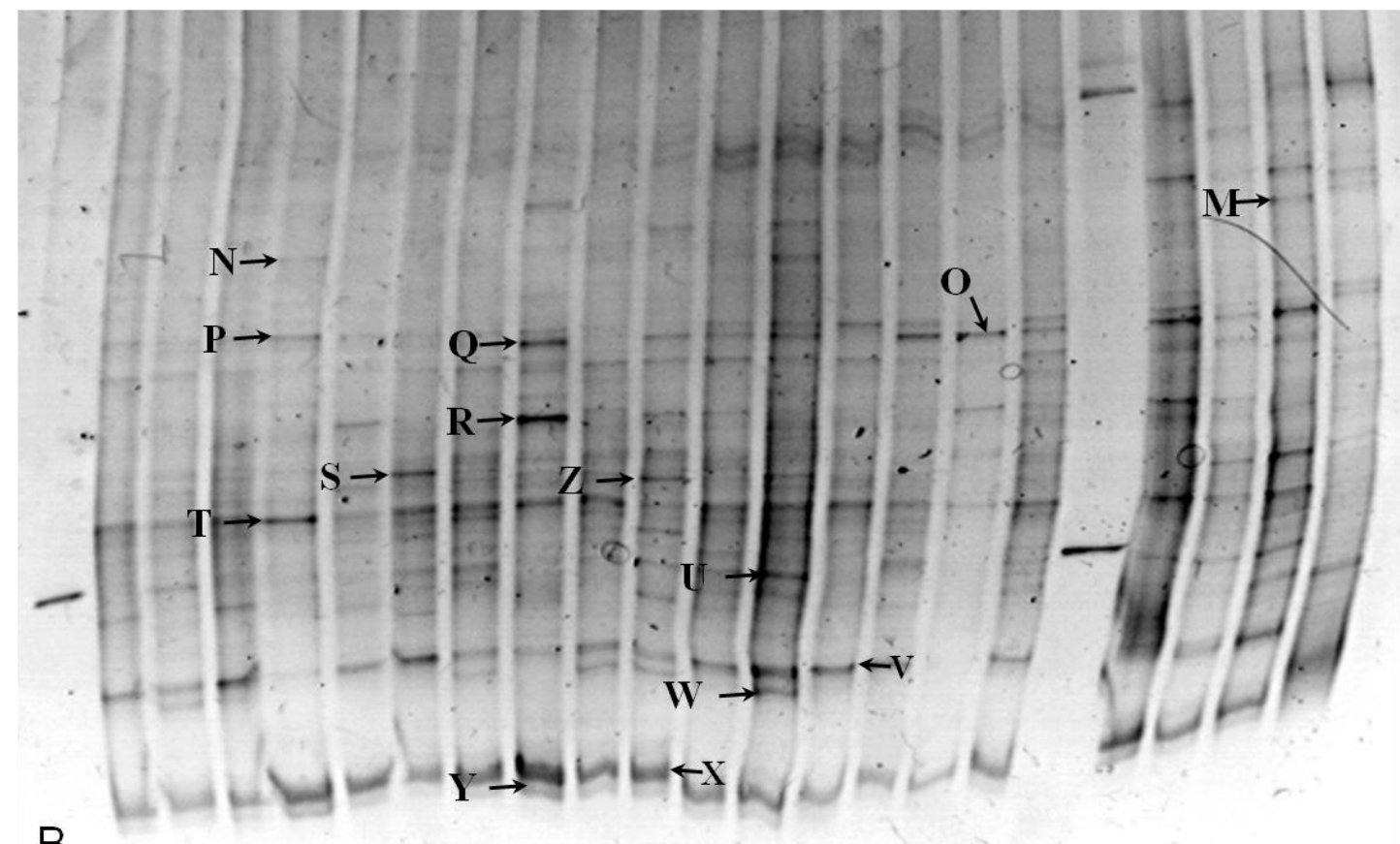

B.

Figure S4. DGGE profiles (A. and B.) derived from the bacterial community of the ground soil of the four different treatments. For each sample $500 \mathrm{ng}$ of PCR product were applied to a DGGE gel containing $9 \%$ acrylamide and 45 to $60 \%$ denaturant. The excised and sequenced banding patterns (Fig. 5) are marked. The different treatments are indicated as follows: $\mathrm{A}-=$ without ants; $\mathrm{A}+=$ with ants; $\mathrm{H}-$ without honeydew; $\mathrm{H}+$ with honeydew; control $=$ without any treatment. 
2.

\title{
Influence of Lasius ants on soil microbial communities in grasslands - a functional and molecular approach
}

\author{
Evelyn Gerund ${ }^{1}$, Birgit Pfeiffer ${ }^{2}$, Rolf Daniel $^{2}$, and Christian Platner ${ }^{1,3}$
}

Manuscript draft

1) Abteilung Ökologie, Johann-Friedrich-Blumenbach Institut für Zoologie und Anthropologie, Georg-August-Universität, Berliner Str. 28, 37073 Göttingen, Germany

${ }^{2)}$ Genomic and Applied Microbiology, University of Göttingen, Grisebachstr. 8, 37077 Göttingen, Germany

${ }^{3)}$ Experimentelle Ökologie und Ökosystembiologie, Universität Bielefeld, Universitätsstr. 25, 33615 Bielefeld, Germany

Author contributions to the work:

Performed the experiments: E. Gerund, B. Pfeiffer

Analyzed the data: E. Gerund, B. Pfeiffer

Wrote the paper: $\quad$ E. Gerund, B. Pfeiffer, C. Platner, R. Daniel

Conceived and designed the experiments: C. Platner, R. Daniel 


\title{
Graphical Abstract
}
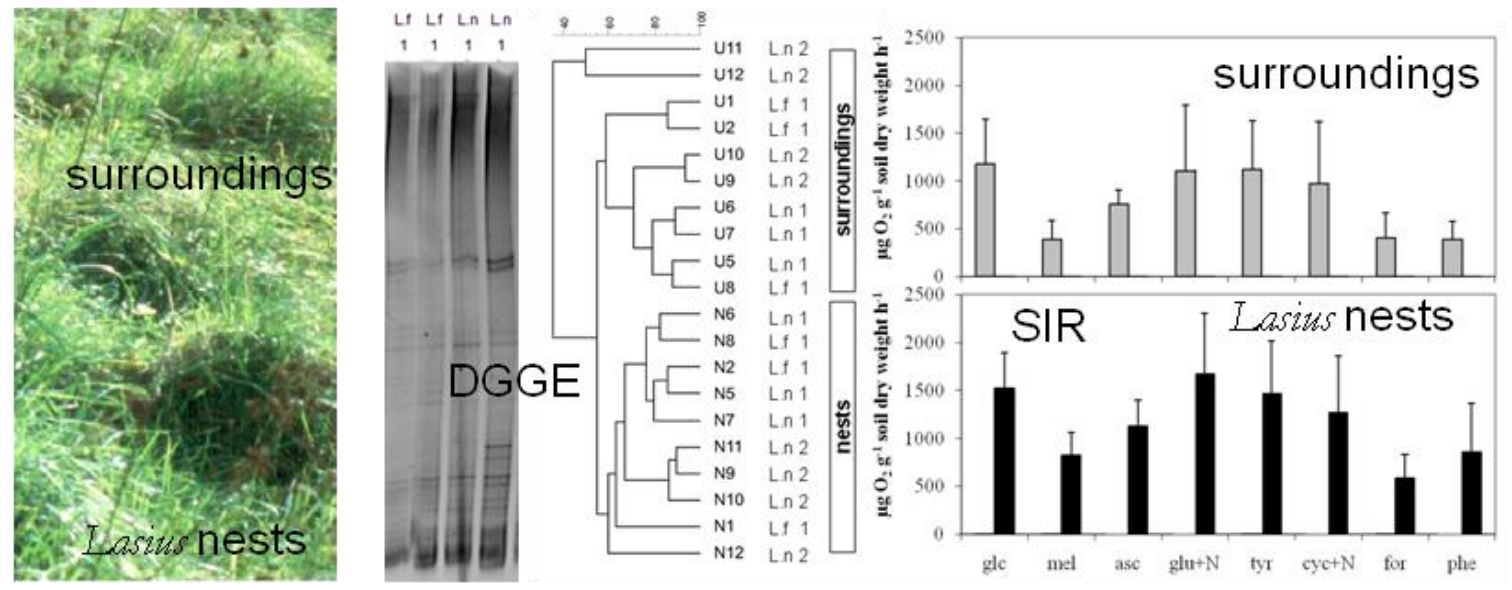

\begin{abstract}
Ants are recognized as one of the most functionally important and ecologically dominant animal groups in soils, but their influence on microbial diversity remains under-explored. We studied functional diversity of microorganisms in Lasius ant nests and surrounding soil from two different grassland habitats (Leptosol and Cambisol) by in situ respiration response. The degree of substrate usage of microorganisms varied with ant presence. Soil microorganisms present in ant nests preferred using ant-related substances such as melecitose, formic acid and phenylic acid. The enhanced initial respiratory response and cumulative respiration in nests compared to surrounding soil after addition of most substrates was more pronounced at the Cambisol site than at the Leptosol site. Denaturing gradient gel electrophoresis (DGGE) indicated differences in bacterial community composition. The results indicate that ants affect the structure and functioning of bacterial communities in grassland by nest building and providing organic substances. Furthermore, soil-nesting ants intensify differences in soil conditions and thereby enhance the overall habitat diversity for the microbial community. Variations in the impact of Lasius ants on soil microorganisms were more pronounced between grassland habitats than between ants of different life form (Lasius niger and L. flavus).
\end{abstract}

\section{Keywords}

Formicidae; Ant mounds; Microbial activity; Physiological profile; Substrate-induced respiration; Soil bacterial communities 


\section{Introduction}

Soil organisms are embedded in complex food webs that are fuelled by dead plant matter (detritus) and living plant roots (Wardle et al., 2004). These organisms are important structuring forces of belowground terrestrial ecosystems and drive decomposition, nutrient cycling and plant nutrition (Bardgett et al., 2005), thereby affecting plants and their consumers. Soil microorganisms form the base of soil food webs and they provide nutrients for plants and regulate populations of other soil organisms. Therefore, they are crucial for carbon (C) and nitrogen $(\mathrm{N})$ cycling. Shifts in the activity of microbial communities due to environmental changes (e.g., soil management and climate change) have lasting effects on ecosystem functioning (Emmerling et al., 2002). Ants are important ecosystem engineers changing their habitat through nest building (Jones et al., 1994; Dauber and Wolters, 2000). Uptake of organic substances and foraging activities lead to the accumulation of nutrients within their nests (Wagner et al., 1997; Nkem et al., 2000). Thus, ants alter the resource availability of organisms that are less mobile and dependent on nutrients in their immediate vicinity. High nutrient availability in ant nests generates 'hot spots' for microbial activity that enhance nutrient turnover, soil fertility, primary productivity as well as plant and herbivore biomass. Bottom-up effects via increased nutrient input have been found to increase the number of juvenile Collembola and changed the community composition of spiders (Fountain et al., 2008). Thus, ants can induce a nutrient-based bottom-up effect on higher trophic level in aboveground as well as in belowground systems (Platner, 2006).

In this study, we analysed microbial community functioning by measuring the response of microorganisms to an array of different substrates added to soil from Lasius ant nest mounds and surrounding soil (physiological profiles). Further, microbial community structure was assessed by denaturing gradient gel electrophoresis (DGGE).soil from Lasius ant nest mounds and surrounding soil (physiological profiles). Further, microbial community structure was assessed by denaturing gradient gel electrophoresis (DGGE). 


\section{Material and Methods}

\section{Sampling sites}

We chose two sampling locations with different soil characteristics and sampled Lasius ant nests and surrounding soil. A total of 10 Lasius ant nests were sampled in September 2007. The first sampling site (site 1) was located on the southwest facing slope of the Werra valley (Witzenhausen Freudenthal, Northern Hessen, Germany). The site is characterised by dry calcareous grassland at $180 \mathrm{~m}$ a.s.l. Three Lasius niger nests and three Lasius flavus nests were sampled. The former pasture at site 1 was abandoned 20 years ago and the soil is now a shallow Rendzina (Leptosol) on Triassic limestone with a diverse herb layer dominated by Brachypodium pinnatum L. with a soil $\mathrm{pH}$ of 7.4, mean annual temperature of $9{ }^{\circ} \mathrm{C}$ and average annual precipitation of $700 \mathrm{~mm}$ (Platner, 2006).

The second sampling site (site 2) was located $3 \mathrm{~km}$ south of Göttingen (Lower Saxony, Northern Germany) near the river Leine at $160 \mathrm{~m}$ a.s.l. Only Lasius niger nests were present at this site, of which four were chosen randomly. The area was an abandoned grassland site dominated by Picris hieracioides L. The soil was a Cambisol on a loamy floodplain consisting on clayey silt of a soil $\mathrm{pH}$ of 7.5, mean annual temperature of 8.7 ${ }^{\circ} \mathrm{C}$ and average annual precipitation of $639 \mathrm{~mm}$ (Schuch et al., 2009).

Nest samples were taken to a depth of $10 \mathrm{~cm}$ from the middle of nest hill; control soil samples were taken at a distance of $1 \mathrm{~m}$ from the nest. Samples were sieved $(4 \mathrm{~mm})$ and stored at field moisture at $5{ }^{\circ} \mathrm{C}$.

Microbial metabolism

The microbial community response to eight different substrates, belonging to four groups of organic compounds was investigated. Carbohydrates were added as $\mathrm{D}(+)$ glucose and $\mathrm{D}(+)$-melecitose-monohydrate. Carboxylic acids were added as glutaric-, ascorbic-, formic-, and phenylacetic acid. Additionally, the amino acid L-tyrosine and the polymer $\alpha$-cyclodextrine were used. Substrates were added as aqueous solution adjusting the water content to $70 \%$ (dry weight) and were added equivalent to $3.2 \mathrm{mg} \mathrm{C}$ $\mathrm{g}^{-1}$ soil dry weight. Glutaric acid and cyclodextrine were added together with nitrogen (ammonium sulphate) at a mass ratio of 10:2 (Anderson and Domsch, 1980). We measured physiological profiles of microbial communities of all substrates using an $\mathrm{O}_{2^{-}}$ microcompensation apparatus (Scheu, 1992) at $22{ }^{\circ} \mathrm{C}$ for $48 \mathrm{~h}$. We distinguished the 
maximum initial respiratory response (MIRR) and the cumulative respiration response (CRR) during microbial growth, which reflects the potential catabolic activity of soil microorganism (Scheu et al., 2002). Values for MIRR and CRR were calculated as the difference between samples with substrate addition and the control (no substrate addition; basal respiration, BAS $)$. Microbial biomass $\left(\mathrm{C}_{\text {mic }}\right)$ and specific respiration $\left(\mathrm{BAS} / \mathrm{C}_{\mathrm{mic}}\right)$ was calculated according to the formula given by Beck et al. (1997) for substrate induced respiration.

Lasius flavus and L. niger nest and control soil from site 1 were tested for species effect using a GLM, employing 'ants' to compare nest and control, and 'species' (testing $L$. niger vs. L. flavus) as factors.

We inspected differences in soil conditions between sample sites by comparing control soil from site 1 with site 2 using analysis of variances with 'site' as factor. Basal respiration (BAS), microbial biomass $\left(\mathrm{C}_{\text {mic }}\right)$, initial respiration response (MIRR) and cumulative respiration (CRR) were analyzed employing GLM with 'ants' and 'site' as factors (Sokal and Rohlf, 2001). Statistical analysis was carried out using the software SAS 8.1 (SAS Institute Inc., Cary, NC).

Microbial community structure

Microbial community structure was analyzed by denaturing gradient gel electrophoresis (DGGE) of the bacterial community in each nest and the corresponding surrounding soil. Soil samples were stored at $-80{ }^{\circ} \mathrm{C}$ until use. Genomic DNA was isolated from 250 $\mathrm{mg}$ of soil by employing the UltraClean PowerSoil ${ }^{\mathrm{TM}}$ DNA Isolation Kit (MO BIO Laboratories Inc., Carlsbad, CA, USA) according to the manufacturer's protocol. The final DNA elution step was carried out with $100 \mu$ water. The $16 \mathrm{~S}$ rRNA gene was amplified with the universal bacterial primers BAC $341 \mathrm{~F} \quad 5^{\prime}$ CCTACGGGAGGCAGCAG-3') and BAC 907R (5'-CCGTCAATTCCTTTRAGTTT3) according to Muyzer et al. (1995) and Muyzer and Smalla (1998). A 40 bp GC clamp (5’-CGCCCGCCGCGCCCCGCGCCCGTCCCGCCGCC-CCCGCCCG-3’) was attached at the 5' end of the forward primer BAC 341F (Muyzer et al., 1995). The PCR mixture $(50 \mu \mathrm{l})$ contained $5 \mu \mathrm{l} 10$-fold polymerase buffer (MBI Fermentas, St. LeonRot, Germany), $200 \mu \mathrm{M}$ of each of the four deoxynucleoside triphosphates, $2 \mathrm{mM}$ $\mathrm{MgCl}_{2}, 2 \mu \mathrm{M}$ of each primer, $1 \mathrm{U}$ of Taq DNA polymerase (MBI Fermentas, St. LeonRot, Germany), and $20 \mathrm{ng}$ soil DNA as template. The following thermal cycling scheme was used: initial denaturation at $95{ }^{\circ} \mathrm{C}$ for $2 \mathrm{~min}, 13$ cycles of denaturation at $94{ }^{\circ} \mathrm{C}$ for 
$1 \mathrm{~min}$, annealing for $1 \mathrm{~min}$ at a decreasing temperature gradient ranging from $64{ }^{\circ} \mathrm{C}$ to $51{ }^{\circ} \mathrm{C}\left(1{ }^{\circ} \mathrm{C}\right.$ decrease per cycle), and extension at $72{ }^{\circ} \mathrm{C}$ for $3 \mathrm{~min}$. Subsequently, 12 cycles of denaturation at $94{ }^{\circ} \mathrm{C}$ for $1 \mathrm{~min}$, annealing for $1 \mathrm{~min}$ at $51{ }^{\circ} \mathrm{C}$, and extension at $72{ }^{\circ} \mathrm{C}$ for $3 \mathrm{~min}$ were performed. Finally, an extension period at $72{ }^{\circ} \mathrm{C}$ for $10 \mathrm{~min}$ was carried out. The PCR products were seperated on $1.5 \%$ Agarose gels and purified using the CyclePure PCR purification kit (Peqlab Biotechnologie GmbH, Erlangen, Germany) following the manufacturer's instructions. The concentration of the purified PCR products was quantified using a NanoDrop ND-1000 spectrophotometer (Peqlab Biotechnologie GmbH, Erlangen, Germany). Subsequently, approximately $500 \mathrm{ng}$ of purified amplicons were separated by electrophoresis using the INGENY phorU system (Ingeny International BV, The Netherlands) applying a $9 \%$ (wt/vol) polyacrylamide gel containing a $45 \%$ to $60 \%$ denaturing gradient (100\% denaturant consisted of $7 \mathrm{M}$ urea and $40 \%$ formamide). Electrophoresis was performed at $60{ }^{\circ} \mathrm{C}$ and $100 \mathrm{~V}$ for $16 \mathrm{~h}$ in one-fold TAE buffer (0.04 M Tris, $0.02 \mathrm{M}$ sodium acetate and $0.001 \mathrm{M}$ disodium), and afterwards the gels were stained with SYBR Gold (Invitrogen, Karlsruhe, Germany) for 30 min. The resulting DGGE profiles were analyzed by using the GelCompare II software (Applied Maths, Kortrijk, Belgium). Patterns were converted into a presenceabsence matrix, and samples were grouped using the UPGMA method. Background subtraction was applied and position tolerance was set at $1 \%$. 


\section{Results and discussion}

Microbial metabolism

Neither basal respiration and microbial biomass nor the cumulative respiration after addition of the different substrates differed significantly between mount materials of the two ant species. Thus, samples from both ant species were pooled for further analyses.

Basal respiration in ant nests was significantly lower than in surrounding soil (2.37 and $3.45 \mu \mathrm{g} \mathrm{O}_{2} \mathrm{~g}^{-1}$ soil dry $\mathrm{wt} \mathrm{h}^{-1}$, respectively; $\mathrm{F}_{1,16}=13.01, \mathrm{p}=0.0024$, factor 'ants' in GLM; Figure 1), whereas microbial biomass was not generally significant affected by ants $\left(\mathrm{F}_{1,16}=1.53, \mathrm{p}=0.2333\right.$, Figure 2$)$. Basal respiration and microbial biomass differed significantly between the two sampling sites, (BAS: $F_{1,16}=38.31, p=<0.0001, C_{\text {mic }}$ : $\mathrm{F}_{1,16}=9.42, \mathrm{p}=0.0073$, factor 'site' in GLM in each case; Figure 1 and 2). A marginal significant 'ants' $\times$ 'site' interaction for microbial biomass $\left(\mathrm{F}_{1,16}=4.02, \mathrm{p}=0.0622\right.$, 'ants' $\times$ 'site' in GLM) indicates that differences between sites were predominantly attributed to an increase in nest microbial biomass in Cambisol soil (site 2) and that the ant effect on soil microorganisms depended on nest site location.

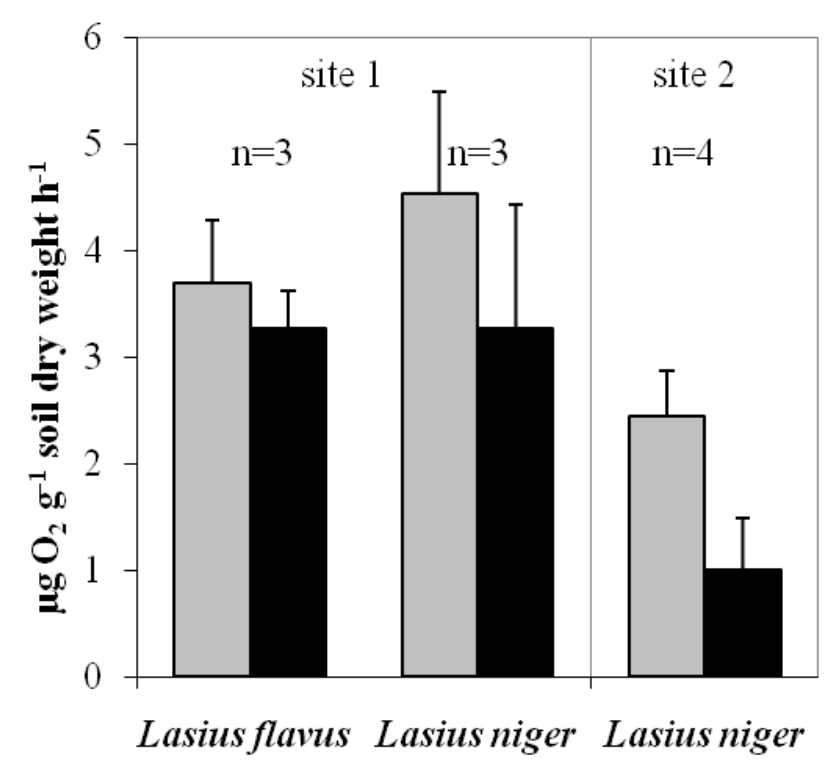

Figure 1. Influence of ants on basal respiration. Control soils are represented by grey bars and ant nests by black bars. Error bars depict standard deviations. 


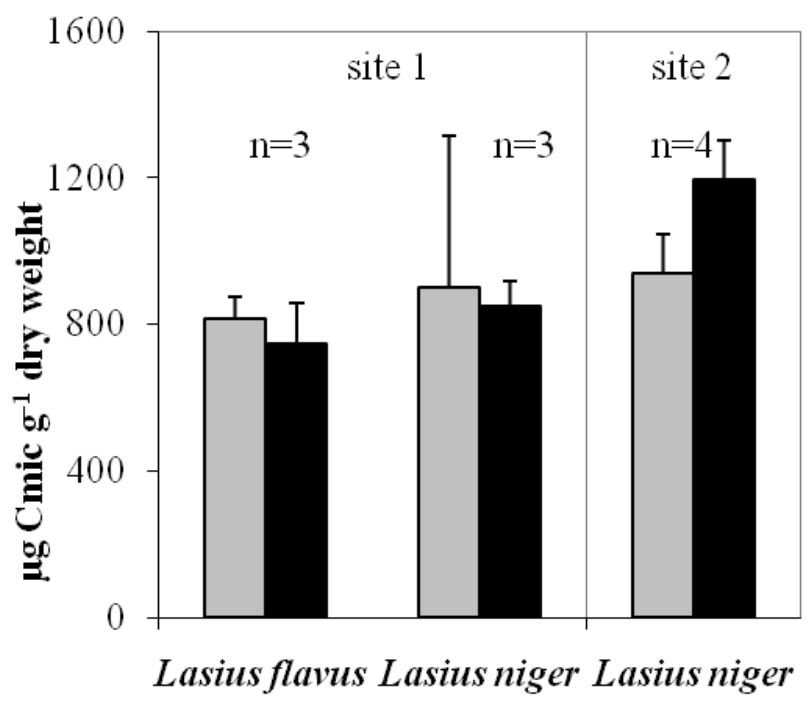

Figure 2. Influence of ants on microbial biomass. Control soils are represented by grey bars and ant nests by black bars. Error bars depict standard deviations.

A separate one-factorial GLM revealed significant differences in microbial biomass between nest and surrounding soil in site $2\left(\mathrm{~F}_{1,6}=11.95, \mathrm{p}=0.0135\right)$ The same trend was also recorded for the specific respiration: microbial biomass comparison between nest and surroundings in site 1 (nest 4.1, surrounding 4.8) revealed no difference, whereas in site 2 a strong decrease was found in ant nests (nest 0.8, surrounding 2.6). The lower specific respiration $\left(B A S / C_{\text {mic }}\right)$ in control soil of site $2\left(2.6 \mu \mathrm{g} \mathrm{O}_{2} \mathrm{~h}^{-1} \mathrm{mg}^{-1} \mathrm{C}_{\text {mic }}\right)$ compared to site $1\left(4.8 \mu \mathrm{g} \mathrm{O}_{2} \mathrm{~h}^{-1} \mathrm{mg}^{-1} \mathrm{C}_{\text {mic }}\right)$ indicates higher resource use efficiency at site 2 (Anderson and Domsch, 1978). Out of the tested soil samples nests in site 2 provide the best conditions for soil microbial development.

Ants can affect the soil microbial community by altering soil conditions and nutrient availability. Accumulation of substances by ants generate 'hot spots' for microorganism by increasing $\mathrm{NO}_{3}-\mathrm{N}$ and $\mathrm{PO}_{4}-\mathrm{P}$ concentrations in nests (Nkem et al., 2000; Platner et al., 2001), but the effect varies with the nutrient status of the soil in which the nests are located (Frouz et al. 2003). For example, pH values in nests increased in acidic soil but decreased in alkaline soil. Additionally, as the content of available phosphorus $(\mathrm{P})$ in the surrounding soil increased the enrichment of $\mathrm{P}$ in the nest was higher than outside the nest.

In ant nests, the initial (MIRR) and cumulative respiratory response (CRR) were higher for each of the substrates, except cyclodextrine, compared to the control soil [MIRR increased by factors of 1.2 (glucose, ascorbic acid), 1.3 (glutaric acid, tyrosine), 1.4 (formic acid) and 1.6 (melecitose, phenylic acid); CRRby factors of 1.3 (glucose, 
tyrosine), 1.4 (formic acid), 1.5 (ascorbic acid, glutaric acid), 2.1 (melecitose) and 2.2 (phenylic acid); Figure 3].
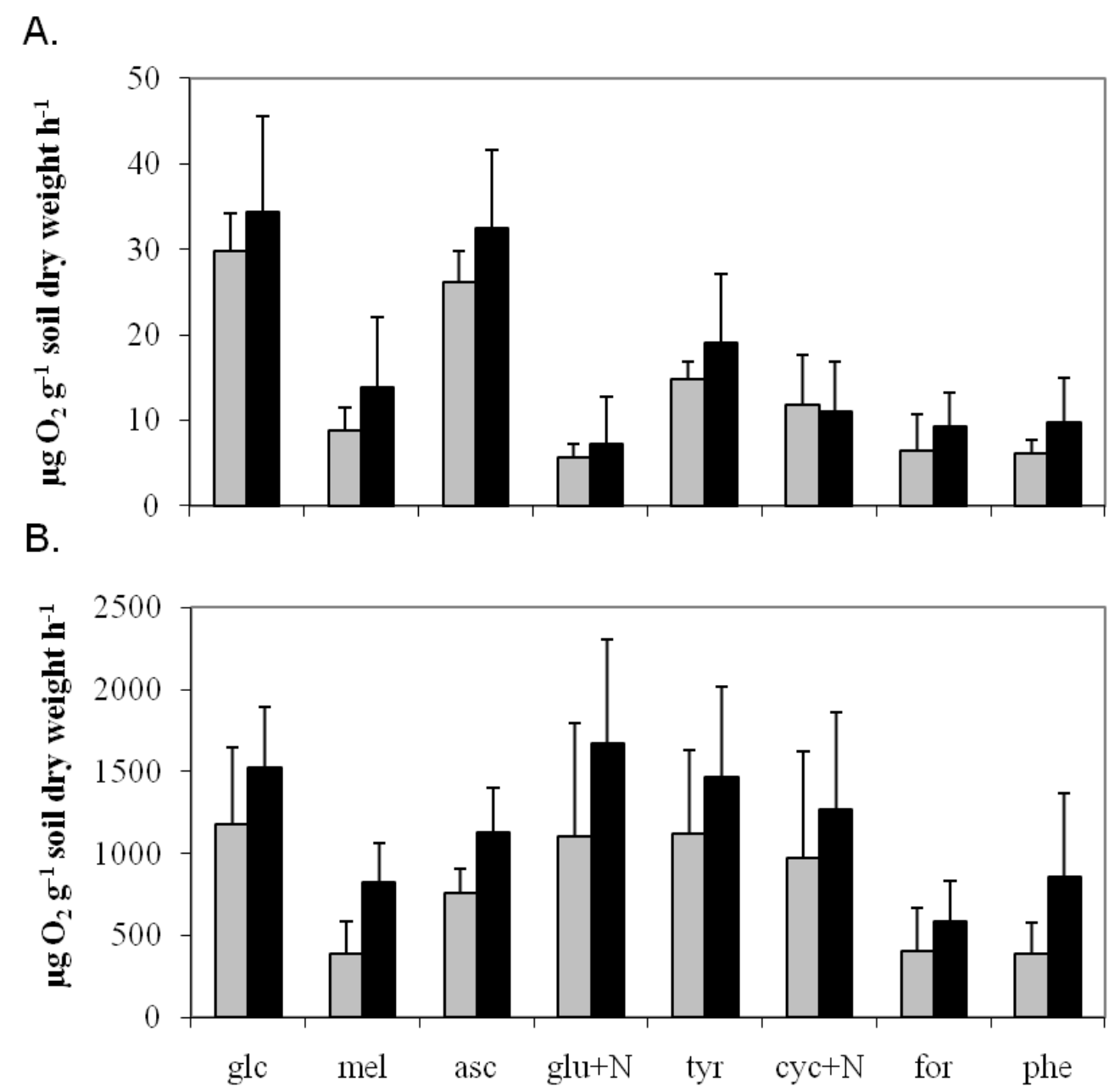

Figure 3. Initial respiration response (MIRR; A.) and integral of respiration response (CRR; B.) after addition of eight different substrates in nests (black bars) and control soils (grey bars). Glc=glucose, mel=melecitose, asc=ascorbic acid, glu=glutaric acid, tyr=tyrosine, cyc $=$ cyclodextrine, for $=$ formic acid, phe $=$ phenylic acid, $+\mathrm{N}=$ added together with ammonium sulphate.

The initial and cumulative respiratory responses to most substances were significantly affected by sampling site (Table 1). The ant effect on MIRR to melecitose, tyrosine, ascorbic and phenylic acid, and the ant effect on CRR toascorbic and phenylic acid was dependent on ant nest location (significant interaction between 'ants' $\times$ 'site' for MIRR and CRR to the different substrates, Table 1). This site effect was predominantly caused by strong response in site 2 and less by changes in site 1 . The strong response of MIRR and CRR in Cambisol soil (site 2) was associated by the high microbial biomass in ant nests at this site. 


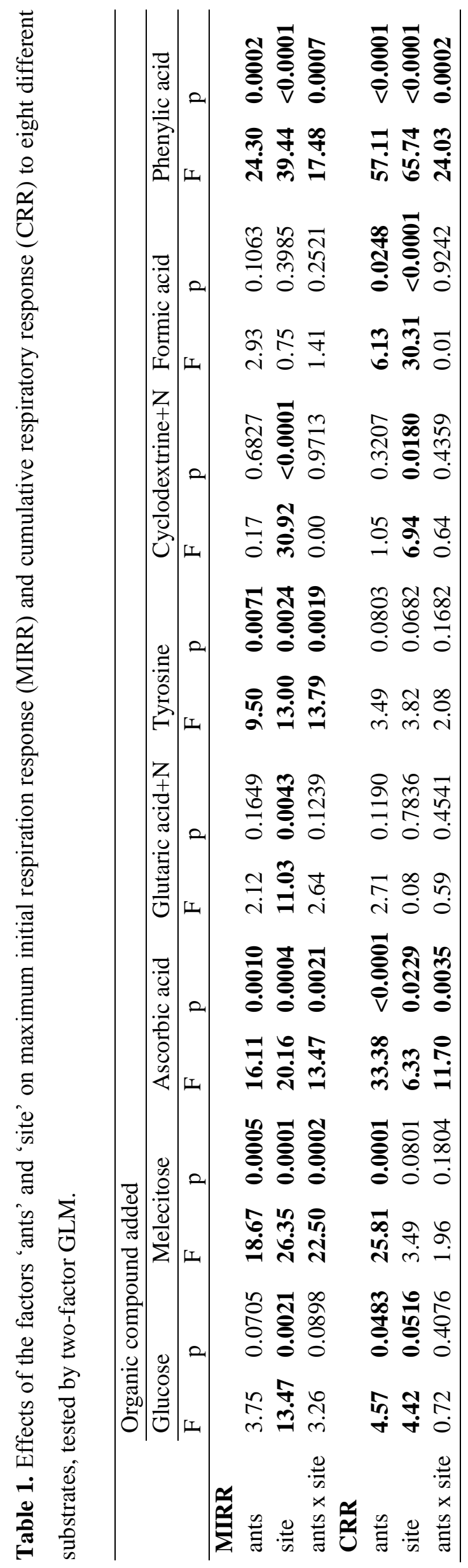


The tested substances included three ant-related substances: melecitose, as the dominant sugar in aphid honeydew (Fischer et al., 2005) to attract ants (Kiss, 1981); and phenylic acid and formic acid, excreted by ants and suspected to have antibiotic properties (Hölldobler and Wilson, 1990). Respiration was highest after addition of these antrelated substrates in ant nest soil from site 2. MIRR increased for melecitose, formic acid, and phenylic acid 2.4-, 2.3-, and 2.1-fold, compared to surrounding soil at site 2, for CRR 2.4-, 1.3-, and 2.7-fold, respectively. Melecitose accounts for $40.5 \%$ of carbohydrates in honeydew of lime aphids (Dighton, 1978). Ants actively tend the aphids and collect their sugar-rich droppings reducing the amount of honeydew that reaches the soil surface by $50 \%$ (Seeger and Filser 2008). Tending activity, the accumulation of prey, organic substances, and the bioturbation by nest building can increase carbon availability for microorganisms in nests and consequently promote microbial biomass. Formic acid and phenylic acid were expected to reduce microbial respiration because of their antibiotic activity, but in our study they increased microbial respiration, which indicates an active utilization by microorganism.

Higher respiration response to substrates and lower basal respiration in ant nests, in particular at site 2, compared to surroundings can be explained by ants`activity as ecosystem engineers (Jones, 1994; Dauber and Wolters, 2000), which influence physical and chemical properties of soils by nest construction, and foraging and consumption of food (Nkem et al., 2000; Frouz et al., 2003).

The accumulation of ammonium, nitrate and phosphate in ant nests is well documented (Wagner et al., 1997; Nkem et al., 2000; Platner et al., 2001) and microorganisms in soil are controlled by energy and nutrient availability. Commonly microbial growth in soils is primarily limited by carbon, but the utilization of different $\mathrm{C}$ resources depends on the availability of other nutrients (Scheu and Schaefer, 1998). The site-dependent nutrient availability for soil microorganisms can explain the differences in substrate utilization between sites. The shallow Leptosol of site 1 has severe limitations to rooting and the excessive internal drainage. Combined with the warm microclimate on the south exposed hill slope, severe droughts in the summer can occur (Platner, 2006), which inhibit microbial development. In contrast, moderately developed and base-saturated Cambisols of temperate regions ("Braunerden"), which derived from floodplain loess (as found at site 2), are productive soils. Thus, different nutrient limitations in habitats can mask ant effects, especially, when different sites or seasonal changes are compared (Frouz et al., 2003; Platner, 2006). 
In control soils, differences between site 1 and site 2 were relatively low for MIRR in the case of following substrates: melecitose 0.58 , ascorbic acid 1.88, tyrosine 0.19 and phenylic acid $1.85 \mu \mathrm{g} \mathrm{O}_{2} \mathrm{~g}^{-1}$ soil dry wt $\mathrm{h}^{-1}$. This was in contrast to nest soils, where strong differences between sites were detected in response to these substrates: melecitose 14.54, ascorbic acid 15.71, tyrosine 12.89 and phenylic acid $9.21 \mu \mathrm{g} \mathrm{O}_{2} \mathrm{~g}^{-1}$ soil dry $w \mathrm{t} \mathrm{h}^{-1}$.

Similar to the MIRR, local differences of CRR were stronger in nests (glucose 525, melecitose 297, ascorbic- 436, formic- 403 and phenylic acid $973 \mu \mathrm{g} \mathrm{O}_{2} \mathrm{~g}^{-1}$ soil dry wt $\mathrm{h}^{-1}$ ) than in controls (glucose 222, melecitose 43, ascorbic- 66, formic- 390 and phenylic acid $231 \mu \mathrm{g} \mathrm{O}_{2} \mathrm{~g}^{-1}$ soil dry wt $\mathrm{h}^{-1}$ ). These results indicated that ant presence in site $2 \mathrm{had}$ a stronger impact on soil microbial communities than in site 1 . This might be a result of differences in nutrient availability and initial species diversity between sampling sites, at least during summer. In spring and late summer, Platner (2006) could detect a significantly higher microbial biomass in ant nests from site 1 compared to the surrounding soil, but not in very dry time periods or soil horizons. These observations and experimental results are consistent with our results.

Changes in microbial community composition can influence higher trophic levels because microbes represent the basis of the belowground food web (Pokarzhevskii et al., 2003). At our study site 2, Schuch et al. (2008) detected up to four times higher densities of Collembola next to nest mounds of $L$. niger than at a distance of $2 \mathrm{~m}$. Laakso and Setälä (1998) detected that bacteria-feeding nematodes were more frequent in nests of Formica aquilonia compared to surrounding forest soil, indicating changes in the composition of bacterial based food web. Thus, knowledge on community composition of microorganisms and their range of substrate utilization is important for understanding key ecological processes. The use of physiological profiles is a promising tool to study differences in the functional diversity of soil microbes. Nevertheless, to understand key ecological processes, information on microbial community structure is important, which we obtained by molecular approaches. 


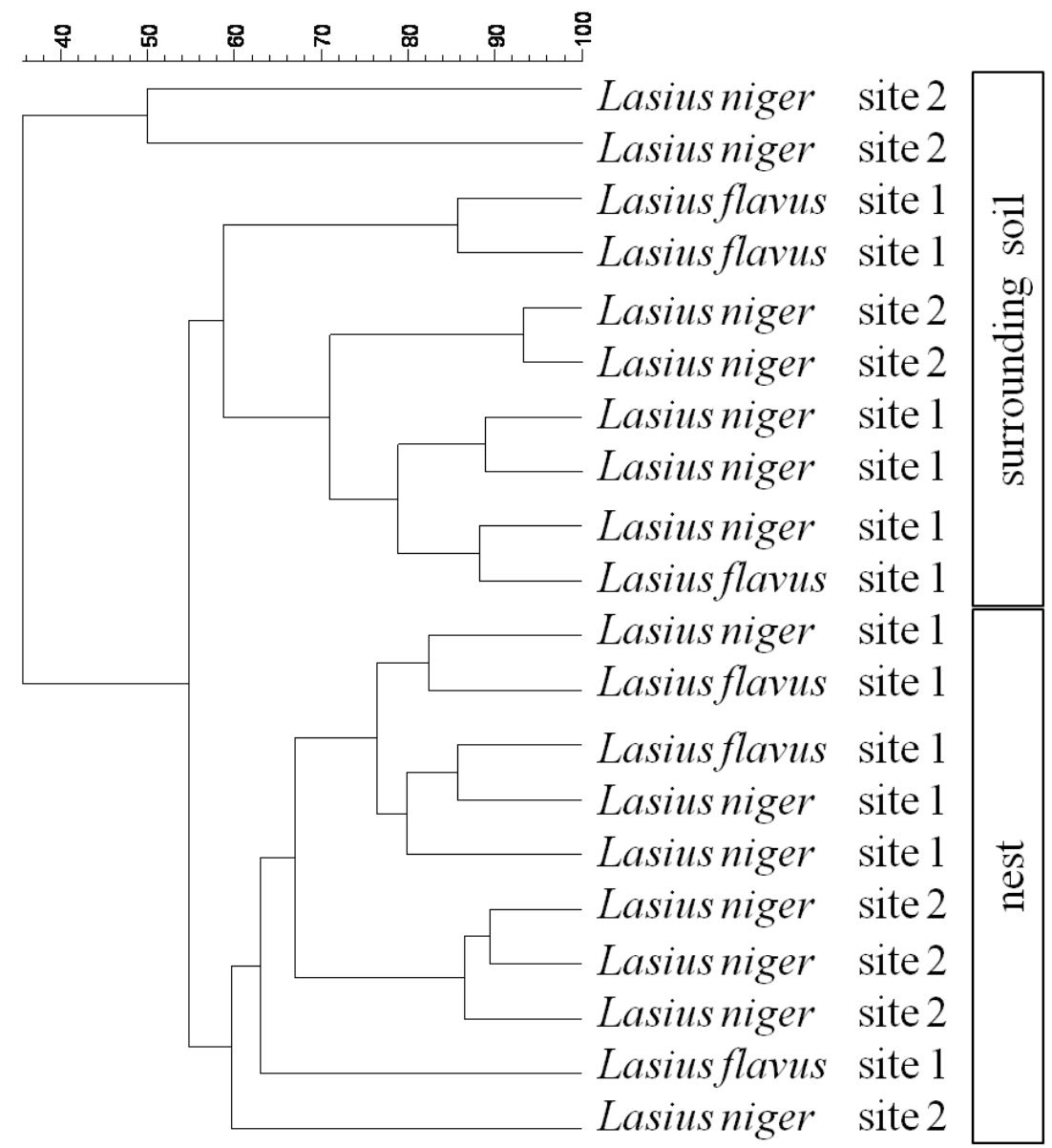

Figure 4. Dendrogram showing cluster analysis of the digitized DGGE bacterial profile. The UPMGA method was applied, which takes the presence or absence of bands at certain positions in each lane into account.

Bacterial community structure

In order to provide robust assessment of patterns, three independent PCR reactions were performed for each sample. The average number of bands per sample was $14.2 \pm 3.5$.

The DGGE patterns of nests for the two ant species, L. niger and L. flavus were similar to those of the respective surrounding soil for both sampling sites. Nevertheless, a higher species abundance within the bacterial communities of the nest samples was indicated, as the bands from the nest samples showed a greater intensity than those derived from the surrounding soils. The UPGMA dendrogram derived from the cluster analysis of the obtained DGGE patterns showed two clearly separated groups (Figure 4). All nest bacterial communities grouped together and were separated from the surrounding soil communities. Two surrounding soil samples of Lasius niger nests from site 2 grouped outside and were separated from the surroundings soil and the nest bacterial communities. Within the nest cluster, matches to site occurred more often than 
matches to different Lasius species, indicating that site differences affected bacterial communities in nests stronger than differences in ants' life strategy. A similar trend was shown during cluster analysis.

Correspondingly, the DGGE patterns of bacterial communities showed site-dependent differences of the ant nests. In site 1, DGGE band patterns differed only slightly between nests and surrounding soil, in particular one band, which occurred in the profile of Lasius niger mound of site 1 (see arrow in supplementary Figure S1). The pattern of site-dependent differences was observed for microbial biomass as well as in the physiological profiles.

The DGGE profile of the nest samples showed a larger number of bands, which were also more defined and intense compared to the surrounding soil samples. This indicates a higher abundance of species represented by these more intense patterns. Taking the limitation of the DGGE technique into account, that one band may represent more than one species (Muyzer, 1999), therefore we avoided the calculation of richness and diversity indices. However, these more intense DGGE patterns of the nest samples may reflect the ant activity, which led to changes in microbial biomass. Gronli et al. (2005) pointed out that the most consistent parameter for the variation in microbial soil community was the 'block', suggesting a strong spatial structure in the soil microbial community. Conditions for microbial development can differ between sites and the initial species diversity of soil organism strongly depends on previous land use (Hedlund et al., 2003). The influence of ant activity on the microbial community can be dependent on the site specific initial diversity of microorganism, soil nutrients, soil water content, soil structure, and other characteristics of the respective habitats. Nutrient limitation for microorganisms can differ between environments, in some soils nutrients are already available for microorganisms, but in nutrient-poor soils ants can provide the limiting resources. In the latter case, the effects of ants on the microbial community structure and activity are strong. However, the clear ant effect on bacterial community structure, superposing site and ant species effects, as revealed by the cluster analysis of the digitized DGGE profiles, confirm the strong bottom-up effects of these ecosystem engineers. 


\section{Conclusions}

Ant activity led to changes in bacterial communities and physiological profiles, but the degree of the ants' impact on microbial communities and their activity depended on nest site. This general effect was demonstrated by PCR-DGGE as well as by respiration analysis. The strong variation in the physiological activity between different habitats can mask the ant effect and make comparisons between sites or other studies difficult. In our study, site more strongly affected microorganisms than the ant species that inhabit the nest.

In ant nests from site 2 in Reinhausen (Lower Saxony, Germany) we detected high microbial biomass and respiration response, which was reflected in DGGE analyses by more diverse bacterial community patterns and higher abundance of bacterial soil community members. Similar patterns of physiological and DGGE profiles suggest that respiration response to the different substrates predominantly reflected activity of bacterial communities. The structures of these bacterial communities were clearly separated between soil from ant nest mounds and surrounding soil. In summary, the results indicated that ants affect both the structure and functioning of soil microorganisms in their nests by nest building activity and accumulation of organic substances with the effect varying with soil fertility.

\section{Acknowledgement}

We thank Matthias Schaefer, Carola Simon and Stefan Scheu for valuable discussions and comments on the manuscript. The work of R.D. and B.P. was supported by the 'Functional biodiversity research cluster of excellence' funded by the Ministry of Science and Culture of Lower Saxony and the 'Niedersächsisches Vorab'. 


\section{References}

Anderson, J.P.E., Domsch, K.H., 1978. A physiological method for quantitative measurement of microbial biomass in soils. Soil Biology \& Biochemistry 10, 519-525.

Anderson, J.P.E., Domsch, K.H., 1980. Quantities of plant nutrition in the microbial biomass of selected soils. Soil Science 130, 211-216.

Bardgett, R.D., Bowman, W.D., Kaufmann, R., Schmidt, S.K., 2005. A temporal approach to linking aboveground and belowground ecology. Trends in Ecology and Evolution 20, 634-641.

Beck, T., Joergensen, R.G., Kandeler, E., Makeschin, F., Nuss, E., Oberholzer, H.R., Scheu, S., 1997. An inter-laboratory comparison of ten different ways of measuring soil microbial biomass C. Soil Biology \& Biochemistry 29, 10231032.

Dauber, J., Wolters, V., 2000. Microbial activity and functional diversity in the mounds of three different ant species. Soil Biology \& Biochemistry 32, 93-99.

Degens, B.P., Harris, J.A., 1997. Development of a physiological approach to measuring the catabolic diversity of soil microbial communities. Soil Biology \& Biochemistry 29, 1309-1320.

Dighton, J., 1978. In vitro experiments simulating the possible fates of honeydew sugars in soil. Soil Biology \& Biochemistry 30, 53-57.

Emmerling, C., Schloter, M., Hartmann, A., Kandeler, E., 2002. Functional diversity of soil organisms-a review of recent research activities in Germany. Journal of Plant Nutrition and Soil Science 165, 408-420.

Fischer, M.K., Völkl, W., Hoffmann, H., 2005. Honeydew production and honeydew sugar composition of polyphagous black bean aphid, Aphis fabae (Hemiptera, Aphididae) on various host plants and implications for ant attendance. European Journal of Entomology 102, 155-160.

Fountain, M.T., Brown, V.K., Gange, A.C., Symondson, W.O.C., Murray, P.J., 2008. Multitrophic effects on nutrient addition in upland grassland. Bulletin of Entomological Research 98, 283-292.

Frouz, J., Holec, M., Kalčík, J., 2003. The effect of Lasius niger (Hymenoptera, Formicidae) ant nest on selected soil chemical properties. Pedobiologia 47, 205212. 
Gronli, K.E., Frostegard, A., Bakken, L.R., Ohlson, M., 2005. Nutrient and carbon addition to the microbial soil community and ist impact on tree seedlings in a boreal spruce forest. Plant and Soil 278, 275-291.

Hedlund, K., Santa Regina, I., Van der Putten, W.H., Korthals, G.W., Diaz, T., Leps, J., Roy, J., Lavorel, S., Gormsen, D., Mortimer, S.R., Smilauer, P., Smilauerova, M., Van Dijk, C., Brown, V.K., C RB, 2003. Plant species diversity, plant biomass and responses of the soil community on abandoned land across Europe: idosyncracy or above-belowground time lags. Oikos 103, 45-58.

Hölldobler, B., Wilson, E.O., 1990. The ants. Springer, Berlin, Heidelberg, NY.

Joergensen, R.G., Scheu, S., 1998. Response of soil microorganisms to the addition of carbon, nitrogen and phosphorus in a forest Rendzina. Soil Biology \& Biochemistry 31, 859-866.

Jones, C.G., Lawton, J.H., Shachak, M., 1994. Organisms as ecosystem engineers. Oikos 69, 373-386.

Kiss, A., 1981. Melezitose, aphids and ants. Oikos 37, 382.

Laakso, J., Setälä, H., 1998. Composition and trophic structure of detrital food web in ant nest mounds of Formica aquilonia and the surrounding forest soil. Oikos 81, 266-278.

Muyzer, G., Teske, A., Wirsen, C.O., Jannasch, H.W., 1995. Phylogenetic relationships of Thiomicrospira species and their identification in deep-sea hydrothermal vent samples by denaturing gradient gel electrophoresis of $16 \mathrm{~S}$ rDNA fragments. Archives of Microbiology 164, 165-172.

Muyzer, G., Smalla, K., 1998. Application of denaturing gradient gel electrophoresis (DGGE) and temperature gradient gel electrophoresis (TGGE) in microbial ecology. Antonie van Leewenhoek 73, 127-141.

Muyzer,G., 1999. DGGE/TGGE a method for identifying genes from natural ecosystems. Current Opinion in Microbiology 2, 317-322

Nkem, J.N., Lobry de Bruyn, L.A., Grant, C.D., Hulugalle, N.R., 2000. The impact of ant bioturbation and foraging activities on surrounding soil properties. Pedobiologia 44, 609-621.

Platner, C., Schaefer, M., Scheu, S., 2001. Der Einfluss von Ameisen auf den Boden und die mikrobielle Gemeinschaft trockener Brachwiesen. Mitteilungen der Deutschen Bodenkundlichen Gesellschaft 95, 84-87. 
Platner, C., 2006. Ameisen als Schlüsseltiergruppe in einem Grasland. Studien zu ihrer Bedeutung für die Tiergemeinschaft, das Nahrungsnetz und das Ökosystem. Biodiversity and Ecology Series 1, Universitätsverlag, Göttingen.

Pokarzhevskii, A.D., van Straalen, N.M., Zaboev, D.P., Zaitsev, A.S., 2003. Microbial links and element flows in nested detrital food-webs. Pedobiologia 47, 213-224.

Scheu, S., 1992. Automated measurement of the respiratory response of soil microcompartments: active microbial biomass in earthworm faeces. Soil Biology \& Biochemistry 24, 1113-1118.

Scheu, S., Schaefer, M., 1998. Bottom-up control of the soil macrofauna community in a beechwood on limestone: Manipulation of food resources. Ecology 79, 1573 1585 .

Scheu, S., Schlitt, N., Tiunov, A.V., Newington, J.E., Jones, T.H., 2002. Effects of the presence and community composition of earthworms on microbial community functioning. Oecologia 133, 254-260.

Schuch, S., Platner, C., Sanders, D., 2008. Potential positive effect of the ant species Lasius niger on linyphiid spiders. Journal of Applied Entomology 132, 375-381.

Seeger, J., Filser, J., 2008. Bottom-up down from the top: Honeydew as a carbon source for soil organisms. European Journal of Soil Biology 44, 483-490.

Sokal, R.R., Rohlf, F.J., 2001. Biometry. 4th edition. WH Freeman and Co., New York.

Wagner, D., Brown, M.F.J., Gordon, D.M., 1997. Harvester ant nests, soil biota and soil chemistry. Oecologia 112, 232-236.

Wardle, D.A., Bardgett, R.D., Klironomos, J.N., Setala, H., Van der Putten, W.H., Wall, D.H., 2004. Ecological linkages between aboveground and belowground biota. Science 304, 1629-1633. 


\section{B.IV Microbial communities inhabiting biological soil crusts}

An additional project was the assessment and comparison of microbial communities present in biological soil crusts. The respective soil crusts were sampled at two sites in extrazonal mountain dry steppes in northern Mongolia. The two sampling sites differed in their disturbance history and thus differed in the development stages of the specific biological soil crusts. To analyze the microbial community structure of these soil crusts 16S rRNA-gene libraries were constructed and sequenced. 
1.

\section{Bacterial diversity in biological soil crusts from extrazonal mountain dry steppes in northern Mongolia}

Anne Kemmling ${ }^{1,2}$, Birgit Pfeiffer ${ }^{2}$, Rolf Daniel ${ }^{2}$, and Michael Hoppert ${ }^{2,3}$

Erforschung biologischer Ressourcen der Mongolei. Band 12 (2012)

${ }^{1)}$ Department of Conservation Biology, University of Göttingen, Bürgerstraße 50, 37073 Göttingen, Germany

${ }^{2)}$ Genomic and Applied Microbiology, University of Göttingen, Grisebachstr. 8, 37077

Göttingen, Germany

${ }^{3)}$ Courant Research Centre of Geobiology, Goldschmidtstraße 3, 37033 Göttingen, Germany

Author contributions to the work:

Performed the experiments: A. Kemmling, B. Pfeiffer

Analyzed data: $\quad$ A. Kemmling, B. Pfeiffer

Wrote the paper: $\quad$ A. Kemmling, M. Hoppert, B. Pfeiffer, R. Daniel

Conceived and designed the experiments: A. Kemmling, M. Hoppert 
Erforsch. biol. Ress. Mongolei (Halle/Saale) 2012 (12): 437-449

\title{
Bacterial diversity in biological soil crusts from extrazonal mountain dry steppes in northern Mongolia
}

\author{
A. Kemmling, B. Pfeiffer, R. Daniel \& M. Hoppert
}

\begin{abstract}
Biological Soil Crusts (BSCs), consisting of prokaryotes, microalgae, lichens, mosses and eventually small vascular plants, cover wide areas in arid and semi-arid environments. In the present study, the microbial diversity of these crusts was explored at extrazonal mountain steppe sites in the western Khentej (Northern Mongolia). At the study site the Siberian taiga borders on the Mongolian-Daurian forest steppe, resulting in a unique intermixture of the dark taiga, the light taiga, and forest steppe (DULAMSUREN 2004). Due to the presence of boreal, temperate and dauric elements the forest steppe is eminently rich in species (MÜHLENBERG et al. 2004).

BSCs in the western Khentej only occur in mainly non-forest areas of the Carex amgunensis-, Festuca lenensis-, Pulsatilla ambigua- and Artemisia frigida-mountain-dry-steppe and Ulmus pumila-open woodland (DULAMSUREN 2004). BSCs at these sites contain small vascular plants, mosses, lichens, and different microorganisms in varying ratios. In this communication, the diversity of BSCs, especially with respect to bacterial phylotypes in two different sites with a diverging degree of disturbance is presented. According to results based on $16 \mathrm{~S} \mathrm{rDNA}$ analysis, the relative abundance of Cyanobacteria decreases on disturbed sites, whereas abundances of other large groups increase. Generally, the more disturbed site appears to be more diverse.
\end{abstract}

Key words: biological soil crusts, biodiversity, arid environment, western Khentej, Mongolia

\section{Introduction}

Biological soil crusts (BSCs), also known as microbiotic, cryptogamic, cryptobiotic or biogenic soil crusts, are highly complex systems. Intriguingly, crust structure and morphology is determined by prokaryotes, eukaryotic microalgae and multicellular cryptograms. They occur on the upper soil layer and are some millimeters to several centimeters thick. BSCs of this study are composed by mosses, microfungi, lichen, diatoms, green algae, cyanobacteria, and other prokaryotes. In addition, the BSCs provide a habitat for higher organisms like small vascular plants and insects. They are ubiquitous and appear generally at locations where higher vegetation is disturbed or is completely lacking (e.g. parts of cold and hot deserts, dunes and mountain dry steppe sites).

Climate in Mongolia is marked by extreme continentality as the region is surrounded by mountain ranges in the centre of the Asian continent. The absolute thermal fluctuation is $90^{\circ} \mathrm{C}\left(\mathrm{T}_{\max }=40^{\circ}\right.$ $\mathrm{C} ; \mathrm{T}_{\min }=-50^{\circ} \mathrm{C}$ ), whereas the daily fluctuation in summer can reach about $25^{\circ} \mathrm{C}$. The vegetation period lasts just $90-120$ days. Frost may occur as late as May and as early as August, snowfall in late July. Precipitation averages between $250-350 \mathrm{~mm}$ per year. The yearly fluctuations are high. $75-90 \%$ of the annual precipitation occurs as summer rain, especially in July and August. Thus, the main growing season is in summer. Winters are cold and dry; the thickness of the snow cover does not exceed $10-15 \mathrm{~cm}$.

Khan Khentej is a low mountain range that occupies $48.000 \mathrm{~km}^{2}$ and borders to Siberia in the North. It is part of the transbaicalic mountain system, which mostly consists of proterozoic and paleozoic geological formations, mainly granite. The elevations range from about $2800 \mathrm{~m}$ above sea level in the Central Khentej to about $600 \mathrm{~m}$ in the Northeastern foothills. Khonin Nuga is located Northwest of the center. The river valleys are approximately $900 \mathrm{~m}$ above sea level, the highest elevations are at around $1600 \mathrm{~m}$. The soils in Khentej are strongly affected by permafrost. 
The climatic factors and the resulting cryogenic processes lead to soil podzolization (SCHEFFER \& SCHACHTSCHABEL 1995, WYSS 2006). Generally, it should be expected that the podzolic soils, depleted in organic carbon, favor development of BSCs.

Valleys of the Khan Khentej mountain range are mostly oriented from East to West, the mountain ridges are mostly even or rounded. The main wind direction perpendicular to the mountain ridges (north to northwest) leads to a multitude of mesoclimatic conditions, with considerable variations depending on elevation and exposition. There are big differences in the mesoclimate of northern and southern slopes. Northern slopes of the mountains represent the upwind flank. Slowdown and cooling down of the ascending air masses lead to increased precipitation at the northern slopes. The lee side (southern slopes) accumulates less precipitation (OGORODNIKOV 1981). With the distance to the mountain ridge at the southern slope the temperature increases, precipitation and air moisture decrease (VIPPER 1953). The exposition also affects radiation. The northern slopes are normally afforested, while on southern slopes the different types of mountain dry steppe occur (DULAMSUREN 2004). Between the sparse cover of mostly low vascular plants is enough space for the settlement of BSCs.

The appearance of a BSC strongly depends on its degree of succession. In many regions, even in temperate latitudes, initial states of BSCs form after a disturbance by destruction of the original vegetation. Just in moist sites, the BSCs are overgrown by fast growing and more competitive ruderal plant species. The BSC in its initial state is often dominated by Cyanobacteria, which in many cases are mobile by gliding. These Cyanobacteria secrete polysaccharide sheaths, and spread quickly due to their mobility, often leaving behind the empty sheaths (MAZOR et al. 1996). These sheaths are holdfasts and organic substrate for other microorganisms. The polysaccharide absorbs and stores water for longer time periods (KEMMLING et al. 2001). Based on the ability of many Cyanobacteria to fix nitrogen, even on poor soils more fastidious organisms will settle in this microhabitat. Over time, horizontally layered structures may develop within complex BSCs, including anaerobic zones (e.g. GARCIA-PICHEL \& BELNAP 1996). More complex crusts that contain mosses or lichens, may only form where BSCs are not outcompeted by faster growing vascular plants. In their initial stages, BSCs are often pioneer settlers at disturbed locations, but their further development depends on the existence or absence of disturbances like natural physical erosion, or fire. Thus BSCs may be considered as indicators for fast changing ecosystems.

Little knowledge on BSCs or prokaryotic diversity of dryland soils for Northern Asia is available, including the Mongolian steppe (BELNAP et al. 1999, rev. by BÜDEL 2001), which differs greatly from Khan Khentej. For Siberia, only a few observations were documented, implying the presence of diverse BSCs. Studies by NOVICHKOVA-IVANOVA $(1977,1980,1988)$ dealt with the diversity of soil algae in several deserts and steppes of Turkmenistan and the Gobi desert. All in all, more than 400 species of algae were discovered and it was observed that the microbial biomass strongly depends on soil conditions and moisture content of the soil.

In this study, we compare two sites with different disturbance histories and hence specific types or stages of BSCs. Here, we use $16 S$ rDNA, amplified from isolated environmental DNA to compare the microbial communities of BSCs at two different sites (cf. AMANN et al. 2003).

\section{Material and methods}

\section{Sample collection and DNA extraction}

The samples were collected in July 2007 at two different sites (see fig. 1 and table 2) in the northwestern part of Khan Khentej near Khonin Nuga research station ( $\left.49^{\circ} 05^{\prime} \mathrm{N}, 107^{\circ} 17^{\prime} \mathrm{E}\right)$. In both sites, dry specimens of BSCs were collected at three different sampling sites. The specimens of each site were combined, macerated and intensively mixed by shaking. $0.25 \mathrm{~g}$ of the resulting powder was used for the following DNA extraction. DNA was extracted with the Power Soil ${ }^{T M}$ DNA-Kit according to the manufacturers protocol (MoBio, Carlsbad, California, USA). 


\section{Clone library construction}

The PCR (polymerase chain reaction) mixture $(50 \mu \mathrm{l})$ for amplification of 16S rRNA genes contained $5 \mu \mathrm{l}$ of Mg-free polymerase buffer (MBI Fermentas, St. Leon-Rot, Germany), $200 \mu \mathrm{M}$ of each of the four deoxynucleoside triphosphates, $1.75 \mathrm{mM} \mathrm{MgCl}_{2}$, as well as $2 \mu \mathrm{M}$ of each of the primers, $1 \mathrm{U}$ of Taq DNA polymerase (MBI Fermentas), and $25 \mathrm{ng}$ of isolated DNA as a template. The PCR was performed in a Mastercycler Gradient thermal cycler (Eppendorf, Hamburg, Germany) at $94^{\circ} \mathrm{C}$ for $2 \mathrm{~min}$ (for initial denaturation and activation of the polymerase); followed by 28 cycles at $94^{\circ} \mathrm{C}$ for $1 \mathrm{~min}$ of denaturation at $94^{\circ} \mathrm{C}$ for $1 \mathrm{~min}$, annealing at $58^{\circ} \mathrm{C}$ for $1.5 \mathrm{~min}$, extension at $72^{\circ} \mathrm{C}$ for $1.3 \mathrm{~min}$ and final extension at $72^{\circ} \mathrm{C}$ for $10 \mathrm{~min}$. For both clone libraries $16 \mathrm{~S}$ rRNA genes were amplified with universal reverse oligonucleotide primer $1114 \mathrm{R}$ and forward primer $8 \mathrm{~F}$ (see table 1).

Table 1: PCR-primers

\begin{tabular}{llll}
\hline primer & \multicolumn{1}{c}{ sequence $\left(\mathbf{5}^{\circ} \mathbf{- 3}^{\circ}\right)$} & specifity & \multicolumn{1}{c}{ reference } \\
\hline $8 \mathrm{~F}$ & GGATCCAGACTTTGATYMTGGCTCAG & Bacteria & BEN-DOV et al. (2006) \\
1114R & GGGTTGCGCTCGTTRC & Bacteria & $\begin{array}{l}\text { modificated from REYSEN- } \\
\text { BACH \& PACE (1995) }\end{array}$ \\
\hline
\end{tabular}

The amplified 16S rDNA was further checked and purified by electrophoresis in a $1 \%(\mathrm{wt} / \mathrm{vol})$ agarose gel. DNA fragments of expected sizes were excised and recovered from the agarose using the PeqGold Gel Extraction Kit TM (PeqLab Biotechnologie GmbH, Erlangen, Germany) according to the manufacturers protocol. $100 \mu \mathrm{g}$ DNA was ligated with a topoisomerase into the vector pCR2.1-TOPO® (Invitrogen, Karlsruhe, Germany) and afterwards cloned into heat shock-competent E.coli-TOP $10 \AA$-cells according to the manufacturers protocol. After plating on $\mathrm{LB} / \mathrm{kanamycin}$ agar plates and incubation over night at $37^{\circ} \mathrm{C}$, positive clones were picked into liquid LB-medium and incubated over night at $37^{\circ} \mathrm{C}$. Subsequently, plasmid preparation with the Qiagen Plasmid Midi Kit (Qiagen, Hilden, Germany) was conducted. Plasmids were checked for inserts by digestion with EcoRI restriction endonuclease (MBI Fermentas, St. Leon-Rot, Germany).

\section{Sequencing and phylogenetic analysis of bacterial libraries}

16S rRNA gene sequencing was performed by the Göttingen Genomics Laboratory (Göttingen, Germany). The Sanger sequencing reaction was conducted with the primer pair $8 \mathrm{~F}$ and $1114 \mathrm{R}$. The raw sequences were then edited with the Staden Package (STADEN et al., 2000). Initially, Pregap4 (BONFIELD et al., 1995) was applied to remove vectorial contaminations and less-quality sequences. After Pregap4 processing the sequences were assembled with the program Gap4. This was done via the PHRAP algorithm (http://bozeman.mbt.washington.edu/phrap.docs/phrap.html), for detection of sequence overlaps. Assembly mistakes were corrected manually. Afterwards all sequences were adjusted into sense-direction with Orientation Checker (http://www.bioinformatics-toolkit.org/). Chimera were detected with Bellerophon chimera detection program (http://foo. maths.uq.edu.au/ huber/bellerophon.pl.; HUBER et al. 2004) and Mallard (ASHEL-FORD et al. 2006) and removed from the datasets. Operational taxonomical units (OTU's; SCHLOSS \& HANDELSMANN 2005) were determined using DOTUR. For species-level phylotypes, genetic distances of $0.03(3 \%)$ were defined. Distances of $0.2(20 \%)$ were defined as phylum level. Shannon-Weaver and Simpson indices (as a description of the diversity within a dataset), abundance-based coverage estimator (ACE) as well as nonparametric abundance estimator based on one- and two-elemental masses (Chao1) and rarefaction curves were also calculated with DOTUR. Sequences generated in this study have been deposited to GenBank under the accession numbers JX254918-JX255375. 


\section{Soil chemistry and other habitat conditions}

$50 \mathrm{~g}$ samples of dry soil taken from the O-horizon were collected at three different sampling sites within the two sites and mixed afterwards. The soil samples were sieved with a 2-mm-sieve. The soil chemical parameters $\left(\mathrm{pH}, \mathrm{pH}_{\mathrm{KCl}}, \mathrm{C} / \mathrm{N}\right)$ were determined according to FENDER et al. (2012).

The maximum water holding capacity $\left(\mathrm{WHC}_{\max }\right)$ was measured gravimetrically using $20 \mathrm{~g}$ dry soil. The soil was saturated for 30 hours with water and was weighted again. The resulting mass difference represents $\mathrm{WHC}_{\max }$ in grams stored water per gram dry soil.

The mean temperature of the ground was measured according to PALLMANN (1940) for 10 days during the sampling period on topsoil, on the basis of sucrose hydrolysis to "invert sugar" (glucose and fructose) which was quantified using a polarimeter (Zeiss, Oberkochen, Germany).

\section{Results and discussion}

The structure of BSCs depends to a high degree on their age. It is known that generally filamentous cyanobacteria play a key role in crust growth and dispersal. BELNAP et al. (2008) defined six stages in development of BSCs dominated by cyanobacteria. For this they used the observation that the cyanobacterial crust progressively darkens during succession (HOUSMAN et al. 2006), thereby providing UV protection for less pigmented species (BOWKER et al. 2002). In some regions, instead of Cyanobacteria, mosses are the important colonizers of the BSCs (e.g. READ et al. 2011). According to our own field observations, putatively young BSCs are dominated by Cyanobacteria and mosses. Lichen-containing BSCs were interpreted as later stages in crust development: first lichens of low complexity like Collema sp., then assumedly Cladonia sp. and Psora sp. and later the complex leafy lichen Xanthoparmelia sp. Based on this, we assume that the BSCs in site A in average are older, because they contain complex leafy lichens like Xanthoparmelia spec. We also found thinner crusts of the initial type.

It should be expected that the BSCs are particularly affected by trampling of livestock. Nonanthropogenic effectors are erosion by wind, rain, wild animals or slope movement. The last one especially applies at the study site B. Crust damage through trampling cause loss of crust biomass and a reduction of the cryptogamic species diversity (rev. by ELDRIDGE \& KOEN 1998). Other factors such as air pollution, application of herbicides or motor vehicles may be excluded for our particular site.

The capacity of regeneration for BSCs varies, depending on species composition, season, and organic carbon contents. Dry BSCs are mostly brittle and heavily affected by mechanical compression and shear forces, other than moistened BSCs (HARPER \& MARBLE 1988). Moreover, the crust-building organisms are only active in a wet state; regeneration of the dry crust is not possible (LANGE 2001), which restricts the metabolic activity, crust regeneration and growth mainly to July and August.

In order to find determinants that may influence structure and composition of BSCs, some soil chemical parameters were determined. Table 2 shows an overview of the topological, soil chemi$\mathrm{cal}$ and plant ecological differences of both study sites. The soil $\mathrm{pH}$ value of the O-horizon of site $\mathrm{A}$ is between 6.7 and 6.8 and that of site $B$ at 7.7 (neutral - slightly alkaline). The $\mathrm{pH}_{\mathrm{KC}}$ as indicator for the potential acidity of the soil is quite low for both sites $(-0.39[\mathrm{~A}]$ and $-0.17[\mathrm{~B}])$. The $\mathrm{C} / \mathrm{N}$-ratio of site $A$ is between 11.24 and 11.64 and of site $B$ at 10.98 . Reference values for the $\mathrm{C} / \mathrm{N}$-ratio are approximately 11 for grassland, 14 for farmland soils, and $28-50$ for forests (SCHEFFER \& SCHACHTSCHABEL 1992). The maximum water holding capacity of the organic soil components $\left(\mathrm{WHC}_{\text {max }}\right)$ depends on the width of the pores (compaction parameters) and therefore on particle size. The finer the soil particles, the more water can be absorbed and stored (BOSSEL 1997). The maximum water holding capacities of the upper soil of the both sites are equal. 


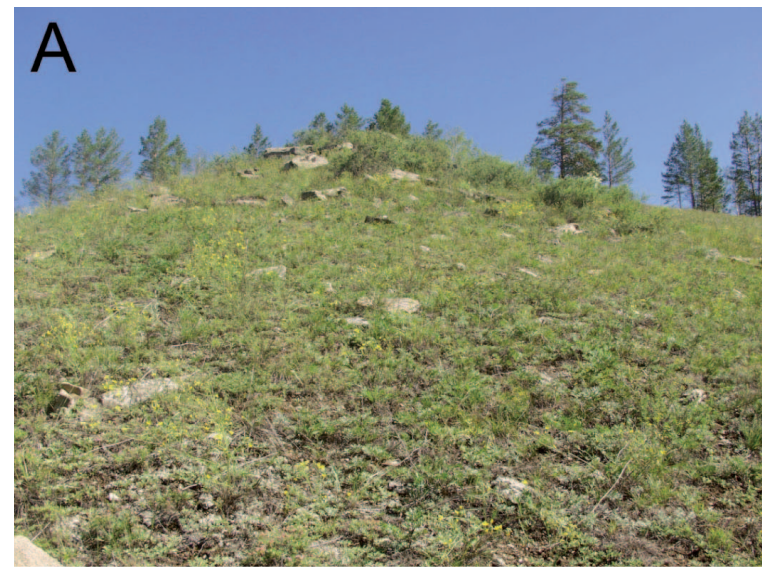

\section{B}
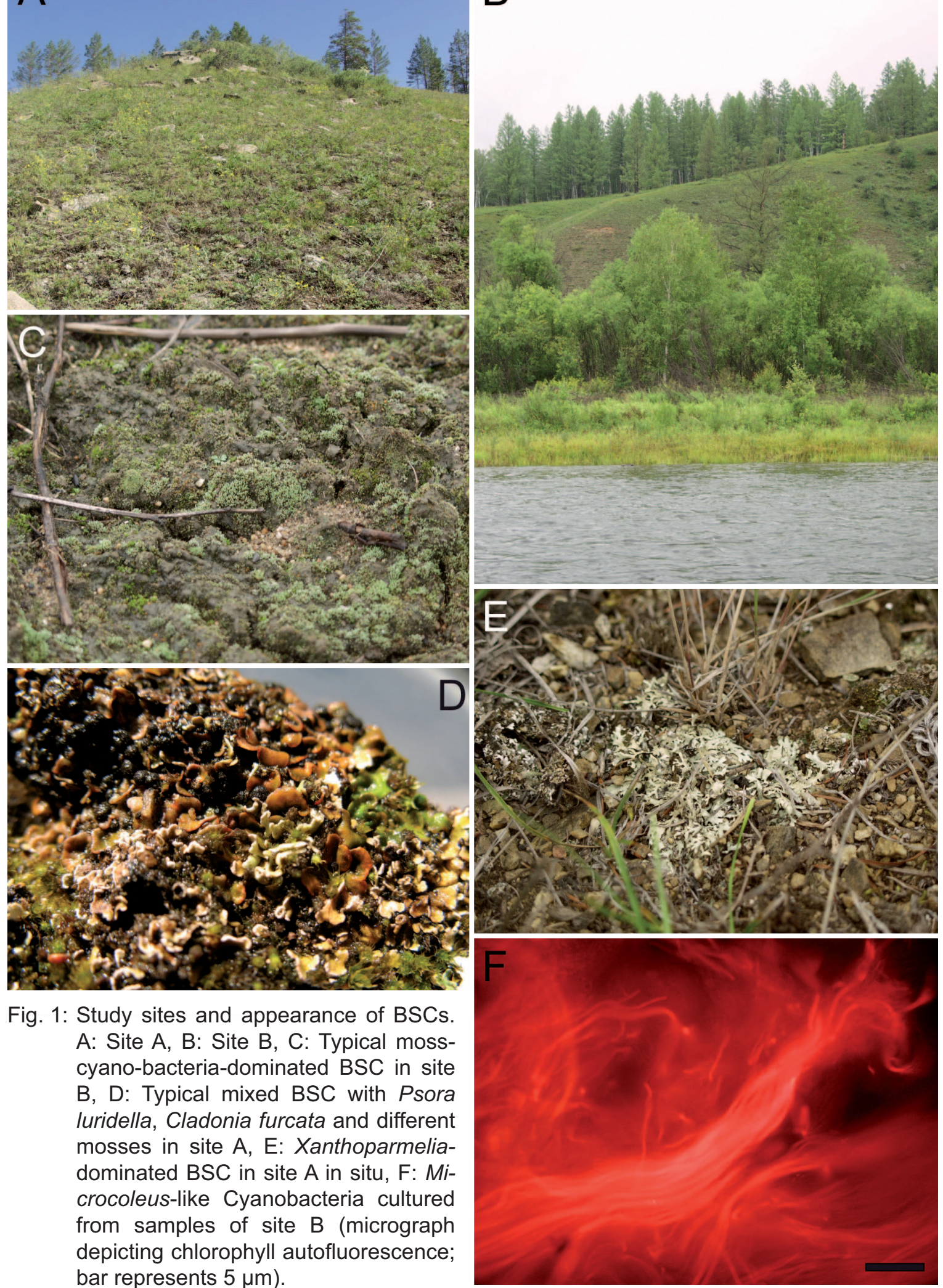

Fig. 1: Study sites and appearance of BSCs. A: Site A, B: Site B, C: Typical mosscyano-bacteria-dominated BSC in site B, D: Typical mixed BSC with Psora luridella, Cladonia furcata and different mosses in site A, E: Xanthoparmeliadominated BSC in site A in situ, F: Microcoleus-like Cyanobacteria cultured from samples of site B (micrograph depicting chlorophyll autofluorescence; bar represents $5 \mu \mathrm{m})$. 
At slope $A$ there is a wide range of different expositions, (SE - SW). The exposition of slope B is orientated south to southwest; this slope is, on average, steeper.

Table 2: Characteristics of the sites

\begin{tabular}{|c|c|c|}
\hline characteristics & slope A & slope B \\
\hline disturbance & low & high \\
\hline location & UTM: 48U06673965438800 & UTM: 48U0666979 5440021 \\
\hline height & $1002 \mathrm{~m}$ above sea-level & $954 \mathrm{~m}$ above sea-level \\
\hline exposition & $135-240^{\circ}$ & $180-220^{\circ}$ \\
\hline inclination & $25-40^{\circ}$ & $30-50^{\circ}$ \\
\hline $\begin{array}{l}\text { position in the land- } \\
\text { scape }\end{array}$ & $\begin{array}{l}\text { wooded at the foot of the hill, } \\
\text { but no shading in the BSC } \\
\text { field }\end{array}$ & $\begin{array}{l}\text { unforested, oriented } \\
\text { towards the river valley }\end{array}$ \\
\hline \multicolumn{3}{|c|}{ number of characteristic species for } \\
\hline Artemisia frigida - MDS & 4 & 2 \\
\hline Carex amgunensis - MDS & - & - \\
\hline Festuca lenensis - MDS & 1 & 1 \\
\hline Pulsatilla ambigua - MDS & - & - \\
\hline Ulmus pumila - OWL & 2 & 2 \\
\hline $\begin{array}{l}\text { Plant cover } \\
\text { within the BSC field }\end{array}$ & $60-95$ & $10-40$ \\
\hline BSC type dominating & $\begin{array}{l}\text { Xanthoparmelia spec., } \\
\text { Cladonia spec., Psora luridella, } \\
\text { Catapyrenium lachneum }\end{array}$ & $\begin{array}{l}\text { Catapyrenium lachneum, } \\
\text { Collema spec., mosses, } \\
\text { initial crusts with algae }\end{array}$ \\
\hline BSC coverage & $10-70 \%$ & $0-10 \%$ \\
\hline $\begin{array}{l}\text { Number of } \\
\text { cryptogamic species }\end{array}$ & 18 & 6 \\
\hline $\mathrm{pH}$ & 6.74 & 7.67 \\
\hline$\Delta \mathrm{pH}$ (with $\mathrm{KCl}$ addition) & $-0,39$ & -0.17 \\
\hline $\begin{array}{l}\text { Quantities of heat } \% \\
\text { inverted }(100 \%=\text { com- } \\
\text { pletely shaded) }\end{array}$ & $40.28(34.69-50.68)$ & 49.15 \\
\hline WHC $_{\max }$ (g water/g soil) & 0.6 & 0.6 \\
\hline $\mathrm{C}_{\text {total }}(\mathrm{mmol} / \mathrm{g})$ & 2.93 & 2.2 \\
\hline $\mathrm{N}_{\text {total }}(\mathrm{mmol} / \mathrm{g})$ & 0.26 & 0.19 \\
\hline $\mathrm{C}_{\text {org }}(\mathrm{mmol} / \mathrm{g})$ & 2.91 & 2.09 \\
\hline $\mathrm{C}_{\text {org }} / \mathrm{N}_{\text {total }}(\mathrm{mol} / \mathrm{mol})$ & 11.43 & 10.98 \\
\hline
\end{tabular}




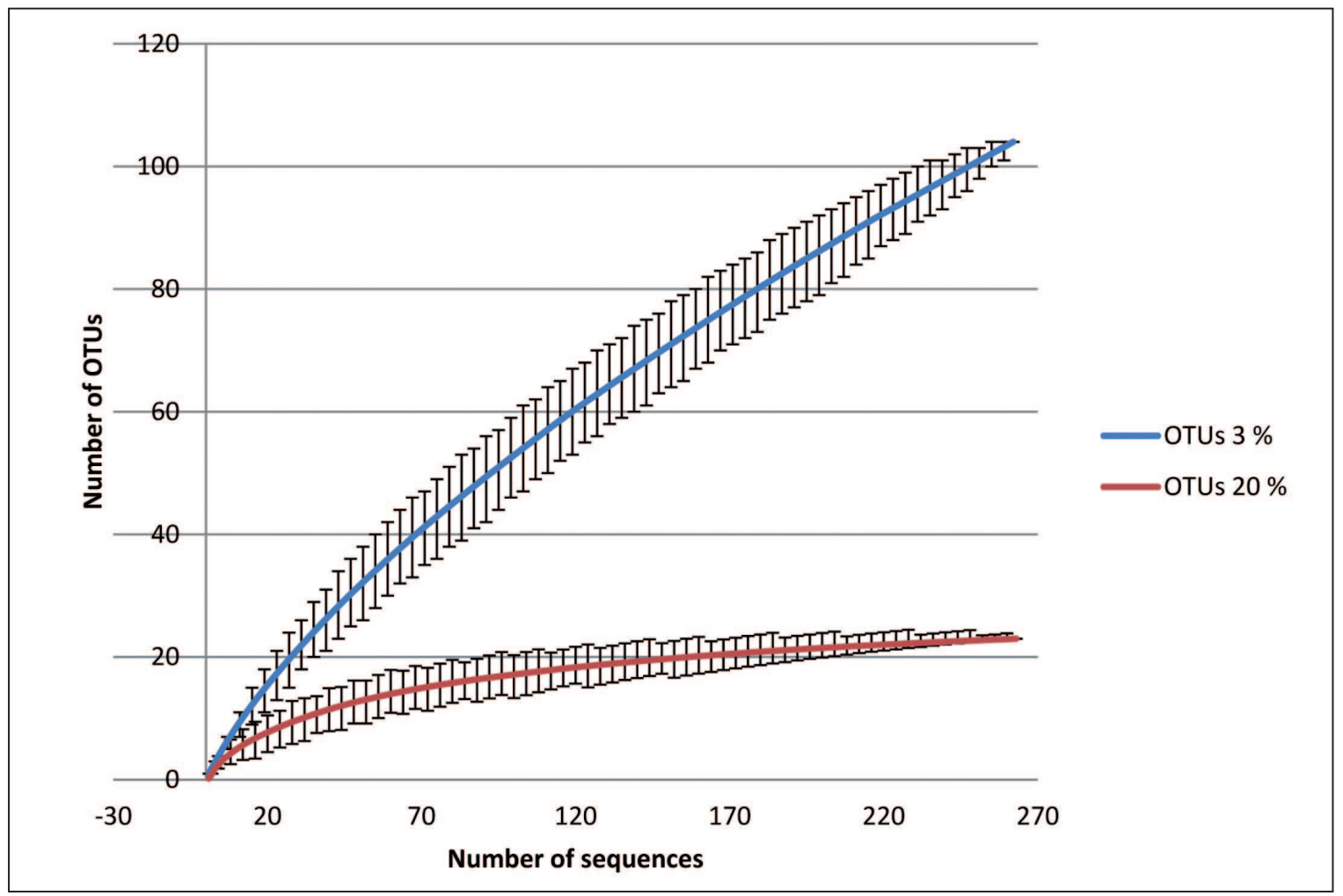

Fig. 2a: Rarefaction analyses by the program DOTUR for site A.

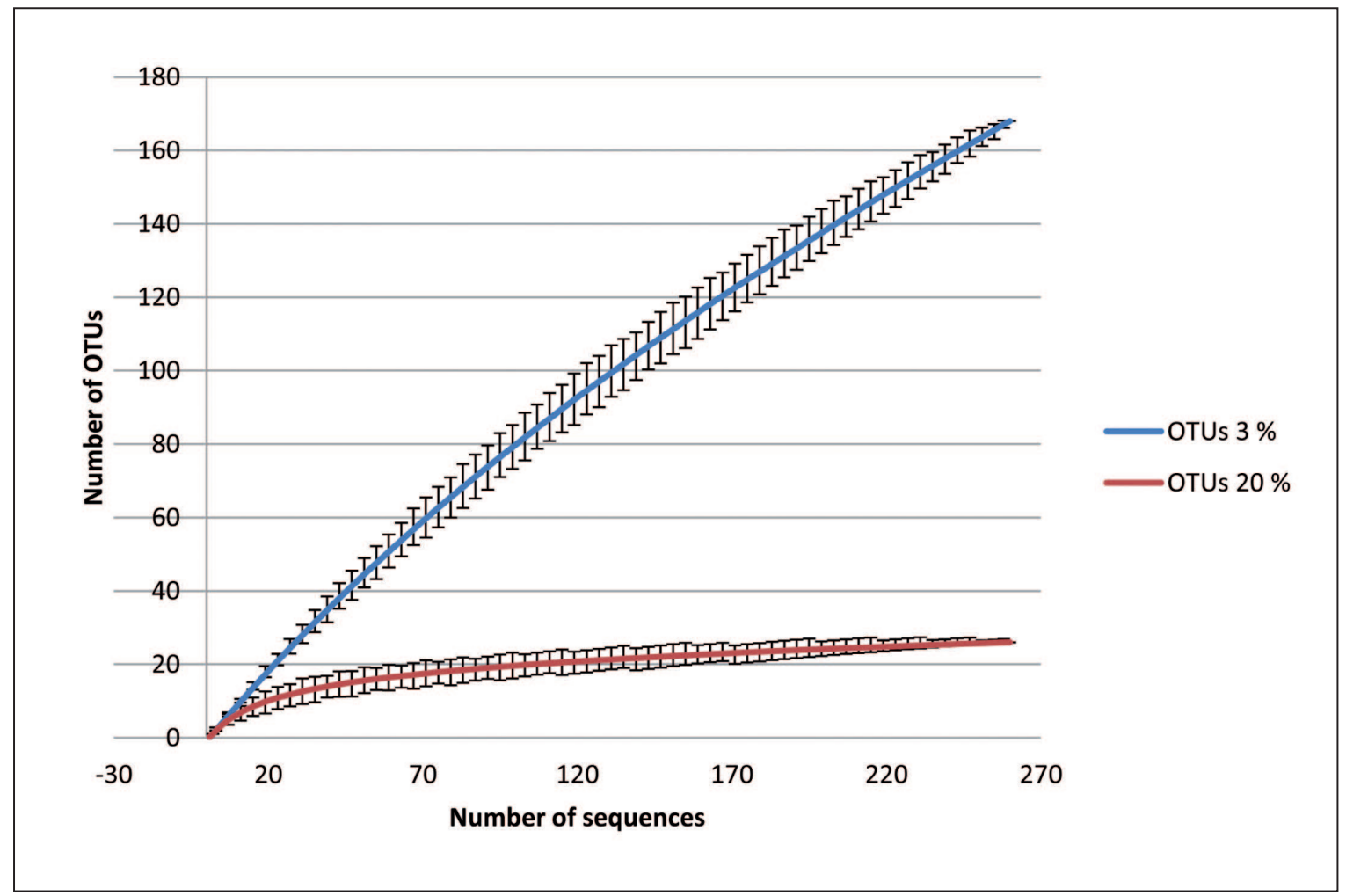

Fig. 2b: Rarefaction analyses by the program DOTUR for site B. 
Site A however is situated behind a forested hill and less affected by grazers than site B, as estimated by the amount of hoofprint and feces. Lichens of the genera Psora and Cladonia were dominant, Xanthoparmelia and Collema were frequent. The cover with phanerogams was considerably higher than at site B.

For phylogenetic analysis, a total of 259 (site A) and 258 (site B) high-quality 16S rRNA gene sequences were retrieved after Chimera check. Rarefaction curves are shown in fig. 2 a, b. The error bars are confidence intervals of the estimate values. The results show for both sites that the bacterial diversity at phylum level is near saturation, whereas the bacterial diversity on species level is even after the evaluation of 260 sequences far away from saturation.

Table 3: Detected OTUs (operational taxonomical units) compared with estimated values

\begin{tabular}{cccccc}
\hline site & distance & number of OTUs & ACE $^{*}$ & Chao1 & Shannon-Weaver \\
\hline \multirow{2}{*}{ A } & 0.03 & 104 & 304 & 282 & 3.93 \\
& 0.2 & 23 & 26 & 25 & 2.12 \\
\hline \multirow{2}{*}{ B } & 0.03 & 168 & 483 & 494 & 4.93 \\
& 0.2 & 26 & 33 & 30 & 2.64 \\
\hline
\end{tabular}

* abundance based coverage estimator (ACE), not parametric abundance estimator based on abundance $(>10)$ and rareness $(<10)$ of OTUs; ${ }^{* *}$ not parametric abundance estimator based on oneand two-elemental masses; ${ }^{* *}$ Shannon-Weaver-index of diversity; as higher as more diverse

The amount of OTUs detected via DOTUR analysis at a genetic distance of 0.03 (at least $97 \%$ identity of the sequences) and 0.2 (80\% identity) is shown in fig. 6 , as well as the values calculated via the coverage estimators (ACE) and of Chao1. For site $\mathrm{A}$, at a distance of 0.03 (species level) coverage of approximately $35 \%$ was achieved. For a genetic distance of 0.2 (phylum level) 25 to 26 OTUs were expected by the richness estimators and 23 were in fact detected. This corresponds to a coverage of approximately $90 \%$. For the site B, similar values were determined ( $35 \%$ at species level, $80 \%$ to $85 \%$ at phylum level). Differing values result from the two different estimation methods $A C E$ and Chao1. It has to be pointed out that for genetic distances below $5 \%$ the rarefaction analyses rather underestimates bacterial diversity whereas Chao 1 rather overestimates it (ROESCH et al. 2007). The Shannon-Weaver index, describing the biodiversity in a specific sample on either species or phylum level, is within the expected range: for the bacterial diversity of BSCs, values between 2 and 5 were frequently found (e.g. NAGY et al. 2005, FIERER \& JACKSON 2006, BACHAR et al. 2010, ABED et. al. 2010), although the different methods used by various authors have to be taken into account. Furthermore, the ShannonWeaver index depends on the amount of samples; for direct comparison, this amount should be approximately equal. Concerning our own study, it is obvious that the bacterial diversity on site B is higher than on site A. This was not expected, as at site A an older and higher developed crust cover was observed. Generally, disturbance reduces biodiversity in BSCs with respect to higher cryptogams (mosses, lichens) and vascular plants (ELDRIDGE \& KOEN 1998). KUSKE et al. (2012) also observed after 10 years of human foot trampling a decline in the number of individuals of the Cyanobacterium Microcoleus vaginatus, besides the decrease in higher cryptogams (see also below). In contrast, the intermediate disturbance hypothesis (CONNELL 1978) points out that site with intermediate rates of disturbance will show highest species diversities. Supporting observations were made in various studies (HUANG et al. 2011, MARILLEY \& ARAGNO 1999). According to our example, disturbance may lead to an increase in diversity of bacterial communities. 
The Classifier tool of the Ribosomal Database Project (MAIDAK et al. 1994) was used to assign analyzed sequences to specific phyla. See BRENNER et al. (2004) for a detailed description of the bacterial phyla. Site B exhibits more phyla than site A, but this finding should not be overinterpreted. Low abundant phyla (Planctomycetes, Firmicutes) may have escaped from analysis or may be underestimated due to technical limitations during DNA extraction. Five phyla (Bacteriodetes, Actinobacteria, Cyanobacteria, Acidobacteria and Proteobacteria) are highly abundant in both sites, but at different proportions. Bacteroidetes represent at site B $18.6 \%$ of all sequences, while they are less abundant at site $\mathrm{A}(9.6 \%)$. The abundances of Actinobacteria ( $6.6 \%$ at $B$ and $8.7 \%$ at $A)$, and the largely unknown Acidobacteria (14.4 \% in B, $10.6 \%$ in $A)$ are similar at both sides. Proteobacteria are a phylogenetically diverse group of Gram negative bacteria, among them typical soil inhabitants, representing $25.3 \%$ of all sequences at site B and $33 \%$ of all sequences at site A. It has to be noted that the subgroup of Deltaproteobacteria within the Proteobacteria is completely missing at site A. For Cyanobacteria the differences in abundance were highest among all groups ( $9 \%$ in $B, 24 \%$ in $A)$.

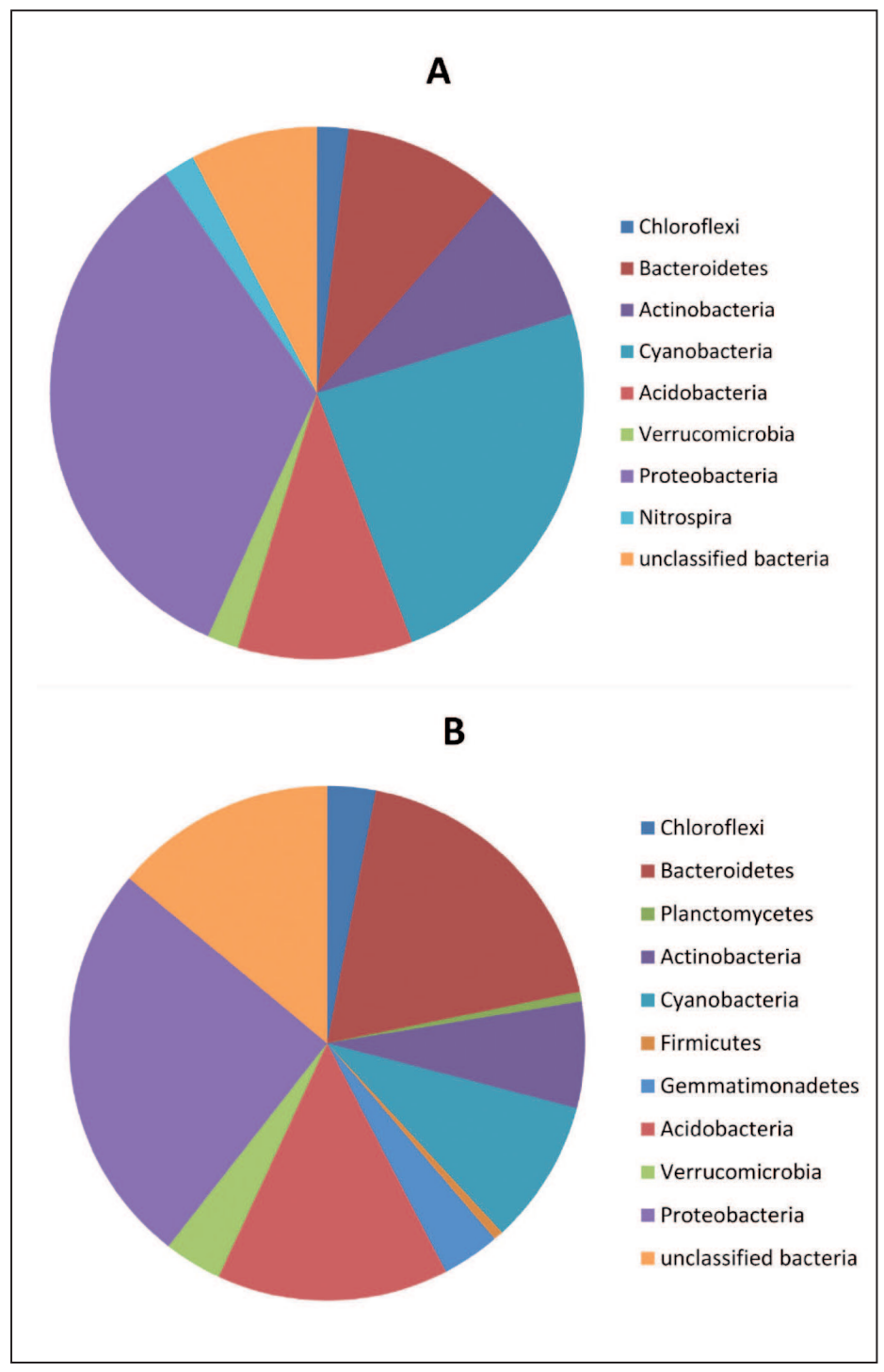

Fig. 3: Phyla distribution of the $16 \mathrm{~S}$ rRNA gene sequences at sites $A$ and $B$, based on RDP classification (MAIDAK et al. 1994).
It is obvious that the sites differ in diversity of the bacterial communities, but also in the proportions of abundant groups This is particularly the case for Cyanobacteria. Though the dominance of Cyanobacteria in BSC's based on microscopic identification and/or spectrometry is widely known (see above), analysis based on environmental rRNA gene sequences are still rare. ABED et al. (2010) described bacterial diversity of desert BSCs from the Sultanate Oman where Cyanobacteria were found to be dominant, representing $80 \%$ of all sequences, and Proteobacteria are the second largest group. BACHAR et al. (2010) showed that the abundance of Cyanobacteria increased with aridity of sites in the Negev desert (Israel). However, in their study, Actinobacteria were dominant, followed by Proteobacteria and Acidobacteria.

Many authors, who examined factors influencing the bacterial community in soil found the $\mathrm{pH}$ to be important, sometimes it was described as most important factor (LAUBER et al. 2009, JONES et al. 2009). NACKE et al. (2011) detected a positive correlation between the phyla Bacteroidetes and Actinobacteria, and soil $\mathrm{pH}$, but at a much broader $\mathrm{pH}$ range as on the sites described here. 
Other factors influencing the bacterial community structure may be the soil type (GIRVAN et al. 2003) or texture (SESSITSCH et al. 2001), nitrogen availability (FREY et al. 2004) or surrounding plant species (WIELAND et al. 2001). The influence of root exudates on BSCs is so far unknown. ZUL et al. (2007) observed that the presence of higher plants may affect the species composition of bacteria even outside the rhizosphere.

KUSKE et al. (2012) reported a reduction of cyanobacterial species and an increase in other bacterial phyla in Colorado Plateau BSCs after disturbance by trampling, which is in accordance with our observations. Under stress conditions other phyla may then replace Cyanobacteria in the crust cover and diversity may increase. Thus, the abundances of phylogenic groups may be a significant parameter for disturbance with respect to BSCs.

\section{Acknowledgements}

We would like to thank the Field Research Station "Khonin Nuga" from the Universities Ulaanbaatar and Göttingen for supplying infrastructure during the field periods and all of our Russian, Mongolian and German colleagues there for their support especially Prof. Dr. Samjaa and Prof. Dr. Mühlenberg as leaders of Khonin Nuga. More thanks to the DAAD for funding and to the colleagues of the AG Daniel and the Göttingen Genomics Laboratory for their support, to AG Leuschner (Plant Ecology and Ecosystem Research, Göttingen) for soil analyses and a special thank to Einar Timdal (Oslo) for the identification of Psora luridella.

\section{References}

ABED, R.M.M.; AL KHARUSI, S.; SCHRAMM, A.; ROBINSON, M.D. (2010): Bacterial diversity, pigments and nitrogen fixation of biological desert crusts from the Sultanate of Oman. - FEMS Microbiology Ecology 72: 418-428.

AMANN, R.I.; LUDWIG, W.; SCHLEIFER, K.H. (1995): Phylogenetic identification and in situ detection of individual microbial cells without cultivation. - Microbiology Reviews 59: 143-169.

ASHELFORD, K.E.; CHUZHANOVA, N.A.; FRY, J.C.; JONES, A.J.; WEIGHTMAN, A.J. (2006): New Screening software shows that most recent large 16S rRNA gene clone libraries contain chimeras. - Applied Environmental Microbiology 72: 5734-5741.

BACHAR, A.; AL-ASHHAB, A.; SOARES, M.I.M.; SKLARZ, M.Y.; ANGEL, R.; UNGAR, E.D.; GILLOR, O. (2010): Soil microbial abundance and diversity along a low precipitation gradient. Microbial Ecology 60: 453-461.

BELNAP, J.; OJIMA, D.; PHILIPPS, S.; BARGER, N. (1999): Biological soil crusts of inner and Outer Mongolia: impacts of grazing and precipitation on nitrogen cycles. In: ELDRIDGE, D.J.; TONGWAY, D.; KING, G. (eds.): Proc. $6^{\text {th }}$ Int. Rangeland Congr., Townsville, Australia.

BELNAP, J.; PHILLIPS S.L.; WITWICKI, D.L.; MILLER, M.E. (2008): Visually assessing the level of development and soil surface stability of cyanobacterially dominated biological soil crusts. Journal of Arid Environments 72: 1257-1264.

BEN-DOV, E.; SHAPIRO, O.H.; SIBONI, N.; KUSHMARO, A. (2006): Advantage of using insosine at the 3 termini of $16 \mathrm{~S}$ rRNA gene universal primers for the study of microbial diversity. Applied Environmental Microbiology 72: 6902-6906.

BONFIELD, J.K.; BEAL, K.F.; STADEN, R. (1995): A new DNA sequence assembly program. Nucleic Acids Research 23: 2992-4999.

BOSSEL, H. (2004): Systemzoo 2: Klima, Ökosysteme und Ressourcen. - Books On Demand, Norderstedt, Germany.

BOWKER, M.A.; REED, S.C.; BELNAP, J.; PHILLIPPS, S.L. (2002): Temporal variation in Community Composition, Pigmentation, and Fv/Fm of Desert Cyanobacterial Soil Crusts. - Microbiology Ecology 43: 13-25. 
BRENNER, D.J.; KRIEG, N.R.; GARRITY, G.M.; STALEY, J.T.; BOONE, D.R.; VOS, P.; GOODFELLOW, M.; RAINEY, F.A.; SCHLEIFER, K. (eds.) (2004): Bergey's Manual of Systematic Bacteriology, (5 volumes). - Springer, Heidelberg, Germany.

CONNELL, J.H. (1978): Diversity in tropical rain forests and coral reefs. - Science 199: 13021310.

DULAMSUREN, CH. (2004): Floristische Diversität, Vegetation und Standortbedingungen in der Gebirgstaiga des West-Khentej, Nordmongolei. - Diss., Univ. Göttingen.

ELDRIDGE, D.J.; KOEN, T.B. (1998): Cover and floristics of microphytic soil crusts in relation to indices of landscape health. - Plant Ecology 137: 101-114.

FENDER, A.-C.; PFEIFFER, B.; GANSERT, D.; LEUSCHNER, C.; DANIEL, R.; JUNGKUNST, H.F. (2012): The inhibiting effect of nitrate fertilization on methane uptake of a temperate forest soil is influenced by labile carbon. - Biology and Fertility of Soils (online first). DOI 10.1007/ s00374-011-0660-3.

FIERER, N.; JACKSON, R.J. (2006): The diversity and biogeography of soil bacterial communities. - Proc. Nat. Acad. Sci. USA 103: 626-631.

FREY, S.D.; KNORR, M.; PARRENT, J.L.; SIMPSON, R.T. (2004): Chronic nitrogen enrichment affects the structure and function of the soil microbial community in temperate hardwood and pine forests. - Forest Ecology and Management 196: 159-171.

GARCIA-PICHEL, F.; BELNAP, J. (1996): Microenvironments and microscale productivity of cyanobacterial desert crusts. - Journal of Phycology 32: 774-782.

GIRVAN, M.S.; BULLIMORE, J.; PRETTY, J.N.; OSBORN, A.M.; BALLS, A.S. (2003): Soil type is the primary determinant of the composition of the total and active bacterial communities in arable soils. - Applied and Environmental Microbiology 69: 1800-1809.

HARPER, K.T.; MARBLE, J.R. (1988): A role for nonvascular plants in management of arid and semi-arid rangelands. - In: TUELLER, P.T. (ed.): Vegetation science applications for rangeland analysis and management. - Kluwer Academic Publishers, Dordrecht, p. 136-169.

HOUSMAN, D.C.; POWERS, H.H.; COLLINS, A.D.; BELNAP, J. (2006): Carbon and nitrogen fixation differ between successional stages of biological soil crusts in the Colorado Plateau and Chihuahuan Desert. - Journal of Arid Environments 66: 620-634.

HUANG, L.-N.; TANG, F.-Z.; SONG, Y.-S.; WAN, C.-Y.; WANG, S.-L.; LIU, W.-Q.; SHU, W.-S. (2011): Biodiversity, abundance, and activity of nitrogen-fixing bacteria during primary succession on a copper mine tailings. - FEMS Microbiology Ecology 78: 439-450.

HUBER, T.; FAULKNER, G.; HUGENHOLTZ, P. (2004): Bellerophon: a program to detect chimeric sequences in multiple sequence alignments. - Bioinformatics 20: 2317-2319.

JONES, R.T.; ROBESON, M.S.; LAUBER, C.L.; HAMADY, M.; KNIGHT, R.; FIERER, N. (2009): A comprehensive survey of soil acidobacterial diversity using pyrosequencing and clone library analyses. - The ISME Journal 3: 442-453.

KEMMLING, A.; KÄMPER, M.; FLIES, C.; SCHIEWECK, O.; HOPPERT, M. (2004): Biofilms and extracellular matrices on geomaterials. - Environmental Geology 46: 429-435.

KUSKE, C.R.; YEAGER, C.M,; JOHNSON, S.; TICKNOR, L.O.; BELNAP, J. (2012): Response and resiliance of soil biocrust bacterial communities to chronic physical disturbance in arid shrublands. - The ISME Journal 6: 886-897.

LANGE, O.L. (2001): Photosynthesis of Soil Crust Biota as Dependent on Environmental Factors. - In: BELNAP, J.; LANGE, O.L. (eds.): Biological Soil Crusts: Structure, Function and Management. - Springer, Berlin, Heidelberg, New York, p. 217-240. 
LAUBER, C.L.; HAMADY, M.; KNIGHT, M.; FIERER, N. (2009): Pyrosequencing-based assessment of soil $\mathrm{H}$ as a predictor of soil bacterial community structure at the continental scale. - Applied and Environmental Microbiology 75: 5111-5120.

MAIDAK, B.L.; LARSEN, N.; MCCAUGHEY, M.J.; OVERBEEK, R.; OLSEN, G.J.; FOGEL, K.; BLANDY, J.; WOESE, C.R. (1994): The Ribosomal Database project. - Nucleic Acids Research 22: $3485-3487$.

MARILLEY, L.; ARAGNO, M. (1999): Phylogenetic diversity of bacterial communities differing in degree of proximity of Lobium perenne and Trifolium repens roots. - Applied Soil Ecology 13: $127-136$.

MAZOR, G.; KIDRON, G.J.; VONSHAK, A. (1996): The role of cyanobacterial exopolysaccharides in structuring desert microbial crusts. - FEMS Microbiology Ecology 21: 121-130.

MÜHLENBERG, M.; HONDONG, H.; DULAMSUREN, CH.; VON GADOW, K. (2004): Large-scale biodiversity research in the southern taiga, Northern Mongolia. - Forest, Snow and Landscape Research 78: 93-118.

NACKE, H.; TÜRMER, A.; WOLLHERR, A.; WILL, C.; HODAC, L.; HEROLD, N.; SCHÖNING, I.; SCHRUMPF, M.; DANIEL, R. (2011): Pyrosequencing-based assessment of bacterial community structure along different management types in German forest and grassland soils. - Plos One 6: 1-12.

NAGY, M.L.; PEEREZ, A.; GARCIA-PICHEL, F. (2005): The prokaryotic diversity of biological soil crusts in the Sonoran Desert (Organ Pipe Cactus National Monument, AZ). - FEMS Microbiology Ecology 54: 233-245.

NOVICHKOVA-IVANOVA, L.N. (1977): Terrestrial algae of deserts in the Dgungar (Dzungarin) and Zaaltai (Transaltai) Gobi. - Botanicheskii Zhurnal 62: 1709-1719.

NOVICHKOVA-IVANOVA, L.N. (1980): Pochvennye vodorosli fitocenozov Saharo-Gobiiskoi pustynnoi oblasti (Soil algae of Sahara-Gobi desert region). - Nauka, Leningrad, pp. 1-256.

NOVICHKOVA-IVANOVA, L.N. (1988): Epilithic cenosis of algae of the Transaltai Gobi. - In Natural Conditions, Plant Cover and Animals of Mongolia. - Puschino, pp. 276-282.

OGORODNIKOV, A.V. (1981): Soils of mountain forests in Poeple's Republic of Mongolia. Nauka, Novosibirsk, 144 pp.

PALLMANN, H.; EICHENBERGER, E.; HASLER, A. (1940): Eine neue Methode der Temperaturmessung bei ökologischen und bodenkundlichen Untersuchungen. - Berichte der Schweizer Botanischen Gesellschaft 50: 337-362.

READ, C.F.; DUNCAN, D.H.; VESK, P.A.; ELITH, J. (2011): Surprisingly fast recovery of biological soil crusts following livestock removal in southern Australia. - Journal of Vegetation Science 22: 905-916.

REYSENBACH, A.-L.; PACE, N.R. (1995): Thermophiles. - In: ROBB, F.T.; PLACE, A.R. (eds.): Archaea: A Laboratory Manual - Cold Spring Harbour Laboratory Press, New York, pp. 101-107.

ROESCH, L.F.W.; FULTHORPE, R.R.; RIVA, A.; CASELLA, G.; HADWIN, A.K.M.; KENT, A.D.; DAROUB, S.H.; CAMARGO, F.A.O.; FARMERIE, W.G.; TRIPLETT, E.W. (2007): Pyro-sequencing enumerates and contrasts soil microbial diversity. - The ISME Journal 1: 283-290.

SCHEFFER, F.; SCHACHTSCHABEL, P. (1992): Lehrbuch der Bodenkunde. - 13. Aufl., EnkeVerl., Stuttgart, Germany.

SCHLOSS, P.D.; HANDELSMANN, J. (2005): Introducing DOTUR, a computer program for defining operational taxonomic units and estimating species richness. - Applied and Environmental Microbiology 71:1501-1506. 
SESSITSCH, A.; WEILHARTER, A.; GERZABEK, M.H.; KIRCHMANN, H.; KANDELER, E. (2001): Microbial population structures in soil particle size fractions of a long-time fertilizer field experiment. - Applied and Environmental Microbiology 67: 4215-4224.

STADEN, R.; BEAL K.F.; BONFIELD, J.K. (2000): The Staden Package, 1998. - Bioinformatics Methods Protocols 132: 115-130.

VIPPER, P.B. (1953): Forests of the Southwestern Khentej Mountains. - Trudy Mongol'skoy Kommissii 54: 1-55.

WIELAND, G.; NEUMANN, R.; BACKHAUS, H. (2001): Variation of microbial communities in soil, rhizosphere in response to crop species, soil type, and crop development. - Applied and Environmental Microbiology 67: 5849-5854.

WYSS, D. (2006): Waldmanagement in der Mongolei. - Diss., FU Berlin, Germany.

ZUL, D.; DENZEL, S.; KOTZ, A.; OVERMANN, J. (2007): Effect of plant biomass, plant diversity, and water content on bacterial communities in soil lysimeters: implications for the determinants of bacterial diversity. - Applied and Environmental Microbiology 73: 6916-6929.

\section{Addresses:}

Anne Kemmling*

Department of Conservation Biology

University of Göttingen

Bürgerstraße 50, 37073

D-37073 Göttingen

Corresponding author:

e-mail: a_kemmling@yahoo.de

Birgit Pfeiffer

Rolf Daniel

Michael Hoppert**

Institut für Mikrobiologie und Genetik

University of Göttingen

Grisebachstraße 8

D-37077 Göttingen

*and:

Institut für Mikrobiologie und Genetik

University of Göttingen

** and: Courant Research Centre

of Geobiology

Goldschmidtstraße 3

D-37033 Göttingen 
"When things get too complicated, it sometimes makes sense to stop and wonder: Have

I asked the right question?"

Enrico Bombieri (*1962)

(Author and Journalist)

\section{Discussion}

Microbial diversity, abundance, and activity in soils depend on physiochemical conditions and resources, such as $\mathrm{pH}$, temperature, salinity, availability of minerals, and nutrient content. Soil-inhabiting microorganisms are metabolically diverse and play a key role in nutrient cycles. Thus, microorganisms in return influence the physiochemical conditions of the soil habitat, and impact ecosystem functioning. The main objective of this project was to assess the impact of tree species identity, tree species diversity, leaf litter overlay, $\mathrm{N}$ fertilization, and ant activity on soil prokaryotic diversity, community composition, and activity. Therefore, eight studies were conducted in the laboratory, in climatic chambers, and in the field. These studies can be devided into three major topics:

1) Effect of tree species identity, tree species diversity, leaf litter presence and sampling time on soil microbial communities

2) Impact of $\mathrm{N}$ fertilization on soil microbial communities and greenhouse gas fluxes

3) Influence of Lasius ants acting as ecosystem engineers

For the analyses of prokaryotic community composition and diversity, amplicon-based sequencing and denaturing gradient gel electrophoresis (DGGE) were employed. Diversity and richness estimations were calculated and the impact of the respective influencing factor was investigated by statistical analyses. 


\section{Effect of tree species identity, tree species diversity, leaf litter presence, and sampling time effects on soil microbial communities}

The soil microbial communities analyzed in Chapter B.I were influenced directly and indirectly by differences related to tree species, such as leaf litter or root exudation. The DGGE-based cluster analyses, as well as the amplicon-derived data of the first study, suggest that leaf litter decomposition and its presence as a covering layer affects soil bacterial community composition in pH-stable soils (Pfeiffer et al. 2013). It was shown that tree litter affected the nutrient status and the soil $\mathrm{pH}$ in the upper soil horizon (Guckland et al. 2009; Jacob et al. 2009; Thoms et al. 2010). Leaf litter differs in its nutrient composition depending on the tree species and thus differentially affects soil nutrient pools. Litter originating from Fagus sylvatica has the lowest and Fraxinus excelsior the highest $\mathrm{N}$ and $\mathrm{P}$ concentrations compared to Tilia spp., Carpinus betulus, Acer pseudoplatanus, and Acer platanoides (Jacob et al. 2009). Additionally, it was shown that the $\mathrm{C}: \mathrm{N}$ ratio, an indicator of tissue quality and $\mathrm{N}$ availability, and the $\mathrm{C}: \mathrm{P}$ and lignin: $\mathrm{N}$ ratio were negatively correlated with leaf litter decomposition (Jacob et al. 2010). Beech litter has a higher $\mathrm{C}: \mathrm{N}$ ratio and litter content than ash litter and is regarded as low-quality litter (Jacob et al. 2010). High-quality ash litter is decomposed fast and disappears after two years in the field (Jacob et al. 2009). A study revealed that the microbial community structure in autumn, assessed by phospholipid fatty acid analysis (PFLA), was primarily influenced by beech litter and the effect of this tree species on soil pH values (Thoms and Gleixner 2013). In early summer, the microbial community was influenced more directly by tree species, as higher microbial abundances occurred in sites with increased amounts of high-quality litter, such as ash litter (Thoms and Gleixner 2013).

Nutrients originating from litter are channeled to soil via litter leaching and microbial driven decomposition. As microorganisms need $\mathrm{C}$ and $\mathrm{N}$ for their growth, the nutrient availability in soils has the greatest effect on microbial abundance and community composition (Thoms et al. 2010). Litter species qualities differently affect soil nutrient stocks, in which repeated input of low-quality litter results in significantly lower soil nutrient stocks (Guckland et al. 2009; Thoms and Gleixner 2013). Moreover, the decomposition and leaching of different litter qualities influences the rate of soil acidification (Guckland et al. 2009). Soil acidification was excluded as an influencing factor in the first survey, as the investigated soil had a high natural carbonate content 
buffering soil acidification (Pfeiffer et al. 2013). Another factor indirectly influencing soil microbial communities indirectly is the amount of leaf litter present as a cover layer on the forest floor which influences abiotic factors such as soil temperature and moisture (Chemidlin Prevost-Boure et al. 2011). This is in accordance with the results from the first study, which suggests a growing and persistent influence of the leaf litter layer on the soil-inhabiting bacterial community over time (Pfeiffer et al. 2013). The amount of litter deposited by the growing young tree presumably increased during the study.

Although no influence of tree species diversity on soil microbial community structure and diversity was observed, an impact of young tree species on the diversity of the active soil bacterial community was indicated (Pfeiffer et al. 2013). Nacke et al. (2011) found statistically significant effects of tree species on soil bacterial diversity, richness, and community composition in forest soils. These findings are partially supported by the results obtained in the second survey. The obtained data point out that beech and ash interact differentially with the soil microbial community (Cesarz et al. 2013). Beech roots affected the belowground system by their exudates and thus influence microbial communities in the rhizosphere and soil C dynamics (Cesarz et al. 2013). The tree species Fagus sylvatica L. (European beech) and Fraxinus excelsior L. (European ash), used in both surveys, differ strongly in their litter quality and root morphology. Beech has a higher specific root tip abundance, specific fine root surface area, specific fine root length and a lower fine root diameter than ash (Meinen et al. 2009). Moreover, both tree species have different mycorrhizal colonization pattern, as beech roots are colonized by ectomycorrhizal fungi, while ash roots are inhabited by arbuscular fungi (Smith and Read 2008). Fender et al. (2013) found increased concentrations of formate and acetate close to the roots of beech whereas, acetate concentrations were higher in the vicinity of ash roots. It has been shown that organic acids released by roots caused significant increases in soil bacterial community richness and shifts in the community structure (Shi et al. 2011). This might be attributed to higher amounts of added carbon, soil organic matter solubilization, or induced soil pH shifts (Shi et al. 2011).

Different taxa within the orders Azospirillales, Bradyrhizobiales, Caulobacterales, Rhizobiales, Sphingomonadales, Burkholderiales, Nitrosomonadeles and Pseudomonadales were affected positively by root-derived organic acids (Shi et al. 2011). Furthermore, it has been shown that the low molecular weight $\mathrm{C}$ compounds (glucose and citric acid), released by tree roots significantly affect the relative 
abundance of bacterial phyla and proteobacterial classes, such as Alpha-, Gamma- and Betaproteobacteria, as well as the Bacteroidetes and Actinobacteria (Eilers et al. 2010). In conclusion, tree species actively shape soil bacterial communities by their root exudates, including organic acids, amino acids, sugars, fatty acids, growth factors, and dead cells (Uren 2007; Dennis et al. 2010).

Soil acidification by beech saplings observed in the second study, was also shown by Holzwarth et al. (2011) and Langenbruch et al. (2012). Organic acids released by plants increase nutrient availability, which is also supported by plant-driven soil acidification (Jones et al. 2004). As a consequence, beech shapes soil bacterial communities more strongly than ash, indirectly by soil acidification and directly by the release and allocation of nutrients. Thoms et al. (2010) concluded that microbial diversity is driven by indirect interactions with specific plant traits rather than by tree species diversity itself. Although the comparison of the total and active bacterial community inhabiting the analyzed rhizotrons revealed differences, the soil bacterial community composition was not affected significantly by tree saplings or inserted ash litter (Cesarz et al. 2013, Figure 3 and 4).

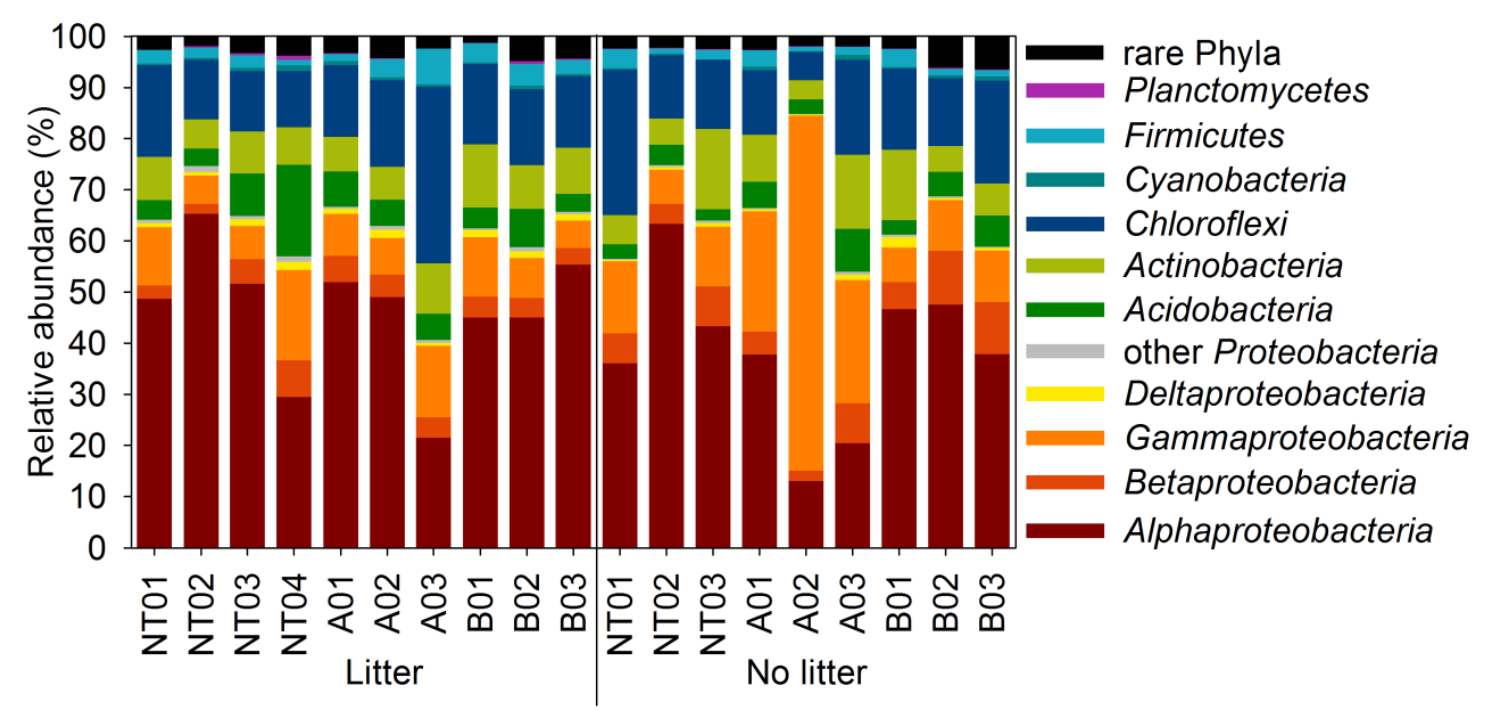

Figure 3. Relative abundance of the most abundant proteobacterial classes and bacterial phyla identified in the analyzed soil samples, based on 16S rRNA gene analysis. Taxa accounting for less than $1 \%$ of all analyzed sequences are summarized as rare phyla. Numbers indicate replicates of the control rhizotrons without tree saplings (NT) and the rhizotrons planted with ash (A) and beech (B) saplings. 


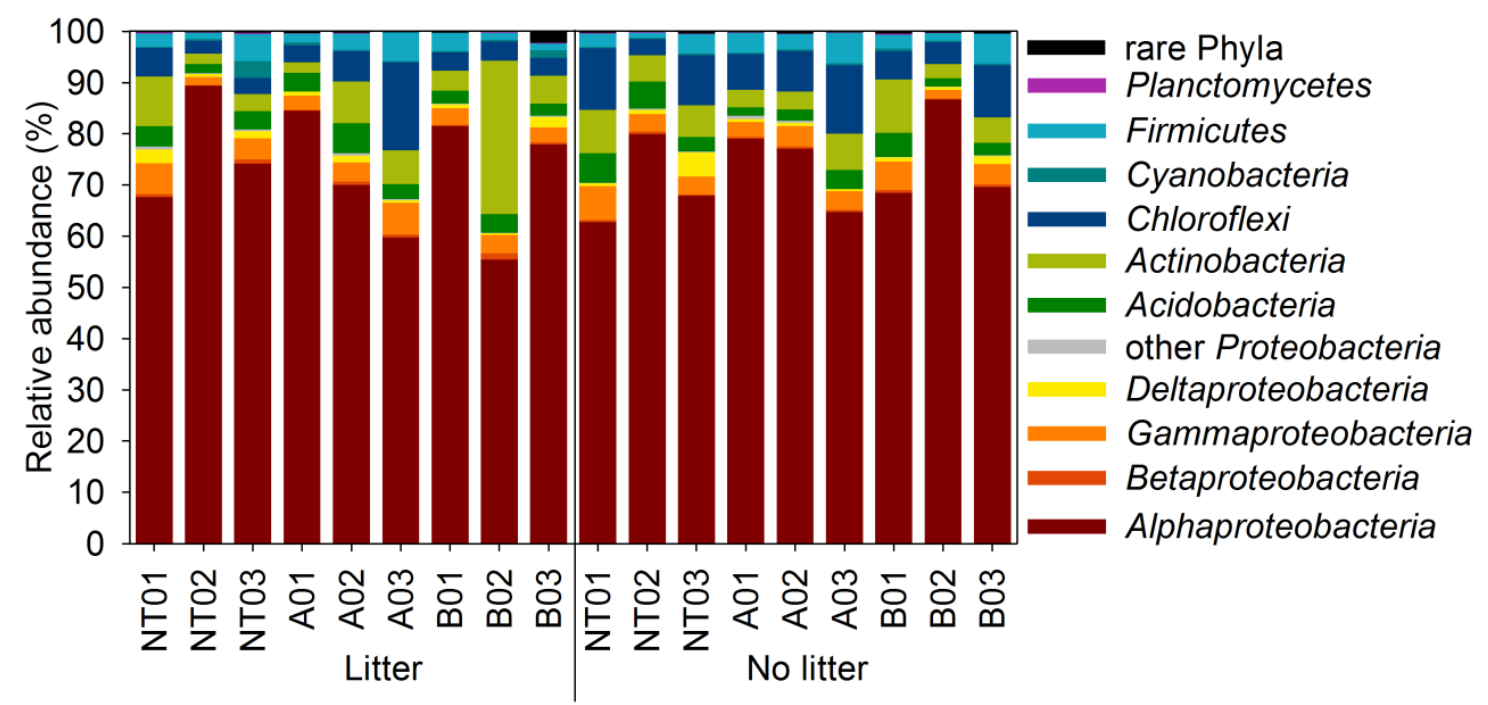

Figure 4. Relative abundance of the most abundant proteobacterial classes and bacterial phyla identified in the analyzed soil samples, based on $16 \mathrm{~S}$ rRNA analysis. Taxa accounting for less than $1 \%$ of all analyzed sequences are summarized as rare phyla. Numbers indicate replicates of the control rhizotrons without tree saplings (NT) and the rhizotrons planted with ash (A) and beech (B) saplings.

Phospholipid fatty acid analysis (PFLA) exhibited an increased fungal dominance, presumably of saprotrophic fungi, as low colonization rates (46 $\pm 6 \%$ ) of ectomycorrhizal fungi were determined for beech rhizotrons (Cesarz et al. 2013). PFLA data also revealed a suppression of Gram-negative and Gram-positive bacteria in the presence of beech saplings (Cesarz et al. 2013). Thus, the soil pH adjusted by beech root exudation inhibited bacterial growth but facilitated fungal growth, which was shown recently (Rousk et al. 2009). Preliminary results of the third survey indicate that bacterial and fungal diversity in natural spruce forest soil were largely driven by the soil $\mathrm{pH}$ (Goldmann et al. unpublished). The influence of $\mathrm{pH}$ on soil bacterial communities has been shown repeatedly (Fierer and Jackson 2006; Hartman et al. 2008; Lauber et al. 2009; Rousk et al. 2009; Dimitriu and Grayston 2010; Nacke et al. 2011; Yamamura et al. 2013). Nevertheless, if the soil $\mathrm{pH}$ affects the soil microbial community directly or indirectly remains unclear, as a number of soil properties are directly or indirectly related to $\mathrm{pH}$ (Brady and Weil 2002).

However, it was shown that specific bacterial genera such as Amaricoccus, Nocardioides, and Leptothrix were significant more abundant in beech forest soils, while Methylocapsa and Burkholderia showed significant higher abundances in spruce forest soils (Nacke et al. 2011). Deltaproteobacteria were less abundant in spruce forest than in beech forest soils (Nacke et al. 2011). So far, statistically reliable data are rare, 
as replicates are often missing, and due to the complexity of soil, single factors influencing the microbial community are often difficult to identify.

First results of the third study revealed a significant impact of the analyzed tree species on soil bacterial and fungal community composition (Goldmann, K., Nacke, H., Schöning, I. et al. unpublished data). In addition, it has been shown that the genetic diversity of Populus spp., determining functional plant traits, strongly affects soil microbial communities and soil processes (Schweitzer et al. 2011).

A recent survey suggests that plant-induced variations in resource availability in beech forests led to seasonal variations in functional properties of soil microorganisms. These patterns are attributed to seasonal changes in microbial community structure and physiological adaptations of microorganisms. Koranda et al. (2013) observed different microbial patterns reflecting distinct physiological capacities of winter and summer communities. The winter community revealed a higher capacity for degradation of complex $\mathrm{C}$ substrates such as cellulose and plant cell wall constituents, and a lower utilization capacity for labile $\mathrm{C}$ sources than the summer community (Koranda et al. 2013). These results were supported by the findings of the first survey, in which a sampling time effect (autumn vs. spring) on the soil inhabiting bacterial community was observed (Pfeiffer et al. 2013). It has been suggested that tree species identity may substantially alter the soil source and sink strength for greenhouse gases through rootrelated processes (Fender et al. 2013). The measured $\mathrm{CH}_{4}$ uptake was significantly lower and $\mathrm{N}_{2} \mathrm{O}$ gas emission was higher in beech rhizotrons than in ash treatments (Fender et al. 2013). This supports the assumption made in this study, that tree species and their specific activity affects soil bacterial diversity, richness, and community composition in forest soils (Pfeiffer et al. 2013). Furthermore, the results suggest that tree species developmental stage influences soil microbial communities, as old and big trees release more root exudates and deposit a higher litter amount compared to young trees.

\section{Impact of rising Nitrogen deposition into forest soils on bacterial activity and community composition}

Another factor influencing soil microbial community composition and activity are the rising soil N deposition rates (Duce et al. 2008; Galloway et al. 2008). Th effect of high soil $\mathrm{N}$ deposition was analyzed in Chapter B.II. To simulate the impact of high $\mathrm{N}$ 
depositions into soils on the greenhouse gas emission and forest soil bacterial communities, a mesocosms study was established under controlled laboratory conditions (Figure 5). An additional experiment analyzed the effect of a labile $\mathrm{C}$ source on $\mathrm{N}_{2} \mathrm{O}$ and $\mathrm{CH}_{4}$ gas fluxes in forest soils (Fender et al. 2012; Fender, AC., Leuschner, C., Pfeiffer, B., Daniel, R. and Jungkunst, HF. unpublished data). The greenhouse gas fluxes and the soil properties were analyzed. Furthermore, the structure and diversity of the active soil microbial community was determined 3 days after the first fertilization and at the end of the first study phase on day 41 using $16 \mathrm{~S}$ rRNA-based pyrosequencing.

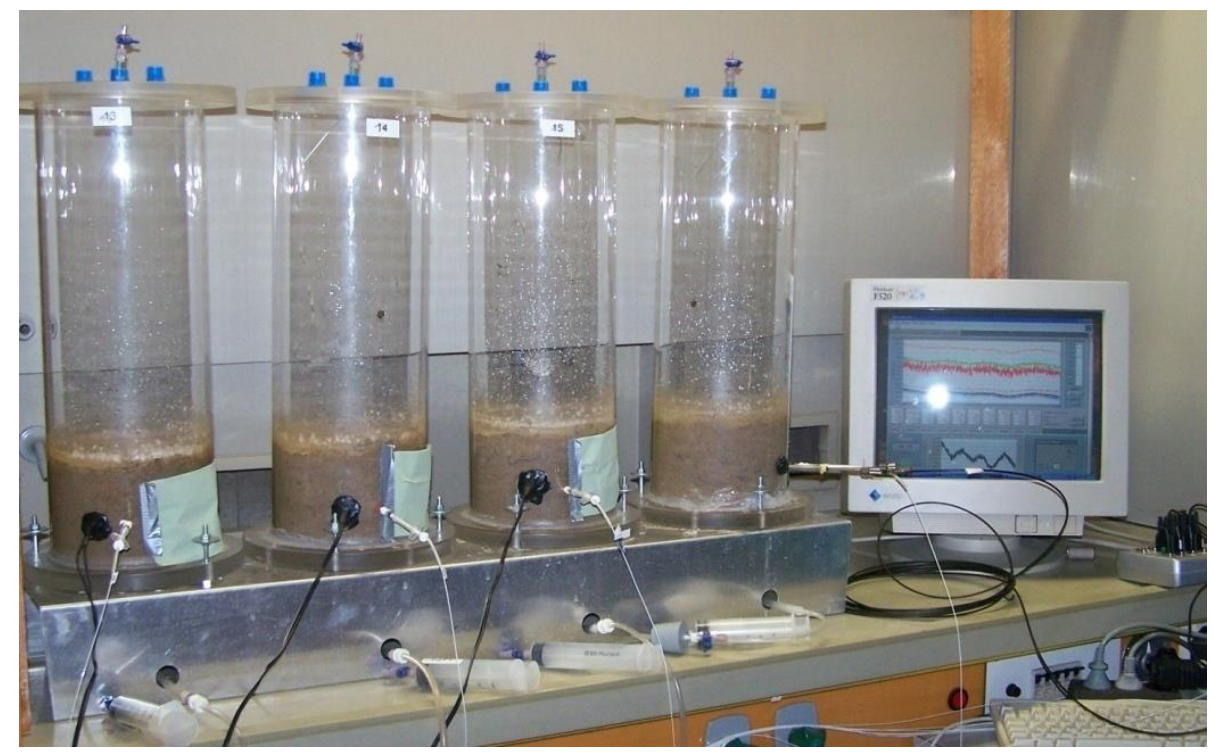

Figure 5. Experimental set-up of the fertilized and non-fertilized soil columns analyzed in Chapter B.II.

The comparison of $\mathrm{CH}_{4}$ uptake rates in fertilized and non-fertilized soil columns showed a significant decline of $97 \%$ in $\mathrm{NO}_{3}{ }^{-}$fertilized mesocosms, indicating an inhibitory effect of $\mathrm{NO}_{3}{ }^{-}$fertilization on $\mathrm{CH}_{4}$ oxidation (Fender et al. 2012). In contrast, low doses of $\mathrm{NO}_{3}{ }^{-}$stimulated $\mathrm{CH}_{4}$ uptake rates and bacterial growth (Rigler and Zechmeister-Boltenstern 1999). The latter presumably benefits from the thus created higher $\mathrm{N}$ availability in $\mathrm{N}$ limited soils. Another survey showed that high doses of $\mathrm{NO}_{3}^{-}$ had no effect on the $\mathrm{CH}_{4}$ uptake in a boreal spruce forest soil (Whalen and Reeburgh 2000). Other surveys support our findings of a negative effect of $\mathrm{NO}_{3}{ }^{-}$application on $\mathrm{CH}_{4}$ uptake rates (Butterbach-Bahl et al. 1998; Ishizuka et al. 2009). It was shown that the suppression of $\mathrm{CH}_{4}$ oxidation in soils by high doses of nitrogenous fertilizers is 
contradictory, as long lasting as well as short time effects were observed (Hütsch et al. 1993; 1994). The observed reduction of $\mathrm{CH}_{4}$ uptake rates by $\mathrm{NO}_{3}{ }^{-}$can be explained by a competitive substrate inhibition of the $\mathrm{CH}_{4}$ oxidizing enzyme methane monooxygenase (Dunfield and Knowles 1995). Nitrate is either reduced to $\mathrm{N}_{2} \mathrm{O}$ or $\mathrm{N}_{2}$ by denitrifying microorganisms or to $\mathrm{NH}_{4}{ }^{+}$by microorganism capable of dissimilatory $\mathrm{NO}_{3}{ }^{-}$reduction to ammonium (DNRA). The latter is supported by the observed increased $\mathrm{NH}_{4}{ }^{+}$ concentration within the analyzed fertilized soil samples. Methanotrophs, a subgroup of the methylotrophic bacteria, utilize $\mathrm{CH}_{4}$ and other mono-carbon compounds as their sole energy and C-source (Trotsenko and Murrell 2008; Dedysh and Dunfield 2011). Thereby, the oxidation of $\mathrm{CH}_{4}$ to methanol $\left(\mathrm{CH}_{3} \mathrm{OH}\right)$ is catalyzed by the particulate or soluble methane monooxygenase (pMMO or sMMO, respectively) (Dedysh and Dunfield 2011). The particulate methane monooxygenase (pMMO) is closely related to the ammonium monooxygenase (AMO) and has the ability to oxidize ammonia to nitrite, which competitively inhibits the $\mathrm{CH}_{4}$ uptake in soils (Mosier et al. 1991; Dunfield and Knowles 1995; Klotz and Norton 1998). In conclusion, nitrifiers possessing the AMO that oxidize ammonium to hydroxylamine are able to oxidize $\mathrm{CH}_{4}$ (Hyman and Wood 1983; Jones and Morita 1983; Ward 1987; Bédard and Knowles 1989; Holmes et al. 1995). In this study, the relative abundance of the archaeal genus Candidatus Nitrosotalea increased in non-fertilized soil columns compared to fertilized columns (Pfeiffer, B., Fender, AC., Jungkunst. HF. and Daniel, R. submitted for publication). The eponym of Candidatus Nitrosotalea is the chemolithotrophic and obligately acidophilic ammonia-oxidizing archaeon Nitrosotalea devanaterra (Lehtovirta-Morley et al. 2011). Moreover, the bacterial genus Nitrosospira was identified in the amplicon-derived data-set, accounting for $0.14 \%$ of the analyzed sequences in non-fertilized samples and $0.03 \%$ in fertilized samples (Pfeiffer, B., Fender, AC., Jungkunst. HF. and Daniel, R. submitted for publication). Although identified only in low abundances, both genera may contribute considerably to the observed $\mathrm{CH}_{4}$ uptake rates in non-fertilized samples. Surprisingly, the active methanotrophic community analyzed using specific primers showed no difference in the relative abundance of the identified methanotrophic genera in both, fertilized and nonfertilized, soil samples (Pfeiffer, B., Fender, AC., Jungkunst. HF. and Daniel, R. submitted for publication). This accounts for the competitive substrate inhibition of the $\mathrm{CH}_{4}$ oxidizing enzyme by the observed increased $\mathrm{NH}_{4}{ }^{+}$concentration within the analyzed fertilized soil samples (Fender et al. 2012). Furthermore, hydroxylamine and 
nitrite built up during methanotrophic ammonia oxidation and nitrification can be toxic to methanotrophic bacteria and thus lead to a reduced methane consumption in fertilized soil columns (Schnell and King 1994). Nitrite-dependent anaerobic methane oxidation possibly contributed to the remaining $\mathrm{CH}_{4}$ emission of $3.23 \pm 0.14 \mu \mathrm{g} \mathrm{C} \mathrm{m}^{-2} \mathrm{~h}^{-1}$ in fertilized soil columns (Ettwig et al. 2008; Ettwig et al. 2010).

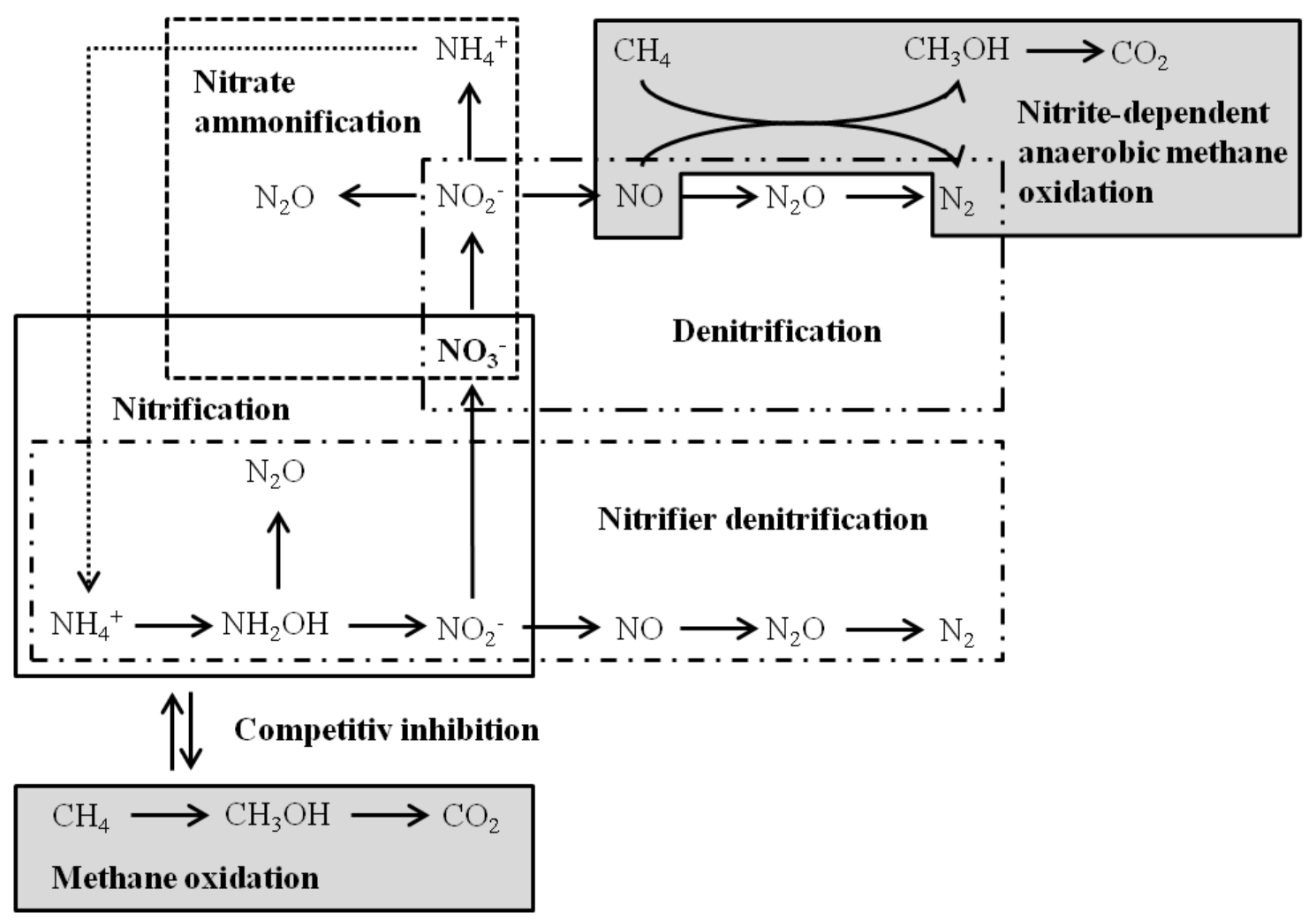

Figure 6. Coupling of microbial processes contributing to $\mathrm{N}_{2} \mathrm{O}$ and $\mathrm{CO}_{2}$ emissions, and the uptake of $\mathrm{CH}_{4}$ in forest soils. Adapted from Wrage et al.(2001), Baggs (2008) and Ettwig et al. (2010).

The coupling of the soil microbial processes responsible for the observed patterns in $\mathrm{CH}_{4}$ and $\mathrm{N}_{2} \mathrm{O}$ gas fluxes is depicted in Figure 6. Within the fertilized soil columns the bacterial diversity was reduced and the bacterial community shifted towards a denitrifying community (Pfeiffer, B., Fender, AC., Jungkunst. HF. and Daniel, R. submitted for publication). The latter was supported by the increased $\mathrm{N}_{2} \mathrm{O}$ emission rates measured in the course of the survey (Fender, AC., Leuschner, C., Pfeiffer, B., Daniel, R. and Jungkunst, HF. unpublished data). The relative abundances of the Deltaproteobacteria, Acidobacteria, Gemmatimonadetes, and Verrucomicrobia decreased significantly whereas, the relative abundance of the Gammaproteobacteria 
increased significantly (Pfeiffer, B., Fender, AC., Jungkunst. HF. and Daniel, R. submitted for publication). The bacterial community of the fertilized soil columns was dominated by the genus Rhodanobacter (Gammaproteobacteria), accounting for 46.9 $\pm 20.3 \%$ of the analyzed sequences. Members of this genus such as Rhodanobacter thiooxydans or Rhodanobacter denitrificans sp. are capable of denitrification (van den Heuvel et al. 2010; Prakash et al. 2012). The latter was shown to be capable of complete denitrification (Prakash et al. 2012). Recently, it has been shown that the genus Rhodanobacter dominates bacterial communities inhabiting soils and groundwater with low $\mathrm{pH}$ and high $\mathrm{NO}_{3}{ }^{-}$concentrations (van den Heuvel et al. 2010; Green et al. 2012). Furthermore, the decline in bacterial diversity may also partially be attributed to changes in the soil $\mathrm{pH}$, although this is not very likely as the fertilized soil columns exhibited a higher $\mathrm{pH}(4.23 \pm 0.06)$ compared to the non-fertilized (3.84 \pm 0.08$)$.

The examined archaeal community was not influenced significantly by the applied fertilization, but differences in the relative abundance of the Candidatus Nitrosotalea (Thaumarchaeota) were observed (Pfeiffer, B., Fender, AC., Jungkunst. HF. and Daniel, R. submitted for publication). Additionally, the significantly higher $\mathrm{CO}_{2}$ emission rates in non-fertilized soil columns compared to fertilized columns indicate a reduced bacterial activity. The decreased $\mathrm{CO}_{2}$ emission rates measured in both treatments indicated a reduction of available $\mathrm{C}$ in $\mathrm{C}$-limited soil samples over time. The $\mathrm{C}$ limitation is caused by microbial activity which in return reduced bacterial activity. This was also supported by soil $\mathrm{C}: \mathrm{N}$ ratio, which dropped throughout the experiment more strongly in $\mathrm{N}$ fertilized than in non-fertilized microcosms. Gillam et al. (2008) also showed that the $\mathrm{C}$ availability affects the $\mathrm{NO}_{3}{ }^{-}$reduction in soils and thus controls $\mathrm{N}_{2} \mathrm{O}$ emissions.

The second phase of the survey revealed that the addition of glucose as a labile $\mathrm{C}$ source, overcoming the $\mathrm{C}$ limitation in the soil, resulted in significantly increased $\mathrm{CO}_{2}$ emission rates in fertilized and non-fertilized soil columns (Fender, AC., Leuschner, C., Pfeiffer, B., Daniel, R. and Jungkunst, HF. unpublished data). Furthermore, $\mathrm{N}_{2} \mathrm{O}$ emission rates increased significantly in both treatments after the addition of labile $\mathrm{C}$, indicating a higher bacterial activity due to a more balanced and favorable $\mathrm{C}: \mathrm{N}$ ratio. The addition of labile $\mathrm{C}$ inhibited the $\mathrm{CH}_{4}$ uptake in non-fertilized soil columns presumably due to another easily available $\mathrm{C}$ source. 


\section{Influence of Lasius ants acting as ecosystem engineers}

The impact of Lasius ants on nutrient flows from aboveground systems into belowground systems and on the soil-inhabiting microbial communities was analyzed in Chapter B.III. In the first study, the interaction between ants (Lasius niger), aphids (Aphis fabae), and the soil microbial community was investigated in soil mesocosms using DGGE as a molecular approach. Furthermore, stable isotope techniques were used to follow the $\mathrm{N}$ flow from Phaseolus vulgaris plants inhabited by aphids into soil and the soil microbial community. The amount of honeydew dropping on the litter surface is reduced by ants which consume it as a reward for protection (Gerund, E., Pfeiffer, B., Daniel, R. and Platner, C. (a) unpublished data). In this way, the microbial biomass in the litter layer is reduced due to the decrease of this additional carbon source (Gerund, E., Pfeiffer, B., Daniel, R. and Platner, C. (a) unpublished data). It has been reported that the amount of honeydew reaching the soil ground was reduced by approximately $50 \%$ due to ant activity (Seeger and Filser 2008). In addition, the reallocation of honeydew into ant nests and the surrounding soil increased the basal respiration and microbial biomass in comparison to the control, indicating a higher activity of the microbial community (Gerund, E., Pfeiffer, B., Daniel, R. and Platner, C. (a) unpublished data). In contrast, the cluster analysis of the derived DGGE profiles revealed no distinct separation of the different treatments, possibly due to other, more influential soil parameters (Gerund, E., Pfeiffer, B., Daniel, R. and Platner, C. (a) unpublished data). Another explanation might be that the microbial community inhabiting the artificial microcosms was not fully adapted to the influence of ant activity. Nevertheless, it was assumed that C-limitation is the most important factor influencing microbial growth and activity in soils (Scheu and Schaefer 1998). Honeydew is an easily available and rapidly consumable resource for microorganisms, providing sugars and amino acids. Thus, the input of additional sugars and nitrogen-rich organic compounds into the soil promoted by ants supports prokaryotic activity and increases microbial biomass.

The second survey analyzed differences in bacterial community structure in Lasius niger and Lasius flavus ant nests, and the surrounding soil in two different grassland sites. The functional diversity of microorganisms was analyzed by in situ respiration response. The obtained results showed that ant activity led to shifts in structure and functioning of microbial communities in ant nests compared to the surrounding soil 
(Gerund, E., Pfeiffer, B., Daniel, R. and Platner, C. (b) unpublished data). Lasius ants increase nutrient concentrations such as $\mathrm{NO}_{3}{ }^{-}$, phosphate, potassium and calcium in nest mounts by the accumulation of food such as honeydew or other organic substances (Nkem et al. 2000; Frouz et al. 2003; Frouz et al. 2005). Furthermore, ants adjust the pH in their nest mounts. It was shown that $\mathrm{pH}$ values in ant nests on acidic soils increase compared to the surrounding soil, while the $\mathrm{pH}$ in nests on alkaline soils decrease (Frouz et al. 2003). In mounts ant activities increase soil porosity into a depth of about $200 \mathrm{~cm}$ (Nkem et al. 2000).

The observed variations in microbial community structure and functioning were more pronounced between the grassland sites than between the different ant species (Gerund, E., Pfeiffer, B., Daniel, R. and Platner, C. (b) unpublished data). This indicates a higher impact of site specific properties, such as $\mathrm{C}: \mathrm{N}$ ratio, organic $\mathrm{C}$ content, $\mathrm{pH}$ or water content. As mentioned previously, it was shown that soil properties such as $\mathrm{pH}$, moisture, and nutrient availability influence soil microbial communities (Thoms et al. 2010; Nacke et al. 2011; Brockett et al. 2012). Both sites differed in the soil type (Leptosol vs. Cambisol), but had a comparable pH (7.4 vs. 7.5), annual temperature and precipitation (Gerund, E., Pfeiffer, B., Daniel, R. and Platner, C. (b) unpublished data). Thus, the observed variations might be attributed to differences in the nutrient content and soil type of the two sites studied. Higher microbial biomass and respiration response, as well as more diverse bacterial community patterns were observed in the Cambisol site (Gerund, E., Pfeiffer, B., Daniel, R. and Platner, C. (b) unpublished data). Furthermore, the cluster analysis of the obtained DGGE profiles revealed a clear separation of soil microbial communities inhabiting ant nests and surrounding soils (Gerund, E., Pfeiffer, B., Daniel, R. and Platner, C. (b) unpublished data).

\section{Conclusion}

The studies presented in the first chapter of this thesis revealed a direct and indirect impact of tree species related traits such as leaf litter and root exudation on the diversity and structure of soil microbial communities. Leaf litter acting as a long-term $\mathrm{C}$ and nutrient source as well as tree species specific root exudation affected soil bacterial community composition and diversity. The obtained data further indicated that tree species diversity and seasonal fluctuations had only a minor effect on soil microbial communities compared to the effect of leaf litter and root exudation. The synthesis of 
the different studies suggested that increasing tree species developmental stages result in a higher deposition of leaf litter and root exudates. Thus, the intensity of tree species influence on soil microbial communities was rising with plant age. However, there is still a knowledge gap about the dynamics between tree developmental stages and microbial community structure as well as function. As this question has not been fully answered yet, further studies have to be conducted addressing this issue in more detail. Surveys presented in the second chapter analyzed the effect of high $\mathrm{N}$ depositions on soil prokaryotic communities and revealed a shift in the bacterial community structure towards a denitrifying community with reduced bacterial diversity. These studies provided a detailed insight into the coupling of greenhouse gas fluxes and $\mathrm{N}$ fertilization with the soil prokaryotic community structure and diversity. As forests are highly important $\mathrm{CH}_{4}$ sinks and sources of $\mathrm{N}_{2} \mathrm{O}$, knowledge about this coupling is crucial for estimating the effect of rising $\mathrm{N}$ depositions on global greenhouse gas balance and, consequently, life on Earth.

Studies in the third chapter were aimed at investigating the effect of ants on the aboveground and belowground system under natural and artificial conditions. In mesocosm experiments, it was shown that ants collecting aphids honeydew increased basal respiration and microbial biomass in the soil. However, distinct differences in soil microbial community structures were not observed. In contrast to this finding, ant activity in natural grassland habitats induced changes in microbial community composition as well as basal respiration and microbial biomass. Ants are important players in maintaining ecosystem functioning. They are modifying newly colonized ecosystems to match their needs and, additionally, stabilize conditions in already occupied ones. However, their complex interaction with these ecosystems especially with soil microbes, the other group of ecosystem engineers, is not fully understood as large comparative studies are missing. Thus, the studies presented in this thesis helped to close this fundamental knowledge gap.

The conducted studies emphasized the assumption that the complexity of soil and the diverse interactions taking place in this habitat make it difficult to identify and assess single influencing factors. Nevertheless, taking all the studies conducted in the term of this thesis into account soil $\mathrm{pH}$ seems to be the strongest manipulator of soil microbial community structure and diversity. 


\section{References}

Baggs, E.M. (2008) A review of stable isotope techniques for $\mathrm{N}_{2} \mathrm{O}$ source partitioning in soils: recent progress, remaining challenges and future considerations. Rapid Communications in Mass Spectrometry 22, 1664-1672.

Brady, N.C. and Weil, R.R. (2002) The Nature and Properties of Soils. Upper Saddler River, New Jersey 07458: Pearson Education.

Brockett, B.F.T., Prescott, C.E. and Grayston, S.J. (2012) Soil moisture is the major factor influencing microbial community structure and enzyme activities across seven biogeoclimatic zones in western Canada. Soil Biology and Biochemistry 44, 9-20.

Butterbach-Bahl, K., Gasche, R., Huber, C., Kreutzer, K. and Papen, H. (1998) Impact of $\mathrm{N}$-input by wet deposition on $\mathrm{N}$-trace gas fluxes and $\mathrm{CH}_{4}$-oxidation in spruce forest ecosystems of the temperate zone in Europe. Atmospheric Environment 32, $559-564$.

Bédard, C. and Knowles, R. (1989) Physiology, biochemistry, and specific inhibitors of $\mathrm{CH}_{4}, \mathrm{NH}_{4}^{+}$, and $\mathrm{CO}$ oxidation by methanotrophs and nitrifiers. Microbiological Reviews 53, 68-84.

Cesarz, S., Fender, A.-C., Beyer, F., Valtanen, K., Pfeiffer, B., Gansert, D., Hertel, D., Polle, A., Daniel, R., Leuschner, C. and Scheu, S. (2013) Roots from beech (Fagus sylvatica L.) and ash (Fraxinus excelsior L.) differentially affect soil microorganisms and carbon dynamics. Soil Biology and Biochemistry 61, 23-32.

Chemidlin Prevost-Boure, N., Maron, P.-A., Ranjard, L., Nowak, V., Dufrene, E., Damesin, C., Soudani, K. and Lata, J.-C. (2011) Seasonal dynamics of the bacterial community in forest soils under different quantities of leaf litter. Applied Soil Ecology 47, 14-23.

Dedysh, S.N. and Dunfield, P.F. (2011) Facultative and obligate methanotrophs how to identify and differentiate them. Methods in Enzymology 495, 31-44.

Dennis, P.G., Miller, A.J. and Hirsch, P.R. (2010) Are root exudates more important than other sources of rhizodeposits in structuring rhizosphere bacterial communities? FEMS Microbiology Ecology 72, 313-327. 
Dimitriu, P.A. and Grayston, S.J. (2010) Relationship between soil properties and patterns of bacterial beta-diversity across reclaimed and natural boreal forest soils. Microbial Ecology 59, 563-573.

Duce, R., LaRoche, J., Altieri, K., Arrigo, K., Baker, A., Capone, D., Cornell, S., Dentener, F., Galloway, J., Ganeshram, R., Geider, R., Jickells, T., Kuypers, M., Langlois, R., Liss, P., Liu, S., Middelburg, J., Moore, C., Nickovic, S., Oschlies, A., Pedersen, T., Prospero, J., Schlitzer, R., Seitzinger, S., Sorensen, L., Uematsu, M., Ulloa, O., Voss, M., Ward, B. and Zamora, L. (2008) Impacts of atmospheric anthropogenic nitrogen on the open ocean. Science 320, 893-897.

Dunfield, P. and Knowles, R. (1995) Kinetics of inhibition of methane oxidation by nitrate, nitrite, and ammonium in a humisol. Applied and Environmental Microbiology 61, 3129-3135.

Eilers, K., Lauber, C., Knight, R. and Fierer, N. (2010) Shifts in bacterial community structure associated with inputs of low molecular weight carbon compounds to soil. Soil Biology and Biochemistry, 896-903.

Ettwig, K., Shima, S., van de Pas-Schoonen, K., Kahnt, J., Medema, M., Op den Camp, H., Jetten, M. and Strous, M. (2008) Denitrifying bacteria anaerobically oxidize methane in the absence of Archaea. Environmental Microbiology 10, 3164-3173.

Ettwig, K.F., Butler, M.K., Le Paslier, D., Pelletier, E., Mangenot, S., Kuypers, M.M.M., Schreiber, F., Dutilh, B.E., Zedelius, J., de Beer, D., Gloerich, J., Wessels, H.J.C.T., van Alen, T., Luesken, F., Wu, M.L., van de Pas-Schoonen, K.T., Op den Camp, H.J.M., Janssen-Megens, E.M., Francoijs, K.-J., Stunnenberg, H., Weissenbach, J., Jetten, M.S.M. and Strous, M. (2010) Nitritedriven anaerobic methane oxidation by oxygenic bacteria. Nature 464, 543-548.

Fender, A.-C., Gansert, D., Jungkunst, H.F., Fiedler, S., Beyer, F., Schützenmeister, K., Thiele, B., Valtanen, K., Polle, A. and Leuschner, C. (2013) Root-induced tree species effects on the source/sink strength for greenhouse gases $\left(\mathrm{CH}_{4}, \mathrm{~N}_{2} \mathrm{O}\right.$ and $\mathrm{CO}_{2}$ ) of a temperate deciduous forest soil. Soil Biology and Biochemistry 57, 587597.

Fender, A.-C., Pfeiffer, B., Gansert, D., Leuschner, C., Daniel, R. and Jungkunst, H. (2012) The inhibiting effect of nitrate fertilisation on methane uptake of a temperate forest soil is influenced by labile carbon. Biology and Fertility of Soils 48, 621-631. 
Fender, A.-C., Leuschner, C., Pfeiffer, B., Daniel, R. and Jungkunst, H. Combined effects of nitrate and labile $\mathrm{C}$ on the $\mathrm{N}_{2} \mathrm{O}$ emissions of a temperate forest soil. unpublished data

Fierer, N. and Jackson, R. (2006) The diversity and biogeography of soil bacterial communities. Proceedings of the National Academy of Sciences U S A 103, 626631.

Frouz, J., Holec, M. and Kalčík, J. (2003) The effect of Lasius niger (Hymenoptera, Formicidae) ant nest on selected soil chemical properties. Pedobiologia 47, 205212.

Frouz, J., Kalcik, J. and Cudlin, P. (2005) Accumulation of phosphorus in nests of red wood ants Formica s. str. Annales Zoologici Fennici 42, 269-275.

Galloway, J.N., Townsend, A.R., Erisman, J.W., Bekunda, M., Cai, Z., Freney, J.R., Martinelli, L.A., Seitzinger, S.P. and Sutton, M.A. (2008) Transformation of the nitrogen cycle: recent trends, questions, and potential solutions. Science 320, 889892.

Gerund, E., Pfeiffer, B., Daniel, R. and Platner C. (a) Nutrient flow from aboveground to belowground systems and changes in soil microbial community driven by ants and homopteran honeydew. unpublished data

Gerund, E., Pfeiffer, B., Daniel, R. and Platner C. (b) Influence of Lasius ants on soil microbial communities in grasslands - a functional and molecular approach. unpublished data

Gillam, K.M., Zebarth, B.J. and Burton, D.L. (2008) Nitrous oxide emissions from denitrification and the partitioning of gaseous losses as affected by nitrate and carbon addition and soil aeration. Canadian Journal of Soil Science 88, 133-143.

Goldmann, K., Nacke, H., Schöning, I., Pfeiffer, B., Kaiser, K., Castillo-Villamizar, G., Wubet, T., Schrumpf, M., Buscot, F., and Daniel, R. Tree effects on diversity and structure of soil bacterial and fungal communities. unpublished data

Green, S.J., Prakash, O., Jasrotia, P., Overholt, W.A., Cardenas, E., Hubbard, D., Tiedje, J.M., Watson, D.B., Schadt, C.W., Brooks, S.C. and Kostka, J.E. (2012) Denitrifying bacteria from the genus Rhodanobacter dominate bacterial communities in the highly contaminated subsurface of a nuclear legacy waste site. Applied and Environmental Microbiology 78, 1039-1047.

Guckland, A., Jacob, M., Flessa, H., Thomas, F.M. and Leuschner, C. (2009) Acidity, nutrient stocks, and organic-matter content in soils of a temperate deciduous forest 
with different abundance of European beech (Fagus sylvatica L.). Journal of Plant Nutrition and Soil Science 172, 500-511.

Hartman, W., Richardson, C., Vilgalys, R. and Bruland, G. (2008) Environmental and anthropogenic controls over bacterial communities in wetland soils. Proceedings of the National Academy of Sciences U S A 105, 17842-17847.

Holmes, A.J., Costello, A., Lidstrom, M.E. and Murrell, J.C. (1995) Evidence that particulate methane monooxygenase and ammonia monooxygenase may be evolutionarily related. FEMS Microbiology Letters 132, 203-208.

Holzwarth, F.M., Daenner, M. and Flessa, H. (2011) Effects of beech and ash on smallscale variation of soil acidity and nutrient stocks in a mixed deciduous forest. Journal of Plant Nutrition and Soil Science 174, 799-808.

Hyman, M.R. and Wood, P.M. (1983) Methane oxidation by Nitrosomonas europaea. Biochemical Journal 212, 31-37.

Hütsch, B.W., Webster, C.P. and Powlson, D.S. (1993) Long-term effects of nitrogen fertilization on methane oxidation in soil of the broadbalk wheat experiment. Soil Biology and Biochemistry 25, 1307-1315.

Hütsch, B.W., Webster, C.P. and Powlson, D.S. (1994) Methane oxidation in soil as affected by land use, soil $\mathrm{pH}$ and $\mathrm{N}$ fertilization. Soil Biology and Biochemistry 26, 1613-1622.

Ishizuka, S., Sakata, T., Sawata, S., Ikeda, S., Sakai, H., Takenaka, C., Tamai, N., Onodera, S.-i., Shimizu, T., Kan-na, K., Tanaka, N. and Takahashi, M. (2009) Methane uptake rates in Japanese forest soils depend on the oxidation ability of topsoil, with a new estimate for global methane uptake in temperate forest. Biogeochemistry 92, 281-295.

Jacob, M., Viedenz, K., Polle, A. and Thomas, F.M. (2010) Leaf litter decomposition in temperate deciduous forest stands with a decreasing fraction of beech (Fagus sylvatica). Oecologia 164, 1083-1094.

Jacob, M., Weland, N., Platner, C., Schaefer, M., Leuschner, C. and Thomas, F.M. (2009) Nutrient release from decomposing leaf litter of temperate deciduous forest trees along a gradient of increasing tree species diversity. Soil Biology and Biochemistry 41, 2122-2130.

Jones, D., Hodge, A. and Kuzyakov, Y. (2004) Plant and mycorrhizal regulation of rhizodeposition. New Phytologist 163, 459-480. 
Jones, R.D. and Morita, R.Y. (1983) Methane Oxidation by Nitrosococcus oceanus and Nitrosomonas europaea. Applied and Environmental Microbiology 45, 401-410.

Klotz, M.G. and Norton, J.M. (1998) Multiple copies of ammonia monooxygenase (amo) operons have evolved under biased AT/GC mutational pressure in ammonia-oxidizing autotrophic bacteria. FEMS Microbiology Letters 168, 303311.

Koranda, M., Kaiser, C., Fuchslueger, L., Kitzler, B., Sessitsch, A., ZechmeisterBoltenstern, S. and Richter, A. (2013) Seasonal variation in functional properties of microbial communities in beech forest soil. Soil Biology and Biochemistry $\mathbf{6 0}$, 95-104.

Langenbruch, C., Helfrich, M. and Flessa, H. (2012) Effects of beech (Fagus sylvatica), ash (Fraxinus excelsior) and lime (Tilia spec.) on soil chemical properties in a mixed deciduous forest. Plant and Soil 352, 389-403.

Lauber, C., Hamady, M., Knight, R. and Fierer, N. (2009) Pyrosequencing-Based Assessment of Soil pH as a Predictor of Soil Bacterial Community Structure at the Continental Scale. Applied and Environmental Microbiology 5111-5120.

Lauber, C.L., Strickland, M.S., Bradford, M.A. and Fierer, N. (2008) The influence of soil properties on the structure of bacterial and fungal communities across landuse types. Soil Biology and Biochemistry 40, 2407-2415.

Lehtovirta-Morley, L.E., Stoecker, K., Vilcinskas, A., Prosser, J.I. and Nicol, G.W. (2011) Cultivation of an obligate acidophilic ammonia oxidizer from a nitrifying acid soil. Proceedings of the National Academy of Sciences U S A 108, 15892-7.

Meinen, C., Hertel, D. and Leuschner, C. (2009) Biomass and morphology of fine roots in temperate broad-leaved forests differing in tree species diversity: is there evidence of below-ground overyielding? Oecologia 161, 99-111.

Mosier, A., Schimel, D., Valentine, D., Bronson, K. and Parton, W. (1991) Methane and nitrous oxide fluxes in native, fertilized and cultivated grasslands. Nature 350, $330-332$.

Nacke, H., Thürmer, A., Wollherr, A., Will, C., Hodac, L., Herold, N., Schöning, I., Schrumpf, M. and Daniel, R. (2011) Pyrosequencing-based assessment of bacterial community structure along different management types in German forest and grassland soils. PLoS One 6, e17000. 
Nkem, J.N., Lobry de Bruyn, L.A., Grant, C.D. and Hulugalle, N.R. (2000) The impact of ant bioturbation and foraging activities on surrounding soil properties. Pedobiologia 44, 609-621.

Pfeiffer, B., Fender, A.-C., Lasota, S., Hertel, D., Jungkunst, H.F. and Daniel, R. (2013) Leaf litter is the main driver for changes in bacterial community structures in the rhizosphere of ash and beech. Applied Soil Ecology 72, 150-160.

Pfeiffer, B., Fender, A.-C., Jungkunst, H.F. and Daniel, R. N fertilization shapes the composition and diversity of active soil bacterial communities. submitted to PLoS One

Prakash, O., Green, S.J., Jasrotia, P., Overholt, W.A., Canion, A., Watson, D.B., Brooks, S.C. and Kostka, J.E. (2012) Rhodanobacter denitrificans sp. nov., isolated from nitrate-rich zones of a contaminated aquifer. International Journal of Systematic and Evolutionary Microbiology 62, 2457-2462.

Rigler, E. and Zechmeister-Boltenstern, S. (1999) Oxidation of ethylene and methane in forest soils - effect of $\mathrm{CO}_{2}$ and mineral nitrogen. Geoderma 90, 147-159.

Rousk, J., Brookes, P.C. and Bååth, E. (2009) Contrasting Soil pH Effects on Fungal and Bacterial Growth Suggest Functional Redundancy in Carbon Mineralization. Applied and Environmental Microbiology 75, 1589-1596.

Scheu, S. and Schaefer, M. (1998) Bottom-up control of the soil macrofauna community in a beechwood on limestone: Manipulation of food resources. Ecology 79, 1573-1585.

Schnell, S. and King, G.M. (1994) Mechanistic Analysis of Ammonium Inhibition of Atmospheric Methane Consumption in Forest Soils. Applied and Environmental Microbiology 60, 3514-3521.

Schweitzer, J., Fischer, D., Rehill, B., Wooley, S., Woolbright, S., Lindroth, R., Whitham, T., Zak, D. and Hart, S. (2011) Forest gene diversity is correlated with the composition and function of soil microbial communities. Population Ecology 53, 35-46.

Seeger, J. and Filser, J. (2008) Bottom-up down from the top: Honeydew as a carbon source for soil organisms. European Journal of Soil Biology 44, 483-490.

Shi, S., Richardson, A.E., O'Callaghan, M., DeAngelis, K.M., Jones, E.E., Stewart, A., Firestone, M.K. and Condron, L.M. (2011) Effects of selected root exudate components on soil bacterial communities. FEMS Microbiology Ecology 77, 600610. 
Smith, S.E. and Read, D.J. (2008) Mycorrhizal Symbiosis: Academic Press, London, UK.

Thoms, C., Gattinger, A., Jacob, M., Thomas, F. and Gleixner, G. (2010) Direct and indirect effects of tree diversity drive soil microbial diversity in temperate deciduous forest. Soil Biology and Biochemistry 42, 1558-1565.

Thoms, C. and Gleixner, G. (2013) Seasonal differences in tree species' influence on soil microbial communities. Soil Biology and Biochemistry 66, 239-248.

Trotsenko, Y.A. and Murrell, J.C. (2008) Metabolic aspects of aerobic obligate methanotrophy. Advances in Applied Microbiology 63, 183-229.

Uren, N.C. (2007) Types, Amounts, and Possible Functions of Compounds Released into the Rhizosphere by Soil-Grown Plants. In The Rhizosphere. pp.1-21: CRC Press.

van den Heuvel, R.N., van der Biezen, E., Jetten, M.S., Hefting, M.M. and Kartal, B. (2010) Denitrification at $\mathrm{pH} 4$ by a soil-derived Rhodanobacter-dominated community. Environmental Microbiology 12, 3264-3271.

Ward, B.B. (1987) Kinetic studies on ammonia and methane oxidation by Nitrosococcus oceanus. Archives of Microbiology 147, 126-133.

Whalen, S.C. and Reeburgh, W.S. (2000) Effect of nitrogen fertilization on atmospheric methane oxidation in boreal forest soils. Chemosphere - Global Change Science 2, 151-155.

Wrage, N., Velthof, G.L., van Beusichem, M.L. and Oenema, O. (2001) Role of nitrifier denitrification in the production of nitrous oxide. Soil Biology and Biochemistry 33, 1723-1732.

Yamamura, T., Schwendenmann, L. and Lear, G. (2013) Tree species identity has little impact on the structure of soil bacterial communities in a 10-year-old tropical tree plantation. Biology and Fertility of Soils 49, 819-828. 


\section{Summary}

Soil microbial communities are directly and indirectly influenced by a complex system of cross-interactions between different biotic and abiotic factors influencing each other, such as plant species and their respective traits, soil nutrient content, and $\mathrm{pH}$. Microorganisms shape their environment, as important drivers of the $\mathrm{C}$ and $\mathrm{N}$ cycle. Within the present thesis, several studies were conducted under controlled field and laboratory conditions as well as under natural conditions to unravel the contribution of different influencing factors. The soil prokaryotic community composition of the different soil samples was analyzed DNA-based and RNA-based using 16S rRNA genes and 16S rRNA as phylogenetic marker. The amplicon-based data were processed and diversity and richness estimates were calculated. Betadiversity analyses were conducted to assess overall differences between the different treatments. The obtained DGGE profiles were used for cluster analyses to reveal similarities or differences in the bacterial community structure.

The present thesis provided insight into the impact of tree species, tree species diversity, leaf litter and sampling time on the composition and diversity of soil bacterial communities. The obtained data revealed that the leaf litter layer was the major driver of the bacterial community composition in the rhizosphere of young beech and ash trees. It was indicated that different tree species and tree species diversity levels as well as seasonal differences have a minor effect on bacterial community composition. The results revealed that the microbial community composition was not affected significantly by beech and ash saplings, possibly due to the early developmental stage of the tree saplings. Nevertheless, the obtained data revealed that beech saplings inhibited bacterial growth and promoted fungal growth by a root exudation induced soil $\mathrm{pH}$ shift. Tree species, differing in their morphology differentially impact soil microbial communities. The analysis of the soil bacterial and fungal communities in natural forest soils under adult beech and spruce trees revealed a significant impact of the analyzed tree species on soil bacterial and fungal community composition. It was indicated that the bacterial and fungal diversity in the analyzed spruce forest soil was driven by soil $\mathrm{pH}$.

The impact of high $\mathrm{NO}_{3}{ }^{-}$depositions on $\mathrm{CH}_{4}$ and $\mathrm{N}_{2} \mathrm{O}$ gas fluxes, and the soil-inhabiting active bacterial and archaeal communities was studied in mesocosms containing soil from a temperate broad-leaved forest. Strong impacts of $\mathrm{NO}_{3}^{-}$fertilization on $\mathrm{CH}_{4}$ 
uptake rates and $\mathrm{N}_{2} \mathrm{O}$ emissions in fertilized soil columns were recorded. $\mathrm{N}$ fertilization inhibited the $\mathrm{CH}_{4}$ uptake, while the $\mathrm{N}_{2} \mathrm{O}$ emission increased. The soil bacterial community shifted over the course of the survey towards a denitrifying community, which was dominated by the genus Rhodanobacter. Furthermore, the bacterial diversity and $\mathrm{CO}_{2}$ emissions were reduced within the $\mathrm{N}$-fertilized soil columns. Moreover, $\mathrm{CO}_{2}$ emission rates dropped in both treatments throughout the experiment. This indicated a reduced activity of soil microorganisms, which might be due to $\mathrm{C}$ limitation in the used forest soil. Although a shift in the relative abundance of the nitrifying archaeal genus Nitrosotalea occurred, a significant shift in the archaeal community composition was not observed. The results indicate a considerable contribution of methylotrophic, methanotrophic and nitrifying bacterial species, occurring in low abundance, to the observed $\mathrm{CH}_{4}$ uptake.

The impact of ants and their activity on the activity and diversity of soil microbial communities were studied. Ant activity channeled honeydew into soils and thereby reduced the microbial biomass in the litter layer. The $\delta 15 \mathrm{~N}$ signature, the basal respiration and microbial biomass increased in the soil. In contrast, the cluster analysis of the derived DGGE profiles revealed no distinct differences of the microbial community structure in response to the different treatments. Ant activity affected the structure of bacterial communities in grasslands, due to nest building activity and the input of organic substances. Cluster analysis of the obtained DGGE profiles revealed differences in bacterial community composition in response to the sampling site and ant activity. In addition, bacterial community structures in ant nests differed from the surrounding soil.

A secondary project of this thesis was the assessment and comparison of microbial communities present in biological soil crusts, sampled at two sites in extrazonal mountain dry steppes in northern Mongolia. The study revealed clear differences in microbial community structure of the two sampling sites differing in their disturbance history. 


\section{Acknowledgments}

First of all, special thanks to Prof. Dr. Rolf Daniel for giving me the opportunity to work in this project. Many thanks for the constant support, friendly supervision, and critical reading of several manuscripts. I am also very grateful for the opportunity to attend national and international conferences.

I am grateful to PD Dr. Michael Hoppert for willingness to be the second examiner of this thesis.

I also want to thank Prof. Dr. Hermann F. Jungkunst, Prof. Dr. Stefanie Pöggeler, Prof. Dr. Stefan Irniger, and Jun.-Prof. Dr. Kai Heimel for their willingness to be members of the examination board.

The fruitful cooperation with Prof. Dr. Hermann F. Jungkunst and Ann-Catrin Fender opened the field of greenhouse gas fluxes and their connection to $\mathrm{N}$ fertilization for me. Hermann, I am thankful for your support, encouragement, and enthusiasm for my work.

Thanks go to PD Dr. Dirk Gansert, Dr. Lars Köhler, and Dr. Heinz Coners for their support and technical assistance during the construction and demounting of mesocosms and rhizotrons.

I highly appreciate the proofreading of my manuscripts and this thesis by Bernd, Heiko, Julia, Sarah, Kristin, Amelie, Anca, Dominik, and Martin. Thanks to the G2L, especially to Andrea, Frauke, and Sonja for the pyrosequencing and always being patient with crazy PhD-students. I also want to thank Bernd, Dominik, Sascha, and Denis for the unresting help with QIIME and the damn command lines. Never enter "rm $-\mathrm{rd} * * *$;.

Special thanks go to the "Rhizoladies" or tenderly used "Rhizogören" namely AnnCatrin Fender, Simone Cesarz, Friderike Beyer, and Kerttu Valtanen for the hard work we shared, the cold fingers and wet feet, as well as the funny moments we had. We spend hours installing mesocosms and rhizotrons, sorting leafs, sieving soil, counting worms, cleaning greenhouses, and watering trees, and without a lot of tea and sweets non of us would have survived. I will never forget the "Doppelkopf" and other game events we had. I really enjoyed working together with you and I appreciate the time we spend together. 
I also want to thank my lab mates Sarah, Steffi, Heiko, Dominik, Kristin, Mechtild, Bernd, Christiane, Silja, Amelie, Minji, Tanja, Carola, Christina, Jörn, Martin, Marvin, Michael, Romano, Robert, John, Sandra, Katrin, Leo, Genis, Tanja, and of course all students for a crazy, fruitful and pleasant time. I also want to thank "my" students Sabine, Sandra, Maria, and at least to $1 / 2$ Leo for the support, long laboratory sessions, and entertaining hours outside the lab.

Great thanks go to Carola, Heiko, and Prof. Dr. Gottschalk for sharing an exciting and wonderful time in South Africa. I will always remember our Kruger park safari.

I also want to thank some special people I meet on my way. Evelyn and Sarah, thank you for always being there for me, open minded and with a cup of coffee or a beer. The same is true for Julia, who always supported me. Many thanks go to Nicole, Stephan, and Matilda, as well as Christina, Thomas, and Johannes for always offering a refuge from work and Göttingen when necessary and helping me to focus on the essential things in life. Thanks to Bernd and Franzi with little Erik for being good friends and helping me with delicious food and long nights playing games.

And last but not least I want to say "Thank you" to my family, in particular to my mum and dad, and my brother Michael: Ich bin unglaublich Dankbar Euch zu haben. Ohne Eure Unterstützung, unendliche Geduld und die Möglichkeit sich bei Mama und Papa zu verkriechen, wann immer die Arbeit zu viel wurde, würde es diese Doktorarbeit nicht geben. Ein besonderer Dank gilt auch meinem Bruder, der es in seiner eigenen Art immer wieder schaffte mich auf den Boden der Tatsachen zu holen und mir Mut zu machen. Ich liebe Euch! 


\section{Curriculum vitae}

\section{Birgit Pfeiffer}

Date of Birth: $\quad 28^{\text {th }}$ July, 1981

Place of Birth: $\quad$ Forst/Lausitz

04/2008 - 12/2013 PhD thesis at the Institute of Microbiology and Genetics, Georg-August University of Göttingen, Germany

10/2001 - 07/2007 Study of Biology at the University of Rostock, Germany

Degree: German Diploma (equivalent to Master of Science) Thesis: "Development of an PCR-independent 16S rRNA Single-Strand-Conformationpolymorphism $\quad$ (SSCP) Method"

Major: $\quad$ Microbiology

Minors: Molecular Biology and Genetics, Animal Physiology and Biotechnology

06/2001 Abitur at the Friedrich-Ludwig-Jahn Gymnasium, Forst/Lausitz 